\title{
NOVEL ANALYTICAL STRATEGIES FOR TRACING THE ORGANIC CARBON CYCLE IN MARINE AND RIVERINE PARTICLES
}

\author{
By \\ Sarah Zhou Rosengard \\ S.B., Brown University, 2011 \\ Submitted in partial fulfillment of the requirements for the degree of \\ Doctor of Philosophy \\ at the \\ MASSACHUSETTS INSTITUTE OF TECHNOLOGY \\ and the \\ WOODS HOLE OCEANOGRAPHIC INSTITUTION
}

February 2017

(C) 2017 Sarah Rosengard

All rights reserved.

The author hereby grants to MIT and WHOI permission to reproduce and to distribute publicly paper and electronic copies of this thesis document in whole or in part in any medium now known or hereafter created.

Signature of Author

Joint Program in Chemical Oceanography Massachusetts Institute of Technology and Woods Hole Oceanographic Institution

December 30, 2016

Certified by

Valier Galy
Thesis Co-supervisor

Certified by

Phoebe Lam

Thesis Co-supervisor

Accepted by

Chair, Joint Committee for Chemical Oceanography

Shuhei Ono 


\title{
Novel analytical strategies for tracing the organic carbon cycle in marine and riverine particles
}

by

Sarah Zhou Rosengard

Submitted to the MIT/WHOI Joint Program in Chemical Oceanography on December 30, 2016 in partial fulfillement of the requirements for the degree of Doctor of Philosophy

\begin{abstract}
Particulate organic carbon (POC) in the ocean and mobilized by rivers on land transfers $\sim 0.1 \%$ of global primary productivity to the deep ocean sediments. This small fraction regulates the long-term carbon cycle by removing carbon dioxide from the atmosphere for centuries to millennia. This thesis investigates mechanisms of POC transfer to the deep ocean by analyzing particles collected in transit through two globally significant carbon reservoirs: the Southern Ocean and the Amazon River Basin. These endeavors test the hypothesis that organic matter composition controls the recycling and transfer efficiency of POC to the deep ocean, and illustrate new applications for ramped pyrolysis/oxidation (RPO), a growing method of POC characterization by thermal stability. By coupling RPO to stable and radiocarbon isotope analyses of riverine POC, I quantify three thermally distinct soil organic carbon pools mobilized by the Amazon River, and evaluate the degradability and fate of these different pools during transport to the coastal Atlantic Ocean. More directly, RPO analyses of marine samples suggest that POC transfer in the water column is in fact selective. Observations of consistent biomolecular changes that accompany transport of phytoplankton-derived organic matter to depth across the Southern Ocean support the argument for preferential degradation of specific POC pools in the water column. Combining discussions of POC recycling and transfer across both marine and terrestrial systems offer new perspectives of thermal stability as a proxy for diagenetic stability and POC degradation state. The challenges of interpreting RPO data in these two environments set the stage for applying the technique to more controlled experiments that trace POC from source to long-term sink.
\end{abstract}

Thesis Co-advisors:

Valier Galy, Associate Scientist, WHOI

Phoebe Lam, Assistant Professor, University of California- Santa Cruz 
This thesis is dedicated to four important women: Marjorie Rosengard, Barbara Rosengard, my grandmother and Miah. Thank you for your unconditional love and nurturing.

\section{Acknowledgements}

The research in this dissertation was funded by the National Science Foundation Graduate Research Fellowship Program, the Woods Hole Research Center Board of Trustees, the WHOI Ocean Exploration Institute Student Fellowship, WHOI Ocean Ventures Fund, the WHOI Coastal Ocean Institute Grant, the National Ocean Sciences Accelerator Mass Spectrometry student research and development support, the WHOI Academic Programs Office, the PAOC Houghton Fund, WHOI start up funds, and several NSF and NASA awards: NSF OCE-090880, NSF OCE-0961660, NSF OCE1443577, NSF OCE-1333387, NSF OCE-1233272, NASA NNX11A072G, and NASA NNX11AL93G.

In the completion of this thesis, I must express gratitude to my advisors Phoebe Lam and Valier Galy, thesis chair Bernhard Peucker-Ehrenbrink, and my thesis committee members, Ken Buesseler, Ann McNichol, Robert Spencer and Mick Follows. This group provided me important opportunities to develop as a scientist, collaborate widely in my field, struggle through diverse challenges, and gain skills in speaking and presenting confidently. I stress the word diverse here because they enabled me to think about carbon cycle processes in two very different environments.

Relatedly, I am deeply grateful for the field work experiences that Phoebe, Bernhard, Valier and Rob offered me in the past five years. Thank you to Wendy Kingerlee for managing perhaps the most important aspect of my Amazon trips: my Brazilian research visa. It was a pleasure to brave Southern Ocean swells with the science team and crew of the $R / V$ Revelle, face the insects and maned wolves of the Southern Amazon with Paul Lefebvre, and engineer makeshift boat frames with the Amazon research group at Woods Hole Research Center and Jose Mauro's group from Santarem, Brazil. Together, these field experiences were not only essential to my research, but introduced me to the collaborative, cross-cultural and financial aspects of earth science. I hope to take these perspectives with me in my future career, and share my own passions for being in the field whenever possible - for example, when I, one day, am a mentor to students!

Next, I thank the MIT-WHOI Joint Program for providing an intellectually engaging, socially supportive and administratively functional environment for graduate students. The Academic Programs Office and student body helped me strike a work life balance over five years. Jim Yoder was always very supportive of my involvement in the Broader Impacts Group, which enabled me to explore other passions in oceanography: teaching, science communication and outreach. I also thank APO and the Joint Program for being the home base for the Graduate Climate Conference and the Society for Women in Marine Science, as well.

Beyond the Joint Program, I was fortunate to be part of the chemistry department and the broader WHOI community. The solutions to various problems I faced as a graduate student were always within walking distance. I extend special thanks to Sheila Clifford, Donna Mortimer, Mary Murpy, Mary Zawoysky, Maureen Auro, Carl Johnson, 
Scott Birdwhistell, Tristan Horner, Stephanie Madsen, all of my lab peers (especially Paul Lerner, Jordon Hemingway, Dan Ohnemus, Kristina Brown, Katherine French, Laurel Childress, and Kyrstin Fornace), and the entire NOSAMS staff (especially Anne Cruz, Al Gagnon, Kalina Gospodinova, Mary Lardie, Li Xu, Nan Trowbridge). This community trained me to become the analytical chemist I am today.

Finally, I probably would not have survived this process without my close friends and family. To some extent, my statement is literal: thank you to everyone who gave me food in the last few months, who drove me home or to the supermarket, who lent me last minute flashlights for braving the darkness, especially on those short winter days, and who forced me to relax. But, I also thank those who were part of my running breaks (e.g., the WHOI Women's Basketball team); my roommates Emily Estes, Winn Johnson, Moxie and Kenji; the motorcycle "club"; my Brazilian connections for maintaining Portuguese (Cristina Schultz); and several other support groups in Woods Hole and Boston (Julie, Whitney, Kate, Kyrstin, Deepak, Reed, Danielle \& Joe, Kelly, Cara, Markrete, Carolyn \& Celis, Marielle, Craig, Hanny, Cris, Alex, Harriet, and Izi).

Finally, my family was my strongest support group. Somehow, my parents, aunts and sister always believed that I could finish this even without always knowing what I was doing in Woods Hole or seeing evidence of my progress. My evolution in graduate school was just as much theirs as it was mine. 


\section{Table of Contents}

CHAPTER 1: INTRODUCTION

1 THE MODERN CARBON CYCLE 13

2 RESEARCH OBJECTIVES 14

3 MECHANISMS OF POC EXPORT AND TRANSFER EFFICIENCY 15

4 EVALUATING POC QUALITY ACROSS MARINE AND TERRESTRIAL SOURCES

REFERENCES

CHAPTER 2: CARBON EXPORT AND TRANSFER TO DEPTH ACROSS THE SOUTHERN OCEAN GREAT CALCITE BELT

ABSTRACT

1 INTRODUCTION 24

2 METHODS 27

3 RESULTS 33

4 DisCUSSION 36

5 CONCLUSION 49

AUTHOR CONTRIBUTIONS: $\quad 49$

ACKNOWLEDGEMENTS: $\quad 49$

$\begin{array}{ll}\text { REFERENCES } & 50\end{array}$

CHAPTER 3: THE EFFECT OF SAMPLE DRYING TEMPERATURE ON MARINE PARTICULATE ORGANIC CARBON COMPOSITION 73

ABSTRACT

1 INTRODUCTION

2 METHODS

3 RESULTS

4 DisCUSSION

$\begin{array}{lr}\text { CONCLUSION } & 89\end{array}$

ACKNOWLEDGEMENTS 90

$\begin{array}{ll}\text { REFERENCES } & 90\end{array}$

CHAPTER 4: USING RAMPED OXIDATION TO TRACK CHANGES IN EUPHOTIC AND MESOPELAGIC ZONE PARTICULATE ORGANIC CARBON COMPOSITION

ABSTRACT

1 INTRODUCTION

2 Methods

107

3 RESULTS

116

4 DisCUSSION

123

5 CONCLUSION

139

ACKNOWLEDGEMENTS 140

REFERENCES

140 
CHAPTER 5: DIAGNOSING AND QUANTIFYING ORGANIC CARBON SOURCES

TO SUSPENDED SEDIMENTS IN THE AMAZON RIVER MAIN STEM 165

ABSTRACT

1 INTRODUCTION

166

2 Methods

168

3 RESULTS

177

4 DISCUSSION

186

5 CONCLUSIONS

198

ACKNOWLEDGEMENTS

199

REFERENCES

199

CHAPTER 6: CONCLUSIONS

APPENDIX A

APPENDIX B

APPENDIX C 


\section{Table Guide}

\section{Chapter 2 (Pages 57-61)}

Table 1. Sampling locations and times during two cruises across the Southern Ocean Great Calcite Belt region.

Table 2. Particulate organic carbon fluxes and attenuation in the mesopelagic zone.

Table 3. POC, ${ }^{234} \mathrm{Th}$ and biomineral export fluxes from the euphotic zone.

Table 4. Zonal averages of export fluxes, POC: ${ }^{234} \mathrm{Th}$ and biomineral: ${ }^{234} \mathrm{Th}$ ratios across sampling region.

\section{Chapter 3 (Pages 93-95)}

Table 1. Woods Hole dock samples and blank, and their bulk composition.

Table 2. $\delta^{13} \mathrm{C}$ of ramped pyrolysis/oxidation (RPO) fractions of dock test samples.

Table 3. Alcohol/sterol standard constituents.

\section{Chapter 4 (Pages 147-151)}

Table 1. Three profiles of $<51 \mu \mathrm{m}$ particle sample composition in the Southern

Ocean.

Table 2. Relative and absolute POC and PIC quantities in end-member and matrix samples for RPO analysis.

Table 3. Comparisons of bulk and RPO-based total carbon and $\delta^{13} \mathrm{C}$ measurements.

Table $4 . \delta^{13} \mathrm{C}$ of $\mathrm{CO}_{2}$ evolved within two temperature intervals of each particle sample thermogram.

\section{Chapter 5 (Pages 205-214)}

Table 1. Sample locations and times in Amazon River Basin.

Table 2. Substrates for enzyme assays on Amazon River suspended particles.

Table 3. Bulk sample composition in the Amazon River Basin.

Table 4. Ramped RPO fraction composition of fumigated/rinsed vs. untreated samples.

Table 5. Deconvolution of Amazon River Basin sample thermograms.

Appendix A (Pages 235-243)

Table S1: Tabulated ${ }^{234}$ Th activity, ${ }^{234} \mathrm{U}$ activity and ${ }^{234} \mathrm{Th}$ flux profiles

Table S2: Tabulated ${ }^{234} \mathrm{Th}$ and POC fluxes and POC: ${ }^{234} \mathrm{Th}$ ratios at the ${ }^{234} \mathrm{Th}^{238} \mathrm{U}$ equilibrium depth.

\section{Appendix C (Pages 259-270)}

Table $\mathrm{S} 1 . \delta^{13} \mathrm{C}$ and abundances of straight chain $n$-alkanes in Amazon River Basin suspended sediments.

Table S2. $\delta^{13} \mathrm{C}$ and abundances of straight chain fatty acids in Amazon River Basin suspended sediments.

Table S3. Enzyme activities in suspended sediments at Óbidos in July 2014. 


\section{Figure Guide}

\section{Chapter 1 (Page 21)}

Figure 1. Schematic of the ramped pyrolysis/oxidation (RPO) unit at NOSAMS. Chapter 2 (Pages 62-72)

Figure 1. Cruise tracks, GB1 and GB2, across Southern Ocean Great Calcite Belt region.

Figure 2. Images of $>51 \mu \mathrm{m}$ particles collected at different depths in the water column.

Figure 3. $>51 \mu \mathrm{m}$ POC concentration profiles fit to a power law.

Figure 4. Total ${ }^{234} \mathrm{Th}$ and ${ }^{238} \mathrm{U}$ activity profiles measured at GB1 and GB2 stations.

Figure 5. Distribution of ${ }^{234} \mathrm{Th}$ and POC fluxes measured at various water column depths across GB1 and GB2 stations.

Figure 5. Distribution of ${ }^{234} \mathrm{Th}$ and POC fluxes measured at various water column depths across GB1 and GB2 stations.

Figure 6. Distribution of biomineral fluxes and POC size partitioning at the export depth.

Figure 7. Distribution of primary productivity, export efficiency and transfer efficiency.

Figure 8. Distribution of $>51 \mu \mathrm{m}$ POC concentration and vertical attenuation. Figure 9. POC export fluxes and transfer efficiency as a function of biomineral export fluxes.

Figure 10. Attenuation coefficient as a function of $>51 \mu \mathrm{m}[\mathrm{BSi}]$ and POC size partitioning at the export depth.

Chapter 3 (Pages 96-101)

Figure 1. Dock sample drying method strategy and images.

Figure 2. All dock test sample and blank thermograms from ramped pyrolysis/oxidation (RPO) analysis.

Figure 3. Comparisons of straight-chain saturated fatty acid abundances in dock samples across drying methods.

Figure 4. Comparisons of straight-chain unsaturated fatty acid abundances.

Figure 5. Comparisons of branched saturated fatty acid abundances.

Figure 6. Comparisons of sterol/alcohol abundances.

\section{Chapter 4 (Pages 152-163)}

Figure 1. Distribution of biomineral ratios in $>51 \mu \mathrm{m}$ particles collected at the export depth across cruise tracks GB1 and GB2.

Figure 2. Profiles of bulk, PIC and POC $\delta^{13} \mathrm{C}$ values at three stations in the Southern Ocean.

Figure 3. Thermograms of fumigated and rinsed vs. untreated $<51 \mu \mathrm{m}$ particle samples.

Figure 4. Thermograms of two PIC end-members.

Figure 5. Thermograms of E. huxleyi culture biomass.

Figure 6. Three profiles of particle sample thermograms.

Figure 7. Three deployment blank thermograms. 
Figure $8 . \delta^{13} \mathrm{C}$ of RPO fractions collected during RPO analysis of all particle samples.

Figure 9. Matrix sample thermograms.

Figure 10. Observed vs. expected/null POC- and PIC-derived $\mathrm{CO}_{2}$ in $\mathrm{RPO}$ fractions of matrix sample thermograms.

Figure 11. Profiles of three metrics that illustrate changes in sample thermogram shape with depth.

Figure 12. $\delta^{13} \mathrm{C}$ of $\mathrm{CO}_{2}$ evolved within two temperature intervals of each sample thermogram.

\section{Chapter 5 (Pages 215-226)}

Figure 1a. Map of Amazon River Basin

Figure 1b. Hydrograph, and water velocity distributions in Óbidos cross-section in 2014.

Figure 2. Depth profiles of total suspended sediment composition at Óbidos in 2014.

Figure 3. Rouse fits of total suspended sediment concentration profiles at Óbidos.

Figure 4a. All Amazon River Basin sample thermograms and $F_{m}$ of RPO fractions.

Figure 4b. All Amazon River Basin sample thermograms and $\delta^{13} \mathrm{C}$ of RPO fractions.

Figure 5. $\delta^{13} \mathrm{C}$ and abundances of straight chain $n$-alkanes in Amazon River Basin suspended sediments.

Figure 6. Average chain length of straight chain $n$-alkanes and fatty acids in Amazon River Basin suspended sediments.

Figure 7. $\delta^{13} \mathrm{C}$ and abundances of straight chain fatty acids in Amazon River Basin suspended sediments.

Figure 8. Profiles of eight enzyme activities in suspended sediments at Óbidos in July 2014.

Figure 9. Scatterplots of (a) bulk sample $\delta^{13} \mathrm{CPOC}$ as a function of bulk N/C, and (b) RPO fraction $F_{m}$ as a function of RPO fraction $\delta^{13} \mathrm{C}$.

Figure 10. Illustrations of deconvolution of Amazon River Basin sample thermograms.

\section{Chapter 6 (Pages 232-233)}

Figure 1. Thermograms of phytoplankton-derived, mesopelagic zone and Amazon River organic matter along a degradation spectrum.

Figure 2. Comparisons of thermal stability and fraction modern of RPO fractions from analysis of Southern Ocean and Amazon River samples.

Appendix A (Pages 245-251)

Figure S1. Plotted profiles of POC: ${ }^{234} \mathrm{Th}, \mathrm{PIC}:{ }^{234} \mathrm{Th}$ and $\mathrm{BSi}:{ }^{234} \mathrm{Th}$ above $400 \mathrm{~m}$. Figure S2. Euphotic zone diatom or coccolithophore abundance as a function of [BSi] or [PIC], respectively.

Figure S3: The natural log ratio of [PIC] to [BSi] as a function of the natural log ratio of total euphotic zone coccolithophore to diatom abundances.

Figure S4: Percentage of total cell counts that are diatoms at $Z_{\mathrm{PAR}}$ as a function of [POC] size fractionation at the export depth.

\section{Appendix B (Pages 253-256)}


Figure S1. PIC hydrolysis time-series over $\sim 25$ hour reaction.

Figure S2. E. huxleyi cell concentration time-series over six day incubation.

Figure S3. Replicate RPO analyses of the same Southern Ocean particle sample. Figure S4. Illustrations of calculation of metrics plotted in chapter 4, Figure 11. Appendix C (Pages 271-272)

Figure S1. Profiles of soil composition measured from a soil pit in the Tanguro Ranch.

Figure S2. Comparisons of total suspended sediment composition among three streams in the Tanguro Ranch. 


\section{Chapter 1: Introduction}

\section{The modern carbon cycle}

Fossil fuel emissions in the industrial era have cumulatively released $\sim 545$ gigatons $(\mathrm{Gt})$ of carbon dioxide $\left(\mathrm{CO}_{2}\right)$, a prominent greenhouse gas, to the atmosphere, resulting in the highest atmospheric $\mathrm{CO}_{2}$ concentrations in human history. Within this relatively short period, the increase in atmospheric $\mathrm{CO}_{2}$ concentrations has been largely moderated by carbon fixation into organic matter by land plants and marine phytoplankton, and dissolution of $\mathrm{CO}_{2}$ into the surface ocean (Sabine et al., 2004). Because these terrestrial and marine reservoirs turn over carbon on relatively short, decadal time scales, their storage size and the rates at which they absorb atmospheric $\mathrm{CO}_{2}$ have fluctuated throughout the $20^{\text {th }}$ century in response to rising anthropogenic carbon emissions, heat accumulation in the atmosphere and oceans and, in the case of the terrestrial vegetation, land use change (Houghton et al., 1999; Körner, 2003; Behrenfeld et al., 2006; Khatiwala et al., 2009).

This research compilation focuses primarily on the small fraction $(<1 \%)$ of terrestrial and surface ocean primary productivity that is further exported into the deep ocean (Volk and Hoffert, 1985; Martin et al., 1987), where residence times for carbon extend to millennia. Marine particles produced in the surface ocean and terrestrial particles mobilized through rivers are the primary vehicles for export to the deep ocean. Transport of marine particulate organic carbon (POC), or the biological pump, is driven by sinking particles from the euphotic zone to the deep ocean ( $>2000 \mathrm{~m}$ depths) (Riley et al., 2012). The terrestrial analogue to the marine biological pump is active transport of primarily vegetation and soil-derived organic matter (Meybeck, 1982; Hedges et al., 1997) in riverine particles to the coastal ocean and continental shelf. The physical journey of riverine POC depends on the downstream velocity within the river channel and the inland landscape (Burd et al., 2016).

The fraction of marine primary productivity exported out of the surface ocean and terrestrial primary productivity exported from land into rivers equates to $\sim 16 \mathrm{Gt} / \mathrm{yr}$ of marine POC (Falkowski et al., 1998) and 0.2 Gt/yr of terrestrial POC (Galy et al., 2015), 
which in sum are comparable to the current rate of annual carbon emissions. An even smaller fraction of total primary productivity, $<0.5 \%$ (Martin et al., 1987; Burdige, 2007), equivalent to $0.1-0.2 \mathrm{Gt} / \mathrm{yr}$, reaches the seafloor sediment surface. These fluxes into the deep ocean are small, owing to rapid heterotrophic remineralization and photo-oxidation in the water column and within rivers (Martin et al., 1987; Amon and Benner, 1996; Benner and Biddanda, 1998; Mayorga et al., 2005; Buesseler and Boyd, 2009; Ward et al., 2013; Giering et al., 2014), but they remove carbon from the atmosphere for centuries to millennia. Over these long time scales, this deep reservoir amasses several orders of magnitude more carbon than do the terrestrial and marine primary producer reservoirs. The storage capacity of the deep ocean reservoir has likely remained unperturbed throughout the industrial era ( Sarmiento and Le Quéré, 1996; Sarmiento et al., 1998), and is expected to buffer long-term anthropogenic $\mathrm{CO}_{2}$ accumulation in the atmosphere (Kwon et al., 2009).

\section{$2 \quad$ Research objectives}

Particle transport studies have reported significant geographical and temporal variations in the fraction of marine and terrestrial primary productivity exported (export efficiency) and sequestered (transfer efficiency) in the deep ocean (Hedges and Oades, 1997; Henson et al., 2011; Moreira - Turcq et al., 2013). The following chapters of this dissertation aim to expand mechanistic understanding of this variation in POC export and transfer efficiency by (1) comparing multiple factors that govern the fraction of primary productivity transferred to the deep ocean and (2) assessing different empirical approaches to sampling and analyzing the dynamics of POC exported from the water column and through rivers. The sample data span two globally significant carbon sinks for atmospheric $\mathrm{CO}_{2}$ : the Southern Ocean, which supports 1-4 Gt/year marine primary productivity (Arrigo et al., 1998; Priddle et al., 1998), and the Amazon River Basin, which harbors the largest tropical rain forest and river on the planet in terms of discharge and watershed area. Both regions are likely to shift disproportionately in response to climate change (Gille, 2002; Laufkötter et al., 2015) and landscape transformation across the Amazon River Basin (Davidson et al., 2012; Brienen et al., 2015). 


\section{$3 \quad$ Mechanisms of POC export and transfer efficiency}

The fraction of both marine and terrestrial primary productivity sequestered in the deep ocean is a balance between two competing but not mutually exclusive forces: the physical processes that drive particle movement, and the geochemical processes that influence rates of respiration. Physical processes include particle size and density (Rouse, 1950; Wilson et al., 2008; Burd and Jackson, 2009; Bouchez et al., 2011; Lupker et al., 2011), mineral-POC associations (Armstrong et al., 2002; Francois et al., 2002; Klaas and Archer, 2002; Mayer et al., 2004; Bouchez et al., 2014), and advection and mixing of water parcels (Dall'Olmo and Mork, 2014). Processes that control remineralization rates include the composition of phytoplankton, zooplankton and particle-associated bacterial communities (Battin et al., 2008; Guidi et al., 2009; Buesseler and Boyd, 2009; Satinsky et al., 2014), and relatedly, the composition and quality of POC exported by different phytoplankton communities (Francois et al., 2002). Abiotic remineralization processes like photo-oxidation are not addressed in this thesis.

Chapter 2 takes advantage of the variable diatom and coccolithophore communities across the Southern Ocean to compare how biomineral ballast mechanisms influence POC transfer efficiency (Armstrong et al., 2002; Francois et al., 2002; Klaas and Archer, 2002). Comparisons among POC, biogenic silica and calcite fluxes in particles through the upper 1000 meters of the water column did not provide consistent evidence for mineral ballasting with depth, leading instead to the hypothesis that phytoplankton community composition and POC quality influence POC export more than mineral ballasting by controlling POC remineralization rates in the water column (Francois et al., 2002; Rosengard et al., 2015).

\section{$4 \quad$ Evaluating POC quality across marine and terrestrial sources}

The hypothesis posited at the end of chapter 2 directed me to seek more direct evidence linking POC transfer efficiency to POC quality and primary producer community composition in chapters 3,4 and 5. The argument that organic matter 
"quality" controls its degradability by bacteria in the environment and therefore POC transfer efficiency is based on the perspective that POC degradation is selective.

Observations that specific molecular classes of organic matter accumulate in the deeper ocean, both terrestrial and marine-derived (Wakeham et al., 1997; Elias et al., 2000; Baldock et al., 2004; Burd et al., 2016), imply that certain pools of organic matter are more diagenetically stable than others. If quantitatively significant, selective remineralization of less stable pools by heterotrophs during POC transport would impact the export and transfer efficiencies of primary productivity into the deep ocean.

Our ability to address the POC quality hypothesis depends on our ability to describe POC composition and the degradability of distinct POC pools. Organic geochemists employ several techniques to probe organic matter quality, from bulk compositional metrics that integrate across the diverse molecular matrix of POC (e.g., Trull and Armand, 2001), to analyses of specific biomolecular tracers (e.g., Elias et al., 2000). Chapters 3-5 utilize a range of these strategies, and further apply a relatively novel technique for assessing organic matter composition by its thermal stability: ramped pyrolysis/oxidation (RPO) (Fig. 1). This method oxidizes or pyrolyzes a sample to $\mathrm{CO}_{2}$ throughout a constant temperature ramp, generating plots of $\mathrm{CO}_{2}$ release against temperature, referred to as thermograms, that can be interpreted as the activation energy distribution of POC (Cramer, 2004). Previous applications of RPO have suggested that the activation energy of $\mathrm{POC}$ decomposition during ramped oxidation could serve as a proxy for the stability of POC in the environment ( Rosenheim et al., 2008; Rosenheim and Galy, 2012; Rosenheim et al., 2013). Chapter 3 uses a controlled sampling experiment in Woods Hole to demonstrate that different sample drying temperatures do not compromise the thermal stability of POC, implying that RPO analyses are appropriate for POC sampled, dried and stored across a range of temperatures.

Collectively, chapters 4 and 5 explore different applications of RPO to probe the relationship between POC composition and export/transfer efficiency. Chapter 4 directly follows up on chapter 2 by comparing the thermal stability and quality of POC produced and exported from different phytoplankton communities across the Southern Ocean. The results offer a unique perspective of compositional transformations in POC that accompany degradation of marine POC. Chapter 5 further demonstrates that RPO is 
useful for distinguishing and quantifying input of compositionally distinct sources of terrestrial POC to the Amazon River. Because the river basin drains diverse vegetative landscapes and soil pools spanning different degradation histories, the data provide insights towards the diagenetic stability and proportions of these different sources in riverine POC exported to the coastal Atlantic Ocean.

\section{References}

Amon, R. M. W. and Benner, R.: Photochemical and microbial consumption of dissolved organic carbon and dissolved oxygen in the Amazon River system, Geochimica et Cosmochimica Acta, 60, 1783-1792, 1996.

Armstrong, R. A., Lee, C., Hedges, J. I., Honjo, S., and Wakeham, S. G.: A new, mechanistic model for organic carbon fluxes in the ocean based on the quantitative association of POC with ballast minerals, Deep-Sea Research Part IITopical Studies in Oceanography, 49, 219-236, 2002.

Arrigo, K. R., Worthen, D., Schnell, A., and Lizotte, M. P.: Primary production in Southern Ocean waters, Journal of Geophysical Research-Oceans, 103, 1558715600, 1998.

Baldock, J. A., Masiello, C. A., Gélinas, Y., and Hedges, J. I.: Cycling and composition of organic matter in terrestrial and marine ecosystems, Marine Chemistry, 92, 3964, 2004.

Battin, T. J., Kaplan, L. A., Findlay, S., Hopkinson, C. S., Marti, E., Packman, A. I., Newbold, J. D., and Sabater, F.: Biophysical controls on organic carbon fluxes in fluvial networks, Nature Geoscience, 1, 95-100, 2008.

Behrenfeld, M. J., O'Malley, R. T., Siegel, D. A., McClain, C. R., Sarmiento, J. L., Feldman, G. C., Milligan, A. J., Falkowski, P. G., Letelier, R. M., and Boss, E. S.: Climate-driven trends in contemporary ocean productivity, Nature, 444, 752-755, 2006.

Benner, R. and Biddanda, B.: Photochemical transformations of surface and deep marine dissolved organic matter: Effects on bacterial growth, Limnology and Oceanography, 43, 1373-1378, 1998.

Bouchez, J., Galy, V., Hilton, R. G., Gaillardet, J., Moreira-Turcq, P., Pérez, M. A., France-Lanord, C., and Maurice, L.: Source, transport and fluxes of Amazon River particulate organic carbon: insights from river sediment depth-profiles, Geochimica et Cosmochimica Acta, 133, 280-298, 2014.

Bouchez, J., Métivier, F., Lupker, M., Maurice, L., Perez, M., Gaillardet, J., and France-Lanord, C.: Prediction of depth-integrated fluxes of suspended sediment in the Amazon River: Particle aggregation as a complicating factor, Hydrological processes, 25, 778-794, 2011.

Brienen, R. J., Phillips, O., Feldpausch, T., Gloor, E., Baker, T., Lloyd, J., LopezGonzalez, G., Monteagudo-Mendoza, A., Malhi, Y., and Lewis, S. L.: Long-term decline of the Amazon carbon sink, Nature, 519, 344-348, 2015.

Buesseler, K. O. and Boyd, P. W.: Shedding light on processes that control particle 
export and flux attenuation in the twilight zone of the open ocean, Limnology and Oceanography, 54, 1210-1232, 2009.

Burd, A. B., Frey, S., Cabre, A., Ito, T., Levine, N. M., Lønborg, C., Long, M., Mauritz, M., Thomas, R. Q., and Stephens, B. M.: Terrestrial and marine perspectives on modeling organic matter degradation pathways, Global change biology, 22, 121136, 2016.

Burd, A. B. and Jackson, G. A.: Particle Aggregation, Annual Review of Marine Science, 1, 65-90, 2009.

Burdige, D. J.: Preservation of Organic Matter in Marine Sediments: Controls, Mechanisms, and an Imbalance in Sediment Organic Carbon Budgets?, Chemical Reviews, 107, 467-485, 2007.

Cramer, B.: Methane generation from coal during open system pyrolysis investigated by isotope specific, Gaussian distributed reaction kinetics, Organic Geochemistry, 35, 379-392, 2004.

Dall'Olmo, G. and Mork, K. A.: Carbon export by small particles in the Norwegian Sea, Geophysical Research Letters, 41, 2921-2927, 2014.

Davidson, E. A., de Araújo, A. C., Artaxo, P., Balch, J. K., Brown, I. F., Bustamante, M. M., Coe, M. T., DeFries, R. S., Keller, M., and Longo, M.: The Amazon basin in transition, Nature, 481, 321-328, 2012.

Elias, V., Cardoso, J., and Simoneit, B.: Acyclic lipids in Amazon shelf waters, Estuarine, Coastal and Shelf Science, 50, 231-243, 2000.

Falkowski, P. G., Barber, R. T., and Smetacek, V.: Biogeochemical controls and feedbacks on ocean primary production, Science, 281, 200-206, 1998.

Fornace, K. L.: Late Quaternary climate variability and terrestrial carbon cycling in tropical South America, 2016. Massachusetts Institute of Technology and Woods Hole Oceanographic Institution, 2016.

Francois, R., Honjo, S., Krishfield, R., and Manganini, S.: Factors controlling the flux of organic carbon to the bathypelagic zone of the ocean, Global Biogeochemical Cycles, 16, doi:10.1029/2001GB001722, 2002.

Galy, V., Peucker-Ehrenbrink, B., and Eglinton, T.: Global carbon export from the terrestrial biosphere controlled by erosion, Nature, 521, 204-207, 2015.

Giering, S. L. C., Sanders, R., Lampitt, R. S., Anderson, T. R., Tamburini, C., Boutrif, M., Zubkov, M. V., Marsay, C. M., Henson, S. A., Saw, K., Cook, K., and Mayor, D. J.: Reconciliation of the carbon budget in the ocean/'s twilight zone, Nature, 2014.

Gille, S. T.: Warming of the Southern Ocean Since the 1950s, Science, 295, 1275-1277, 2002.

Guidi, L., Stemmann, L., Jackson, G. A., Ibanez, F., Claustre, H., Legendre, L., Picheral, M., and Gorsky, G.: Effects of phytoplankton community on production, size and export of large aggregates: A world-ocean analysis, Limnology and Oceanography, 54, 1951-1963, 2009.

Hedges, J., Keil, R., and Benner, R.: What happens to terrestrial organic matter in the ocean?, Organic geochemistry, 27, 195-212, 1997.

Hedges, J. I. and Oades, J. M.: Comparative organic geochemistries of soils and marine sediments, Organic Geochemistry, 27, 319-361, 1997.

Henson, S. A., Sanders, R., Madsen, E., Morris, P. J., Le Moigne, F., and Quartly, G. D.: 
A reduced estimate of the strength of the ocean's biological carbon pump, Geophysical Research Letters, 38, L04606, 2011.

Houghton, R. A., Hackler, J. L., and Lawrence, K. T.: The U.S. Carbon Budget: Contributions from Land-Use Change, Science, 285, 574-578, 1999.

Khatiwala, S., Primeau, F., and Hall, T.: Reconstruction of the history of anthropogenic $\mathrm{CO}_{2}$ concentrations in the ocean, Nature, 462, 346-349, 2009.

Klaas, C. and Archer, D. E.: Association of sinking organic matter with various types of mineral ballast in the deep sea: Implications for the rain ratio, Global Biogeochemical Cycles, 16, 1116-1129, 2002.

Körner, C.: Ecological impacts of atmospheric $\mathrm{CO}_{2}$ enrichment on terrestrial ecosystems, Philosophical Transactions of the Royal Society of London A: Mathematical, Physical and Engineering Sciences, 361, 2023-2041, 2003.

Kwon, E. Y., Primeau, F., and Sarmiento, J. L.: The impact of remineralization depth on the air-sea carbon balance, Nature Geoscience, 2, 630-635, 2009.

Laufkötter, C., Vogt, M., Gruber, N., Aumont, O., Bopp, L., Doney, S., Dunne, J., Hauck, J., John, J., Lima, I., Seferian, R., and Völker, C.: Projected decreases in future marine export production: the role of the carbon flux through the upper ocean ecosystem, Biogeosciences, 13, 4023-4047, 2016.

Lupker, M., France - Lanord, C., Lavé, J., Bouchez, J., Galy, V., Métivier, F., Gaillardet, J., Lartiges, B., and Mugnier, J. L.: A Rouse - based method to integrate the chemical composition of river sediments: Application to the Ganga basin, Journal of Geophysical Research: Earth Surface, 116, 2011.

Martin, J. H., Knauer, G. A., Karl, D. M., and Broenkow, W. W.: Vertex - Carbon Cycling in the Northeast Pacific, Deep-Sea Research Part a-Oceanographic Research Papers, 34, 267-285, 1987.

Mayer, L. M., Schick, L. L., Hardy, K. R., Wagai, R., and McCarthy, J.: Organic matter in small mesopores in sediments and soils, Geochimica et Cosmochimica Acta, 68, 3863-3872, 2004.

Mayorga, E., Aufdenkampe, A. K., Masiello, C. A., Krusche, A. V., Hedges, J. I., Quay, P. D., Richey, J. E., and Brown, T. A.: Young organic matter as a source of carbon dioxide outgassing from Amazonian rivers, Nature, 436, 538-541, 2005.

Meybeck, M.: Carbon, nitrogen, and phosphorus transport by world rivers, American Journal of Science, 282, 401-450, 1982.

Moreira - Turcq, P., Bonnet, M. P., Amorim, M., Bernardes, M., Lagane, C., Maurice, L., Perez, M., and Seyler, P.: Seasonal variability in concentration, composition, age, and fluxes of particulate organic carbon exchanged between the floodplain and Amazon River, Global Biogeochemical Cycles, 27, 119-130, 2013.

Priddle, J., Boyd, I., Whitehouse, M., Murphy, E., and Croxall, J.: Estimates of Southern Ocean primary production - constraints from predator carbon demand and nutrient drawdown, Journal of Marine Systems, 17, 275-288, 1998.

Riley, J. S., Sanders, R., Marsay, C., Le Moigne, F. A. C., Achterberg, E. P., and Poulton, A. J.: The relative contribution of fast and slow sinking particles to ocean carbon export, Global Biogeochemical Cycles, 26, GB1026, 2012.

Rosengard, S. Z., Lam, P. J., Balch, W. M., Auro, M. E., Pike, S., Drapeau, D., and Bowler, B.: Carbon export and transfer to depth across the Southern Ocean Great Calcite Belt, Biogeosciences, 12, 3953-3971, 2015. 
Rosenheim, B. E. and Galy, V.: Direct measurement of riverine particulate organic carbon age structure, Geophysical Research Letters, 39, L19703, 2012.

Rosenheim, B. E., Roe, K. M., Roberts, B. J., Kolker, A. S., Allison, M. A., and Johannesson, K. H.: River discharge influences on particulate organic carbon age structure in the Mississippi/Atchafalaya River System, Global Biogeochemical Cycles, 27, 154-166, 2013.

Rosenheim, B. E., Thorrold, S. R., and Roberts, M. L.: Accelerator mass spectrometry

${ }^{14} \mathrm{C}$ determination in $\mathrm{CO}_{2}$ produced from laser decomposition of aragonite, Rapid communications in mass spectrometry : RCM, 22, 3443-3449, 2008.

Rouse, H. (1950), Engineering Hydraulics, Wiley, New York.

Sabine, C. L., Feely, R. A., Gruber, N., Key, R. M., Lee, K., Bullister, J. L., Wanninkhof, R., Wong, C. S., Wallace, D. W. R., Tilbrook, B., Millero, F. J., Peng, T.-H., Kozyr, A., Ono, T., and Rios, A. F.: The Oceanic Sink for Anthropogenic $\mathrm{CO}_{2}$, Science, 305, 367-371, 2004.

Sarmiento, J. L., Hughes, T. M. C., Stouffer, R. J., and Manabe, S.: Simulated response of the ocean carbon cycle to anthropogenic climate warming, Nature, 393, 245249, 1998.

Sarmiento, J. L. and Le Quéré, C.: Oceanic Carbon Dioxide Uptake in a Model of Century-Scale Global Warming, Science, 274, 1346-1350, 1996.

Satinsky, B. M., Zielinski, B. L., Doherty, M., Smith, C. B., Sharma, S., Paul, J. H., Crump, B. C., and Moran, M. A.: The Amazon continuum dataset: quantitative metagenomic and metatranscriptomic inventories of the Amazon River plume, June 2010, Microbiome, 2, 1, 2014.

Trull, T. and Armand, L.: Insights into Southern Ocean carbon export from the $\delta^{13} \mathrm{C}$ of particles and dissolved inorganic carbon during the SOIREE iron release experiment, Deep Sea Research Part II: Topical Studies in Oceanography, 48, 2655-2680, 2001.

Volk, T. and Hoffert, M. I.: Ocean carbon pumps: Analysis of relative strengths and efficiencies in ocean-driven atmospheric $\mathrm{CO}_{2}$ changes, Geophysical Monographs, 32, 99-110, 1985.

Wakeham, S. G., Lee, C., Hedges, J. I., Hernes, P. J., and Peterson, M. J.: Molecular indicators of diagenetic status in marine organic matter, Geochimica et Cosmochimica Acta, 61, 5363-5369, 1997.

Ward, N. D., Keil, R. G., Medeiros, P. M., Brito, D. C., Cunha, A. C., Dittmar, T., Yager, P. L., Krusche, A. V., and Richey, J. E.: Degradation of terrestrially derived macromolecules in the Amazon River, Nature Geoscience, 6, 530-533, 2013.

Wilson, S. E., Steinberg, D. K., and Buesseler, K. O.: Changes in fecal pellet characteristics with depth as indicators of zooplankton repackaging of particles in the mesopelagic zone of the subtropical and subarctic North Pacific Ocean, DeepSea Research Part II-Topical Studies in Oceanography, 55, 1636-1647, 2008. 


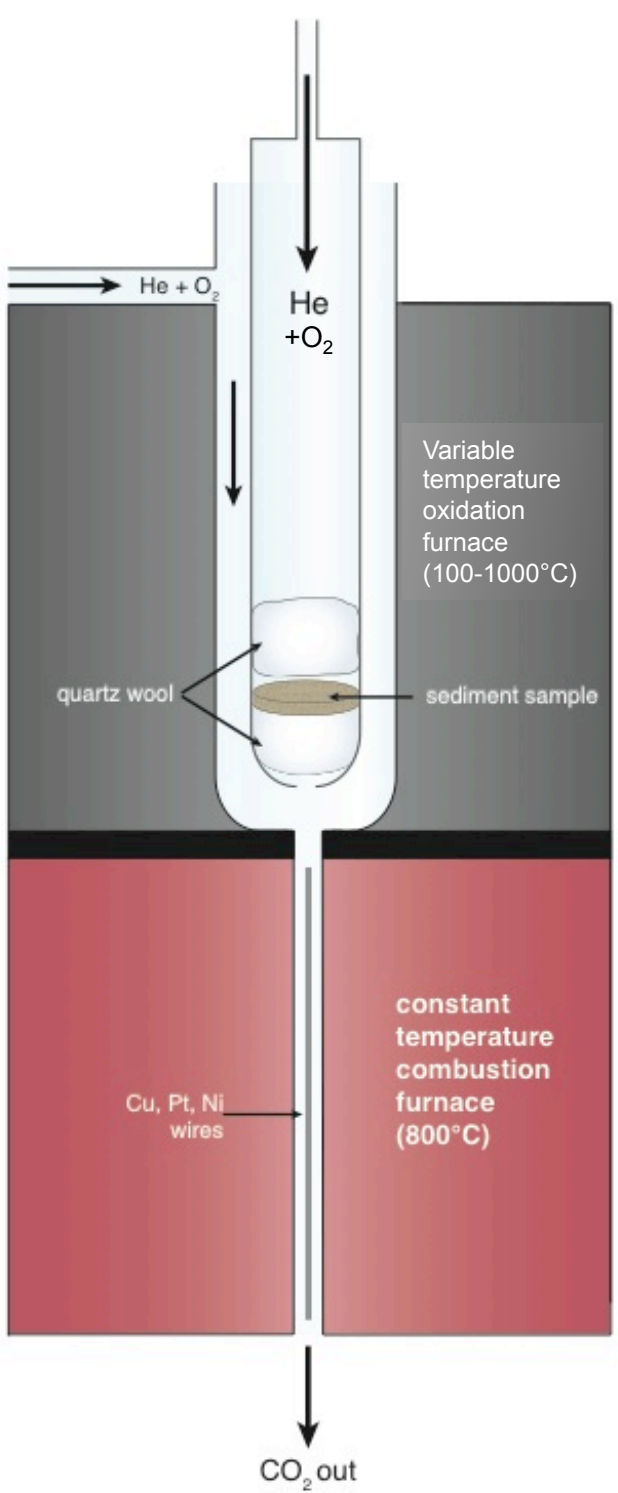

Figure 1. Schematic of the ramped pyrolysis/oxidation (RPO) unit at the National Ocean Sciences Accelerator Mass Spectrometery facility at WHOI. Adapted from (Fornace, 2016). 


\section{Chapter 2:}

\section{Carbon export and transfer to depth across the Southern Ocean Great Calcite Belt}

Adapted from manuscript published Biogeosciences, cited as follows:

Rosengard, S. Z., Lam, P. J., Balch, W. M., Auro, M. E., Pike, S., Drapeau, D., and Bowler, B.: Carbon export and transfer to depth across the Southern Ocean Great Calcite Belt, Biogeosciences, 12, 3953-3971, doi:10.5194/bg-12-3953-2015, 2015.

Under the Creative Commons Attribution 3.0 License, I am authorized to share this manuscript as a chapter of my thesis dissertation. I fully acknowledge the author contributions to the work. 


\begin{abstract}
Sequestration of carbon by the marine biological pump depends on the processes that alter, remineralize and preserve particulate organic carbon (POC) during transit to the deep ocean. Here, we present data collected from the Great Calcite Belt, a calcite-rich band across the Southern Ocean surface, to compare the transformation of POC in the euphotic and mesopelagic zones of the water column. The ${ }^{234} \mathrm{Th}$-derived export fluxes and size-fractionated concentrations of POC, particulate inorganic carbon (PIC), and biogenic silica (BSi) were measured from the upper $1000 \mathrm{~m}$ of 27 stations across the Atlantic and Indian sectors of the Great Calcite Belt. POC export out of the euphotic zone was correlated with BSi export. PIC export was not, but did correlate positively with POC flux transfer efficiency. Moreover, regions of high BSi concentrations, which corresponded to regions with proportionally larger particles, exhibited higher attenuation of $>51 \mu \mathrm{m}$ POC concentrations in the mesopelagic zone. The interplay among POC size partitioning, mineral composition and POC attenuation suggests a more fundamental driver of POC transfer through both depth regimes in the Great Calcite Belt. In particular, we argue that diatom-rich communities produce large and labile POC aggregates, which generate high export fluxes but also drive more remineralization in the mesopelagic zone. We observe the opposite in communities with smaller calcifying phytoplankton, such as coccolithophores. We hypothesize that these differences are influenced by inherent differences in the lability of POC exported by different phytoplankton communities.
\end{abstract}

\title{
$1 \quad$ Introduction
}

The biological pump sequesters atmospheric carbon dioxide $\left(\mathrm{CO}_{2}\right)$ in the ocean (Volk and Hoffert, 1985) by way of phytoplankton-driven $\mathrm{CO}_{2}$ fixation, followed by the sinking of this fixed particulate organic carbon (POC) as aggregates and fecal pellets down the water column (Riley et al., 2012). The quantity per unit area and time of POC exiting the base of the euphotic zone defines the export flux, while export efficiency represents the fraction of bulk primary production comprising this flux (Buesseler, 1998). In the mesopelagic zone (from the base of the euphotic zone to $\sim 1000 \mathrm{~m}$ ), export flux attenuates due to remineralization mediated by zooplankton grazing and bacteria 
(Buesseler and Boyd, 2009; Giering et al., 2014; Martin et al., 1987). The flux of this processed organic carbon leaving the mesopelagic zone, only $\leq 10 \%$ of export flux, directly scales with the quantity of atmospheric $\mathrm{CO}_{2}$ sequestered by the marine biological pump over hundreds to thousands of years (Kwon et al., 2009).

On average, only $\sim 1 \%$ of the organic matter produced by phytoplankton in the surface reaches the deep sea (Martin et al., 1987). However, export and sequestration flux vary widely by region, as do export efficiencies and attenuation of export flux ( Martin et al., 1987; Buesseler et al., 2007; Thomalla et al., 2008; Buesseler and Boyd, 2009; Henson et al., 2012b; Henson et al., 2011). Such variations may drive observed differences in the weight percent of organic carbon deposited at the sediment surface (Hedges and Oades, 1997), suggesting that the overall strength of the biological pump as a carbon sink is not globally uniform. These geographical differences have spurred decades of research into how mechanisms in the shallower ocean - the euphotic and mesopelagic zones - alter sinking particulate organic matter during vertical transit.

As an example, Armstrong et al. (2002), Klaas and Archer (2002) and (Francois et al. (2002) posited that mineral associations with sinking organic carbon could explain these variations. Their ballast hypothesis model suggested that minerals enhanced the biological pump (1) by increasing the density, and consequently, the sinking speed of particulate organic matter and (2) by inhibiting organic carbon remineralization down the water column. Expediting vertical transit decreases the time for remineralization to act on sinking particulate organic matter, increasing its chances of reaching the deep sea. The authors observed that calcite flux in the bathypelagic zone $(>1000 \mathrm{~m})$ explains roughly half of the variation in the magnitude of POC flux reaching the deep sea (Klaas and Archer, 2002), and may also account for some of the observed geographical variation in POC flux attenuation with depth (Francois et al., 2002).

In its conception and infancy, the ballast hypothesis was based upon observed correlations between mineral and organic carbon fluxes in the deep (>1000 m) sea. Yet, evidence for the ballast mechanism in the euphotic and mesopelagic zones remains equivocal, as deeper correlations are scarcely matched by shallower ocean observations (Le Moigne et al., 2012). Several surface regions do not exhibit ballast correlations between mineral flux and POC flux (e.g., Thomalla et al., 2008; Henson et al., 2012b). In 
the Atlantic and Southern Oceans, (Le Moigne et al., 2012) found a significant fraction of POC export flux to remain unassociated with minerals altogether. Moreover, tank incubations simulating POC and mineral suspensions yield conflicting results: some have observed mineral associations to increase aggregate sinking rates (Engel et al., 2009), while others find no such effect (Passow and De la Rocha, 2006). De La Rocha et al. (2008) even suggest that sticky polymers from POC might ballast sinking minerals, rather than vice-versa.

The scarcity of evidence supporting a shallow ocean ballast mechanism suggests that the transit of particulate organic carbon in the surface, mesopelagic and deeper ocean is mechanistically de-coupled (Lomas et al., 2010; Lam et al., 2011). Indeed, the debate surrounding the ballast hypothesis arises from a deeper issue of whether the mechanisms that influence carbon export from the euphotic zone are the same as those that control its remineralization in the mesopelagic zone, and/or its transfer beyond the mesopelagic zone into the deep sea.

The following report compares the export of organic carbon from the euphotic zone with its transfer through the mesopelagic zone across the region of the Great Calcite Belt (Balch et al., 2011a; Balch et al., 2014; Fig. 1). Spanning across the Southern Ocean, particularly between the Subtropical and Polar Fronts, the Great Calcite Belt defines a highly reflective band observed from space during each austral spring and summer. Its high reflectivity is caused by calcite-rich surface waters produced by coccolithophore blooms in the Southern Ocean. In this zone, coccolithophores are more abundant than in regions north and south of the Belt. South of the Polar Front, coccolithophore abundances decline dramatically as dissolved silica concentrations increase and diatoms flourish (Balch et al., 2011a).

Spanning a large range in surface mineral concentrations, primary productivity, and phytoplankton community composition (Balch et al., 2011a), the Great Calcite Belt provides an excellent opportunity to assess the processes controlling organic carbon export, export efficiency, and attenuation of POC concentration ([POC]) with depth. Here, we report estimates of ${ }^{234} \mathrm{Th}$-derived POC fluxes and [POC] through both the euphotic and mesopelagic zones within the Atlantic and Indian sectors of the Great Calcite Belt. We focus on the upper $1000 \mathrm{~m}$ of the Great Calcite Belt because the 
attenuation of POC flux and concentration is most dramatic within this depth interval (Martin et al., 1987; Lam et al., 2011). As the following discussion illuminates, this study additionally weighs the ballast hypothesis against other mechanisms hypothesized to control the transfer of organic carbon through the water column, and ultimately into the deep sea, where carbon residence time modulates atmospheric $\mathrm{pCO}_{2}$ and climate over hundreds to thousands of years (Kwon et al., 2009).

\section{Methods}

\section{1 $\quad$ Field site}

Samples from the Great Calcite Belt were collected during two research cruises, GB1 and GB2, which transited the Atlantic and Indian sectors of the Great Calcite Belt during the austral summer of 2011 and 2012, respectively (Fig. 1), concurrent with the putative coccolithophore bloom (Balch et al., 2011a). In 2011, for cruise GB1 (MV1101), the $R / V$ Melville crossed the Atlantic sector from Punta Arenas, Chile to Cape Town, South Africa, sampling between $39^{\circ} \mathrm{S}$ and $59^{\circ} \mathrm{S}$. One year later, for cruise GB2 (RR1202), the $R / V$ Revelle crossed the Indian sector from Durban, South Africa to Perth, Australia, sampling between $37^{\circ} \mathrm{S}$ and $60^{\circ} \mathrm{S}$ (Table 1). Both cruise tracks crossed the Subtropical, Subantarctic and Polar fronts, which are approximately located at $40^{\circ} \mathrm{S}, 45^{\circ} \mathrm{S}$ and 52 ${ }^{\circ}$ S (e.g., Belkin and Gordon, 1996; Sokolov and Rintoul, 2009), respectively, defining observed shifts in temperature and nutrient characteristics of the surface ocean.

Each day during GB1 and GB2, 30-L Niskin samples were collected pre-dawn for measuring primary production. A Biospherical Instruments (San Diego, CA) sensor was mounted on the $\mathrm{CTD} /$ rosette and referenced to a deck sensor mounted on the ship's superstructure to measure Photosynthetically Available Radiation (PAR) during the casts. Water was then sampled at fixed light depths relative to surface irradiance to match light levels in deck-board incubators: $36.5 \%, 21.1 \%, 11.7 \%, 3.55 \%, 1.93 \%$ and $0.28 \%$. The light depths were calculated two ways: (a) between 10:00 and 14:00 h local time (during daylight hours), percentages of surface irradiance were derived directly from the downcast PAR profile immediately preceding bottle firing, or (b) at all other times, the 
light levels were back-calculated from the previously-determined relationship between beam transmittance and diffuse attenuation of PAR (Balch et al., 2011b). From these casts, primary production rates were measured using the ${ }^{14} \mathrm{C}$ microdiffusion technique (Paasche and Brubak, 1994) with modifications by Balch et al. (2000) (see also Fabry and Balch, 2010).

\subsection{Size-fractionated particle collection}

We report measurements of total and particulate ${ }^{234}$ Th activity and sizefractionated particle composition from 27 stations (Fig. 1; Table 1).

Size-fractionated particles were collected at eight depths in the upper $1000 \mathrm{~m}$ of fourteen stations from GB1 and thirteen stations from GB2, using modified battery operated in-situ pumps (McLane WTS-LV). The modified pumps directed seawater through two flow paths (Lam et al., 2015), each of which passed through a "miniMULVFS" filter holder designed to retain large particles (Bishop et al., 2012). Seawater first passed through $51 \mu \mathrm{m}$ polyester pre-filters in both filter holders for collection of large $(>51 \mu \mathrm{m})$ size-fraction particles, and then through paired $0.8 \mu \mathrm{m}$ polyethersulfone $\left(\right.$ Supor $^{\mathrm{TM}}$ ) filters in one flow path and paired $1 \mu \mathrm{m}$ quartz fiber (Whatman ${ }^{\mathrm{TM}} \mathrm{QMA}$ ) filters in the other flow path, both of which collected small $(<51 \mu \mathrm{m})$ size-fraction particles. An average of $200 \mathrm{~L}$ and $500 \mathrm{~L}$ of seawater passed through the Supor and QMA flow paths over 1-2.5 hours, respectively. Immediately after collection, half to all of the $>51 \mu \mathrm{m}$ size-fraction particles from one flow path were rinsed off of the polyester prefilters and onto $25 \mathrm{~mm} 1 \mu \mathrm{m}$ Sterlitech silver filters using $0.2 \mu \mathrm{m}$-filtered seawater, and dried at $50^{\circ} \mathrm{C}$ for subsequent analysis of particulate ${ }^{234} \mathrm{Th}$, particulate organic carbon (POC), and particulate inorganic carbon (PIC, or calcium carbonate). Subsamples of QMA filters were likewise dried at $50^{\circ} \mathrm{C}$ for ${ }^{234} \mathrm{Th}$ and POC analysis in the $<51 \mu \mathrm{m}$ sizefraction. Finally, the polyester pre-filters from the other flow path and Supor filters were dried in a laminar flow hood at room temperature.

In the euphotic zone, where most POC is produced, these operationally defined size fractions allude primarily to the structure of phytoplankton communities producing POC (e.g., large diatoms would be found in $>51 \mu \mathrm{m}$ size-fraction particles). In the 
mesopelagic zone, which extends from the base of the euphotic zone to $1000 \mathrm{~m}$ in depth, $>51 \mu \mathrm{m}$ POC is predominantly comprised of phytoplankton and bacterial biomass that has been repackaged into aggregates and fecal pellets. The $>51 \mu \mathrm{m}$ particles collected at station GB1- 85 illustrate these different size-fraction interpretations by depth. Shallower particles collected at $25 \mathrm{~m}$ and $73 \mathrm{~m}$, the base of the euphotic zone, are mainly comprised of intact phytoplankton cells (Figs. 2a, 2b). By contrast, deeper particles collected at 173 $\mathrm{m}$ exhibit the features of particulate aggregates and fecal pellets (Fig. 2c).

\subsection{Particle composition}

Bulk concentrations of POC, PIC, biogenic silica (BSi), and particulate ${ }^{234} \mathrm{Th}$ activity were measured in both $<51 \mu \mathrm{m}$ and $>51 \mu \mathrm{m}$ fractions of particles collected at each station. POC concentrations were measured at all depths of the profiles, while [PIC] and [BSi] were mainly measured at select depths above $200 \mathrm{~m}$ and at the deepest depth (800-1000 m) of the profile. Particulate ${ }^{234}$ Th activities in all sub-fractions of $>51 \mu \mathrm{m}(25$ $\mathrm{mm}$ silver filters) and $<51 \mu \mathrm{m}$ (25 mm QMA filters) samples were measured using low

level Risø beta counters immediately on the ship and in the lab at least $\operatorname{six}{ }^{234} \mathrm{Th}$ half-lives post-collection for background activity.

After counting for ${ }^{234} \mathrm{Th}$ background activity, $\sim 25 \%$ of the silver filter $(\sim 115 \mathrm{~L}$ equivalent) was fumed overnight (12-17 hours) with concentrated hydrochloric acid to remove inorganic carbon, before measuring $>51 \mu \mathrm{m}[\mathrm{POC}]$ using an elemental $\mathrm{CHN}$ analyzer. A similar protocol was followed to measure $<51 \mu \mathrm{m}$ [POC] from one $12 \mathrm{~mm}$ diameter subsample of each QMA filter, representing $\sim 1 \%$ of the entire sample $(\sim 5 \mathrm{~L}$ equivalent). Vertical profiles of $>51 \mu \mathrm{m}$ and $<51 \mu \mathrm{m}$ [POC] between the base of the euphotic zone and the deepest measurement at $800-1000 \mathrm{~m}$ were fitted to a power-law function to describe the attenuation of [POC] with depth, based on a function first applied to POC flux by Martin et al. (1987) and then analogously to POC concentration by Lam and Bishop (2007),

$$
[\mathrm{POC}]_{\mathrm{z}}=[\mathrm{POC}]_{0}\left(\frac{z}{z_{P A R}}\right)^{-b}
$$

where, at most stations, $\mathrm{Z}_{\mathrm{PAR}}$ represents the depth of $0.3 \%$ photosynthetically available radiation (see Section 2.4). The exponent $\mathrm{b}$ represents the attenuation coefficient, with 
higher attenuation coefficients (more negative exponents) for profiles with greater attenuation of $>51 \mu \mathrm{m}[\mathrm{POC}]$ with depth. We focus our discussion on the attenuation of $>51 \mu \mathrm{m}[\mathrm{POC}]$, because we assume that they contribute disproportionately to sinking fluxes compared to the $<51 \mu \mathrm{m}$ size fraction (McCave, 1975; Lam and Bishop, 2007; Lam et al., 2011). Figure 3 and Table 2 show all significant $(p<0.05)$ power law fits for $>51 \mu \mathrm{m}[\mathrm{POC}]$ profiles.

PIC in the samples was assumed to be biomineral calcium carbonate $\left(\mathrm{CaCO}_{3}\right)$, and was derived from particulate calcium (Ca) corrected for salt $\mathrm{Ca}$ using a seawater $0.0382 \mathrm{Ca}: \mathrm{Na}$ (g:g) ratio (Lam and Bishop, 2007; Pilson, 2012). In the in-situ pump samples, salt-derived Ca typically accounted for $\sim 60 \%$ of total $\mathrm{Ca}$. The $>51 \mu \mathrm{m}$ PIC sizefraction concentrations were measured mainly in subsamples of remaining pre-filter material and occasionally in sub-fractions of the silver filters, if the former were unavailable. The $<51 \mu \mathrm{m}$ size fraction [PIC] was measured in three $12 \mathrm{~mm}$ circular QMA subsamples, representing $\sim 15 \mathrm{~L}$ or $\sim 3 \%$ of the sample. Subsamples were leached in $0.6 \mathrm{~N}$ ultrapure Sea-Star ${ }^{\mathrm{TM}}$ Baseline hydrochloric acid $(\mathrm{HCl})$ at $60^{\circ} \mathrm{C}$ for $12-16$ hours. The leachate was subsequently filtered through a $0.4 \mu \mathrm{m}$ polycarbonate membrane filter, diluted to $0.12 \mathrm{~N} \mathrm{HCl}$, and spiked with $1 \mathrm{ppb}$ of Indium as an internal standard. The spiked leachate solution was then analyzed for $\mathrm{Ca}, \mathrm{Na}$ and $\mathrm{P}$ using an Element 2 sectorfield inductively-coupled plasma mass spectrometer (ICP-MS) in medium and high resolution. Counts per second were converted to concentration using external mixed element standard curves.

For measuring $>51 \mu \mathrm{m}$ and $<51 \mu \mathrm{m}$ [BSi], prefilter or Supor subsamples, respectively, were leached in $0.2 \mathrm{~N}$ sodium hydroxide at $85^{\circ} \mathrm{C}$ for one hour, and analyzed by standard spectrophotometric detection of the blue silico-molybdate complex in each leachate within 24 hours of the leach (Strickland and Parsons, 1968; Brzezinski and Nelson, 1989). Absorbance through each sample was converted to concentration using an external Si standard curve.

\section{$2.4 \quad{ }^{234}$ Th-derived flux estimates}


Particle fluxes were estimated at each station by measuring the water-column disequilibrium between ${ }^{234} \mathrm{Th}$ and ${ }^{238} \mathrm{U}$ in the upper $350 \mathrm{~m}$ of the water-column (Savoye et al., 2006). ${ }^{234} \mathrm{Th}$ is the radioactive daughter of ${ }^{238} \mathrm{U}$ with a short enough half-life (24.1 days) relative to ${ }^{238} \mathrm{U}$ such that it is assumed to be in secular equilibrium with its parent isotope in the absence of particle scavenging (i.e., ${ }^{234} \mathrm{Th}$ activity $={ }^{238} \mathrm{U}$ activity).

Disequilibria between the two isotope activities in the water column are attributed to the scavenging of ${ }^{234} \mathrm{Th}$ by sinking particles (Savoye et al., 2006). Integrating the deficit in ${ }^{234} \mathrm{Th}$ relative to ${ }^{238} \mathrm{U}$ provides a measure of particle flux down the water column (Buesseler et al., 2006). Because of the short half-life of ${ }^{234} \mathrm{Th}$, deviation from secular equilibrium exists only in regions of high particle flux. Thus, ${ }^{234} \mathrm{Th}$-based flux estimates are most frequently applied in the euphotic zone of the ocean where particle export is maximal.

${ }^{234} \mathrm{Th}-{ }^{238} \mathrm{U}$ deficits were determined by measuring total water-column activities of both isotopes. ${ }^{238} \mathrm{U}$ activity $\left(\mathrm{A}_{\mathrm{U}-238}\right)$ profiles were calculated from salinity by the following relationship (Owens et al., 2011):

$$
A_{\mathrm{U}-238}\left(\mathrm{dpm} \mathrm{L}{ }^{-1}\right)=(0.0786 \times \text { Salinity })-0.315
$$

Total water-column ${ }^{234} \mathrm{Th}$ activity $\left(\mathrm{A}_{\mathrm{Th}-234}\right)$ profiles were determined from $4 \mathrm{~L}$ seawater samples collected by CTD casts down to 300-350 $\mathrm{m}$ at each station (Pike et al., 2005). Shortly after collection, each $4 \mathrm{~L}$ seawater sample was acidified to $\mathrm{pH} 2$ using concentrated nitric acid $\left(\mathrm{HNO}_{3}\right)$, spiked with $1 \mathrm{~g}$ of ${ }^{230} \mathrm{Th}$ of a known activity (50.06 dpm $\mathrm{g}^{-1}$ ) as a yield monitor, equilibrated for 8 hours, and finally brought up to $\mathrm{pH} 8.5$ using ammonium hydroxide $\left(\mathrm{NH}_{4} \mathrm{OH}\right)$ (van der Loeff et al., 2006). Manganese chloride $\left(\mathrm{MnCl}_{2}\right)$ and potassium permanganate $\left(\mathrm{KMnO}_{4}\right)$ were added to the neutralized seawater to form a manganese oxide $\left(\mathrm{MnO}_{2}\right)$ precipitate, which efficiently scavenges both natural ${ }^{234} \mathrm{Th}$ and added ${ }^{230} \mathrm{Th}$. After 12 hours, the precipitate was filtered onto a quartz fiber filter, dried at $50^{\circ} \mathrm{C}$, and then mounted beneath a sheet of Mylar and aluminum foil. ${ }^{234} \mathrm{Th}$ activity in the precipitate was measured on board by low level Risø beta counters and post-cruise after at least $\operatorname{six}{ }^{234} \mathrm{Th}$ half-lives for background activity. The ${ }^{230} \mathrm{Th}$ spike was recovered by fully dissolving the $\mathrm{MnO}_{2}$ precipitate, adding a $1 \mathrm{~g}$ spike of ${ }^{229} \mathrm{Th}$ of a known activity ( $69.74 \mathrm{dpm} \mathrm{g}^{-1}$ ), and measuring ${ }^{229} \mathrm{Th}^{230} \mathrm{Th}$ ratios on an Element 2 sectorfield ICP-MS in low resolution. Recovery of ${ }^{230} \mathrm{Th}$ spike was derived from this ratio, and 
used to correct for inefficiencies in the scavenging of total seawater ${ }^{234} \mathrm{Th}$ by $\mathrm{MnO}_{2}$ precipitation.

To calibrate beta counting efficiency for each cruise, total deep water (i.e., below $2000 \mathrm{~m}){ }^{234} \mathrm{Th}$ activities were compared to total deep water ${ }^{238} \mathrm{U}$ activities, as measured in 4-5 replicate samples from 2-3 deep water CTD casts during each cruise (at $5000 \mathrm{~m}$ during GB1, and at $2500 \mathrm{~m}$ during GB2). Beta counting efficiencies were adjusted such that ${ }^{234} \mathrm{Th}$ and ${ }^{238} \mathrm{U}$ activities were equal in these deep measurements, as secular equilibrium would be expected at such depths. We only report upper water-column activities $(<350 \mathrm{~m})$ after correcting for experimental efficiencies in both the seawater collection process and beta detector counting. Uncertainties in the total ${ }^{234} \mathrm{Th}$ activity profiles averaged $4.5 \%$ and were propagated from errors associated with counting statistics, recoveries, and beta-counting efficiency.

To calculate ${ }^{234} \mathrm{Th}$ export flux, ${ }^{234} \mathrm{Th}$ activity deficits were integrated down to the base of the euphotic zone (ZPAR) (Buesseler et al., 2008; Thomalla et al., 2008):

$$
{ }^{234} \mathrm{Th} \text { Flux }\left(\mathrm{dpm} \mathrm{m} \mathrm{m}^{-2} \mathrm{~d}^{-1}\right)=\int_{0}^{z_{P A R}}\left(A_{\mathrm{U}-238}-A_{\mathrm{Th}-234}\right) d z
$$

At most stations, the export depth, ZPAR, was chosen to be the depth where light levels were $0.3 \%$ of surface-level PAR. The exception was station GB2-27, which did not include a PAR measurement profile. For this station, the $\mathrm{Z}_{\mathrm{PAR}}$ value of $105 \mathrm{~m}$ was defined as the depth where the transmissometry-based particle concentration decreased. These export depths were compared to one additional metric describing particle concentration in seawater: the depths where ${ }^{234} \mathrm{Th}$ and ${ }^{238} \mathrm{U}$ activities re-established secular equilibrium, or $\mathrm{Z}_{\mathrm{Th} / \mathrm{U}}$. We explore the sensitivity of ${ }^{234} \mathrm{Th}$ flux estimates to choice of $\mathrm{Z}_{\mathrm{PAR}}$ in Sects. 3 and 4.1.

${ }^{234}$ Th flux estimates were converted to POC, PIC and BSi fluxes by multiplication with ratios of $>51 \mu \mathrm{m}$ POC, PIC, and BSi concentrations to particulate ${ }^{234}$ Th activity in samples at Z ZAR (Thomalla et al., 2008; Sanders et al., 2010):

$$
\begin{aligned}
& \text { POC Flux }\left(\mu \mathrm{mol} \mathrm{m}^{-2} \mathrm{~d}^{-1}\right)=[\mathrm{POC}]: A_{\mathrm{Th}-234} \times{ }^{234} \mathrm{Th} \text { Flux }\left(\mathrm{dpm} \mathrm{m}^{-2} \mathrm{~d}^{-1}\right) \\
& \text { PIC Flux }\left(\mu \mathrm{mol} \mathrm{m}{ }^{-2} \mathrm{~d}^{-1}\right)=[\mathrm{PIC}]: A_{\mathrm{Th}-234} \times{ }^{234} \text { Th Flux }\left(\mathrm{dpm} \mathrm{m}{ }^{-2} \mathrm{~d}^{-1}\right) \\
& \text { Si Flux }\left(\mu \mathrm{mol} \mathrm{m}{ }^{-2} \mathrm{~d}^{-1}\right)=[\mathrm{BSi}]: A_{\mathrm{Th}-234} \times{ }^{234} \text { Th Flux }\left(\mathrm{dpm} \mathrm{m}{ }^{-2} \mathrm{~d}^{-1}\right)
\end{aligned}
$$

\subsection{Interpolation of data}


In all cases where ${ }^{234} \mathrm{Th}$ activity, $>51 \mu \mathrm{m}$ and $<51 \mu \mathrm{m}[\mathrm{POC}]$ and mineral concentrations, and $>51 \mu \mathrm{m}$ particulate ${ }^{234} \mathrm{Th}$ measurements were unavailable at $\mathrm{Z}_{\mathrm{PAR}}$, linear interpolations between the sampling depths above and below ZPAR were used to estimate a value at the export depth (Table 1). The $>51 \mu \mathrm{m}$ and $<51 \mu \mathrm{m}$ size-fraction POC concentrations were interpolated by the power law attenuation function when fits were significant $(\mathrm{p}<0.05)$, or linearly when these power-law fits were not significant or inconsistent with the broader shape of the $[\mathrm{POC}]$ profile at that particular station. In general, corresponding POC: ${ }^{234} \mathrm{Th}, \mathrm{BSi}:{ }^{234} \mathrm{Th}$, and PIC: ${ }^{234} \mathrm{Th}$ ratios are quotients of these interpolated values except as noted in Tables 2 and 3.

\section{$3 \quad$ Results}

${ }^{234} \mathrm{Th}$ activity profiles were measured over the upper $300-350 \mathrm{~m}$ at the 27 stations of cruises GB1 and GB2 (Fig. 4; Appendix A, Table S1). Each activity profile is associated with two metrics that have been used in previous studies to define the export depth (see Section 2.4): the base of the euphotic zone ( $\left.Z_{P A R}\right)$, which we define at $0.3 \%$ surface photosynthetically available radiation (PAR) (e.g., Buesseler and Boyd (2009), and $\mathrm{z}_{\mathrm{Th} / \mathrm{U}}$, where ${ }^{234} \mathrm{Th}$ and ${ }^{238} \mathrm{U}$ activities re-establish secular equilibrium (Table 1). In most stations, profiles exhibited ${ }^{234} \mathrm{Th}$ activity deficits over a range from surface to $75-$ $170 \mathrm{~m}$ in depth, below which ${ }^{234} \mathrm{Th}$ activity generally returned to secular equilibrium with ${ }^{238} \mathrm{U}$ activity, within error. The notable exceptions were profiles at stations GB1-6, and GB1-16, which did not return to secular equilibrium by $170 \mathrm{~m}$ in depth. Considering that stations GB1-6 and GB1-16 are closest to shore, their sustained ${ }^{234}$ Th deficits may have been influenced by lateral advection of particles from the continental shelf. At these stations, $\mathrm{z}_{\mathrm{Th} / \mathrm{U}}$ depths were approximated by the depth below which ${ }^{234} \mathrm{Th}$ activities remain constant with depth. For example, at station GB1-6, $\mathrm{z}_{\mathrm{Th} / \mathrm{U}}=130 \mathrm{~m}$ because below this depth ${ }^{234} \mathrm{Th}$ activities remained relatively constant.

In the Atlantic sector, sampled in January - February 2011, all observed ZPAR depths were significantly shallower than $\mathrm{z}_{\mathrm{Th} / \mathrm{U}}$ depths (Student's t-test $\mathrm{p}<0.05$ ); on average, $\mathrm{Z}_{\mathrm{PAR}}$ was $66 \pm 44 \%$ shallower than $\mathrm{z}_{\mathrm{Th} / \mathrm{U}}$. By contrast, in the Indian sector, 
sampled roughly a year later in February - March 2012, ZPAR was not significantly different from $\mathrm{z}_{\mathrm{Th} / \mathrm{U}}(\mathrm{p}>0.05)$, and the average relative difference was $-6 \pm 29 \%$. In general, when water-column ${ }^{234} \mathrm{Th}$ activity is at steady-state, the euphotic zone should correspond to the region of ${ }^{234} \mathrm{Th}$ deficit relative to ${ }^{238} \mathrm{U}$ (Buesseler et al., 2008; Buesseler and Boyd, 2009), i.e., $\mathrm{z}_{\mathrm{PAR}}$ should equal $\mathrm{z}_{\mathrm{Th} / \mathrm{U}}$.

Using integrated activity deficits, export fluxes of ${ }^{234} \mathrm{Th}$, POC, PIC, and BSi at ZPAR were estimated at the 27 sites (Figs. 5, 6; Table 3). Overall mean ${ }^{234} \mathrm{Th}$ fluxes at ZPAR were $1,413 \pm 432 \mathrm{dpm} \mathrm{m}^{-2} \mathrm{~d}^{-1}$ (mean \pm 1 s.d.), and ranged from 717 to $2,437 \mathrm{dpm} \mathrm{m}^{-2} \mathrm{~d}^{-1}$ at stations GB2-112 and GB1-6, respectively. Mean derived POC fluxes at ZPAR were 4.5 $\pm 3.9 \mathrm{mmol} \mathrm{m}^{-2} \mathrm{~d}^{-1}$, ranging from 0.97 to $20 \mathrm{mmol} \mathrm{m}^{-2} \mathrm{~d}^{-1}$ at stations GB2-112 and GB185 , respectively. Mean PIC fluxes were $1.2 \pm 1.7 \mathrm{mmol} \mathrm{m}^{-2} \mathrm{~d}^{-1}$, and ranged from 0.067 to $6.2 \mathrm{mmol} \mathrm{m}^{-2} \mathrm{~d}^{-1}$ at stations GB2-73 and GB1-59, respectively. Finally, mean BSi fluxes at $Z_{P A R}$ were $3.8 \pm 5.8 \mathrm{mmol} \mathrm{m}^{-2} \mathrm{~d}^{-1}$, ranging from 0.17 to $28 \mathrm{mmol} \mathrm{m}^{-2} \mathrm{~d}^{-1}$ at stations GB2-46 and GB1-85, respectively. Higher POC export stations frequently corresponded with higher BSi export stations (e.g., station GB1-85), but less so with higher PIC export stations.

The highest and lowest measured biomineral (PIC and BSi) fluxes at $\mathrm{Z}_{\mathrm{PAR}}$ were in GB1 and GB2, respectively, but mean values were not significantly different between ocean basins because of high variability within each basin (Fig. 6). However, mean POC fluxes at $Z_{P A R}$ were significantly higher in GB1 (mean \pm 1 s.d. $=6.0 \pm 4.9 \mathrm{mmol} \mathrm{m}^{-2} \mathrm{~d}^{-1}$ ) than in GB2 $\left(3.0 \pm 1.7 \mathrm{mmol} \mathrm{m}^{-2} \mathrm{~d}^{-1}\right)$ (Student's t-test $\left.\mathrm{p}>0.05\right)$. Because POC: ${ }^{234} \mathrm{Th}$ values did not differ between GB1 and GB2 $(p<0.05)$, we attribute this inter-basin difference in POC fluxes primarily to significantly higher ${ }^{234} \mathrm{Th}$ fluxes in GB1 $\left(1,574 \pm 463 \mathrm{dpm} \mathrm{m} \mathrm{m}^{-2}\right.$ $\left.\mathrm{d}^{-1}\right)$ relative to fluxes in GB2 $\left(1,240 \pm 330 \mathrm{dpm} \mathrm{m}^{-2} \mathrm{~d}^{-1}\right)$.

Further, there were significant latitudinal differences among export fluxes and particulate composition ratios in three temperature/nutrient regimes across both sectors (Fig.1; Table 4): (1) north of $45^{\circ} \mathrm{S}$, the approximate location of the Subantarctic front, where temperatures exceeded $\sim 10^{\circ} \mathrm{C}$; (2) south of $52^{\circ} \mathrm{S}$, the approximate location of the Polar Front (e.g., (Belkin and Gordon, 1996; Sokolov and Rintoul, 2009), where temperatures remained below $\sim 5^{\circ} \mathrm{C}$; and (3) between $45^{\circ} \mathrm{S}$ and $52^{\circ} \mathrm{S}$, where temperatures ranged from $\sim 5-10{ }^{\circ} \mathrm{C}$. The $>51 \mu \mathrm{m}$ size-fraction POC: $:^{234} \mathrm{Th}$ values at ZPAR 
were significantly lower in the most equatorward zone north of $45^{\circ} \mathrm{S}$, where average

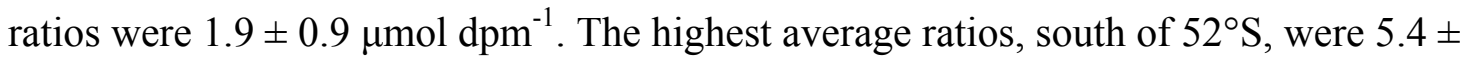
$3.0 \mu \mathrm{mol} \mathrm{dpm}{ }^{-1}$, illustrating the wide variation in POC: $:^{234} \mathrm{Th}$ ratios with ecosystem type (Buesseler et al., 2006; Jacquet et al., 2011). Likewise, zonally averaged POC export fluxes in the most equatorward zone $\left(2.7 \pm 2.3 \mathrm{mmol} \mathrm{m}^{-2} \mathrm{~d}^{-1}\right)$ were significantly lower than average fluxes in the most poleward zone $\left(8.0 \pm 6.3 \mathrm{mmol} \mathrm{m}^{-2} \mathrm{~d}^{-1}\right)$. BSi: ${ }^{234} \mathrm{Th}$ values were significantly different in all three zones, with highest average ratios south of $52^{\circ} \mathrm{S}$ $\left(7.1 \pm 4.1 \mu \mathrm{mol} \mathrm{dpm}{ }^{-1}\right)$ and smallest ratios north of $45^{\circ} \mathrm{S}\left(0.3 \pm 0.1 \mu \mathrm{mol} \mathrm{dpm}{ }^{-1}\right)$.

Similarly, average BSi export fluxes were also significantly different from each other in all three zones, with the greatest average values south of $52^{\circ} \mathrm{S}\left(10 \pm 8.7 \mathrm{mmol} \mathrm{m}^{-2} \mathrm{~d}^{-1}\right)$, and lowest values north of $45^{\circ} \mathrm{S}\left(0.35 \pm 0.16 \mathrm{mmol} \mathrm{m}^{-2} \mathrm{~d}^{-1}\right)$. Finally, PIC: $:^{234} \mathrm{Th}$ ratios, which averaged $0.72 \pm 0.85 \mu \mathrm{mol} \mathrm{dpm}^{-1}$ across all zones, and PIC export fluxes were not significantly different from each other in any zone defined by these latitudinal bands.

These fluxes are sensitive to the choice of export depth ( $\mathrm{z}_{\mathrm{PAR}}$ or $\mathrm{z}_{\mathrm{Th} / \mathrm{U}}$ ), not only because the export depth determines the magnitude of ${ }^{234} \mathrm{Th}$ flux by influencing the integrated ${ }^{234} \mathrm{Th}$ deficit, but also because the export depth determines which POC: ${ }^{234} \mathrm{Th}$ ratio best describes particles sinking from the chosen depth (Appendix A, Fig. S1). Across stations, the depth metrics $\mathrm{z}_{\mathrm{PAR}}$ and $\mathrm{z}_{\mathrm{Th} / \mathrm{U}}$ differed from each other to varying extents (Fig. 4; Table 1). As exemplified by stations GB1-92, GB1-16, and GB2-100, POC fluxes changed significantly between $\mathrm{z}_{\mathrm{PAR}}$ and $\mathrm{z}_{\mathrm{Th} / \mathrm{U}}$ (Figs. 5b, 5c; Appendix A, Table S2). At station GB1-92, where $\mathrm{z}_{\mathrm{PAR}}$ was $40 \mathrm{~m}$ shallower than $\mathrm{z}_{\mathrm{Th} / \mathrm{U}}$, POC flux decreased from $8.0 \mathrm{mmol} \mathrm{m}^{-2} \mathrm{~d}^{-1}$ at $\mathrm{Z}_{\mathrm{PAR}}$ to $5.1 \mathrm{mmol} \mathrm{m}^{-2} \mathrm{~d}^{-1}$ at $\mathrm{z}_{\mathrm{Th} / \mathrm{U}}$. In contrast, at station GB1-16, where $\mathrm{Z}_{\mathrm{PAR}}$ was $80 \mathrm{~m}$ shallower than $\mathrm{z}_{\mathrm{Th} / \mathrm{U}}$, POC fluxes increased from $5.9 \mathrm{mmol}$ $\mathrm{m}^{-2} \mathrm{~d}^{-1}$ to $6.6 \mathrm{mmol} \mathrm{m}^{-2} \mathrm{~d}^{-1}$. At station GB2-100, one of few stations where ZPAR was deeper than $\mathrm{z}_{\mathrm{Th} / \mathrm{U}}$, POC fluxes decreased from 3.3 to $1.5 \mathrm{mmol} \mathrm{m}^{-2} \mathrm{~d}^{-1}$ going deeper. At this station, the POC: ${ }^{234} \mathrm{Th}$ ratio at $\mathrm{z}_{\mathrm{Th} / \mathrm{U}}$ was $102 \%$ greater than ratios at $\mathrm{Z}_{\mathrm{PAR}}$, while ${ }^{234} \mathrm{Th}$ fluxes at $\mathrm{z}_{\mathrm{Th} / \mathrm{U}}$ were $6 \%$ greater than fluxes at $\mathrm{Z}_{\mathrm{PAR}}$, demonstrating that changes in particle composition disproportionately contributed to the observed difference in POC export at $\mathrm{Z}_{\mathrm{PAR}}$ and $\mathrm{z}_{\mathrm{Th} / \mathrm{U}}$. By contrast, at station GB1-16, the relative change in ${ }^{234} \mathrm{Th}$ fluxes from $\mathrm{Z}_{\mathrm{PAR}}$ to $\mathrm{Z}_{\mathrm{Th} / \mathrm{U}}(+29 \%)$ contributed more to the increase in POC flux with depth than the relative change in POC: ${ }^{.34} \mathrm{Th}$ ratio (-13\%). Finally, for station GB1-92, the relative 
change in ${ }^{234} \mathrm{Th}$ flux with depth (-19\%) was similar to the relative change in POC: ${ }^{234} \mathrm{Th}$ with depth (-21\%), demonstrating that the export flux estimate was equally sensitive to changes in both parameters.

\section{Discussion}

The following discusses these flux measurements in the context of other Southern Ocean observations, and hypotheses surrounding the transformation of sinking organic carbon within the euphotic and mesopelagic zones of the water column.

\subsection{Choice of export depth}

The two possible depths we use to calculate export flux, $\mathrm{z}_{\mathrm{PAR}}$ and $\mathrm{z}_{\mathrm{Th} / \mathrm{U}}$, are significantly different in the Atlantic sector, which influences the magnitude of flux estimated (see Section 3). We offer here two possible and not mutually exclusive explanations for why $\mathrm{z}_{\mathrm{Th} / \mathrm{U}}$ depths were on average deeper than $\mathrm{z}_{\mathrm{PAR}}$ depths at GB1 stations.

One hypothesis is that the ${ }^{234} \mathrm{Th}-{ }^{238} \mathrm{U}$ profiles used to calculate export fluxes may not have been at steady-state during the time of sampling on the GB1 cruise. Non-steady state conditions in the ${ }^{238} \mathrm{U}_{-}^{234} \mathrm{Th}$ system do occur during phytoplankton blooms, particularly during their decline and ascent (Savoye et al., 2006; Buesseler et al., 2009). For example, a recent and rapid increase in the near-surface particle concentration could decrease the depth of light penetration faster than the ${ }^{238} \mathrm{U}_{-}^{234} \mathrm{Th}$ system can adjust, leading to a $\mathrm{Z}_{\mathrm{PAR}}$ measured on station that is shallower than the $\mathrm{z}_{\mathrm{Th} / \mathrm{U}}$, which reflects conditions prior to the rapid increase. Since the GB1 cruise in the Atlantic sector took place a month earlier in the growing season (January-February 2011) than the GB2 cruise in the Indian sector (February-March 2012), the two sectors may have been sampled at different stages of the seasonal bloom, contributing to differences in agreement between $\mathrm{Z}_{\mathrm{PAR}}$ and $\mathrm{z}_{\mathrm{Th} / \mathrm{U}}$. Satellite chlorophyll time-series, if well-resolved, can shed light on how dynamic primary production was around the time of sampling at each station of GB1 and GB2, whether rapid (i.e., within three weeks) changes in particle production and sinking 
fluxes from a bloom could have decoupled ${ }^{234} \mathrm{Th}^{238} \mathrm{U}$ deficits from light profiles into the surface ocean of the Great Calcite Belt. Eight-day composites of chlorophyll imagery from December 2010 to February 2011 were required to overcome spatial patchiness in the data due to clouds, and indicate that the changes leading up to sampling during GB1 were not consistent across all stations where $\mathrm{z}_{\mathrm{PAR}}<\mathrm{z}_{\mathrm{Th} / \mathrm{U}}$. At several stations, chlorophyll concentrations declined towards the sampling date; at others, chlorophyll did not change or increased towards the sampling date. Moreover, out of the three stations where $\mathrm{Z}_{\mathrm{PAR}}=$ $\mathrm{Z}_{\mathrm{Th} / \mathrm{U}}$, only one exhibited relatively constant chlorophyll concentrations in the month preceding sampling. In GB2, where the differences between $\mathrm{z}_{\mathrm{PAR}}$ and $\mathrm{z}_{\mathrm{Th} / \mathrm{U}}$ were not significant, chlorophyll tended to be constant preceding more sampling stations. Nonetheless, as in GB1, several locations still experienced increasing or decreasing chlorophyll concentrations in the weeks before sampling, despite having a similar $\mathrm{Z}_{\mathrm{PAR}}$ and $\mathrm{z}_{\mathrm{Th} / \mathrm{U}}$.

The inability of the chlorophyll time-series to unequivocally resolve the differences between $\mathrm{Z}_{\mathrm{PAR}}$ and $\mathrm{z}_{\mathrm{Th} / \mathrm{U}}$ points to other possible mechanisms underlying the discrepancy. One other mechanism, which does not necessarily preclude non-steady state in the ${ }^{234} \mathrm{Th}$ system, is sinking particle production below the euphotic zone ZPAR (Trull et al., 2008). Physical aggregation and fecal pellet production by zooplankton grazing in the region below $Z_{P A R}$ (i.e., the upper mesopelagic zone) can increase the speed and total abundance of sinking of particles by transforming phytoplankton biomass exiting the euphotic zone, thereby contributing to sustained ${ }^{234}$ Th deficits below Z ZAR (Steinberg et al., 2008; Wilson et al., 2008; Abramson et al., 2010). Why this occurs only in GB1 and not GB2 is not known.

For example, the $\sim 70 \mathrm{~m}$ difference in $\mathrm{z}_{\mathrm{PAR}}$ and $\mathrm{z}_{\mathrm{Th} / \mathrm{U}}$ at a station like GB1-85 (Table 1) may be attributed to additional production or repackaging of sinking particles in the upper mesopelagic zone, causing ${ }^{234}$ Th deficits to persist beyond the euphotic zone of

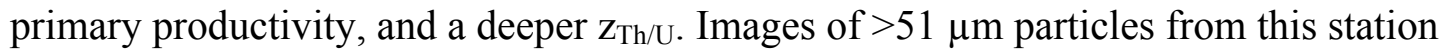
highlight the changing nature of $>51 \mu \mathrm{m}$ particles with depth (Fig. 2), from primarily large phytoplankton in the euphotic zone to predominantly fecal pellets in the mesopelagic zone. The difference in POC fluxes measured at both depths may arise from the evolution of these particles during vertical transit, from predominantly intact and 
relative buoyant diatoms at $\mathrm{Z}_{\mathrm{PAR}}$ to degraded, sinking fecal pellets produced between $\mathrm{Z}_{\mathrm{PAR}}$ and $\mathrm{z}_{\mathrm{Th} / \mathrm{U}}$.

Going forward, it is most important to keep in mind how the choice of export depth impacts flux estimates. For this study, all export fluxes are defined by ZPAR so that they can be compared with integrated primary production measurements (Buesseler and Boyd, 2009). Non-steady-state effects of ${ }^{234}$ Th profiles on export fluxes will not be considered further because we do not have Lagrangian observations at multiple time points necessary to detect such effects (Buesseler et al., 2003; Resplandy et al., 2012).

\subsection{Comparison of export fluxes to previous studies}

The ${ }^{234}$ Th fluxes we report (mean \pm S.D. $=1,413 \pm 432 \mathrm{dpm} \mathrm{m}^{-2} \mathrm{~d}^{-1}$ ) are generally within range of measurements from other Southern Ocean studies $\left(1,615 \pm 1,050 \mathrm{dpm} \mathrm{m}^{-}\right.$ ${ }^{2} \mathrm{~d}^{-1}$ ) (compilation by Le Moigne et al., 2013: Shimmield et al., 1995; Rutgers Van Der Loeff et al., 1997; Buesseler, 1998; Cochran et al., 2000; Buesseler et al., 2001; Friedrich and van der Loeff, 2002; Buesseler et al., 2003; Coppola et al., 2005; Morris et al., 2007; Thomalla et al., 2008; Savoye et al., 2008; Rodriguez y Baena et al., 2008; Jacquet et al., 2011; Rutgers van der Loeff et al., 2011; Zhou et al., 2012; Planchon et al., 2013). By contrast, the POC fluxes we report $\left(4.5 \pm 3.9 \mathrm{mmol} \mathrm{m}^{-2} \mathrm{~d}^{-1}\right)$ are on average three times lower than fluxes from other studies $\left(12.6 \pm 13.3 \mathrm{mmol} \mathrm{m}^{-2} \mathrm{~d}^{-1}\right)$ due to lower POC: ${ }^{234} \mathrm{Th}$ ratios measured in $>51 \mu \mathrm{m}$ particles. In general, POC: ${ }^{234} \mathrm{Th}$ ratios can vary widely as a function of season, ecosystem composition, size-fraction, depth, and particle sampling methodology (Coppola et al., 2005; Buesseler et al., 2006; Santschi et al., 2006; Jacquet et al., 2011). In GB1 and GB2, an ecosystem effect likely accounts for the 14-fold difference in POC: ${ }^{.234} \mathrm{Th}$ between oligotrophic waters (e.g, $0.8 \mu \mathrm{mol} \mathrm{dpm}{ }^{-1}$ at GB2-106)

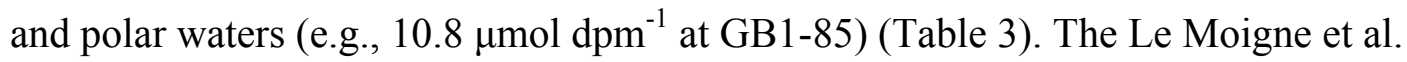
(2013) dataset may include more studies from diatom-rich ecosystems with high POC: ${ }^{234}$ Th organic particles, such as observed by (Buesseler, 1998; not included in Le Moigne et al. 2013), driving some of the discrepancy between our observations and POC fluxes reported by (Le Moigne et al., 2012). 
Other potential reasons for POC: ${ }^{234}$ Th differences are the choice of export depth (see Section 4.1) and different sampling methodologies in the previous studies. For instance, in-situ pump filter holders with a small-diameter central intake and thus higher intake velocities have been observed to sample more zooplankton, which typically have higher POC: ${ }^{234}$ Th ratios, than filter holders with diffuse intakes (Bishop et al., 2012). This is because swimming zooplankton can avoid the gentle intake velocities of filter holders with diffuse intakes but not the higher velocities of small diameter intakes. This would be expected to affect estimates of ${ }^{234} \mathrm{Th}$-derived POC flux more than ${ }^{234} \mathrm{Th}$-derived biomineral fluxes.

There have been far fewer estimates of ${ }^{234} \mathrm{Th}$-derived biomineral export fluxes (Thomalla et al., 2008; Sanders et al., 2010; Le Moigne et al., 2012; Le Moigne et al., 2013). BSi and PIC fluxes observed during GB1 and GB2 are within the range previously observed during the Crozex study by the Crozet islands (Le Moigne et al., 2012), the site of station GB2-27. Thomalla et al. (2008) also reported biomineral fluxes from the Atlantic Meridional Transect (AMT), north of the Subantarctic Front. While AMT PIC export fluxes were only two times smaller than our mean PIC fluxes in the Great Calcite Belt region, AMT BSi fluxes were ten times smaller. The disparity in BSi fluxes is unsurprising, since the AMT cruise track was through waters with low abundance of silicifiers. We also find that the PIC and BSi fluxes from our Great Calcite Belt study are 4 and 10 times larger than biomineral fluxes estimated by Henson et al. (2012b), respectively, who used a steady-state model of nutrient uptake against nutrient export (Sarmiento et al., 2002; Sarmiento et al., 2004). The Henson et al. method used annual climatologies of nutrient concentration profiles for their estimates, whereas the ${ }^{234}$ Th-derived export method used here integrates over several weeks in the growing season. This difference in timescales of integration likely accounts for the smaller biomineral fluxes in Henson et al. (2012b).

\subsection{Export efficiency}

We found no significant relationship observed between integrated primary productivity and POC flux at $\mathrm{Z}_{\mathrm{PAR}}$, highlighting the variable export efficiency across GB1 
and GB2. Export efficiencies, or "Ez-ratios" (Buesseler and Boyd, 2009), were calculated as the ratio of POC flux at $\mathrm{Z}_{\mathrm{PAR}}$ to total integrated primary production in the euphotic zone (Fig. 7b; Table 3). Mean export efficiencies were $0.26 \pm 0.19$, and ranged from 0.04 to 0.77 at stations GB1-16 and GB2-63, respectively. The lack of association between primary productivity and POC export flux confirms previously observed decoupling between the factors that drive export and those that modulate primary productivity (Buesseler et al., 2001; Coppola et al., 2005; Maiti et al., 2010).

\subsection{Vertical attenuation of POC flux and concentration}

At most stations, both POC flux and $>51 \mu \mathrm{m}$ [POC] decline with depth below $Z_{P A R}$ as a result of remineralization. In the following, we use two metrics to describe POC transfer in the mesopelagic zone: (1) the attenuation of $>51$ um [POC] in the mesopelagic zone, expressed as the attenuation coefficients extracted from power-law fits of mesopelagic $>51 \mu \mathrm{m}$ [POC] (exponent from Eq. 1) and (2) the POC flux transfer efficiency $\left(\mathrm{T}_{100}\right)$, defined as the fraction of ${ }^{234} \mathrm{Th}$-based POC flux that survives remineralization and is transferred $100 \mathrm{~m}$ below ZPAR (Buesseler and Boyd, 2009). The first metric describes the disappearance of POC concentration, and applies to the entire mesopelagic zone; the second metric describes the survival of POC flux, and applies to the upper mesopelagic zone.

The mean $\mathrm{T}_{100}$ was $0.71 \pm 0.38$, ranging from 0.20 to 1.8 at stations GB2-119 and GB1-25, respectively (Fig. 7c; Table 2), generally falling within the spread of values observed globally as well as specifically in the Southern Ocean (Buesseler and Boyd, 2009). At stations GB1-6, GB1-16, GB1-25, GB1-59, and GB2-106, $\mathrm{T}_{100}$ values are greater than 1.0 and reflect an increase in POC flux with depth between $\mathrm{Z}_{\text {PAR }}$ and $100 \mathrm{~m}$ below ZPAR (Figs. 5b, 5d). Transfer efficiencies greater than 1 can occur during a declining bloom (Henson et al., 2015), but examination of satellite chlorophyll timeseries does not indicate that these stations were sampled at such conditions. At GB1-6, GB1-16 and GB1-59, the ${ }^{234} \mathrm{Th}^{2}{ }^{238} \mathrm{U}$ disequilibrium extends relatively deep ( $\left.>200 \mathrm{~m}\right)$ into

the water column, thus leading to continually increasing ${ }^{234}$ Th flux with depth, suggesting that either renewed particle production at depth or lateral advection of particles away 
from these coastal stations could sustain the ${ }^{234} \mathrm{Th}$ deficit below $\mathrm{Z}_{\mathrm{PAR}}$. Moreover, because ZPAR depths are significantly shallower than $\mathrm{z}_{\mathrm{Th} / \mathrm{U}}$ in most GB1 stations, including GB1-6, GB1-16 and GB1-59, the transfer efficiency calculation at these stations in GB1 captures an increase in ${ }^{234} \mathrm{Th}$ flux between ZPAR and $100 \mathrm{~m}$ below ZPAR. Thus, for the following discussion, it is important to view transfer efficiency values with the caveat that GB1 and GB2 stations display different ${ }^{234} \mathrm{Th}^{2}{ }^{238} \mathrm{U}$ disequilibria profiles with respect to ZPAR and $\mathrm{Z}_{\mathrm{Th} / \mathrm{U}}$, and this difference impacts all calculations that use $\mathrm{a}^{234} \mathrm{Th}$ flux component.

At the two other stations for which $\mathrm{T}_{100}>1, \mathrm{~GB} 1-25$ and GB2-106, the increases in POC flux below ZPAR arise primarily from increasing POC: ${ }^{234} \mathrm{Th}$ ratios rather than increasing ${ }^{234} \mathrm{Th}$ flux with depth (Appendix A, Figs. S1a, S1d). The increase in these ratios results from a faster decrease in particulate ${ }^{234} \mathrm{Th}$ activity compared to changes in $>51 \mu \mathrm{m}[\mathrm{POC}]$ with depth. This is unexpected and at all other stations, $>51 \mu \mathrm{m}$ [POC] decreases more quickly than particulate ${ }^{234} \mathrm{Th}$ activity due to organic carbon remineralization. We suspect that poor $>51 \mu \mathrm{m}$ particle distribution on filters from GB2106 may have led to anomalously low POC around $\mathrm{Z}_{\mathrm{PAR}}$, but do not have an explanation for the consistent increase in POC:Th with depth at GB1-25 (Appendix A, Figs. S1a). We proceed by excluding the $T_{100}$ transfer efficiencies from these two stations from statistical tests, but identify them for completeness (Figs. 7, 9).

The general decline in POC flux with depth at most stations is mirrored by a decrease in $>51 \mu \mathrm{m}$ [POC], both of which are a result of remineralization. Attenuation coefficients from power-law fits of mesopelagic $>51 \mu \mathrm{m}[\mathrm{POC}]$ at 22 stations describe this transformation from $\mathrm{ZPAR}_{\mathrm{PAR}}$ to the lower mesopelagic zone, where $>51 \mu \mathrm{m}$ [POC] between $800-1000 \mathrm{~m}$ was 1.5 to 137 times lower than $>51 \mu \mathrm{m}$ [POC] at ZPAR (Figs. $8 \mathrm{~b}$, 8c; Table 2). We discount the attenuation value at station GB2-93 from discussion because it had an anomalously low $>51 \mu \mathrm{m}[\mathrm{POC}]$ at $800 \mathrm{~m}$, likely due to incomplete rinsing of particles from the prefilter. This drove the power law fit to yield an anomalously high attenuation coefficient, an outlier, as approximated by Chauvenet's Theorem (Glover et al., 2011). Attenuation coefficients were $1.1 \pm 0.50$ on average, and varied from 0.4 to 1.9 at stations GB1-25 and GB2-43, respectively (Fig. 8c; Table 2), which spans the global range compiled by (Lam et al., 2011). 
The $>51 \mu \mathrm{m}[\mathrm{POC}]$ at $\mathrm{Z}_{\mathrm{PAR}}$ is not correlated with $>51 \mu \mathrm{m}[\mathrm{POC}]$ at lower mesopelagic depths, suggesting that processes controlling $>51 \mu \mathrm{m}[\mathrm{POC}]$ at the top of the mesopelagic differ from those controlling $>51 \mu \mathrm{m}$ [POC] at the base of the mesopelagic zone. This is supported by the great variation in attenuation coefficients and transfer efficiencies, and suggests that POC concentrations at $\mathrm{Z}_{\mathrm{PAR}}$ are decoupled from [POC] at $\mathrm{z}$ $\geq 800 \mathrm{~m}$, as has also been noted in other POC flux and concentration observations (Lomas et al., 2010; Lam et al., 2011; Henson et al., 2012b). There are some exceptions, such as at GB1-85, which exhibited the highest $>51 \mu \mathrm{m}$ [POC] both at $\mathrm{Z}_{\mathrm{PAR}}$ and below $800 \mathrm{~m}$, but there is no overall relationship across the dataset. The remaining discussion aims to tease apart the processes that control POC flux and $>51 \mu \mathrm{m}[\mathrm{POC}]$ in each depth regime.

\subsection{Biomineral-POC flux correlations at $\mathrm{Z}_{\mathrm{PAR}}$}

We compared POC fluxes to mineral fluxes at ZPAR (Figs. 9a, 9b) to test the hypothesis that mineral ballasting facilitates POC export out of the euphotic zone, as has been observed in deeper flux datasets $>1000 \mathrm{~m}$ (Klaas and Archer, 2002; Armstrong et al., 2002; Francois et al., 2002). Because we use ${ }^{234}$ Th activity deficits and the same particulate ${ }^{234} \mathrm{Th}$ activities to derive all fluxes (Eq. (4-6), comparing export fluxes is equivalent to comparing concentrations of $>51 \mu \mathrm{m}$ POC, BSi and PIC at $\mathrm{Z}_{\mathrm{PAR}}$. In this dataset, minor differences between flux versus concentration comparisons (not shown) arise from differences in interpolation methods for POC: ${ }^{234} \mathrm{Th}, \mathrm{BSi}:{ }^{234} \mathrm{Th}$, and PIC: ${ }^{234} \mathrm{Th}$ ratios at $\mathrm{Z}_{\mathrm{PAR}}$ (Table 3).

Pearson correlation tests between shallow POC export and the two biomineral fluxes revealed a significantly positive correlation between POC and BSi fluxes $\left(\mathrm{p}<<0.001, \mathrm{r}^{2}=0.77\right)$. By contrast, there was no significant relationship between shallow POC and PIC fluxes ( $\left.p=0.24, r^{2}=0.06\right)$. Both BSi and POC export fluxes tend to increase poleward from the region north of the Subtropical/Subantarctic fronts to the inter-frontal zone to the region south of the Polar front (Figs. 5b, 6a, 6b). Station GB1-85, which sits just south of the Polar Front $\left(\sim 52^{\circ} \mathrm{S}\right)$, is a high BSi and POC flux outlier. When removed, the BSi flux vs. POC flux correlation remains significant, though weaker $\left(\mathrm{r}^{2}=0.43\right)$, 
suggesting that although this correlation is strongly influenced by station GB1-85, the shallow BSi ballast association still remains valid for the rest of the dataset.

We also compared POC export fluxes to both PIC and BSi export fluxes simultaneously by multiple linear regression:

$$
\text { POC Flux }=\left(m_{\mathrm{BSi}} \times \text { BSi Flux }\right)+\left(m_{\mathrm{PIC}} \times \text { PIC Flux }\right)+\text { constant } \quad(7)
$$

The multiple linear regression only explains an additional $5 \%$ of the variance in POC flux at $\mathrm{Z}_{\mathrm{PAR}}\left(\mathrm{r}^{2}=0.82, \mathrm{p}<<0.001\right)$, affirming that BSi flux explains most of the variation in POC export fluxes at ZPAR across the Atlantic and Indian sectors of the Great Calcite Belt region.

The per-mole carrying capacities of BSi and PIC for POC, or the slopes $\mathrm{m}_{\mathrm{BSi}}$ and $\mathrm{m}_{\text {PIC }}$ in the multiple linear regression Eq. (7), are 0.60 and 0.50 , respectively. The perweight carrying capacities of BSi and PIC for POC are 0.23 and 0.13 , respectively, assuming $12 \times 2.199 \mathrm{~g} \mathrm{~mol}^{-1} \mathrm{POC}, 67.3 \mathrm{~g} \mathrm{SiO}_{2} 0.4 \mathrm{H}_{2} \mathrm{O} \mathrm{mol}^{-1} \mathrm{BSi}$ and $100.1 \mathrm{~g} \mathrm{CaCO}_{3}$ $\mathrm{mol}^{-1}$ PIC (Klaas and Archer 2002). The unassociated POC flux, the constant in Eq. (7),

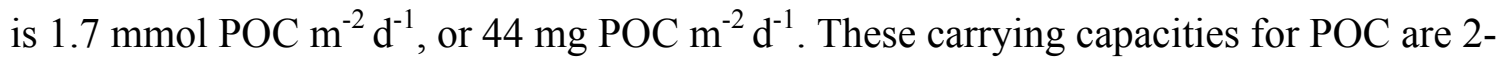
10 times higher than global biomineral carrying capacities of deeper $(>2000 \mathrm{~m})$ flux data $\left(\mathrm{m}_{\mathrm{BSi}}=0.025-0.026, \mathrm{~m}_{\mathrm{PIC}}=0.070-0.074 ;\right.$ Klaas and Archer, 2002), reflecting how POC remineralization with depth consistently reduces apparent mineral carrying capacities between the base of the euphotic zone and the deep sea.

These upper ocean carrying capacities, especially $\mathrm{m}_{\mathrm{PIC}}$, are considerably different than corresponding per-weight carrying capacities reported in the Crozex study in the Indian sector of the Southern Ocean $\left(\mathrm{m}_{\mathrm{BSi}}=0.16, \mathrm{~m}_{\mathrm{PIC}}=-0.11\right.$, constant $=105 \mathrm{mg}$ POC m${ }^{-2}$ $\mathrm{d}^{-1}$ ) (Le Moigne et al., 2012). But, as the Crozex study was carried out several months earlier in the growing season than our sampling of the same area within the Great Calcite Belt, seasonal changes in the phytoplankton communities and their associated food webs could account for the differences in upper ocean carrying capacities. The Le Moigne et al. (2012) study also highlighted that variable ecosystem composition contributed to regional variations in upper ocean carrying capacities (Le Moigne et al. 2014), echoing a contemporaneous study that showed that even the deep ( $>1500 \mathrm{~m}$ ) flux carrying capacities have statistically significant spatial variability (Wilson et al., 2012). 
It is worth noting that Le Moigne et al. (2012) included lithogenic minerals in their multiple linear regressions. We did not measure lithogenic minerals on GB1 and GB2, as we assumed lithogenic fluxes to be small in the Southern Ocean due to low terrestrial dust inputs (e,g., Honjo et al., 2000). While omitting this lithogenic component from the multiple linear regression could potentially impact derived $\mathrm{m}_{\mathrm{BSi}}$ and $\mathrm{m}_{\mathrm{PIC}}$ values, lithogenic material is nonetheless unlikely to be an important carrier of POC flux because of its low flux in the Southern Ocean. Indeed, regional studies have found that the lithogenic carrying capacity (Wilson et al., 2012) and the lithogenic-associated POC fluxes (Le Moigne et al., 2012) are very low in the Southern Ocean.

\subsection{Mineral-POC flux correlations in the mesopelagic zone}

To directly test whether minerals facilitate POC transfer through the upper mesopelagic zone of the water column as well, we compared flux transfer efficiencies $100 \mathrm{~m}$ below the base of the euphotic zone $\left(\mathrm{T}_{100}\right)$ with BSi and PIC fluxes at ZPAR (Figs. 9c, 9d). If the mineral ballast model were to apply to the upper mesopelagic zone, one would expect greater transfer efficiencies (i.e., lower attenuation of POC flux) in regions of higher mineral export. The data highlight several key differences between the role of minerals in the euphotic and upper mesopelagic zones. For one, the correlation between PIC flux and $\mathrm{T}_{100}$, excluding values at GB1-25 and GB2-106, is significantly positive $\left(\mathrm{p}<0.001, \mathrm{r}^{2}=0.39\right)$. The relationship remains even when assessing data from each cruise individually (for GB1, $\mathrm{p}=0.047, \mathrm{r}^{2}=0.34$; for GB2, $\mathrm{p}=0.009, \mathrm{r}^{2}=0.52$ ), lending further support to a potential role for PIC in POC transfer through the upper mesopelagic zone.

Further, there was no significant correlation, with or without GB1-25 and GB2$106 \mathrm{~T}_{100}$ values, between BSi export fluxes in GB2 and $\mathrm{T}_{100}$. However, higher particulate biogenic silica concentrations ( $>51 \mu \mathrm{m}[\mathrm{BSi}])$ at $\mathrm{Z}_{\mathrm{PAR}}$ did correspond with greater attenuation of $>51 \mu \mathrm{m}$ [POC] below $Z_{P A R}\left(p=0.004, r^{2}=0.35\right.$; Fig. 10a), suggesting that in contrast to its role in the euphotic zone, BSi is associated with greater degradation in the mesopelagic zone of the water column.

\subsection{Other controls on POC transfer}


The correlation between the attenuation of $>51 \mu \mathrm{m}[\mathrm{POC}]$ and the size fractionation of POC $(\%>51 \mu \mathrm{m}$ [POC] $)$ at $\mathrm{Z}_{\mathrm{PAR}}$ is even stronger than with $>51 \mu \mathrm{m}$ [BSi] $\left(\mathrm{p}<<0.001, \mathrm{r}^{2}=0.63\right.$; Fig. 10b). GB1-85 appears to be an outlier for both relationships in Fig. 10, but especially for the relationship between $>51 \mu \mathrm{m}$ [POC] attenuation and $>51$ $\mu \mathrm{m}$ [BSi] (Fig. 10a). The correlation remains significant when the high [BSi] value from station GB1-85 is removed. Notably, the power law fit at GB1-85 is not very good in the upper mesopelagic; fitting $>51 \mu \mathrm{m}$ [POC] between $\mathrm{Z}_{\mathrm{PAR}}$ and $500 \mathrm{~m}$ yields a better fit (higher $r^{2}$; see Fig. 3) with a higher attenuation coefficient of 2.35 (compared to 1.7 for the entire mesopelagic zone). This modified upper mesopelagic attenuation at GB1-85 improves the overall correlations between the attenuation coefficient and both $>51 \mu \mathrm{m}$ $[\mathrm{BSi}]\left(\mathrm{p}<<0.001, \mathrm{r}^{2}=0.60\right)$ and $\%>51 \mu \mathrm{m}[\mathrm{POC}]\left(\mathrm{p}<<0.001 ; \mathrm{r}^{2}=0.78\right)$, further strengthening the argument that $>51 \mu \mathrm{m}[\mathrm{BSi}]$ and $\%>51 \mu \mathrm{m}[\mathrm{POC}]$ at $\mathrm{ZPAR}_{\mathrm{PA}}$ are important factors in POC transfer in the upper mesopelagic zone.

The relationships between the attenuation of $>51 \mu \mathrm{m}[\mathrm{POC}]$ and $>51 \mu \mathrm{m}$ [BSi] and particle size fractionation may arise from a more fundamental feature shared by both high-[BSi] and large-particle stations of the Great Calcite Belt: diatom-rich phytoplankton communities. Indeed, we also observe a strong correlation between $>51$ $\mu \mathrm{m}[\mathrm{BSi}]$ and $\%>51 \mu \mathrm{m}[\mathrm{POC}]$ at $\mathrm{Z}_{\mathrm{PAR}}\left(\mathrm{p}<<0.001, \mathrm{r}^{2}=0.65\right.$; not shown). This is a consistent feature across diatom-rich populations, which produce large, BSi-rich organic aggregates that sink rapidly out of the euphotic zone (Michaels and Silver, 1988; Buesseler, 1998; Thomalla et al.). Indeed, euphotic zone diatom abundances enumerated with a FlowCam ${ }^{\circledR}$ are significantly correlated with $>51 \mu \mathrm{m}[\mathrm{BSi}]$ at zPAR at corresponding stations in GB1 and GB2 (Appendix A, Fig. S2a). Thus, characteristics describing ecosystem structure may underlie the correlation between BSi export and POC export in the Great Calcite Belt (Francois et al., 2002; Thomalla et al., 2008; Henson et al., 2012a; Henson et al., 2012b).

However, ecosystem composition does not directly explain why larger particles exported into the mesopelagic zone are remineralized more vigorously hundreds of meters below (Fig. 10b). It is paradoxical that the same large particles that sink quickly out of the euphotic zone would then remineralize faster, as well. This association between 
attenuation coefficient and particle size suggests that these particles sink more slowly than expected in the mesopelagic zone given their size (for example, as a result of high porosity and low excess density), and/or that they are subject to faster remineralization compared to regions with more POC in the small size fraction. Francois et al. (2002) noted a negative relationship between bathypelagic transfer efficiency and opal flux, and attributed this to increased lability in large diatom aggregates. Though we do not observe any negative correlation between upper mesopelagic transfer efficiency $\left(\mathrm{T}_{100}\right)$ and BSi fluxes at $Z_{P A R}$, we suggest that potentially higher degradability of POC produced by diatom-rich communities may similarly explain the relationship between particle size and $>51 \mu \mathrm{m}[\mathrm{POC}]$ attenuation in the upper mesopelagic zone.

The view of POC quality as a driving factor behind POC transfer argues for a deterministic role of euphotic zone community structure in POC transfer below the euphotic zone. It supports the conventional perspective that diatom-dominated communities are strong exporters of large, sinking POC particles out of the euphotic zone (Buesseler, 1998; Guidi et al., 2009), but also adds to the growing view that these communities have poor transfer efficiency and high attenuation through the mesopelagic zone (Francois et al., 2002; Guidi et al., 2009; Henson et al., 2012b; Henson et al., 2012a).

For instance, station GB1-85, with over half of [POC] in the $>51 \mu \mathrm{m}$ size class fraction in the euphotic zone (Fig. 6c; Table 3), has a low $>51 \mu \mathrm{m}$ [PIC]:[BSi] ratio of 0.035 at $\mathrm{Z}_{\mathrm{PAR}}$ (indicated in log-scale in Figs. 10a and 10b), which indicates relatively high diatom populations producing large BSi-rich aggregates (Appendix A, Figs. 2, S2, S3). Station GB1-85 exhibits a high export efficiency (Ez-ratio=0.38, within the upper quartile of the data set), and the highest $>51 \mu \mathrm{m}$ [POC] and export fluxes at $\mathrm{Z}_{\mathrm{PAR}}$ (Figs. $5 \mathrm{~b}, 7 \mathrm{~b}, 8 \mathrm{a}$; Table 3). Notably, $>51 \mu \mathrm{m}$ [POC] values in the lower mesopelagic zone are also the highest at GB1-85, despite attenuating greatly below zPAR (attenuation coefficient $=1.7)($ Figs. 3, 8b, 8c; Table 2). But, because of high attenuation, proportionally less organic carbon transfers to the deep sea at GB1-85. The same diatomrich communities that vigorously export POC ultimately may not sequester as much organic carbon in the deep ocean or draw down as much atmospheric $\mathrm{CO}_{2}$ (Kwon et al., 2009) as would be expected considering the magnitude of export alone. 
In contrast to a model diatom community like station GB1-85, station GB1-25 is BSi-deplete, with a $>51 \mu \mathrm{m}$ [PIC]:[BSi] ratio of 1.4 at ZPAR (indicated in log-scale in Fig. 10a), indicating relatively more coccolithophores in the community (Appendix A, Figs. S2, S3). With proportionally less POC in the $>51 \mu \mathrm{m}$ size-fraction (only 3.2\%) (Figs. 6c, 10b; Table 3), $>51 \mu \mathrm{m}[\mathrm{POC}]$ at GB1-25 attenuates little through the mesopelagic zone (attenuation coefficient $=0.4$, the lowest of the data set) such that a third of the $>51 \mu \mathrm{m}$ [POC] at $\mathrm{Z}_{\mathrm{PAR}}$ remains at $1000 \mathrm{~m}$, compared to only $1.4 \%$ at station GB1-85 (Fig. 3). At GB1-25, export efficiency is very low (Ez-ratio $=0.04$ ), suggesting that the particles exiting the euphotic zone here have been recycled vigorously in the euphotic zone prior to export, which may explain their low $>51 \mu \mathrm{m}$ [POC] and high proportion in the $<51 \mu \mathrm{m}$ size-fraction at ZPAR. In the mesopelagic zone, these particles are not very reactive and thus remineralize very little, perhaps sequestering a higher proportion of the $\mathrm{CO}_{2}$ fixed in the euphotic zone.

Several other stations with proportionally more small particles and weaker $>51$ $\mu \mathrm{m}[\mathrm{POC}]$ attenuation in the mesopelagic zone exhibit higher $>51 \mu \mathrm{m}[\mathrm{PIC}]$ than $>51 \mu \mathrm{m}$ [BSi] at $\mathrm{Z}_{\mathrm{PAR}}$ (labeled in the lower left quadrant of Fig. 10b), suggesting that export regimes characterized by high relative abundance of coccolithophores consistently transfer less reactive POC to the mesopelagic zone. Artificial roller tank experiments have demonstrated that coccolithophore cultures can produce smaller, more compact aggregates than diatom cultures, partly because of smaller cell sizes (Iversen and Ploug, 2010). However, smaller size does not necessarily mean slower sinking velocities (e.g., (McDonnell and Buesseler, 2010). Iversen and Ploug (2010) showed that the higher excess density of these small aggregates generated faster sinking speeds than similarly sized pure diatom aggregates. Another roller tank study that compared aggregate formation by calcifying versus non-calcifying coccolithophores observed that aggregates formed from calcifying coccolithophores were smaller but faster sinking (Engel et al., 2009). In regions like the Great Calcite Belt, dense coccolithophore populations may similarly export small, highly degraded and compact particles out of the euphotic zone. As a result, these communities would efficiently transfer POC towards the base of the mesopelagic zone, even if the magnitude of exported POC is not as high as in diatom-rich regions (Thomalla et al., 2008; Guidi et al., 2009; Henson et al., 2012b). This may 
explain why higher PIC export fluxes are associated with higher transfer efficiencies but not higher POC flux at ZPAR (Fig. 9), and also why the ballast association between PIC and POC fluxes appears only at greater depths (Francois et al., 2002; Klaas and Archer, 2002).

Attenuation coefficients for $>51 \mu \mathrm{m}[\mathrm{POC}]$ across diatom-rich regions exhibit a great spread (standard deviation $=0.47$ ), ranging from 0.47 to 1.88 . Not all diatom-rich stations (i.e., $>51 \mu \mathrm{m}[\mathrm{PIC}]:[\mathrm{BSi}]<1$ at $\mathrm{Z}_{\mathrm{PAR}}$ ) have proportionally larger particles or higher b-values (e.g., stations GB1-70, GB1-77 and GB2-87; Fig. 10b). In contrast, attenuation coefficients across coccolithophore-rich regions (i.e., $>51 \mu \mathrm{m}[\mathrm{PIC}]:[\mathrm{BSi}] \geq 1$ at $\mathrm{ZPAR}_{\mathrm{PAR}}$ ) exhibit a lower standard deviation (0.31) and a smaller range, 0.35 to 1.12 . The greater variance in attenuation across BSi-rich regions may result from sampling the diatom populations at different seasons of the bloom cycle (Lam et al., 2011), and implies that there may be less seasonality in POC transfer to depth in coccolithophore-rich regions. Indeed, massive diatom export events with high transfer efficiency through the mesopelagic zone have been observed (Martin et al., 2011; Smetacek et al. 2012), so there are clearly conditions that can lead to efficient mesopelagic POC transfer from diatom blooms.

It is worth noting that $>51 \mu \mathrm{m}[\mathrm{PIC}]:[\mathrm{BSi}]$ ratios did increase with depth at most stations of the Great Calcite Belt, as might be expected because BSi is undersaturated in seawater. The possibility that BSi dissolves faster than PIC in particles sinking through the mesopelagic zone would complicate the connections we draw between diatom-rich communities in the euphotic zone and the attenuation of $>51 \mu \mathrm{m}$ [POC]. But, there are no associations between the magnitude of [PIC]:[BSi] increase and $>51 \mu \mathrm{m}[\mathrm{BSi}]$ at $\mathrm{Z}_{\mathrm{PAR}}$, $>51 \mu \mathrm{m}[\mathrm{PIC}]$ at $\mathrm{Z}_{\mathrm{PAR}}$ or $>51 \mu \mathrm{m}[\mathrm{POC}]$ attenuation with depth, suggesting that the issue of differential dissolution should not significantly impact our earlier interpretations. In the future, directly evaluating the degradability of sinking POC using organic characterization techniques (e.g., ramped pyrolysis or biomarker isolation) (e.g., (Wakeham et al., 2002; Rosenheim et al., 2008; Rosenheim and Galy, 2012; Rosenheim et al., 2013) would greatly improve our ability to track the transformation of POC produced by different ecosystem assemblages across the Great Calcite Belt. 


\section{Conclusion}

In summary, we argue here that phytoplankton assemblages play a fundamental role (Francois et al., 2002; Thomalla et al., 2008; Henson et al., 2012b; Henson et al., 2012a) in determining the fate of POC export through the Great Calcite Belt region, the effect of which sometimes, but not always, appears as a mineral ballast mechanism in the euphotic zone (Lam et al., 2011; Henson et al., 2012a; Lima et al., 2014). Though shallow BSi export fluxes were strongly correlated with POC export fluxes, they are also associated with diatom communities that produce larger particles that attenuate more quickly through the mesopelagic zone, such that proportionally less POC reaches the lower mesopelagic zone, and proportionally more is returned to the water column as remineralized carbon (dissolved inorganic and organic carbon).

\section{Author contributions:}

S.Z. Rosengard, the primary author, participated in the GB2 field work, sample analysis in lab and writing. P.J. Lam contributed to field work during GB2, and participated in both data interpretation and editing the manuscript. W.M. Balch, supplied the primary productivity and light profile data included here, as well as coccolithophore and diatom cell count data in the supplement, and provided valuable feedback during writing. M.E. Auro and S. Pike participated in field work and sample analysis during and after GB1. D. Drapeau and B. Bowler contributed to field work during both GB1 and GB2, as well as sample analysis, particularly with respect to primary productivity and light profile data.

\section{Acknowledgements:}

Many thanks to Ken Buesseler for discussions and lending us field equipment; Dan Ohnemus, Angela Warner, Michael Brown, Rebecca Fowler, and Marina Van der Eb for help at sea; and Laura Lubelczyk, Paul Henderson, and Scott Birdwhistell for analytical work/assistance. This work was funded by NSF OCE-0960880 to P.J. Lam, and NSF OCE-0961660, NASA NNX11A072G and NNX11AL93G to W.M. Balch. 


\section{References}

Abramson, L., Lee, C., Liu, Z. F., Wakeham, S. G., and Szlosek, J.: Exchange between suspended and sinking particles in the northwest Mediterranean as inferred from the organic composition of in situ pump and sediment trap samples, Limnology and Oceanography, 55, 725-739, 2010.

Armstrong, R. A., Lee, C., Hedges, J. I., Honjo, S., and Wakeham, S. G.: A new, mechanistic model for organic carbon fluxes in the ocean based on the quantitative association of POC with ballast minerals, Deep-Sea Research Part IITopical Studies in Oceanography, 49, 219-236, 2002.

Balch, W. M., Drapeau, D., and Fritz, J.: Monsoonal forcing of calcification in the Arabian Sea, Deep-Sea Research II, 47, 1301-1337, 2000.

Balch, W. M., Drapeau, D. T., Bowler, B. C., Lyczkowski, E. R., Lubelczyk, L. C., Painter, S. C., and Poulton, A. J.: Surface biological, chemical, and optical properties of the Patagonian Shelf coccolithophore bloom, the brightest waters of the Great Calcite Belt, Limnology and Oceanography, 59, 1715-1732, 2014.

Balch, W. M., Drapeau, D. T., Bowler, B. C., Lyczskowski, E., Booth, E. S., and Alley, D.: The contribution of coccolithophores to the optical and inorganic carbon budgets during the Southern Ocean Gas Exchange Experiment: New evidence in support of the "Great Calcite Belt" hypothesis, J. Geophys. Res., 116, C00F06, $2011 \mathrm{a}$.

Balch, W. M., Poulton, A. J., Drapeau, D. T., Bowler, B. C., Windecker, L. A., and Booth, E. S.: Zonal and meridional patterns of phytoplankton biomass and carbon fixation in the Equatorial Pacific Ocean, between $110^{\circ} \mathrm{W}$ and $140^{\circ} \mathrm{W}$, Limnology and Oceanography, 59, 1715-1732, $2011 \mathrm{~b}$.

Belkin, I. M. and Gordon, A. L.: Southern Ocean fronts from the Greenwich meridian to Tasmania, Journal of Geophysical Research: Oceans (1978-2012), 101, 36753696, 1996.

Bishop, J. K. B., Lam, P. J., and Wood, T. J.: Getting good particles: accurate sampling of particles by large volume in-situ filtration, Limnology and Oceanography Methods, 10, 681-710, 2012.

Brzezinski, M. A. and Nelson, D. M.: Seasonal changes in the silicon cycle within a Gulf Stream warm-core ring, Deep Sea Research Part A. Oceanographic Research Papers, 36, 1009-1030, 1989.

Buesseler, K., Lamborg, C. H., Cai, P., Escoube, R., Johnson, R., Pike, S., Masque, P., McGillicuddy, D., and Verdeny, E.: Particle fluxes associated with mesoscale eddies in the Sargasso Sea, Deep-Sea Research II, 55, 1426-1444, 2008.

Buesseler, K. O.: The decoupling of production and particulate export in the surface ocean, Global Biogeochemical Cycles, 12, 297-310, 1998.

Buesseler, K. O., Antia, A. N., Chen, M., Fowler, S. W., Gardner, W. D., Gustafsson, O., Harada, K., Michaels, A. F., van der Loeffo, M. R., Sarin, M., Steinberg, D. K., and Trull, T.: An assessment of the use of sediment traps for estimating upper ocean particle fluxes, Journal of Marine Research, 65, 345-416, 2007.

Buesseler, K. O., Ball, L., Andrews, J., Cochran, J. K., Hirschberg, D. J., Bacon, M. P., Fleer, A., and Brzezinski, M.: Upper ocean export of particulate organic 
carbon and biogenic silica in the Southern Ocean along 170 degrees W, Deep-Sea

Research Part II-Topical Studies in Oceanography, 48, 4275-4297, 2001.

Buesseler, K. O., Barber, R. T., Dickson, M. L., Hiscock, M. R., Moore, J. K., and Sambrotto, R.: The effect of marginal ice-edge dynamics on production and export in the Southern Ocean along 170 degrees W, Deep-Sea Research Part IITopical Studies in Oceanography, 50, 579-603, 2003.

Buesseler, K. O., Benitez-Nelson, C. R., Moran, S. B., Burd, A., Charette, M., Cochran, J. K., Coppola, L., Fisher, N. S., Fowler, S. W., and Gardner, W. D.: An assessment of particulate organic carbon to thorium-234 ratios in the ocean and their impact on the application of 234Th as a POC flux proxy, Marine Chemistry, $100,2006$.

Buesseler, K. O. and Boyd, P.: Shedding light on processes that control particle export and flux attenuation in the twilight zone of the open ocean, Limnology and Oceanography, 54, 1210-1232, 2009.

Buesseler, K. O., Pike, S., Maiti, K., Lamborg, C. H., Siegel, D. A., and Trull, T. W.: Thorium-234 as a tracer of spatial, temporal and vertical variability in particle flux in the North Pacific, Deep Sea Research Part I: Oceanographic Research Papers, 56, 1143-1167, 2009.

Cochran, J. K., Buesseler, K. O., Bacon, M. P., Wang, H. W., Hirschberg, D. J., Ball, L., Andrews, J., Crossin, G., and Fleer, A.: Short-lived thorium isotopes (Th-234, Th228) as indicators of POC export and particle cycling in the Ross Sea, Southern Ocean, Deep-Sea Research Part II-Topical Studies in Oceanography, 47, 34513490, 2000.

Coppola, L., Roy-Barman, M., Mulsow, S., Povinec, P., and Jeandel, C.: Low particulate organic carbon export in the frontal zone of the Southern Ocean (Indian sector) revealed by Th-234, Deep-Sea Research Part I-Oceanographic Research Papers, 52, 51-68, 2005.

De La Rocha, C. L., Nowald, N., and Passow, U.: Interactions between diatom aggregates, minerals, particulate organic carbon, and dissolved organic matter: Further implications for the ballast hypothesis, Global Biogeochemical Cycles, 22, 2008.

Engel, A., Szlosek, J., Abramson, L., Liu, Z., and Lee, C.: Investigating the effect of ballasting by $\mathrm{CaCO}_{3}$ in Emiliania huxleyi: I. Formation, settling velocities and physical properties of aggregates, Deep Sea Research Part II: Topical Studies in Oceanography, 56, 1396-1407, 2009.

Fabry, V. J. and Balch, W. M.: Direct measurements of calcification rates in planktonic organisms., U. Riebeseil, V.J. Fabry, L. Hansson and J.-P. Gattuso (Editors), Guide to Best Practices in Ocean Acidification Research and Data Reporting. European Project on Ocean Acidification (EPOCA), Bremerhaven, Germany, 2010. 185-196, 2010.

Francois, R., Honjo, S., Krishfield, R., and Manganini, S.: Factors controlling the flux of organic carbon to the bathypelagic zone of the ocean, Global Biogeochemical Cycles, 16, doi:10.1029/2001GB001722, 2002.

Friedrich, J. and van der Loeff, M. M. R.: A two-tracer (Po-210-Th-234) approach to 
distinguish organic carbon and biogenic silica export flux in the Antarctic Circumpolar Current, Deep-Sea Research Part I-Oceanographic Research Papers, 49, 101-120, 2002.

Giering, S. L. C., Sanders, R., Lampitt, R. S., Anderson, T. R., Tamburini, C., Boutrif, M., Zubkov, M. V., Marsay, C. M., Henson, S. A., Saw, K., Cook, K., and Mayor, D. J.: Reconciliation of the carbon budget in the ocean's twilight zone, Nature, advance online publication, 2014.

Glover, D. M., Jenkins, W. J., and Doney, S. C.: Modeling methods for marine science., Cambridge University Press, 2011. 2011.

Guidi, L., Stemmann, L., Jackson, G. A., Ibanez, F., Claustre, H., Legendre, L., Picheral, M., and Gorsky, G.: Effects of phytoplankton community on production, size and export of large aggregates: A world-ocean analysis, Limnology and Oceanography, 54, 1951-1963, 2009.

Hedges, J. I. and Oades, J. M.: Comparative organic geochemistries of soils and marine sediments, Organic Geochemistry, 27, 319-361, 1997.

Henson, S., Lampitt, R., and Johns, D.: Variability in phytoplankton community structure in response to the North Atlantic Oscillation and implications for organic carbon flux, Limnology and Oceanography, 57, 1591, 2012a.

Henson, S. A., Sanders, R., and Madsen, E.: Global patterns in efficiency of particulate organic carbon export and transfer to the deep ocean, Global Biogeochemical Cycles, 26, GB1028, 2012b.

Henson, S. A., Sanders, R., Madsen, E., Morris, P. J., Le Moigne, F., and Quartly, G. D.: A reduced estimate of the strength of the ocean's biological carbon pump, Geophysical Research Letters, 38, L04606, 2011.

Honjo, S., Francois, R., Manganini, S., Dymond, J., and Collier, R.: Particle fluxes to the interior of the Southern Ocean in the Western Pacific sector along 170 degrees W, Deep-Sea Research Part II-Topical Studies in Oceanography, 47, 3521-3548, 2000.

Iversen, M. H. and Ploug, H.: Ballast minerals and the sinking carbon flux in the ocean: carbon-specific respiration rates and sinking velocity of marine snow aggregates, Biogeosciences, 7, 2613-2624, 2010.

Jacquet, S. H. M., Lam, P. J., Trull, T., and Dehairs, F.: Carbon export production in the subantarctic zone and polar front zone south of Tasmania, Deep Sea Research Part II: Topical Studies in Oceanography, 58, 2277-2292, 2011.

Klaas, C. and Archer, D. E.: Association of sinking organic matter with various types of mineral ballast in the deep sea: Implications for the rain ratio, Global Biogeochemical Cycles, 16, 1116-1129, 2002.

Kwon, E. Y., Primeau, F., and Sarmiento, J. L.: The impact of remineralization depth on the air-sea carbon balance, Nature Geoscience, 2, 630-635, 2009.

Lam, P. J. and Bishop, J. K. B.: High Biomass Low Export regimes in the Southern Ocean, Deep Sea Research Part II: Topical Studies in Oceanography, 54, 601638, 2007.

Lam, P. J., Doney, S. C., and Bishop, J. K. B.: The dynamic ocean biological pump: Insights from a global compilation of particulate organic carbon, $\mathrm{CaCO} 3$, and opal concentration profiles from the mesopelagic, Global Biogeochemical Cycles, 25, GB3009, 2011. 
Lam, P. J., Ohnemus, D. C., and Auro, M. E.: Size-fractionated major particle composition and concentrations from the US GEOTRACES north Atlantic zonal transect, Deep Sea Research Part II: Topical Studies in Oceanography, 116, 303$320,2015$.

Le Moigne, F., Henson, S., Sanders, R., and Madsen, E.: Global database of surface ocean particulate organic carbon export fluxes diagnosed from the $234 \mathrm{Th}$ technique, Earth System Science Data Discussions, 6, 163-187, 2013.

Le Moigne, F. A. C., Sanders, R. J., Villa-Alfageme, M., Martin, A. P., Pabortsava, K., Planquette, H., Morris, P. J., and Thomalla, S. J.: On the proportion of ballast versus non-ballast associated carbon export in the surface ocean, Geophysical Research Letters, 39, L15610, 2012.

Lima, I. D., Lam, P. J., and Doney, S. C.: Dynamics of particulate organic carbon flux in a global ocean model, Biogeosciences, 11, 1177-1198, 2014.

Lomas, M. W., Steinberg, D. K., Dickey, T., Carlson, C. A., Nelson, N. B., Condon, R. H., and Bates, N. R.: Increased ocean carbon export in the Sargasso Sea linked to climate variability is countered by its enhanced mesopelagic attenuation, Biogeosciences, 7, 57-70, 2010.

Maiti, K., Benitez-Nelson, C. R., and Buesseler, K. O.: Insights into particle formation and remineralization using the short-lived radionuclide, Thoruim-234, Geophysical Research Letters, 37, 2010.

Martin, J. H., Knauer, G. A., Karl, D. M., and Broenkow, W. W.: Vertex - Carbon Cycling in the Northeast Pacific, Deep-Sea Research Part a-Oceanographic Research Papers, 34, 267-285, 1987.

Martin, P., Lampitt, R. S., Jane Perry, M., Sanders, R., Lee, C., and D'Asaro, E.: Export and mesopelagic particle flux during a North Atlantic spring diatom bloom, Deep Sea Research Part I: Oceanographic Research Papers, 58, 338-349, 2011.

McCave, I. N.: Vertical flux of particles in the ocean, Deep Sea Research and Oceanographic Abstracts, 22, 491-502, 1975.

McDonnell, A. M. P. and Buesseler, K. O.: Variability in the average sinking velocities of marine particles, Limnology and Oceanography, 55, 2085-2096, 2010.

Michaels, A. F. and Silver, M. W.: Primary production, sinking fluxes and the microbial food web, Deep Sea Research Part A. Oceanographic Research Papers, 35, 473-490, 1988.

Morris, P. J., Sanders, R., Turnewitsch, R., and Thomalla, S.: Th-234-derived particulate organic carbon export from an island-induced phytoplankton bloom in the Southern Ocean, Deep-Sea Research Part Ii-Topical Studies in Oceanography, 54, 2208-2232, 2007.

Owens, S., Buesseler, K., and Sims, K.: Re-evaluating the ${ }^{238} \mathrm{U}$-salinity relationship in seawater: Implications for the ${ }^{238} \mathrm{U}^{234} \mathrm{Th}$ disequilibrium method, Marine Chemistry, 127, 31-39, 2011.

Paasche, E. and Brubak, S.: Enhanced calcification in the coccolithophorid Emiliania huxleyi (Haptophyceae) under phosphorus limitation, Phycologia, 33, 324-330, 1994.

Passow, U. and De la Rocha, C. L.: Accumulation of mineral ballast on organic aggregates, Global Biogeochemical Cycles, 20, 2006.

Pike, S. M., Buesseler, K. O., Andrews, J., and Savoye, N.: Quantification of Th-234 
recovery in small volume sea water samples by inductively coupled plasma-mass spectrometry, Journal of Radioanalytical and Nuclear Chemistry, 263, 355-360, 2005.

Pilson, M. E. Q.: An Introduction to the Chemistry of the Sea, Cambridge University Press, 2012. 2012.

Planchon, F., Cavagna, A.-J., Cardinal, D., André, L., and Dehairs, F.: Late summer particulate organic carbon export and twilight zone remineralisation in the Atlantic sector of the Southern Ocean, Biogeosciences, 10, 803-820, 2013.

Resplandy, L., Martin, A. P., Le Moigne, F., Martin, P., Aquilina, A., Mémery, L., Lévy, M., and Sanders, R.: How does dynamical spatial variability impact 234Thderived estimates of organic export?, Deep Sea Research Part I: Oceanographic Research Papers, 68, 24-45, 2012.

Riley, J. S., Sanders, R., Marsay, C., Le Moigne, F. A. C., Achterberg, E. P., and Poulton, A. J.: The relative contribution of fast and slow sinking particles to ocean carbon export, Global Biogeochemical Cycles, 26, GB1026, 2012.

Rodriguez y Baena, A. M., Boudjenoun, R., Fowler, S. W., Miquel, J. C., Masqué, P., Sanchez-Cabeza, J.-A., and Warnau, M.: ${ }^{234}$ Th-based carbon export during an iceedge bloom: Sea-ice algae as a likely bias in data interpretation, Earth and Planetary Science Letters, 269, 596-604, 2008.

Rosenheim, B. E., Day, M. B., Domack, E., Schrum, H., Benthien, A., and Hayes, J. M.: Antarctic sediment chronology by programmed-temperature pyrolysis: Methodology and data treatment, Geochemistry, Geophysics, Geosystems, 9, 2008.

Rosenheim, B. E. and Galy, V.: Direct measurement of riverine particulate organic carbon age structure, Geophysical Research Letters, 39, 2012.

Rosenheim, B. E., Roe, K. M., Roberts, B. J., Kolker, A. S., Allison, M. A., and Johannesson, K. H.: River discharge influences on particulate organic carbon age structure in the Mississippi/Atchafalaya River System, Global Biogeochemical Cycles, 27, 154-166, 2013.

Rutgers van der Loeff, M., Cai, P. H., Stimac, I., Bracher, A., Middag, R., Klunder, M. B., and van Heuven, S. M.: ${ }^{234}$ Th in surface waters: Distribution of particle export flux across the Antarctic Circumpolar Current and in the Weddell Sea during the GEOTRACES expedition ZERO and DRAKE, Deep Sea Research Part II: Topical Studies in Oceanography, 58, 2749-2766, 2011.

Rutgers Van Der Loeff, M. M., Friedrich, J., and Bathmann, U. V.: Carbon export during the Spring Bloom at the Antarctic Polar Front, determined with the natural tracer 234Th, Deep Sea Research Part II: Topical Studies in Oceanography, 44, 457-478, 1997.

Sanders, R., Morris, P. J., Poulton, A. J., Stinchcombe, M. C., Charalampopoulou, A., Lucas, M. I., and Thomalla, S. J.: Does a ballast effect occur in the surface ocean?, Geophysical Research Letters, 37, L08602, 2010.

Santschi, P., Murray, J. W., Baskaran, M., Benitez-Nelson, C. R., Guo, L., Hung, C.-C., Lamborg, C., Moran, S. B., Passow, U., and Roy-Barman, M.: Thorium speciation in seawater, Marine Chemistry, 100, 250-268, 2006.

Sarmiento, J. L., Dunne, J., Gnanadesikan, A., Key, R. M., Matsumoto, K., and Slater, 
R.: A new estimate of the $\mathrm{CaCO} 3$ to organic carbon export ratio, Global Biogeochemical Cycles, 16, 2002.

Sarmiento, J. L., Gruber, N., Brzezinski, M. A., and Dunne, J. P.: High-latitude controls of thermocline nutrients and low latitude biological productivity, Nature, 427, 5660, 2004.

Savoye, N., Benitez-Nelson, C., Burd, A. B., Cochran, J. K., Charette, M., Buesseler, K. O., Jackson, G. A., Roy-Barman, M., Schmidt, S., and Elskens, M.: Th-234 sorption and export models in the water column: A review, Marine Chemistry, 100, 234-249, 2006.

Savoye, N., Trull, T. W., Jacquet, S. H. M., Navez, J., and Dehairs, F.: 234Th-based export fluxes during a natural iron fertilization experiment in the Southern Ocean (KEOPS), Deep Sea Research Part II: Topical Studies in Oceanography, 55, 841855, 2008.

Shimmield, G. B., Ritchie, G. D., and Fileman, T. W.: The Impact of Marginal Ice-Zone Processes on the Distribution of Pb-210, Po-210 and Th-234 and Implications for New Production in the Bellingshausen Sea, Antarctica, Deep-Sea Research Part II-Topical Studies in Oceanography, 42, 1313-1335, 1995.

Sokolov, S. and Rintoul, S. R.: Circumpolar structure and distribution of the Antarctic Circumpolar Current fronts: 1. Mean circumpolar paths, Journal of Geophysical Research: Oceans (1978-2012), 114, 2009.

Steinberg, D. K., Van Mooy, B. A. S., Buesseler, K. O., Boyd, P. W., Kobari, T., and Karl, D. M.: Bacterial vs. zooplankton control of sinking particle flux in the ocean's twilight zone, Limnology and Oceanography, 53, 1327-1338, 2008.

Strickland, J. D. and Parsons, T. R.: A practical handbook of seawater analysis, Fisheries Research Board of Canada Ottawa, 1968.

Thomalla, S., Turnewitsch, R., Lucas, M., and Poulton, A.: Particulate organic carbon export from the North and South Atlantic gyres: The 234Th/238U disequilibrium approach, Deep Sea Research Part II: Topical Studies in Oceanography, 53, 16291648.

Thomalla, S. J., Poulton, A. J., Sanders, R., Turnewitsch, R., Holligan, P. M., and Lucas, M. I.: Variable export fluxes and efficiencies for calcite, opal, and organic carbon in the Atlantic Ocean: A ballast effect in action?, Global Biogeochemical Cycles, 22, GB1010, 2008.

Trull, T. W., Bray, S. G., Buesseler, K. O., Lamborg, C. H., Manganini, S., Moy, C., and Valdes, J.: In situ measurement of mesopelagic particle sinking rates and the control of carbon transfer to the ocean interior during the Vertical Flux in the Global Ocean (VERTIGO) voyages in the North Pacific, Deep-Sea Research Part II-Topical Studies in Oceanography, 55, 1684-1695, 2008.

van der Loeff, M. R., Sarin, M. M., Baskaran, M., Benitez-Nelson, C., Buesseler, K. O., Charette, M., Dai, M., Gustafsson, r., Masque, P., Morris, P. J., Orlandini, K.,

Rodriguez y Baena, A., Savoye, N., Schmidt, S., Turnewitsch, R., V^ge, I., and Waples, J. T.: A review of present techniques and methodological advances in analyzing 234Th in aquatic systems, Marine Chemistry, 100, 190-212, 2006.

Volk, T. and Hoffert, M. I.: Ocean carbon pumps: Analysis of relative strengths and efficiencies in ocean-driven atmospheric $\mathrm{CO}_{2}$ changes, Geophysical Monographs, 32, 99-110, 1985. 
Wakeham, S. G., Peterson, M. L., Hedges, J. I., and Lee, C.: Lipid biomarker fluxes in the Arabian Sea, with a comparison to the equatorial Pacific Ocean, Deep-Sea Research Part Ii-Topical Studies in Oceanography, 49, 2265-2301, 2002.

Wilson, J. D., Barker, S., and Ridgwell, A.: Assessment of the spatial variability in particulate organic matter and mineral sinking fluxes in the ocean interior: Implications for the ballast hypothesis, Global Biogeochemical Cycles, 26, GB4011, 2012.

Wilson, S. E., Steinberg, D. K., and Buesseler, K. O.: Changes in fecal pellet characteristics with depth as indicators of zooplankton repackaging of particles in the mesopelagic zone of the subtropical and subarctic North Pacific Ocean, DeepSea Research Part Ii-Topical Studies in Oceanography, 55, 1636-1647, 2008.

Zhou, K., Nodder, S., Dai, M., and Hall, J.: Insignificant enhancement of export flux in the highly productive subtropical front, east of New Zealand: a high resolution study of particle export fluxes based on $234 \mathrm{Th}$ : $238 \mathrm{U}$ disequilibria, Biogeosciences, 9, 973-992, 2012. 
Table 1. Locations and times of sampling of total 234Th and size-fractionated particles on cruises GB1 and GB2. Two export depths are indicated: ZPAR (depth of $0.3 \%$ of surface photosynthetically available radiation) and $\mathrm{z}_{\mathrm{Th} / \mathrm{U}}$ (depth where ${ }^{234} \mathrm{Th}$ and ${ }^{238} \mathrm{U}$ activities return to secular equilibrium below surface deficits).

\begin{tabular}{lrlllll}
\hline Cruise & Station & \multicolumn{1}{l}{ Date } & Lat. & Long. & \multicolumn{1}{l}{$\mathbf{Z}_{\mathbf{P A R}}$} & \multicolumn{2}{l}{$\mathbf{Z}_{\mathbf{T h} / \mathbf{U}}$} \\
\hline & - & & $d d-m m-y y$ & deg. $N$ & \multicolumn{1}{l}{ deg. $E$} & \multicolumn{1}{l}{$m$} \\
GB1 & 6 & 14 Jan 2011 & -51.79 & -56.11 & 79 & 130 \\
GB1 & 16 & 17 Jan 2011 & -46.26 & -59.83 & 62 & 141 \\
GB1 & 25 & 20 Jan 2011 & -45.67 & -48.95 & 62 & 115 \\
GB1 & 32 & 22 Jan 2011 & -40.95 & -46.00 & 69 & 171 \\
GB1 & 38 & 24 Jan 2011 & -36.52 & -43.38 & 121 & 121 \\
GB1 & 46 & 26 Jan 2011 & -42.21 & -41.21 & 63 & 100 \\
GB1 & 59 & 29 Jan 2011 & -51.36 & -37.85 & 60 & 95 \\
GB1 & 70 & 1 Feb 2011 & -59.25 & -33.15 & 100 & 100 \\
GB1 & 77 & 3 Feb 2011 & -57.28 & -25.98 & 98 & 100 \\
GB1 & 85 & 5 Feb 2011 & -53.65 & -17.75 & 73 & 140 \\
GB1 & 92 & 7 Feb 2011 & -50.40 & -10.80 & 59 & 100 \\
GB1 & 101 & 9 Feb 2011 & -46.31 & -3.21 & 81 & 140 \\
GB1 & 109 & 11 Feb 2011 & -42.63 & 3.34 & 76 & 130 \\
GB1 & 117 & 13 Feb 2011 & -38.97 & 9.49 & 62 & 110 \\
GB2 & 5 & 21 Feb 2012 & -36.94 & 39.60 & 78 & 90 \\
GB2 & 27 & 26 Feb 2012 & -45.82 & 51.05 & 105 & 105 \\
GB2 & 36 & 28 Feb 2012 & -46.84 & 58.25 & 90 & 90 \\
GB2 & 43 & 1 Mar 2012 & -47.53 & 64.01 & 108 & 125 \\
GB2 & 53 & 3 Mar 2012 & -49.30 & 71.32 & 81 & 100 \\
GB2 & 63 & 5 Mar 2012 & -54.40 & 74.54 & 109 & 130 \\
GB2 & 73 & 7 Mar 2012 & -59.71 & 77.73 & 93 & 75 \\
GB2 & 87 & 10 Mar 2012 & -54.23 & 88.22 & 107 & 100 \\
GB2 & 93 & 11 Mar 2012 & -49.81 & 94.13 & 113 & 130 \\
GB2 & 100 & 14 Mar 2012 & -44.62 & 100.50 & 113 & 90 \\
GB2 & 106 & 16 Mar 2012 & -40.10 & 105.34 & 102 & 95 \\
GB2 & 112 & 17 Mar 2012 & -40.26 & 109.63 & 76 & 105 \\
GB2 & 119 & 20 Mar 2012 & -42.08 & 113.40 & 92 & 90 \\
\hline & & & & & &
\end{tabular}


Table 2. POC fluxes, concentrations, and attenuation of $>51 \mu \mathrm{m}[\mathrm{POC}]$ in the mesopelagic zone. Attenuation coefficient is the exponent from significant power law fits to $>51 \mu \mathrm{m}$ [POC]. $\mathrm{Z}_{\mathrm{PAR}}+100 \mathrm{~m}$ is $100 \mathrm{~m}$ below $\mathrm{Z}_{\mathrm{PAR}}$, as defined in the Table 1 caption. Transfer efficiency is POC flux at $\mathrm{Z}_{\mathrm{PAR}}+100 \mathrm{~m}$ divided by POC flux at $\mathrm{Z}_{\mathrm{PAR}}$. Deep $>51 \mu \mathrm{m}$ [POC] was measured at $1000 \mathrm{~m}$ and $800 \mathrm{~m}$ for GB1 and GB2, respectively. POC flux errors are propagated from ${ }^{234} \mathrm{Th}$ flux, and POC: ${ }^{234} \mathrm{Th}$ errors.

\begin{tabular}{|c|c|c|c|c|c|c|c|c|}
\hline 苋 & 苞 & 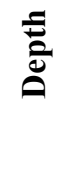 & 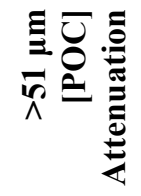 & 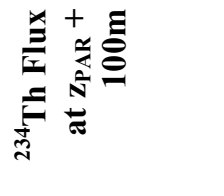 & 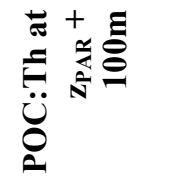 & 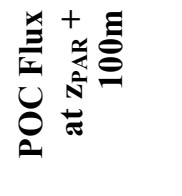 & 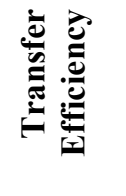 & 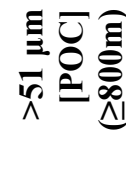 \\
\hline- & - & $m$ & unitless & $d p m m^{-2} d^{-1}$ & $\mu \mathrm{mol} \mathrm{dpm^{-1 }}$ & $m m o l m^{-2} d^{-1}$ & unitless & $\mu M$ \\
\hline GB1 & 6 & 179 & 0.8 & $3,319 \pm 128^{\mathrm{c}}$ & 1.7 & $5.7 \pm 0.31$ & 1.00 & 0.030 \\
\hline GB1 & 16 & 162 & 1.1 & $2,567 \pm 116^{\mathrm{c}}$ & 2.4 & $6.1 \pm 0.30$ & 1.04 & No data \\
\hline GB1 & 25 & 162 & 0.4 & $1,074 \pm 125$ & 2.5 & $2.7 \pm 0.37$ & 1.76 & 0.013 \\
\hline GB1 & 32 & 169 & 0.9 & $1,581 \pm 186$ & 1.3 & $2.0 \pm 0.25$ & 0.86 & 0.006 \\
\hline GB1 & 38 & 221 & No fit & $911 \pm 206$ & 1.6 & $1.5 \pm 0.35$ & 0.70 & 0.026 \\
\hline GB1 & 46 & 163 & 1.0 & $1,937 \pm 146$ & 1.6 & $3.1 \pm 0.27$ & 0.4 & 0.009 \\
\hline GB1 & 59 & 160 & 0.6 & $2,582 \pm 126^{\mathrm{c}}$ & 3.7 & $9.5 \pm 0.56$ & 1.29 & 0.014 \\
\hline GB1 & 70 & 200 & 0.6 & $1,414 \pm 248$ & 3.5 & $5.0 \pm 0.90$ & 0.90 & 0.024 \\
\hline GB1 & 77 & 198 & 0.5 & $1,903 \pm 162$ & 2.1 & $4.0 \pm 0.41$ & 0.44 & 0.012 \\
\hline GB1 & 85 & 173 & $1.7^{\mathrm{a}}$ & $2,076 \pm 207$ & 9 & & 0.41 & 0.035 \\
\hline GB1 & 92 & 159 & 1.1 & $1,339 \pm 170$ & 3.7 & $4.9 \pm 0.64$ & 0.61 & 0.019 \\
\hline GB1 & 101 & 181 & 0.8 & $1,774 \pm 135$ & 1.7 & $3.0 \pm 0.24$ & 0.83 & 0.019 \\
\hline GB1 & 109 & 176 & 1.0 & $1,719 \pm 97$ & 1.1 & $1.9 \pm 0.13$ & 0.87 & 0.006 \\
\hline GB1 & 117 & 162 & 1.1 & $1,258 \pm 86$ & 1.2 & $1.5 \pm 0.13$ & 0.87 & 0.005 \\
\hline GB2 & 5 & 178 & 0.5 & $1,402 \pm 3,706^{\mathrm{c}}$ & 1.1 & $1.5 \pm 6.1$ & 0.5 & No data \\
\hline GB2 & 27 & 205 & No fit & $2,063 \pm 205$ & 1.2 & $2.5 \pm 0.30$ & 0.71 & No data \\
\hline GB2 & 36 & 190 & 1.5 & & & $0.93 \pm 0$ & 0.48 & \\
\hline GB2 & 43 & 208 & 1.9 & $1,247 \pm 200$ & & $2.7 \pm 0.45$ & 0.54 & 0.005 \\
\hline GB2 & 53 & 181 & No fit & $1,013 \pm 220$ & 2.0 & $2.0 \pm 0.45$ & 0.49 & No data \\
\hline GB2 & 63 & 209 & 1.8 & $1,292 \pm 262$ & 1.7 & $2.1 \pm 0.46$ & 0.31 & 0.014 \\
\hline GB2 & 73 & 193 & 1.5 & $807 \pm 189$ & 1.9 & $1.6 \pm 0.37$ & 0.48 & 0.008 \\
\hline GB2 & 87 & 207 & 0.7 & $1,213 \pm 196$ & 1.6 & $1.9 \pm 0.34$ & 0.60 & 0.013 \\
\hline GB2 & 93 & 213 & $2.3^{b}$ & $469 \pm 249$ & 1.6 & $0.77 \pm 0.42$ & 0.53 & 0.001 \\
\hline GB2 & 100 & 213 & 0.8 & $1,132 \pm 190$ & 0.7 & $0.80 \pm 0.15$ & 0.52 & 0.014 \\
\hline GB2 & 106 & 202 & 0.9 & $1,405 \pm 186$ & 1.3 & $1.8 \pm 0.26$ & 1.63 & 0.017 \\
\hline GB2 & 112 & 176 & 1.3 & $270 \pm 186$ & 0.9 & $0.23 \pm 0.21$ & 0.24 & 0.007 \\
\hline GB2 & 119 & 192 & No fit & $756 \pm 218$ & 0.8 & $0.57 \pm 0.17$ & 0.20 & 0.013 \\
\hline
\end{tabular}

\footnotetext{
${ }^{\mathrm{a}}$ attenuation coefficient is 2.35 when only fitting $>51 \mu \mathrm{m}$ [POC] measurements at depths $<500 \mathrm{~m}$ (Fig. 3).

b outlier approximated by Chauvenet's Theorem (Glover, et al., 2011).

${ }^{c}$ values were estimated by linear interpolation of values at upper and lower depths around $\mathrm{z}_{\mathrm{PAR}}+100 \mathrm{~m}$.
} 
Table 3. POC, biomineral, and ${ }^{234}$ Th concentrations and fluxes at ZPAR. Ez- ratio is ${ }^{234}$ Th-derived POC flux at $\mathrm{Z}_{\mathrm{PAR}}$ divided by integrated primary productivity. The $\%>51 \mu \mathrm{m}[\mathrm{POC}]$ metric is the fraction of total $[\mathrm{POC}]$ in the $>51 \mu \mathrm{m}$ size fraction. POC and biomineral flux errors are propagated from ${ }^{234} \mathrm{Th}$ flux, and POC: ${ }^{.234} \mathrm{Th}$ errors.

\begin{tabular}{|c|c|c|c|c|c|c|c|c|c|c|c|c|c|c|c|c|}
\hline 苞 & 泀 & $\begin{array}{l}\stackrel{\cong}{4} \\
\hat{N}\end{array}$ & 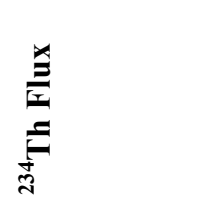 & 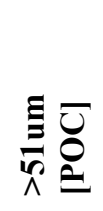 & 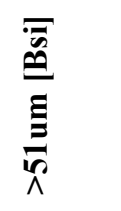 & $\stackrel{\Xi}{\bar{\Xi}}$ & $\stackrel{\Xi}{\Xi}$ & 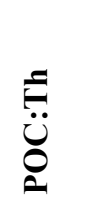 & 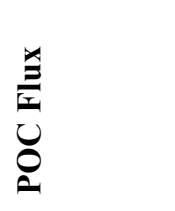 & 泀 & 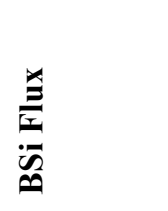 & تِ & $\begin{array}{l}\frac{.}{E} \\
\frac{U}{U}\end{array}$ & 总 & 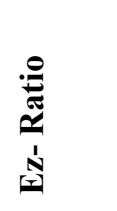 & 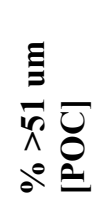 \\
\hline 1 & , & $\equiv$ & 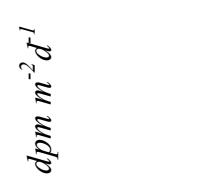 & ミ & ミ & 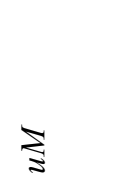 & 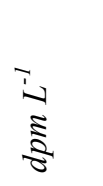 & 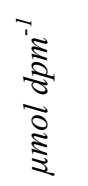 & 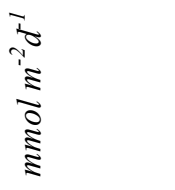 & 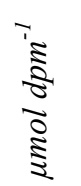 & 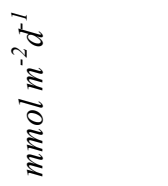 & 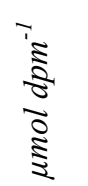 & 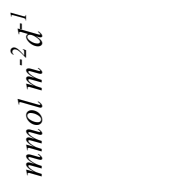 & 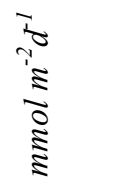 & 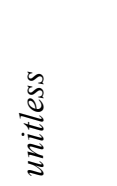 & $d^{0}$ \\
\hline GB1 & 6 & 79 & $2,437 \pm 100$ & $0.23^{\mathrm{b}}$ & $0.03^{\mathrm{a}}$ & $0.124^{\mathrm{a}}$ & $0.07^{\mathrm{a}}$ & $2.3^{\mathrm{a}}$ & $5.7 \pm 0.26$ & 0.4 & $0.9 \pm 0.04$ & 1.8 & $4.3 \pm 0.20$ & 42 & 0.14 & $8.8 \%$ \\
\hline GB1 & 16 & 62 & $1,933 \pm 71$ & 0.38 & 0.08 & 0.390 & 0.12 & 3.0 & $5.9 \pm 0.68$ & 0.6 & $1.2 \pm 0.14$ & 3.1 & $6.1 \pm 0.70$ & 165 & 0.04 & $17.7 \%$ \\
\hline GB1 & 25 & 62 & $862 \pm 46^{\mathrm{a}}$ & 0.04 & $0.005^{\mathrm{a}}$ & $0.015^{\mathrm{a}}$ & 0.02 & 1.8 & $1.6 \pm 0.11$ & 0.2 & $0.2 \pm 0.02$ & 0.7 & $0.6 \pm 0.04$ & 35 & 0.04 & $3.2 \%$ \\
\hline GB1 & 32 & 69 & $1,304 \pm 116$ & 0.07 & 0.01 & 0.027 & 0.04 & 1.8 & $2.3 \pm 0.21$ & 0.3 & $0.3 \pm 0.03$ & 0.7 & $0.9 \pm 0.08$ & 11 & 0.21 & $3.9 \%$ \\
\hline GB1 & 38 & 121 & $809 \pm 126$ & 0.04 & 0.003 & 0.017 & 0.01 & 2.7 & $2.2 \pm 0.35$ & 0.2 & $0.2 \pm 0.03$ & 1.2 & $0.9 \pm 0.15$ & 21 & 0.10 & $8.4 \%$ \\
\hline GB1 & 46 & 63 & $2,123 \pm 69$ & 0.23 & 0.005 & 0.059 & 0.06 & 4.1 & $8.8 \pm 0.38$ & 0.1 & $0.2 \pm 0.02$ & 1.1 & $2.2 \pm 0.10$ & 13 & 0.67 & $5.3 \%$ \\
\hline GB1 & 59 & 60 & $1,844 \pm 102$ & 0.09 & 0.10 & 0.072 & 0.02 & 4.0 & $7.3 \pm 0.52$ & 4.6 & $8.6 \pm 0.53$ & 3.4 & $6.2 \pm 0.39$ & 26 & 0.28 & $5.3 \%$ \\
\hline GB1 & 70 & 100 & $1,280 \pm 94$ & 0.11 & $0.06^{\mathrm{a}}$ & $0.001^{\mathrm{a}}$ & 0.02 & 4.3 & $5.5 \pm 0.44$ & $3.5^{\mathrm{a}}$ & $4.5 \pm 0.35$ & $0.1^{\mathrm{a}}$ & $\begin{array}{r}0.1 \pm \\
0.09\end{array}$ & 10 & 0.53 & $10.6 \%$ \\
\hline GB1 & 77 & 98 & $1,485 \pm 105$ & 0.03 & 0.03 & 0.002 & 0.01 & 6.0 & $9.0 \pm 1.3$ & 5.6 & $8.3 \pm 0.98$ & 0.4 & $0.7 \pm 0.23$ & 57 & 0.16 & $3.6 \%$ \\
\hline GB1 & 85 & 73 & $1,858 \pm 94$ & 2.50 & 3.44 & 0.124 & 0.23 & 10.8 & $20 \pm 1.1$ & 14.9 & $28 \pm 1.5$ & 0.5 & $1.0 \pm 0.05$ & 53 & 0.38 & $52.0 \%$ \\
\hline GB1 & 92 & 59 & $1,639 \pm 77$ & 0.40 & 0.46 & 0.020 & 0.08 & 4.9 & $8.0 \pm 0.40$ & 5.6 & $9.3 \pm 0.46$ & 0.2 & $0.4 \pm 0.02$ & 26 & 0.31 & $11.3 \%$ \\
\hline GB1 & 101 & 81 & $1,763 \pm 82$ & 0.19 & 0.05 & 0.013 & 0.09 & 2.0 & $3.6 \pm 0.18$ & 0.5 & $0.9 \pm 0.04$ & 0.1 & $0.2 \pm 0.01$ & 22 & 0.17 & $12.5 \%$ \\
\hline GB1 & 109 & 76 & $1,524 \pm 76$ & $0.19^{\mathrm{a}}$ & $0.05^{\mathrm{a}}$ & $0.027^{\mathrm{a}}$ & $0.14^{\mathrm{a}}$ & 1.4 & $2.1 \pm 0.11$ & 0.4 & $0.6 \pm 0.03$ & 0.2 & $0.3 \pm 0.02$ & 14 & 0.16 & $21.0 \%$ \\
\hline GB1 & 117 & 62 & $1,177 \pm 50$ & 0.21 & 0.02 & 0.032 & 0.15 & 1.4 & $1.7 \pm 0.07$ & 0.1 & $0.2 \pm 0.01$ & 0.2 & $0.3 \pm 0.01$ & 18 & 0.09 & $6.6 \%$ \\
\hline GB2 & 5 & 78 & $1,889 \pm 5207$ & $0.08^{\mathrm{b}}$ & $0.01^{\mathrm{a}}$ & $0.048^{\mathrm{a}}$ & $0.05^{\mathrm{a}}$ & 1.6 & $3.0 \pm 8.8$ & 0.2 & $0.4 \pm 1.2$ & 1.0 & $1.9 \pm 5.2$ & 8.2 & 0.37 & $7.6 \%$ \\
\hline
\end{tabular}




\begin{tabular}{lrrrrrrrrrrrrrrrrrr} 
GB2 & 27 & 105 & $1,869 \pm 160$ & $0.08^{\mathrm{a}}$ & $0.10^{\mathrm{a}}$ & $0.060^{\mathrm{a}}$ & $0.04^{\mathrm{a}}$ & 1.9 & $3.5 \pm 0.32$ & 2.2 & $4.0 \pm 0.35$ & 1.3 & $2.5 \pm 0.22$ & 8.0 & 0.44 & $6.7 \%$ \\
& & & & & & & & & & & & & & \\
GB2 & 36 & 90 & $988 \pm 89$ & 0.43 & 0.28 & 0.074 & 0.22 & 2.0 & $2.0 \pm 0.18$ & 1.3 & $1.3 \pm 0.12$ & 0.3 & $0.3 \pm 0.03$ & 12 & 0.16 & $15.6 \%$ \\
GB2 & 43 & 108 & $1,221 \pm 153$ & $0.74^{\mathrm{a}}$ & $0.62^{\mathrm{a}}$ & $0.041^{\mathrm{a}}$ & $0.18^{\mathrm{a}}$ & 4.1 & $5.0 \pm 0.63$ & 3.4 & $4.2 \pm 0.53$ & 0.2 & $0.3 \pm 0.04$ & 12 & 0.43 & $37.8 \%$ \\
GB2 & 53 & 81 & $1058 \pm 100^{\mathrm{a}}$ & $0.54^{\mathrm{a}}$ & $0.80^{\mathrm{a}}$ & $0.081^{\mathrm{a}}$ & $0.14^{\mathrm{a}}$ & 3.9 & $4.1 \pm 0.40$ & 5.7 & $6.1 \pm 0.59$ & 0.6 & $0.6 \pm 0.07$ & 16 & 0.25 & $22.5 \%$ \\
$\mathrm{~GB} 2$ & 63 & 109 & $1,229 \pm 138$ & $0.71^{\mathrm{a}}$ & $1.04^{\mathrm{a}}$ & $0.028^{\mathrm{a}}$ & $0.13^{\mathrm{a}}$ & $5.6^{\mathrm{a}}$ & $6.9 \pm 0.78$ & 8.1 & $9.9 \pm 1.1$ & 0.2 & $0.3 \pm 0.03$ & 9.0 & 0.77 & $33.2 \%$ \\
GB2 & 73 & 93 & $977 \pm 108$ & $0.21^{\mathrm{b}}$ & $1.13^{\mathrm{a}}$ & $0.014^{\mathrm{a}}$ & $0.20^{\mathrm{a}}$ & $3.3^{\mathrm{a}}$ & $3.2 \pm 0.36$ & 5.6 & $5.4 \pm 0.60$ & 0.1 & $0.1 \pm 0.01$ & 8.8 & 0.36 & $17.6 \%$ \\
GB2 & 87 & 107 & $1,299 \pm 115$ & $0.06^{\mathrm{b}}$ & $0.30^{\mathrm{a}}$ & $0.041^{\mathrm{a}}$ & $0.06^{\mathrm{a}}$ & $2.5^{\mathrm{a}}$ & $3.2 \pm 0.40$ & 4.7 & $6.1 \pm 0.55$ & 0.6 & $0.8 \pm 0.14$ & 11 & 0.29 & $3.4 \%$ \\
GB2 & 93 & 113 & $1,142 \pm 137$ & $0.07^{\mathrm{a}}$ & $0.01^{\mathrm{a}}$ & $0.023^{\mathrm{a}}$ & $0.05^{\mathrm{a}}$ & 1.3 & $1.5 \pm 0.25$ & 0.2 & $0.3 \pm 0.06$ & 0.4 & $0.5 \pm 0.14$ & 12 & 0.12 & $4.3 \%$ \\
GB2 & 100 & 113 & $1,112 \pm 130$ & 0.08 & 0.02 & 0.006 & 0.06 & 1.4 & $1.5 \pm 0.19$ & 0.3 & $0.3 \pm 0.04$ & 0.1 & $0.1 \pm 0.02$ & 14 & 0.11 & $12.8 \%$ \\
GB2 & 106 & 102 & $1394 \pm 82^{\mathrm{a}}$ & $0.09^{\mathrm{b}}$ & $0.04^{\mathrm{a}}$ & $0.024^{\mathrm{a}}$ & $0.12^{\mathrm{a}}$ & 0.8 & $1.1 \pm 0.86$ & 0.3 & $0.4 \pm 0.02$ & 0.2 & $0.3 \pm 0.02$ & 22 & 0.05 & $12.2 \%$ \\
GB2 & 112 & 76 & $717 \pm 97$ & $0.22^{\mathrm{b}}$ & $0.17^{\mathrm{a}}$ & $0.087^{\mathrm{a}}$ & $0.36^{\mathrm{a}}$ & $1.4^{\mathrm{a}}$ & $1.0 \pm 0.13$ & 0.5 & $0.3 \pm 0.05$ & 0.2 & $0.2 \pm 0.02$ & no data & no data & $13.3 \%$ \\
GB2 & 119 & 92 & $1,223 \pm 124$ & $0.51^{\mathrm{a}}$ & $0.12^{\mathrm{a}}$ & $0.048^{\mathrm{a}}$ & $0.22^{\mathrm{a}}$ & 2.3 & $2.8 \pm 0.29$ & 0.5 & $0.7 \pm 0.07$ & 0.2 & $0.3 \pm 0.03$ & 17 & 0.17 & $21.5 \%$ \\
\hline
\end{tabular}

a values at $\mathrm{z}_{\mathrm{PAR}}$ estimated by linear interpolation of values at upper and lower depths around $\mathrm{z}_{\mathrm{PAR}}$.

b $>51 \mu \mathrm{m}$ [POC] values interpolated by significant power-law fits (Fig. 3).

"no data": not enough depths were sampled and analyzed to interpolate at $\mathrm{Z}_{\mathrm{PAR}}$. 
Table 4. Mean \pm standard deviations of ${ }^{234} \mathrm{Th}$ fluxes, POC: ${ }^{234} \mathrm{Th}, \mathrm{BSi}:{ }^{234} \mathrm{Th}, \mathrm{PIC}:{ }^{234} \mathrm{Th}$, POC fluxes, and biomineral fluxes at $\mathrm{Z}_{\mathrm{PAR}}$, divided by three latitude zones. $45{ }^{\circ} \mathrm{S}$ marks the approximate latitude of the Subantarctic front, while $52{ }^{\circ} \mathrm{S}$ marks the approximate latitude of the Polar front (Belkin and Gordon, 1996; Sokolov and Rintoul, 2009).

\begin{tabular}{|c|c|c|c|c|c|c|c|c|}
\hline 苛 节 & 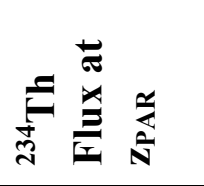 & 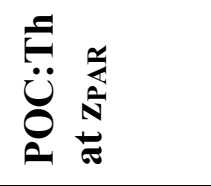 & 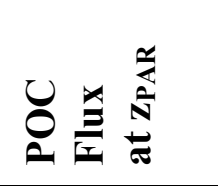 & 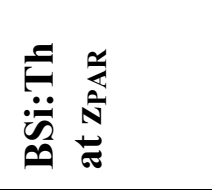 & 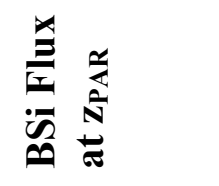 & 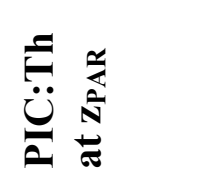 & 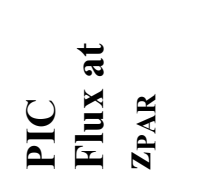 & $\begin{array}{l}\text { E } \\
\text { 荡 } \\
\#\end{array}$ \\
\hline${ }^{\circ} \mathrm{S}$ & $d p m m^{-2} d^{-1}$ & $4 \mathrm{~mol} \mathrm{dpm^{-1 }}$ & $m m o l m^{-2} d^{-1}$ & umol dpm ${ }^{-1}$ & $\mathrm{mmol} \mathrm{m}^{-2} d^{-1}$ & ${ }^{2 m o l ~ d p m^{-1}}$ & $\mathrm{mmol} \mathrm{m} \mathrm{m}^{-2} \mathrm{~d}^{-1}$ & - \\
\hline $36-45$ & $1.3 \pm 0.44$ & $1.9 \pm 0.9$ & $2.7 \pm 2.3$ & $0.3 \pm 0.1$ & $0.33 \pm 0.17$ & $0.5 \pm 0.4$ & $0.73 \pm 0.76$ & 10 \\
\hline $45-52$ & $1.5 \pm 0.50$ & $2.8 \pm 1.2$ & $4.4 \pm 2.2$ & $2.3 \pm 2.2$ & $3.4 \pm 3.3$ & $1.1 \pm 1.2$ & $2.0 \pm 2.4$ & 11 \\
\hline $52->60$ & $1.4 \pm 0.30$ & $5.4 \pm 3.0$ & $8.0 \pm 6.3$ & $7.1 \pm 4.1$ & $10 \pm 8.7$ & $0.3 \pm 0.2$ & $0.49 \pm 0.4$ & 6 \\
\hline
\end{tabular}




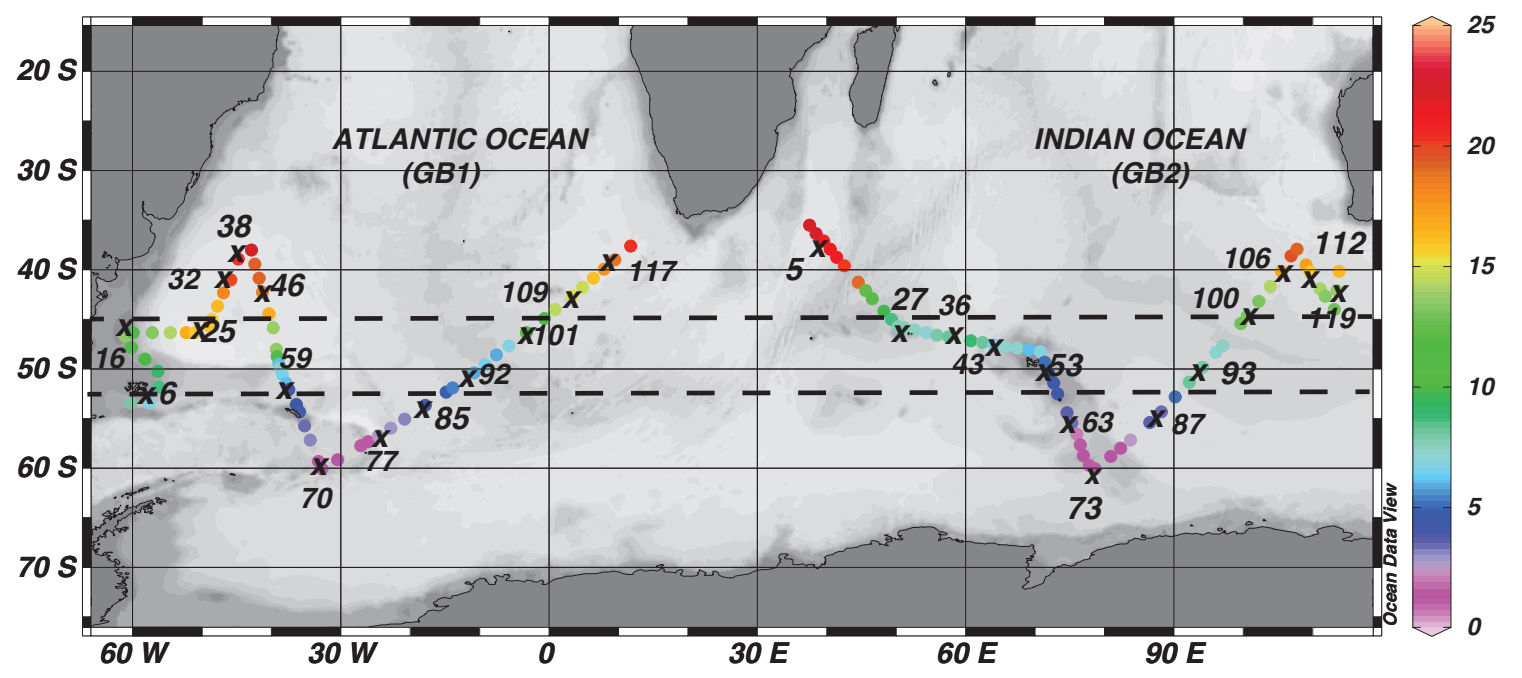

Figure 1. Cruise tracks across the Atlantic (cruise GB1) and Indian (cruise GB2) sectors

of the Great Calcite Belt showing sea surface temperature along the two transects. Station numbers where ${ }^{234} \mathrm{Th}$ and size-fractionated particles were sampled are indicated by crosses. The two horizontal dashed lines at $45^{\circ} \mathrm{S}$ and $52{ }^{\circ} \mathrm{S}$ represent the approximate locations of the Subantarctic and Polar fronts, respectively (Belkin and Gordon, 1996; Sokolov and Rintoul, 2009). 

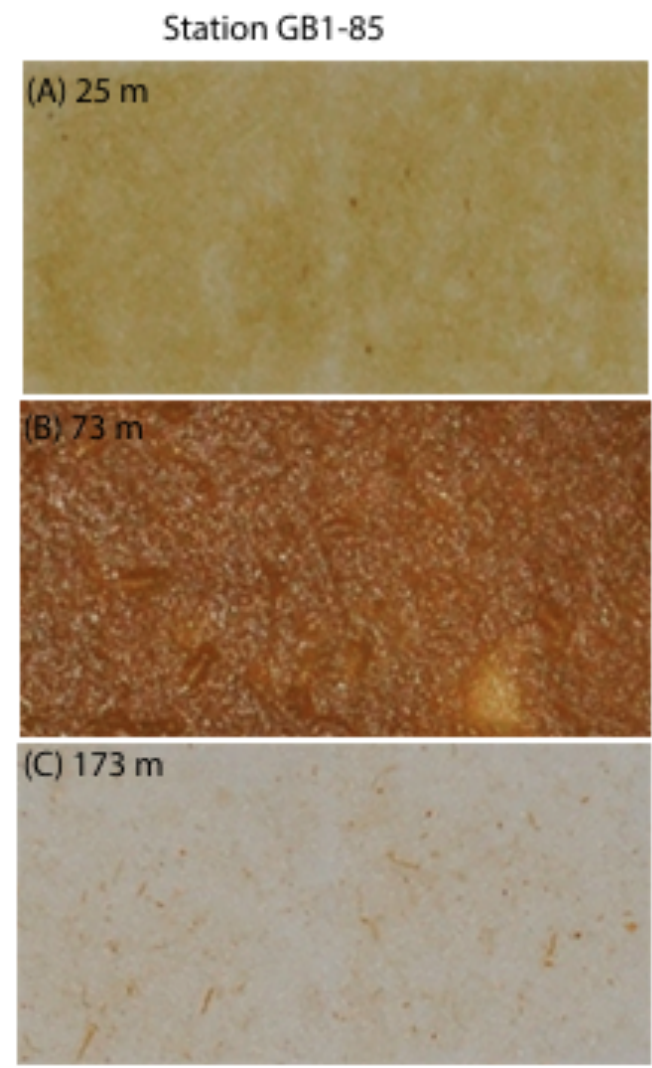

Figure 2. Digital images of $>51 \mu \mathrm{m}$ filters from station GB1-85 (refer to Fig. 1 for station location). $>51 \mu \mathrm{m}$ particles are from (a) $25 \mathrm{~m}$ in the euphotic zone, (b) $73 \mathrm{~m}$, which corresponds to $\mathrm{Z}_{\mathrm{PAR}}$, as defined in Table 1, and (c) at 173m, below both metrics of export depth, $\mathrm{z}_{\mathrm{PAR}}$ and $\mathrm{z}_{\mathrm{Th} / \mathrm{U}}$ (Table 1). $>51 \mu \mathrm{m}$ particles in the euphotic zone appear as dense sheets of intact cells packed onto the filters $(a, b)$ and as more sparsely arranged cylindrical fecal pellets on filters collected below ZPAR (c). 


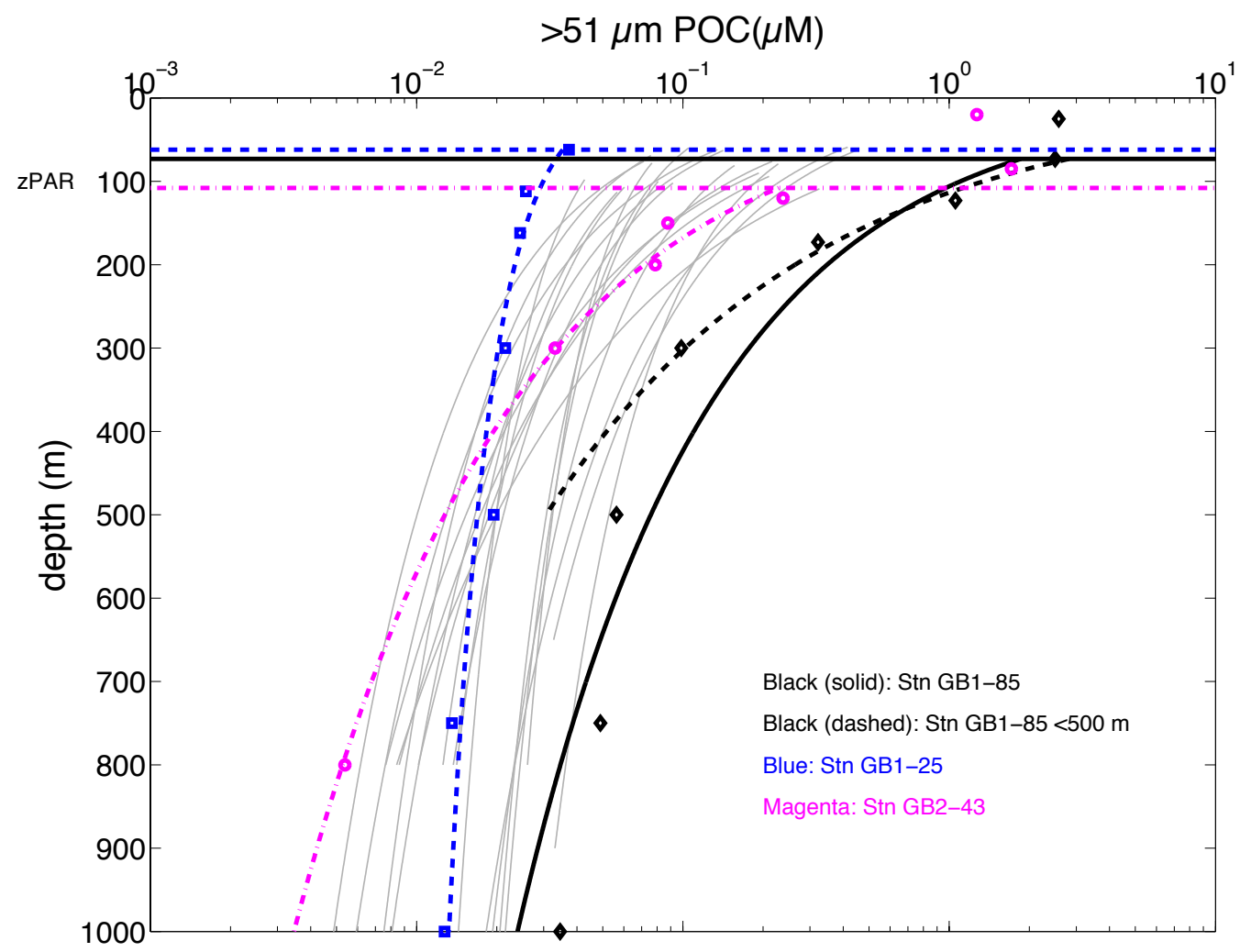

Figure 3. Significant power law fits of $>51 \mu \mathrm{m}$ [POC] below $\mathrm{Z}_{\mathrm{PAR}}$, according to Eq. (1). Only the 22 significant fits are shown as lines. Three stations are highlighted to show the range in $>51 \mu \mathrm{m}$ [POC] attenuation across GB1 and GB2 profiles (symbols represent measurements): GB1-85 had the highest POC concentration through the water column and an attenuation coefficient of 1.7; GB1-25 had the lowest attenuation coefficient (0.4); GB2-43 had the highest attenuation coefficient (1.9) (Table 2). Fitting GB1-85 >51 um [POC] measurements between $\mathrm{Z}_{\mathrm{PAR}}$ and $500 \mathrm{~m}$ yields a higher attenuation coefficient of 2.35. Refer to Fig. 1 for station locations. 

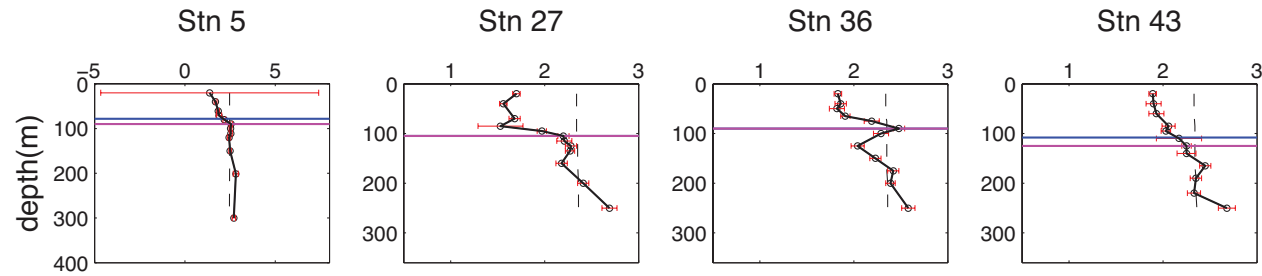

Stn 53

Stn 63

Stn 73

Stn 87
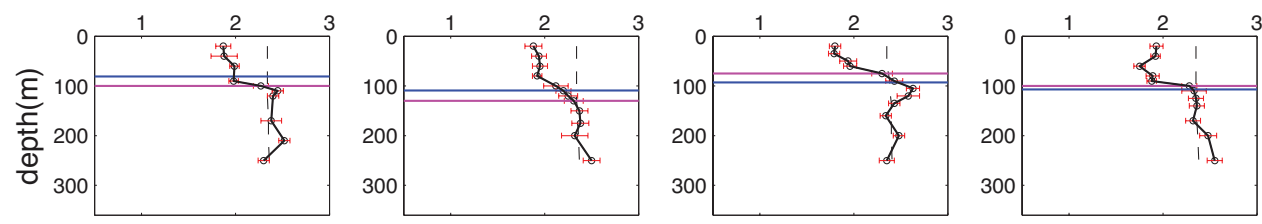

Stn 93

Stn 100

Stn 106

Stn 112
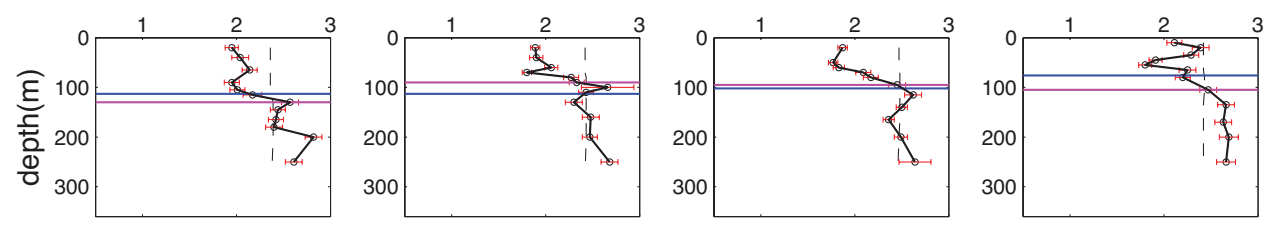

Stn 119

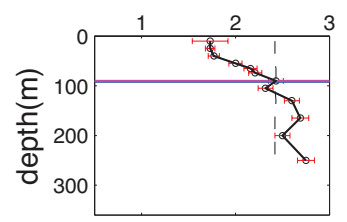

234Th Activity

238U Activity

$z(T h / U)$

zPAR 

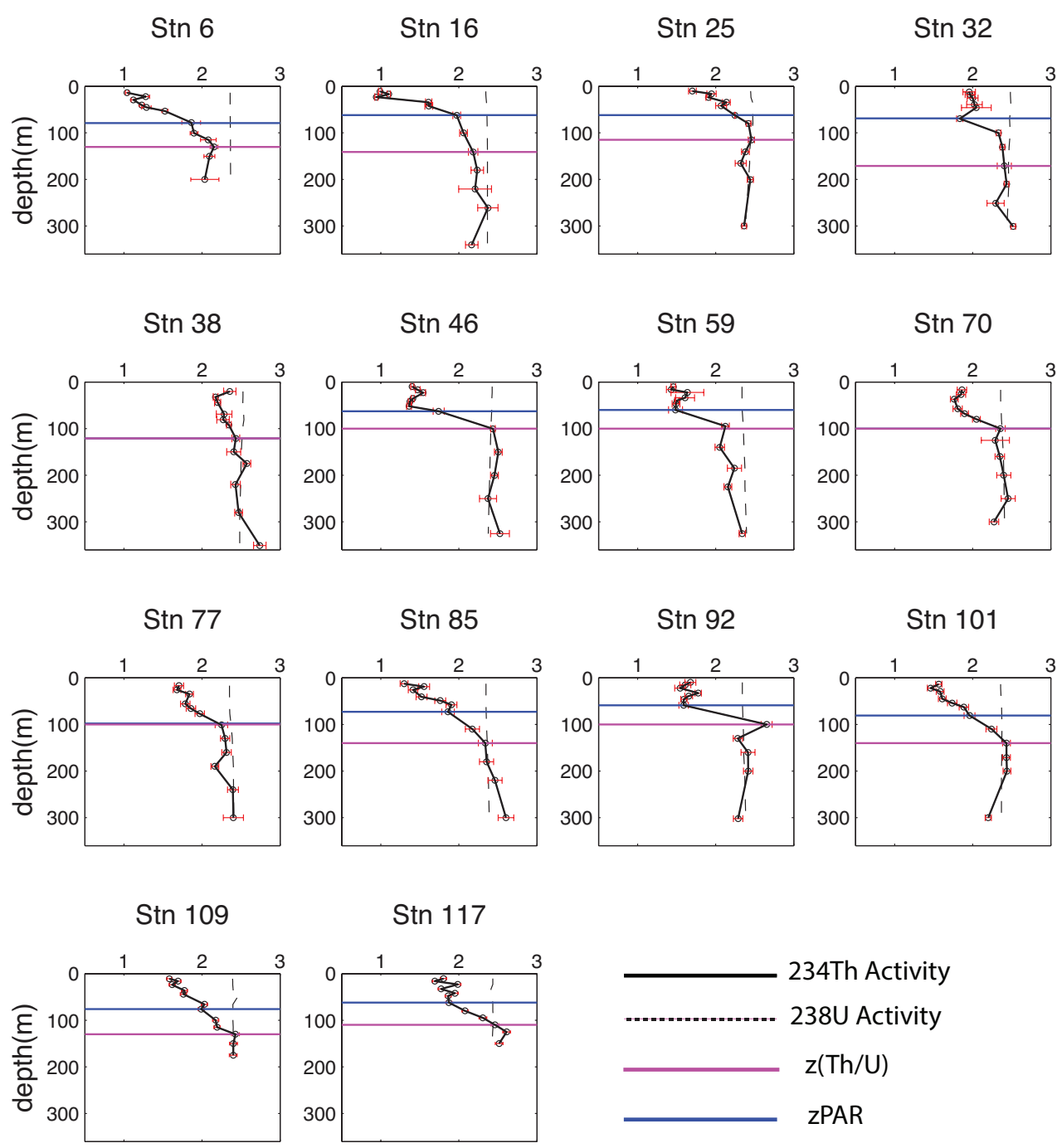

Figure 4. Total ${ }^{234} \mathrm{Th}$ and ${ }^{238} \mathrm{U}$ activity profiles measured at 14 stations of GB1 and 13 stations of GB2 (note different x-axis for station GB2-5) (Appendix A, Table S1). Error bars for ${ }^{234} \mathrm{Th}$ activity are propagated errors. ${ }^{238} \mathrm{U}$ is calculated from salinity. All ${ }^{234} \mathrm{Th}$ activity profiles exhibit a deficit relative to ${ }^{238} \mathrm{U}$ activity at the surface, and mostly return to equilibrium with ${ }^{234} \mathrm{U}$ within error at depth of $\mathrm{z}_{\mathrm{Th} / \mathrm{U}}$ (Table 1). Refer to Fig. 1 for station locations. 

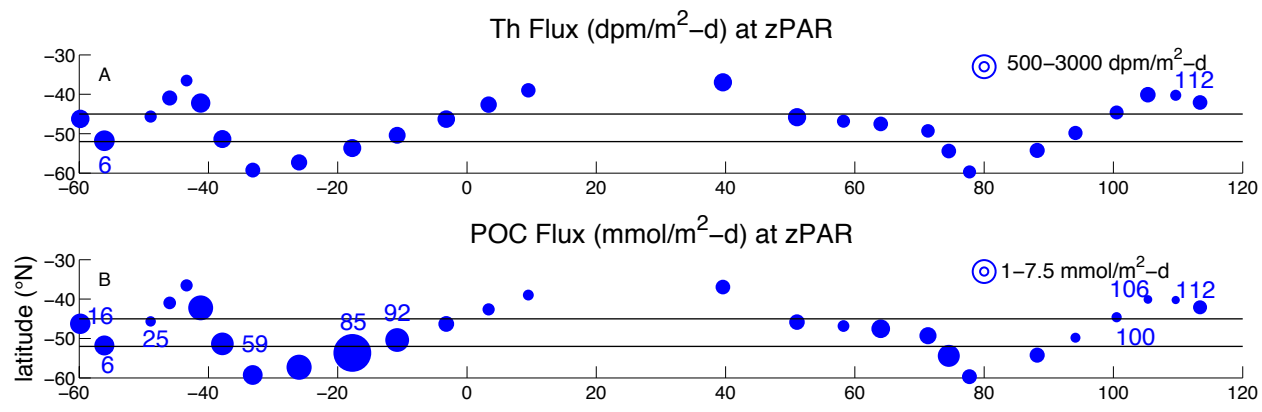

POC Flux $\left(\mathrm{mmol} / \mathrm{m}^{2}-\mathrm{d}\right)$ at $\mathrm{z}(\mathrm{Th} / \mathrm{U})$

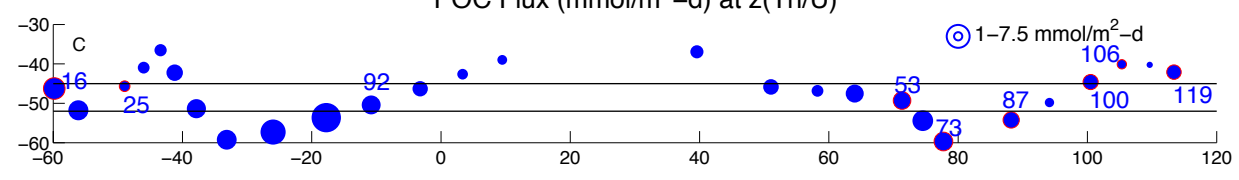

POC Flux $\left(\mathrm{mmol} / \mathrm{m}^{2}-\mathrm{d}\right) 100 \mathrm{~m}$ below zPAR

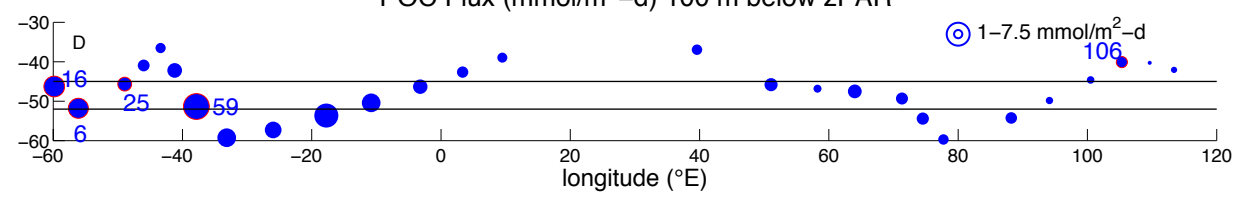

Figure 5. Distribution of ${ }^{234} \mathrm{Th}$ flux and ${ }^{234} \mathrm{Th}$-derived POC flux at 27 stations along GB1 and GB2 (circle area scales with flux magnitude). (a) ${ }^{234} \mathrm{Th}$ fluxes at $\mathrm{Z}_{\mathrm{PAR}}$ range from 717 dpm m m $^{-2} \mathrm{~d}^{-1}$ to 2,437 $\mathrm{dpm} \mathrm{m}^{-2} \mathrm{~d}^{-1}$ at stations GB2-112 and GB1-6, respectively. (b) POC fluxes at ZPAR range from $0.97 \mathrm{mmol} \mathrm{m}^{-2} \mathrm{~d}^{-1}$ to $20 \mathrm{mmol} \mathrm{m}^{-2} \mathrm{~d}^{-1}$ at stations GB2-112 and GB1-85, respectively. (c) POC fluxes at $\mathrm{z}_{\mathrm{Th} / \mathrm{U}}$ range from 0.57 to $12 \mathrm{mmol} \mathrm{m}^{-2} \mathrm{~d}^{-1}$ at stations GB2-112 and GB1-85, respectively (Appendix A, Table S2). (d) POC fluxes at $100 \mathrm{~m}$ below Z ZAR range from 0.23 to $9.5 \mathrm{mmol} \mathrm{m}^{-2} \mathrm{~d}^{-1}$ at stations GB2-112 and GB1-59, respectively. A few station numbers discussed in the text are indicated. Red outlines distinguish stations where fluxes are greater at the specified depth than at ZPAR. The two horizontal dashed lines at $45^{\circ} \mathrm{S}$ and $52^{\circ} \mathrm{S}$ represent the approximate locations of the Subantarctic and Polar fronts, respectively (Belkin and Gordon, 1996; Sokolov and Rintoul, 2009). Refer to Fig. 1 for other station locations. $\mathrm{z}_{\mathrm{PAR}}$ and $\mathrm{z}_{\mathrm{Th} / \mathrm{U}}$ are defined as in Table 1. 

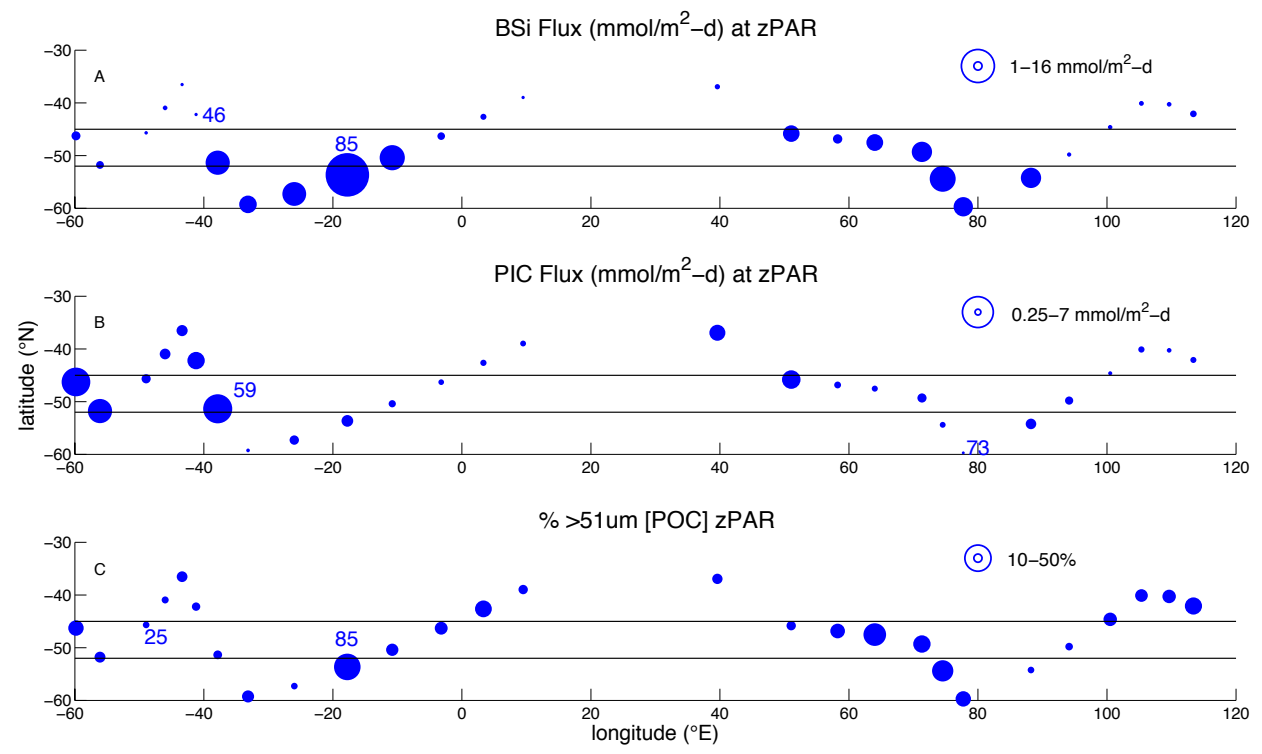

Figure 6. Distribution of BSi flux, PIC flux, and $\%>51 \mu \mathrm{m}[\mathrm{POC}]$, the percent of total $[\mathrm{POC}]$ in the $>51 \mu \mathrm{m}$ size class, at $\mathrm{Z}_{\mathrm{PAR}}$ (Table 1) along GB1 and GB2 (circle area scales with magnitude). (a) BSi fluxes range from $0.17 \mathrm{mmol} \mathrm{m}^{-2} \mathrm{~d}^{-1}$ to $28 \mathrm{mmol} \mathrm{m}^{-2} \mathrm{~d}^{-1}$ at stations GB1-46 and GB1-85, respectively. (b) PIC fluxes range from 0.067 to $6.2 \mathrm{mmol}$ $\mathrm{m}^{-2} \mathrm{~d}^{-1}$ at stations GB2-73 and GB2-59, respectively. (c) The proportion of [POC] in the $>51 \mu \mathrm{m}$ size-fraction at $\mathrm{Z}_{\mathrm{PAR}}$ ranges from $3.3 \%$ to $52 \%$ at stations GB1-25 and GB1-85, respectively. A few station numbers discussed in the text are indicated. The two horizontal dashed lines at $45^{\circ} \mathrm{S}$ and $52{ }^{\circ} \mathrm{S}$ represent the approximate locations of the Subantarctic and Polar fronts, respectively (Belkin and Gordon, 1996; Sokolov and Rintoul, 2009). Refer to Fig. 1 for other station locations. 

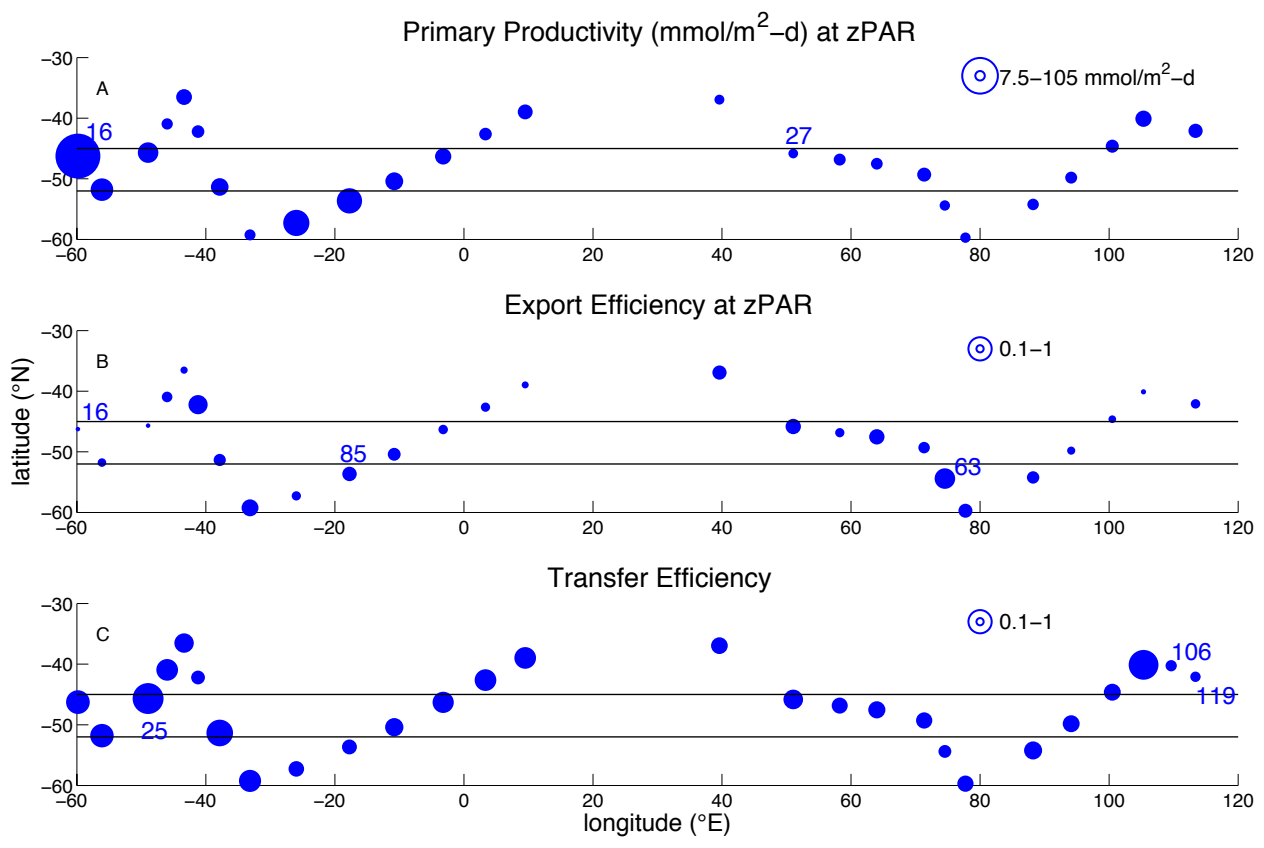

Figure 7. Distribution of primary productivity, export efficiency, and transfer efficiency along GB1 and GB2 (circle area scales with magnitude). (a) Primary productivity integrated through the euphotic zone ranges from 8.0 to $165 \mathrm{mmol} \mathrm{m}^{-2} \mathrm{~d}^{-1}$ at stations GB2-27 and GB1-16, respectively. (b) Export efficiency (Ez-ratio) at ZPAR (Table 1), which is the ratio of ${ }^{234} \mathrm{Th}$-derived $\mathrm{POC}$ flux at $\mathrm{Z}_{\mathrm{PAR}}$ to primary productivity integrated to ZPAR, ranges from 0.04 to 0.77 at stations GB1-16 and GB2-63, respectively. (c) Transfer efficiency at $\mathrm{Z}_{\mathrm{PAR}}$, which is the ratio of POC flux $100 \mathrm{~m}$ below $\mathrm{Z}_{\mathrm{PAR}}$ to POC flux at $\mathrm{Z}_{\mathrm{PAR}}$, ranges from 0.20 to 1.8 at stations GB1-119 and GB1-25, respectively. A few station numbers discussed in the text are indicated. The two horizontal dashed lines at $45^{\circ} \mathrm{S}$ and $52{ }^{\circ} \mathrm{S}$ represent the approximate locations of the Subantarctic and Polar fronts, respectively (Belkin and Gordon, 1996; Sokolov and Rintoul, 2009). Refer to Fig. 1 for other station locations. 

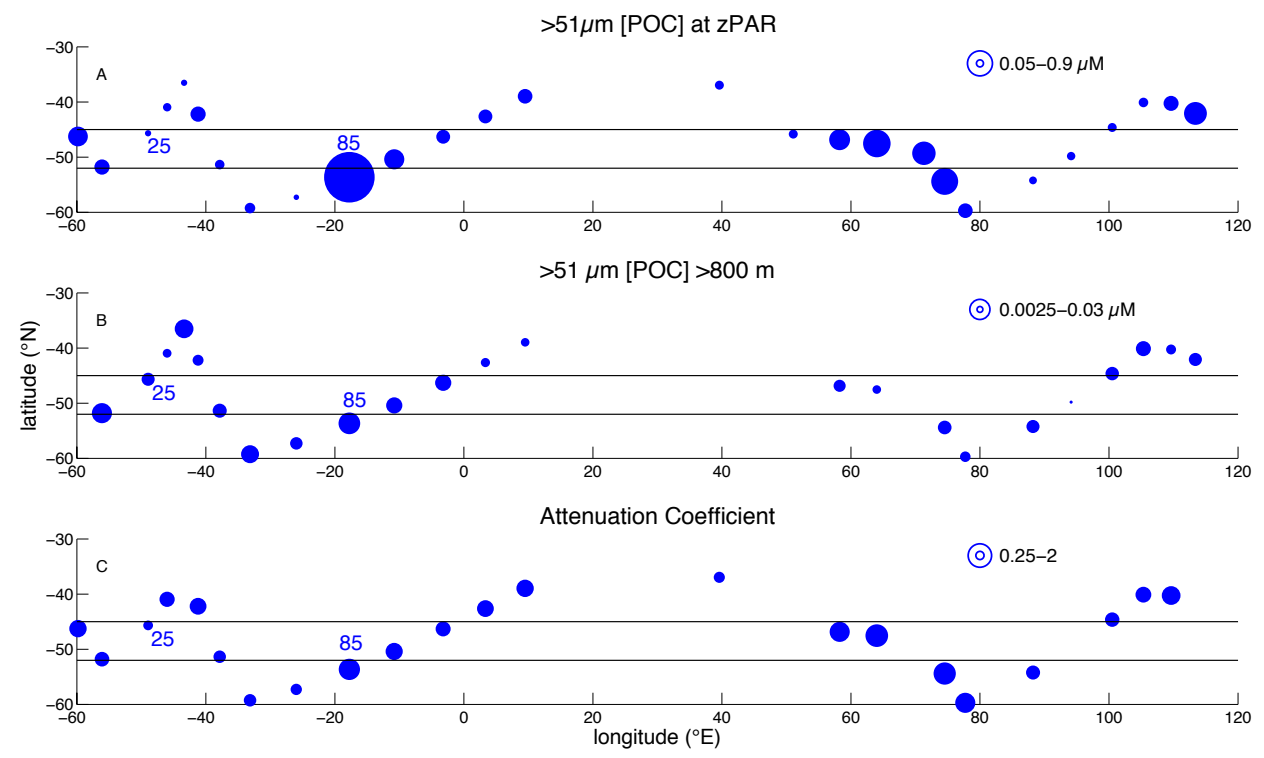

Figure 8. Distribution of [POC] and vertical attenuation coefficient of $>51 \mu \mathrm{m}$ [POC] (circle area scales with magnitude). (a) $>51 \mu \mathrm{m}$ POC concentrations at ZPAR (Table 1) range from $0.03 \mu \mathrm{M}$ to $2.5 \mu \mathrm{M}$ at stations GB1-77 and GB1-85, respectively. (b) $>51 \mu \mathrm{m}$ $[\mathrm{POC}]$ at the deepest pump depth in the lower mesopelagic zone $(800 \mathrm{~m}-1000 \mathrm{~m})$. Concentrations range from $0.001 \mu \mathrm{M}$ to $0.035 \mu \mathrm{M}$ at stations GB2-93 and GB1-85, respectively. (c) Attenuation coefficient from significant power-law fits of $22>51 \mu \mathrm{m}$ [POC] profiles, excluding GB2-93 (see Section 4.4). A few station numbers discussed in the text are indicated. The two horizontal dashed lines at $45^{\circ} \mathrm{S}$ and $52^{\circ} \mathrm{S}$ represent the approximate locations of the Subantarctic and Polar fronts, respectively (Belkin and Gordon, 1996; Sokolov and Rintoul, 2009). Refer to Fig. 1 for other station locations. 

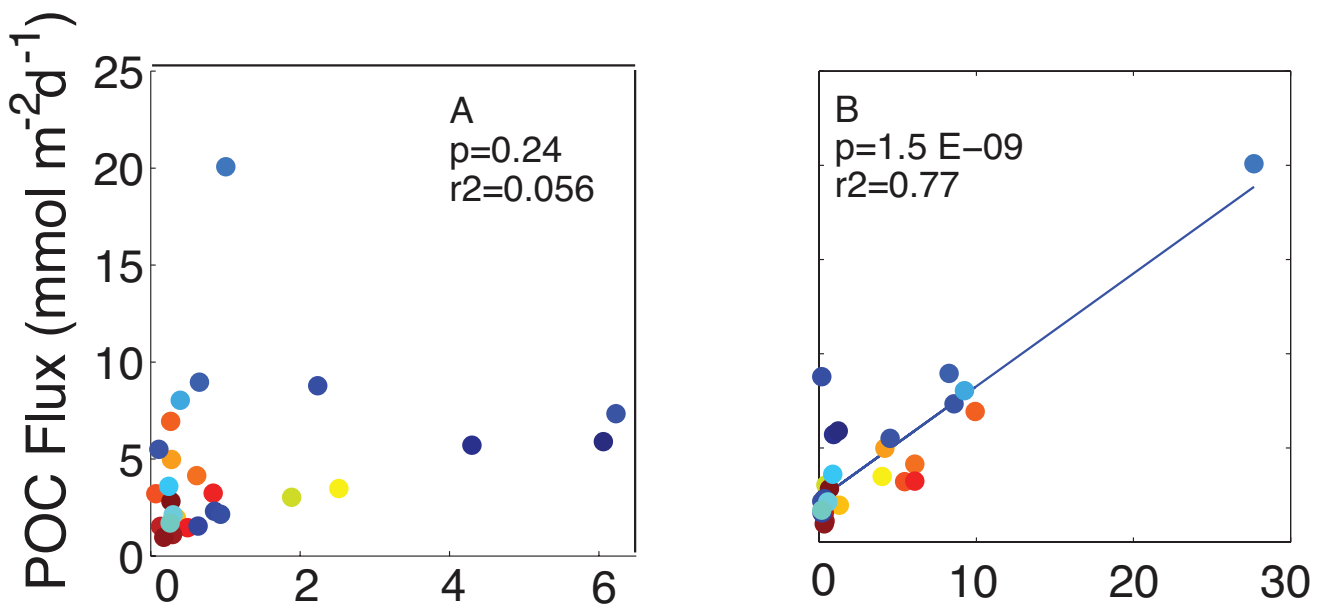

Long. $\left({ }^{\circ} \mathrm{E}\right)$
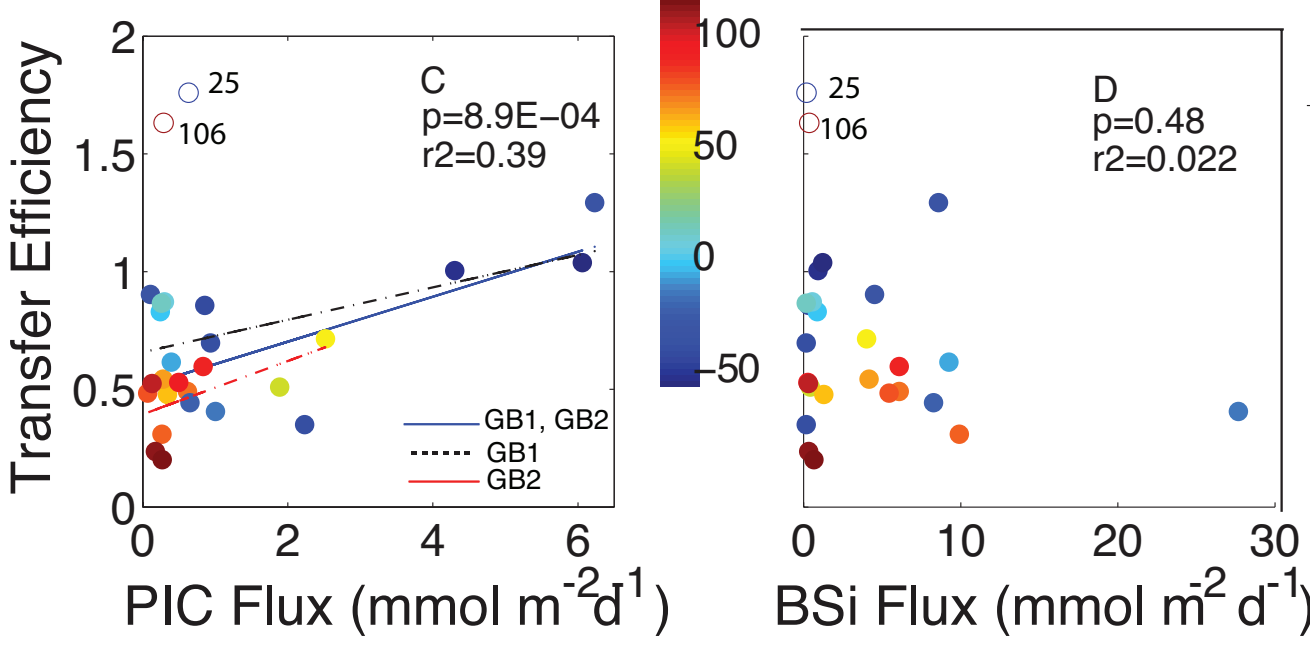

Figure 9. ${ }^{234}$ Th-derived POC flux as a function of (a) PIC flux and (b) BSi flux at ZPAR. POC flux transfer efficiency between $\mathrm{Z}_{\mathrm{PAR}}$ and $\mathrm{Z}_{\mathrm{PAR}}+100 \mathrm{~m}\left(\mathrm{~T}_{100}\right.$, defined in Section 4.4) as a function of (c) PIC flux and (d) BSi flux at ZPAR. Significant linear relationships are plotted as a solid blue line. $\mathrm{T}_{100}$ values at GB1-25 and GB2-106 were excluded from all correlations (Section 4.4). The color bar indicates the longitude of GB1 and GB2 stations. Refer to Fig. 1 for more specific station locations. 


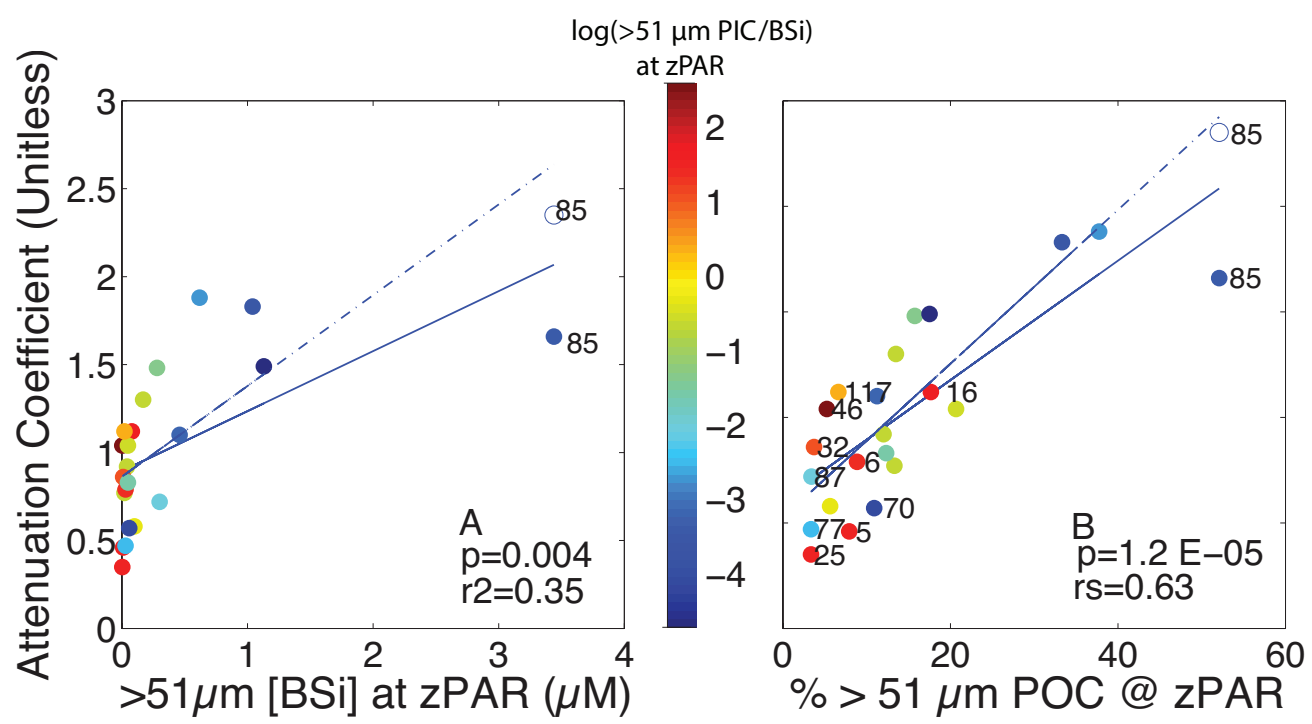

Figure 10. Attenuation coefficient as a function of (a) $>51 \mu \mathrm{m}[\mathrm{BSi}]$ at $\mathrm{Z}_{\mathrm{PAR}}$ and (b) the proportion of [POC] in the $>51 \mu \mathrm{m}$ size-fraction at ZPAR. The open circle indicates where GB1-85 would plot with a higher attenuation coefficient of 2.35 , derived from fitting $>51$ $\mu \mathrm{m}[\mathrm{POC}]$ at depths between $\mathrm{Z}_{\mathrm{PAR}}$ and $500 \mathrm{~m}$. Significant linear relationships using the lower and higher attenuation coefficient values for GB1-85 are shown as solid and dashed lines, respectively; $\mathrm{p}$ and $\mathrm{r}^{2}$ values are provided for the solid lines. The color bar is the natural logarithm of the ratio of $>51 \mu \mathrm{m}$ PIC:BSi at ZPAR. We interpret all warm colors $>0$ to indicate stations with a high relative abundance of coccolithophores, and all cool values $<0$ to indicate stations with a high relative abundance of diatoms (Appendix A, Figs. S2, S3). A few station numbers discussed in the text are indicated. Refer to Fig. 1 for station location. 


\section{Chapter 3:}

\section{The effect of sample drying temperature on marine particulate organic carbon composition}




\begin{abstract}
Compositional changes in marine particulate organic carbon (POC) trace important carbon cycle processes that control the biological pump's efficiency. Each particle sampling effort in the ocean water column is labor-intensive, but also a valuable opportunity to glean more information on the organic composition of POC during transfer to the deep ocean. At the same time, not all particle samples are processed and stored at standards accepted by organic geochemists. For example, particles are often air-dried in an oven or at room temperature, rather than immediately frozen at $-80^{\circ} \mathrm{C}$ and subsequently freeze-dried. This study investigates the effects of different drying methods on three aspects of POC composition: bulk, compound-specific and thermal stability. The last metric derives from ramped pyrolysis/oxidation (RPO), a relatively novel method of organic matter characterization that uses a continuous temperature ramp to differentiate components of organic carbon by their decomposition temperature, i.e., thermal stability. Particle samples for the study were collected in June 2014 off Woods Hole, MA and immediately dried at $56^{\circ} \mathrm{C}$, at room temperature, or stored at $-80^{\circ} \mathrm{C}$ until freeze-dried for analysis. Results show that oven- and air-drying did not shift the bulk or thermal composition of POC in the samples relative to freeze-drying, but did compromise lipid abundances. The effect on lipid abundances depended on compound size and compound type, suggesting that physical mechanisms such as compound volatilization likely accounted for the drying effects. The data suggest that particle samples collected for intentions other than organic geochemical analyses are still appropriate for assessing bulk POC composition and thermal stability. But, different drying and storage temperatures would likely bias analyses of specific lipid classes, which represent a small fraction of the bulk organic carbon in the sample.
\end{abstract}

\title{
$1 \quad$ Introduction
}

Particulate organic carbon (POC) in the ocean's water column is the primary vehicle for the biological pump, which sequesters $\sim 0.2 \mathrm{Gt}$ carbon/year on the seafloor ( $\sim 0.1 \%$ marine primary productivity) for hundreds to thousands of years (Burdige, 
2007). These particles harbor thousands of distinct organic biomolecules produced by primary producers and heterotrophs (Repeta, 2014). Changes in this biomolecular matrix with depth allude to important processes that govern the transport and recycling of marine POC (Burd et al., 2016). Approaches to describing POC composition range from measuring bulk characteristics that integrate over biomolecules (e.g., the stable isotope composition of total POC, reported as $\delta^{13} \mathrm{C}$ ) to quantifying trace abundances of specific biomolecules (e.g., the abundance of specific biomarkers and their $\delta^{13} \mathrm{C}$ values) (Wakeham and Volkman, 1991; Trull and Armand, 2001; Cavagna et al., 2013).

To accurately interpret the composition of POC in the water column, its organic matrix must be preserved at the time of collection. Prior studies have demonstrated that sample storage temperatures post-collection influences the degree of organic matter preservation. Continual microbial degradation following sample collection and storage at room temperature can significantly alter the distribution of lipid abundances after one month (Grimalt et al., 1988). But, even longer-term sample storage at cooler temperatures can still shift the lipid composition of organic matter (Wakeham and Volkman, 1991). For instance, Ohman (1996) observed that storing copepod biomass at $-20^{\circ} \mathrm{C}$ to $-15^{\circ} \mathrm{C}$ increases the extraction efficiency of free fatty acids by rupturing cell membranes, while also depressing polar lipid abundances by concentrating enzymes in solution that decompose lipids. Cumulatively, these effects amounted to negligible change in total lipid abundances, but did compromise the observed abundances within specific compound classes. To avoid these effects, environmental samples are frozen immediately after collection and stored at low enough temperatures, typically $-80^{\circ} \mathrm{C}$, to prohibit heterotrophic remineralization and alteration of organic matter composition prior to analysis.

POC samples intended for bulk elemental analysis are often dried in a heated oven, and samples intended for inorganic analysis are sometimes air-dried, and stored at room temperature before analysis (e.g., Rosengard et al., 2015), all conditions unfavorable to traditional organic analyses (Wakeham and Volkman, 1991). The tremendous labor and financial cost of sampling marine particles across the ocean warrants an answer to how much POC integrity is sacrificed when these distinct drying methods do not meet optimal standards of organic geochemical analysis (i.e., frozen 
immediately post-collection). Adding to the earlier studies that explored issues associated with storage temperatures of wet samples, this study explores the effects of different sample drying methods on three aspects of organic composition. First, we compare the influence of air-drying samples at room-temperature, oven-drying at elevated temperatures and freeze-drying on bulk organic matter composition $\left(\mathrm{C} / \mathrm{N}\right.$ ratio, $\delta^{13} \mathrm{C}$ and total organic carbon content). Then, we assess the effects of different drying treatments on the biomolecular composition of POC, specifically the abundances of specific lipid compounds in the organic matrix. These comparisons differ from the studies described above, as they relate to the effects of different drying methods, instead

Finally, this report further evaluates the effects of different sample drying methods on thermal stability. Here, we define thermal stability as the distribution of temperatures over which a $\mathrm{POC}$ sample decomposes to $\mathrm{CO}_{2}$ during ramped pyrolysis/oxidation (RPO). RPO is a novel but increasingly utilized technique for characterizing the composition of organic matter in the environment, and has been seldom applied to POC from the marine water column. By pyrolyzing or oxidizing POC throughout a controlled temperature ramp from $\sim 100^{\circ} \mathrm{C}$ to $800^{\circ} \mathrm{C}$, and monitoring the release of $\mathrm{CO}_{2}$ throughout the ramp, this technique differentiates distinct pools of bulk organic carbon by their thermal stability, alluding to the activation energy of decomposition/oxidation of specific POC pools in the sample (Cramer, 2004). RPO has been applied over a range of organic matter samples from complex depositional environments, from suspended riverine POC to ocean sediments (Rosenheim et al., 2008; Rosenheim and Galy, 2012; Rosenheim et al., 2013; Subt et al., 2016). Observations of increasing radiocarbon age of $\mathrm{POC}$ with oxidation temperature in these studies have led to the hypothesis that more degraded, recalcitrant pools of organic carbon are generally more thermally stable, with a higher activation energy associated with thermal decomposition. Thus, RPO offers a unique opportunity to relate POC composition to its biological reactivity in the environment, its fate during transport in the water column and, more relatedly, the strength of the biological pump (Francois et al., 2002; Burd et al., 2016).

We hypothesized that air-drying and oven-drying of a sample post-sampling would negligibly influence the bulk composition of POC (e.g., Kaehler and Pakhomov, 
2001). These drying techniques would also impose little changes in thermal stability, as the energy imposed by air-drying and oven-drying relative to freeze-drying is too small to shift the bonding energies (Wagner et al., 1994), and therefore the activation energies of thermal decomposition of the biomolecular matrix (Cramer, 2004). However, we expected that compound-specific abundances would be compromised by the different drying techniques. The results of this report have several implications towards the opportunistic use of marine organic carbon samples for organic analysis, even when not collected and stored according to ideal organic geochemical standards.

\section{Methods}

\subsection{Sample Collection}

Samples of marine POC were collected in June 2014 off the dock of the Woods Hole Oceanographic Institution (WHOI), at $41.524^{\circ} \mathrm{N}, 70.672^{\circ} \mathrm{W}$. The waters near the WHOI reach bloom-level primary productivity in June.

A battery operated in situ pump (McLane WTS-LV) was deployed $~ 10$ meters below surface and pumped seawater through two flow paths (A and B) (Lam et al., 2015). Each flow path directed seawater through a $51 \mu \mathrm{m}$ pore-size polyester pre-filter screen followed by two pre-combusted $1 \mu \mathrm{m}$ pore-size quartz fiber filters (Whatman ${ }^{\mathrm{TM}} \mathrm{QMA}$ ), both mounted onto "mini-MULVFS" filter holders (Bishop et al., 2012). The active collection area of these filters was $125 \mathrm{~cm}^{2}$. The pre-filter retained $>51 \mu \mathrm{m}$ size-fraction particles, while the QMAs collected 1-51 $\mu \mathrm{m}$ size-fraction particles, most of which settled on the topmost QMA filter relative to the seawater influx. After $\sim 45$ minutes, equivalent to 40-100 L seawater filtered, the filters clogged and the pump stopped. The pump was deployed twice, allowing for collection of three pre-filters, three QMA filters (Fig. 1a, c) and two deployment blank QMA filters (Fig. 1b). The second pump deployment immediately followed the first. Depth control was poor, so the two deployments likely occurred at slightly different depths. Two sample filters (QMA1 and QMA2), one filter per flow path, were collected in the first deployment, while one filter from a single flow (QMA3, flow path B) was collected in the second deployment. One 
blank filter was collected per deployment by submerging a filter in between two $51 \mu \mathrm{m}$ pre-filters in a perforated plastic Tupperware, which was externally attached to the McLane pump frame.

Within hours following collection, each sample and blank QMA filter was divided into thirds, one of which was immediately frozen in a freezer, and then transferred to $80^{\circ} \mathrm{C}$ two weeks later (Fig. 1, Table 1). Another third was placed in an oven for drying at $56^{\circ} \mathrm{C}$ for 17-19 hours. Finally, one third was dried under a clean laminar flow hood at room temperature for 17-19 hours. The filters were apportioned as such to account for environmental heterogeneity associated with particle sampling in POC-rich waters (Sections 2.3, 2.4). All oven-dried and air-dried filters were stored in Whirl-Pak bags or combusted glassware at room temperature before analysis. Frozen filters were freezedried for 12 hours before analysis. All blanks and sample particles collected onto the topmost filter relative to the filtration flow path were analyzed within one year of sample collection.

Images of QMA filters were developed at various magnifications for a freezedried portion of deployment blank and sample filters using a scanning electron microscope (Fig. 1b,c). No coccoliths or other calcium carbonate shells were observed in the sample filter. Thus, we assumed that the particulate inorganic carbon content (PIC) in the particle samples was negligible, and would not interfere with any of the POC analyses described in the following sections. The stable isotope data reported in Section 3 will affirm this assumption.

\subsection{Bulk Composition}

The bulk composition of particles collected onto the QMA filters (particulate organic carbon concentration ([POC]), particulate nitrogen concentration ([PN]), $\delta^{13} \mathrm{C}$ and $\delta^{15} \mathrm{~N}$ ) was analyzed using a Fisons Instruments Carlo / Erba 1108 elemental analyzer interfaced via a Finnigan MAT Conflo II to a Thermo Finnigan Delta-Plus stable isotope ratio mass spectrometer (IRMS). Analysis of each drying treatment was conducted on a sub-sample from a different filter replicate prior to combining the thirds from each filter (i.e., the freeze-dried sub-sample came from filter QMA2, the air-dried sub-sample came 
from filter QMA3, and the oven-dried sample came from filter QMA1) (Table 1). One deployment blank sub-sample from a freeze-dried filter portion was analyzed. Each subsample represented $\sim 0.9 \%$ of the active area of a whole QMA filter $\left(125 \mathrm{~cm}^{2}\right)$.

\subsection{Ramped Oxidation Measurements}

The ramped pyrolysis/oxidation (RPO) system at the National Ocean Sciences Accelerator Mass Spectrometry (NOSAMS) facility converts sample organic carbon to carbon dioxide $\left(\mathrm{CO}_{2}\right)$ gas through a continuous temperature ramp, either by pyrolysis or oxidation. For each drying treatment, the same size subsample across the three QMA filters or two deployment blank filters from the three deployments were combined prior to analysis. When combined, the equivalent to $3-5 \%$ of active sample filter area and $\sim 9 \%$ of deployment blank filter area were inserted into a quartz reactor inside a furnace programmed to heat at $5^{\circ} \mathrm{C} /$ minute from room temperature to $1000^{\circ} \mathrm{C}$. Furthermore, $\sim 5 \%$ of a pre-combusted (to $450^{\circ} \mathrm{C}$ ) but non-deployed QMA filter was also analyzed by ramped oxidation.

RPO analyses were conducted following protocol described in Rosenheim et al. (2008) and Hemingway et al. (accepted). During the temperature ramp, a roughly 35 $\mathrm{mL} / \mathrm{min}$. mixture of $92 \%$ Ultra-High Purity helium and $8 \%$ oxygen gas flowed through the quartz insert from the programmed furnace, carrying oxidation products to an $800^{\circ} \mathrm{C}$ furnace equipped with a copper, platinum and nickel catalyst that fully converts the products into $\mathrm{CO}_{2}$ gas. Downstream of the catalyst, the $\mathrm{CO}_{2}$ and carrier gas passed through a Sable Systems $\odot C A-10$ infrared gas analyzer, calibrated at 0 ppm and $>400$ ppm, which measured the outgoing $\mathrm{CO}_{2}$ flux and concentration (ppm). After the gas analyzer, the gas mixture flowed into a cryogenic Pyrex coil that was coupled to a vacuum line, where the $\mathrm{CO}_{2}$ gas was cryogenically trapped, and released into a vacuum line within user-specified temperature intervals. Maintaining consistent flow rates, $\mathrm{He}: \mathrm{O}_{2}$, furnace catalyst material, furnace insulation, and plumbing minimizes instrumental variation across RPO analyses (e.g., Appendix B, Fig. S3).

For each drying treatment, dock test samples were analyzed three times by ramped oxidation. During each analysis, at least one $\mathrm{CO}_{2}$ fraction was flame-sealed into 
Pyrex tubes in the vacuum line with $50 \mathrm{mg}$ copper oxide and $10 \mathrm{mg}$ silver. For one analysis per drying treatment, three fractions were collected, two to three of which were then baked at $525^{\circ} \mathrm{C}$ for 1 hour to ensure the full oxidation of any residual incompletely oxidized carbon compounds from the ramped oxidation run, and then analyzed for its stable isotope composition (reported as $\delta^{13} \mathrm{C}$ ) using a VG Isotech Prism II IRMS. The precision of $\delta^{13} \mathrm{C}$ measurements from this IRMS was $0.1 \%$. $\delta^{13} \mathrm{C}$ values were referenced to Vienna Pee Dee Belemnite (VPDB), using an internal standard calibrated against NBS-19 calcite.

\subsection{Compound-Specific Measurements}

Compound-specific abundances offer the highest resolution comparisons of organic matter composition across drying treatments in this report. We limit analysis to the abundances of fatty acids, sterols and alcohols, which are commonly applied to study marine POC dynamics in the water column (e.g., Wakeham and Canuel, 1988; Cavagna et al., 2013).

About $5 \%$ of the $125 \mathrm{~cm}^{2}$ sample QMA filter active area and $~ 7-15 \%$ of the deployment blank filter area were extracted in $15-20 \mathrm{~mL}$ of 9:1 dichloromethane: methanol (DCM: $\mathrm{MeOH}$ ) at $100^{\circ} \mathrm{C}$ for 20 minutes using a Microwave Accelerated Reaction System (MARS, CEMS Corp.). Each sample extracted was subsampled from the combined sub-fractions of the three sample filter deployments or the two blank filter deployments (Fig. 1). After extraction, the total lipid extract was saponified in $0.5 \mathrm{M}$ potassium hydroxide in $\mathrm{MeOH}$ for 2 hours at $70^{\circ} \mathrm{C}$. Following saponification, liquidliquid extractions separated the basic phase from the acidic phase, each of which was flushed through aminopropyl silica gel columns to separate compounds into five compound classes based on their polarity. Fatty acids of both acid and base phases were recombined and methylated for 12 hours at $70^{\circ} \mathrm{C}$, and purified through another silica gel column prior to analysis on a flame ionization detector coupled to a Hewlett Packard 5890 Series II Gas Chromatograph (GC-FID). Sterols and alcohols of acid and base fractions were acetylated separately in acetic anhydride and pyridine (1:1) for 2 hours at $70^{\circ} \mathrm{C}$ prior to analysis on the GC-FID. 
All sample and deployment blank analyses were accompanied by synthetic standards containing a suite of fatty acids, sterols and alcohols with known concentrations and retention times. Retention times were used to identify specific compounds in the samples and deployment blanks. Other compounds identities, particularly the unsaturated and branched FAMES, were separately validated using an Agilent 7890A gas chromatograph interfaced with a Markes/Almsco BenchTOF-Select time of flight mass spectrometer. To evaluate sample drying effects on compound abundances, we directly compared peak areas across samples and blanks after normalizing the areas to the fraction of QMA filter active area extracted. Peak abundances errors were assumed to be $\sim 10 \%$.

\section{$3 \quad$ Results}

\subsection{Bulk Composition}

Table 1 summarizes the bulk characteristics of particulate organic carbon across sample treatments and one deployment blank (freeze-dried only). All carbon and nitrogen quantities measured on QMA filter sub-samples were normalized to the total active area of the filter $125 \mathrm{~cm}^{2}$ and volume filtered, yielding total $\mathrm{C}$ and total $\mathrm{N}$ concentrations, respectively (Table 1). Filter-normalized total carbon concentrations ranged from 8-14 $\mathrm{mg}$ carbon/QMA, corresponding to $11.9-16.7 \mu \mathrm{M}$. Total nitrogen concentrations were up to an order of magnitude lower in all samples, $1.8 \mu \mathrm{M}$ in the freeze-dried sample and $2.5 \mu \mathrm{M}$ in the oven-dried sample. This corresponded to a small range of molar $\mathrm{C}: \mathrm{N}$ ratios from 6.5 - 6.8. The bulk $\delta^{13} \mathrm{C}$ values of sample carbon ranged from $-23.9 \%$ in the freezedried filter to $-23.6 \%$ in the air-dried filter, while $\delta^{15} \mathrm{~N}$ values ranged from $7.9 \%$ in the air-dried POC to $8.3 \%$ in freeze-dried sample.

The total carbon and nitrogen concentrations on the freeze-dried deployment blank filters were $\sim 20$ times lower than the content on all sample filters analyzed (Table 1). The scanning electron images of the deployment blank filters show that no particles are loaded onto the filter fibers (Fig. 1b), suggesting that the carbon on the deployment blank filters is likely sorbed dissolved organic carbon. The $\delta^{13} \mathrm{C}$ of organic carbon in the 
blank carbon was $-25.6 \%$, which was more depleted than the $\delta^{13} \mathrm{C}$ values of all samples. The $\mathrm{C} / \mathrm{N}$ ratio in the deployment blank was 7.7, which was higher than in the samples. There was not enough organic nitrogen on the deployment blank filters to resolve a blank carbon $\delta^{15} \mathrm{~N}$ value.

\subsection{Ramped Oxidation}

All $<51 \mu \mathrm{m}$ particle samples and deployment blanks, oven-dried, air-dried and freeze-dried, were analyzed by ramped oxidation between $100^{\circ} \mathrm{C}$ and $1000^{\circ} \mathrm{C}$. For each drying treatment, sub-samples were analyzed three times, resulting in three thermograms per drying treatment that recorded $\mathrm{CO}_{2}$ evolved per temperature interval (Fig. 2a-c). When the $\mathrm{CO}_{2}$ concentrations (thermogram y-axis) are normalized to the active area of a QMA filter $\left(125 \mathrm{~cm}^{2}\right)$, the total $\mathrm{CO}_{2}$ quantified by the gas analyzer serves as a rough measurement of the total sample carbon integrated across three different filter deployments treated by the same drying process. The deployment blank thermograms yield two orders of magnitude lower total carbon than the particle sample thermograms. TOC values in the deployment blanks, which were run only once, ranged from $0.28 \mathrm{mg}$ $\mathrm{C} /$ filter in the freeze-dried deployment blank to $0.40 \mathrm{mg} \mathrm{C} /$ filter in the oven-dried blank (Fig. 2d). These values are two to three times greater than the TOC yielded by analyzing a pre-combusted blank QMA, $0.15 \mathrm{mg} /$ filter (Fig. 2e).

Each sample thermogram was corrected for sorption of carbon onto the filter by subtracting the QMA-normalized deployment blank thermograms from the QMAnormalized thermograms of sample carbon dried by the same process. All blankcorrected and deployment blank thermograms show that most of sample and blank carbon oxidizes between $150^{\circ} \mathrm{C}$ and $600^{\circ} \mathrm{C}$ (Fig. 2). The average total filter-normalized carbon across three ramped oxidation analyses of the oven-dried filters is $10.4 \pm 0.5 \mathrm{mg} /$ filter (mean \pm 1 S.D.). The average across three air-dried filter analyses is $10.8 \pm 0.4 \mathrm{mg} /$ filter, and the average across three freeze-dried filter analyses is $10.7 \pm 0.5 \mathrm{mg} /$ filter (Fig. 2a-c).

For one analysis per drying treatment, the stable isotope composition of two to three $\mathrm{CO}_{2}$ gas fractions representing $\sim 95 \%$ of all the $\mathrm{CO}_{2}$ evolved during ramped oxidation of that sample were analyzed within distinct temperature intervals (Section 2.3; 
Table 2). In the lowest temperature fraction $\left(\sim 125^{\circ} \mathrm{C}-415^{\circ} \mathrm{C}\right), \delta^{13} \mathrm{C}$ values ranged from $26.9 \%$ in the oven-dried sample thermogram to $-25.8 \%$ in the freeze-dried sample thermogram. In the mid-temperature fraction $\left(\sim 415^{\circ} \mathrm{C}-620^{\circ} \mathrm{C}\right)$, values ranged from -24.4 $\%$ in the oven-dried sample to $-22.7 \%$ in the freeze-dried sample. The third, highest temperature $\mathrm{CO}_{2}$ fraction was only analyzed in the oven-dried sample run $\left(610^{\circ} \mathrm{C}\right.$ $904^{\circ} \mathrm{C}$ ), which had a more depleted $\delta^{13} \mathrm{C}$ value of $-27.8 \%$. The three fraction $\delta^{13} \mathrm{C}$ values from this sample were normalized to the carbon quantity in each fraction, the sum of which was 2.2-2.5\% more depleted than all bulk $\delta^{13} \mathrm{C}$ measurements (Section 3.1, Table 1). This difference is similar but slightly greater $(0.5 \%)$ than the average weighted sum vs. bulk $\delta^{13} \mathrm{C}$ discrepancy expected from kinetic fractionation during ramped oxidation, which has been observed across several other RPO analyses $(n=66)$ of standard and samples from different environments (Hemingway et al., accepted).

\subsection{Lipid Abundances}

Peak area-based abundances of fatty acids, sterols and alcohols in particle samples and deployment blanks were quantified across a range of molecular sizes. Fatty acids analyzed include saturated straight-chain fatty acids (12 to 24 carbon chain lengths, or $\left.\mathrm{C}_{12}-\mathrm{C}_{24}\right)$, straight-chain unsaturated fatty acids $\left(\mathrm{C}_{14}-\mathrm{C}_{22}\right)$, and saturated branched fatty acids of bacterial origin $\left(\mathrm{C}_{15}, \mathrm{C}_{16}, \mathrm{C}_{17}\right)$. Specific alcohols and sterols were identified using a suite of seven standard compounds with different molar masses, carbon chain lengths and environmental origins (Table 3). For each sample and deployment blank chromatogram, areas of select compound peaks in the chromatograms were normalized to the area of an entire QMA filter, representing an average of three replicate filters deployed in Woods Hole waters. Then, filter-normalized peak areas of specific compounds across the deployment blank chromatograms were subtracted from filternormalized compound abundances in samples with the same drying treatment. Comparing just blank-corrected abundances allowed us to control for potential differences between drying effects on sorbed blank carbon and drying effects on sample POC (Figs. 3-5). Indeed, fatty acid abundances in the oven-dried and air-dried blank 
filters always exceeded abundances in the freeze-dried filters, by up to four times for some compounds.

We then compared ratios of each normalized and blank-corrected peak area in the oven-dried ("O") and air-dried ("A") particle samples to the same normalized peak area in the freeze-dried sample ("F") across chain lengths. For the rest of the discussion, we call these ratios $\mathrm{R}_{\mathrm{O} / \mathrm{F}}$ and $\mathrm{R}_{\mathrm{A} / \mathrm{F}}$, respectively. $\mathrm{R}_{\mathrm{O} / \mathrm{F}}$ and $\mathrm{R}_{\mathrm{A} / \mathrm{F}}$ for saturated straight-chain, unsaturated straight-chain and branched fatty acid peak areas (blank-corrected) in ovendried or air-dried particle samples relative to peaks areas in freeze-dried samples (blankcorrected) were consistently below 1 (Figs. 3-5), indicating that these compounds are less abundant in the oven and air-dried samples relative to the freeze-dried samples. The $\mathrm{R}_{\mathrm{O} / \mathrm{F}}$ values for all fatty acid compounds analyzed were generally lower than the $\mathrm{R}_{\mathrm{A} / \mathrm{F}}$ values for the same compounds, especially among the straight-chain and branched saturated fatty acids (Figs. 3c, 5a-b).

Two alcohol compounds and no sterols were identified in the deployment blanks: 1-hexadecanol and phytol (Table 3). The blanks make up less than 1\% of phytol in the sample peaks, but $18-51 \%$ of the $n$-alcohol, with the highest relative proportions in the freeze-dried deployment blank and the lowest proportions in the oven-dried deployment blank. At the same time, the normalized peak areas of these compounds were not significantly different across deployment blanks with different drying treatments. $\mathrm{R}_{\mathrm{O} / \mathrm{F}}$ values were lowest (0.57) for gorgost-5-en-3-ol, as high as 1.7 for 1-hexadecanol, and averaged at $0.98 \pm 0.08$ across all other compounds (Fig. 6a). Similarly, $\mathrm{R}_{\mathrm{A} / \mathrm{F}}$ values were $0.96 \pm 0.17$ for most compounds, lowest for gorgost-5-en-3-ol (0.68), and highest for 1hexadecanol (1.3) (Fig. 6b).

\section{Discussion}

The following compares the bulk, compound-specific and thermal composition of marine POC collected from the coastal waters of Woods Hole, MA and treated by ovendrying, air-drying or freeze-drying. To interpret thermal stability, we assume that biomolecules in an organic matrix span a range of activation energies of decomposition (Cramer, 2004; Rosenheim et al., 2008; Rosenheim and Galy, 2012; Rosenheim et al., 
2013), which would drive differences in the oxidation temperature of compounds and fragments of compounds during ramped oxidation. Our interpretations of bulk carbon composition and thermal stability rely on the assumption that particulate inorganic carbon (PIC) concentrations in particulate matter are negligible, and that the carbon quantities reported in section 3 correspond predominantly to organic carbon in the samples. The consistently depleted isotope values of the bulk carbon and $\mathrm{CO}_{2}$ collected across thermograms (Tables 1,2) corroborate this assumption. This is further reflected by the lack of any significant calcifying organisms observed on images of particle sample QMA filters (Fig. 1c).

\subsection{Oven- and air-drying do not affect bulk characteristics or thermal stability}

Bulk $\delta^{13} \mathrm{C}, \delta^{15} \mathrm{~N}$ and $\mathrm{C} / \mathrm{N}$ values on QMA filter sub-samples suggest that different drying treatments post-sampling do not appreciably affect bulk POC composition (Table 1). Because the bulk measurements were conducted on individual filter replicates before combination (Section 2.2), environmental variability and heterogeneity of particle loads on the QMA filters may drive the observed differences in the normalized [POC] and [PN] values across filters and deployments, in addition to any effects imposed by the different drying treatments. The fact that the POC concentrations measured in two filters from deployment 1 are more similar to each other than to the concentration measured in deployment 2 implies that temporal and depth-related differences between the two deployments likely contributed to the concentration differences. In addition, considering that $\delta^{13} \mathrm{C}, \delta^{15} \mathrm{~N}$ and $\mathrm{C}: \mathrm{N}$ values are statistically invariant across filters and drying treatments, air-drying and oven-drying marine particle samples do not change the bulk composition of POC relative to freeze-drying. The standard deviation of the three $\delta^{13} \mathrm{C}$ $( \pm 0.1 \%), \delta^{15} \mathrm{~N}( \pm 0.2 \%)$ and $\mathrm{C}: \mathrm{N}( \pm 0.2 \mu \mathrm{mol} / \mu \mathrm{mol})$ values measured across sample filters are comparable or smaller than to the analytical precision of each measurement.

By comparison, the thermograms generated by ramped oxidation of particle samples and blanks do represent the average of three deployed sample replicates or two deployed blank replicates (Section 2.3), and thus integrate influence of environmental heterogeneity associated with different pump deployments and uneven particle loading 
(Fig. 3a-c). Thus, any differences across thermograms reflect effects of different drying treatments more so than uneven particle distributions on the filters. The small variations of the area-normalized $\left(125 \mathrm{~cm}^{2}\right)$ and deployment-blank corrected total carbon yields (i.e., total $\mathrm{CO}_{2}$ evolved) across all nine runs of the three drying treatments (average \pm 1 S.D. $=10.6 \pm 0.4 \mathrm{mg}$ ), demonstrates that these drying treatments do not influence the total carbon and nature of carbon loaded on the filters. This average carbon/filter quantity calculated from the thermograms is comparable to the three average carbon loadings measured in bulk using the elemental analyzer, $11.9 \pm 3.3 \mathrm{mg} /$ filter (Section 3.1, Table 1). Thus, the thermogram data further support the argument that differences in total sample $\mathrm{C}$ concentrations across bulk measurements result from heterogeneity of particle loading among sample filters deployments rather than from the differences in the drying treatments.

The deployment blanks are less susceptible to environmental heterogeneity because the sorption of dissolved carbon compounds to QMA filters is likely to be more homogenous within and between filters. Nonetheless, there are greater relative differences in the total carbon yield among the deployment blank thermograms, which is highest in the oven-dried sample thermogram and lowest in the freeze-dried sample thermogram (Fig. 3d). We posit that these differences result from intrinsically higher relative error associated with analyzing very small quantities by ramped oxidation. Indeed, the non-normalized quantity of $\mathrm{CO}_{2}$ evolved during ramped oxidation of these samples was small, ranging from $25 \mu \mathrm{g}$ in the freeze-dried blank thermogram to $37 \mu \mathrm{g}$ in the oven-dried blank thermogram, i.e., only about ten times the estimated blank contribution for the NOSAMS RPO system (Hemingway et al., accepted).

The differences in thermogram shape across blank-corrected sample thermograms with different drying treatments are comparable to and do not exceed the differences among triplicate thermograms of the same drying treatment (Fig. 2a-c), suggesting that air-drying and oven-drying do not significantly change the thermal stability of the POC relative to freeze-drying (Fig. 2). Use of different programmable ovens could account for some of the smaller differences among the thermogram shapes across triplicate ramped oxidation analyses of the same sample, particularly shifts along the temperature axis. Fig. $2 \mathrm{f}$ shows the particle sample thermograms obtained via replicate analyses using the same 
oven (referred to as Oven A), which line up better in temperature space than repeated analyses of the same sample using different ovens. In the future, running standard compounds with well-defined peaks, such as sodium bicarbonate, periodically in the different sample ovens would help normalize these temperature shifts in thermograms generated by different ovens (Rosenheim et al., 2008).

In addition, different sample ovens could have driven the 1-2\%o differences in the $\delta^{13} \mathrm{C}$ value of $\mathrm{CO}_{2}$ gas fractions trapped and analyzed within similar temperature intervals across different sample thermograms (Table 2). Within each of the two lower temperature fractions, $\mathrm{CO}_{2}$ released by ramped oxidation of the freeze-dried sample was more enriched than $\mathrm{CO}_{2}$ released by ramped oxidation of the oven-dried and air-dried sample. However, as these gas fractions were collected during analyses on different sample ovens, it is possible that differences in oven insulation and unsteady temperature ramp rates on the earlier end of the temperature ramp affected the thermal evolution of isotopically distinct components of POC in the sample to $\mathrm{CO}_{2}$.

As hypothesized, the bulk measurements and ramped oxidation data suggest that preservation of marine POC from the field by drying does not compromise the bulk isotope composition, bulk $\mathrm{C} / \mathrm{N}$ and thermal stability of the sample compared to storage and drying at $-80^{\circ} \mathrm{C}$. Thus, samples dried at temperatures above $-80^{\circ} \mathrm{C}$ can still be characterized using these metrics.

\subsection{Oven- and air-drying shift lipid abundances by compound size and structure}

Comparisons of filter-normalized and blank-corrected peak areas, a proxy for compound abundance, across samples show that oven-drying and air-drying shift lipid abundances, and that the magnitude of this shift depends on compound class and size. The results generally agree with prior studies demonstrating that warmer sample storage temperatures compromise specific lipid classes more than others (Ohman, 1996).

Comparisons of saturated straight-chain fatty acids across samples show that $\mathrm{R}_{\mathrm{O} / \mathrm{F}}$ and $\mathrm{R}_{\mathrm{A} / \mathrm{F}}$ values (Section 3.3) correlate positively with the carbon chain length of the compound $(\mathrm{p}<0.05)$ (Fig. 3). The slope and $\mathrm{r}^{2}$ value of the correlation between $\mathrm{R}_{\mathrm{A} / \mathrm{F}}$ and chain length are higher (Fig. 3b) than corresponding values for the correlation between 
$\mathrm{R}_{\mathrm{O} / \mathrm{F}}$ and chain length (Fig. 3a). This suggests that differences in the volatility of different compounds with different chain lengths and molar masses plays a role in the effects of drying treatment on straight-chain saturated fatty acid abundances (Meylan and Howard, 1991; Lide, 1995; Daubert, 1997; Schwarzenbach et al., 2003). Relatedly, $\mathrm{R}_{\mathrm{A} / \mathrm{F}}$ and $\mathrm{R}_{\mathrm{O} / \mathrm{F}}$ values are similar at lower molecular weights and diverge at higher molecular weights as $\mathrm{R}_{\mathrm{A} / \mathrm{F}}$ values approach 1 more than $\mathrm{R}_{\mathrm{O} / \mathrm{F}}$ values. Thus, drying temperatures can influence the distribution of fatty acids in a sample by driving differential loss of compounds with varying molecular weights.

There is no clear relationship between chain-length and $\mathrm{R}_{\mathrm{O} / \mathrm{F}}$ and $\mathrm{R}_{\mathrm{A} / \mathrm{F}}$ values for unsaturated straight-chain and saturated branched fatty acids quantified across samples (i.e., no significant correlation), as they are relatively invariant and below 1 across chain lengths (Fig. 4-5). Among the straight-chain unsaturated fatty acids, ratios tend to decrease with increasing numbers of double bonds, indicating that compounds with higher degrees of unsaturation are less physically stable and therefore more sensitive to the effects of air-drying and oven-drying (Lide, 1995; Schwarzenbach et al., 2003). Because these branched fatty acids derive from bacteria, the lack of enrichment of the three chain-length branched fatty saturated fatty acids in the oven-dried and air-dried samples relative to the freeze-dried samples implies that the different drying treatments did not enhance microbial degradation of the particles prior to analysis (Ohman, 1996; Wakeham et al., 2002).

Peak areas of seven sterols and alcohols quantified across particle samples are less affected by different drying treatments. $\mathrm{R}_{\mathrm{O} / \mathrm{F}}$ and $\mathrm{R}_{\mathrm{A} / \mathrm{F}}$ values for five of the seven compounds ranged from 0.8 to 1.1 (Fig. 6a-b). Only abundances of gorgost-5-en-3-ol were anomalously depressed $(<0.7)$, while abundances of 1-hexadecanol were anomalously elevated $(>1.25)$ in the oven-dried and air-dried samples. The high abundances of 1-hexadecanol in these oven/air-dried samples relative to the freeze-dried particles can be attributed to proportionally larger sorption blank corrections for this compound in the freeze-dried sample particles. In fact, the ratios of compound abundances between oven-dried, air-dried and freeze-dried samples prior to blank correction are much closer to 1.0 (Fig. 6d-e). Regardless of any biases introduced by 
different blank corrections, different drying treatments affect alcohol and sterol abundances much less than they affect fatty acid abundances.

The fact that specific lipid abundances in oven- and air-drying shift lipid abundances according to their physical properties (e.g., molecular weight and structure), while bulk characteristics and thermal stability remain unaffected across treatments, supports the argument that sample treatment effects are physical rather than biochemical. The oven- and air-drying may impose enough heat and airflow, respectively, to physically remove some of these light-weight, more volatile molecules. The relatively depressed branched fatty acid abundances in the oven-dried and air-dried samples (Fig. 5) indicates that it was likely that the overnight drying period for the oven-dried and airdried samples was short enough to limit any significant alteration by heterotrophic activity observed, which Ohman (1996) had observed after longer periods of wet sample storage.

Typically, lipids make up at most $25 \%$ of total biomass in living microalgae (Finkel et al., 2016), which are the primary contributors to POC in the productive coastal waters of Woods Hole in June. In this study, we have monitored only a small fraction of the marine lipid pool (Wakeham and Volkman, 1991), and have found that some compounds are as much as $\sim 90 \%$ depleted in non-freeze-dried samples relative to freezedried samples. More than $50 \%$ of several of these compounds, however, are still present in oven-dried and air-dried filters. Taken together, such shifts in lipid abundances as a result of different drying treatments must be small relative to the bulk organic matter composition, as bulk $\delta^{13} \mathrm{C}, \delta^{15} \mathrm{~N}, \mathrm{C} / \mathrm{N}$ and thermal stability do not vary across drying treatments.

\section{Conclusion}

The results of this methods study show that bulk $\mathrm{C} / \mathrm{N}, \delta^{13} \mathrm{C}, \delta^{15} \mathrm{~N}$, and thermal stability are not compromised and can be used as tracers of POC composition and cycling in the water column when particle samples are dried rather than frozen following collection and subsequently freeze-dried. Drying treatments like oven-drying or airdrying do shift the lipid distribution in organic matter, however, and possibly the 
distribution of other compound classes. But the magnitude of effects of these drying treatments on compound class abundances are dwarfed by the greater proportion of unaltered material in the bulk carbon pool. More work remains to assess how these compound-specific changes from drying treatments fractionate the stable isotope composition of these biomolecules.

\section{Acknowledgements}

Many thanks to Phoebe Lam, Ulrich Loic Kakou and Paul Lerner for assistance in the field work and collection of samples; Phoebe Lam, Valier Galy and Ann McNichol for assistance in data interpretation; Al Gagnon and Carl Johnson for assistance in the bulk and isotope analyses; Mary Lardie, Jordon Hemingway, Kyrstin Fornace and Guillaume Soulet for the assistance in the used of the RPO system and vacuum line; and Carl Johnson and Liz Canuel for insightful discussions in planning the study.

\section{References}

Bishop, J. K., Lam, P. J., and Wood, T. J.: Getting good particles: Accurate sampling of particles by large volume in-situ filtration, Limnology and Oceanography Methods, 10, 681-710, 2012.

Burd, A. B., Frey, S., Cabre, A., Ito, T., Levine, N. M., Lønborg, C., Long, M., Mauritz, M., Thomas, R. Q., and Stephens, B. M.: Terrestrial and marine perspectives on modeling organic matter degradation pathways, Global Change Biology, 22, 121136, 2016.

Burdige, D. J.: Preservation of Organic Matter in Marine Sediments: Controls, Mechanisms, and an Imbalance in Sediment Organic Carbon Budgets?, Chemical Reviews, 107, 467-485, 2007.

Cavagna, A.-J., Dehairs, F., Bouillon, S., Woule-Ebongué, V., Planchon, F., Delille, B., and Bouloubassi, I.: Water column distribution and carbon isotopic signal of cholesterol, brassicasterol and particulate organic carbon in the Atlantic sector of the Southern Ocean, Biogeosciences, 10, 2787-2801, 2013.

Cramer, B.: Methane generation from coal during open system pyrolysis investigated by isotope specific, Gaussian distributed reaction kinetics, Organic Geochemistry, 35, 379-392, 2004.

Daubert, T. E.: Physical and Thermodynamic Properties of Pure Chemicals, National Standard Reference Data System, New York, 1997.

Finkel, Z. V., Follows, M. J., Liefer, J. D., Brown, C. M., Benner, I., and Irwin, A. J.: Phylogenetic Diversity in the Macromolecular Composition of Microalgae, PloS one, 11, e0155977, 2016. 
Francois, R., Honjo, S., Krishfield, R., and Manganini, S.: Factors controlling the flux of organic carbon to the bathypelagic zone of the ocean, Global Biogeochemical Cycles, 16, doi:10.1029/2001GB001722, 2002.

Grimalt, J. O., Torras, E., and Albaigés, J.: Bacterial reworking of sedimentary lipids during sample storage, Organic Geochemistry, 13, 741-746, 1988.

Hemingway, J. D., Galy, V. V., Gagnon, A. R., Grant, K. E., Rosengard, S. Z., Soulet, G., Zigah, P., and McNichol, A. P.: Assessing the blank carbon contribution, isotope mass balance, and kinetic isotope fractionation of the ramped pyrolysis/oxidation instrument at NOSAMS, Radiocarbon, accepted. accepted.

Kaehler, S. and Pakhomov, E.: Effects of storage and preservation on the $\delta^{13} \mathrm{C}$ and $\delta^{15} \mathrm{~N}$ signatures of selected marine organisms, Marine Ecology Progress Series, 219, 299-304, 2001.

Lam, P. J., Ohnemus, D. C., and Auro, M. E.: Size-fractionated major particle composition and concentrations from the US GEOTRACES north Atlantic zonal transect, Deep Sea Research Part II: Topical Studies in Oceanography, 116, 303320, 2015.

Lide, D.R., Ed.: CRC Handbook of Chemistry and Physics, CRC Press, Boca Raton, Fl, 1996.

Meylan, W. M. and Howard, P. H.: Bond contribution method for estimating Henry's law constants, Environmental Toxicology and Chemistry, 10, 1283-1293, 1991.

Ohman, M.: Freezing and storage of copepod samples for the analysis of lipids, Marine Ecology Progress Series, 130, 295-298, 1996.

Repeta, D. J.: Chemical characterization and cycling of dissolved organic matter. In: Biogeochemistry of marine dissolved organic matter., Hansell, D. A. and Carlson, C. A. (Eds.), Elsevier, 2014.

Rosengard, S. Z., Lam, P. J., Balch, W. M., Auro, M. E., Pike, S., Drapeau, D., and Bowler, B.: Carbon export and transfer to depth across the Southern Ocean Great Calcite Belt, Biogeosciences, 12, 3953-3971, 2015.

Rosenheim, B. E., Day, M. B., Domack, E., Schrum, H., Benthien, A., and Hayes, J. M.: Antarctic sediment chronology by programmed - temperature pyrolysis: Methodology and data treatment, Geochemistry, Geophysics, Geosystems, 9, 2008.

Rosenheim, B. E. and Galy, V.: Direct measurement of riverine particulate organic carbon age structure, Geophysical Research Letters, 39, 2012.

Rosenheim, B. E., Roe, K. M., Roberts, B. J., Kolker, A. S., Allison, M. A., and Johannesson, K. H.: River discharge influences on particulate organic carbon age structure in the Mississippi/Atchafalaya River System, Global Biogeochemical Cycles, 27, 154-166, 2013.

Schwarzenbach, R. P., Gschwend, P. M., and Imboden, D. M.: Environmental organic chemistry, John Wiley \& Sons, 2003.

Subt, C., Fangman, K. A., Wellner, J. S., and Rosenheim, B. E.: Sediment chronology in Antarctic deglacial sediments: Reconciling organic carbon ${ }^{14} \mathrm{C}$ ages to carbonate ${ }^{14} \mathrm{C}$ ages using Ramped PyrOx, The Holocene, 26, 265-273, 2016.

Trull, T. and Armand, L.: Insights into Southern Ocean carbon export from the $\delta 13 \mathrm{C}$ of 
particles and dissolved inorganic carbon during the SOIREE iron release experiment, Deep Sea Research Part II: Topical Studies in Oceanography, 48, 2655-2680, 2001.

Wagner, B. A., Buettner, G. R., and Burns, C. P.: Free Radical-Mediated Lipid Peroxidation in Cells: Oxidizability Is a Function of Cell Lipid bis-Allylic Hydrogen Content, Biochemistry, 33, 4449-4453, 1994.

Wakeham, S. G. and Canuel, E. A.: Organic geochemistry of particulate matter in the eastern tropical North Pacific Ocean: Implications for particle dynamics, Journal of Marine Research, 46, 183-213, 1988.

Wakeham, S. G., Peterson, M. L., Hedges, J. I., and Lee, C.: Lipid biomarker fluxes in the Arabian Sea, with a comparison to the equatorial Pacific Ocean, Deep-Sea Research Part II-Topical Studies in Oceanography, 49, 2265-2301, 2002.

Wakeham, S. G. and Volkman, J. K.: Sampling and analysis of lipids in marine particulate matter, Marine particles: analysis and characterization, 171-179, 1991. 
Table 1. The bulk composition of $<51 \mu \mathrm{m}$ particulate organic matter loaded onto three sample and two blank $<51 \mu \mathrm{m}$ QMA filters (active area $\sim 125 \mathrm{~cm}^{2}$ ), collected during two deployments and then dried in an oven, laminar flow hood or freeze-dried. Filters from each flow path or deployment blank were divided into thirds so that each drying treatment could be applied to each blank or sample filter (Section 2.1, Fig. 1a). Sub-samples from individual thirds of different deployments were analyzed for bulk composition. Sample total carbon and nitrogen contents are not blank-corrected.

\begin{tabular}{|c|c|c|c|c|c|c|c|c|c|c|}
\hline Sample & Deployment & Flow Path & Volume (L) & Treatment & C/QMA & {$[\mathrm{C}]$} & {$[\mathrm{PN}]$} & $\mathbf{C} / \mathbf{N}$ & $\delta^{13} \mathrm{C}$ & $\delta^{13} \mathbf{N}$ \\
\hline-- & -- & -- & $L$ & -- & $m g / Q M A$ & $\mu M$ & $\mu M$ & $\mu \mathrm{mol} / \mu \mathrm{mol}$ & $\%$ & $\%$ \\
\hline QMA1 & 1 & A & 95.4 & oven-dried & & & & & & \\
\hline QMA1 & 1 & A & 95.4 & air-dried & 14 & 12.4 & 1.9 & 6.5 & -23.6 & 7.9 \\
\hline QMA1 & 1 & A & 95.4 & freeze-dried & & & & & & \\
\hline QMA2 & 1 & B & 93.8 & oven-dried & & & & & & \\
\hline QMA2 & 1 & B & 93.8 & air-dried & & & & & & \\
\hline QMA2 & 1 & B & 93.8 & freeze-dried & 13 & 11.9 & 1.8 & 6.8 & -23.9 & 8.3 \\
\hline QMA3 & 2 & B & 40.5 & oven-dried & 8 & 16.7 & 2.5 & 6.8 & -23.8 & 8.2 \\
\hline QMA3 & 2 & B & 40.5 & air-dried & & & & & & \\
\hline QMA3 & 2 & B & 40.5 & freeze-dried & & & & & & \\
\hline $\mathrm{db} 1$ & 1 & N/A & 0 & oven-dried & & & & & & \\
\hline $\mathrm{db} 1$ & 1 & N/A & 0 & air-dried & & & & & & \\
\hline $\mathrm{db} 1$ & 1 & $\mathrm{~N} / \mathrm{A}$ & 0 & freeze-dried & 0.7 & N/A & N/A & 7.7 & -25.6 & BDL \\
\hline $\mathrm{db} 2$ & 2 & N/A & 0 & oven-dried & & & & & & \\
\hline $\mathrm{db} 2$ & 2 & N/A & 0 & air-dried & & & & & & \\
\hline $\mathrm{db} 2$ & 2 & N/A & 0 & freeze-dried & & & & & & \\
\hline
\end{tabular}


Table 2. $\delta^{13} \mathrm{C}$ values of $\mathrm{CO}_{2}$ collected in specific temperature intervals during ramped oxidation of the oven-dried, air-dried and freeze-dried dock test samples. Fraction of total carbon released in each temperature interval was calculated using the gas pressures quantified by a pressure transducer (baratron) in the vacuum line downstream of the RPO system.

\begin{tabular}{cccccc}
\hline Treatment & Oven & Fraction & Temperature Interval & Fraction of Total C & $\boldsymbol{\delta}^{\mathbf{1 3}} \mathbf{C}$ \\
\hline-- & -- & -- & ${ }^{\circ}$ C & $\%$ & $\% o$ \\
Oven-dried & A & 1 & $130-412$ & $68 \%$ & -26.9 \\
Sample & A & 2 & $412-610$ & $31 \%$ & -24.4 \\
& A & 3 & $610-904$ & $1 \%$ & -27.8 \\
Air-dried & B & 1 & $125-415$ & $63 \%$ & -26.8 \\
Sample & B & 2 & $415-617$ & $33 \%$ & -23.2 \\
& B & 3 & $617-900$ & $5 \%$ & no data \\
Freeze-dried & B & 1 & $130-416$ & $67 \%$ & -25.8 \\
Sample & B & 2 & $416-625$ & $28 \%$ & -22.7 \\
& B & 3 & $625-910$ & $5 \%$ & no data \\
\hline
\end{tabular}


Table 3. Constituents of the alcohol/sterol standard and their properties.

\begin{tabular}{ccccl}
\hline Standard compound & Class & Molar Mass & \# Carbon & \multicolumn{1}{c}{ Known sources } \\
\hline-- & -- & $g / m o l$ & $\#$ & -- \\
Phytol & Alcohol & 196.539 & 20 & Chlorophyll \\
1-hexadecanol & Alcohol & 242.447 & 16 & Ubiquitous \\
$5 \alpha$-Androstan-3 $\beta$-ol & Sterol & 276.464 & 19 & \\
cholesterol & Sterol & 386.664 & 27 & Ubiquitous \\
& & & & Cholesterol derivative \\
$5 \alpha$-cholestan-3 $\beta-o l$ & Sterol & 388.68 & 27 & in biological matter \\
Brassicasterol & Sterol & 398.675 & 28 & Unicellular algae, \\
stigmasterol & Sterol & 412.702 & 29 & Terrestrial vegetation \\
\hline
\end{tabular}


QMA 1

A

Deployment 1

Flow Path A: 95.4 L

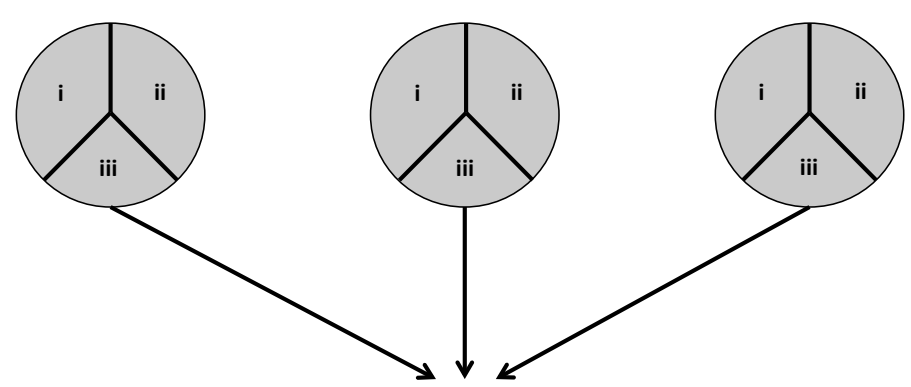

All fraction iii's freeze-dried

All fraction i's oven-dried

All fraction ii's air-dried
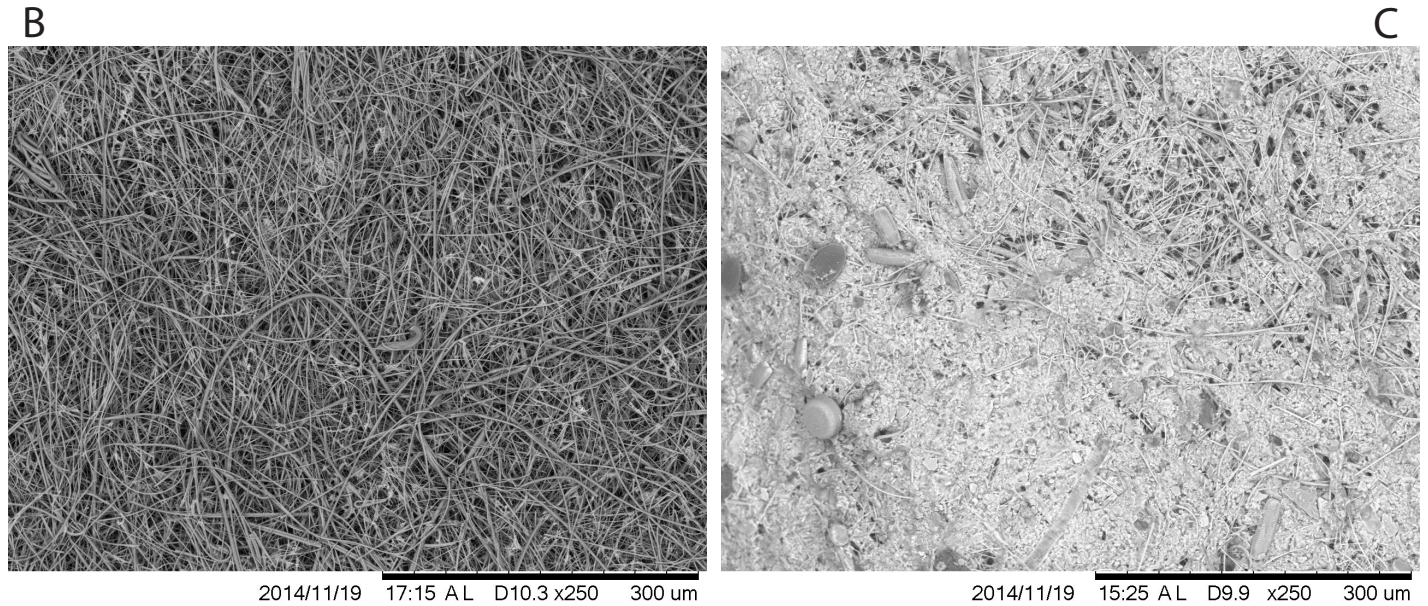

Figure 1. (a) Schematic of dock sample collection and post-processing before analysis. A similar approach was used to apportion the deployment blank filters by drying treatment. (b-c) Scanning electron microscope images of freeze-dried (b) blank and (c) sample particle filters. Total filter active area is $125 \mathrm{~cm}^{2}$, corresponding to a $\sim 12.6 \mathrm{~cm}$ diameter. By comparison, the images below are $\sim 0.6 \mathrm{~cm}$ wide. 

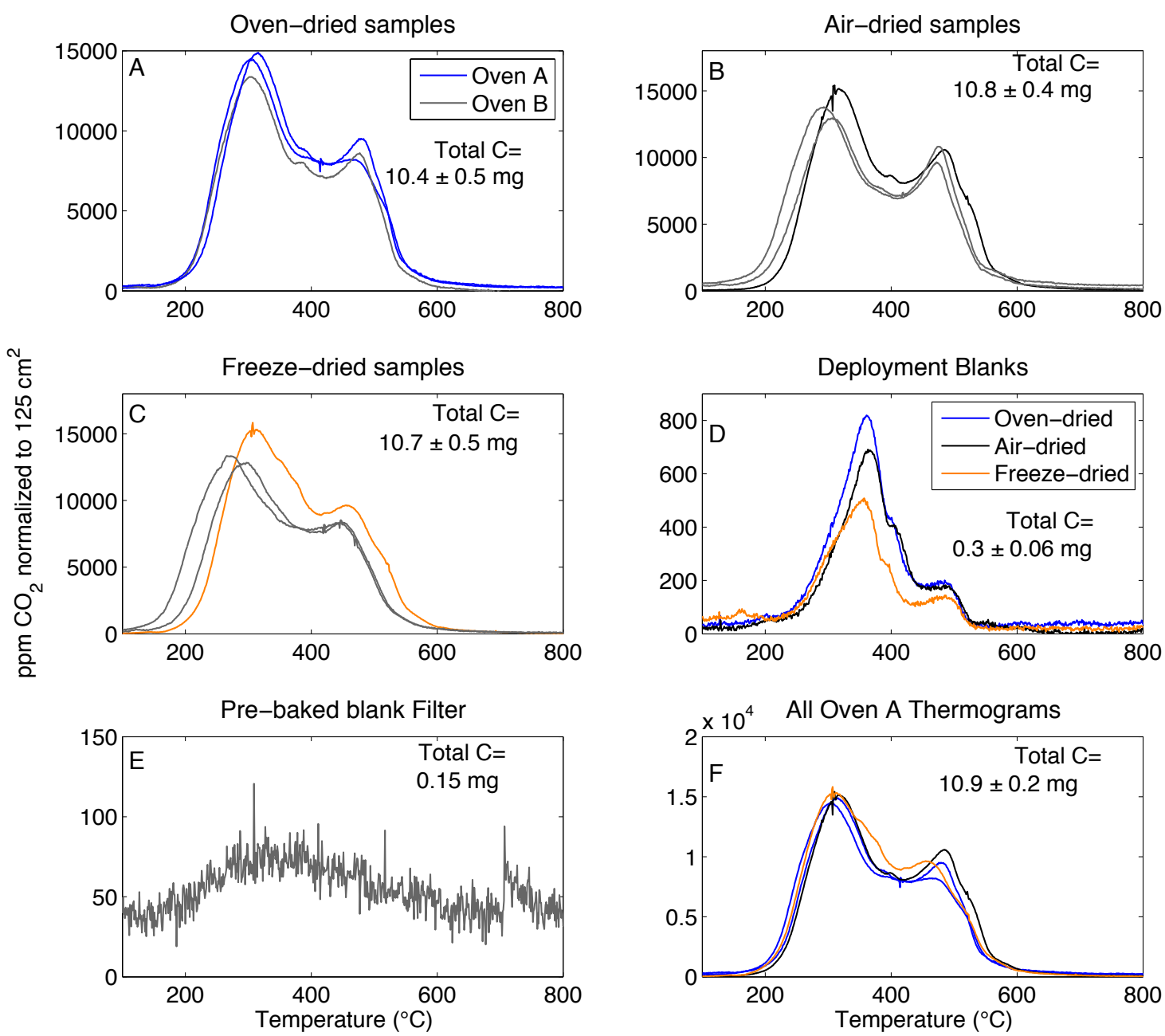

Figure 2. Blank-corrected thermograms of particle sample filters generated by ramped oxidation (a-c). The furnaces used for the temperature ramp are specified as colored lines for oven A vs. gray lines for oven B. Analyses were conducted three times per sample drying treatment. (d) Thermograms of deployment blanks analyzed once per drying treatment using oven A. (e) Thermogram of a pre-combusted non-deployed QMA filter, also analyzed using oven A. (f) All sample particle thermograms analyzed in oven A. The legend in (d) applies to (f). 

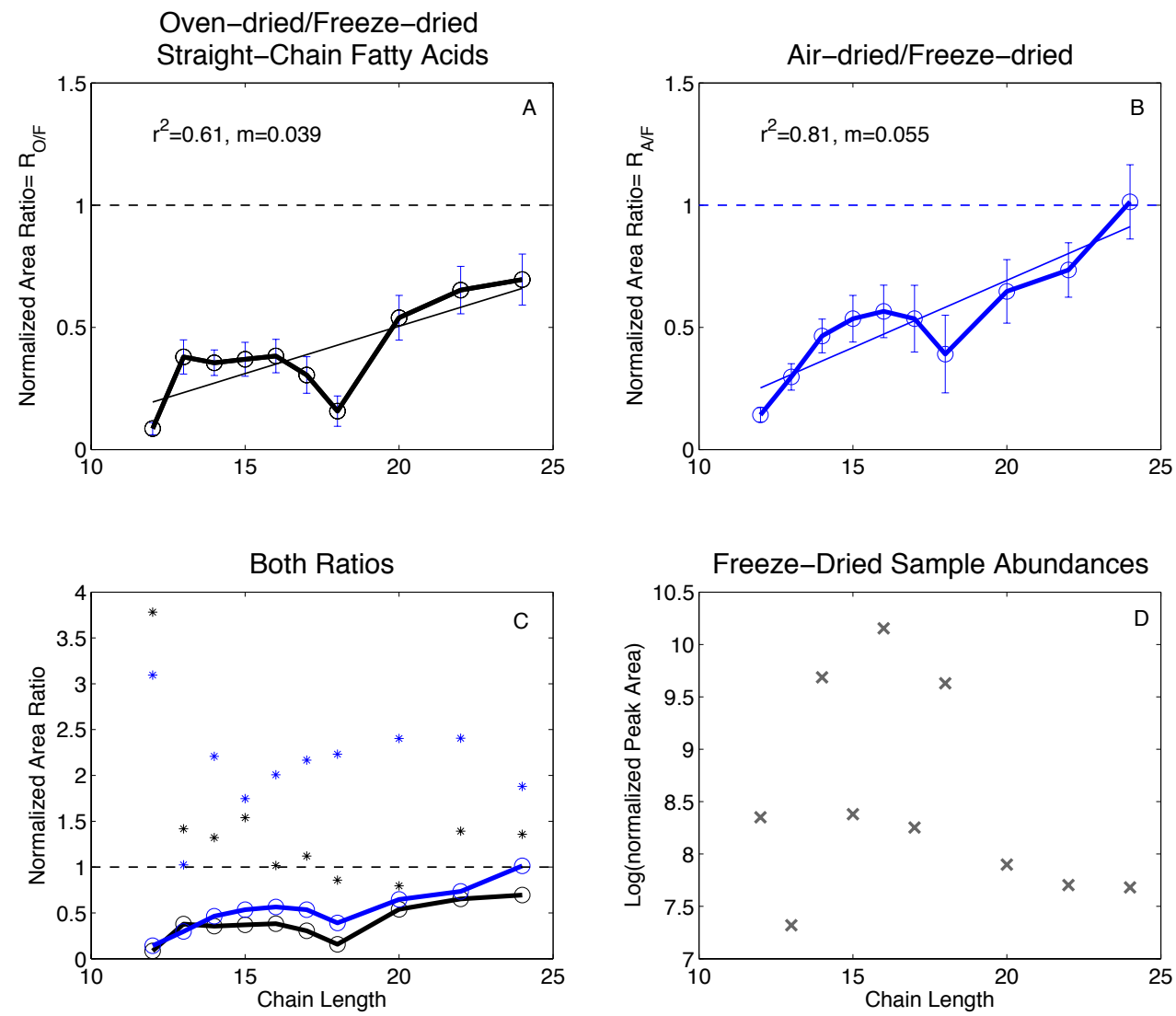

Figure 3. (a-c) Ratios of filter-normalized and blank-corrected peak areas of straightchain saturated fatty acids in (a) oven-dried particle samples relative to freeze-dried samples $\left(\mathrm{R}_{\mathrm{O} / \mathrm{F}}\right)$ and in (b) air-dried samples relative to freeze-dried samples $\left(\mathrm{R}_{\mathrm{A} / \mathrm{F}}\right)$. These ratios correlate significantly with compound carbon chain length $\left(\mathrm{p}<0.05, \mathrm{r}^{2}=0.61-0.81\right)$. (c) $\mathrm{R}_{\mathrm{O} / \mathrm{F}}$ and $\mathrm{R}_{\mathrm{A} / \mathrm{F}}$ plotted on the same axes. The stars are ratios of oven-dried (black) or air-dried (blue) blank compound abundances to freeze-dried blank compound abundances. (d) Absolute normalized and blank-corrected peak areas in just the freezedried samples. 

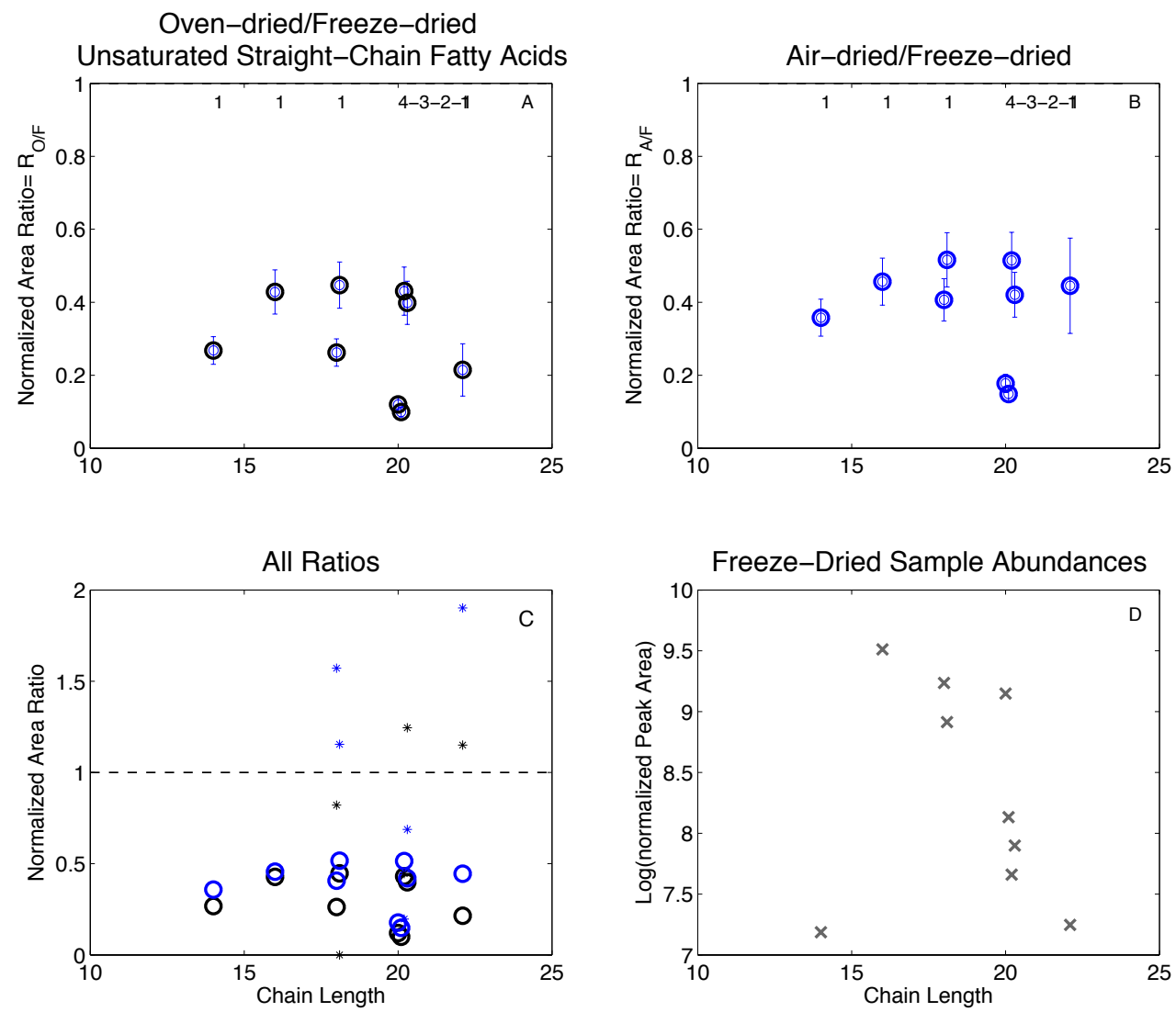

Figure 4. (a-b) Ratios of filter-normalized and blank-corrected peak areas of straightchain unsaturated fatty acids in (a) oven-dried particle samples relative to freeze-dried samples $\left(\mathrm{R}_{\mathrm{O} / \mathrm{F}}\right)$ and in (b) air-dried samples relative to freeze-dried samples $\left(\mathrm{R}_{\mathrm{A} / \mathrm{F}}\right)$. The numbers on the panels indicate the degrees of unsaturation for each chain length (i.e., number of double bonds). (c) $\mathrm{R}_{\mathrm{O} / \mathrm{F}}$ and $\mathrm{R}_{\mathrm{A} / \mathrm{F}}$ plotted on the same axes. The stars are ratios of oven-dried (black) or air-dried (blue) blank compound abundances to freeze-dried blank compound abundances. (d) Absolute normalized and blank-corrected peak areas in just the freeze-dried samples. 

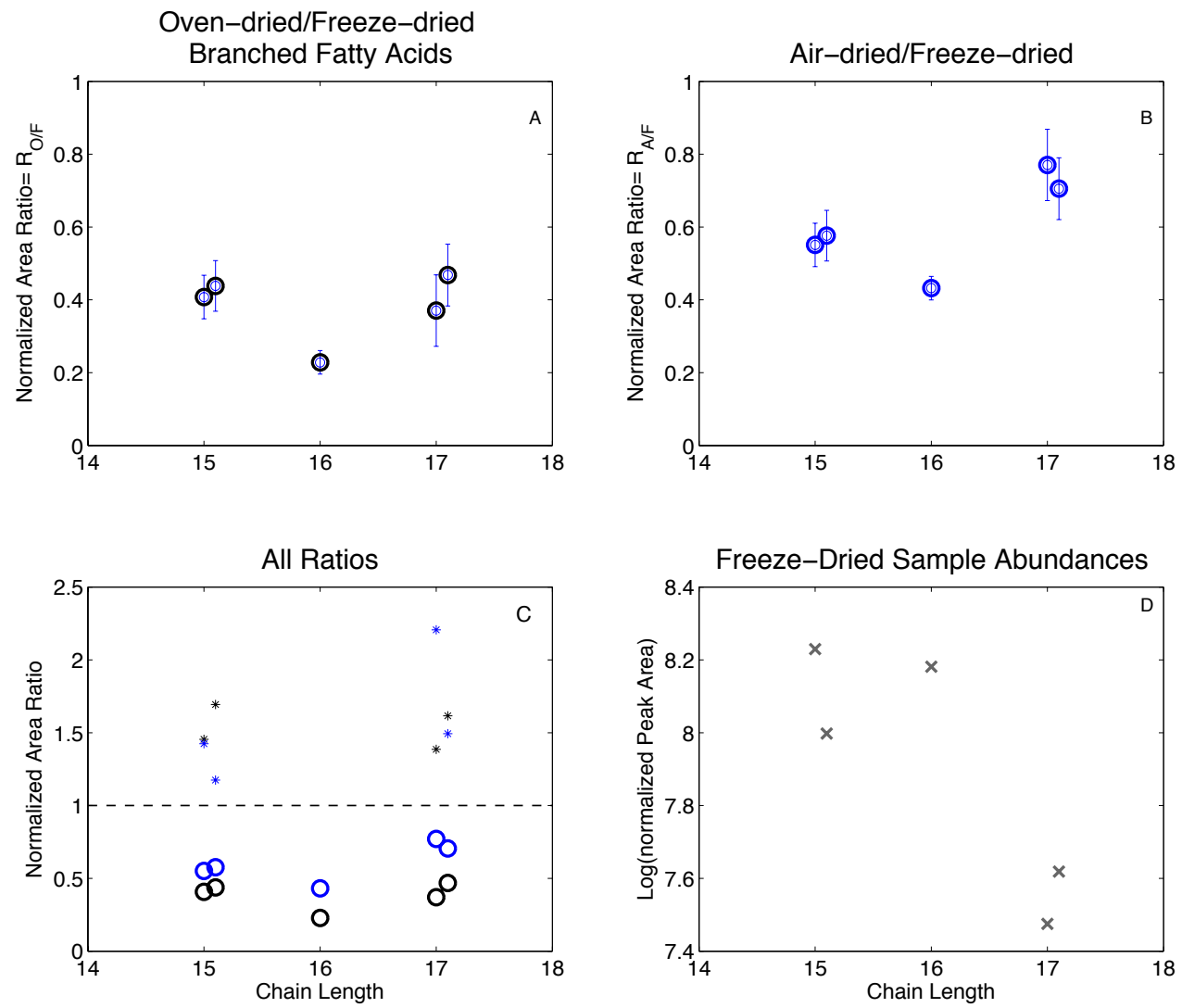

Figure 5. (a-b) Ratios of filter-normalized and blank-corrected peak areas of three branched saturated fatty acids in (a) oven-dried particle samples relative to freeze-dried samples $\left(\mathrm{R}_{\mathrm{O} / \mathrm{F}}\right)$ and in (b) air-dried samples relative to freeze-dried samples $\left(\mathrm{R}_{\mathrm{A} / \mathrm{F}}\right)$. The two clusters of data points for chain lengths 15 and 17 represent isomers of the same size molecule. (c) $\mathrm{R}_{\mathrm{O} / \mathrm{F}}$ and $\mathrm{R}_{\mathrm{A} / \mathrm{F}}$ plotted on the same axes. The stars are ratios of oven-dried (black) or air-dried (blue) blank compound abundances to freeze-dried blank compound abundances. (d) Absolute normalized and blank-corrected peak areas in just the freezedried samples. 

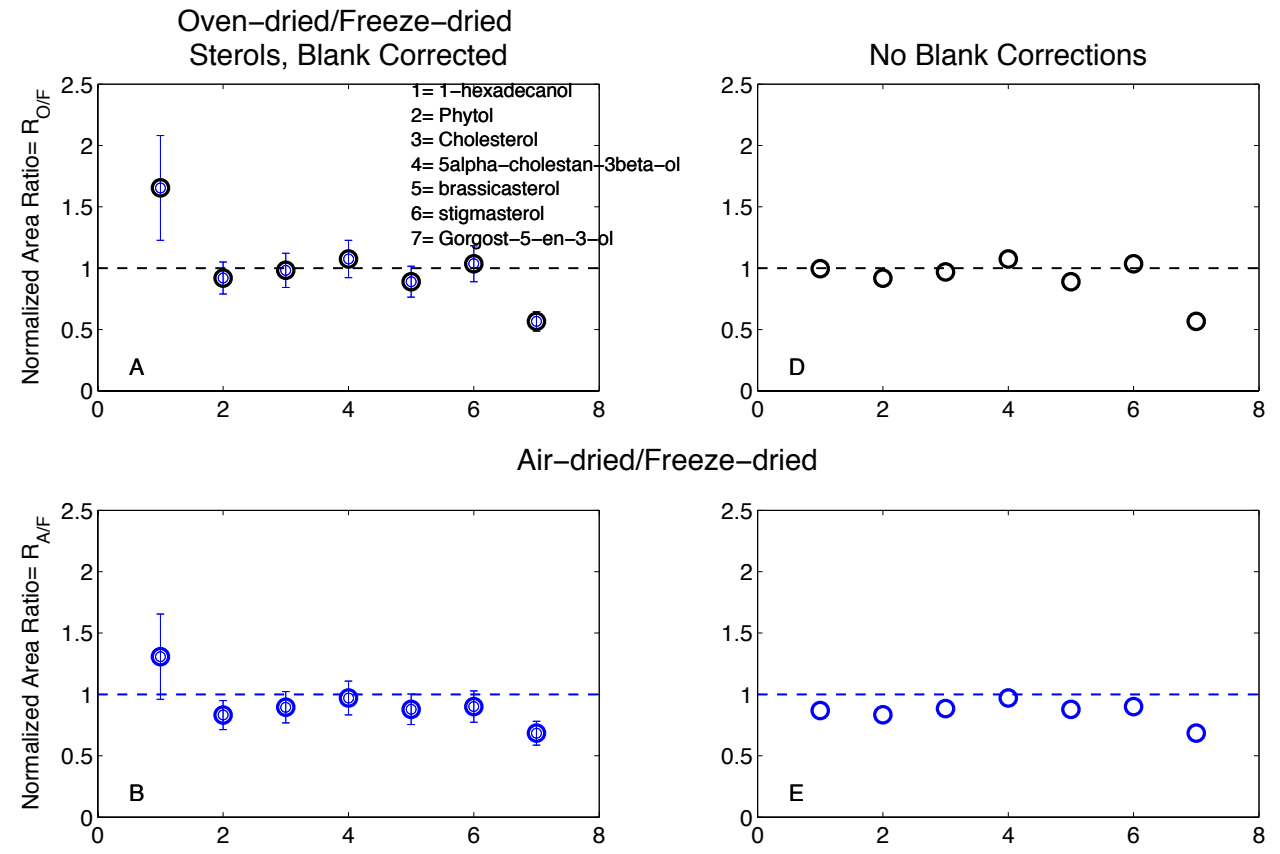

Freeze-Dried Sample Compound Abundances
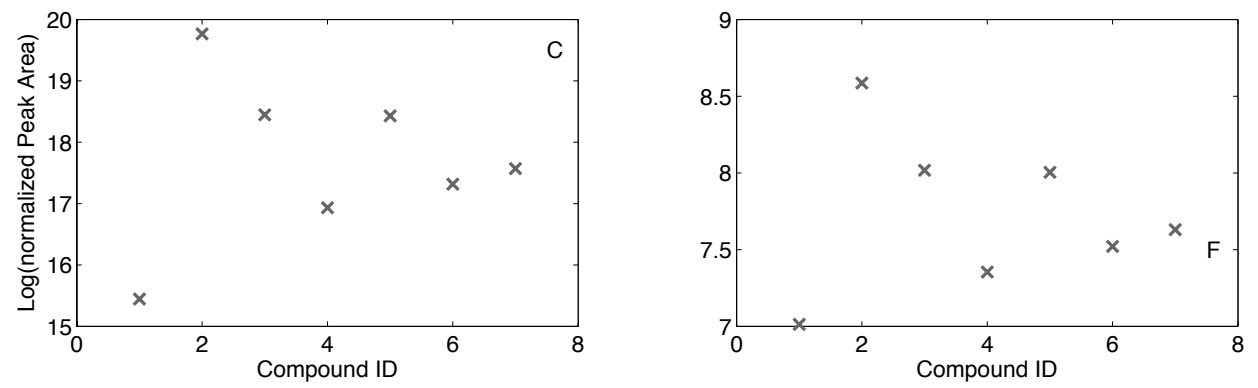

Figure 6. (a-b) Ratios of filter-normalized and blank-corrected peak areas of seven alcohols/sterols in (a) oven-dried particle samples relative to freeze-dried samples $\left(\mathrm{R}_{\mathrm{O} / \mathrm{F}}\right)$ and in (b) air-dried samples relative to freeze-dried samples $\left(\mathrm{R}_{\mathrm{A} / \mathrm{F}}\right)$. The $\mathrm{x}$-axis is the compound ID number, corresponding to the legend in panel a. Refer to Table 3 for compound properties. (c) Absolute normalized blank-corrected peak areas of alcohols/sterols in the freeze-dried sample. Quantities in panels d-f are analogous to quantities in a-c, but are not blank-corrected. 


\section{Chapter 4:}

\section{Using ramped oxidation to track changes in euphotic and mesopelagic zone particulate organic carbon composition}




\begin{abstract}
The euphotic and mesopelagic zones of the water column are the most dynamic depths intervals for particulate organic carbon composition (POC). Ramped oxidation offers a unique perspective of how POC composition changes in these intervals by decomposing a particle sample over a constant temperature, differentiating POC into components by their thermal stability. Here, we report fifteen thermograms, or plots of $\mathrm{CO}_{2}$ released against temperature, generated by ramped oxidation of POC collected within three depth profiles (euphotic zone to $1000 \mathrm{~m}$ ) from three sites of the Southern Ocean Great Calcite Belt region that span a range in primary productivity, phytoplankton community composition and export efficiency. The mixture of organic carbon and calcite in particles at these stations produce sample matrix effects during ramped oxidation that influence the thermal stability distribution of inorganic carbon, which must be accounted for prior to comparing samples by their POC composition alone. The three thermogram profiles demonstrate that the thermal stability range of POC narrows with depth, leading to the accumulation of POC that oxidizes over a mid-temperature range. Further, these transitions occur regardless of location and euphotic zone conditions, supporting the argument for selective preservation of biomolecules in the water column. Changes in the stable isotope values of $\mathrm{CO}_{2}$ released within specific intervals during ramped oxidation of these samples suggest that different biomolecular pools are selectively preserved across stations, owing to differences in POC source and conversion of POC export to heterotrophic biomass.
\end{abstract}

\title{
$1 \quad$ Introduction
}

The biological pump moderates the long-term carbon cycle and climate by exporting ca. 16 gigatons/year of sinking particulate organic carbon (POC) from the euphotic zone (Volk and Hoffert, 1985; Eppley and Peterson, 1979; Behrenfeld and Falkowski, 1997; Falkowski et al., 1998; Kwon et al., 2009). The quantity sequestered in the deep ocean comprises $\leq 1 \%$ of the carbon fixed by primary production because zooplankton and bacterial heterotrophs rapidly consume and remineralize organic carbon in the euphotic and mesopelagic zones of the ocean ( Martin et al., 1987; Buesseler and 
Boyd, 2009; Giering et al., 2014). At the same time, global compilations of POC flux from the surface ocean to $2000 \mathrm{~m}$ (Henson et al., 2011) suggest that the efficiency of the biological pump varies from region to region, as a result of strong latitudinal gradients in both the fraction of primary productivity exported from the euphotic zone and the fraction of POC export transferred to $2000 \mathrm{~m}$. Many interrelated factors have been proposed to drive these variations in POC transport efficiency, from physical processes like advection and the water column temperature gradient (Dall'Olmo and Mork, 2014; Marsay et al., 2015; Laufkötter et al., 2016) to biochemical processes like particle formation and size (Benner et al., 1997; Burd and Jackson, 2009), surface phytoplankton community structure (Francois et al., 2002; Thomalla et al., 2008; Henson et al., 2012a; Henson et al., 2012b), and particle composition (Armstrong et al. 2002; Klaas and Archer, 2002).

This chapter explores the extent to which organic matter quality in particles controls the efficiency of POC transfer in the euphotic and mesopelagic zones of the water column. Defining organic matter quality has challenged marine geochemists for decades, but offers the potential to relate biomolecular reactivity to the biological pump (Burd et al., 2016). Scientific understanding of POC quality has largely evolved with the methods available for characterizing the components of marine POC (Hedges et al., 2000). Yet, different approaches, from bulk carbon isotope measurements to compoundspecific biomolecule abundances, and from field observations to controlled culture experiments, have consistently illustrated that certain biomolecular groups accumulate in degraded organic matter, therefore more likely to survive in particles transiting the water column (Wakeham et al., 1997; Hedges et al., 2000; Freeman, 2001). Global differences in POC quality could further bolster the observed relationships between phytoplankton community composition and POC transfer efficiency if different phytoplankton produce and transfer compositionally distinct pools of POC (Francois et al., 2002; Rosengard et al., 2015).

Ramped pyrolysis/oxidation (RPO) offers a novel approach to characterize marine organic matter composition, and an opportunity to differentiate marine POC by its quality or degradability (Rosenheim et al., 2008; Rosenheim and Galy, 2012; Rosenheim et al., 2013). The technique oxidizes or pyrolyzes carbon at a steady, controlled temperature 
ramp from $100^{\circ} \mathrm{C}$ to up to $1000^{\circ} \mathrm{C}$, and monitors the release of $\mathrm{CO}_{2}$, an oxidation/pyrolysis product, throughout the ramp. Plots of $\mathrm{CO}_{2}$ released against temperature, thereafter referred to as thermograms, separate organic carbon by its thermal stability, or activation energy (Cramer, 2004), offering a perspective of organic matter composition that is finer than bulk measurements, and more quantitative and less laborintensive than compound-specific assessments of POC quality. The reaction can be coupled to a vacuum line to trap and analyze the stable and radiocarbon isotope composition of $\mathrm{CO}_{2}$ gas produced within specific temperature intervals. Applications of RPO coupled to isotope measurements in the last decade have helped identify and parse diverse carbon sources in different river sediments and complex depositional environments, both marine and terrestrial (e.g., Rosenheim et al., 2008; Rosenheim and Galy, 2012; Subt et al., 2016). These earlier RPO data frequently illustrate increases in radiocarbon age with pools of carbon that oxidize at higher temperatures, supporting the hypothesis that thermochemical stability during pyrolysis/oxidation is a proxy for diagenetic stability in nature (Rosenheim et al., 2008; Rosenheim and Galy, 2012; Rosenheim et al., 2013).

Here, we report and interpret the first set of thermograms generated by ramped oxidation of marine POC from the euphotic and mesopelagic zones of the water column. These POC samples originate from different phytoplankton communities across the Atlantic and Indian sectors of the Southern Ocean, including the Great Calcite Belt, a particulate inorganic carbon (PIC) rich feature that has been attributed to a massive coccolithophore bloom (Balch et al., 2011a; Balch et al., 2016). In this sampling region, the highest diatom abundances occur south of the Polar Front and the highest coccolithophore abundances are found north of the Polar Front in the southwest Atlantic. These changes in community composition are accompanied by variations in carbon transfer regimes through the euphotic and mesopelagic zones (Rosengard et al., 2015). POC export fluxes from the euphotic zone vary twenty-fold, from 0.97 to $20 \mathrm{mmol} / \mathrm{m}^{2} / \mathrm{d}$, representing 4 to $77 \%$ of total primary productivity at each respective site. Transfer efficiencies, or the fraction of POC flux transferred to 100 meters below the euphotic zone, ranged from $20 \%$ to over $100 \%$ in zones with particle production or particle advection below the euphotic zone. 
We focus on three depth profiles at stations GB1-117, GB2-43 and GB2-100, which differ in their surface community composition, biomineral composition (i.e., concentrations of biogenic silica, [BSi], and particulate inorganic carbon, [PIC]), POC export efficiency, and the attenuation of POC concentrations in the mesopelagic zone (Fig. 1, Table 1; Rosengard et al., 2015). Thus, analyzing euphotic and mesopelagic zone POC from these three station profiles provides contrasts in primary producer community structure, particle composition, and bulk POC transfer. Coupled to the unique perspective offered by ramped oxidation, we address four questions: (1) What are the compositional differences among POC, in terms of thermal stability and stable carbon isotope ratios, produced by distinct phytoplankton community assemblages in the euphotic zone? (2) How does POC composition change in the mesopelagic zone? (3) How do changes in POC composition with depth relate to the composition of POC produced at the surface?

(4) How does thermal stability relate to the diagenetic stability of POC that has been recently produced and thus should exhibit little variation in radiocarbon age?

\section{$2 \quad$ Methods}

\subsection{Field work}

In January - February 2011 and February - March 2012, the $R / V$ Melville and $R / V$ Revelle traversed the Atlantic and Indian sectors of the Southern Ocean, from Punta Arenas, Chile to Cape Town, South Africa (GB1) and then Durban, South Africa to Perth Australia (GB2), respectively. GB1 and GB2 were timed to coincide with the annual coccolithophore bloom of the austral summer and autumn. Together, both cruise tracks spanned a latitudinal range of $39^{\circ} \mathrm{S}$ to $59^{\circ} \mathrm{S}$, crossing the Subtropical, Subantarctic and Polar Fronts (Fig. 1; Table 1; Balch et al., 2016). Modified dual-flow McLane in-situ pumps (WTS-LV), equipped with $51 \mu \mathrm{m}$ pore-size polyester pre-filters upstream of paired $0.8 \mu \mathrm{m}$ polyethersulfone (Supor ${ }^{\mathrm{TM}}$ ) filters in one flow path, and $51 \mu \mathrm{m}$ prefilters upstream of paired, pre-combusted $1 \mu \mathrm{m}$ quartz fiber (Whatman ${ }^{\mathrm{TM}} \mathrm{QMA}$ ) filters in a second flow path, were deployed at 27 stations across GB1 and GB2 to collect two size classes of particles ( $>51 \mu \mathrm{m}$ and 1-51 $\mu \mathrm{m}$ diameter) from the euphotic zone to 1000 
meters, as described in Rosengard et al. (2015). All filters had an active particle collection area of $125 \mathrm{~cm}^{2}$. Euphotic zone depth, $\mathrm{Z}_{\mathrm{PAR}}$, was defined as the depth at $0.3 \%$ of surface photosynthetically available radiation (Balch et al., 2011b). At each pump cast, complete filter sets sandwiched within a $1 \mu \mathrm{m}$ mesh filter were externally attached to the frame of the deepest pump. As these filters passed through each depth of the profile and remained at the deepest depth throughout the entire pump time, they served as deployment blanks to correct for any sorption of dissolved species to the filters during the cast.

\subsection{Particle composition}

The $>51 \mu \mathrm{m}$ POC concentrations in all $>51 \mu \mathrm{m}$ particle samples and deployment blank pre-filters, as well as $>51 \mu \mathrm{m}$ biomineral (PIC, BSi) concentrations at $\mathrm{Z}_{\mathrm{PAR}}$, were reported in Rosengard et al. (2015). Analyses focus on the more POC-rich $<51 \mu \mathrm{m}$ size class from profiles at stations GB1-117, GB2-43 and GB2-100 because resolving stable carbon isotope measurements within fractions of an RPO run requires $\geq 0.3 \mu \mathrm{mol}$ carbon per fraction. At the base of the euphotic zone, the $>51 \mu \mathrm{m}$ size-fraction particles comprised $14.1 \pm 11.6 \%$ (mean \pm S.D.) of the total particulate organic carbon (Rosengard et al., 2015). This fraction generally decreased towards the deeper mesopelagic zone (800- $1000 \mathrm{~m}$ ), owing to the longer residence time of $<51 \mu \mathrm{m}$ particles (months to years) relative to that of $>51 \mu \mathrm{m}$ particles (days to weeks) in the mesopelagic zone (Riley et al., 2012; McDonnell and Buesseler, 2010).

The $<51 \mu \mathrm{m} \mathrm{BSi}$, organic carbon and nitrogen concentrations were measured following methods described in Rosengard et al. (2015). $<51 \mu \mathrm{m}$ [BSi] values were only measured in particles collected onto Supor ${ }^{\mathrm{TM}}$ filters at $\mathrm{ZPAR}$ and in the deployment blank filters at each station. Organic carbon and nitrogen concentrations were measured in QMA filters from 7-8 depths and one deployment blank per station using a Flash 1112 Elemental Analyzer at Woods Hole Oceanographic Institution (WHOI), following acid fumigation to remove PIC. Only the two shallowest samples from the GB1-117 cast were not fumigated. For these two samples, an independent $<51 \mu \mathrm{m}$ [PIC] measurement from acid hydrolysis (see below) was subtracted from the total carbon concentration obtained 
via elemental analysis (Flash $1112 \mathrm{EA}$ ) to calculate [POC]. Molar C:N ratios were calculated from these quantities. Attenuation of $<51 \mu \mathrm{m}[\mathrm{POC}]$ in the mesopelagic zone (Buesseler and Boyd, 2009; Giering et al., 2014) was measured by fitting POC concentration profiles to the following equation (Martin et al., 1987; Lam and Bishop, 2007):

$$
[\mathrm{POC}]_{\mathrm{z}}=[\mathrm{POC}]_{\mathrm{ZPAR}}\left(\frac{z}{z_{P A R}}\right)^{-b}
$$

where $\mathrm{z}$ is the sample depth. Profiles with greater remineralization and [POC] attenuation have higher $b$ values, or attenuation coefficients.

Finally, $<51 \mu \mathrm{m}$ PIC concentrations in each profile sample and deployment blanks from GB1-117 and GB2-100 were measured by hydrolyzing QMA sub-samples and deployment blanks in $\sim 1.9 \mathrm{M}$ phosphoric acid in a sealed glass vessel following Galy et al. (2007). After $\sim 16$ hours of reaction, well beyond the minimum reaction time observed in a sample time series test (Appendix B, Fig. S1), the $\mathrm{CO}_{2}$ gas product of hydrolysis was quantified manometrically in a vacuum line. The averaged blank PIC quantities were subtracted from the sample PIC quantities. The $\mathrm{CO}_{2}$ gas was cryogenically trapped and its stable isotope composition was measured using a $V G$ Isotech Prism II isotope ratio mass spectrometer (IRMS). The $\mathrm{CO}_{2}$ quantities released during hydrolysis of each blank filter were combined prior to $\delta^{13} \mathrm{C}$ analysis because individual gas quantities from each blank filter were too small for $\delta^{13} \mathrm{C}$ analysis. All $\delta^{13} \mathrm{C}$ values in this report are referenced to Vienna Pee Dee Belemnite (VPDB), using an internal standard calibrated against NBS-19 calcite.

Bulk $\delta^{13} \mathrm{C}$ of sample and blank carbon were also measured by analyzing the total sample $\mathrm{CO}_{2}$ released from closed tube combustion or elemental analysis, using a Prism II IRMS. In closed tube combustion, raw QMA sub-samples were flame sealed in pre-baked evacuated quartz tubes with $2 \mathrm{~g}$ of copper oxide and $100 \mathrm{mg}$ of granulated silver at $850^{\circ} \mathrm{C}$ for six hours (McNichol et al., 1995). During elemental analysis, QMA sub-samples were combusted at $1025^{\circ} \mathrm{C}$ and quantified as $\mathrm{CO}_{2}$ using a Costech Instruments Elemental Combustion System 4010, before the gas was trapped in a vacuum line and analyzed for $\delta^{13} \mathrm{C}_{\text {bulk. }}$. Section 2.6 describes how the $\delta^{13} \mathrm{C}$ value of sample POC was calculated using the measured total sample and blank carbon concentrations, PIC concentrations, $\delta^{13} \mathrm{C}_{\mathrm{PIC}}$, $\delta^{13} \mathrm{C}_{\text {bulk }}$ and $\delta^{13} \mathrm{C}_{\text {blank}}$, as described here. Section 2.6 also compares different ways to 
measure total $[\mathrm{POC}]$ concentration directly and implicitly using the bulk and PIC measurements.

\subsection{Sample PIC treatment prior to RPO}

Fifteen samples of $<51 \mu \mathrm{m}$ particles from five depths per three profiles were analyzed by ramped oxidation without removal of PIC from the sample matrix. Only two additional $>51 \mu \mathrm{m}$ pre-filters from GB2-43 at $20 \mathrm{~m}$ and $80 \mathrm{~m}$ were selected for comparison with the $<51 \mu \mathrm{m} \mathrm{POC}$ at the same depth because $>51 \mu \mathrm{m}$ [POC] was high and the $>51 \mu \mathrm{m}[\mathrm{PIC}]$ and the deployment blank [DOC] contributions to total sample carbon were relatively small, $<2 \%$ (Rosengard et al., 2015). Because pre-filters are made of polyester, the particles were sonicated, flushed off the filters and freeze-dried before being loaded into the RPO reactor. Sub-samples of three deployment blank QMA filters from each profile were also analyzed via ramped oxidation.

The presence of particulate inorganic carbon in particles from the Great Calcite Belt region presents a challenge to interpreting organic matter composition via ramped oxidation, especially if the thermal stability of inorganic carbon overlaps with that of organic carbon. One common approach to separating these two carbon components is to remove the inorganic carbon completely through acid fumigation (Section 2.2). However, residual $\mathrm{CaCl}_{2}$ in the fumigated sample matrix decomposes during the run, releasing $\mathrm{Cl}$ that reacts with the catalyst wire plating in the RPO system (Section 2.5), forming precipitates that obstruct the flow of $\mathrm{CO}_{2}$ and carrier gas to the gas analyzer downstream. Thus, acid-treated samples must be rinsed in Milli-Q water to remove $\mathrm{CaCl}_{2}$ before the RPO analysis, potentially altering the composition and mass-balance of the organic carbon pool. A less chemically-disruptive strategy for separating inorganic from organic carbon is to analyze untreated samples in the RPO system, and mathematically subtract the PIC contribution from the raw sample thermogram.

The first approach requires knowledge of whether and how fumigation and rinsing influence the thermal stability of organic carbon, beyond its "intrinsic" thermal stability, by re-arranging organic bonds, affecting the sample matrix, and directly hydrolyzing, dissolving and flushing away components of the organic carbon (Plante et 
al., 2013). The second approach requires precise knowledge of the thermal stability of inorganic carbon, and is ideal in cases of minimal overlap between the thermal stability of organic carbon and that of inorganic carbon in the sample. We applied both approaches to analyze the marine POC from the Great Calcite Belt region via ramped oxidation. In our discussion, we comment on the applicability of both PIC removal strategies.

To assess the fumigation approach, three $<51 \mu \mathrm{m}$ samples of varying PIC concentration (GB2-43 at $25 \mathrm{~m}$, and GB2-100 at $20 \mathrm{~m}$ and $800 \mathrm{~m}$ ) were fumigated for $\sim 14.5$ hours in $12 \mathrm{~N}$ hydrochloric acid vapor, dried for an additional 13 hours at $60^{\circ} \mathrm{C}$, and flushed with $\sim 75 \mathrm{~mL}$ Milli-Q water (Table 1). These filters were then freeze-dried before ramped oxidation analysis. The three sample thermograms were compared to the non-fumigated sample thermograms to evaluate the efficacy of PIC removal relative to the effect of fumigation/rinsing on the thermal stability of organic carbon.

\subsection{End-member preparation for RPO}

To supplement the no-fumigation approach to PIC removal, we prepared several end-member samples with $>93 \%$ PIC and $100 \%$ POC for RPO analysis. These endmembers provide insight into the range and overlap of thermal stabilities between marine $\mathrm{PIC}$ and POC.

Two PIC end-members were selected from an Icelandic spar (abiotic, 100\% terrestrial calcite) and a Pacific Southern Ocean surface $(0-0.5 \mathrm{~cm})$ sediment sample collected by the Joint Global Ocean Flux Study (JGOFS) at $60^{\circ} \mathrm{S}, 170^{\circ} \mathrm{W}$ (Table 2). The JGOFS sediment contains roughly $62.4 \% \mathrm{BSi}, 31 \%$ calcium carbonate, $0.24 \% \mathrm{POC}$, and $6.2 \%$ lithogenic material by weight, according to prior analyses of average surface sediment composition $(0-5 \mathrm{~cm})$ of this core (Sayles et al., 2001). This value was reaffirmed coulometrically following heated acid hydrolysis of the sediment using a UIC CM140 Total Inorganic Carbon Analyzer at University of California- Santa Cruz, which yielded a $32 \%$ by weight carbonate content in the sediment, equating to a $94 \%: 6 \%$ PIC:POC ratio. The $\delta^{13} \mathrm{C}_{\text {PIC }}$ in the JGOFS sediment was also analyzed following acid hydrolysis in $1.9 \mathrm{M}$ phosphoric acid (Section 2.2). The Icelandic spar was homogenized 
and ground before analysis, while the JGOFS sediment, which had been archived at $80^{\circ} \mathrm{C}$, was freeze-dried, homogenized and ground before analysis. Two different quantities of each end-member were analyzed by ramped oxidation to test the sensitivity of PIC thermal stability to the quantity of PIC in the RPO reactor.

Biomass filtered from axenic cultures of Emiliani huxleyi served as the POC endmember. $417 \mathrm{~mL}$ of $\mathrm{f} / 50$ filtered seawater media were autoclaved and then inoculated with two strains of E. huxleyi: a non-calcifying strain (CCMP373) and a calcifying strain (DHB624) (Guillard, 1975; Harvey et al., 2015). Cultures were grown in triplicate for 6 days alongside non-inoculated $\mathrm{f} / 50$ media as a blank batch at $18^{\circ} \mathrm{C}$ on a 12 hour alternating light/dark cycle in a Percival Intellus Control System. Cells were counted immediately after inoculation, and at three additional time points over six days (Appendix B, Fig. S2), using a Guava easyCtye HT flow cytometer. On the sixth day, when the cell numbers reached a plateau (i.e., negligible growth rate), the cultures were

filtered onto pre-combusted $4.7 \mathrm{~cm}$ diameter QMA filters with an active area of $\sim 9.6 \mathrm{~cm}^{2}$. Three volumes, $120 \mathrm{~mL}$ each, were filtered onto three filters from each replicate of each strain. The filters were freeze-dried before analysis. To verify the assumption that CCMP373 did not calcify, a subsample of a filter from one of the replicates was hydrolyzed in $\sim 1.9 \mathrm{M}$ phosphoric acid in a sealed glass vessel (Section 2.2). A negligible quantity of $\mathrm{CO}_{2}$ gas was recovered and quantified after $\sim 16$ hours of hydrolysis.

\subsection{Ramped oxidation}

The thermal stability distribution of carbon in each end-member, particle sample (both fumigated and untreated), and sorption blank, was analyzed using the RPO system at the National Ocean Sciences Accelerator Mass Spectrometry (NOSAMS) facility at Woods Hole Oceanographic Institution, following Rosenheim et al. (2008) and Hemingway et al. (accepted). For each analysis, sub-samples were loaded into a prebaked $\left(850^{\circ} \mathrm{C}, 6\right.$ hours $)$ quartz reactor within a sample furnace programmed to heat from $100^{\circ} \mathrm{C}$ to $1000^{\circ} \mathrm{C}$ at $5^{\circ} \mathrm{C} /$ minute (Chapter 1 , Fig. 1 ). $35 \pm 3 \mathrm{~mL} /$ minute of mixed ultrahigh purity helium and oxygen gas $\left(7 \pm 3 \% \mathrm{O}_{2}\right)$ flowed through the reactor, from the head of the sample furnace, picking up oxidation products generated throughout the 
temperature ramp, to the constant $800^{\circ} \mathrm{C}$ combustion furnace, and then downstream to an infrared gas analyzer and vacuum line. In the constant $800^{\circ} \mathrm{C}$ combustion oven, which was equipped with copper/platinum/nickel catalyst wire, incomplete oxidation products were oxidized to $\mathrm{CO}_{2}$ gas. The $\mathrm{CO}_{2}$ concentration (ppm) in the gas exiting the combustion furnace was measured using a Sable Systems $\mathbb{C} C A-10$ infrared gas analyzer, calibrated at 0 ppm and $>400$ ppm $\mathrm{CO}_{2}$, yielding thermograms plotting $\mathrm{CO}_{2}$ concentration throughout the entire temperature ramp. All RPO analyses in this report were conducted using one of two sample furnaces with similar temperature ramp conditions, which limited instrument-related variation across thermograms (e.g., Appendix B, Fig. S3). The use of two different sample furnaces rather than one, however, was unavoidable and may have introduced some variability in thermograms along the temperature axis.

Downstream of the gas analyzer, the gas mixture flowed into a pyrex coil submerged in liquid nitrogen $\left(\mathrm{N}_{2}\right)$, which cryogenically trapped $\mathrm{CO}_{2}$ while allowing the $\mathrm{He}$ and other residual gases to vent. At distinct temperatures, the $\mathrm{CO}_{2}$ trapped within a user-specified temperature interval was released into a vacuum line for manometric quantification using a pressure transducer (baratron) and cryogenic recollection into a pre-baked, evacuated pyrex tube with $\sim 50 \mathrm{mg}$ of copper oxide and $\sim 10 \mathrm{mg}$ of granulated silver. These tubes were flame-sealed, and baked at $525^{\circ} \mathrm{C}$ for 1 hour to fully oxidize any incompletely oxidized carbon compounds and scavenge any sulfur- and halogencontaining compounds before re-quantification and stable carbon isotope analysis. Requantification of sample fraction mass after the $525^{\circ} \mathrm{C}$ bake is essential to accurately assess carbon mass balance during the RPO runs because the mass quantified pre-bake includes the non-carbon gas impurities.

\subsection{Isotope corrections}

The sums of post-bake gas quantities from the untreated $<51 \mu \mathrm{m}$ POC, $>51 \mu \mathrm{m}$ POC and deployment blank runs, once normalized to the total filter area, were interpreted as total sample carbon and used to calculate POC content within each filter (Equation 2). In the few cases where the Pyrex tubes were not baked prior to quantification, an average 
offset between the carbon quantities calculated before and quantities calculated after the $525^{\circ} \mathrm{C}$ bake was applied to correct the pre-bake quantities before summing all gas fractions. On average, post-bake quantities were $5 \%$ lower than the pre-bake $\mathrm{CO}_{2}$ quantities, but ranged from $39 \%$ lower to $9 \%$ higher than pre-bake $\mathrm{CO}_{2}$ quantities. We attribute the relatively lower quantities to excess water and volatile halogen-derived compounds that get cryogenically trapped with $\mathrm{CO}_{2}$ in the vacuum line coupled to the RPO system, but then stripped away during the additional bake, cryogenic purification and re-quantification step. The relatively elevated quantities could result from products of incomplete oxidation, which still get trapped in the vacuum line, but are not fully oxidized and accurately quantified until after the additional bake step.

Filter area-normalized quantities of PIC in each sample (Section 2.2) and blank carbon, $\mathrm{C}_{\text {blank, }}$, were subtracted from the total carbon quantified from RPO analyses of each sample, $\mathrm{C}_{\text {bulk }}$, as follows:

$$
\mathrm{POC}=\mathrm{C}_{\mathrm{Bulk}}-\mathrm{C}_{\mathrm{blank}}-\mathrm{PIC}
$$

Concentrations of these individual components were subsequently calculated by normalizing the QMA filter quantities to the volume of water filtered. Compared to the other measured sample [POC] values (Section 2.2), [POC] values calculated from Equation 2 are on average $2 \%$ greater than concentrations measured by closed tube combustion or elemental analysis on the Costech Instruments Elemental Combustion System, and 12\% lower than concentrations measured via elemental analysis on the Flash 1112 Elemental Analyzer (Table 3). The deviations are larger among the deployment blank values, which have relatively low organic carbon loadings, and deeper mesopelagic particles (300-1000 m), where the blank and PIC proportions are high (Table 1). Heterogeneity in the particle load across the QMA filters (Bishop et al., 2012) could also account for such discrepancies. When we discuss POC/filter or concentration quantities in the following sections, we report RPO-based quantities to remain consistent with subsequent calculations that aid in the data interpretation in Section 4. We consider the standard deviations among the two or three POC/QMA values measured for each sample an error for the reported RPO-based quantity that accounts for both instrumental differences and particle heterogeneity upon the filters. 
Similarly, the $\delta^{13} \mathrm{C}$ value of sample POC was calculated by subtracting the PIC and blank contributions to the $\delta^{13} \mathrm{C}_{\text {bulk }}$ values measured via IRMS (Prism II) (Section 2.2), using the relative proportions of PIC, POC and sorption blank carbon:

$$
\delta^{13} C_{\text {POC }}=\left(\delta^{13} C_{\text {Bulk }}-\delta^{13} C_{\text {PIC }} f_{\text {PIC }}-\delta^{13} C_{\text {blank }} f_{C, \text { blank }}\right) \times\left(\frac{1}{f_{\text {POC }}}\right)
$$

In Equation 3, $f_{P I C}, f_{\text {blank }}$ and $f_{P O C}$ are the fractions of the total carbon that are PIC (e.g., PIC/Total C), blank organic carbon and POC, respectively. To maintain methodological consistency, the RPO-based $[\mathrm{OC}]_{b l a n k}$ and $[\mathrm{POC}]$ quantities were also used to calculate $f_{O C, \text { blank }}$ and $f_{P O C}$ Equation 3, respectively. Further, PIC measured separately in the blank filters was subtracted from the total blank carbon measurements to yield $\delta^{13} \mathrm{C}_{\mathrm{OC} \text {,blank }}$ and $f_{O C, \text { blank } \text {. }}$

Further, the bulk $\delta^{13} \mathrm{C}$ measurements measured by IRMS, $\delta^{13} \mathrm{C}_{\text {bulk, }}$, were compared to the weighted sums of $\delta^{13} \mathrm{C}$ values across thermogram gas fractions from each untreated $<51 \mu \mathrm{m}$ and deployment blank run, as well as from one of each PIC end-member run (Table 3). In some sample analyses, where one $\mathrm{CO}_{2}$ fraction was lost during transfer in the vacuum line or during isotope analysis, the isotope value of the missing gas fraction was calculated by mass balance using bulk $\delta^{13} \mathrm{C}_{\text {bulk }}$ and mass-weighted sum values, $\delta^{13} \mathrm{C}_{\text {sum }}$ :

$\delta^{13} \mathrm{C}_{\text {missing }}=\left(\left[\delta^{13} \mathrm{C}_{\text {Bulk }} \times \operatorname{avg}\left(\frac{\delta^{13} \mathrm{C}_{\text {sum }}}{\delta^{13} \mathrm{C}_{\text {bulk }}}\right)\right]-\sum_{1}^{\mathrm{i}} \mathrm{f}_{\mathrm{i}} \delta^{13} \mathrm{C}_{\mathrm{i}}\right) \times\left(\frac{1}{\mathrm{f}_{\text {missing }}}\right)$

Here, $i$ is the $\mathrm{CO}_{2}$ gas fraction, $f_{i}$ and $f_{\text {missing }}$ are the relative mass proportions of $\mathrm{CO}_{2}$ in each measured and lost fraction, respectively. The second term in the first bracket represents the average of all $\delta^{13} \mathrm{C}_{\text {bulk }}$ and $\delta^{13} \mathrm{C}_{\text {sum }}$ values for sample thermograms for which no fractions were lost.

\subsection{Error propagation}


Errors associated with carbon quantities and $\delta^{13} \mathrm{C}$ values of different components of sample carbon derive from various instrumental errors, heterogeneity of particle loads onto QMA filters, and blank or PIC corrections. In the results, the uncertainty in the blank subtraction stems from the standard deviation of blank carbon quantities measured by RPO and two elemental analyzers (Section 2.6). The uncertainty in the PIC correction derives from the standard deviation of the different deployment blank PIC quantities. The error of all directly measured $\delta^{13} \mathrm{C}$ values is equal to the precision of the IRMS, $0.1 \%$ ofor the Prism II. The carbon quantities in thermogram fractions have a relative error of $\sim 1 \%$, which is minimal compared to the standard deviation of carbon quantities calculated across the replicate POC measurements for each sample. These different errors are propagated for any calculated concentrations or $\delta^{13} \mathrm{C}$ values reported in the results and discussion.

\section{$3 \quad$ Results}

\subsection{Bulk composition in marine samples}

Blank-corrected PIC, POC and BSi concentrations measured in $<51 \mu \mathrm{m}$ particle samples were measured in three profiles from the Great Calcite Belt region, GB1-117, GB2-43 and GB2-100 (Table 1). Acid hydrolysis-based [PIC] values range from $0.01 \mu \mathrm{M}$ at $110 \mathrm{~m}$ at station GB2-100 to $0.18 \mu \mathrm{M}$ in the shallowest sample at GB1-117. BSi concentrations at or near the export depth $\mathrm{Z}_{\mathrm{PAR}}$ of each station range from $0.0074 \mu \mathrm{M}$ at GB2-100 to $0.17 \mu \mathrm{M}$ at GB2-43. POC concentrations, calculated from the RPO runs (Equation 2; Section 2.6), range from $0.11 \mu \mathrm{M}$ in the deepest mesopelagic zone sample at GB2-100 to $5.1 \mu \mathrm{M}$ in the shallowest euphotic zone sample at GB1-117. The Flash 1112 EA-based [POC] values, measured at more mesopelagic zone depths than the other [POC] quantification methods, were fit to a power law (Section 2.2, Equation 1) which yielded attenuation coefficients from 0.8 at GB2-43 and 1.1 at GB1-117.

$[\mathrm{PIC}] /[\mathrm{BSi}]$ ratios at or near $\mathrm{Z}_{\mathrm{PAR}}$ are highest at GB1-117 (8.2) and lowest at GB2$43(0.1-0.2)$, in agreement with the relative $[\mathrm{PIC}] /[\mathrm{BSi}]$ ratios observed in the $>51 \mu \mathrm{m}$ size-fraction particles collected at these three stations (Table 1; Rosengard et al., 2015). 
Following Rosengard et al. (2015), we use [PIC]/[BSi] ratios in both size-fractions as an estimate of the relative coccolithophore and diatom abundances at stations GB1-117, GB2-43, and GB2-100.

At all stations, [POC] and [total C] from the untreated, uncorrected ramped oxidation analyses decrease with depth while the proportion of blank carbon and PIC in the total carbon pool increases with depth (Table 1). The quantities of dissolved organic carbon sorbed onto the deployment blank filters, range from $35 \mu \mathrm{mol}$ to $57 \mu \mathrm{mol}$ per filter (Table 1). At station GB1-117, the most PIC-rich station, PIC comprises 3-9\% and blank POC comprises 3-28\% of the total carbon. At station GB2-43, the most BSi-rich and PIC-poor station, PIC comprises 1-4\% of the total carbon, while blank POC comprises $9-47 \%$ of the total organic carbon. At station GB2-100, which is also PIC-rich, PIC contributes to $2-14 \%$ of the total sample carbon, and blank carbon comprises $4-33 \%$ of the total organic carbon.

$\delta^{13} \mathrm{C}_{\mathrm{POC}}$ values, calculated by Equation 3, are overall most ${ }^{13} \mathrm{C}$-enriched at $\mathrm{GB} 1-$ 117 and most depleted at GB2-43 (Table 1, Fig. 2a-c). They are relatively constant with depth at GB1-117 and GB2-100, but increase from -26.9\%o in the euphotic zone to $24.1 \%$ in the mesopelagic zone at GB2-43. At all stations, the $\delta^{13} \mathrm{C}$ values of the deployment blanks are $\geq 5 \%$ lighter than $\delta^{13} \mathrm{C}_{\mathrm{POC}}$ measured in the profile samples.

Blank-corrected $\delta{ }^{13} \mathrm{C}_{\mathrm{PIC}}$ values in each sample are very ${ }^{13} \mathrm{C}$-enriched, varying little between -2 and $1.5 \%$ across stations and depths (Table 1, Fig. $2 \mathrm{~d}-\mathrm{f}$ ). The $\delta^{13} \mathrm{C}_{\mathrm{PIC}}$ averaged across the three deployment blanks is more enriched than the samples $(2.9 \%)$. The range in sample $\delta^{13} \mathrm{C}_{\text {PIC }}$ is comparable to the variation observed in Southern Ocean DIC (Trull and Armand, 2001), in PIC from marine calcifiers (Keigwin et al., 2005), and in the PIC present in core-top sediments from the Pacific sector of the Southern Ocean (Section 3.2).

The following sections expand upon these bulk observations with thermograms generated by oxidizing several sets of samples from $100^{\circ} \mathrm{C}$ to $800^{\circ} \mathrm{C}$ : (1) three fumigated samples of $<51 \mu \mathrm{m}$ POC from the Southern Ocean Great Calcite Belt; (2) $95-100 \%$ pure inorganic carbon, terrestrial and marine; (3) pure organic carbon from axenic coccolithophore cultures; and (4) fifteen untreated samples of $<51 \mu \mathrm{m}$ POC from the Great Calcite Belt. We describe three aspects of thermogram shape across distinct 
temperature intervals: (1) the fraction of total $\mathrm{CO}_{2}$ released, (2) the isotopic composition of $\mathrm{CO}_{2}$ gas released, and (3) $\mathrm{T}_{\max }$ within these intervals, or the temperatures of peak maxima.

\subsection{Acid fuming results}

With significant PIC content in the Great Calcite Belt particles, we explored two methods of correcting for the PIC contribution to total sample carbon in thermograms (Section 2.3). The first method removes PIC prior to ramped oxidation via acid fuming, while the second accounts for PIC by subtracting it from a thermogram of an untreated sample.

To test the first method, we compared three acid-fumigated (and rinsed) and untreated thermograms of three $<51 \mu \mathrm{m}$ POC samples: one $85 \mathrm{~m}$ depth sample from station GB2-43, one $90 \mathrm{~m}$ sample from station GB2-100, and one $800 \mathrm{~m}$ sample from GB2-100. Comparing thermograms of acidified and untreated $800 \mathrm{~m}$ particles, where PIC comprised $14 \%$ of the total carbon before acid treatment (Table 1), provided an assessment of the combined effects of fumigation on POC thermal stability and PIC removal in the sample (Fig. 3a). By contrast, comparisons of fumigated and untreated sample thermograms from surface depths, where PIC represents $<5 \%$ of the total carbon, provided a control for evaluating how fumigation and rinsing influence the thermal stability of particulate carbon dominated by POC alone (Figs. 3b,c).

The data show that the fumigation and rinsing affect PIC-rich sample thermograms just as much as they affect thermograms of PIC-poor samples (Fig. 3). But, the treatment affects the two surface samples differently than it affects the $800 \mathrm{~m}$ sample in terms of mass balance and loss. For all samples, the quantity of carbon released from ramped oxidation after fumigation and rinsing decreased by $22-34 \%$ in the surface samples and $26 \%$ in the deep sample. This difference in carbon yield exceeds the expected heterogeneity in POC loading on QMA filters (Bishop et al., 2012), and is likely a result of carbon lost by fumigation and rinsing. Considering that no more than $10 \%$ of the carbon in the surface samples is PIC and sorption blank contribution, the additional carbon lost must be POC mobilized and/or solubilized by the fumigation and rinsing 
process (Table 1, Figs. 3a-b). These results do not preclude the possibility that the acid treatment and rinsing further shifted the thermal stability of organic carbon in the samples, which also could drive changes in thermogram shape observed in these panels.

By contrast, the carbon lost after treatment and rinsing of the $800 \mathrm{~m}$ sample exceeds the PIC content in the sample (14\% of total carbon) but not the combined PIC and blank organic carbon content (47\% of total carbon) (Table 1, Fig. 3c). Thus, assuming that all the PIC was hydrolyzed, either some but not all of the blank carbon, or a small combination of both POC and blank carbon was removed in the treatment process. Again, it is still possible that fumigation and rinsing could have further shifted the thermal stability of POC in the thermogram.

From these comparisons and our inability to tease apart the effects of fumigation and rinsing on (1) carbon mass balance (POC, blank organic carbon and PIC) and (2) the thermal stability of POC in samples with different PIC:POC, we conclude that such treatments introduce significant methodological artifacts to the thermal stability of POC in a sample. Thus, the remaining discussion focuses on thermograms generated only from untreated samples.

\subsection{End-members}

Having ruled out acid fumigation, we must consider the approach of subtracting the PIC component from a specified temperature range from each Great Calcite Belt sample thermogram. To improve expectations of these different oxidation temperature ranges for marine POC and PIC, thermograms of PIC and POC end-member samples were generated to assess the overlap between PIC and POC thermal stability. The pure end-member samples analyzed here are a terrestrial $\mathrm{CaCO}_{3}$ (calcite), marine biogenic $\mathrm{CaCO}_{3}$, and fresh marine organic carbon (i.e., pure phytoplankton biomass) (Table 2).

The first PIC end-member is an Icelandic spar, pure terrestrial calcite. Two masses of homogenized grains from this sample, equivalent to $\sim 450 \mu \mathrm{g}$ and $\sim 250 \mu \mathrm{g}$ total inorganic carbon, were analyzed through ramped oxidation to assess whether there is an amount effect on its thermal stability. Both thermograms from these analyses display one peak, skewed towards lower temperatures (Fig. 4a). The $\mathrm{T}_{\max }$ is constant across both 
thermograms, suggesting that the thermal stability of the PIC does not depend on the mass of inorganic carbon in the reactor. $\delta^{13} \mathrm{C}$ values in this peak, measured in $\mathrm{CO}_{2}$ gas fractions of the $450 \mu \mathrm{g}$ analysis, are ${ }^{13} \mathrm{C}$-enriched and relatively invariant, varying between 1 and 3\%o (Fig. 4b), indicating small kinetic isotope fractionation of carbon oxidized during the temperature ramp (Hemingway et al., accepted). The weighted sum of these isotope measurements is nearly identical to the separately measured bulk value of $3.0 \%$ (Table 3 ).

The second PIC end-member came from a Southern Ocean core top sediment at $\sim 5 \mathrm{~km}$ water depth $\left(60^{\circ} \mathrm{S}, 170^{\circ} \mathrm{W}\right)$, collected during the U.S. JGOFS sampling campaign (Sayles et al., 2001). $\sim 94 \%$ of the total carbon in this sediment is PIC, according to Sayles et al. (2001) and independent coulometry measurements of inorganic carbon content in the lab. Two quantities, equivalent to $\sim 950 \mu \mathrm{g}$ and $\sim 250 \mu \mathrm{g}$ total carbon, were analyzed by ramped oxidation. Both thermograms exhibit one major negatively skewed peak (Fig. 4c), the $\mathrm{T}_{\max }$ of which shifts from $651^{\circ} \mathrm{C}$ in the $950 \mu \mathrm{g} \mathrm{C}$ analysis to $630^{\circ} \mathrm{C}$ in the $250 \mu \mathrm{g} \mathrm{C}$ thermogram. This shift suggests that the thermal stability and thus the kinetics of PIC decomposition in the JGOFS sediment depends on the carbon quantity available for oxidation and follow a higher than first order kinetic rate.

Compared to the Icelandic spar, the PIC present in this marine sediment oxidizes over a broader distribution of temperatures. Stable carbon isotope measurements in the higher quantity analysis of the JGOFS sediment show that the $\mathrm{CO}_{2}$ evolving between $436^{\circ} \mathrm{C}$ and $721^{\circ} \mathrm{C}$ is similar to the hydrolysis-based $\delta^{13} \mathrm{C}$ of the PIC in this sample $(0.7 \%$ ) and thus originates from the PIC component in the sample (Fig. $4 \mathrm{~d}$, Table 2). $\mathrm{CO}_{2}$ in the first fraction, only $4 \%$ of the total carbon evolved during ramped oxidation, is comparatively ${ }^{13} \mathrm{C}$-depleted (-20.4\%o) and likely derives entirely from organic carbon in the sample. Between $364^{\circ} \mathrm{C}$ and $436^{\circ} \mathrm{C}$, the $\mathrm{CO}_{2}$ likely derives from a mixture of PIC and organic carbon, yielding an intermediate $\delta^{13} \mathrm{C}$ value of $-10 \%$. The weighted sum bulk $\delta^{13} \mathrm{C}$ value from the JGOFS thermogram fractions (-1.1\%) is statistically identical to the independently measured JGOFS $\delta^{13} \mathrm{C}$ value (-0.9\%o) (Table 3).

Figure 5 shows four thermograms of E. huxleyi culture biomass, each generated by oxidizing a filter sub-sample from one culture replicate of either the DHB624 or CCMP373 cultures. In general, the culture POC oxidizes from 150 to $600^{\circ} \mathrm{C}$, spanning a 
wider range of thermal stabilities than the range of thermal stabilities of Icelandic spar and JGOFS sediment-derived PIC. Smaller-scale variations in thermogram shape across sample runs indicate that differences in the distribution of thermal stabilities in biomass from replicates of the same strain (i.e., CCMP373) are comparable to the differences observed across strains (i.e., CCMP373 vs. DHB624). The hydrolysis-derived PIC concentration measurement in one of the strain CCMP373 filters shows that less than $0.5 \%$ of the total carbon on the filters is PIC (Table 2; Section 2.4), affirming that the variations across each replicate thermogram reflect differences in POC composition rather than mixing of POC and PIC. Further, strain DHB624 E. huxleyi, which can create calcite liths, did not appear to calcify in culture prior to filtration, which is supported by similar light $\delta^{13} \mathrm{C}$ values of $\mathrm{CO}_{2}$ fractions across thermograms of both strains (-27.7\% to $-18.5 \%$ ). The $\delta^{13} \mathrm{C}_{\text {of }} \mathrm{CO}_{2}$ fractions from the strain CCMP373 replicate thermograms were not significantly different from isotope values measured within fractions from the one strain DHB624 thermogram ( $\mathrm{p}>0.05$, Student's t-test).

Sub-samples from the same E. huxleyi strain and culture replicate were not analyzed more than once due to sample limitations. However, RPO analyses of two different masses of the same POC-rich Great Calcite Belt sample (Appendix B, Fig. S3) suggest that the reaction kinetics of organic carbon is mass-independent. Most importantly, Fig. 5 demonstrates that while all of the organic carbon from the culture biomass is less thermally stable than the inorganic carbon from the Iceland spar (i.e., no temperature overlap in the thermograms), there is significant overlap between the temperature range for thermal decomposition of PIC from the JGOFS sediment (Fig. $4 \mathrm{c}, \mathrm{d})$ and for oxidation of POC in the culture biomass. In Section 4.2, we discuss the impact of this overlap on interpreting thermograms of samples that comprise a mixture of marine biogenic POC and PIC.

\subsection{Blank-corrected thermograms}

Fifteen thermograms from three stations and five depths per station were generated by analyzing untreated sub-samples of QMA filter particles through ramped oxidation (Fig. 6). In addition, two sub-samples of $>51 \mu \mathrm{m}$ POC collected at $20 \mathrm{~m}$ and 85 
$m$ from station GB2-43, and three sub-samples of the deployment blank QMA filter from each station profile were similarly analyzed (Fig. 7). In all twenty thermograms, most of the total sample carbon - a mixture of POC and PIC - oxidizes from $200^{\circ} \mathrm{C}$ to $600^{\circ} \mathrm{C}$, similar to the oxidation temperature range observed in the E. huxleyi culture thermograms (Fig. 5). At least two prominent peaks are present in thermograms of all samples.

The blank thermograms were directly subtracted from the $<51 \mu \mathrm{m}$ POC thermograms to yield thermograms of total suspended particulate carbon (i.e., sample PIC and POC). The $>51 \mu \mathrm{m}$ POC thermograms were not blank-corrected because the DOC sorption at the two chosen depths of GB2-43 contribute at most $1 \%$ to the total sample carbon (Rosengard et al., 2015).

\section{5 $\quad \delta^{13} \mathrm{C}$ distribution across thermograms}

On average, the weighted sums of all $\delta^{13} \mathrm{C}$ values measured from a thermogram were $\sim 1.2 \%$ lighter than the independently measured bulk isotopic composition (Table 3). This offset is similar in magnitude to other weighted sum vs. bulk comparisons compiled in Hemingway et al. (accepted), but greater than the offset between the $\delta^{13} \mathrm{C}$ sums from the PIC end-member thermograms and their bulk $\delta^{13} \mathrm{C}$ values.

$\delta^{13} \mathrm{C}$ values measured in $\mathrm{CO}_{2}$ trapped throughout the ramped oxidation of the untreated $<51 \mu \mathrm{m}$ POC samples range from $-33.1 \%$ to $-17.4 \%$ o (Fig. 8). The presence of ${ }^{13} \mathrm{C}$-enriched PIC (Table 1) and ${ }^{13} \mathrm{C}$-depleted sorbed organic carbon, which ranged from 35.5 to $-26.9 \%$ across the deployment blank thermogram fractions (Fig. 7), contributes to this wide range, especially for the deeper samples, where $\mathrm{f}_{\mathrm{OC} \text {,blank }}$ and $\mathrm{f}_{\mathrm{PIC}}$ are high (Table 1). But, the average $\delta^{13} \mathrm{C}$ range of $\mathrm{CO}_{2}$ fractions from the surface samples, where the combined PIC and blank contributions represent $<10 \%$ of the total sample carbon, is comparable to the $\delta^{13} \mathrm{C}$ range across fractions from the E. huxleyi thermograms (Fig. 5), and must result from biomolecular differences in the $\mathrm{CO}_{2}$ evolved through temperature. Isotopes measured across $\mathrm{CO}_{2}$ fractions from one of the $>51 \mu \mathrm{m}$ POC thermograms (GB2-43, $85 \mathrm{~m}$ ) are much lighter than the isotopes in the corresponding $<51 \mu \mathrm{m}$ particles, ranging from $-35.7 \%$ o to $-30 \%$. 


\section{Discussion}

In the following section, we use two metrics to compare RPO data: thermal stability and isotope composition. We considered comparisons across two spatial dimensions: (1) a vertical dimension that provides a gradient of degradation state within each profile, and a (2) geographic dimension that provides a gradient in POC export efficiency and phytoplankton community composition.

Thermal stability can be inferred from thermogram shape and the distribution of temperatures across which distinct carbon pools oxidize to $\mathrm{CO}_{2}$. We assume that the spectrum of biomolecules in complex organic mixtures such as marine particles span a range of activation energies of decomposition, causing different biomolecules and subgroups within the larger, more structurally complex biomolecules to oxidize to $\mathrm{CO}_{2}$ throughout the continuous temperature ramp imposed by RPO analysis (Burnham and Braun, 1999; Cramer, 2004; Rosenheim et al., 2008; Hemingway, 2017 thesis). Thus, $\mathrm{CO}_{2}$ that evolves at higher temperatures originates from more thermally stable biomolecules that require more energy to decompose. Conversely, $\mathrm{CO}_{2}$ that evolves at a lower temperature originates from less thermally stable biomolecules with weaker bonds, i.e., lower activation energies. We evaluate the strength of thermal stability and activation energy as a proxy for diagenetic stability, and probe the geochemical information gleaned from coupling thermal stability to stable carbon isotope measurements.

Because the following RPO analyses are limited to $<51 \mu \mathrm{m}$ particles from the Great Calcite Belt region, commonly thought to represent the composition of suspended POC rather than that of sinking POC (e.g., Rosengard et al., 2015). In the euphotic zone, marine particles primarily comprise relatively fresh cells that are still living or were recently alive. By comparison, POC in the mesopelagic zone represents more degraded material, with further differences expected between the $<51 \mu \mathrm{m}$ and $>51 \mu \mathrm{m}$ size fractions because they reside in the mesopelagic zone over significantly different time scales (Sheridan et al. 2002). Assuming that $>51 \mu \mathrm{m}$ particles sink 20-200 meters/day (McDonnell and Buesseler, 2010), a $>51 \mu \mathrm{m}$ particle in the mesopelagic zone is days to weeks old on average. In contrast, the $<51 \mu \mathrm{m}$ size-fraction is composed of very slowly sinking or suspended small particles that originate from disaggregating large, fast-sinking 
particles that can also be subject to re-aggregation (Riley et al., 2012; Lam and Marchal, 2015). Studies using long-lived thorium isotopes and organic biomarkers have shown that aggregation of small to large particles and disaggregation of large to small particles occur throughout the water column (Murnane et al., 1994), but that the level of particle exchange can vary by ecosystem type and season (Abramson et al., 2010).

The mesopelagic $<51 \mu \mathrm{m}$ size fraction thus integrates POC pools that experience longer and more widely ranging residence times, from a few months to a few years, controlled by the rate of respiration, sinking and mass transfer with larger size-fraction particles (Marchal and Lam, 2012; Lam and Marchal, 2015). Because remineralization in the mesopelagic zone is predominantly driven by bacteria, the cumulative conversion of POC exported from the euphotic zone to heterotrophic biomass may further drive differences between $<51 \mu \mathrm{m}$ and $>51 \mu \mathrm{m}$ POC composition (Griffith et al., 2012; Cavagna et al., 2013). The choice to focus analyses on the longer residence time size fraction provides a strong gradient in degradation for evaluating the compositional changes in marine POC through the upper $1000 \mathrm{~m}$ of the water column. For the purposes of this report, differences between euphotic zone and mesopelagic zone $<51 \mu \mathrm{m}$ POC presumably reflect differences in organic matter source and degradation state of organic matter.

\subsection{Latitudinal isotopic depletion in Southern Ocean POC}

Overall, the calculated $\delta^{13} \mathrm{C}_{\mathrm{POC}}$ values from station profiles GB1-117, GB2-43 and GB2-100 fall within the range of values observed in other water column particles from the Southern Ocean (Trull and Armand, 2001; Cavagna et al., 2013). The isotopic depletion across the three stations follows the latitudinal gradient observed in other Southern Ocean studies, agreeing well with the relationship between the $\mathrm{CO}_{2}$ supply and kinetic fractionation associated with photosynthesis. In the Southern Ocean, as euphotic zone waters grow colder and more $\mathrm{CO}_{2(\mathrm{aq})}$-replete with latitude, carbon fixation by phytoplankton discriminates more in favor of ${ }^{12} \mathrm{C}$ (Goericke et al., 1994; Popp et al., 1999). In the Great Calcite Belt samples, we see euphotic zone water temperatures 
decrease from $\sim 15-20^{\circ} \mathrm{C}$ to $\sim 6^{\circ} \mathrm{C}$ (Table 1) from GB1-117 to GB2-43 while surface $\delta^{13} \mathrm{C}_{\mathrm{POC}}$ values decrease from $\sim-20 \%$ to $\sim-25 \%$.

The small magnitude of variation in $\delta^{13} \mathrm{C}$ values of $<51 \mu \mathrm{m}$ POC with depth in these samples is also consistent with other profiles (Cavagna et al., 2013), and supports the notion of non-selective remineralization in POC with depth. However, as the following sections elaborate, the thermogram profiles reveal greater variations in POC composition with depth that are not resolved by these bulk $\delta^{13} \mathrm{C}_{\mathrm{POC}}$ profiles.

\subsection{Sample matrix effects on thermal stability}

A major challenge to interpreting the Great Calcite Belt thermograms (Fig. 6) is the presence of PIC in the particles, especially in those from the mesopelagic zone. Considering that the inorganic carbon in both terrestrial and marine calcite thermally decompose at temperatures above $600^{\circ} \mathrm{C}$ (Fig. 4), it is surprising that little to no $\mathrm{CO}_{2}$ evolves in any of the Great Calcite Belt sample thermograms above $600^{\circ} \mathrm{C}$. We hypothesize that matrix effects in these marine particle samples have lowered the activation energy required to decompose PIC, causing this component to decompose at lower temperatures than expected from Fig. 4. Prior studies have demonstrated matrix effects on sample thermal stability during ramped pyrolysis by showing that thermograms of simple organic compound mixtures deviated from thermograms produced by pyrolyzing the pure compounds separately (Williams et al., 2014). To test the hypothesis that matrix effects also shift PIC thermal stability, five artificial sample matrices were prepared by mixing sub-samples of $E$. huxleyi culture replicates with one of the two PIC end-members at various proportions (Table 2), and analyzed by ramped oxidation. Temperature ramp conditions and the programmable sample oven were kept constant across analyses (Rosenheim et al., 2008; Hemingway et al., accepted). Only strain CCMP373 filters were used in matrix mixtures because they had negligible PIC concentrations and served as an organic end-member (Section 2.4).

Matrix mixtures I and II were composed of roughly equal proportions of POC from the culture sub-samples and terrestrial or marine PIC. Matrices III, IV and V consisted of much higher proportions of organic carbon relative to inorganic carbon. 
Matrices IV and V had essentially the same proportions of culture-derived POC and JGOFS sediment-derived PIC. However, matrix V contained about two times the amount of total carbon than did matrix IV, which enabled us to test for possible effects of massdependent oxidation kinetics on thermogram shape. The PIC quantities were approximated using the known weight \% PIC quantity in the Icelandic spar and JGOFS sediment samples (Section 2.4). The E. huxleyi quantities were approximated using the total carbon recovered per unit filter area from individual RPO runs of each culture triplicate (Section 3.3, Fig. 5). Using these C yields, $\sim 24-82 \%$ filter active area $(\sim 9.6$ $\mathrm{cm}^{2}$ ) was sub-sampled for each matrix mixture. These matrix proportions prepared before RPO analysis were estimates because either small masses of PIC from very PIC-rich samples are difficult to weigh, or the carbon loading on the E. huxleyi culture filters was uneven and therefore the carbon content was difficult to estimate based on filter area. During ramped oxidation, five fractions of $\mathrm{CO}_{2}$ gas were trapped at select temperature intervals and analyzed for $\delta^{13} \mathrm{C}$ composition. The actual proportions of the two endmembers in each mixture, $f_{\text {E.hux,Total }}$ and $f_{\text {Calcite,Total }}$, were determined after ramped oxidation by isotope mass balance among the mass-weighted sums of $\delta^{13} \mathrm{C}$ measured across the matrix thermograms (Fig. 9) and the mass-weighted sums of $\delta^{13} \mathrm{C}$ measured across pure end-member thermograms (Table 3):

$$
\delta^{13} \mathrm{C}_{\text {matrix,Sum }}=\delta^{13} \mathrm{C}_{\text {E.hux.,Sum }} \mathrm{f}_{\text {E.hux.,Total }}+\delta^{13} \mathrm{C}_{\text {Calcite ,Sum }} \mathrm{f}_{\text {Calcite ,Total }}(6)
$$

The values of $f_{E . h u x, \text { Total }}$ and $f_{\text {Calcite, Total }}$ are reported in Table 2. For matrix mixtures II, IV and $\mathrm{V}$, we assume that the organic component from the JGOFS sample contributes negligibly to the isotope mass balance in Equation 6, as it comprises only $6 \%$ of the total carbon in the sediment (Sayles et al., 2001).

To assess the presence of a matrix effect, we compared the expected thermograms that would result from the null hypothesis, a simple linear combination of the endmember thermograms, against measured thermograms from each of the five mixtures (Fig. 9). These "null hypothesis" thermograms were calculated by adding end-member thermograms (Figs. 4, 5) adjusted by their calculated proportions in each matrix sample (Table 2, Equation 6). Because the pure JGOFS thermograms vary by the mass loaded into the RPO reactor (Section 3.3), null thermograms were constructed from the lower quantity RPO analyses in Fig. 4, as similarly low PIC quantities were present in mixtures 
I-V (Table 2). Deviations of the measured from the reference/null thermograms indicate the presence of a matrix effect.

We further compared the actual contribution of PIC (calcite) and POC (culture)derived $\mathrm{CO}_{2}$ to each gas fraction of the matrix thermograms with the expected contributions of PIC- and POC-derived $\mathrm{CO}_{2}$ to each trapped gas fraction from the null hypothesis case. Expected $\mathrm{CO}_{2}$ from PIC in each gas fraction, mass Calcitenull,i $_{\text {was }}$ calculated as:

$$
\text { mass }_{\text {Calcite,null,i }}=\int_{\text {Ti0 }}^{\text {Tif }} \text { Calcite }_{\text {norm }} \mathrm{dt} \times \mathrm{f}_{\text {Calcite,Total }}
$$

where the first term is the integral of the PIC end-member thermogram, normalized to total $\mathrm{CO}_{2}$ evolved, between the start $\left(T_{i 0}\right)$ to the end $\left(T_{i f}\right)$ temperatures for fraction $i$. This term was then scaled by the proportion of PIC in the matrix (Table 2). Similarly, expected $\mathrm{CO}_{2}$ in each gas fraction, , mass $_{E, \text { hux, }, \text { null,i }}$, was calculated as:

$$
\text { mass }_{\text {E.hux.,null,i }}=\int_{\text {Ti0 }}^{\text {Tif }} \text { E. hux.norm } d t \times \mathrm{f}_{\text {E.hux.,Total }}
$$

where the E. huxleyi end-member thermogram, normalized to total $\mathrm{CO}_{2}$, was integrated from the start $\left(T_{i 0}\right)$ to the end $\left(T_{i f}\right)$ temperatures of each fraction $i$ and then scaled by the proportion of culture-derived POC in the matrix (Table 2).

The calculated mass $_{\text {Calcitenull,i }}$ and mass $_{E . h u x, \text { null, }, \text { values were compared to observed }}$ quantities of PIC in each matrix fraction, which were constrained by the matrix gas fraction $\delta^{13} \mathrm{C}$ measurements, or $\delta^{13} \mathrm{C}_{\text {matrix,i, }}$, using the following relationship:

$$
\delta^{13} \mathrm{C}_{\text {matrix,i }}=\mathrm{f}_{\text {Calcite,obs, } \mathrm{i}} \delta^{13} \mathrm{C}_{\text {Calcite }, \mathrm{i}}+\mathrm{f}_{\text {E.hux.,obs }, \mathrm{\delta}} \delta^{13} \mathrm{C}_{\text {E.hux, } \mathrm{i}}
$$

The end-member $\delta^{13} \mathrm{C}$ values for each gas fraction, $\delta^{13} \mathrm{C}_{\text {Calcite, } \mathrm{i}}$ and $\delta^{13} \mathrm{C}_{\mathrm{E} . \text { hux.,i, }}$, were measured in $\mathrm{CO}_{2}$ released within similar temperature intervals during ramped oxidation of each pure end-member (Figs. 4-5). Substituting $f_{E . h u x, i}$ with 1- $f_{\text {calcite obs, } i \text {, we solve for }}$ the fraction of $\mathrm{CO}_{2}$ within gas fraction $i$ that derives from PIC decomposition:

$$
\mathrm{f}_{\text {Calcite,obs,i }}=\frac{\delta^{13} \mathrm{C}_{\text {matrix,i }}-\delta^{13} \mathrm{C}_{\text {E.hux }, \mathrm{i}}}{\delta^{13} \mathrm{C}_{\text {Calcite,matrix,i }}-\delta^{13} \mathrm{C}_{\text {E.hux }, \mathrm{i}}}
$$

Thus, the observed PIC-derived $\mathrm{CO}_{2}$ quantity in each gas fraction, mass Calcite, obs,, , was then calculated as:

$$
\text { mass }_{\text {Calcite,obs }, \mathrm{i}}=\mathrm{C}_{\mathrm{i}} \times \mathrm{f}_{\text {Calcite,obs, } \mathrm{i}}
$$


where $C_{i}$ is the total $\mathrm{CO}_{2}$ released within each gas fraction $i$ of the matrix thermogram. Similarly, the measured $\mathrm{CO}_{2}$ from POC for each gas fraction, mass $_{P O C, \text { meas }, i}$ was calculated as:

$$
\text { mass }_{\text {E.hux.,obs,i }}=\mathrm{C}_{\mathrm{i}} \times\left(1-\mathrm{f}_{\text {Calcite,obs,i }}\right)
$$

The Matrix I thermogram, composed of 50\% organic carbon and 50\% inorganic carbon from the Icelandic spar, differs from the null hypothesis thermogram (Fig. 9a). The most ${ }^{13} \mathrm{C}$-enriched $\left(\delta^{13} \mathrm{C}_{\text {matrix,i }}=3 \%\right.$ ) peak in the thermogram, thus derived purely from PIC, has a $\mathrm{T}_{\max }$ of $680^{\circ} \mathrm{C}$. This Tmax is $14^{\circ} \mathrm{C}$ cooler than would be expected in the absence of matrix effects, indicating that the sample matrix has lowered the thermal stability of the Icelandic spar in this mixture. Further, the $\delta^{13} \mathrm{C}$ enrichment observed in fractions $3\left(427-529^{\circ} \mathrm{C}\right)$ and $4\left(529-599^{\circ} \mathrm{C}\right)$ of matrix I relative to the depleted $\delta^{13} \mathrm{C}$ value of $\mathrm{CO}_{2}$ trapped at similar intervals from the E. huxleyi thermograms can only be explained by the presence of PIC in these fractions. The quantity of PIC required to produce this ${ }^{13} \mathrm{C}$-enrichment in these two intervals is greater than the theoretical quantity of PIC expected from the linear addition of PIC and POC from each end-member, respectively (Fig. 10a). This explains why less PIC than expected in the null hypothesis thermally decomposes above $600^{\circ} \mathrm{C}$.

Matrix III was constructed from a greater proportion of culture-derived POC relative to Icelandic spar PIC (Fig. 9c). With one isotope measurement missing between 531 and $599^{\circ} \mathrm{C}$, it is not possible to use Equation 6 to constrain the actual proportions of inorganic and organic carbon in the matrix. But, assuming 15\% inorganic carbon and $85 \%$ organic carbon, which were the target proportions during sample preparation, there are significant differences in observed vs. null thermogram shape. $\mathrm{CO}_{2}$ released above $600^{\circ} \mathrm{C}$ is mostly PIC, with an enriched $\delta^{13} \mathrm{C}$ value $\left(1.5 \%\right.$ ), but again peaks $14^{\circ} \mathrm{C}$ cooler than the peak in the pure PIC thermogram. The smaller relative area of total $\mathrm{CO}_{2}$ in this fraction and greater relative area of $\mathrm{CO}_{2}$ between $525^{\circ} \mathrm{C}$ and $600^{\circ} \mathrm{C}$, compared to the null case, indicates that the matrix effect has shifted the thermal stability of PIC towards a lower temperature range, as well (Fig. 10c).

The carbon in matrix II, 59\% organic culture biomass and 41\% PIC from the JGOFS sediment, mostly oxidizes between $200^{\circ} \mathrm{C}$ and $600^{\circ} \mathrm{C}$ (Fig. 9b). The thermogram displays two prominent peaks at $500^{\circ} \mathrm{C}$ and $610^{\circ} \mathrm{C}$. Again, the results differ from what 
would be expected had the thermogram reflected just a linear sum of the pure endmember thermograms. The most ${ }^{13} \mathrm{C}$-enriched peak, mostly derived from PIC, with a $\mathrm{T}_{\max }$ of $610^{\circ} \mathrm{C}$, must correspond to the highest $\mathrm{CO}_{2}$ concentration peak in the JGOFS thermogram, which also has a $\mathrm{T}_{\max }$ of $610^{\circ} \mathrm{C}$. At the same time, it is clear that the amount of $\mathrm{CO}_{2}$ that evolves above $600^{\circ} \mathrm{C}$ in matrix II is lower than the amount released in the null hypothesis case (Figs. 10b). The isotopic enrichment of $\mathrm{CO}_{2}$ across the matrix II thermogram relative to the $\mathrm{CO}_{2}$ analyzed the E. huxleyi thermograms shows that this difference is compensated by more inorganic carbon decomposing between $426^{\circ} \mathrm{C}$ and $599^{\circ} \mathrm{C}$ than expected in the null case.

Finally, both matrix IV and matrix V contain 88\% POC from E. huxleyi culture biomass and 12\% PIC from the JGOFS sediment, the closest analogue to the Great Calcite Belt samples. The absolute quantity of POC and PIC that were loaded into the RPO reactor differ, with matrix $\mathrm{V}$ containing twice the amount of carbon than matrix IV (Table 2). Despite this mass difference, the two thermograms are similar, and have similar deviations from their respective null thermograms. First, the highest temperature peak observed in the pure JGOFS sediment thermogram above $600^{\circ} \mathrm{C}$ is absent in the two matrix thermograms (Figs. 9d, 9e). The isotopic enrichment of the $\mathrm{CO}_{2}$ released above $400^{\circ} \mathrm{C}$ relative to the $\mathrm{CO}_{2}$ released in similar intervals across the E. huxleyi thermograms indicates that nearly all of the PIC expected to react above $600^{\circ} \mathrm{C}$ in the null hypothesis case has oxidized between $\sim 420^{\circ} \mathrm{C}$ and $600^{\circ} \mathrm{C}$ (Figs. 10d, e). The fact that these shifts in thermal stability occur regardless of the differences in PIC mass in mixtures IV and V implies that these effects are predominantly driven by the matrix rather than by the absolute mass of PIC available for reaction. This result further implies that with high enough POC:PIC proportions in a mixture, matrix effects dominate amount effects on PIC thermal stability.

Overall, the results show that the mixing of POC and PIC can significantly lower the activation energy of PIC. Comparing matrix II, IV and V, the matrix effect on the PIC from the JGOFS sediment is non-linear and sensitive to matrix proportions. It is difficult to discern whether the higher sensitivity of the JGOFS sediment to matrix proportions stems from an intrinsic thermodynamic property of marine biogenic PIC, or from the non-carbon matrix in the sediment itself (i.e., 62\% BSi) (Sayles et al., 2001). Using 
matrix IV and V thermograms as the best analogues to Southern Ocean particles in terms of POC:PIC, the presence of BSi in the sample matrix, and the marine origin of PIC in the particles, we conclude that the PIC in the Great Calcite Belt thermograms most likely reacts between $420^{\circ} \mathrm{C}$ and $600^{\circ} \mathrm{C}$.

In addition, isotope comparisons of $\mathrm{CO}_{2}$ across each matrix (excluding matrix III) and E. huxleyi thermogram allowed for calculation of POC mass in each matrix fraction (Eq. 9b). Comparisons to the null hypothesis POC quantities calculated in the matrix fractions (Eq. 7b) show that the thermal stability of POC has shifted in all matrix mixtures (Fig. 10). For example, the matrix I analysis shows that less $\mathrm{CO}_{2}$ from organic carbon evolves below $427^{\circ} \mathrm{C}$ and more evolves between $427^{\circ} \mathrm{C}$ and $530^{\circ} \mathrm{C}$ (Fig. 10a). In the matrix II thermogram, more POC evolves between $325^{\circ} \mathrm{C}$ and $530^{\circ} \mathrm{C}$, compared to the null case (Fig. 10b). In more POC-rich mixtures IV and V, POC-associated shifts are smaller (Figs. 10d, e). It is likely that a combination of matrix effects and the formation of thermally stable char from incomplete oxidation of POC increases the activation energy of distinct organic carbon pools in these thermograms (Williams et al., 2014). Because marine POC oxidizes over a wide temperature range, it is challenging to distinguish and correct for these possible effects in the Southern Ocean thermograms. The following discussion only takes into account matrix effects on PIC thermal stability, as such effects likely exceed the matrix/charring effects on POC thermal stability.

\subsection{Narrowing thermal stability range with depth}

All twelve blank-corrected (but not PIC-corrected) $<51 \mu \mathrm{m}$ POC thermograms of samples collected above $800 \mathrm{~m}$ across GB1-117, GB2-43 and GB2-100 highlight striking differences between the thermal stability of euphotic zone POC and that of mesopelagic zone POC that exceed differences among stations (Fig. 6). In the euphotic zone thermograms, where most sample carbon derives from POC (PIC content is $\leq 5 \%$ of total C), $\mathrm{CO}_{2}$ is released over a broad, bimodal temperature distribution with a lower temperature peak $\mathrm{T}_{\max }$ at $355 \pm 15^{\circ} \mathrm{C}$ (average \pm 1 standard deviation across seven euphotic zone thermograms) and a higher temperature peak $\mathrm{T}_{\max }$ at $508 \pm 5^{\circ} \mathrm{C}$. By contrast, mesopelagic zone POC reacts over a narrower range of oxidation temperatures 
(Fig. 6), and is distributed more homogenously over this narrower range, rather than distributed bimodally around two peak temperatures. This can be measured by computing the temperature range over which the normalized $\mathrm{CO}_{2}$ concentrations exceed the entire thermogram half maximum (Fig. 11a-c; Appendix B, Fig. S4). The temperature range decreases in thermograms from $\mathrm{Z}_{\mathrm{PAR}}$ to the deeper mesopelagic zone. A similar pattern appears when considering just the $\mathrm{CO}_{2}$ released at temperatures below $420^{\circ} \mathrm{C}$, where little PIC decomposes (Section 4.2; Fig. 11d-f; Appendix B, Fig. S4). The temperature range over which evolved $\mathrm{CO}_{2}$ concentrations exceed the half maximum $\mathrm{CO}_{2}$ concentration below $420^{\circ} \mathrm{C}$ is significantly lower among the mesopelagic zone thermograms than among the euphotic zone thermograms (Student's t-test, $\mathrm{p}<0.05$ ).

At the same time, the proportion of total carbon that decomposes to $\mathrm{CO}_{2}$ within a middle range of temperatures or activation energies increases with depth (Fig. 11g-i; Appendix B, Fig. S4). We define the lower bound of this range as the average $T_{\max }$ of the lower temperature peak across the seven euphotic zone thermograms $\left(355^{\circ} \mathrm{C}\right)$. The upper bound of this range is operationally defined as the highest temperature at which we expect only sample POC (and no PIC) to decompose to $\mathrm{CO}_{2}$ due to the matrix effects described in Section 4.2. This fraction is significantly higher in the mesopelagic zone thermograms than in the euphotic zone thermograms $(\mathrm{p}<0.05)$. The ingrowth of this midtemperature fraction with depth is balanced by a decrease in the fraction of POC that oxidizes between $100^{\circ} \mathrm{C}$ and $355^{\circ} \mathrm{C}$, and a decrease in the PIC-corrected fraction of POC that oxidizes above $420^{\circ} \mathrm{C}$ at stations GB2-100 and GB1-117. This highest temperature POC fraction increases with depth at GB2-43.

The transition from a defined POC partitioning between two activation energy distributions in euphotic zone particles to a more homogenous distribution of POC across a narrower, intermediate range of activation energies occurs regardless of the "starting" POC distribution in the euphotic zone thermograms (Fig. 6), and regardless of the composition of phytoplankton communities producing and exporting the POC from the surface (Table 1). The data suggest that the broader distribution of thermal stability exhibited in the euphotic zone thermograms is characteristic of fresh organic matter, recently produced by photosynthesis. This also may explain why the thermograms of pure and freshly produced E. huxleyi culture biomass (Fig. 5) resemble the euphotic zone 
thermograms more than they resemble deeper mesopelagic zone thermograms, even though they are compositionally different from the complex biomass sources to particles in the open ocean.

Thermograms of the two euphotic zone $>51 \mu \mathrm{m}$ particle samples analyzed from GB2-43 (Fig. 6), which have a very low PIC and blank component (Rosengard et al., 2015), also overlap closely with blank-corrected thermograms of the $<51 \mu \mathrm{m}$ samples from the same depths and station. Interestingly, the $\delta^{13} \mathrm{C}$ values of $\mathrm{CO}_{2}$ collected across the $85 \mathrm{~m}>51 \mu \mathrm{m}$ thermogram are 1-6\%o lighter than the $\delta^{13} \mathrm{C}$ values across the $<51 \mu \mathrm{m}$ thermogram. This indicates that, in spite of similarities in thermogram shape, the POC in the two size-fractions is compositionally distinct (Fig. 8), possibly due to POC production by different size classes of phytoplankton (Trull and Armand, 2001; Finkel et al., 2016), and/or minimal exchange of organic carbon between the two size-fractions ( Wakeham and Canuel, 1988; Abramson et al., 2010). Thus, the broad bimodal distribution evolved $\mathrm{CO}_{2}$ in both size fraction thermograms reflects their similar diagenetic state, irrespective of compositional differences. It is possible that dissolution of $>51 \mu \mathrm{m}$ POC to DOC and incomplete flushing of the total POC pool off of the polyester pre-filters during sonication introduced methodological artifacts to the $>51 \mu \mathrm{m}$ POC thermograms and gas fraction $\delta^{13} \mathrm{C}$ measurements. These processes would remove certain organic carbon subpools (Buesseler et al., 1998) and/or shift the thermal stability of the remaining organic carbon matrix prior to RPO analysis. Nonetheless, the close overlap in thermogram shape between the two POC size-fractions suggests that these artifacts are minimal.

\subsection{Increasing diversity of $\delta^{13} C_{P O C}$ with depth}

The stable isotope composition of POC oxidized throughout thermograms further allows us to explore the biomolecular changes that accompany transitions in thermogram shape (Fig. 11) between fresher euphotic zone samples and more degraded mesopelagic zone samples. Significant variation in the $\delta^{13} \mathrm{C}$ values of $\mathrm{CO}_{2}$ released during ramped oxidation of POC-replete euphotic zone samples and E. huxleyi culture biomass (Figs. 5, 8) likely reflects the heterogeneity of biomolecular classes produced by different metabolic pathways (Hayes et al., 1990; Freeman, 2001). 
To compare $\delta^{13} \mathrm{C}$ values across thermograms of Southern Ocean POC, it is necessary to subtract the PIC component from the $420^{\circ} \mathrm{C}-600^{\circ} \mathrm{C}$ range of all thermograms. The $\delta^{13} \mathrm{C}$ measurements across $\mathrm{CO}_{2}$ fractions of each sample thermogram are not significantly enriched within any narrow temperature range above $420^{\circ} \mathrm{C} \mathrm{(Fig.} \mathrm{8),}$ indicating that the PIC component, which varies between -2\%o and 2\%o (Fig. 2d-f), is spread unevenly throughout the $420^{\circ} \mathrm{C}-600^{\circ} \mathrm{C}$ interval, rather than as a predictable peak (e.g., Fig. 4a). As a result, we bisect every bulk carbon and deployment blank thermogram into two components above and below $420^{\circ} \mathrm{C}$ that comprise fractional proportions of $\mathrm{A}_{1}$ and $\mathrm{A}_{2}$ within intervals $T_{1}$ and $T_{2}$, respectively, and only subtract the acid hydrolysis-based PIC contributions to the bulk isotope composition within $\mathrm{T}_{2}$. This strategy to compare the $\delta^{13} \mathrm{C}$ distribution across two components is largely methodologydriven, not an intrinsic property of marine thermal stability.

Towards this end, we first calculate the $\delta^{13} \mathrm{C}$ value of $\mathrm{CO}_{2}$ released within intervals $T_{1}$ and $T_{2}$ of each bulk sample thermogram and deployment blank thermogram by inverting the following matrix (Rosenheim et al., 2008):

$$
\left[\begin{array}{c}
\delta^{13} C_{1} \\
\vdots \\
\delta^{13} C_{i}
\end{array}\right]=\left[\begin{array}{cc}
f 1, T 1 & f 1, T 2 \\
\vdots & \vdots \\
f i, T 1 & f i, T 2
\end{array}\right] \times\left[\delta^{13} C_{T 1} \delta^{13} C_{T 2}\right]
$$

This inversion solves for $\delta^{13} \mathrm{C}$ values of $\mathrm{CO}_{2}$ released in temperature intervals $\mathrm{T}_{1}$ and $\mathrm{T}_{2}$ : $\delta^{13} \mathrm{C}_{\mathrm{Bulk}, \mathrm{T} 1}, \delta^{13} \mathrm{C}_{\mathrm{Bulk}, \mathrm{T} 2}, \delta^{13} \mathrm{C}_{\mathrm{Blank}, \mathrm{T} 1}$, and $\delta^{13} \mathrm{C}_{\mathrm{Blank}, \mathrm{T} 2}$. In Equation 10, $i$ is the number of $\mathrm{CO}_{2}$ fractions trapped and analyzed, $\delta^{13} \mathrm{C}_{\mathrm{i}}$ is the stable isotope value measured in each fraction, and $f_{i, T 1}$ and $f_{i, T 2}$ are the fractions of $A_{1}$ and $A_{2}$ in each temperature interval over which fractions were collected. The sum of all fractions in the same row of the matrix equates to 1 .

Next, each $\delta^{13} \mathrm{C}_{\text {blank,T1 }}$ and $\delta^{13} \mathrm{C}_{\text {blank,T2 }}$ value calculated from the deployment blank thermograms was subtracted from each $\delta^{13} \mathrm{C}_{\mathrm{Bulk}, \mathrm{T1}}$ and $\delta^{13} \mathrm{C}_{\mathrm{Bulk}, \mathrm{T} 2}$ value calculated from the $<51 \mu \mathrm{m}$ sample thermograms, respectively (Equation 11a, 12a). The ${ }^{13} \mathrm{C}$-enriched PIC contribution was subtracted from the $\delta^{13} \mathrm{C}_{\mathrm{Bulk}, \mathrm{T} 2}$ values from each sample thermogram (Equation 11b, 12b). 


$$
\begin{aligned}
\delta^{13} \mathrm{C}_{\text {POC,T1 }}= & {\left[\delta^{13} \mathrm{C}_{\text {Bulk,T1 }}-\delta^{13} \mathrm{C}_{\text {Blank,T1 }} \mathrm{f}_{\text {Blank,T1 }}\right] / \mathrm{f}_{\text {POC,T1 }} } \\
\delta^{13} \mathrm{C}_{\text {POC,T2 }}= & {\left[\delta^{13} \mathrm{C}_{\text {Bulk,T2 }}-\delta^{13} \mathrm{C}_{\text {PIC }} \mathrm{f}_{\text {PIC,T2 }}-\delta^{13} \mathrm{C}_{\text {Blank,T2 }} \mathrm{f}_{\text {Blank,T2 }}\right] / \mathrm{f}_{\text {POC,T2 }} } \\
& \mathrm{f}_{\text {POC,T1 }}=1-\mathrm{f}_{\text {Blank,T1 }} \\
& \mathrm{f}_{\text {POC,T2 }}=1-\mathrm{f}_{\text {Blank,T2 }}-\mathrm{f}_{\text {PIC }}
\end{aligned}
$$

The fractions of blank carbon in each component of the bulk sample thermogram, $f_{\text {Blank,TI }}$ and $f_{\text {Blank,T2 }}$, were calculated by dividing the integrated area of the blank thermograms within each temperature interval by the same integrated area within each non blankcorrected sample thermogram. $\delta^{13} \mathrm{C}_{\text {PIC }}$ was determined by acid hydrolysis (Section 2.2). The fractional contribution of PIC to the bulk sample carbon in $\mathrm{T}_{2}, f_{P I C, T 2}$, was calculated by multiplying $f_{P I C}$ (Table 1 ) by the total carbon in each non blank-corrected sample thermogram, and then dividing this product by the total carbon within $T_{2}$ of the sample thermogram.

Figure 12 illustrates $\delta^{13} \mathrm{C}_{\mathrm{POC}, \mathrm{T} 1}$ and $\delta^{13} \mathrm{C}_{\mathrm{POC}, \mathrm{T} 2}$ profiles across three stations (Table 4). Because of small kinetic fractionation of carbon during ramped oxidation, we only consider isotopic differences $>2 \%$ in magnitude significant (Hemingway et al., accepted). The $\delta^{13} \mathrm{C}$ values of the deepest samples at GB2-43 and GB2-100 have a very high propagated error (up to $\pm 17.0 \%$ ), owing to relatively high blank and PIC corrections at these depths (Table 4). We assume that the error of sample $\delta^{13} \mathrm{C}_{\mathrm{T} 1}$ and $\delta^{13} \mathrm{C}_{\mathrm{T} 2}$ values calculated in Equation 10 prior to blank and PIC subtraction are similar to the precision of the IRMS, $0.1 \%$. At GB2-43, the weighted sum of the $\delta^{13} \mathrm{C}$ values of these two $800 \mathrm{~m}$ components is $6.7 \%$ heavier than the bulk $\delta^{13} \mathrm{C}_{\mathrm{POC}}$ value (Table 4, Table 1). For this reason, we only focus on $\delta^{13} \mathrm{C}$ values above $800 \mathrm{~m}$ at GB2-43. The weighted sum of the $800 \mathrm{~m} \delta^{13} \mathrm{C}$ values at GB2-100 agree more closely with the bulk $\delta^{13} \mathrm{C}_{\mathrm{POC}}$ value at that depth, but the individual component-specific $\delta^{13} \mathrm{C}$ values, $-42 \%$ for $\mathrm{T}_{1}$ POC and $-16 \%$ for $\mathrm{T}_{2}$ POC, exceed the range of previously observed $\delta^{13} \mathrm{C}$ values for organic matter in the Southern Ocean (Trull and Armand, 2001; Cavagna et al., 2013). Thus, at GB2-100, we cautiously include the $800 \mathrm{~m} \delta^{13} \mathrm{C}$ values in our interpretation. Finally, we are more confident about the GB1-117 $\delta^{13} \mathrm{C}$ profiles because the weighted $\delta^{13} \mathrm{C}$ sums of the two components $\left(\delta^{13} \mathrm{C}_{\mathrm{POC}, \mathrm{T} 1}\right.$ and $\left.\delta^{13} \mathrm{C}_{\mathrm{POC}, \mathrm{T} 2}\right)$ closely match the bulk $\delta^{13} \mathrm{C}_{\mathrm{POC}}$ values at all depths, and the errors of $\delta^{13} \mathrm{C}_{\mathrm{POC}, \mathrm{T} 1}$ and $\delta^{13} \mathrm{C}_{\mathrm{POC}, \mathrm{T} 2}$ at $1000 \mathrm{~m}$ are smaller. 
While absolute values of and changes in $\delta^{13} \mathrm{C}_{\mathrm{POC}, \mathrm{T} 1}$ and $\delta^{13} \mathrm{C}_{\mathrm{POC}, \mathrm{T} 2}$ through each profile differ by station, the difference between the two values $\left(\delta^{13} \mathrm{C}_{\mathrm{POC}, \mathrm{T} 1}-\delta^{13} \mathrm{C}_{\mathrm{POC}, \mathrm{T} 2}\right)$ $\Delta \delta^{13} \mathrm{C}_{\mathrm{POC}}$ increases with depth at all stations. $\Delta \delta^{13} \mathrm{C}_{\mathrm{POC}}$ is small $(-2$ to $+2 \%)$ in the euphotic zone and generally increases to $>3 \%$ (Fig. 12d-e, Table 4). In all of the mesopelagic zone samples for which we could calculate $\delta^{13} \mathrm{C}_{\mathrm{POC}, \mathrm{T1}}$, the lower thermal stability component is consistently heavier than the higher thermal stability component. In GB2-43, this positive $\Delta \delta^{13} \mathrm{C}_{\mathrm{POC}}$ is primarily due to an increase in the depth-averaged $\delta^{13} \mathrm{C}_{\mathrm{POC}, \mathrm{T} 1}$ from the euphotic zone to the mesopelagic zone, with no change in $\delta^{13} \mathrm{C}_{\mathrm{POC}, \mathrm{T} 2}$. In GB2-100, this positive difference is a combination of increasing average $\delta^{13} \mathrm{C}_{\mathrm{POC}, \mathrm{T} 1}$ and a decreasing $\delta^{13} \mathrm{C}_{\mathrm{POC}, \mathrm{T} 2}$ with depth. In GB1-117, the positive $\Delta \delta^{13} \mathrm{C}_{\mathrm{POC}}$ can be attributed to a decrease in $\delta^{13} \mathrm{C}_{\mathrm{POC}, \mathrm{T} 2}$ with depth, without any change in $\delta^{13} \mathrm{C}_{\mathrm{POC}, \mathrm{T} 1}$.

The increase in $\Delta \delta^{13} \mathrm{C}_{\mathrm{POC}}$ with depth implies increasingly different biomolecular groups are distributed across a narrower range of activation energies. While we cannot determine the identity of the biomolecules that persist in the deeper mesopelagic zone samples, two trends are clear. First, when depth-averaged $\delta^{13} \mathrm{C}_{\mathrm{POC}, \mathrm{T} 1}$ values change with depth, as in the GB2-43 and GB2-100 profiles, they become more ${ }^{13} \mathrm{C}$-enriched. Second, when depth-averaged $\delta^{13} \mathrm{C}_{\mathrm{POC}, \mathrm{T} 2}$ values shift with depth, as in GB2-100 and GB1-117, they become more ${ }^{13} \mathrm{C}$-depleted. Thus, at each station, relatively heavy low thermal stability biomolecules and/or lighter high thermal stability molecules accumulate with depth, as well. The low thermal stability biomolecules may contain proportionally more amino acids and carbohydrates because they are relatively enriched (Deines, 1980; Galimov, 2006). A weak but significantly positive correlation $(p<0.05)$ between $\delta^{13} \mathrm{C}_{\mathrm{POC}, \mathrm{T1}}$ values and molar $\mathrm{C}: \mathrm{N}$ ratios in particle sub-samples analyzed by elemental analysis (Table 1, Table 4; correlation not shown) suggests that the heavier biomolecules preserved within interval $\mathrm{T}_{1}$ could be more carbohydrate-derived rather than amino acidderived, because amino acids have relatively low C:N ratios. Meanwhile, the high thermal stability POC pool that grows lighter with depth could be influenced by an increasing proportion of ${ }^{13} \mathrm{C}$-depleted lipids (Hayes et al., 1990). It is important to acknowledge that these interpretations are limited by the possibility that thermograms further reflect the decomposition of not only discrete biomolecules, but sub-groups of larger molecules that are isotopically distinct from the rest of the compound (Wagner et 
al., 1994; Westerhout et al., 1997). Thus, the compounds accumulating in $T_{1}$ could also be enriched fragments of other structurally complex biomolecules, not necessarily carbohydrates, decomposing to $\mathrm{CO}_{2}$ within this temperature interval.

\subsection{Selective biomolecular preservation}

The changes in thermogram shape with depth across station profiles (Section 4.3, Fig. 11) support the argument for selective preservation of POC. At all stations, the proportion of the lowest activation energy POC components in the euphotic zone samples decreases with depth as the fraction of POC oxidizing over a narrow, middle range of activation energies accumulates. It is not surprising that the lowest activation energy compounds are most reactive in the water column, especially if these thermally unstable components are smaller and more readily available to bacterial uptake (Benz and Bauer, 1988). The preferential removal of POC from higher thermal stability ranges with depth in profiles at GB2-100 and GB1-117 is more unexpected. However, it is possible for the most thermally stable POC pools to be equally degradable in the water column because marine heterotrophs use enzymes to break apart structurally complex and large biomolecules before assimilation (Chröst, 1991; Hedges et al., 2000; Sinsabaugh et al., 2009). Thus, the data demonstrate that thermal stability is not a straightforward proxy for diagenetic stability, at least on the higher thermal stability end of the spectrum (Section $1)$.

Because the range in activation energy distributions of POC in the water column decrease regardless of differences in euphotic zone POC composition, the data support the perspective that a similar suite of degradation/organic matter alteration reactions in the water column transform organic matter regardless of its source composition when exported (Baldock et al., 2004). This trend is similar to observations that the proportion of labile and identifiable organic compounds (amino acids, carbohydrates and lipids) decreases with water column depth as the proportion of stable and molecularly uncharacterizable carbon (MUC) accumulates (Wakeham et al., 1997; Hedges et al., 2000). Wakeham et al. (1997) were only able to characterize $\sim 30 \%$ of Equatorial Pacific POC collected in sediment traps at $1000 \mathrm{~m}$ as either amino acids, lipids or carbohydrates. 
This amount was significantly smaller than the characterizable quantity in shallower POC, from fresh phytoplankton biomass in the euphotic zone to sediment traps at $150 \mathrm{~m}$ ( $\sim 80 \%)$. Large proportions ( $>50 \%$ ) of MUC have been observed in other sections of the Equatorial Pacific with different rates of primary productivity, and elsewhere, including deep sections of the Cariaco and Santa Barbara Basins, the Eastern Subtropical Atlantic, Northeast Pacific, and Southern Ocean (Hwang and Druffel, 2003; Roland et al., 2008; Wang and Druffel, 2001).

It is likely that over half the POC in the deeper mesopelagic zone samples of each Great Calcite Belt profile is also molecularly uncharacterizable POC. This would imply that the processes that render POC uncharacterizable also manifest in a narrower, more homogenous POC distribution across activation energies of decomposition (Fig. 11). Hypotheses for MUC formation include structural linkages among biomolecules that make them difficult to access by exoenzymes or too large to pass through bacterial cell membranes, and the creation of metabolic intermediates during heterotrophic remineralization (Del Rio et al., 1996; Wakeham et al., 1997; Hedges et al., 2000; Freeman, 2001). Both processes would lead to the loss of characterizable compounds and lower the biomolecular diversity of mesopelagic zone POC, which may also manifest in a more homogenous distribution of POC about a smaller activation energy range. It is unlikely that abiotic cross-linking alone would decompose the highest activation energy pools of euphotic zone POC, which is thermodynamically unfavorable (Hedges et al., 2000). More likely, a combination of cross-linking and heterotrophic reworking of organic matter by enzymes accounts for the observed removal of both the lowest and highest activation energy POC pools with depth.

While the POC activation energy distribution narrows with depth, POC becomes more isotopically diverse (Section 4.4, Fig. 12d-e). If a significant proportion of MUC in the thermograms of deeper samples were formed by linkages of discrete biomolecules into larger, recalcitrant structures during remineralization in the water column, we would expect $\Delta \delta^{13} C_{P O C}$ values to decrease with the combination of isotopically distinct biomolecules. The fact that $\Delta \delta^{13} \mathrm{C}_{\mathrm{POC}}$ increases instead points to conversion of euphotic zone POC to metabolic intermediates by heterotrophy and/or exchange of biomolecular fragments during cross-linking followed by break up into isotopically diverse smaller 
molecules, both of which could drive greater variations in isotopic composition of the POC pool.

\subsection{Compositional differences in accumulated POC}

Selective preservation implies that MUC is compositionally and structurally distinct from the identifiable biomolecule classes, and accumulates with depth because it is intrinsically recalcitrant. The individual $\delta^{13} \mathrm{C}_{\mathrm{POC}, \mathrm{T} 1}$ and $\delta^{13} \mathrm{C}_{\mathrm{POC}, \mathrm{T} 2}$ profiles (Fig. 12a-c) illustrate three different scenarios of selective POC preservation from three ecologically distinct sites of the Southern Ocean (Table 4), indicating that compositionally different biomolecules persist in deeper mesopelagic zone POC. With the information available, there are no clear relationships among phytoplankton community composition, the $<51$ $\mu \mathrm{m}[\mathrm{POC}]$ attenuation (Table 1), POC stability and the identity of these biomolecules that accumulate with depth.

Differences in deep $\delta^{13} \mathrm{C}_{\mathrm{POC}}$ composition among stations could result from different sources of euphotic zone POC. Trull and Armand (2001) observed that different size-fractions of organic particles in the Southern Ocean exhibited different $\delta^{13} \mathrm{C}$ values, ranging by as much as $\sim 8 \%$ between $1-5 \mu \mathrm{m}$ to $>200 \mu \mathrm{m}$ size classes, and that selective feeding of distinct size classes could shift bulk $\delta^{13} \mathrm{C}$ with depth. In this data set, we saw that $>51 \mu \mathrm{m}$ POC is isotopically distinct (i.e., lighter) from $<51 \mu \mathrm{m}$ POC in the euphotic zone (Section 4.3; Fig. 8). But, because sample size limitations precluded the analysis of $>51 \mu \mathrm{m}$ POC by RPO in the mesopelagic zone, size-specific degradation processes are beyond the scope of this study. In the future, applications of ramped oxidation could be designed to explore the contribution of factors such as advection and size-partitioning to compositional changes in POC through the water column.

Differences in the community composition of heterotrophs in the mesopelagic zone could also cause differences among $\delta^{13} \mathrm{C}_{\mathrm{POC}, \mathrm{T} 1}$ and $\delta^{13} \mathrm{C}_{\mathrm{POC}, \mathrm{T} 2}$ profiles across stations. Indeed, the conversion of POC to heterotrophic biomass can comprise a significant fraction of POC at these depths (McCarthy et al., 1998; Hedges et al., 2000; Griffith et al., 2012). Accumulation of different heterotrophic communities at different rates in mesopelagic zone particles could mask any relationships between phytoplankton 
community composition, thermal stability and the identity of biomolecules preserved from the euphotic zone. More work remains to determine whether the thermal stability and activation energy range for heterotrophic biomass would manifest in the distributions observed in the mesopelagic zone (Figs. 6, 11). Future ramped oxidation studies should focus on controlled "end-member" experiments, such as comparing axenic E. huxleyi biomass thermograms (Fig. 5) to cultures inoculated with bacterial biomass.

One lingering caveat in this discussion is the closed system perspective that $<51$ $\mu \mathrm{m}$ POC in the mesopelagic zone derives from the POC produced in the euphotic zone. Deeper advection of even more highly degraded $<51 \mu \mathrm{m}$ particles could further influence the organic matter matrix we observe in the mesopelagic zone and drive differences in

$\delta^{13} \mathrm{C}_{\mathrm{POC}, \mathrm{T} 1}$ and $\delta^{13} \mathrm{C}_{\mathrm{POC}, \mathrm{T} 2}$ profiles in Fig. 12 (Griffith et al., 2012; Cavagna et al., 2013). If significant enough, advection would impact the conclusion that MUC derives from selective preservation (Roland et al., 2008). However, it would not change the position that the same processes that form and concentrate MUC with depth also concentrate organic matter within a narrow activation energy distribution (Section 4.2).

\section{Conclusion}

Ramped oxidation of marine POC in the water column reveals significant differences in the composition of euphotic and mesopelagic zone $<51 \mu \mathrm{m}$ POC, supporting the perspective that organic matter degradation/preservation in the water column selects for specific biomolecules or fragments of them. Taking into account matrix effects of sample minerals, particularly calcite, is important for accurately interpreting POC composition using this method. These data set the stage for future applications of ramped oxidation to samples collected from more controlled environments and towards testing specific hypotheses of organic matter transformation and fate during particle transport through the water column. 


\section{Acknowledgements}

Many thanks to Phoebe Lam for the opportunity to collect these samples from the Southern Ocean; to Valier Galy, Phoebe Lam, Ann McNichol and Ken Buesseler for assistance in experiment design; to Rob Spencer, Mick Follows, P. Zigah and J. Hemingway for discussions; to A. Gagnon, A.J. Cruz, M. Lardie, M. Auro, K. Elder, L. Xu and P. Henderson for analytical assistance; C. Johnson, T. Mincer, L. Harvey, A. Pearson, A. Flynn-Carroll, and Susan Carter for assistance in preparation of end-member samples; and Katherine French, Reed Porada, and Paul Lerner for discussions of strategies for error propagation for this complex data set.

\section{References}

Abramson, L., Lee, C., Liu, Z. F., Wakeham, S. G., and Szlosek, J.: Exchange between suspended and sinking particles in the northwest Mediterranean as inferred from the organic composition of in situ pump and sediment trap samples, Limnology and Oceanography, 55, 725-739, 2010.

Armstrong, R. A., Lee, C., Hedges, J. I., Honjo, S., and Wakeham, S. G.: A new, mechanistic model for organic carbon fluxes in the ocean based on the quantitative association of POC with ballast minerals, Deep-Sea Research Part IITopical Studies in Oceanography, 49, 219-236, 2002.

Balch, W. M., Bates, N. R., Lam, P. J., Twining, B. S., Rosengard, S. Z., Bowler, B. C., Drapeau, D. T., Garley, R., Lubelczyk, L. C., and Mitchell, C.: Factors regulating the Great Calcite Belt in the Southern Ocean and its biogeochemical significance, Global Biogeochemical Cycles, 30, 1124-1144, 2016.

Balch, W. M., Drapeau, D. T., Bowler, B. C., Lyczskowski, E., Booth, E. S., and Alley, D.: The contribution of coccolithophores to the optical and inorganic carbon budgets during the Southern Ocean Gas Exchange Experiment: New evidence in support of the "Great Calcite Belt" hypothesis, Journal of Geophysical Research, 116, C00F06, $2011 \mathrm{a}$.

Balch, W. M., Poulton, A. J., Drapeau, D. T., Bowler, B. C., Windecker, L. A., and Booth, E. S.: Zonal and meridional patterns of phytoplankton biomass and carbon fixation in the Equatorial Pacific Ocean, between $110^{\circ} \mathrm{W}$ and $140^{\circ} \mathrm{W}$, Limnology and Oceanography, 59, 1715-1732, $2011 \mathrm{~b}$.

Baldock, J. A., Masiello, C. A., Gélinas, Y., and Hedges, J. I.: Cycling and composition of organic matter in terrestrial and marine ecosystems, Marine Chemistry, 92, 3964, 2004.

Behrenfeld, M. J. and Falkowski, P. G.: Photosynthetic rates derived from satellite - 
based chlorophyll concentration, Limnology and Oceanography, 42, 1-20, 1997.

Benner, R., Biddanda, B., Black, B., and McCarthy, M.: Abundance, size distribution, and stable carbon and nitrogen isotopic compositions of marine organic matter isolated by tangential-flow ultrafiltration, Marine Chemistry, 57, 243-263, 1997.

Benz, R. and Bauer, K.: Permeation of hydrophilic molecules through the outer membrane of gram-negativ bacteria, European Journal of Biochemistry, 176, 119, 1988.

Bishop, J. K., Lam, P. J., and Wood, T. J.: Getting good particles: Accurate sampling of particles by large volume in-situ filtration, Limnology and Oceanography Methods, 10, 681-710, 2012.

Buesseler, K., Ball, L., Andrews, J., Benitez-Nelson, C., Belastock, R., Chai, F., and Chao, Y.: Upper ocean export of particulate organic carbon in the Arabian Sea derived from thorium-234, Deep-Sea Research Part II-Topical Studies in Oceanography, 45, 2461-2487, 1998.

Buesseler, K. O. and Boyd, P.: Shedding light on processes that control particle export and flux attenuation in the twilight zone of the open ocean, Limnology and Oceanography, 54, 1210-1232, 2009.

Burd, A. B., Frey, S., Cabre, A., Ito, T., Levine, N. M., Lønborg, C., Long, M., Mauritz, M., Thomas, R. Q., and Stephens, B. M.: Terrestrial and marine perspectives on modeling organic matter degradation pathways, Global Change Biology, 22, 121$136,2016$.

Burd, A. B. and Jackson, G. A.: Particle Aggregation, Annual Review of Marine Science, 1, 65-90, 2009.

Burnham, A. K. and Braun, R. L.: Global kinetic analysis of complex materials, Energy \& Fuels, 13, 1-22, 1999

Cavagna, A.-J., Dehairs, F., Bouillon, S., Woule-Ebongué, V., Planchon, F., Delille, B., and Bouloubassi, I.: Water column distribution and carbon isotopic signal of cholesterol, brassicasterol and particulate organic carbon in the Atlantic sector of the Southern Ocean, Biogeosciences, 10, 2787-2801, 2013.

Chröst, R.: Microbial enzymes in aquatic environments, Springer-Verlag, New York, 1991.

Cramer, B.: Methane generation from coal during open system pyrolysis investigated by isotope specific, Gaussian distributed reaction kinetics, Organic Geochemistry, 35, 379-392, 2004.

Dall'Olmo, G. and Mork, K. A.: Carbon export by small particles in the Norwegian Sea, Geophysical Research Letters, 41, 2921-2927, 2014.

Deines, P.: The isotopic composition of reduced organic carbon, Handbook of environmental isotope geochemistry, 1980. 329-406, 1980.

Del Rio, J., Martin, F., and Gonzalez-Vila, F.: Thermally assisted hydrolysis and alkylation as a novel pyrolytic approach for the structural characterization of natural biopolymers and geomacromolecules, TrAC Trends in Analytical Chemistry, 15, 70-79, 1996.

Eppley, R. W. and Peterson, B. J.: Particulate organic matter flux and planktonic new production in the deep ocean, Nature, 282, 677-680, 1979.

Falkowski, P. G., Barber, R. T., and Smetacek, V.: Biogeochemical controls and feedbacks on ocean primary production, Science, 281, 200-206, 1998. 
Finkel, Z. V., Follows, M. J., Liefer, J. D., Brown, C. M., Benner, I., and Irwin, A. J.: Phylogenetic Diversity in the Macromolecular Composition of Microalgae, PloS one, 11, e0155977, 2016.

Francois, R., Honjo, S., Krishfield, R., and Manganini, S.: Factors controlling the flux of organic carbon to the bathypelagic zone of the ocean, Global Biogeochemical Cycles, 16, doi:10.1029/2001GB001722, 2002.

Freeman, K. H.: Isotopic biogeochemistry of marine organic carbon, Reviews in Mineralogy and Geochemistry, 43, 579-605, 2001.

Galimov, E.: Isotope organic geochemistry, Organic geochemistry, 37, 1200-1262, 2006.

Galy, V., Bouchez, J., and France - Lanord, C.: Determination of total organic carbon content and $\delta{ }^{13} \mathrm{C}$ in carbonate - rich detrital sediments, Geostandards and Geoanalytical Research, 31, 199-207, 2007.

Giering, S. L. C., Sanders, R., Lampitt, R. S., Anderson, T. R., Tamburini, C., Boutrif, M., Zubkov, M. V., Marsay, C. M., Henson, S. A., Saw, K., Cook, K., and Mayor, D. J.: Reconciliation of the carbon budget in the ocean/'s twilight zone, Nature, advance online publication, 2014.

Goericke, R., Montoya, J., and Fry, B.: Physiology of isotopic fractionation in algae and cyanobacteria, Stable isotopes in ecology and environmental science. Blackwell, 1994. 187-221, 1994.

Griffith, D. R., McNichol, A. P., Xu, L., McLaughlin, F. A., Macdonald, R. W., Brown, K. A., and Eglinton, T. I.: Carbon dynamics in the western Arctic Ocean: insights from full-depth carbon isotope profiles of DIC, DOC, and POC, Biogeosciences, 9, 1217-1224, 2012.

Guillard, R. R.: Culture of phytoplankton for feeding marine invertebrates. In: Culture of marine invertebrate animals, Springer, 1975.

Harvey, E. L., Bidle, K. D., and Johnson, M. D.: Consequences of strain variability and calcification in Emiliania huxleyi on microzooplankton grazing, Journal of Plankton Research, 37, 1137-1148, 2015.

Hayes, J., Freeman, K. H., Popp, B. N., and Hoham, C. H.: Compound-specific isotopic analyses: a novel tool for reconstruction of ancient biogeochemical processes, Organic Geochemistry, 16, 1115-1128, 1990.

Hedges, J. I., Eglinton, G., Hatcher, P. G., Kirchman, D. L., Arnosti, C., Derenne, S., Evershed, R. P., Kögel-Knabner, I., De Leeuw, J., and Littke, R.: The molecularly-uncharacterized component of nonliving organic matter in natural environments, Organic Geochemistry, 31, 945-958, 2000.

Hemingway, J. D., Galy, V. V., Gagnon, A. R., Grant, K. E., Rosengard, S. Z., Soulet, G., Zigah, P., and McNichol, A. P.: Assessing the blank carbon contribution, isotope mass balance, and kinetic isotope fractionation of the ramped pyrolysis/oxidation instrument at NOSAMS, Radiocarbon, accepted.

Hemingway, J.D.: Understanding terrestrial organic carbon export: A time-series approach, 2017. Massachusetts Institute of Technology and Woods Hole Oceanographic Institution, 2017.

Henson, S., Lampitt, R., and Johns, D.: Variability in phytoplankton community structure in response to the North Atlantic Oscillation and implications for organic carbon flux, Limnology and Oceanography, 57, 1591, 2012a.

Henson, S. A., Sanders, R., and Madsen, E.: Global patterns in efficiency of particulate 
organic carbon export and transfer to the deep ocean, Global Biogeochemical Cycles, 26, GB1028, 2012b.

Henson, S. A., Sanders, R., Madsen, E., Morris, P. J., Le Moigne, F., and Quartly, G. D.: A reduced estimate of the strength of the ocean's biological carbon pump, Geophysical Research Letters, 38, L04606, 2011.

Hwang, J. S. and Druffel, E. R. M.: Lipid-like material as the source of the uncharacterized organic carbon in the ocean?, Science, 299, 881-884, 2003.

Keigwin, L., Bice, M., and Copley, N.: Seasonality and stable isotopes in planktonic foraminifera off Cape Cod, Massachusetts, Paleoceanography, 20, 2005.

Klaas, C. and Archer, D. E.: Association of sinking organic matter with various types of mineral ballast in the deep sea: Implications for the rain ratio, Global Biogeochemical Cycles, 16, 1116-1129, 2002.

Kwon, E. Y., Primeau, F., and Sarmiento, J. L.: The impact of remineralization depth on the air-sea carbon balance, Nature Geoscience, 2, 630-635, 2009.

Lam, P. J. and Bishop, J. K. B.: High Biomass Low Export regimes in the Southern Ocean, Deep Sea Research Part II: Topical Studies in Oceanography, 54, 601638, 2007.

Lam, P. J. and Marchal, O.: Insights into particle cycling from thorium and particle data, Annual review of marine science, 7, 159-184, 2015.

Laufkötter, C., Vogt, M., Gruber, N., Aumont, O., Bopp, L., Doney, S., Dunne, J., Hauck, J., John, J., Lima, I., Seferian, R., and Völker, C.: Projected decreases in future marine export production: the role of the carbon flux through the upper ocean ecosystem, Biogeosciences, 13, 4023-4047, 2016.

Marchal, O. and Lam, P. J.: What can paired measurements of Th isotope activity and particle concentration tell us about particle cycling in the ocean?, Geochimica Et Cosmochimica Acta, 90, 126-148, 2012.

Marsay, C. M., Sanders, R. J., Henson, S. A., Pabortsava, K., Achterberg, E. P., and Lampitt, R. S.: Attenuation of sinking particulate organic carbon flux through the mesopelagic ocean, Proceedings of the National Academy of Sciences, 112, 10891094, 2015.

Martin, J. H., Knauer, G. A., Karl, D. M., and Broenkow, W. W.: Vertex - Carbon Cycling in the Northeast Pacific, Deep-Sea Research Part a-Oceanographic Research Papers, 34, 267-285, 1987.

McCarthy, M. D., Hedges, J. I., and Benner, R.: Major bacterial contribution to marine dissolved organic nitrogen, Science, 281, 231-234, 1998.

McDonnell, A. M. P. and Buesseler, K. O.: Variability in the average sinking velocities of marine particles, Limnology and Oceanography, 55, 2085-2096, 2010.

McNichol, A., Gagnon, A., Osborne, E., Hutton, D., and Schneid, R.: Improvements in procedural blanks at NOSAMS: Reflections of improvements in sample preparation and accelerator operation, Radiocarbon, 37, 683-691, 1995.

Murnane, R., Cochran, J., and Sarmiento, J.: Estimates of particle-and thorium-cycling rates in the northwest Atlantic Ocean, Journal of Geophysical Research- All Series, 99, 3373-3373, 1994.

Plante, A. F., Beaupré, S. R., Roberts, M. L., and Baisden, T.: Distribution of radiocarbon ages in soil organic matter by thermal fractionation, Radiocarbon, 55, 1077-1083, 2013. 
Popp, B. N., Trull, T., Kenig, F., Wakeham, S. G., Rust, T. M., Tilbrook, B., Griffiths, B., Wright, S. W., Marchant, H. J., and Bidigare, R. R.: Controls on the carbon isotopic composition of Southern Ocean phytoplankton, Global Biogeochemical Cycles, 13, 827-843, 1999.

Riley, J. S., Sanders, R., Marsay, C., Le Moigne, F. A. C., Achterberg, E. P., and Poulton, A. J.: The relative contribution of fast and slow sinking particles to ocean carbon export, Global Biogeochemical Cycles, 26, GB1026, 2012.

Roland, L. A., McCarthy, M. D., and Guilderson, T.: Sources of molecularly uncharacterized organic carbon in sinking particles from three ocean basins: a coupled $\Delta^{14} \mathrm{C}$ and $\delta^{13} \mathrm{C}$ approach, Marine Chemistry, 111, 199-213, 2008.

Rosengard, S. Z., Lam, P. J., Balch, W. M., Auro, M. E., Pike, S., Drapeau, D., and Bowler, B.: Carbon export and transfer to depth across the Southern Ocean Great Calcite Belt, Biogeosciences, 12, 3953-3971, 2015.

Rosenheim, B. E., Day, M. B., Domack, E., Schrum, H., Benthien, A., and Hayes, J. M.: Antarctic sediment chronology by programmed - temperature pyrolysis: Methodology and data treatment, Geochemistry, Geophysics, Geosystems, 9, 2008.

Rosenheim, B. E. and Galy, V.: Direct measurement of riverine particulate organic carbon age structure, Geophysical Research Letters, 39, 2012.

Rosenheim, B. E., Roe, K. M., Roberts, B. J., Kolker, A. S., Allison, M. A., and Johannesson, K. H.: River discharge influences on particulate organic carbon age structure in the Mississippi/Atchafalaya River System, Global Biogeochemical Cycles, 27, 154-166, 2013.

Sayles, F. L., Martin, W. R., Chase, Z., and Anderson, R. F.: Benthic remineralization and burial of biogenic $\mathrm{SiO} 2, \mathrm{CaCO} 3$, organic carbon, and detrital material in the Southern Ocean along a transect at 170 degrees West, Deep-Sea Research Part IITopical Studies in Oceanography, 48, 4323-4383, 2001.

Sheridan, C. C., Lee, C., Wakeham, S. G., and Bishop, J. K. B.: Suspended particle organic composition and cycling in surface and midwaters of the equatorial Pacific Ocean, Deep-Sea Research Part I-Oceanographic Research Papers, 49, 1983-2008, 2002.

Sinsabaugh, R. L., Hill, B. H., and Follstad Shah, J. J.: Ecoenzymatic stoichiometry of microbial organic nutrient acquisition in soil and sediment, Nature, 462, 795-798, 2009.

Subt, C., Fangman, K. A., Wellner, J. S., and Rosenheim, B. E.: Sediment chronology in Antarctic deglacial sediments: Reconciling organic carbon $14 \mathrm{C}$ ages to carbonate 14C ages using Ramped PyrOx, The Holocene, 26, 265-273, 2016.

Thomalla, S. J., Poulton, A. J., Sanders, R., Turnewitsch, R., Holligan, P. M., and Lucas, M. I.: Variable export fluxes and efficiencies for calcite, opal, and organic carbon in the Atlantic Ocean: A ballast effect in action?, Global Biogeochemical Cycles, 22, GB1010, 2008.

Trull, T. and Armand, L.: Insights into Southern Ocean carbon export from the $\delta 13 \mathrm{C}$ of particles and dissolved inorganic carbon during the SOIREE iron release experiment, Deep Sea Research Part II: Topical Studies in Oceanography, 48, 2655-2680, 2001.

Volk, T. and Hoffert, M. I.: Ocean carbon pumps: Analysis of relative strengths and 
efficiencies in ocean-driven atmospheric $\mathrm{CO}_{2}$ changes, Geophysical Monographs, 32, 99-110, 1985.

Wagner, B. A., Buettner, G. R., and Burns, C. P.: Free Radical-Mediated Lipid Peroxidation in Cells: Oxidizability Is a Function of Cell Lipid bis-Allylic Hydrogen Content, Biochemistry, 33, 4449-4453, 1994.

Wakeham, S. G. and Canuel, E. A.: Organic geochemistry of particulate matter in the eastern tropical North Pacific Ocean: Implications for particle dynamics, Journal of Marine Research, 46, 183-213, 1988.

Wakeham, S. G., Lee, C., Hedges, J. I., Hernes, P. J., and Peterson, M. J.: Molecular indicators of diagenetic status in marine organic matter, Geochimica et Cosmochimica Acta, 61, 5363-5369, 1997.

Wang, X. C. and Druffel, E. R. M.: Radiocarbon and stable carbon isotope compositions of organic compound classes in sediments from the NE Pacific and Southern Oceans, Marine Chemistry, 73, 65-81, 2001.

Westerhout, R., Waanders, J., Kuipers, J., and Van Swaaij, W.: Kinetics of the lowtemperature pyrolysis of polyethene, polypropene, and polystyrene modeling, experimental determination, and comparison with literature models and data, Industrial \& Engineering Chemistry Research, 36, 1955-1964, 1997.

Williams, E. K., Rosenheim, B. E., McNichol, A. P., and Masiello, C. A.: Charring and non-additive chemical reactions during ramped pyrolysis: Applications to the characterization of sedimentary and soil organic material, Organic Geochemistry, 77, 106-114, 2014. 
Table 1. Bulk properties of particulate organic carbon (POC) and deployment blank filters sampled from the euphotic zone to $1000 \mathrm{~m}$ at stations GB1-117, GB2-43 and GB2-100 from the Southern Ocean Great Calcite Belt region. Bolded numbers correspond to values at (or above/below at GB2-43) ZPAR, the export depth, defined by the depth of $0.3 \%$ PAR. $f_{C \text {,blank }}$ and $f_{P I C}$ are the proportions of total carbon that are deployment blank carbon and particulate inorganic carbon, respectively. POC error is equivalent to one standard deviation across three [POC] concentrations measured by different methods described in Section 2.2 (Table 3).

\begin{tabular}{|c|c|c|c|c|c|c|c|c|c|c|c|c|c|c|c|}
\hline 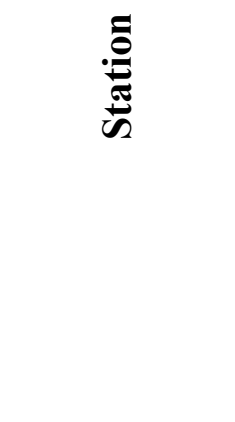 & 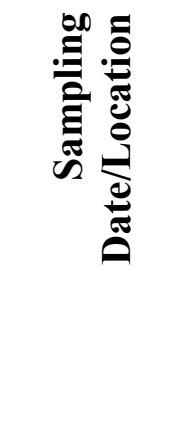 & อั & שֶ. & 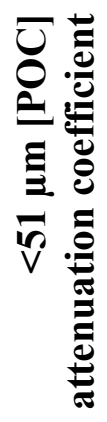 & 告 & 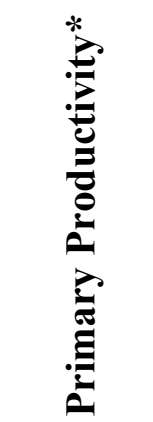 & 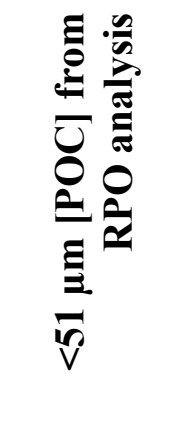 & $\begin{array}{l}\bar{U} \\
\bar{E} \\
\frac{E}{\sqrt{E}}\end{array}$ & 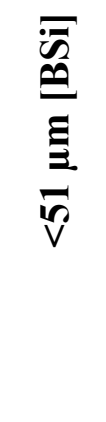 & 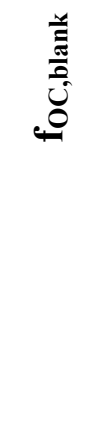 & $\stackrel{U}{=}$ & $\begin{array}{l}\bar{U} \\
\underline{\theta} \\
\ddot{\bar{U}} \\
0 \\
\underline{\Xi} \\
\frac{\Xi}{E} \\
\ddot{v}\end{array}$ & $\underset{m}{\tilde{U}}$ & $\bigcup_{\frac{m}{\infty}}^{\circlearrowright}$ & $\ddot{\ddot{U}}$ \\
\hline - & - & $m$ & ${ }^{\circ} \mathrm{C}$ & $\mu M$ & $\%$ & $m g / m^{2} d$ & $\mu M$ & $\mu M$ & $\mu M$ & - & - & - & $\%$ & $\%$ & - \\
\hline GB1-117 & $13-F e b-11$ & 25 & 18.7 & & & & $5.09 \pm 0.63$ & 0.177 & & 0.03 & 0.03 & 29 & 1.0 & -21.0 & 7.1 \\
\hline GB1-117 & $38.97^{\circ} \mathrm{S}$ & 62 & 14.2 & 1.14 & 9 & 218 & $2.46 \pm 0.28$ & 0.084 & 0.010 & 0.03 & 0.03 & 29 & 0.1 & -21.9 & 6.3 \\
\hline GB1-117 & $9.49^{\circ} \mathrm{E}$ & 162 & 11.6 & & & & $0.39 \pm 0.04$ & 0.045 & & 0.12 & 0.09 & 9 & -0.04 & -21.91 & 6.7 \\
\hline GB1-117 & $\mathrm{zPAR}=$ & 300 & 9.7 & & & & $0.41 \pm 0.02$ & 0.019 & & 0.19 & 0.04 & 22 & -1.96 & -20.14 & 5.1 \\
\hline GB1-117 & $62 \mathrm{~m}$ & 1000 & 5.4 & & & & $0.12 \pm 0.03$ & 0.017 & & 0.28 & 0.09 & 7 & -0.91 & -23.07 & $\mathrm{~N}=\mathrm{BDL}$ \\
\hline GB1-117 blank & & N/A & & & & & $35 \pm 9.9^{\mathrm{b}}$ & $1.9^{\mathrm{b}}$ & & 0.95 & 0.05 & 18 & $2.87^{\mathrm{a}}$ & -31.6 & $\mathrm{~N}=\mathrm{BDL}$ \\
\hline GB2-43 & 1-Mar-12 & 20 & 6.5 & & & & $1.75 \pm 0.05$ & 0.011 & & 0.09 & 0.01 & 166 & -1.7 & -26.9 & 5.7 \\
\hline GB2-43 & $47.53^{\circ} \mathrm{S}$ & 85 & 6.2 & 0.81 & 43 & 140 & $1.76 \pm 0.10$ & 0.022 & 0.15 & 0.09 & 0.01 & 82 & -0.4 & -27.3 & 5.7 \\
\hline GB2-43 & $64.01^{\circ} \mathrm{E}$ & 120 & 4.6 & 0.81 & 43 & 140 & $0.89 \pm 0.03$ & 0.037 & 0.17 & 0.13 & 0.03 & 24 & 0.7 & -27.8 & 5.1 \\
\hline GB2-43 & $\mathrm{zPAR}=$ & 300 & 3.0 & & & & $0.28 \pm 0.07$ & 0.013 & & 0.29 & 0.03 & 21 & $-0.6^{\mathrm{a}}$ & -24.1 & 7.2 \\
\hline GB2-43 & $108 \mathrm{~m}$ & 800 & 2.6 & & & & $0.13 \pm 0.02$ & 0.012 & & 0.47 & 0.04 & 11 & -0.9 & -24.1 & $\mathrm{~N}=\mathrm{BDL}$ \\
\hline GB2-43 blank & & $\mathrm{N} / \mathrm{A}$ & & & & & $57 \pm 7.8^{\mathrm{b}}$ & $2.6^{\mathrm{a}, \mathrm{b}}$ & & 0.96 & 0.04 & 22 & $2.87^{\mathrm{a}}$ & -31.6 & $\mathrm{~N}=\mathrm{BDL}$ \\
\hline GB2-100 & 14-Mar-12 & 20 & 13.0 & & & & $2.91 \pm 0.38$ & 0.133 & & 0.04 & 0.04 & 22 & 1.5 & -22.5 & 6.1 \\
\hline
\end{tabular}




\begin{tabular}{|c|c|c|c|c|c|c|c|c|c|c|c|c|c|c|c|}
\hline GB2-100 & $44.62^{\circ} \mathrm{S}$ & 90 & 12.7 & & & & $2.76 \pm 0.02$ & 0.151 & & 0.05 & 0.05 & 18 & 0.6 & -22.5 & 6.3 \\
\hline GB2-100 & $100.50^{\circ} \mathrm{E}$ & 110 & 11.4 & 0.89 & 11 & 171 & $0.50 \pm 0.02$ & 0.010 & 0.0074 & 0.12 & 0.02 & 50 & $0.4^{\mathrm{a}}$ & -24.2 & 7.6 \\
\hline GB2-100 & zPAR= & 300 & 10.4 & & & & $0.22 \pm 0.07$ & 0.030 & & 0.20 & 0.09 & 7 & 0.4 & -21.4 & 7.8 \\
\hline GB2-100 & $113 \mathrm{~m}$ & 800 & 7.9 & & & & $0.11 \pm 0.05$ & 0.028 & & 0.33 & 0.14 & 4 & -0.7 & -21.6 & 9.4 \\
\hline GB2-100 blank & & N/A & & & & & $36 \pm 15^{\mathrm{b}}$ & $3.2^{\mathrm{b}}$ & & 0.92 & 0.08 & 11 & $2.87^{\mathrm{a}}$ & -33.3 & $\mathrm{~N}=\mathrm{BDL}$ \\
\hline
\end{tabular}

*Values published in Rosengard et al. (2015).

${ }^{a}$ averaged value of other station measurements because not enough PIC for resolving measurement/gas lost after acid-hydrolysis.

${ }^{b}$ normalized to the total active area of the Whatman ${ }^{\mathrm{TM}}$ QMA filters, $125 \mathrm{~cm}^{2}$.

$\mathrm{BDL}=$ below detection limit. 
Table 2. Quantities of POC and PIC in each end-member and matrix (I-V) sample RPO analysis. The roman numerals following the Icelandic Spar and JGOFS sample ID's refer to the analysis number. The numerals following the E. huxleyi strain numbers refere to the culture replicate number. The total carbon loaded into the RPO reactor, $\mathrm{C}_{\text {Total, }}$, was calculated as the total $\mathrm{CO}_{2}$ evolved from the sample during ramped oxidation. $\mathrm{f}_{\mathrm{E}, \text { hux,,Total }}$ and $\mathrm{f}_{\text {Calcite,Total }}$ of each matrix mixture was calculated using the weighted sum $\delta^{13} \mathrm{C}$ values of all $\mathrm{CO}_{2}$ gas fractions across the matrix thermograms (Equation 6, Table 3).

\begin{tabular}{|c|c|c|c|c|c|c|c|c|}
\hline 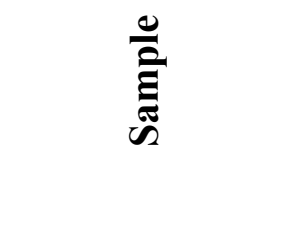 & 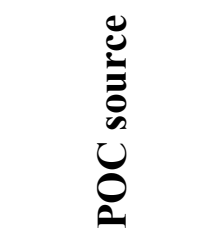 & 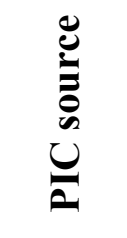 & & 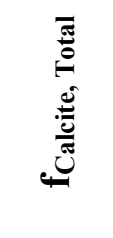 & U⿺辶 & 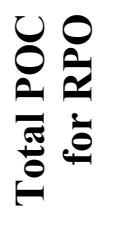 & 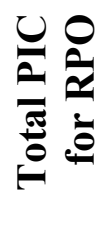 & 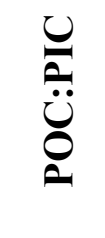 \\
\hline- & - & - & - & - & $\mu g$ & $\mu g$ & $\mu g$ & - \\
\hline Icelandic Spar - I & N/A & N/A & 0.00 & 1.00 & 450 & 0 & 450 & 0 \\
\hline Icelandic Spar -II & N/A & $\mathrm{N} / \mathrm{A}$ & 0.00 & 1.00 & 250 & 0 & 250 & 0 \\
\hline JGOFS MC-1-8 -I & N/A & $\mathrm{N} / \mathrm{A}$ & $0.06^{\mathrm{a}}$ & 0.94 & 950 & 57 & 893 & 0.06 \\
\hline JGOFS MC-1-8 -II & $\mathrm{N} / \mathrm{A}$ & $\mathrm{N} / \mathrm{A}$ & $0.06^{\mathrm{a}}$ & 0.94 & 250 & 0 & 235 & 0.06 \\
\hline E.hux.-373-I & N/A & $\mathrm{N} / \mathrm{A}$ & 1.00 & 0.00 & 593 & 593 & 0 & no PIC \\
\hline E.hux.-373-II & N/A & N/A & 1.00 & 0.00 & 570 & 570 & 0 & no PIC \\
\hline E.hux.-373-III & N/A & N/A & 1.00 & 0.00 & 828 & 828 & 0 & no PIC \\
\hline E.hux.-624-I & N/A & $\mathrm{N} / \mathrm{A}$ & 1.00 & 0.00 & 678 & 678 & 0 & no PIC \\
\hline Matrix I & E.hux.-373-III & Spar & 0.50 & 0.50 & 506 & 253 & 253 & 1 \\
\hline Matrix II & E.hux.-373-III & JGOFS & 0.59 & 0.41 & 464 & 274 & 190 & 1 \\
\hline Matrix III & E.hux.-373-II & Spar & $0.85^{*}$ & $0.15 *$ & 863 & $732 *$ & $132 *$ & $6^{*}$ \\
\hline Matrix IV & E.hux.-373-II & JGOFS & 0.88 & 0.12 & 339 & 299 & 41 & 7 \\
\hline Matrix V & E.hux.-373-I & JGOFS & 0.88 & 0.12 & 652 & 573 & 78 & 7 \\
\hline
\end{tabular}

* Approximation because of incomplete isotope quantification.

${ }^{a}$ Fraction of organic carbon in sample, assumed to be negligible in the matrix mixtures II, IV, and V. 
Table 3. Carbon quantities and bulk $\delta^{13} \mathrm{C}$ values of Great Calcite Belt samples and PIC end-members measured by different approaches. The three POC quantities were normalized to QMA filter area $\left(125 \mathrm{~cm}^{2}\right)$ and either calculated as the total $\mathrm{CO}_{2}$ evolved during ramped oxidation, measured by closed tube combustion (CTC), or measured by two different elemental analyzers. The weighted sums $\delta^{13} \mathrm{C}$ values of thermogram gas fractions were compared to separately measured $\delta^{13} \mathrm{C}_{\text {bulk }}$ values.

\begin{tabular}{|c|c|c|c|c|c|c|c|c|c|}
\hline 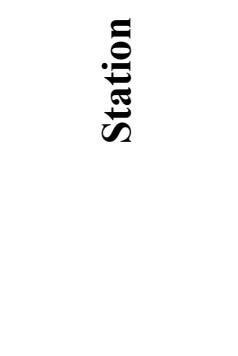 & $\frac{\bar{a}}{\tilde{0}}$ & 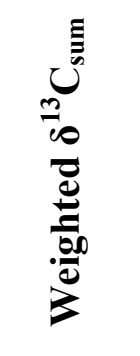 & 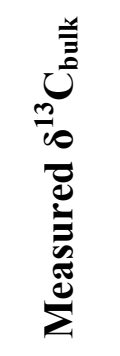 & 造 & 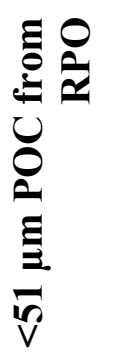 & 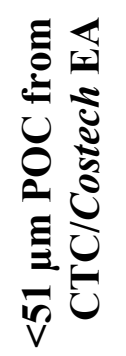 & 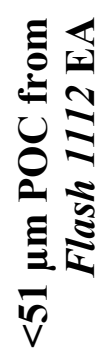 & 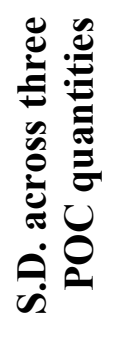 & 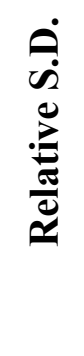 \\
\hline- & meters & $\%$ & $\%$ & $\%$ & umol & umol & $\mu m o l$ & $\mu m o l$ & $\%$ \\
\hline Spar & N/A & 2.7 & 3.0 & -0.25 & N/A & N/A & N/A & N/A & N/A \\
\hline JGOFS & $\mathrm{N} / \mathrm{A}$ & -1.1 & -0.9 & -0.18 & N/A & N/A & N/A & $\mathrm{N} / \mathrm{A}$ & N/A \\
\hline GB1-117 & 25 & -21.2 & -20.5 & -0.74 & 1272 & 1497 & 1573 & 157 & $11 \%$ \\
\hline GB1-117 & 62 & no data* & -21.5 & no data & 1262 & 1488 & 1530 & 144 & $10 \%$ \\
\hline GB1-117 & 162 & -22.3 & -20.9 & -1.36 & & 281 & 269 & 23 & $9 \%$ \\
\hline GB1-117 & 300 & -24.3 & -21.3 & -3.04 & 153 & 154 & 165 & 7 & $4 \%$ \\
\hline GB1-117 & 1000 & -23.7 & -23.0 & -0.75 & 83 & 42 & 67 & 21 & $32 \%$ \\
\hline GB1-117 blank & N/A & no data* & -29.81 & no data & 35 & 54 & 42 & 10 & $23 \%$ \\
\hline GB2-43 & 20 & -28.4 & -27.1 & -1.32 & 625 & 604 & 642 & 19 & $3 \%$ \\
\hline GB2-43 & 85 & no data* & -27.3 & no data & 616 & 637 & 686 & 36 & $6 \%$ \\
\hline GB2-43 & 120 & -28.3 & -27.1 & -1.20 & 390 & 373 & 368 & 12 & $3 \%$ \\
\hline GB2-43 & 300 & -26.7 & -25.1 & -1.60 & 143 & 116 & 187 & 36 & $24 \%$ \\
\hline GB2-43 & 800 & no data* & -25.9 & no data & 62 & 69 & 79 & 9 & $12 \%$ \\
\hline GB2-43 blank & N/A & -33.1 & -30.12 & -3.00 & 57 & 66 & 50 & 8 & $13 \%$ \\
\hline GB2-100 & 20 & -21.5 & -21.8 & 0.28 & 1007 & no data & 1193 & 131 & $12 \%$ \\
\hline GB2-100 & 90 & no data* & -21.8 & no data & 749 & no data & 755 & 4 & $1 \%$ \\
\hline GB2-100 & 110 & -26.1 & -24.5 & -1.62 & 284 & 279 & 297 & 10 & $3 \%$ \\
\hline GB2-100 & 300 & -22.1 & -21.2 & -0.90 & 136 & 116 & 192 & 40 & $27 \%$ \\
\hline GB2-100 & 800 & -24.1 & -21.6 & -2.53 & 63 & no data & 106 & 30 & $36 \%$ \\
\hline GB2-100 blank & $\mathrm{N} / \mathrm{A}$ & -30.8 & -30.41 & -0.36 & 36 & 40 & 64 & 15 & $32 \%$ \\
\hline
\end{tabular}


Table 4. $\delta^{13} \mathrm{C}$ values of $\mathrm{CO}_{2}$ evolved within intervals $\mathrm{T}_{1}\left(100^{\circ} \mathrm{C}-420^{\circ} \mathrm{C}\right)$ and $\mathrm{T}_{2}\left(420^{\circ} \mathrm{C}-\right.$ $700^{\circ} \mathrm{C}$ ) of each sample thermogram. These values are corrected for the contributions of blank carbon sorption and PIC to the total carbon in each temperature interval (Equations 10-12). Starred recombined bulk values deviate the most from the bulk $\delta^{13} \mathrm{C}_{\mathrm{POC}}$ reported in Table 1. Underlined numbers refer to the numbers used to calculate the average euphotic zone $\delta^{13} \mathrm{C}_{\mathrm{POC}, \mathrm{T} 1}$ and $\delta^{13} \mathrm{C}_{\mathrm{POC}, \mathrm{T} 2}$ values reported in Fig. 12.

\begin{tabular}{|c|c|c|c|c|c|}
\hline Station & Depth & $\delta^{13} C_{P O C, T 1}$ & $\delta^{13} C_{P O C, T 2}$ & $\Delta \delta^{13} C_{\text {POC }}$ & $\begin{array}{c}\text { Recombined } \\
\text { bulk } \delta^{13} \mathbf{C}\end{array}$ \\
\hline- & meters & $\% o$ & $\% o$ & $\left(T_{1}-T_{2}\right) \% o$ & $\%$ \\
\hline 117 & 25 & $-22.7 \pm 0.1$ & $-21.0 \pm 0.3$ & -1.7 & -21.9 \\
\hline 117 & 62 & $-21.8 \pm 0.1$ & $-23.8 \pm 0.3$ & 2.0 & -23.0 \\
\hline 117 & 162 & $-22.4 \pm 0.4$ & $\overline{-27.7 \pm 1.4}$ & 5.3 & -24.5 \\
\hline 117 & 300 & $-23.7 \pm 0.8$ & $-24.0 \pm 0.9$ & 0.3 & -23.9 \\
\hline 117 & 1000 & $-24.0 \pm 0.9$ & $-28.8 \pm 1.6$ & 4.8 & -26.0 \\
\hline 43 & 20 & $-29.52 \pm 0.14$ & $-26.9 \pm 0.1$ & -2.6 & -28.2 \\
\hline 43 & 85 & $-30.0 \pm 0.1$ & $-27.9 \pm 0.2$ & -2.1 & -29.0 \\
\hline 43 & 120 & $-27.1 \pm 0.2$ & $-31.0 \pm 0.3$ & 3.9 & -28.9 \\
\hline 43 & 300 & $-23.0 \pm 1.5$ & $-26.0 \pm 0.7$ & 3.0 & -24.7 \\
\hline 43 & 800 & $-8.0 \pm-7.0$ & $-23.1 \pm 1.0$ & No data & -17.3 \\
\hline 100 & 20 & $-20.8 \pm 0.3$ & $-22.9 \pm 0.4$ & 2.1 & -22.1 \\
\hline 100 & 90 & No data & No data & No data & No data \\
\hline 100 & 110 & $-26.2 \pm 0.4$ & $-25.7 \pm 0.2$ & -0.5 & -26.0 \\
\hline 100 & 300 & $-18.0 \pm 2.8$ & $-26.5 \pm 3.2$ & 8.5 & -22.2 \\
\hline 100 & 800 & $-16.0 \pm 5.0$ & $-42.0 \pm 17.0$ & No data & -26.3 \\
\hline
\end{tabular}

*>4 \%o different from $\delta^{13} \mathrm{C}_{\text {bulk }}$ 


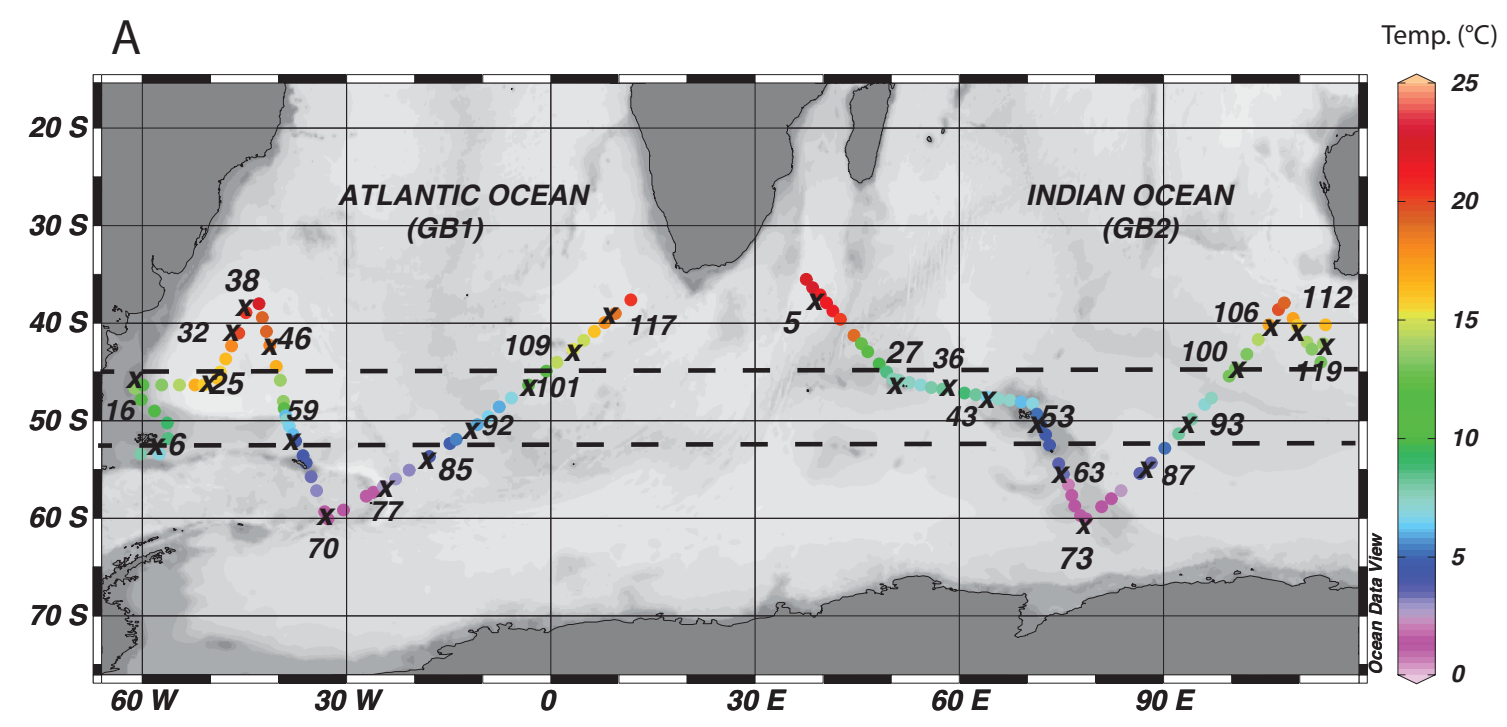

B

$\mathrm{PIC}$ :BSi ratios in $>51 \mu \mathrm{m}$ particles at $\mathrm{z}_{\mathrm{PAR}}$

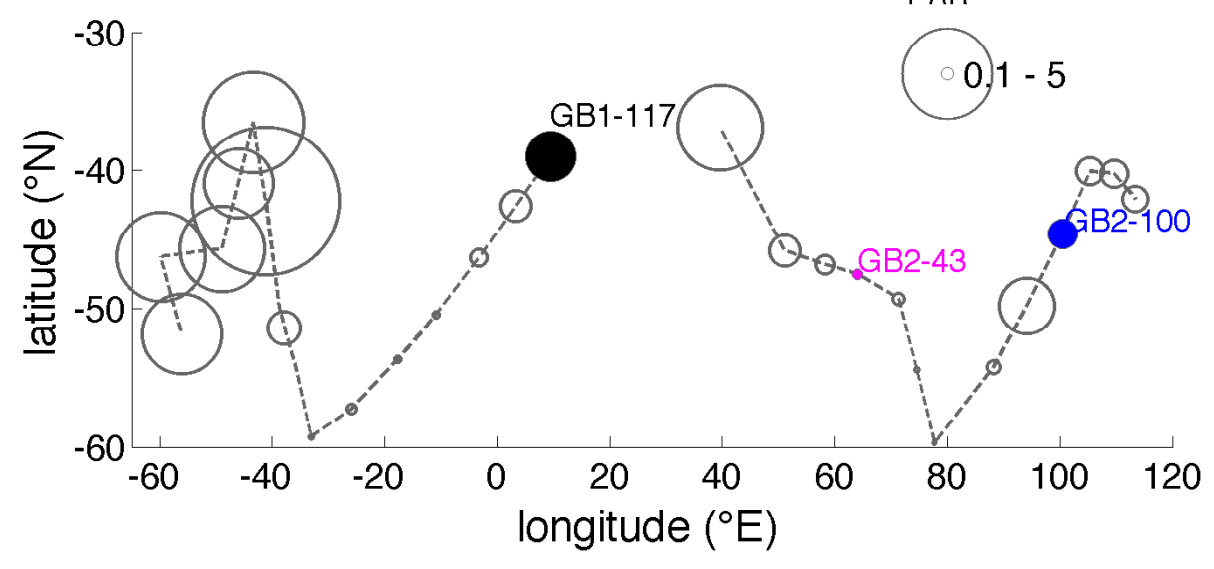

Figure 1. (a) Cruise tracks GB1 and GB2 across the Southern Ocean Great Calcite Belt region (image from Rosengard et al., 2015). The " $x$ " notation indicates each profile of $<51$ and $>51 \mu \mathrm{m}$ diameter particles. The color bar represents surface seawater temperature $\left({ }^{\circ} \mathrm{C}\right)$. (b) $>51 \mu \mathrm{m}[\mathrm{PIC}] /[\mathrm{BSi}]$ ratios at the export depth $\mathrm{z}_{\mathrm{PAR}}$, or the depth of $0.3 \%$ photosynthetically available radiation, of every particle sampling station (values reported in Rosengard et al., 2015). The bubble sizes scale with the ratio. The filled bubbles indicate the ratios at stations selected for RPO analysis. 

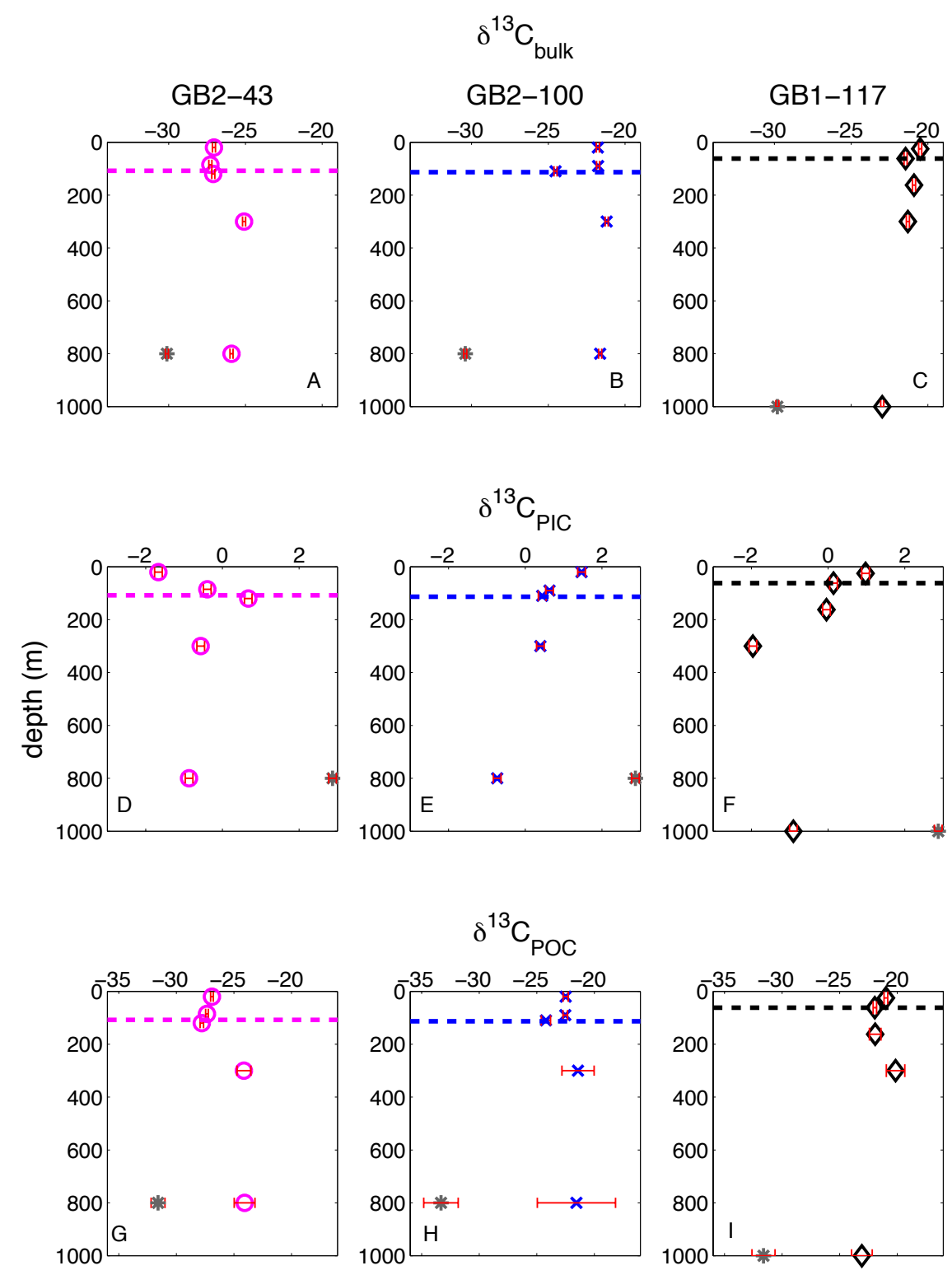

Figure 2. (a-c) Profiles of $\delta^{13} \mathrm{C}_{\text {bulk }}$ (\%) measured in $<51 \mu \mathrm{m}$ POC samples and deployment blanks at stations GB2-43, GB2-100 and GB1-117. (d-f) $\delta^{13} \mathrm{C}_{\text {PIC }}(\%)$ profiles in samples and blanks, measured after acid hydrolysis. (g-i) $\delta^{13} \mathrm{C}_{\mathrm{POC}}(\%)$ profiles, calculated by Equation 3. In all panels, the horizontal lines are the depth of ZPAR (Table 1 ), and the gray stars represent the respective $\delta^{13} C_{\text {bulk }}, \delta^{13} C_{\mathrm{PIC}}$ or $\delta^{13} \mathrm{C}_{\mathrm{POC}}$ values of the deployment blank collected at each station. 


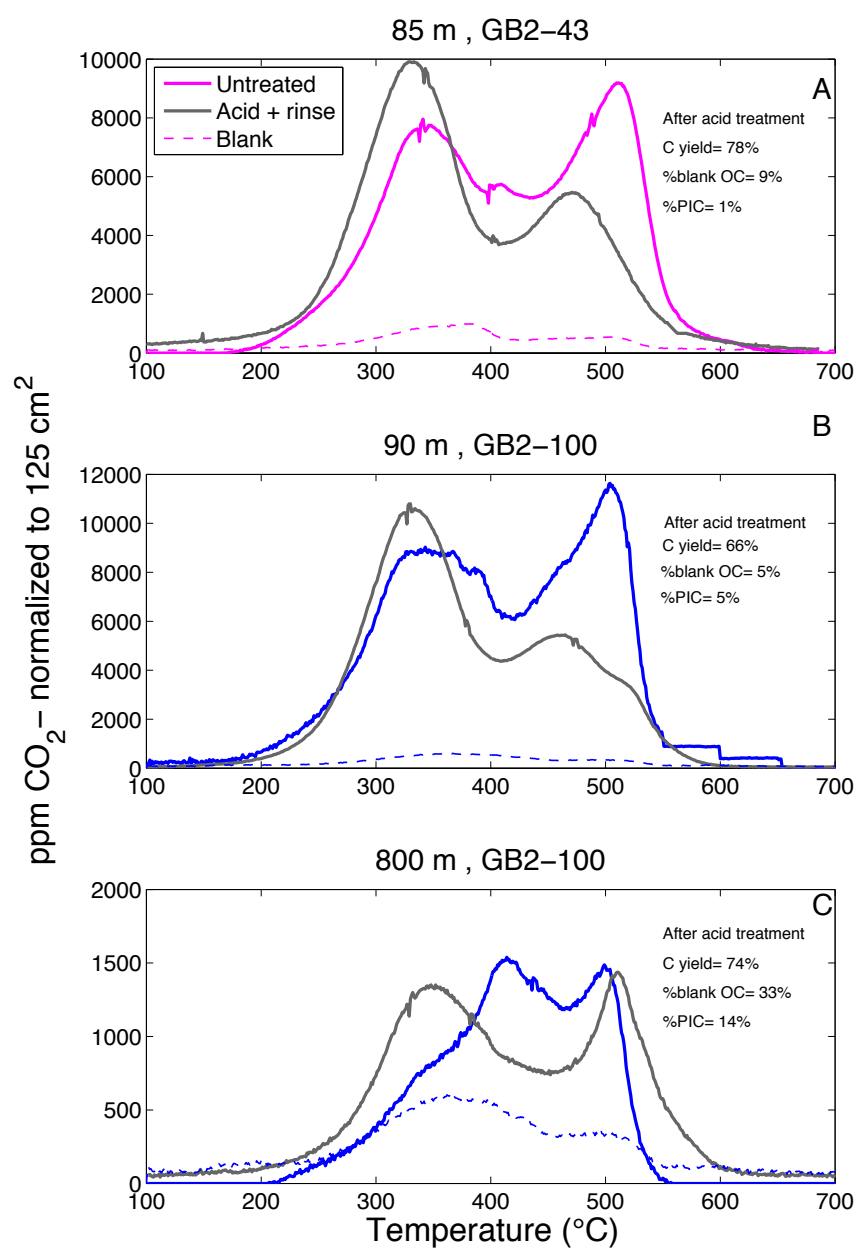

Figure 3. Thermograms of three Great Calcite Belt samples analyzed once after acid fumigation and rinsing (solid gray line), and again without any treatment (solid colored line). All y-axis values have been normalized to the $125 \mathrm{~cm}^{2}$ active QMA filter area. The normalized y-axis values for the untreated thermogram were blank-corrected by subtracting the contribution from the filter-normalized blank carbon thermogram (dashed colored line). Carbon yield, reported on each panel, is the $\mathrm{CO}_{2}$ quantity released in the fumigated sample run relative to the $\mathrm{CO}_{2}$ quantity released in the non-fumigated sample run. 


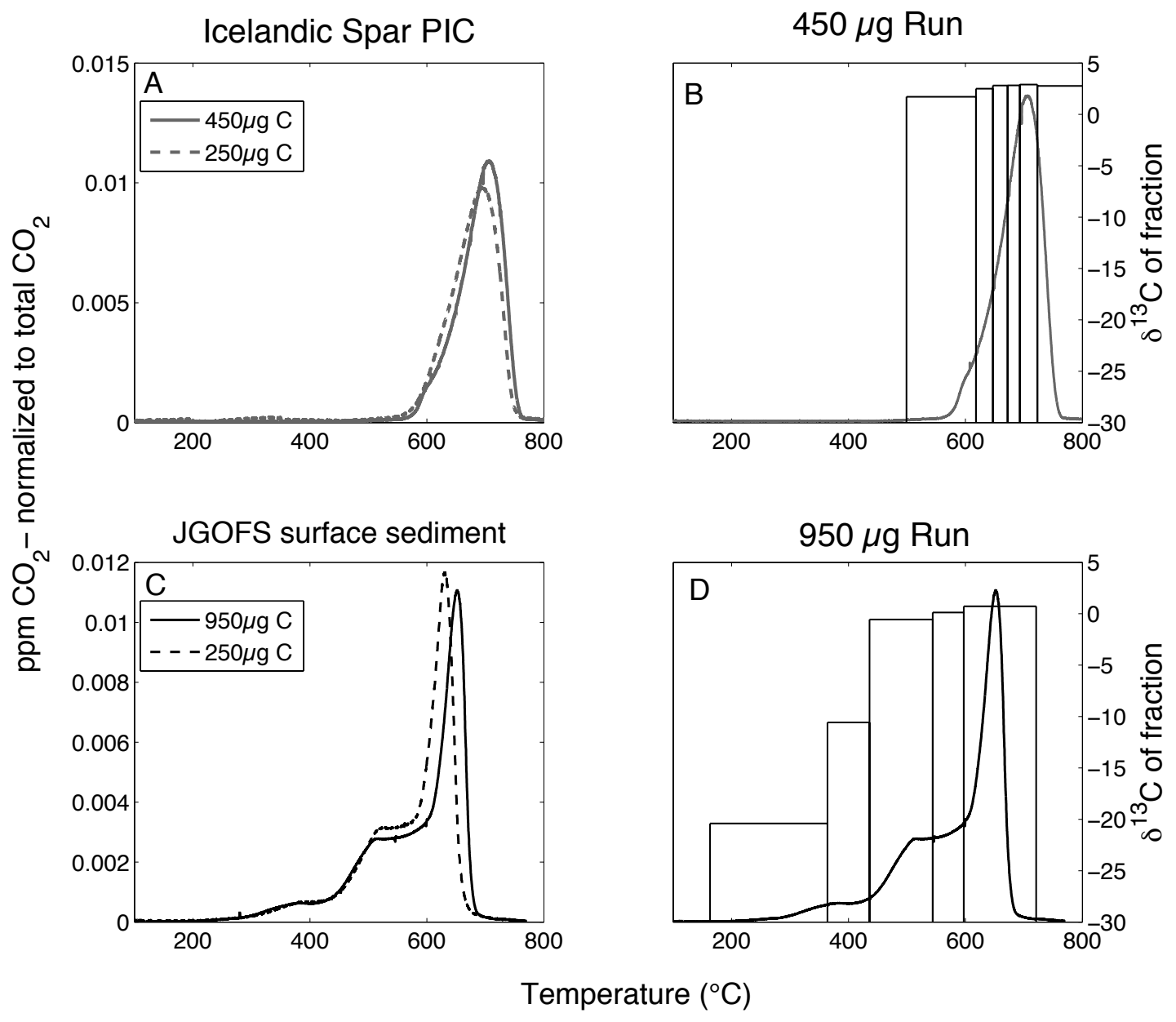

Figure 4. (a-b) Thermograms of two quantities of 100\% PIC Icelandic spar analyzed by ramped oxidation. $\delta^{13} \mathrm{C}(\%)$ of gas fractions, only measured in the $450 \mu \mathrm{g}$ analysis, are represented by the height of the bars. (c-d) Thermograms of two quantities of JGOFS sediment from a Southern Ocean core top at $60^{\circ} \mathrm{S}, 170^{\circ} \mathrm{W} . \delta^{13} \mathrm{C}$ of gas fractions were only measured in the $1000 \mu \mathrm{g}$ analysis. All y-axis quantities in panels a and c are normalized to the total $\mathrm{CO}_{2}$ released during ramped oxidation. 


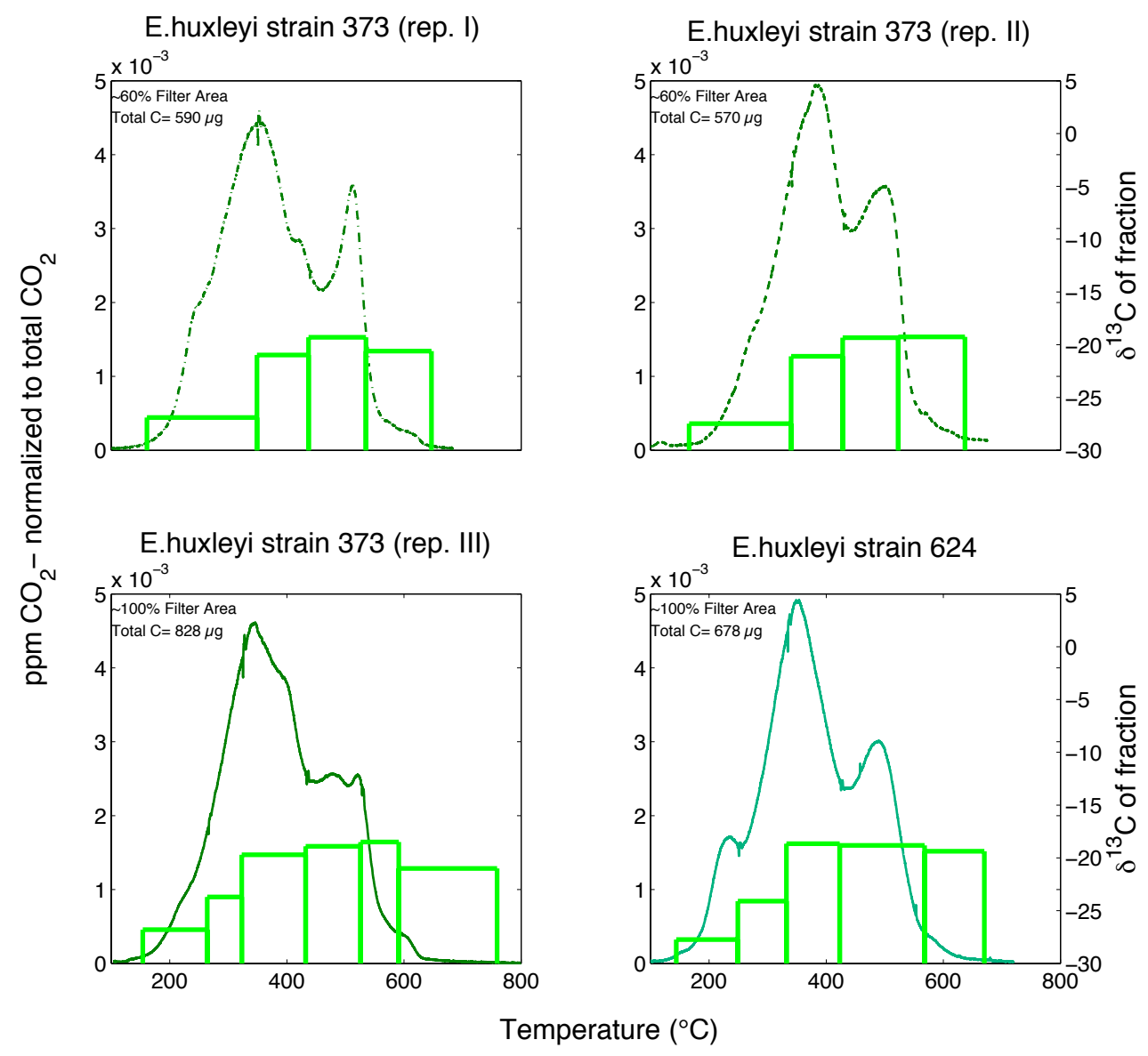

Figure 5. Thermograms and gas fraction $\delta^{13} \mathrm{C}$ values (\%; height of bars) of three replicates (rep. I, rep. II, rep. III) of E. huxleyi strain CCMP373 and one replicate of $E$. huxleyi strain DHP624. All y-axis quantities are normalized to the total $\mathrm{CO}_{2}$ released during ramped oxidation. 

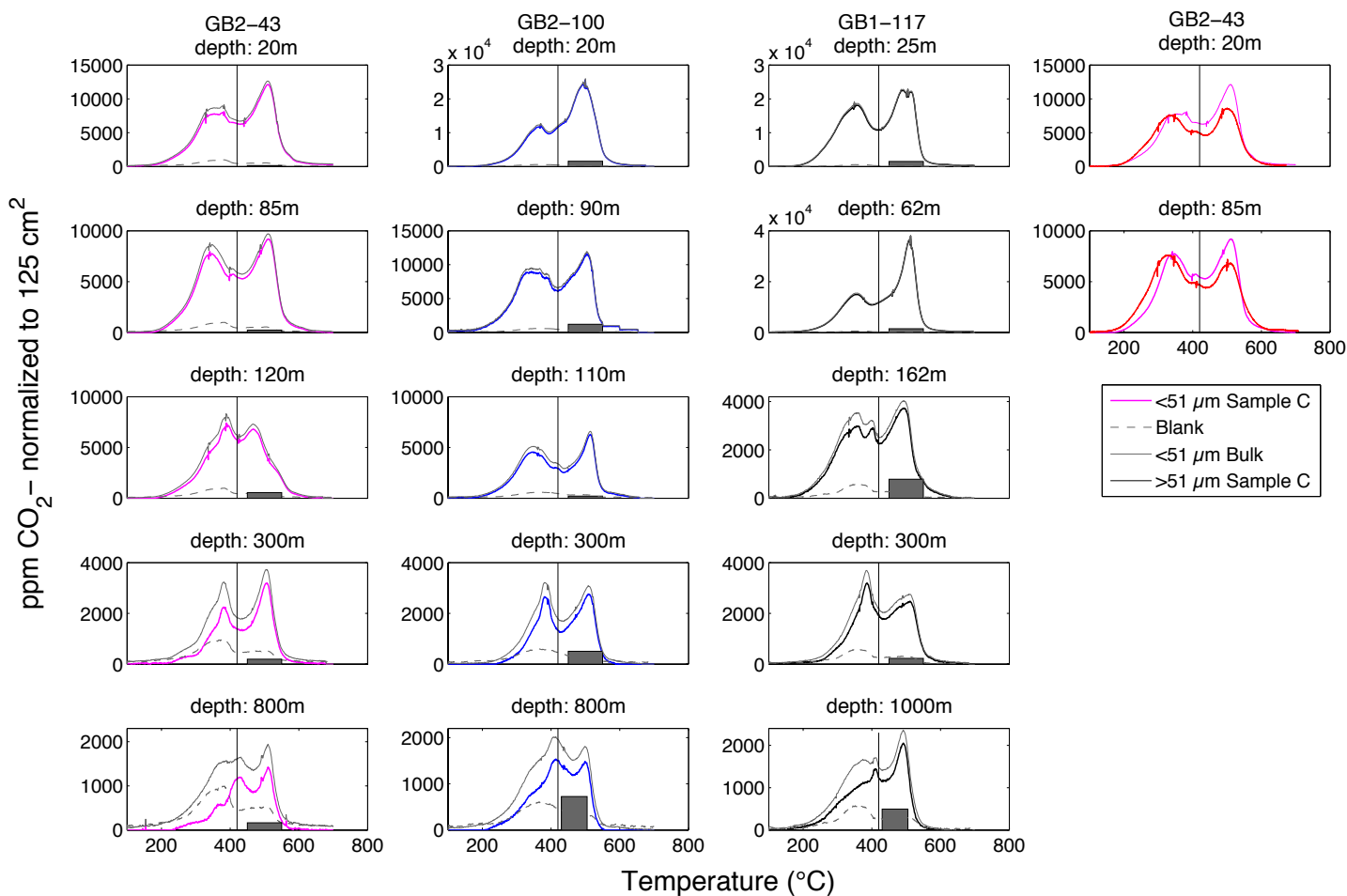

Figure 6. Thermograms of total carbon in fifteen $<51 \mu \mathrm{m}$ particle samples (solid gray lines) at five depths at GB2-43 (column 1), GB2-100 (column 2), and GB1-117 (column 3). All y-axis values represent $\mathrm{CO}_{2}$ concentrations normalized to $125 \mathrm{~cm}^{2}$ active QMA filter area. The dashed gray lines are thermograms of deployment blank carbon at each station. Blank thermograms were subtracted from the particle thermograms to yield sample carbon thermograms, shown as colored lines. The PIC contribution in each sample is represented in the area of the gray bar shown above $420^{\circ} \mathrm{C}$ (Table 1). Column 4 also shows thermograms of $>51 \mu \mathrm{m}$ particles from two depths at GB2-43, which were not blank or PIC-corrected. 

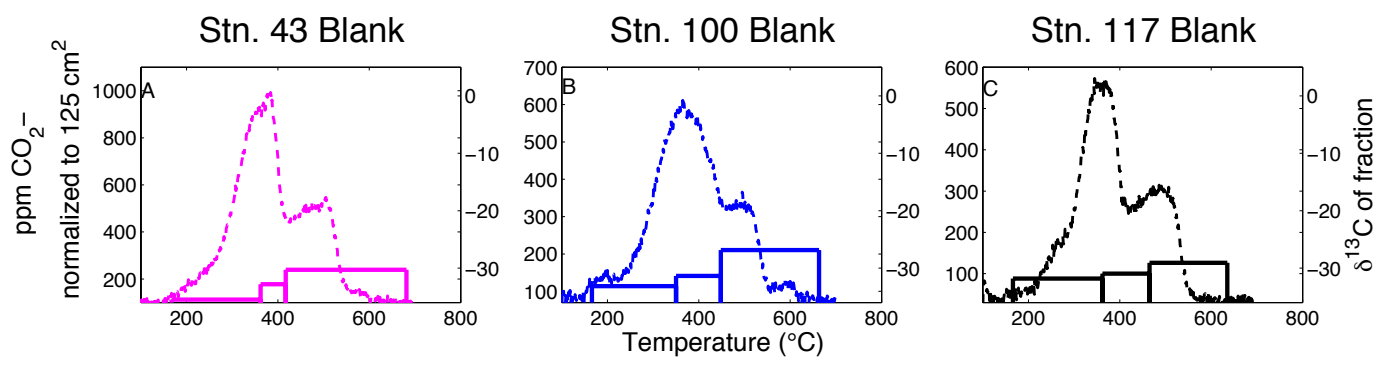

Figure 7. Thermograms of deployment blank filters and $\delta^{13} \mathrm{C}$ of $\mathrm{CO}_{2}$ gas fractions (\%; height of bars) collected within three specific temperature intervals. The y-axis is the range of $\mathrm{CO}_{2}$ concentration normalized to the active area of the QMA filters. 


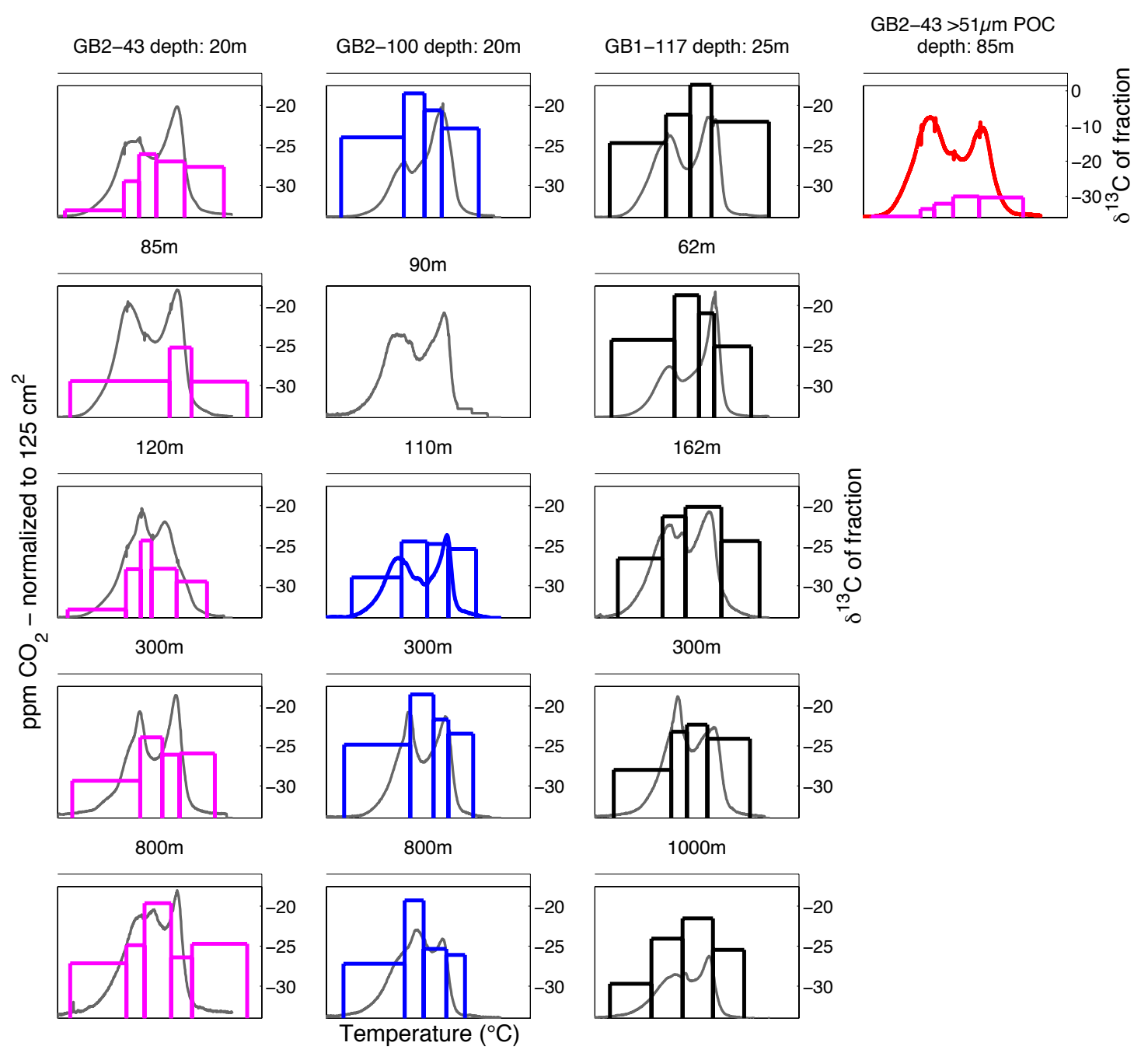

Figure 8. Thermograms of total $<51 \mu \mathrm{m}$ sample carbon and $\delta^{13} \mathrm{C}$ of gas fractions (\%o; height of bars) collected in specific temperature intervals. The $\delta^{13} \mathrm{C}$ of gas fractions collected in one $>51 \mu \mathrm{m}$ sample thermogram (GB2-43, $85 \mathrm{~m}$ ) is shown in the fourth column. The y-axis is the range of $\mathrm{CO}_{2}$ concentration normalized to the active area of the QMA filter (Fig. 6). 

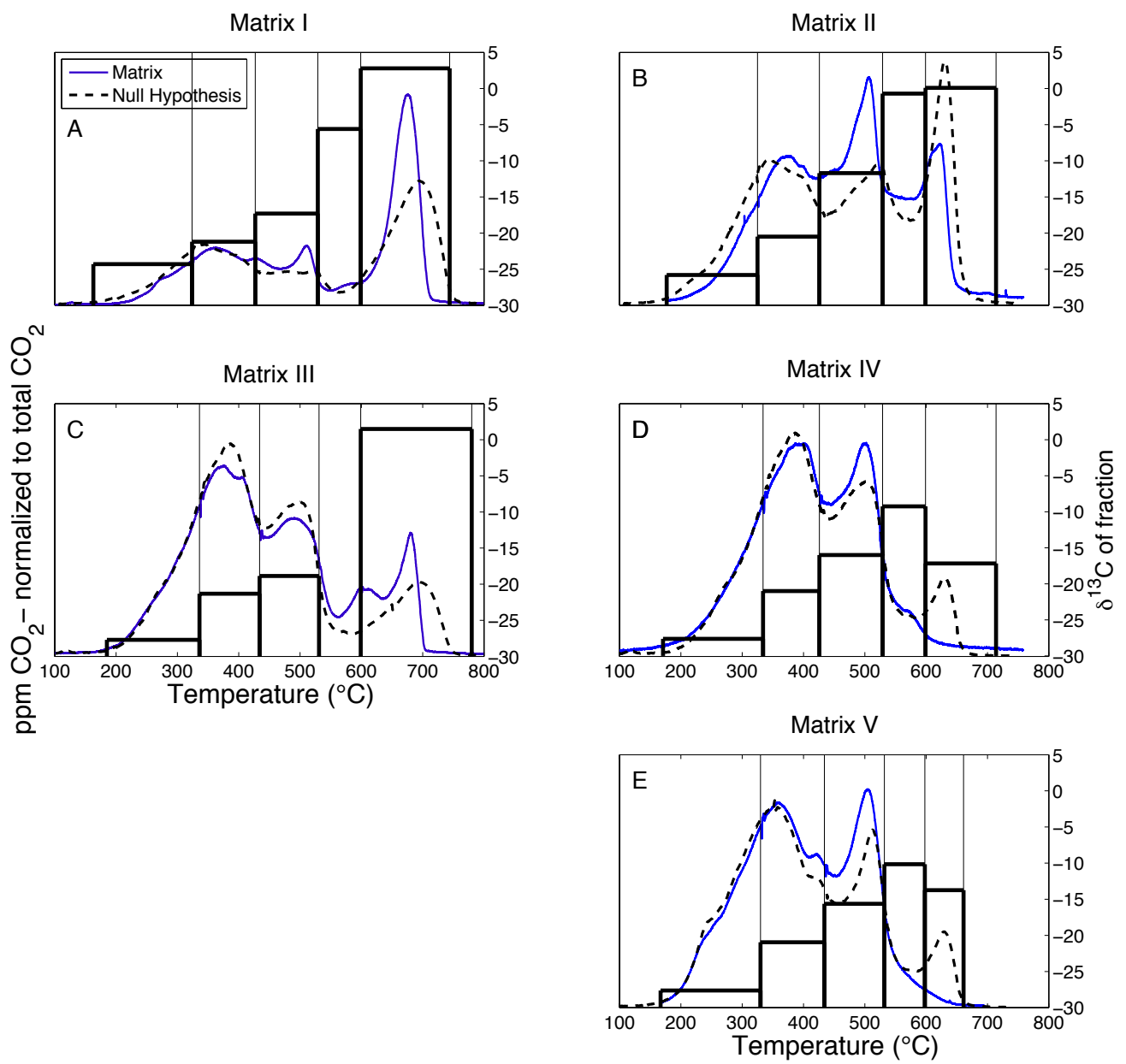

Figure 9. Thermograms of five artificial mixtures with varying proportions of $E$. huxleyi culture-derived organic carbon and PIC (colored solid lines) (Table 2). The source in matrices I and III is an Icelandic Spar (a, c), while the PIC source in matrices II, IV and V $(b, d, e)$ is a Southern Ocean core top sediment collected during JGOFS (Sayles et al., 2001). Roughly equal molar proportions of POC and PIC comprise mixtures I and II, while mixtures III, IV and V are more POC-rich. The bar heights represent the $\delta^{13} \mathrm{C}(\%)$ of $\mathrm{CO}_{2}$ gas fractions within specific temperatures. The dashed lines represent "null hypothesis" thermograms generated by the linear addition of each organic and PIC-rich end-member thermogram scaled to the POC:PIC ratios in each matrix (Table 2). 

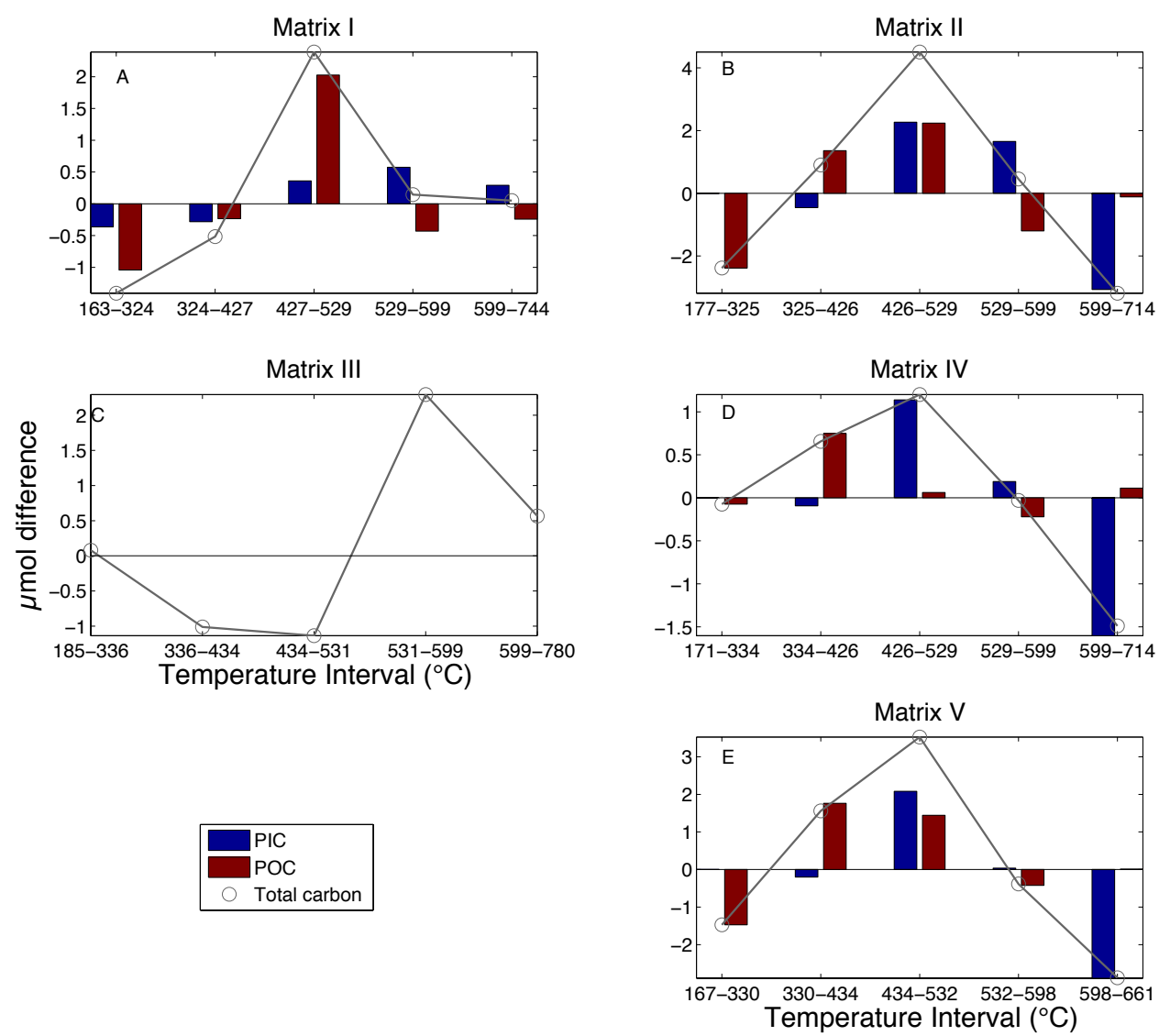

Figure 10. The absolute difference ( $\mu \mathrm{mol})$ between the masses of culture- or PIC-derived $\mathrm{CO}_{2}$ observed within temperature intervals of each matrix thermogram and expected within similar intervals of each null hypothesis thermogram. These differences are equivalent to $\operatorname{mass}_{\text {Calcite,obs, },}-$ mass $_{\text {Calcite, null, },}$ for the blue bars and $\operatorname{mass}_{E . h u x ., o b s, i}-$ $\operatorname{mass}_{E . h u x ., n u l l, i}$ for the red bars, as defined by Equations 7-9. No actual POC and PIC differences were calculated in panel $\mathrm{C}$ because of a lost $\delta^{13} \mathrm{C}$ measurement. The cumulative POC or PIC lost across some fractions does not always equal the cumulative POC or PIC mass gain in other fractions because of imprecision in the calculation of $f_{\text {Calcite, obs, } i}$ in Equation 8, which affects the calculations in Equation 9. 


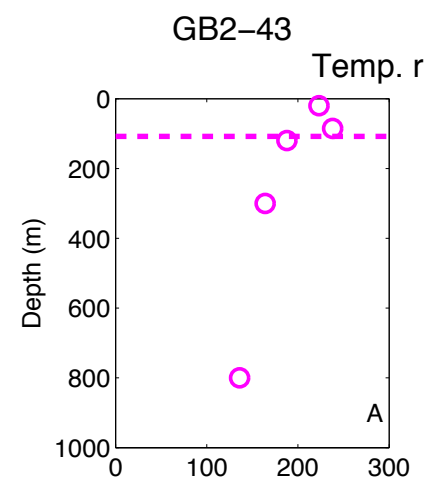

GB2-100

GB1-117
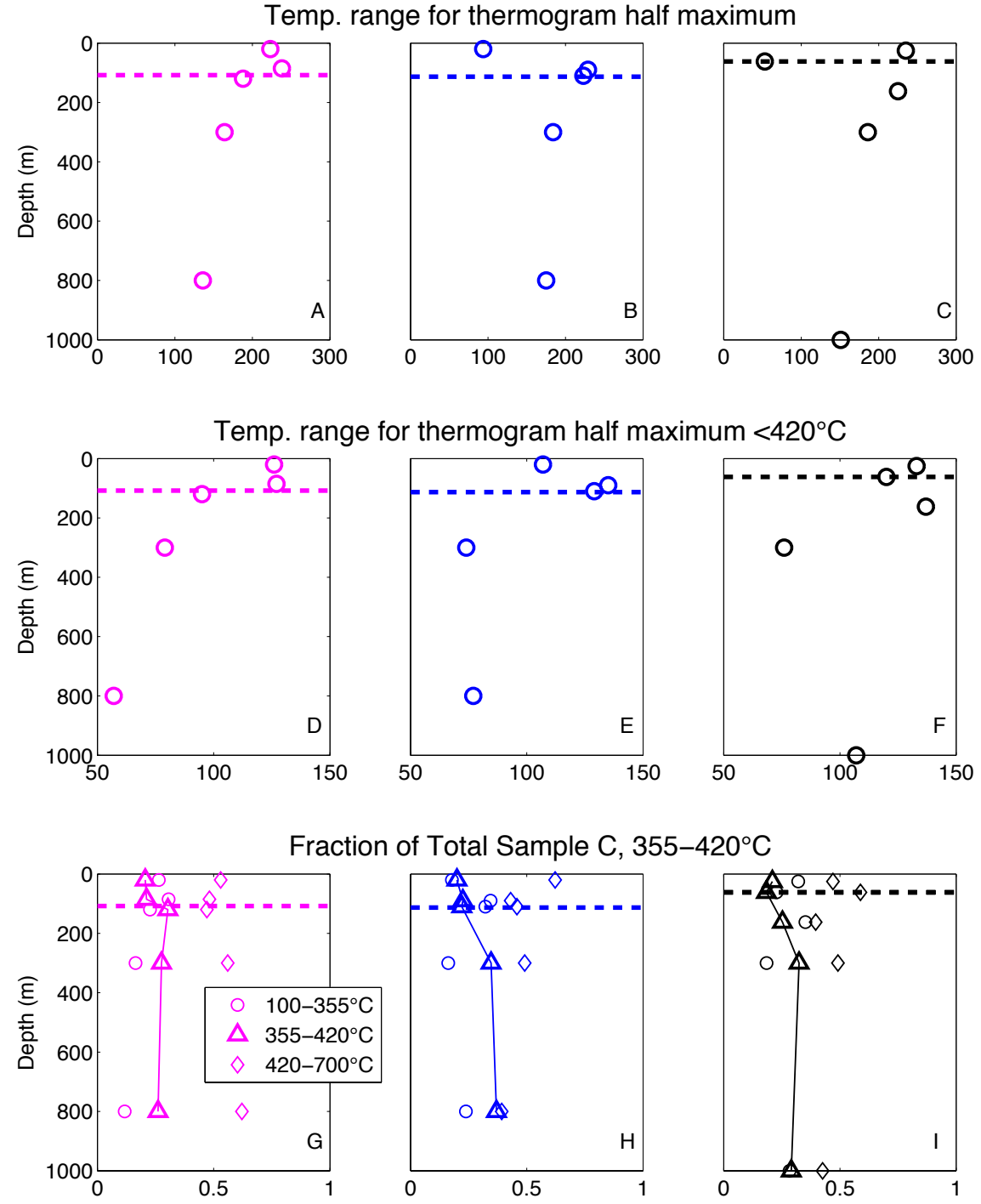

Figure 11. Three metrics that describe the narrowing thermal stability distribution of POC with depth across GB2-43, GB2-100 and GB1-117 (Table 1, Fig. 1). (a-c) The temperature range over which thermogram $\mathrm{CO}_{2}$ concentration exceeds the half maximum. (d-f) The temperature range over which thermogram $\mathrm{CO}_{2}$ concentration below $420^{\circ} \mathrm{C}$ exceeds the half maximum below $420^{\circ} \mathrm{C}$. (g-i) The fraction of total POC that oxidizes between $100-355^{\circ} \mathrm{C}, 355-420^{\circ} \mathrm{C}$, and $420-700^{\circ} \mathrm{C} .355^{\circ} \mathrm{C}$ is the average $\mathrm{T}_{\max }$ of the lowest temperature peak in the euphotic zone sample thermograms, while $420^{\circ} \mathrm{C}$ is operationally defined as the lower limit of PIC decomposition. The highest temperature fraction is PIC-corrected. In all panels, the dashed line is the depth of Z ZPR (Table 1). Illustrations of how each metric was calculated are provided in Appendix B, Fig. S4. 

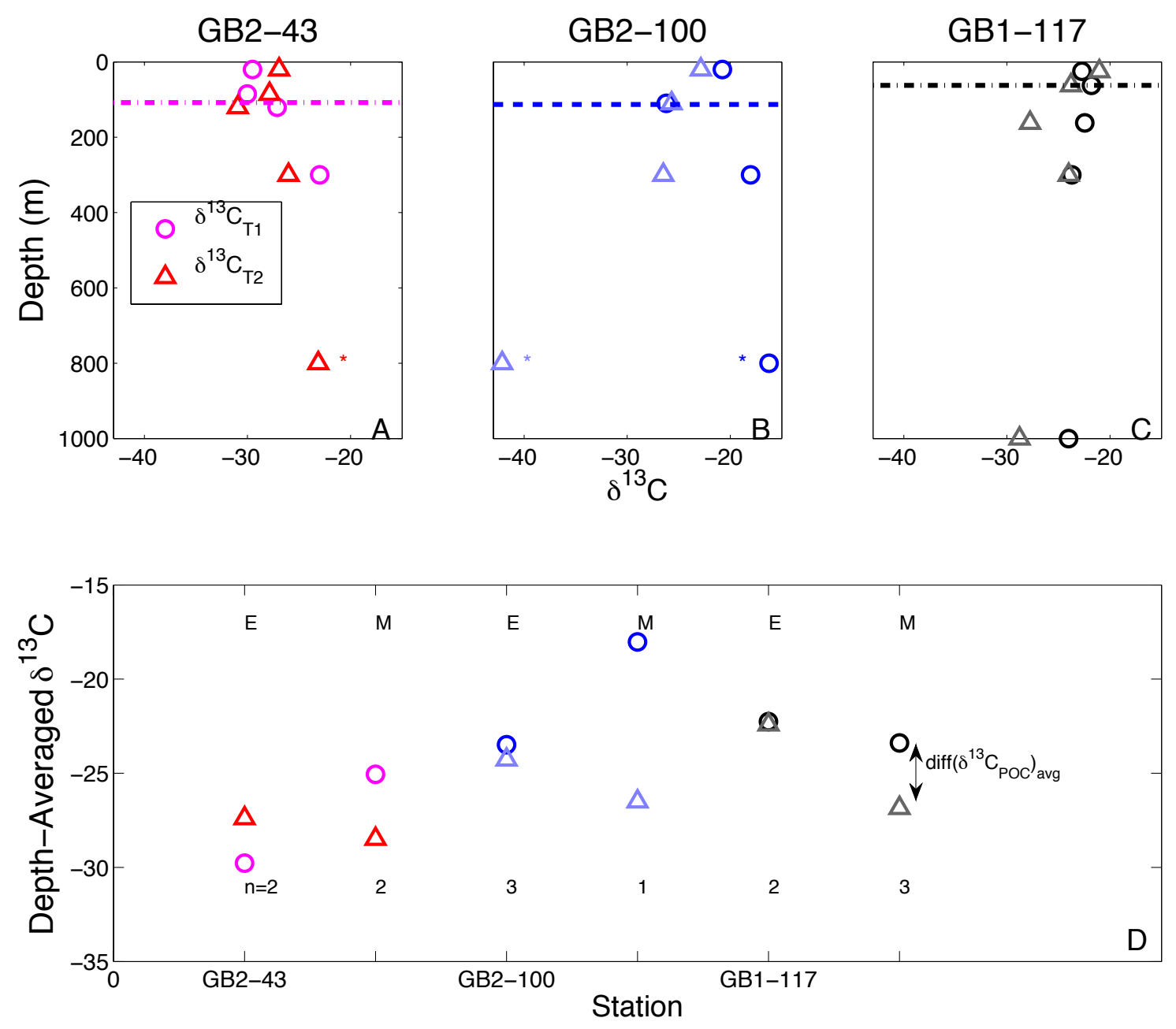

Figure 12. (a-c) $\delta^{13} \mathrm{C}_{\mathrm{POC}}$ values (\%o) of $\mathrm{CO}_{2}$ oxidized within intervals $\mathrm{T}_{1}$ and $\mathrm{T}_{2}$ $\left(\delta^{13} \mathrm{C}_{\mathrm{POC}, \mathrm{T} 1}\right.$ and $\delta^{13} \mathrm{C}_{\mathrm{POC}, \mathrm{T} 2}$, respectively) of the $<51 \mu \mathrm{m}$ sample thermograms. The starred values have high error bars due to relatively large blank and PIC corrections, and are either omitted from or cautiously interpreted in the discussion. The dashed lines represent the export depth, $\mathrm{Z}_{\mathrm{PAR}}$ (Table 1). (d) Average $\delta^{13} \mathrm{C}_{\mathrm{POC}, \mathrm{T} 1}$ (circles) and $\delta^{13} \mathrm{C}_{\mathrm{POC}, \mathrm{T} 2}$ (triangles) across euphotic zone (labeled "E" above data points) and mesopelagic zone (labeled "M" above data points) sample thermograms. The number of sample values averaged in each depth zone is indicated below the data points. 


\section{Chapter 5:}

\section{Diagnosing and quantifying organic carbon sources to suspended sediments in the Amazon River main stem}




\begin{abstract}
The Amazon River mobilizes organic carbon across one of the world's largest terrestrial carbon reservoirs, supplying $\sim 6-8 \%$ of the global riverine particulate organic carbon (POC) flux to the oceans. Constraining the contribution of different terrestrial sources to this flux, and their fate in the coastal Atlantic Ocean, is challenging in such a vast and dynamic system, but essential to understanding the role of Amazonia in the global carbon cycle. Here, we identify and quantify different sources to the POC flux at Óbidos, the most downstream gauging station of the Amazon main stem, by integrating bulk, compound-specific, and ramped pyrolysis/oxidation (RPO) analyses of riverine POC. The latter uses a controlled temperature ramp to decompose samples into constituents with different thermal stabilities that can be further analyzed for isotopic composition (stable carbon and radiocarbon). Ten to eleven suspended sediment samples were analyzed from within the cross-section at Óbidos (Brazil) during two different stages of the river's hydrologic cycle. These data were compared to analyses of surface suspended sediment samples from the Madeira, Solimões and Tapajós Rivers. Bulk isotope and $\mathrm{C}: \mathrm{N}$ compositions suggest that riverine POC in the Amazon River is predominantly soil-derived, while the RPO data point to input from three thermally distinct soil pools from a range of landscapes and/or degradation histories. The RPO data also show that up to $4 \%$ of total main stem POC is petrogenic, confirming earlier assessments based on bulk OC radiocarbon analysis. Using Acoustic Doppler Current Profiler transects data from 2014, we calculate the flux of these soil and petrogenic components through the cross-section at Óbidos. Finally, using RPO analyses of POC collected from three other major tributaries upstream and downstream of Óbidos, we discuss the diagenetic stability of the four thermally distinct POC pools as they are exported to the ocean.
\end{abstract}

\title{
$1 \quad$ Introduction
}

The Amazon River Basin, a global biodiversity hotspot, is one of the largest reservoirs for reactive organic carbon on the planet. The river network includes eight 
major tributaries and supplies $\sim 6.3 \times 10^{12} \mathrm{~m}^{3} /$ year of water (Molinier et al., 1996) to the coastal Atlantic Ocean, comprising 20\% of the global freshwater flux. Draining through six million square kilometers of flooded rainforest, drier savannah, high-elevation Andean landscape, as well as cropland and pasture, the river delivers $\sim 12-14 \mathrm{Tg} / \mathrm{yr}$ particulate organic carbon (POC) from the basin to the Atlantic Ocean, $\sim 6-8 \%$ of the global annual riverine POC export to the ocean (Richey et al., 1990; Galy et al., 2015). Accurately tracking the fate of this massive flux has bearings on the residence time of terrestrial organic carbon from the Amazon reservoir, and our understanding of the Amazon basin's role in the global carbon cycle (Cole et al., 2007; Aufdenkampe et al., 2007; Butman et al., 2016;).

There are several options for the fate of POC mobilized by the Amazon River (Cole et al., 2007): it can be respired by bacteria or photo-oxidized in transit (Richey et al., 1990; Amon and Benner, 1996; Mayorga et al., 2005) or in the coastal Atlantic Ocean (Aller et al., 1996; Blair and Aller, 2012), buried for the shorter-term in the river bed or flood plains (Guyot et al., 1996), or buried for longer time scales on the continental shelf (Kastner and Goñi, 2003). Quantifying how riverine POC partitions among these pathways relies on accurately measuring carbon fluxes and describing the POC composition in suspended river sediments. POC composition is particularly important because several studies have shown that certain classes of biomolecules in the organic matrix preferentially degrade during transit in the river (Mayorga et al., 2005; Ward et al., 2013), suggesting that POC quality is important for the fate of Amazon River POC.

Several challenges constrain our ability to accurately measure POC flux and composition in the Amazon River Basin. One challenge is where measurements and river sampling occur. Most studies of riverine geochemistry and POC transport through the Amazon River main stem occur near the municipality Óbidos in the state of Pará (Fig. 1a), the most downstream gaging station that is still outside the zone of salt intrusion from the Atlantic Ocean, $\sim 900 \mathrm{~km}$ upstream of the river's mouth. The river's particle composition at Óbidos integrates sediment input from most of the major Amazonian tributaries, including the Solimões and Madeira rivers. Still, measurements at Óbidos exclude the influences of influx from the Tapajós, Trombetas, Xingu and Tocantins rivers. The omission of these downstream tributaries has bearings on interpretations of 
POC flux to the ocean from the Amazon River, and has encouraged more recent studies to sample along transects of the river system between Óbidos, or sites upstream, and the river plume (e.g., Ward et al., 2015). Further, interpreting point measurements at one location of the river network is limiting because large rivers systems like the Amazon are heterogeneous in space and time. Within the Amazon cross-section, hydrodynamic sorting causes large grain-size sediments to settle faster and thus concentrate at deeper depths (Rouse 1950; Gibbs, 1967; Curtis et al., 1979; Bouchez et al., 2011b), leading to compositional differences between the deeper, coarser sediments and the shallower, finer sediments (Bouchez et al., 2011a; Bouchez et al., 2014). Finally, seasonality presents another challenge to measuring fluxes. Water levels in the Amazon River alone fluctuate by at least a factor of two between the rainy and dry seasons (Moreira-Turcq et al., 2013), which manifests in variability in POC flux and composition as well (Richey et al., 1990; Kim et al., 2012; Ward et al., 2015).

This study addresses some of these challenges by combining measurements of POC flux and composition along three dimensions: among tributaries near Óbidos, within the cross-section of the main stem, and across time. Integrating a suite of geochemical analyses, from bulk POC composition to compound-specific lipid assessments, the results identify key sources of POC mobilized by the Amazon River. We show how coupling these measurements to measurements of POC thermal stability using the ramped pyrolysis/oxidation (RPO) technique (Rosenheim et al., 2008; Rosenheim and Galy, 2012; Rosenheim et al., 2013) enables us to partition POC flux at Óbidos among these sources. The application of RPO by geochemists has been particularly useful for environments that integrate diverse sources of organic carbon that vary in age and degradation history, such as large, complex river systems. This study utilizes RPO to construct an age distribution of POC exported at Óbidos and comments on the reactivity of these different sources in the river system.

\section{Methods}

\subsection{Sampling location and timing}


Suspended sediment sampling in 2014 focused on a region of the Amazon main stem near the city of Óbidos (Table 1, Fig. 1a). In 2014, main stem discharge at Óbidos varied by a factor of two between the low discharge dry season (Southern Hemisphere spring/summer) and the high discharge rainy season (Southern Hemisphere winter/fall) (Fig. 1b-c). When sampling occurred in March/April and July 2014, the river levels were high, near their peak in May/June. In April, the river levels were rising, and in July, river levels were falling.

The 2014 sampling effort at Óbidos was supplemented by several additional sampling locations (Table 1, Fig. 1a), including one additional sample that was collected from Óbidos during another sampling campaign in June 2005, one near the Madeira River mouth to the Amazon River ( Foz Madeira) and one near the Solimões River mouth to the main stem ( Manacapuru) from that same expedition. The Tapajós River was further sampled in July 2014 to allow for comparison between Óbidos and its most immediate downstream tributary. Additional details of the June 2005 sampling campaign are described in (Bouchez et al., 2011b).

\subsection{Suspended sediment collection}

Suspended sediments were filtered from two types of river water samples: a large volume (100-200 L) sample of surface river water and a small volume (10 L) sample at select depths below surface. The exact volumes were calculated by weighing the water samples after collection and converting mass to volume using the density of fresh water, $1 \mathrm{~kg} / \mathrm{L}$. With the exception of the 2005 samples, all water samples were filtered in pressurized Teflon units through $0.22 \mu \mathrm{m}$ diameter pore size Millipore PES membrane filters within two days after collection. Between collection and filtration, samples were either covered in a dark tarp or stored in the shade to minimize exposure to sunlight. After filtration, the particles on the filters were immediately frozen in a freezer on board the ship. Although previous studies have highlighted the compositional differences across particle size fractions in the Amazon River (Hedges et al., 1986; Hedges et al., 1994; Aufdenkampe et al., 2001; Aufdenkampe et al., 2007), we have chosen to pool all particles above $0.22 \mu \mathrm{m}$ in diameter for analysis (Bouchez et al., 2014). 
The large volume samples were collected at Óbidos (April 2014, July 2014 and June 2005), and each upstream and downstream tributary site using a bucket submerged a few centimeters below the surface. Each sampling location was roughly in the center of each river channel. The $10 \mathrm{~L}$ samples were collected within three depth profiles at Óbidos in April and July 2014, using a depth-specific isokinetic sampler. Each profile, consisting of three to five depths from 2-3 $\mathrm{m}$ to $>50 \mathrm{~m}$, was located at a different position in the channel of the main stem, from near the right bank to near the left bank (Óbidos side of the river crossing) (Table 1). The depth-specific water sampler was equipped with a depth sensor to accurately record the collection depths.

In addition to suspended sediment samples, bedload samples from the Tapajós River and main stem at Óbidos were taken using a bedload sampler in July 2014. A flood deposit sample from the right bank of the main stem, across from Óbidos, was also collected and frozen on the ship.

\subsection{Enzyme activity assays}

Enzyme assays were conducted on suspended particles from the July 2014 Óbidos depth profiles to probe variations in heterotrophic activity with variations in particle

composition in the Óbidos cross-section. Samples were analyzed using-AMC (7-amino4-methylcoumarin) and-MUB (4-methylumbelliferone)-based fluoregenic substrate proxies (Steen and Arnosti, 2013; Table 2) and buffered with $100 \mathrm{mM}$ carbonate buffer ( $\mathrm{pH}=6.85)$. Assays were performed in triplicate for all samples and for one control, boiled to denature all enzymes, which served as a blank correction. Fluorescence was measured three to four times during 4 hour sample and control incubations in $1 \mathrm{~mL}$ cuvettes at ambient temperature (Table 1). Enzyme activities in each sample were inferred by the blank-subtracted substrate hydrolysis rates calculated from these four time points.

\subsection{Flux calculations}


During each sampling month in 2014, water velocity profiles were measured across the main stem channel using a Sontek RiverSurveyor ${ }^{\circledR}$ M9 Acoustic Doppler Current Profiler (ADCP). The ADCP operated on a $1 \mathrm{MHz}$ frequency, and was equipped with a $0.5 \mathrm{MHz}$ vertical beam sensor for river depth measurements and an external GPS for compass heading, latitude and longitude tracking. The external GPS did not function over most of the transect in April, so an average offset from the external GPS was applied to correct the internal Sontek compass, which did provide continuous heading measurements. The raw velocity cross-sections and depth gauges helped guide the choice of sample depths and locations for each depth profile (Table 1, Section 2.2).

The Sontek RiverSurveyor-M9 ADCP only measured three velocity components (E, N, U) down to $40 \mathrm{~m}$ depth. Horizontal velocities, $V_{\text {mag }}$, were calculated as the vector combination of the $\mathrm{E}$ (east) and $\mathrm{N}$ (north) components. Because $40 \mathrm{~m}$ was often shallower than the river bed and a further $10 \%$ of each velocity profile data was discarded prior to data export, the deepest measured velocities had to be extrapolated to the river bed, using the following relationship between horizontal velocity, $V_{\text {mag }}$, and vertical distance above river bed, $z$ (Chen, 1989; Mueller et al., 2009):

$$
\mathrm{V}_{\text {mag }}=\mathrm{a}_{\mathrm{v}} \mathrm{z}^{1 / 6}
$$

The $a_{v}$ values for each ADCP transect position were first extracted by fitting the measured $V_{m a g}$ profiles to Equation 1 . Then, the extrapolated $V_{\text {mag }}$ values for all depths between the deepest measured $V_{m a g}$ and the river bed were calculating using the fitted $a_{v}$ values.

For each sampling month, the RiverSurveyor ${ }^{\circledR}$ software integrated velocities measured through the instrument's transect and modeled within the "edge" regions between each end of the instrument transect and the nearest river bank to calculate a water discharge value through the river's cross-section. Using the transect velocity data exported from the software, we further calculated suspended sediment fluxes at Óbidos during each sampling month by integrating the product of suspended sediment concentration and water velocity across channel position and over river depth (Bouchez et al., 2011b):

$$
\text { TSS flux }=\iint \mathrm{V}_{\text {mag }} C_{z} d x d z
$$


In Equation 2, $d x$ values were calculated by projecting the distance of the boat track using ADCP transect coordinates (Fig. 1d-e) against the azimuth of the main stem at Óbidos. Profiles of $V_{m a g}$ across the channel were a combination of measured and extrapolated values (Equation 1).

Suspended sediment concentration, $C_{z}$, values in Equation 2 were modeled according to the hypothesis that the Amazon River main stem was deep enough in April and July 2014 to allow for separation of sediment grain size and density by depth (Rouse 1950). Following Bouchez et al. (2011b), who also reported hydrodynamic sorting in the Amazon main stem, all depth-specific (from $10 \mathrm{~L}$ samples) suspended sediment concentrations from each sampling month were fitted to a Rouse equation, which relates sediment concentration to river depth:

$$
\frac{\mathrm{C}_{\mathrm{z}}}{\mathrm{C}_{\mathrm{a}}}=\left(\frac{\mathrm{H}-\mathrm{z}}{\mathrm{z}} \frac{\mathrm{a}}{\mathrm{H}-\mathrm{a}}\right)^{\mathrm{z}_{\mathrm{R}}}
$$

In this relationship, $C_{z}$ is suspended sediment concentration at $z$, the vertical distance above the river bed, which has a depth of $H . a$ is the depth of the shallowest point measurement in the depth profile, $C_{a}$ is the suspended sediment concentration at $a$, and $z_{R}$ is the Rouse number. We used a nonlinear least-squares fit to calculate the Rouse number for April and July. The Rouse fits allowed us to model $C_{z}$ across the entire main stem cross-section by varying $H$ from the $\mathrm{ADCP}$ data, but using constant $C_{a}$ values, averaged across the surface-most measurement of the three channel positions in each sampling month.

\subsection{Bulk particle composition}

In the laboratory, each suspended sediment sample was re-suspended from the filters in milli-Q water, and freeze-dried. Bed samples were directly freeze-dried. The dried sediment and bed samples were sieved through a $2 \mathrm{~mm}$ mesh to remove any coarse impurities such as small rocks fragments and large leaf debris, and homogenized before subsequent analyses. The homogenized quantities of suspended sediments were weighed to calculate suspended sediment concentrations as mg homogenized sediment/L water filtered, which were later applied to Equation 3. 
The distribution of grain sizes in the homogenized particle samples was analyzed using a Beckman Coulter Laser Diffraction Particle Size Analyzer (LS 13 320). Samples were sonicated for 10 seconds in tap water before loading into the detector. The LS 13 320 detects particles in the $0.4 \mu \mathrm{m}$ to $2 \mathrm{~mm}$ size range, and reports mean and median grain size for each sample. The software additionally calculates the volumetric contribution of particle sizes throughout the distribution, as well as the $\mathrm{d} 10, \mathrm{~d} 50$, and $\mathrm{d} 90$ diameters, which delineate the $10^{\text {th }}, 50^{\text {th }}$ and $90^{\text {th }}$ percentiles of the size distribution.

Bulk weight $\%$ organic carbon ( $\%$ OC), weight $\%$ nitrogen $(\% \mathrm{ON}), \delta^{13} \mathrm{C}$, and $\delta^{15} \mathrm{~N}$ in the homogenized suspended and bed sediments were analyzed using a Fisons Instruments Carlo Erba 1108 elemental analyzer interfaced via a Finnigan MAT Conflo II to a Delta-Plus Stable Light isotope ratio mass spectrometer (IRMS). Prior to measuring $\% \mathrm{OC}$ and $\delta^{13} \mathrm{C}$, sub-samples were weighed, loaded in $\mathrm{Ag}$ boats and fumigated in concentrated hydrochloric acid $(12 \mathrm{~N} \mathrm{HCl})$ vapors for 72 hours at $60^{\circ} \mathrm{C}$, and then dried in a desiccator at $60^{\circ} \mathrm{C}$ for 72 hours to remove the inorganic carbon contribution to the total carbon in the sediment (Whiteside et al., 2011). One bedload sediment from Óbidos (July 2014) was analyzed just after 12-16 hours of acid fumigation. Weighed sub-samples were not fumigated prior to measuring $\% \mathrm{~N}$ and $\delta^{15} \mathrm{~N}$. All analyses were conducted in triplicate. The results only report the averages of the triplicate measurements, and their standard deviation as an estimate of analytical precision.

For bulk radiocarbon composition, a sub-sample of each sediment was similarly decarbonated via acid fumigation for 72 hours. After drying, the fumigated sample was sealed in an evacuated quartz tube with $2 \mathrm{~g}$ copper oxide, and baked at $850^{\circ} \mathrm{C}$ for 6 hours, which converted all the sample organic carbon to $\mathrm{CO}_{2}$ gas (McNichol et al., 1995). The evolved $\mathrm{CO}_{2}$ was then cryogenically purified under vacuum and subsequently graphitized by iron catalysis in pure $\mathrm{H}_{2}$ gas at $450^{\circ} \mathrm{C}$ and analyzed for its radiocarbon composition at the National Ocean Sciences Accelerator Mass Spectrometry (NOSAMS) facility at Woods Hole Oceanographic Institution (McNichol et al., 1992).

\subsection{Ramped Oxidation}


Ramped pyrolysis/oxidation (RPO) offers a higher resolution approach to analyzing the composition of organic carbon in complex environmental settings. The technique oxidizes $\mathrm{OC}$ in a sediment sample at a steady, controlled temperature ramp from $\sim 100^{\circ} \mathrm{C}$ to up to $1000^{\circ} \mathrm{C}$, and monitors the release of $\mathrm{CO}_{2}$ throughout the ramp. Plots of evolved $\mathrm{CO}_{2}$ concentration against temperature, hereafter referred to as thermograms, separate organic carbon by its thermal stability. The reaction can be coupled to a vacuum line to trap $\mathrm{CO}_{2}$ gas produced over specific user-defined temperature intervals for stable and radiocarbon isotope analysis.

All samples were analyzed by ramped oxidation at the National Ocean Sciences Accelerator Mass Spectrometry (NOSAMS) facility following methods described in Rosenheim et al. (2008) and Hemingway et al. (accepted). Sub-samples were placed into a quartz reactor receiving a constant flow of ultra high-purity helium carrier gas and oxygen ( $\sim 92 \%: 8 \%)$. As the temperature increases in the reactor, the carbon in the sample oxidizes and volatilizes into the carrier gas, passing through an $800^{\circ} \mathrm{C}$ oven equipped with a catalyst wire (nickel, cadmium and platinum) to ensure complete conversion of the combustion products to $\mathrm{CO}_{2}$. Downstream of the ovens, a Sable Systems $\odot$ CA-10 infrared gas analyzer continuously measures the concentration of evolved $\mathrm{CO}_{2}$ in the carrier gas matrix.

Beyond the gas analyzer, the $\mathrm{CO}_{2}$ is cryogenically frozen between user-selected temperature intervals and re-expanded into a vacuum line, where the gas is purified (cryogenic water stripping) and flame-sealed in pyrex tubes with $50 \mathrm{mg}$ copper oxide and $10 \mathrm{mg}$ silver for analysis. These tubes were baked at $525^{\circ} \mathrm{C}$ for 1 hour as an additional step to convert any incomplete oxidation products to $\mathrm{CO}_{2}$, as well as to remove any impurities from the gas fraction, prior to graphitization and isotope analysis. These gas fractions were then re-quantified in the vacuum line using a pressure transducer (baratron). One split of the gas fractions was converted to graphite for radiocarbon measurements (reported as fraction modern, or $\mathrm{F}_{\mathrm{m}}$ ), while the rest was analyzed by the VG Isotech Prism II IRMS to measure stable isotope composition (reported as $\delta^{13} \mathrm{C}$ ). The sum of all gas quantities recovered from each sample after the bake step was compared to the amount of POC loaded into the reactor (calculated as sediment mass times $\% \mathrm{OC}$ of that sample) to monitor the yield of the ramped oxidation. 
We have analyzed six depth-specific suspended samples from Óbidos 2014 depthprofiles center channel, and each large volume sample from 2005 and 2014 (Table 1). Four to five fractions of $\mathrm{CO}_{2}$ gas were trapped and analyzed during each ramped oxidation analysis. One depth-specific sample was fumigated for 72 hours, dried for 72 hours and rinsed in $\mathrm{Q}-\mathrm{H}_{2} \mathrm{O}$ prior to ramped oxidation. Rinsing was necessary to remove residual $\mathrm{Cl}$ from fumigation, which reacts with the catalyst wire, forming precipitates at higher temperatures $\left(>400^{\circ} \mathrm{C}\right)$ that clog the reactor. The thermogram generated by this treated sample was compared to the thermogram of another sub-sample that was analyzed without any acid treatment. Based on the results of this comparison, discussed in Section 3.4 , the rest of the samples were not acid-treated prior to ramped oxidation.

\subsection{Compound-specific lipid analysis}

Abundances of specific biomolecules provide even higher-resolution details of organic matter composition. Straight-chain $n$-alkanes, $n$-alcohols, and fatty acids were quantified in each large-volume sample collected in 2014 and 2005 and four depthspecific samples collected in 2014 (Table 1). Total lipids were extracted from sediment into $15-20 \mathrm{~mL}$ of 9:1 dichloromethane $(\mathrm{DCM}) /$ methanol at $100^{\circ} \mathrm{C}$ for 20 minutes using a Microwave Accelerated Reaction System (MARS, CEMS Corp.). The total lipid extracts were then saponified in $15 \mathrm{~mL}$ of $0.5 \mathrm{M}$ potassium hydroxide $(\mathrm{KOH})$ in wet methanol at $70^{\circ} \mathrm{C}$ for two hours. After adding $20 \mathrm{~mL}$ milli-Q water and $0.5 \mathrm{~g}$ of sodium chloride to the $\mathrm{KOH}$ solution, the basic lipids were extracted from the aqueous phase via five hexane rinses. The remaining $\mathrm{KOH}$ solution was acidified to $\mathrm{pH} 2$ using $12 \mathrm{~N} \mathrm{HCl}$ to isolate the acidic lipids in five rinses with 4:1 hexane/DCM.

Each basic and acidic lipid fraction was separated into five biomolecular classes on the basis of polarity. The concentrated lipid fractions were loaded onto aminopropyl silica gel columns and sequentially flushed with hexane (n-alkanes), 4:1 hexane/DCM (ketones), 9:1 DCM/acetone (sterols, alcohols and other polar compounds), 2.6\% oxalic acid in methanol (fatty acids), and 1:1 DCM/methanol (residual). Both acidic and basic fraction-derived fatty acids were re-combined and methylated in 95:5 methanol:HCl with

a known $\delta^{13} \mathrm{C}$ value and ${ }^{14} \mathrm{C}$ composition overnight, for $12-16$ hours, at $70^{\circ} \mathrm{C}$. The fatty 
acid methyl esters (FAMES) were isolated on an additional aminopropyl silica gel column after methylation. Prior to compound-specific isotope analysis of the straightchain saturated FAMES and $n$-alkanes, two additional purification steps were required. First, for $\delta^{13} \mathrm{C}$ analysis, all FAMES and $n$-alkanes were urea-adducted in $40 \mathrm{mg} / \mathrm{mL}$ methanol urea solution to separate the branched compounds from straight-chain compounds.

All compound abundances were measured using a flame ionization detector coupled to a Hewlett Packard 5890 Series II Gas Chromatograph (GC-FID). Ureaadducted, combined acid and base fractions of $n$-alkanes were injected in high purity hexane. The urea-adducted FAMES were directly injected in hexane. In addition, the non-adducted fractions of FAMES and $n$-alkanes, as well as the other fractions of the post-methylation FAMES columns were analyzed in the FID-GC. Any "residual" FAMES and $n$-alkane quantities in these other fractions were added to the FAMES and $n$ alkane quantities from the purified fractions, and are reported as such in the next section.

All GC-FID analyses were accompanied by a suite of standard $n$-alkanes and FAMES to cross-reference sample peak retention times and quantify compound abundances by peak areas. Some analyses were accompanied by just one standard injection at one known concentration, while others were accompanied by injection of three different standard concentrations. When three standard concentration chromatograms were available, standard curves were applied to sample peak areas to estimate analyte mass (nanograms). When analyses included just one standard concentration, a response factor, equivalent to the average peak area/ng compound across standard compounds, was used to convert sample peak area to mass.

The $\delta^{13} \mathrm{C}$ values of specific FAMES and $n$-alkanes were measured using a HP6890 gas chromatograph fitted with a Gerstel PTV and interfaced via a Finnigan MAT Conflo II to a Delta-Plus IRMS. When compounds were abundant enough, they were analyzed in duplicate or triplicate.

\subsection{Statistics and error analysis}


We equate the error of the average $\% \mathrm{OC}, \% \mathrm{~N}$, bulk $\delta^{13} \mathrm{C}$ and $\delta^{15} \mathrm{~N}$, and compound-specific $\delta^{13} \mathrm{C}$ to the standard deviation of the replicate analyses of each sample. The relative error in bulk $F_{m}$ values ranged from $0.2 \%-0.6 \%$, while the relative error in the $\mathrm{F}_{\mathrm{m}}$ values of RPO fractions ranged from $0.2 \%-1.2 \%$. The errors of all RPO fraction $\delta^{13} \mathrm{C}$ values of $\mathrm{CO}_{2}$ fractions trapped during ramped oxidation were $0.1 \%$. Because these RPO $\delta^{13} \mathrm{C}$ and $\mathrm{F}_{\mathrm{m}}$ errors are relatively small, they are not reported in the figures and tables of the following sections. The average relative error of the lipid masses per extraction, quantified from the GC-FID, is $\pm 10 \%$. Errors were propagated for any metrics calculated from these values, such as methylation-corrected compound-specific $\delta^{13} \mathrm{C}$ values and POC-normalized lipid abundances.

\section{$3 \quad$ Results}

\subsection{Discharge at Óbidos}

In 2014, maximum river depth of the Amazon main stem at Óbidos was 67-68 m (mode 61 m) in both April and July (Fig. 1f-g). The M9 RiverSurveyor ADCP logged $>1400$ velocity profiles from surface to riverbed in April and $>1300$ profiles in July. In April, the average water velocity was $1.9 \pm 0.1 \mathrm{~m} / \mathrm{s}$ across the transect, only slightly faster in July, $1.6 \mathrm{~m} / \mathrm{s} \pm 0.1 \mathrm{~m} / \mathrm{s}$. Velocities were always highest (3-4 m/s) across the deeper part of the channel, where depths exceeded $40 \mathrm{~m}$. Velocities near the river bed were slower, less than $1.5 \mathrm{~m} / \mathrm{s}$. Because of similar velocity distributions and river depths, total discharge at Óbidos did not change significantly between sampling months, ranging from 246,000 $\mathrm{m}^{3} / \mathrm{s}$ in April and 247,000 m³ $/ \mathrm{s}$ in July (Table 1). This agrees with continuous gauge measurements near Óbidos conducted by Brazil's Agencia Nacional de Aguas, which show that in 2014, monthly-averaged discharge peaked at $\sim 290,000 \mathrm{~m}^{3} / \mathrm{s}$ in May and June. Water levels were also highest during these months. Thus, the two sampling months in 2014 reflect different river stages, rising in April and falling in July, on both sides of the peak discharge. The following sections describe variations in the quantity and organic composition of suspended particulate material across the channel at 
Óbidos, from surface to river bed, and between the two stages of the hydrological cycle, April/rising water and July/falling water.

\subsection{TSS concentrations and fluxes at Óbidos}

The total suspended sediment concentrations ([TSS]) throughout the main-stem cross-section at Óbidos varied from 55.5 to $318.5 \mathrm{mg} / \mathrm{L}$ in April, and from 16.4 to 741.4 $\mathrm{mg} / \mathrm{L}$ in July (Fig. 2, Table 3). Concentrations are highest in the deepest samples of the near-right bank profiles in both April and July 2014. Because the right bank (across from the town of Óbidos) is located on the inside of a bend in the Amazon main stem, the combination of more turbulent water and lower horizontal velocities may entrain a greater amount of suspended sediments from the river bed, leading to higher TSS concentrations in this section of the river cross-section.

[TSS] concentrations increased with depth in all profiles at Óbidos (Fig. 2, Table 3). Generally, all grain size metrics, including mean, median/d50, d10, and $\mathrm{d} 90$ values increased with depth and [TSS], providing clear evidence for hydrodynamic sorting of sediment in the cross-section (Rouse 1950; Bouchez et al., 2011b; Bouchez et al., 2011a). All the [TSS] values measured in $10 \mathrm{~L}$ profile samples within each sampling month were fitted to the Rouse equation (Equation 3). Channel depths varied more by channel position than by season (Fig. 1). $z_{a}$, the reference height above the river bed, varied from $36.9 \mathrm{~m}$ to $56.2 \mathrm{~m}$ in April and from 41.5 to $58.9 \mathrm{~m}$ in July. C(a), the suspended sediment concentration at $\mathrm{z}(\mathrm{a})$, varied from 71.6 to $106.8 \mathrm{mg} / \mathrm{L}$ in April and from 43.9 to 102.7 $\mathrm{mg} / \mathrm{L}$ in July. We chose to combine profiles within each sampling rather than calculate one Rouse number per channel position profile per month because Bouchez et al. (2011b) found that the errors from fitting individual, more scarcely resolved depth profiles from a specific channel position exceeded errors from fitting a combined profile across the entire river transect.

Fits of April TSS concentrations yielded a Rouse number of 0.26, while fits of July TSS concentrations yielded a Rouse number of 0.34 (Table 1). The modeled concentration profiles fit the data well, suggesting that the Rousean description of hydrodynamic sorting adequately explains our observations (Fig. 3). The integrated 
product of [TSS] and water velocity within each cross-section yielded suspended sediment fluxes of 53,000 kg/s in April and 48,000 kg/s in July (Equation 2). These values do not take into account the water discharge and sediment concentrations in the cross-sectional distance between each river bank and the ends of the ADCP transects (i.e., the "edge" discharge values), but discharge in these "edge" sections of the transect represents less than $1 \%$ of total discharge at the main stem.

\subsection{Bulk POC composition}

The weight $\%$ organic carbon $(\% \mathrm{OC})$ within suspended sediments at Óbidos ranged from $0.5-1.52 \%$ and decreased with depth in all profiles across channel positions and seasons, except within the right bank profile in July, which exhibited no significant change in $\% \mathrm{OC}$ (Table 3, Fig. 2). At the same time, particulate organic carbon concentrations ([POC]), which ranged from $0.6-5.9 \mathrm{mg} / \mathrm{L}$, increased with depth as TSS concentrations increased. Weight $\%$ nitrogen $(\% \mathrm{~N})$ values in suspended sediments ranged from $0.05-0.24 \%$ and also decreased with depth. Molar C:N ratios exhibited a large range from 7.4 to 14.1, and tended to increase with depth in all profiles. Even though [TSS], \%OC, and [POC] varied within profiles at Óbidos, the isotopic composition of organic carbon in the sediments did not vary significantly with depth. $\delta^{13} \mathrm{C}$ values ranged from $-29.1 \%$ to $-28.0 \%$ across all profiles and seasons, while $\delta^{15} \mathrm{~N}$ values ranged from $3.1 \%$ to $4.3 \%$. The range in fraction modern $\left(\mathrm{F}_{\mathrm{m}}\right)$ values was also small $(0.74-0.80)$, corresponding to a radiocarbon age span of 680 years (1790 to 2470 years).

The composition of suspended POC was compared to bed and bank sediments collected near Óbidos and the Tapajós River in July, as well as several large volume surface sediments collected from the Amazon River at Óbidos (April 2014, July 2014 and June 2005), the Tapajós River (July 2014), the Solimões River (June 2005), and the Madeira River (June 2005) (Table 1). The suspended sediment concentration at the main stem surface in 2005, reported in Bouchez et al. (2011b), was within the range observed in the surface and depth-specific sediment samples collected in $2014 . \% \mathrm{OC}, \% \mathrm{~N}$ and stable isotope composition of POC in all main stem surface samples from 2005 and 2014 
were similar to the POC composition of depth-specific samples from 2014. The only difference was that the POC in these surface samples was consistently older, with $\mathrm{F}_{\mathrm{m}}$ values as low as 0.71 , than the POC analyzed from the depth-specific samples.

Surface suspended sediment concentrations in the Solimões and Madeira rivers, collected in 2005, were also similar to the range observed at Óbidos (Bouchez et al., 2011b). The \% OC in these sediments ranged from $0.49 \%$ in the Madeira River to $1.1 \%$ in the Solimoes River (Table 3). $\% \mathrm{~N}$ ranged from $0.08 \%$ in the Madeira River to $0.17 \%$ in the Solimoes River. Stable carbon and radiocarbon measurements of POC in the Solimões and Madeira river sediments were slightly more ${ }^{13} \mathrm{C}$-enriched and older than the Óbidos depth-specific samples. The Tapajós River had the most compositionally distinct suspended sediments of the data set. Surface suspended sediment concentrations in July 2014 were much lower than observed at any other river, only $0.52 \mathrm{mg} / \mathrm{L}$. But, \% OC in these sediments was the highest measured, $15.7 \%$. $\% \mathrm{~N}$ was also high, $2.7 \%$. The $\mathrm{F}_{\mathrm{m}}$ value was 0.89 , corresponding to a younger ${ }^{14} \mathrm{C}$ age than any of the values measured at Óbidos.

The weight $\%$ OC and $\% \mathrm{~N}$ in the three bed sediment samples from near the left bank of Óbidos, the right bank of Óbidos, and the Tapajós River were lower than corresponding values in all depth-specific samples, ranging from $0.06 \%$ to $0.14 \%$ organic carbon and from $0.01 \%$ to $0.02 \%$ nitrogen, consistent with other bedload observations in the basin (Bouchez et al., 2014). $F_{m}$ values of the bed samples varied from 0.60 to 0.87 at Óbidos, both older and younger than the POC in the depth-specific samples, respectively, while the Tapajós bed sample was modern $\left(\mathrm{F}_{\mathrm{m}}>1.0\right)$, younger than POC in the Tapajos suspended sediment. \%OC and \% $\mathrm{N}$ of right bank flood deposit near the Óbidos crosssection were more similar to the range in depth-specific sediments, $0.5 \%$ and $0.05 \%$, respectively. The stable isotope composition of the flood deposit was closer to the range observed across depth-specific samples, as well.

\subsection{Ramped oxidation results}

Suspended sediment sub-samples from three depths of the centermost profile of each sampling month at Óbidos, as well as four surface sediment samples were selected 
for thermal stability analysis via ramped oxidation (Table 4). In addition, the deepest (54 m) sample collected in July 2014, was analyzed twice: once following fumigation in hydrochloric acid to remove particulate inorganic carbon, and once without any treatment (Table 4). The fumigated sample was further rinsed in Milli-Q water to remove any residual $\mathrm{Cl}$ (Section 2.5). The rest of the samples were analyzed untreated.

We note a small difference between the $\mathrm{CO}_{2}$ evolved in the acid-treated vs. untreated thermograms of the deep July sample between $200^{\circ} \mathrm{C}$ and $400^{\circ} \mathrm{C}$ and above $550^{\circ} \mathrm{C}$ (Fig. 4). At the same time, the difference between the mass-weighted sums of $\delta^{13} \mathrm{C}$ values from both thermograms, $-29.3 \%$ to $-29.1 \%$, is not statistically significant (Tables $3,4)$. These sums are also comparable to the $\delta^{13} \mathrm{C}$ value of bulk POC, $-28.4 \%$, which was measured after sample fumigation but without rinsing (Tables 3, 4). This $0.7 \%$ - 0.9\%o difference is similar to the observed average difference between the sum of RPO fractions and the bulk $\delta^{13} \mathrm{C}$ value for a compilation of data (Hemingway et al., accepted). The fact that the weighted sum $\delta^{13} \mathrm{C}$ values from the untreated sample analysis are similar to the bulk $\delta^{13} \mathrm{C}$ value of sample POC implies that the quantity of PIC is likely negligible relative to the POC quantity and that acid fumigation did not greatly shift the thermal stability distribution of POC in the sample. This agrees well with observations that the PIC content in Amazon riverine POC is negligible (Galy et al., 2007; Mayorga et al., 2005; Bouchez et al., 2014) . Because all the untreated thermograms are very similar to each other (Fig. 4a- bottom right), we assume that the PIC quantity is small in all of them. For these reasons, we did not fumigate any other samples prior to ramped oxidation, and solely interpret and compare the untreated sample thermograms in the remaining discussion. In fact, all untreated sample thermogram carbon yields, calculated as the fraction of total mass of $\mathrm{CO}_{2}$ gas quantified after trapping and baking relative to the amount expected from the bulk \% OC and sediment mass, averaged around $99 \pm 5 \%$, much greater than the yield observed for the fumigated sample, $86 \%$.

The weighted sum $F_{m}$ value across fractions of the untreated sample thermogram is $0.82,0.02$ units $(2.5 \%)$ higher than the bulk POC $F_{m}$ value of 0.80 (Tables 3,4$)$. This difference likely results from loss of a small fraction of older, ${ }^{14} \mathrm{C}$-poor carbon during fumigation. By comparison, the weighted $\mathrm{F}_{\mathrm{m}}$ sum from fractions of the fumigated and rinsed sample thermogram is $0.77,0.03$ units $(3.5 \%)$ lower than the separate $F_{m}$ 
measurements of the bulk POC and 0.05 units lower than the weighted sum $F_{m}$ from the untreated sample thermogram. Further, $\mathrm{CO}_{2}$ evolved in the two lower temperature intervals of the treated sample thermograms, which represents $52 \%$ of total sample carbon, has a lower $\mathrm{F}_{\mathrm{m}}$ value than $\mathrm{CO}_{2}$ evolved in corresponding intervals of the treated thermogram (Fig. 4a), suggesting that acid fumigation and rinsing remove younger, ${ }^{14} \mathrm{C}$ enriched and thermally unstable POC pools from the suspended sediment, which would also lower the carbon yield during ramped oxidation.

All six untreated sample thermograms overlap closely across depths and seasons, oxidizing from $100^{\circ} \mathrm{C}$ to $800^{\circ} \mathrm{C}$ (Fig. 4). Most of the carbon evolves at temperatures below $700^{\circ} \mathrm{C}$, roughly the temperature at which several ramped oxidation analyses were terminated. But some analyses that continued recording $\mathrm{CO}_{2}$ concentrations above $750^{\circ} \mathrm{C}$ show that a small fraction of total sample carbon (0.5\%, averaged across thermograms) oxidizes to $\mathrm{CO}_{2}$ between $700^{\circ} \mathrm{C}$ and $800^{\circ} \mathrm{C}$. Stable carbon isotope values measured within specific $\mathrm{CO}_{2}$ fractions of the thermograms ranged from $-32.2 \%$ o to $-25.4 \%$ (Fig. 4b), while $F_{m}$ values ranged from 0.39 to 0.94 (Fig. 4b).

All the surface sediments from Óbidos in 2005, and the Tapajós, Madeira, and Solimões Rivers generated broadly similar thermograms compared to thermograms from the depth-specific Óbidos samples (Fig. 4). The only exception was the Tapajós thermogram, which shows that little carbon oxidizes above $600^{\circ} \mathrm{C}$. The $\delta^{13} \mathrm{C}$ and $\mathrm{F}_{\mathrm{m}}$ values in fractions of $\mathrm{CO}_{2}$ collected across the 2005 Óbidos, Solimões and Madeira sample thermograms were similar to values observed in $\mathrm{CO}_{2}$ fractions from all depthspecific thermograms. Again, the Tapajós sample thermogram generated the most isotopically distinct fractions of all runs, lighter $\left(\delta^{13} \mathrm{C}=-35.1 \%\right.$ o to $-31.49 \%$ o $)$ and younger $\left(\mathrm{F}_{\mathrm{m}}=0.82-0.91\right)$.

For some analyses, one to two fractions were lost during $\mathrm{CO}_{2}$ recovery in the vacuum line, graphitization or preparation for radiocarbon analysis (Fig. 4). If just one fraction is lost, the $\mathrm{F}_{\mathrm{m}}$ value of that fraction can be calculated using the separately measured $F_{m}$ value of the bulk POC (Equation $4 a$ ). But, $F_{m, B u l k, P O C}$ values do not equate the weighted sum $F_{m}$ values from the RPO analyses of samples in which no fractions were lost, owing to kinetic fractionation during the temperature ramp (Hemingway et al., accepted) and different sample preparation prior to bulk and RPO analysis. Thus, we used 


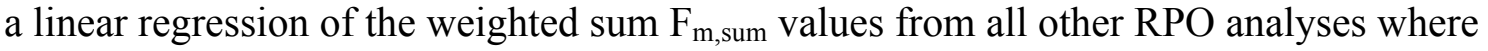

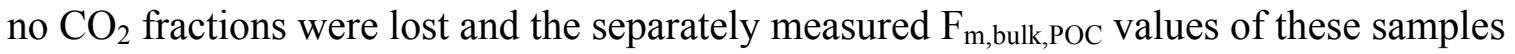
(Equation 4b), and applied the best fit line to Equation 4a.

$$
\begin{aligned}
F_{\text {m,lost }} & =\frac{\left(\left[F_{m, \text { Bulk POC }} \times 1.24\right]-0.17\right)-\sum_{1}^{i} f_{i} F_{m, i}}{f_{\text {lost }}} \\
F_{m, \text { sum }} & =1.24 \cdot F_{m, \text { Bulk POC }}-0.17
\end{aligned}
$$

Here, $i$ is the number of measured isotope values from the $\mathrm{CO}_{2}$ fractions, and $f_{i}$ and $f_{\text {lost }}$ are the fractional contribution of each measured and lost fraction to total sample carbon,

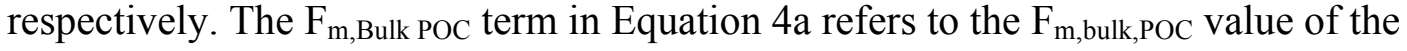
sample with the lost $\mathrm{CO}_{2}$ fraction. The regression $\left(\mathrm{r}^{2}=0.98\right)$ was applied to calculate the $\mathrm{F}_{\mathrm{m}}$ value of $\mathrm{CO}_{2}$ fractions lost from two April 2014 (49 $\mathrm{m}$ and $3 \mathrm{~m}$ ) sample analyses, but not for the fraction lost in the Madeira River sample thermogram because two RPO gas fractions were lost and thus the mass proportions each fraction lost are not known (Fig. $4 \mathrm{a})$. The linear regression between bulk and weighted sum $\delta^{13} \mathrm{C}$ values was weaker, and thus was not used to calculate the $\delta^{13} \mathrm{C}$ values of the missing $\mathrm{CO}_{2}$ gas fractions. The regression was even weaker when assuming an intercept of 0 , implying that $\delta^{13} \mathrm{C}$ of lost gas fractions could not be calculated by a constant offset, either.

In general, $\mathrm{CO}_{2}$ fractions tended to get more ${ }^{14} \mathrm{C}$-depleted (older) and more ${ }^{13} \mathrm{C}$ enriched with increasing temperature during ramped oxidation (Fig. 4a). The magnitude of variation in isotopic composition of $\mathrm{CO}_{2}$ collected from thermograms of tributary samples was less than the variation from Óbidos sample thermograms. The range of $F_{m}$ values across Óbidos sample thermograms varied from 0.42 to 0.53 . The range was much lower in the Tapajós suspended sediment thermogram (0.14) and the Solimões 2005 thermogram (0.22). The range of all $\delta^{13} \mathrm{C}$ values across the Óbidos thermograms varied from 3.63-6.39. Again, this range was slightly lower in the Tapajós and Solimões 2005 samples. No range was calculated for the Madeira River sample thermogram because the first $\mathrm{CO}_{2}$ fraction, likely the youngest and most depleted, was lost prior to any isotopic analysis.

\subsection{Lipid abundances and isotope composition}


Total lipids were extracted from all large-volume suspended sediment samples from the surface of the Amazon River main stem (June 2005, April 2014 and July 2014), the Tapajós River, the Solimões River and the Madeira River, as well as from four depthspecific samples from the two 2014 Óbidos center profiles (Table 1). Compound-specific $\delta^{13} \mathrm{C}$ values were not resolved for the April $2.7 \mathrm{~m}$ sample, where abundances extracted were too small.

Abundances of straight-chain $n$-alkanes in Óbidos samples $(2014,2005)$ were quantified for sixteen carbon chain lengths from $19\left(\mathrm{C}_{19}\right)$ to $35\left(\mathrm{C}_{35}\right)$, and ranged from 0.001 to $0.4 \mathrm{ng} / \mu \mathrm{g}$ of total POC (Appendix C, Table S1, Fig. 5c-e). The distribution of abundances above chain lengths $\mathrm{C}_{23}$ displayed an odd-over-even carbon chain length predominance in all samples, characteristic of terrestrial vegetation (Eglinton and Hamilton, 1963) (Fig. 5c-e). Within each sampling month, the POC-normalized compound abundances measured at the surface were greater than the abundances measured deeper in the water column. Average chain lengths (ACL) for $n$-alkanes (Equation 5a; Jeng, 2006) ranged from 29.6 to 30.1 and decreased slightly with depth, but did not vary significantly between the two months (Fig. 6b). Stable isotope values of odd chain-length leaf wax-derived $n$-alkanes exhibited a larger range than all $\delta^{13} \mathrm{C}$ values measured in bulk and across single thermograms from the Óbidos depth profiles, ranging from $-37.3 \%$ to $-28.3 \%$ (Appendix C, Table S2; Fig. 5 a-b).

$$
\begin{gathered}
\text { ACL }_{\text {n-alkane }}=\frac{25\left[\mathrm{C}_{25}\right]+27\left[\mathrm{C}_{27}\right]+29\left[\mathrm{C}_{29}\right]+31\left[\mathrm{C}_{31}\right]+33\left[\mathrm{C}_{33}\right]+35\left[\mathrm{C}_{35}\right]}{\left[\mathrm{C}_{25}\right]+\left[\mathrm{C}_{27}\right]+\left[\mathrm{C}_{29}\right]+\left[\mathrm{C}_{31}\right]+\left[\mathrm{C}_{33}\right]+\left[\mathrm{C}_{35}\right]} \\
\text { ACL }_{\text {fatty acid }}=\frac{24\left[\mathrm{C}_{24}\right]+26\left[\mathrm{C}_{26}\right]+28\left[\mathrm{C}_{28}\right]+30\left[\mathrm{C}_{30}\right]+32\left[\mathrm{C}_{32}\right]+34\left[\mathrm{C}_{34}\right]}{\left[\mathrm{C}_{24}\right]+\left[\mathrm{C}_{26}\right]+\left[\mathrm{C}_{28}\right]+\left[\mathrm{C}_{30}\right]+\left[\mathrm{C}_{32}\right]+\left[\mathrm{C}_{34}\right]}
\end{gathered}
$$

Straight chain $n$-alkane abundances in the Solimões and Madeira river surface suspended sediments collected in 2005 spanned a similar range (Fig. 5c). $n$-alkanes from the Solimões River exhibited odd-over-even predominance, but the $n$-alkanes from the Madeira River did not. Average chain lengths in these samples were similar to the values calculated from Óbidos n-alkanes in 2014 (Fig. 7b). Compound-specific $\delta^{13} \mathrm{C}$ values were not measured in these samples. 
Abundances of saturated straight-chain fatty acids $\left(\mathrm{C}_{14}-\mathrm{C}_{34}\right)$ measured at Óbidos ranged from 0.008 to $4.0 \mathrm{ng} / \mu \mathrm{g}$ POC (Appendix C, Table S2; Fig. 7d-i). The most abundant compounds were $\mathrm{C}_{16}$ and $\mathrm{C}_{18}$. At chain lengths above 23 , the abundances exhibited even-over-odd predominance in all samples, reflecting an important contribution from terrestrial vegetation. River stage and depth-related differences in the abundance of even chain-length compounds were negligible at chain-lengths above $\mathrm{C}_{22}$. The ACL of fatty acids (Fig. 6a; Equation 5b; Jeng, 2006) increased with depth in the April 2014 profile, from 27.6 at the surface to 28.6 at $49 \mathrm{~m}$. The increase in ACL with depth in July 2014 was smaller. The stable isotope distribution across even chain-length

fatty acids in the depth-specific samples spanned a greater range than bulk $\delta^{13} \mathrm{C}_{\mathrm{POC}}$ values in the same samples, $-34.2 \%$ to $-27.7 \%$ o (Fig. 6b-c).

Straight-chain fatty acids were also quantified in surface suspended sediment samples from Óbidos (June 2005), and the Tapajós, Solimões and Madeira rivers. All Óbidos, Solimões River and Madiera river samples exhibited similar fatty acid abundances (Appendix C, Table S2; Fig. 7d,g). Only the Tapajós River sample showed very elevated concentrations of $\mathrm{C}_{14}, \mathrm{C}_{16}$ and $\mathrm{C}_{18}$ that were $\sim 40$ times higher than the abundances of these fatty acids across all other 2014 and 2005 samples. All 2005 and tributary samples displayed strong even-over-odd predominance among the higher chainlength fatty acids. ACL values in all samples except Tapajós POC were similar to the range observed in the Óbidos profiles (Fig. 6a). The ACL calculated from Tapajós River fatty acids was 25.8 , the lowest of the data set. All fatty acids in these samples were more depleted than the values observed in the 2014 Óbidos profiles (Fig. 7a). The $\delta^{13} \mathrm{C}_{\mathrm{C} 22}$ value of Tapajós River POC was $-39.4 \%$. The differences in $\delta^{13} \mathrm{C}$ values across samples were smallest in the highest chain-length fatty acids $\left(>\mathrm{C}_{28}\right)$.

\subsection{Enzyme activities}

Activities of eight enzymes measured at various depths within the Óbidos crosssection in July 2014 ranged from 0 to $0.09 \mu \mathrm{mol} / \mathrm{L}-\mathrm{hr}$ (Fig 8; Appendix C, Table S3). Values generally did not vary with depth or channel position. Activities of the N- and Pyielding enzymes (i.e., leucyl aminopeptidase, phenylalanyl aminopeptidase, and 
phosphomonoesterase) (Table 2), were exceeded activities of the C-yielding enzymes (i.e., cellulase, beta-glucosidase and xylanase) throughout profiles.

\section{Discussion}

The following sections first examine the dynamics underlying variation in TSS load and POC loading with cross-sectional depth. Then, coupling bulk and compoundspecific data to thermograms generated by ramped oxidation of these sediment samples, we quantify the sources of organic carbon exported at Óbidos and discuss the reactivity of these different sources in the river network.

\subsection{From depth profiles to POC flux at Óbidos}

Increasing [TSS] with depth in all profiles compiled at Óbidos in April and July 2014 are indicative of hydrodynamic sorting (Rouse 1950), and consistent with prior depth profiles of the same size-fraction of sediments compiled by Bouchez et al. (2011b) across the central Amazon River Basin (Fig. 2). This is supported by even lower TSS concentrations in the surface large-volume samples ( $<1 \mathrm{~m}$ depth) (Table 3$)$ and a concurrent increase in grain size (i.e., mean and median diameter, as well as d10, d50 and d90) with depth. The Rouse numbers that we report are similar in magnitude and temporal variation to the numbers estimated from profiles at Óbidos in March $2006\left(\mathrm{z}_{\mathrm{R}}=\right.$ 0.24) and June $2005\left(z_{R}=0.39\right)$ (Bouchez et al., 2011b).

It is interesting that $\mathrm{z}_{\mathrm{R}}$ values are so different between April and July 2014, despite the lack of change in river discharge between months. Significantly higher mean, d50 and d90 grain diameters in July relative to April (Student's t-test, $p<0.05$ ), especially in the deeper locations of the channel cross-section, could lead to greater hydrodynamic sorting of [TSS] in July and therefore higher $\mathrm{z}_{\mathrm{R}}$ values. Considering that water levels in the Negro and Solimões rivers, the confluence of which forms the Amazon River main stem, upstream of Óbidos, are usually higher in July than in April, their increased input to Óbidos in July may contribute to larger grain sizes in the cross-sectional profiles (Moreira-Turcq et al., 2003). As the Negro River is very sediment-deplete (Kim et al., 
2012), variations in Solimões discharge contribute relatively more to variations in sediment grain size through time in the main stem. By comparison, discharge and [TSS] in the Madeira River, the other major tributary to the main stem between the Solimões River and Óbidos, decreases between April and July (Moreira-Turcq et al., 2003; Bouchez et al., 2011b). Thus, a higher relative input of discharge and suspended sediments from the Solimões River to Óbidos between April and July could cause significant increases in the mean, median, d50 and d90 grain sizes in suspended sediments at Óbidos, creating a larger gradient in [TSS] between river surface and river bed and hence a higher $z_{R}$ value in [TSS] profiles.

Suspended sediment fluxes, 53,000 kg/second in April and 48,000 kg/s in July (Table 1), are similar in magnitude but less variable than fluxes estimated by Bouchez et al. (2011b) in June 2005 and March 2006. Collectively, these quantities would greatly exceed flux estimates based on surface [TSS] measurements alone. For example, our fluxes are more than five times greater than surface-based fluxes calculated by Kim et al. (2012) during two expeditions to Óbidos in 2005 and 2009. The comparison is not perfect because the authors measured [TSS] in a slightly different size fraction of particles $(>0.7$ $\mu \mathrm{m})$. Nonetheless, the differences highlight the necessity and impact of accounting for cross-sectional variation in [TSS] when calculating TSS fluxes out of the river crosssection.

While TSS concentrations increase with depth, the $\% \mathrm{OC}$ and $\% \mathrm{~N}$ per unit sediment weight decrease in all April and July 2014 profiles at Óbidos (Fig. 2, Table 3). Bouchez et al. (2014) argued that associations between POC and mineral surfaces and/or coincident concentration of fine carbon rich particles from buoyant organic debris drive declines in POC loading with coarser sediments with depth. But, the increase in C:N values across profiles suggest an accumulation of vegetative debris with depth. This is especially apparent in the deep section of Óbidos in July, which bears a higher $F_{m}$ value than in April, indicating input of younger organic carbon at depth. Bulk POC $F_{m}$ values are also older near the surface in July than in April, pointing instead to greater addition of finer, older and possibly more buoyant organic matter flushed in from floodplain soils during receding river levels. 
At the same time, [POC] (mg/L) values increase with depth because [TSS] concentrations are much higher in deeper sections of the river. For each sampling season, [POC] correlates positively with $[\mathrm{TSS}]$ in all profile samples $(\mathrm{p}<0.05)$. Linearly regressing the two concentrations yields a slope (mg [TSS]/mg [POC]) and intercept $(\mathrm{mg} / \mathrm{L}[\mathrm{POC}])$, which can then be substituted into the Rouse-modeled $C_{z}$ in Equation 3 to calculate POC fluxes during each sampling month:

$$
[\mathrm{POC}]=\mathrm{m}[\mathrm{TSS}]+\mathrm{b}
$$

In this equation, $m$ is the slope of the linear relationship $(0.0079 \mathrm{mg} \mathrm{TSS} / \mathrm{mg}$ POC in April and $0.0072 \mathrm{mg}$ TSS/mg POC in July) while $b$ is the intercept (0.46 mg POC in April and $0.075 \mathrm{mg}$ POC in July). The difference in the intercepts between months suggests that more POC in April is not associated with the mineral load in the suspended sediments.

The integrated POC flux in April 2014 was $540 \mathrm{~kg} / \mathrm{s}$, while the integrated POC flux in July 2014 was $370 \mathrm{~kg} / \mathrm{s}$ (Table 1). This difference can be explained by a significant decrease in the average \%OC in suspended sediments from $1.2 \pm 0.2 \%$ (mean \pm 1 S.D.) in April to $0.88 \pm 0.27 \%$ in July (Student's t-test, $\mathrm{p}<0.05$ ). Again, these fluxes are similar to those reported in Bouchez et al. (2014), and 50-200\% higher than those reported by Kim et al. (2012). Extrapolating these fluxes over one year results in an estimated annual POC flux from Óbidos of 12-17 Tg/year, which is likely an overestimation because April and July 2014 represent the high discharge period and therefore do not capture the full variation expected in TSS fluxes expected over an annual cycle in the Amazon River basin. Nonetheless, our annual fluxes are similar to earlier flux estimates of $14 \mathrm{Tg} /$ year by Richey et al. (1990) who deployed a depth-integrated sampler to measure TSS concentrations (Richey et al., 1986).

\subsection{Prominent soil-derived POC source to the main stem}

Earlier studies of carbon cycling in the Amazon River partitioned riverine POC between two size fractions, $\mathrm{a}<63 \mu \mathrm{m}$ "fine" fraction and a $>63 \mu \mathrm{m}$ "coarse" fraction, arguing that the smaller size fraction derived from older, degraded soils while the coarser fraction derived from fresher vegetation debris (Hedges et al., 1994; Aufdenkampe et al., 
2001; Aufdenkampe et al., 2007). Compound specific abundances of $n$-alkanes and fatty acids measured in one size-fraction $(>0.22 \mu \mathrm{m})$ of suspended sediments from various depths at Óbidos and at the surface of the Solimões and Madeira Rivers support the perspective that terrestrial vegetation is indeed an important source to riverine POC within the main stem cross-section as well as upstream. Odd-over-even predominance of the higher chain length $n$-alkanes $\left(\mathrm{C}_{25}-\mathrm{C}_{35}\right)$, even-over-odd predominance of the higher chain length fatty acids $\left(\mathrm{C}_{24}-\mathrm{C}_{34}\right)$, and relatively high average chain lengths (ACL) of each compound class reflect input from land plants (Figs. 5-7). Further, $n$-alkanes and fatty acids are more depleted than the bulk $\delta^{13} \mathrm{C}_{\mathrm{POC}}$ of each sample, especially at higher chain lengths $\left(\mathrm{C}_{24}-\mathrm{C}_{34}\right.$ for fatty acids; $\mathrm{C}_{25}-\mathrm{C}_{35}$ for n-alkanes), which indicate that these compounds derive from terrestrial plants (Cranwell, 1982).

However, at the same time, the bulk composition of these samples vary little with depth and season (Table 3, Fig. 2) and are largely characteristic of soil organic matter (Quesada et al., 2010; Kim et al., 2012), suggesting that Amazon River POC derives predominantly from a mixture of soils. The radiocarbon age and stable isotope distribution of POC across sample thermograms generated by ramped oxidation of main stem samples supports this perspective. $\mathrm{No}^{\mathrm{CO}_{2}}$ gas fraction is modern, exhibiting a bomb ${ }^{14} \mathrm{C}$ component, and all gas fraction $\delta^{13} \mathrm{C}$ values are within the range observed for Amazonian soils (Fig. 4, Table 5, Fig. 9). This suggests that fresh vegetation comprises a minor fraction of riverine POC, and biomarkers for vegetation observed in Figs. 5-7 instead trace inputs of degraded vegetation flushed into the river through soil organic carbon reservoirs.

The composition of Tapajós POC, very N-enriched (high N:C) and ${ }^{13} \mathrm{C}$-depleted, clearly falls off the mixing line in Fig. 9a, reflecting dominant input of in situ production, consistent with prior observations of Tapajós River POC composition (Mortillaro et al., 2011; Kim et al., 2012; Ward et al., 2015). The combination of a relatively deep euphotic zone depth and slower water velocities in the Tapajós River, especially during high water in July, encourages the growth of phytoplankton and cyanobacteria (Mortillaro et al., 2011). The highly depleted and anomalously low ACL fatty acids at the tributary surface (Figs. 6a; 7a,d,g) indicate that lower chain length lipids produced by aquatic phytoplankton (Cranwell, 1982) contribute much more to POC in this tributary and are 
effectively absent in POC from the main stem and upstream (the Solimões and Madeira rivers).

\subsection{Radiocarbon distribution of POC flux at Óbidos}

The bulk and compound-specific analyses of riverine POC do not quantify the soil sources of POC to the Amazon main stem. Data generated by ramped oxidation of suspended sediment samples from various depths of the main stem at Óbidos (Table 1) and the surface of the Tapajós, Solimões and Madeira Rivers offer a unique opportunity to partition POC quantitatively among distinct sources from the drainage basin (Fig. 4).

To interpret thermograms, we assume that organic matrices span a range of activation energies $\left(\mathrm{E}_{\mathrm{a}}\right)$ of decomposition, which causes different biomolecules to oxidize at different times during a controlled temperature ramp (Burnham and Braun, 1999; Cramer, 2004; Rosenheim et al., 2008; Hemingway, 2017 thesis). Thus, more thermally stable components of POC, which oxidize and release $\mathrm{CO}_{2}$ at higher temperatures, have higher activation energies of decomposition. With this model, we transform thermograms to a distribution of activation energies, according an inverse algorithm coded in Python (Hemingway, 2016; Hemingway, 2017 thesis). The software deconvolves the calculated distribution of activation energies into a series of Gaussian distributions and reconstructs a thermogram as $\mathrm{CO}_{2}$ concentration against temperature by summing these individual component distributions.

When transforming and deconvolving thermograms, users can customize a "smoothing factor" that limits the sensitivity of the Gaussian fit to features in the $\mathrm{E}_{\mathrm{a}}$ distribution and therefore the number of components that the algorithm fits. The same "smoothing factor" was applied to all sample thermogram in this sample set to resolve a similar number and spread of components. The exception was the thermogram of the $2 \mathrm{~m}$ suspended sediment sample from the July 2014 Óbidos profile, to which we applied a lower "smoothing factor", derived from an optimization algorithm in the package, in order to deconvolve a similar number components to the other thermograms. Peaks that overlapped significantly in $\mathrm{E}_{\mathrm{a}}$ space were combined before thermogram reconstruction. Although all of these parametrizations introduce user bias to the analysis, we justify these 
choices by the fact that all sample thermograms exhibit a strikingly similar $\mathrm{CO}_{2}$ distribution across temperatures and thus should be analyzed under similar statistical constraints (i.e., the number of peaks fitted and recombined to construct thermograms in temperature space).

Furthermore, the isotopic composition $\left(\delta^{13} \mathrm{C}, \mathrm{F}_{\mathrm{m}}\right)$ of each deconvolved component can be calculated by inverting the following matrix, also described in Rosenheim et al. (2008):

$$
\begin{gathered}
\delta 13 \mathrm{C}_{1} \\
\vdots \\
\delta 13 \mathrm{C}_{\mathrm{i}}
\end{gathered}=\left[\begin{array}{cc}
\mathrm{f}_{1,1} & \cdots \mathrm{f}_{1, j} \\
\vdots & \vdots \\
\mathrm{f}_{\mathrm{i}, 1} \cdots & \cdots \mathrm{f}_{\mathrm{i}, \mathrm{j}}
\end{array}\right] \times\left[\delta 13 \mathrm{C}_{\mathrm{F} 1} \cdots \delta 13 \mathrm{C}_{\mathrm{Fj}}\right]
$$

In Equation 7, $i$ is the number of $\mathrm{CO}_{2}$ fractions trapped and analyzed, $j$ is the number of components deconvolved, $\delta^{13} \mathrm{C}_{\mathrm{i}}$ is the stable isotope composition of each fraction (measured by IRMS), $\delta^{13} \mathrm{C}_{\mathrm{Fj}}$ is the isotopic composition of the component $\mathrm{F}$ and $f_{i, j}$ is the fraction of $\mathrm{CO}_{2}$ measurement $i$ in component $j$. The sum of all fractions in the same row of the matrix equals 1 . Altogether, this approach allows us to interpret thermal stability distributions using several metrics: (1) the number of components per thermogram, (2) the mean activation energy and maximum temperature ( $\left.T_{\max }\right)$ of each component, (3) the contribution of each component to the total carbon (assumed to be $\sim 100 \%$ organic carbon according to Section 3.4), and (4) the isotopic composition $\left(\delta^{13} \mathrm{C}\right.$ and $\left.\mathrm{F}_{\mathrm{m}}\right)$ of each component.

Nine thermograms of suspended sediment samples, all analyzed untreated, were deconvolved using this approach. The thermogram of suspended sediments collected from the Madeira River was not deconvolved because, as illustrated in Fig. 4, we cannot trust $\mathrm{CO}_{2}$ concentration measurements beyond $500^{\circ} \mathrm{C}$. The deconvolutions yielded three major components throughout all other thermograms, which from hereon forth we call components $F_{1}, F_{2}$ and $F_{3}$ (Table 5 ). The root mean square error of the peak fits ranged from 7.5 E-04 to $5.0 \mathrm{E}-03$. The $\mathrm{T}_{\max }$ of the two lower temperature components varies little across all nine samples: $299 \pm 10^{\circ} \mathrm{C}$ (average \pm 1 standard deviation) for $\mathrm{F}_{1}$ and 404 $\pm 12^{\circ} \mathrm{C}$ for $\mathrm{F}_{2}$. The fractions of total carbon that these peaks represent are relatively constant across samples too: $66 \pm 4 \%$ for $F_{1}$ and $25 \pm 6 \%$ for $F_{2}$. Only the Óbidos 2005 sample thermogram yielded a low $F_{1}$ fraction of $57 \%$ (Fig. 4a). The difference in the Óbidos 2005 thermogram deconvolution could have resulted from longer river water 
sample storage times prior to filtration (Section 2.2), prolonging in situ degradation and/or primary production, which would have shifted the POC composition in the sample relative to the POC composition at the time of sampling. The relative consistency of these components across all 2014 Óbidos samples suggest that $\sim 2 / 3$ of the POC flux from the main stem in April and July 2014, corresponding to $\mathrm{F}_{1}$, consists of younger, more ${ }^{13} \mathrm{C}$ depleted soil-derived POC $\left(F_{\mathrm{m}}=0.90 \pm 0.07\right) . \sim 1 / 4$ of the total POC, corresponding to $F_{2}$, consists of an older, more degraded and ${ }^{13} \mathrm{C}$-enriched source $\left(\mathrm{F}_{\mathrm{m}}=0.75 \pm 0.12\right)$.

The highest activation energy and temperature component, $\mathrm{F}_{3}$, is the most variable across thermogram deconvolutions, with an average $\mathrm{T}_{\max }$ of $511 \pm 20^{\circ} \mathrm{C}$ and fractional contribution of $9 \pm 7 \%$ across samples. The relatively high standard deviations can be attributed to inherently higher errors associated with resolving components with a lower fractional contribution to total sample carbon. In fact, for four thermograms, a fourth, even higher activation energy peak was resolved by deconvolution, which comprised 0.5 $-4 \%$ of the total sample carbon (Table 5; Fig. 10c-d). But, because this four-peak fit yields stable isotope values that vastly deviate from the expected $\delta^{13} \mathrm{C}$ range of riverine POC, we have combined the third and fourth peak, $\mathrm{F}_{3}$ ' and $\mathrm{F}_{4}$, into the component we report as $\mathrm{F}_{3}$. The fractional contribution of this fourth peak to total sample carbon is also very variable because fitting this peak depends on the highest temperature to which $\mathrm{CO}_{2}$ data was collected. For instance, during ramped oxidation of the Óbidos 2005 sample, the gas analyzer measured concentrations of $\mathrm{CO}_{2}$ released until $795^{\circ} \mathrm{C}$, which extends beyond the temperature range of several other thermograms for which the fourth peak could not be resolved (Figs. 4). Taken together, these factors would account for some of the observed variability in component $\mathrm{F}_{3}$ fractions and $\mathrm{T}_{\max }$ values among thermograms that resolve $\mathrm{F}_{4}$ and thermograms that do not.

Because the properties of $F_{1}$ and $F_{2}$ are very similar across Óbidos sample thermograms, and because methodological artifacts impacted the deconvolution of $F_{3}$ vs. $\mathrm{F}_{3}$, we suggest that this fourth component is likely present in all samples from the main stem. Further, we posit that $\mathrm{F}_{4}$ represents radiocarbon-dead petrogenic organic carbon, which is expected to be most thermally recalcitrant (Galy et al., 2008; Rosenheim and Galy, 2012) (Fig. 4a). Much of the petrogenic organic carbon source to the Amazon River likely derives from the Andes, where rapid flushing of steep bedrock occurs (Clark 
et al., 2013; Bouchez et al., 2014). It is possible that some of the $\mathrm{CO}_{2}$ evolved at higher temperatures in the thermograms derives from charring products of intrinsically lower thermal stability POC in the sample (Williams et al., 2014). Nonetheless, the small fraction we propose to be $F_{4}$ is consistent with the sharp decrease in $F_{m}$ values with increasing temperature observed across thermogram gas fractions, and independent estimates of petrogenic organic carbon in suspended sediments at Óbidos (Bouchez et al., 2014).

Assigning an $\mathrm{F}_{\mathrm{m}, \mathrm{F} 4}$ value of 0 in the four thermograms that resolve $\mathrm{F}_{4}$ (Table 5; Fig. 10c-d), the proportion of $\mathrm{F}_{4}$ prior to combination with $\mathrm{F}_{3}$, can be used to calculate the $F_{m}$ value of $F_{3}$, (Equation 8). These calculated $F_{m, 3}$, values range from 0.37-0.50 in Óbidos samples, similar to the original $\mathrm{F}_{3}$ values, and the fractional contribution of $\mathrm{F}_{4}$ to total sample POC ( $f_{F 4}$ in Equation 8$)$ ranges from $0.5 \%$ to $4 \%$. Again, this relatively wide range results from the Óbidos 2005 thermogram deconvolution, which yielded anomalously large $\mathrm{F}_{3}$, and $\mathrm{F}_{4}$ components ( $22 \%$ and $4 \%$ of total carbon, respectively), but is still consistent with estimates of petrogenic organic carbon content reported by Bouchez et al. (2014). Fraction $F_{3}$, has a higher $F_{m}$ value of 0.60 in the Solimões sample, where the fractional contribution of $\mathrm{F}_{4}$ is $2 \%$. Because $\delta^{13} \mathrm{C}$ values for petrogenic carbon are variable and only weakly constrained in the Amazon basin (Bouchez et al., 2014), we refrain from using the same mass balance approach to calculate the $\delta^{13} \mathrm{C}^{2}$ value of $\mathrm{F}_{3}$. But, Bouchez et al. (2014) estimated that petrogenic organic carbon in the Amazon River Basin would have a $\delta^{13} \mathrm{C}$ of $\sim 25 \%$. Considering the consistent enrichment of $\mathrm{CO}_{2}$ with temperature across the thermograms (Fig. $4 \mathrm{~b}$ ), it is likely that $\mathrm{F}_{4}$ would be more enriched than three F3 values resolved from the Óbidos sample thermograms ( $-34.6 \%$ to $-25.9 \%$; Table 5), which agrees with previous estimates.

$$
\mathrm{F}_{\mathrm{m}, \mathrm{F} 3}=\mathrm{F}_{\mathrm{m}, \mathrm{F} 3 \prime} \frac{\mathrm{f}_{\mathrm{F} 3 \prime}}{\mathrm{f}_{\mathrm{F} 3}+\mathrm{f}_{\mathrm{F} 4}}+\mathrm{F}_{\mathrm{m}, \mathrm{F} 4} \frac{\mathrm{f}_{\mathrm{F} 4}}{\mathrm{f}_{\mathrm{F} 3 \prime}+\mathrm{f}_{\mathrm{F} 4}}
$$

Altogether, the deconvolutions of Óbidos sample thermograms can be used to apportion POC flux at Óbidos into three soil organic matter pools and a petrogenic organic carbon pool. The component proportions $\mathrm{F}_{1}, \mathrm{~F}_{2}$, and $\mathrm{F}_{3} / \mathrm{F}_{3}$, across thermograms amount to fluxes of $\sim 240-360 \mathrm{~kg} / \mathrm{second}$ of relatively young and recently degraded soil POC, $90-130 \mathrm{~kg} / \mathrm{s}$ and $30-50 \mathrm{~kg} / \mathrm{s}$ of two older soil pools that are more ${ }^{13} \mathrm{C}$-enriched with age, respectively. The highest thermal stability and more fractionally variable component 
$\mathrm{F}_{4}$ amounts to a flux between 2 and $22 \mathrm{~kg} / \mathrm{s}$ of petrogenic organic carbon (calculated from the range of $\mathrm{F}_{4}$ fractions resolved from three main stem thermograms) at Óbidos between April and July 2014.

\subsection{Differentiating soil organic matter sources to riverine POC}

In general, bulk and RPO fraction $\mathrm{F}_{\mathrm{m}}$ values trace a negative relationship with bulk and RPO fraction $\delta^{13} \mathrm{C}$ values from Óbidos and tributary samples (Fig. 9b), indicating that bulk POC in most of these samples consists of a mixture of young, low activation energy ${ }^{13} \mathrm{C}$-depleted soil organic matter and old, high activation energy ${ }^{13} \mathrm{C}$ enriched soil pools. Component $\mathrm{F}_{\mathrm{m}}$ values also tend to decrease as component $\delta^{13} \mathrm{C}$ values increase (Table 5). Fig. 9a illustrates a weak but significant correlation between bulk N:C and $\delta^{13} \mathrm{C}_{\mathrm{POC}}$ values measured in suspended sediments at Óbidos, also highlighting a mixing relationship between a fresher, low $\mathrm{N}: \mathrm{C}$, and ${ }^{13} \mathrm{C}$-depleted endmember and a more degraded, high $\mathrm{N}: \mathrm{C}$ and ${ }^{13} \mathrm{C}$-enriched end-member $\left(\mathrm{p}<0.05, \mathrm{r}^{2}=0.28\right)$, consistent with the thermogram data. This is consistent with perspective that soil organic matter is a mixture of distinct pools at different stages of degradation, and thus exhibits a range of radiocarbon ages (Plante et al., 2013).

Two non-mutually exclusive hypotheses could explain the compositional variations in the thermally distinct soil POC sources to riverine POC (Table 5; Fig. 9). First, main stem POC could reflect mixing of soil sources from different landscapes that bear distinct $\delta^{13} \mathrm{C}_{\mathrm{POC}}$ signals and degradation histories. The drainage basin includes both ${ }^{13} \mathrm{C}$-depleted, C3 landscapes in the low-lying floodplain (most of Amazonia) and more ${ }^{13} \mathrm{C}$-enriched $\mathrm{C} 4$ and higher altitude Andean landscapes traversed by the western tributaries, including the Solimões and Madiera rivers (Fig. 1a, O'Leary, 1981; Körner et al., 1991). Isotopic differences among the Solimões River, Madeira River and main stem RPO gas fractions provide evidence for differences among soil age distributions across geographical space (Fig. 9b).

Mixing of geographically and isotopically diverse soil sources in the main stem could explain the slight differences in the bulk POC composition observed at Óbidos samples between sampling months. Lower average molar C:N ratios of $8.7 \pm 0.88$ in 
April, compared to $10.7 \pm 1.2$ in July ( $<<0.05$, Student's t-test), as well as significantly less depleted bulk $\delta^{13} \mathrm{C}_{\text {POC }}$ values in April (-28.2 $\pm 0.1 \%$ ) than in July $(-28.8 \pm 0.2 \%$ ), suggest a small shift in soil source between river stages. The lower bulk $\delta^{13} \mathrm{C}_{\text {POC }}$ and N:C values throughout the July profile (Table 3; Fig. 9a) are consistent with increased drainage of the adjacent floodplain during receding water levels, as the floodplain and varzea lakes are dominated by soils replete with the residual organic carbon from $\mathrm{C} 3$ plants (Moreira-Turcq et al., 2013). By contrast, the data imply that main stem POC in April, during rising waters, is influenced by a greater proportion of POC from the upstream tributaries, including POC transported by the Solimões and Madiera Rivers to the main stem, which are more ${ }^{13} \mathrm{C}$-enriched and $\mathrm{N}$-enriched (Table 3; Fig. 9a). Increased incidence of landslides in the Andes during the months leading up to April, i.e., the Amazon rainy season, would increase the input of high altitude ${ }^{13} \mathrm{C}$-enriched POC from these tributaries to Óbidos (Clark et al., 2013; Clark et al., 2016). The higher N:C of POC in this sampling month would also imply that these sources are more degraded (Ometto et al., 2006; Cleveland and Liptzin, 2007), consistent with lower bulk and RPO gas fraction $\mathrm{F}_{\mathrm{m}}$ values observed for the Solimões and Madeira river samples. Thus, we posit that preferential transport of the more degraded pools of this Andean soil source to Óbidos would explain the both more degraded and ${ }^{13} \mathrm{C}$-enriched signatures of POC observed in April (Feng et al., 2016; Mayorga et al., 2005). Note that these bulk differences do not manifest in observable differences in thermogram shape and the isotope composition of RPO fractions or components among the Óbidos samples (Fig. 4, Table 5).

Second, main stem POC could also comprise a mixture of soils from different depth horizons rather than from different landscapes. This hypothesis provides a strong mechanistic explanation for concurrent decreases in $\mathrm{F}_{\mathrm{m}}$ and increases in $\delta^{13} \mathrm{C}$ with increasing thermal stability (Figs. 4, 9a-b), but does not exclude the influence of the first hypothesis described above. This would be expected because $\delta^{13} \mathrm{C}$ of soil organic matter gets more enriched with depth across the Amazon River Basin (De Camargo et al., 1999; Ehleringer et al., 2000; Ometto et al., 2006; Appendix C, Fig. S1). Thus, more thermally stable pools of POC in the Óbidos thermograms would derive from deeper, more degraded and ${ }^{13} \mathrm{C}$-enriched soil pools. This hypothesis could similarly explain the temporal shifts in bulk $\delta^{13} \mathrm{C}$ and $\mathrm{C}: \mathrm{N}$ values of POC at Óbidos, particularly the greater 
input of ${ }^{13} \mathrm{C}$-depleted, higher $\mathrm{C}: \mathrm{N}$ and less degraded soil POC in July, as the river draws more carbon from the superficial layers of the floodplain. Input of this fresher floodplainderived organic matter to the river in July is consistent with accumulation of higher $\mathrm{F}_{\mathrm{m}}$ POC, possibly from coarser and less degraded vegetation debris, in the deeper sections of the river (Table 3, Fig. 2).

\subsection{Bioreactivity of POC in the main stem}

Sections 4.2-4.4 show that the Amazon River predominantly mobilizes organic carbon from longer residence time reservoirs in soils and bedrock, rather than from the more actively recycled reservoirs of living/aboveground terrestrial biomass. The mass of POC ultimately transported to the ocean, $12-14 \mathrm{Tg}$ POC/yr (Richey et al. 1990; Galy et al., 2015), is the mass difference between the quantity of soil and petrogenic POC flushed into the river and heterotrophic respiration of this POC in the river, which equates to a $\mathrm{CO}_{2}$ outgassing flux of $\sim 500 \mathrm{Tg} / \mathrm{yr}$ (Richey et al., 1990; Richey et al. 2002; Mayorga et al. 2005). Observations that certain pools of riverine POC contribute disproportionately to in situ oxidation (Richey et al., 1990; Mayorga et al., 2005; Ward et al. 2013) have led to the hypothesis that preferential degradation of organic matter plays an important role in this balance, and thus the river basin's role in the global organic carbon cycle (Cole et al., 2007).

The lack of any modern or bomb ${ }^{14} \mathrm{C}$-influenced component in riverine suspended POC at Óbidos implies that either younger sources of POC (e.g., fresh vegetation) are rapidly decomposed in the river over other POC sources (Mayorga et al., 2005), or that these fresher inputs to the river system are insignificant, perhaps because they are rapidly degraded in soils prior to being flushed into the river (e.g., Feng et al., 2016). The similarity in thermograms of POC between Óbidos and the two major tributaries upstream (Solimões and Madeira rivers) supports this argument, as the two upstream thermograms also show a lack of a significant modern POC component across RPO fractions. However, that the isotopic differences between the upstream and Óbidos sample thermograms could reflect turnover of older soil-derived components from 
different soil horizons or geographical sources (Section 4.4) between the Solimões River mouth, Madeira River mouth and Óbidos.

If we consider thermal stability a proxy for diagenetic stability or biological reactivity (Rosenheim et al., 2008; Rosenheim and Galy, 2012), the invariant thermograms of samples from Óbidos suggest that the diagenetic reactivity of POC in the main stem is relatively homogenous throughout the Amazon main stem (Fig. 4). Hydrodynamic sorting does not impose an observable control on the recycling of carbon within the river cross-section. This perspective is supported by lack of depth-dependent variation in bulk and compound-specific metrics for POC composition (Figs. 2, 5-7), and invariant enzyme activities throughout the Óbidos cross-section in July 2014 (Fig. 8; Appendix C, Fig. S3) that suggest that heterotrophic activity on POC remains constant with depth (e.g., Steen and Arnosti, 2013; Thao et al., 2015). At the same time, it is worth considering whether the three thermally distinct components of riverine POC at Óbidos have different fates downstream of Óbidos. The sample thermograms suggest that $\sim 2 / 3$ of POC flux from the Amazon River main stem, derived from a less degraded soil pool, is more likely to degrade in transit towards or within the coastal ocean water column than the other third.

Finally, the lack of change in thermogram shape among samples upstream and downstream of Óbidos would suggest that mixing of isotopically distinct POC from different tributaries does not alter the thermal stability of POC in the Amazon main stem. Alternatively, the similarity in sample thermogram shape could be a methodological limitation of the extent of degradation that thermal stability can resolve. Perhaps organic matter pools beyond a specific degradation state generate invariant thermograms despite isotopic differences in the $\mathrm{CO}_{2}$ evolved during ramped oxidation. It is particularly perplexing that the Tapajós POC thermogram is similar to the upstream sample thermograms, except that it lacks a high temperature (petrogenic OC) component, while the isotopic composition of gas fractions indicates that in situ production must dominate the $\mathrm{CO}_{2}$ evolved (Fig. 4; Fig. 9). At the same time, bulk POC in the Tapajós River is not modern $\left(\mathrm{F}_{\mathrm{m}}=0.88\right)$ and even-over-odd predominance observed across higher chain-length fatty acids (Fig. $7 \mathrm{~g}$ ) points to a significant input of vegetation-derived POC to the river. As POC concentrations are so low in the Tapajós River $(0.08 \mathrm{mg} / \mathrm{L})$, DOC leached from 
degraded soils in the drainage basin and sorbed onto particles produced by in situ production could noticeably influence the apparent bulk $\mathrm{F}_{\mathrm{m}}$ and fatty acid distribution in POC. Enough sorbed DOC could even shift the thermal stability of the sample via matrix interactions between the older DOC and fresher POC in the sample (see Chapter 4 Section 4.2; Williams et al., 2014), causing the thermogram to resemble the others in Fig. 4.

\section{Conclusions}

Combining ramped oxidation with bulk and compound-specific analyses of POC composition has enabled us to quantify three thermally and isotopically distinct soilderived components and one relatively small petrogenic organic carbon-derived component of POC exported by the Amazon River main stem. The data show that 2/3 of POC flux at Óbidos is less thermally stable and younger, presumably representing a less degraded soil pool, than the other two soil pools, suggesting that biomolecules from this fraction are more likely to remineralize between Óbidos and the coastal Atlantic Ocean. The small highest thermal stability petrogenic POC component in the river flux would be least likely to degrade. As petrogenic POC most likely originates from the Andeaninfluenced Solimões and Madeira river basins (Clark et al., 2013; Bouchez et al., 2014), its presence at Óbidos suggests that it persists between the confluence of these upstream tributaries with the main stem and Óbidos, and may continue to persist in route to the Atlantic Ocean.

However, thermal stability does not necessarily equate to diagenetic stability. Williams et al. (2015) analyzed the ${ }^{14} \mathrm{C}$ distribution of POC stored mudbank sediments from the French Guiana region of the Amazon River Basin shelf by ramped pyrolysis and found that petrogenic organic carbon was absent in these sediments, suggesting that this pool of old terrestrial organic matter turns over between the floodplain and the coastal ocean. Ward et al. (2013) also suggested that even lignins, considered the most recalcitrant terrestrial biomolecules (Gough et al., 1993), are actively remineralized during river transport across the basin. Thus, perspectives of environmental reactivity and 
selective degradation vs. preservation in the Amazon need review, perhaps with the unique perspectives and analytical opportunities offered by ramped oxidation.

Looking to the future, RPO analyses of riverine POC collected over a higherresolution transect upstream and downstream of Óbidos will be essential to constrain the different sources of soil POC we observe across the thermograms from Óbidos, assess their reactivity through the river system, and resolve the paradox of identical thermograms across isotopically distinct POC sources in the current data set. Finally, as the Amazon landscape shifts in response to climate change and land use change policies ( (Davidson et al., 2012; Gloor et al., 2013; Brienen et al., 2013), export of sediments and organic carbon to the river system are expected to change (Butman et al., 2015; Dias et al., 2015), as well. RPO offers a tool to assess whether these transitions would manifest in changes in the quantity, quality and recycling of soil organic carbon flushed into the river system.

\section{Acknowledgements}

Special thanks to Rob Spencer, Valier Galy, the Amazon Research group at Woods Hole Research Center, and Jose Mauro S. Moura from Universidade Federal do Oeste do Para for their support in organizing the field work component of this chapter; Andrew Steen for the enzyme assay data and interpretations; the scientific and ship crews of the Tapajós River (especially Rardiles Branches, Miyuki Mitsuya, Gabriela, Paula); Bernhard Peucker-Ehrenbrink, Kate Bulygina, Britta Voss, and Joshua West for assistance in field preparation; Brittany Jenner and the Sontek support team for assistance in analyzing and interpreting the ADCP data; and Ann McNichol, Carl Johnson, Al Gagnon, Kyrstin Fornace, Jordon Hemingway, Mary Lardie, Li Xu, Kalina Gospodinova, and Katherine French for analytical assistance. The research was funded by the trustees of the Woods Hole Research Center, and the WHOI Coastal Ocean Institute grant.

\section{References}

Aller, R., Blair, N., Xia, Q., and Rude, P.: Remineralization rates, recycling, and storage of carbon in Amazon shelf sediments, Continental Shelf Research, 16, 753-786, 1996. 
Amon, R. M. W. and Benner, R.: Photochemical and microbial consumption of dissolved organic carbon and dissolved oxygen in the Amazon River system, Geochimica et Cosmochimica Acta, 60, 1783-1792, 1996.

Aufdenkampe, A. K., Hedges, J. I., Richey, J. E., Krusche, A. V., and Llerena, C. A.: Sorptive fractionation of dissolved organic nitrogen and amino acids onto fine sediments within the Amazon Basin, Limnology and Oceanography, 46, 19211935, 2001.

Aufdenkampe, A. K., Mayorga, E., Hedges, J. I., Llerena, C., Quay, P. D., Gudeman, J., Krusche, A. V., and Richey, J. E.: Organic matter in the Peruvian headwaters of the Amazon: compositional evolution from the Andes to the lowland Amazon mainstem, Organic Geochemistry, 38, 337-364, 2007.

Blair, N. E. and Aller, R. C.: The Fate of Terrestrial Organic Carbon in the Marine Environment, Annual Review of Marine Science, 4, 401-423, 2012.

Bouchez, J., Gaillardet, J., France - Lanord, C., Maurice, L., and Dutra - Maia, P.: Grain size control of river suspended sediment geochemistry: Clues from Amazon River depth profiles, Geochemistry, Geophysics, Geosystems, 12, 2011a.

Bouchez, J., Galy, V., Hilton, R. G., Gaillardet, J., Moreira-Turcq, P., Pérez, M. A., France-Lanord, C., and Maurice, L.: Source, transport and fluxes of Amazon River particulate organic carbon: insights from river sediment depth-profiles, Geochimica et Cosmochimica Acta, 133, 280-298, 2014.

Bouchez, J., Métivier, F., Lupker, M., Maurice, L., Perez, M., Gaillardet, J., and FranceLanord, C.: Prediction of depth-integrated fluxes of suspended sediment in the Amazon River: particle aggregation as a complicating factor, Hydrological Processes, 25, 778-794, $2011 \mathrm{~b}$.

Brienen, R. J., Phillips, O., Feldpausch, T., Gloor, E., Baker, T., Lloyd, J., LopezGonzalez, G., Monteagudo-Mendoza, A., Malhi, Y., and Lewis, S. L.: Long-term decline of the Amazon carbon sink, Nature, 519, 344-348, 2015.

Burnham, A. K. and Braun, R. L.: Global kinetic analysis of complex materials, Energy \& Fuels, 13, 1-22, 1999.

Butman, D. E., Wilson, H. F., Barnes, R. T., Xenopoulos, M. A., and Raymond, P. A.: Increased mobilization of aged carbon to rivers by human disturbance, Nature Geoscience, 8, 112-116, 2015.

Butman, D., Stackpoole, S., Stets, E., McDonald, C. P., Clow, D. W., and Striegl, R. G.: Aquatic carbon cycling in the conterminous United States and implications for terrestrial carbon accounting, Proceedings of the National Academy of Sciences, 113, 58-63, 2016.

Chen, C.-L.: Power Law of Flow Resistance in Open Channels, Manning's Formula Revisited, 1989. 1989.

Clark, K. E., Hilton, R. G., West, A. J., Malhi, Y., Gröcke, D. R., Bryant, C. L., Ascough, P. L., Robles Caceres, A., and New, M.: New views on "old" carbon in the Amazon River: Insight from the source of organic carbon eroded from the Peruvian Andes, Geochemistry, Geophysics, Geosystems, 14, 1644-1659, 2013.

Clark, K., West, A., Hilton, R., Asner, G., Quesada, C., Silman, M., Saatchi, S., FarfanRios, W., Martin, R., and Horwath, A.: Storm-triggered landslides in the Peruvian Andes and implications for topography, carbon cycles, and biodiversity, Earth Surface Dynamics, 4, 47, 2016. 
Cleveland, C. C. and Liptzin, D.: C: N: P stoichiometry in soil: is there a "Redfield ratio" for the microbial biomass?, Biogeochemistry, 85, 235-252, 2007.

Cole, J. J., Prairie, Y. T., Caraco, N. F., McDowell, W. H., Tranvik, L. J., Striegl, R. G., Duarte, C. M., Kortelainen, P., Downing, J. A., Middelburg, J. J., and Melack, J.: Plumbing the global carbon cycle: Integrating inland waters into the terrestrial carbon budget, Ecosystems, 10, 171-184, 2007.

Cramer, B.: Methane generation from coal during open system pyrolysis investigated by isotope specific, Gaussian distributed reaction kinetics, Organic Geochemistry, 35, 379-392, 2004.

Cranwell, P.: Lipids of aquatic sediment and sedimentary particles, Progress in Lipid Research, 21, 205-221, 1982.

Curtis, W. F., Meade, R. H., Nordin, C. F., Price, N. B., and Sholkovitz, E. R.: Nonuniform vertical distribution of fine sediment in the Amazon River, Nature, 280, 381-383, 1979.

Davidson, E. A., de Araújo, A. C., Artaxo, P., Balch, J. K., Brown, I. F., Bustamante, M. M., Coe, M. T., DeFries, R. S., Keller, M., and Longo, M.: The Amazon basin in transition, Nature, 481, 321-328, 2012.

De Camargo, P. B., Trumbore, S. E., Martinelli, L., Davidson, E., Nepstad, D. C., and Victoria, R. L.: Soil carbon dynamics in regrowing forest of eastern Amazonia, Global Change Biology, 5, 693-702, 1999.

Dias, L. C. P., Macedo, M. N., Costa, M. H., Coe, M. T., and Neill, C.: Effects of land cover change on evapotranspiration and streamflow of small catchments in the Upper Xingu River Basin, Central Brazil, Journal of Hydrology: Regional Studies, 4, Part B, 108-122, 2015.

Eglinton, G. and Hamilton, R.: The distribution of alkanes, Chemical plant taxonomy, 187, 217, 1963.

Ehleringer, J. R., Buchmann, N., and Flanagan, L. B.: Carbon isotope ratios in belowground carbon cycle processes, Ecological Applications, 10, 412-422, 2000.

Feng, X., Feakins, S. J., Liu, Z., Ponton, C., Wang, R. Z., Karkabi, E., Galy, V., Berelson, W. M., Nottingham, A. T., Meir, P., and West, A. J.: Source to sink: Evolution of lignin composition in the Madre de Dios River system with connection to the Amazon basin and offshore, Journal of Geophysical Research: Biogeosciences, 121, 1316-1338, 2016.

Galy, V., Beyssac, O., France-Lanord, C., and Eglinton, T.: Recycling of graphite during Himalayan erosion: A geological stabilization of carbon in the crust, Science, 322, 943-945, 2008.

Galy, V., Bouchez, J., and France - Lanord, C.: Determination of total organic carbon content and $\delta{ }^{13} \mathrm{C}$ in carbonate-rich detrital sediments, Geostandards and Geoanalytical research, 31, 199-207, 2007.

Galy, V., Peucker-Ehrenbrink, B., and Eglinton, T.: Global carbon export from the terrestrial biosphere controlled by erosion, Nature, 521, 204-207, 2015.

Gibbs, R. J.: Amazon River: Environmental Factors That Control Its Dissolved and Suspended Load, Science, 156, 1734-1737, 1967.

Gloor, M., Brienen, R. J., Galbraith, D., Feldpausch, T., Schöngart, J., Guyot, J. L., 
Espinoza, J., Lloyd, J., and Phillips, O.: Intensification of the Amazon hydrological cycle over the last two decades, Geophysical Research Letters, 40, 1729-1733, 2013.

Gough, M. A., Fauzi, R., Mantoura, C., and Preston, M.: Terrestrial plant biopolymers in marine sediments, Geochimica et Cosmochimica Acta, 57, 945-964, 1993.

Guyot, J. L., Fillzola, N., Quintanilla, J., and Cortez, J.: Dissolved solids and suspended sediment yields in the Rio Madeira basin, from the Bolivian Andes to the Amazon, IAHS Publication, 1996. 55-64, 1996.

Hedges, J. I., Clark, W. A., Quay, P. D., Richey, J. E., Devol, A. H., and Santos, U. d. M.: Compositions and fluxes of particulate organic material in the Amazon River, Limnology and Oceanography, 31, 717-738, 1986.

Hedges, J. I., Cowie, G. L., Richey, J. E., Quay, P. D., Benner, R., Strom, M., and Forsberg, B. R.: Origins and processing of organic matter in the Amazon River as indicated by carbohydrates and amino acids, Limnology and Oceanography, 39, 743-761, 1994.

Hemingway, J. D., Galy, V. V., Gagnon, A. R., Grant, K. E., Rosengard, S. Z., Soulet, G., Zigah, P., and McNichol, A. P.: Assessing the blank carbon contribution, isotope mass balance, and kinetic isotope fractionation of the ramped pyrolysis/oxidation instrument at NOSAMS, Radiocarbon, accepted. accepted.

J.D. Hemingway. rampedpyrox: open-source tools for thermoanalytical data analysis, 2016-,http://github.com/FluvialSeds/rampedpyrox [online; accessed 2016-12-26]

Hemingway, J.D.: Understanding terrestrial organic carbon export: A time-series approach, 2017. Massachusetts Institute of Technology and Woods Hole Oceanographic Institution, 2017.

Jeng, W.-L.: Higher plant n-alkane average chain length as an indicator of petrogenic hydrocarbon contamination in marine sediments, Marine Chemistry, 102, 242251, 2006.

Kastner, T. P. and Goñi, M. A.: Constancy in the vegetation of the Amazon Basin during the late Pleistocene: evidence from the organic matter composition of Amazon deep sea fan sediments, Geology, 31, 291-294, 2003.

Kim, J.-H., Zell, C., Moreira-Turcq, P., Pérez, M. A., Abril, G., Mortillaro, J.-M., Weijers, J. W., Meziane, T., and Damsté, J. S. S.: Tracing soil organic carbon in the lower Amazon River and its tributaries using GDGT distributions and bulk organic matter properties, Geochimica et Cosmochimica Acta, 90, 163-180, 2012.

Körner, C., Farquhar, G., and Wong, S.: Carbon isotope discrimination by plants follows latitudinal and altitudinal trends, Oecologia, 88, 30-40, 1991.

Mayorga, E., Aufdenkampe, A. K., Masiello, C. A., Krusche, A. V., Hedges, J. I., Quay, P. D., Richey, J. E., and Brown, T. A.: Young organic matter as a source of carbon dioxide outgassing from Amazonian rivers, Nature, 436, 538-541, 2005.

McNichol, A., Gagnon, A., Jones, G., and Osborne, E.: Illumination of a black box: analysis of gas composition during graphite target preparation, Radiocarbon, 34, 321-329, 1992.

McNichol, A., Gagnon, A., Osborne, E., Hutton, D., and Schneid, R.: Improvements in procedural blanks at NOSAMS: Reflections of improvements in sample preparation and accelerator operation, Radiocarbon, 37, 683-691, 1995.

Molinier, M., Guyot, J.-L., De Oliveira, E., and Guimarães, V.: Les regimes 
hydroiogiques de l'Amazone et de ses affluents, IAHS Publication, 1996. 209222, 1996.

Moreira-Turcq, P., Bonnet, M. P., Amorim, M., Bernardes, M., Lagane, C., Maurice, L., Perez, M., and Seyler, P.: Seasonal variability in concentration, composition, age, and fluxes of particulate organic carbon exchanged between the floodplain and Amazon River, Global Biogeochemical Cycles, 27, 119-130, 2013.

Moreira-Turcq, P., Seyler, P., Guyot, J. L., and Etcheber, H.: Exportation of organic carbon from the Amazon River and its main tributaries, Hydrological Processes, 17, 1329-1344, 2003.

Mortillaro, J., Abril, G., Moreira-Turcq, P., Sobrinho, R., Perez, M., and Meziane, T.: Fatty acid and stable isotope $\left(\delta^{13} \mathrm{C}, \delta^{15} \mathrm{~N}\right)$ signatures of particulate organic matter in the lower Amazon River: seasonal contrasts and connectivity between floodplain lakes and the mainstem, Organic Geochemistry, 42, 1159-1168, 2011.

Mueller, D. S., Wagner, C. R., Rehmel, M. S., Oberg, K. A., and Rainville, F.: Measuring discharge with acoustic Doppler current profilers from a moving boat, US Department of the Interior, US Geological Survey, 2009.

O'Leary, M. H.: Carbon isotope fractionation in plants, Phytochemistry, 20, 553-567, 1981.

Ometto, J. P. H. B., Ehleringer, J. R., Domingues, T. F., Berry, J. A., Ishida, F. Y., Mazzi, E., Higuchi, N., Flanagan, L. B., Nardoto, G. B., and Martinelli, L. A.: The stable carbon and nitrogen isotopic composition of vegetation in tropical forests of the Amazon Basin, Brazil, Biogeochemistry, 79, 251-274, 2006.

Plante, A. F., Beaupré, S. R., Roberts, M. L., and Baisden, T.: Distribution of radiocarbon ages in soil organic matter by thermal fractionation, Radiocarbon, 55, 1077-1083, 2013.

Quesada, C., Lloyd, J., Schwarz, M., Patĩ̃º, S., Baker, T., Czimczik, C., Fyllas, N., Martinelli, L., Nardoto, G., and Schmerler, J.: Variations in chemical and physical properties of Amazon forest soils in relation to their genesis, Biogeosciences, 7, 2010.

Richey, J., E, e., Hedges, J. I., Devol, A. H., Quay, P. D., Victoria, R., Martinelli, L., and Forsberg, B. R.: Biogeochemistry of carbon in the Amazon River, Limnology and Oceanography, 35, 352-371, 1990.

Richey, J. E., Meade, R. H., Salati, E., Devol, A. H., Nordin, C. F., and Dos Santos, U.: Water discharge and suspended sediment concentrations in the Amazon River: 1982-1984, Water Resources Research, 22, 756-764, 1986.

Richey, J. E., Melack, J. M., Aufdenkampe, A. K., Ballester, V. M., and Hess, L. L.: Outgassing from Amazonian rivers and wetlands as a large tropical source of atmospheric $\mathrm{CO}_{2}$, Nature, 416, 617-620, 2002.

Rosenheim, B. E., Day, M. B., Domack, E., Schrum, H., Benthien, A., and Hayes, J. M.: Antarctic sediment chronology by programmed-temperature pyrolysis: Methodology and data treatment, Geochemistry, Geophysics, Geosystems, 9, 2008.

Rosenheim, B. E. and Galy, V.: Direct measurement of riverine particulate organic carbon age structure, Geophysical Research Letters, 39, 2012.

Rosenheim, B. E., Roe, K. M., Roberts, B. J., Kolker, A. S., Allison, M. A., and 
Johannesson, K. H.: River discharge influences on particulate organic carbon age structure in the Mississippi/Atchafalaya River System, Global Biogeochemical Cycles, 27, 154-166, 2013.

Rouse, H., Engineering Hydraulics, Wiley, New York, 1950.

Steen, A. D. and Arnosti, C.: Extracellular peptidase and carbohydrate hydrolase activities in an Arctic fjord (Smeerenburgfjord, Svalbard), Aquatic Microbial Ecology, 69, 93-99, 2013.

Thao, N. V., Nozawa, A., Obayashi, Y., Kitamura, S.-I., Yokokawa, T., and Suzuki, S.: Extracellular proteases are released by ciliates in defined seawater microcosms, Marine environmental research, 109, 95-102, 2015.

Ward, N. D., Keil, R. G., Medeiros, P. M., Brito, D. C., Cunha, A. C., Dittmar, T., Yager, P. L., Krusche, A. V., and Richey, J. E.: Degradation of terrestrially derived macromolecules in the Amazon River, Nature Geoscience, 6, 530-533, 2013.

Ward, N. D., Krusche, A. V., Sawakuchi, H. O., Brito, D. C., Cunha, A. C., Moura, J. M. S., da Silva, R., Yager, P. L., Keil, R. G., and Richey, J. E.: The compositional evolution of dissolved and particulate organic matter along the lower Amazon River-Óbidos to the ocean, Marine Chemistry, 177, 244-256, 2015.

Whiteside, J. H., Olsen, P. E., Eglinton, T. I., Cornet, B., McDonald, N. G., and Huber, P.: Pangean great lake paleoecology on the cusp of the end-Triassic extinction, Palaeogeography, Palaeoclimatology, Palaeoecology, 301, 1-17, 2011.

Williams, E. K., Rosenheim, B. E., Allison, M., McNichol, A. P., and Xu, L.: Quantification of refractory organic material in Amazon mudbanks of the French Guiana Coast, Marine Geology, 363, 93-101, 2015.

Williams, E. K., Rosenheim, B. E., McNichol, A. P., and Masiello, C. A.: Charring and non-additive chemical reactions during ramped pyrolysis: Applications to the characterization of sedimentary and soil organic material, Organic Geochemistry, 77, 106-114, 2014. 
Table 1. Sample locations and times. Depth-specific samples at Óbidos were collected in three positions across the main stem channel, referenced to the right bank across from Óbidos (Fig. 1). The 2005 data are taken from Bouchez et al. (2011b; 2014). Discharge, total suspended solid (TSS) and particulate organic carbon (POC) fluxes, and water temperatures are provided when possible, as well. $\mathrm{z}_{\mathrm{R}}$, or Rouse numbers, were calculated by fitting TSS concentration profiles in each sampling month to Equation 3, following Bouchez et al. (2011b).

\begin{tabular}{|c|c|c|c|c|c|c|c|c|c|c|c|c|}
\hline 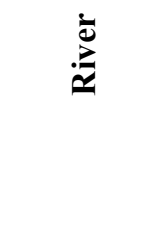 & & 䒿 & 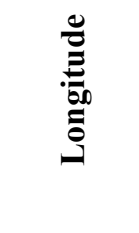 & $\stackrel{\mathscr{I}}{\tilde{\Xi}}$ & 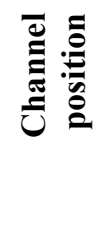 & 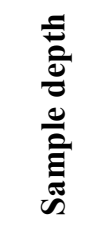 & 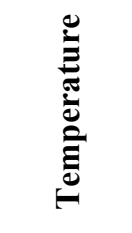 & $\dot{0}$ & 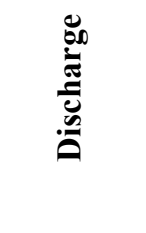 & $\stackrel{\Upsilon}{N}$ & 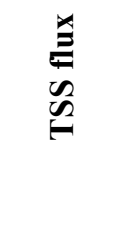 & 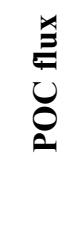 \\
\hline -- & -- & ${ }^{\circ} S$ & ${ }^{\circ} W$ & -- & $\mathrm{km}$ & $m$ & ${ }^{\circ} \mathrm{C}$ & & $\mathrm{m}^{3} / \mathrm{s}$ & unitless & $\mathrm{kg} / \mathrm{s}$ & $\mathrm{kg} / \mathrm{s}$ \\
\hline main stem & Óbidos & $1.9367^{*}$ & $55.503 *$ & $6 / 8 / 05$ & - & $\mathbf{0}$ & no data & $>100 \mathrm{~L}$ & 128,000 & 0.39 & 61,300 & 604 \\
\hline Madeira & Foz Madeira & $3.450^{*}$ & $58.808^{*}$ & $6 / 6 / 05$ & - & $\mathbf{0}$ & no data & $>100 \mathrm{~L}$ & 21,800 & 0.09 & 17,400 & 168 \\
\hline Solimões & Manacapuru & $3.314^{*}$ & $60.554 *$ & $6 / 4 / 05$ & - & $\mathbf{0}$ & no data & $>100 \mathrm{~L}$ & 124,700 & 0.10 & 1,300 & 14 \\
\hline main stem & Óbidos & 1.946 & 55.510 & $4 / 2 / 14 \quad 10: 30$ & 0.32 & 35.49 & 25.9 & $\sim 10 \mathrm{~L}$ & 246,000 & 0.26 & 53,000 & 540 \\
\hline main stem & Óbidos & 1.946 & 55.510 & $4 / 2 / 14 \quad 10: 30$ & 0.32 & 15.3 & 27.3 & $\sim 10 \mathrm{~L}$ & 246,000 & 0.26 & 53,000 & 540 \\
\hline main stem & Óbidos & 1.946 & 55.510 & $4 / 2 / 14 \quad 10: 30$ & 0.32 & 2.1 & no data & $\sim 10 \mathrm{~L}$ & 246,000 & 0.26 & 53,000 & 540 \\
\hline main stem & Óbidos & 1.942 & 55.503 & $4 / 2 / 14 \quad 10: 30$ & 1.1 & $\underline{49.1}$ & no data & $\sim 10 \mathrm{~L}$ & 246,000 & 0.26 & 53,000 & 540 \\
\hline main stem & Óbidos & 1.942 & 55.503 & $4 / 2 / 14 \quad 10: 30$ & 1.1 & $\underline{30.15}$ & 27.5 & $\sim 10 \mathrm{~L}$ & 246,000 & 0.26 & 53,000 & 540 \\
\hline main stem & Óbidos & 1.942 & 55.503 & $4 / 2 / 14 \quad 10: 30$ & 1.1 & 13.33 & 26.8 & $\sim 10 \mathrm{~L}$ & 246,000 & 0.26 & 53,000 & 540 \\
\hline main stem & Óbidos & 1.942 & 55.503 & $4 / 2 / 14 \quad 10: 30$ & 1.1 & $\underline{2.7}$ & 26.4 & $\sim 10 \mathrm{~L}$ & 246,000 & 0.26 & 53,000 & 540 \\
\hline main stem & Óbidos & 1.938 & 55.496 & $4 / 2 / 14 \quad 10: 30$ & 2.00 & 27.8 & 27.5 & $\sim 10 \mathrm{~L}$ & 246,000 & 0.26 & 53,000 & 540 \\
\hline main stem & Óbidos & 1.938 & 55.496 & $4 / 2 / 14 \quad 10: 30$ & 2.00 & 10.4 & 26.1 & $\sim 10 \mathrm{~L}$ & 246,000 & 0.26 & 53,000 & 540 \\
\hline main stem & Óbidos & 1.938 & 55.496 & $4 / 2 / 14 \quad 10: 30$ & 2.00 & 2.8 & 26.1 & $\sim 10 \mathrm{~L}$ & 246,000 & 0.26 & 53,000 & 540 \\
\hline main stem & Óbidos & 1.94 & 55.501 & $4 / 1 / 14 \quad 10: 30$ & - & $\mathbf{0}$ & 28.0 & $>100 \mathrm{~L}$ & 246,000 & N/A & 53,000 & 540 \\
\hline
\end{tabular}




\begin{tabular}{|c|c|c|c|c|c|c|c|c|c|c|c|c|}
\hline Tapajós & Tapajós & no data & no data & $7 / 27 / 14$ 13:00 & - & $\mathbf{0}$ & no data & $>100 \mathrm{~L}$ & no data & N/A & no data & no data \\
\hline Tapajós & Tapajós & no data & no data & $7 / 27 / 14$ & - & bed & no data & N/A & no data & N/A & no data & no data \\
\hline main stem & Óbidos & 1.946 & 55.509 & $7 / 28 / 14$ 14:00 & 0.34 & 42.8 & 28.9 & $\sim 10 \mathrm{~L}$ & 247,000 & 0.34 & 48,000 & 370 \\
\hline main stem & Óbidos & 1.945 & 55.510 & $7 / 28 / 14$ 14:00 & 0.34 & 20.6 & no data & $\sim 10 \mathrm{~L}$ & 247,000 & 0.34 & 48,000 & 370 \\
\hline main stem & Óbidos & 1.945 & 55.509 & $7 / 28 / 14 \quad 14: 00$ & 0.34 & 3.5 & no data & $\sim 10 \mathrm{~L}$ & 247,000 & 0.34 & 48,000 & 370 \\
\hline main stem & Óbidos & 1.944 & 55.494 & $7 / 28 / 1414: 00$ & 1.6 & $\underline{54}$ & 28.9 & $\sim 10 \mathrm{~L}$ & 247,000 & 0.34 & 48,000 & 370 \\
\hline main stem & Óbidos & 1.942 & 55.497 & $7 / 28 / 14$ 14:00 & 1.6 & 39.83 & 29 & $\sim 10 \mathrm{~L}$ & 247,000 & 0.34 & 48,000 & 370 \\
\hline main stem & Óbidos & 1.941 & 55.499 & $7 / 28 / 1414: 00$ & 1.6 & $\underline{30.4}$ & 28.9 & $\sim 10 \mathrm{~L}$ & 247,000 & 0.34 & 48,000 & 370 \\
\hline main stem & Óbidos & 1.941 & 55.499 & $7 / 28 / 1414: 00$ & 1.6 & 14.95 & no data & $\sim 10 \mathrm{~L}$ & 247,000 & 0.34 & 48,000 & 370 \\
\hline main stem & Óbidos & 1.939 & 55.501 & $7 / 28 / 1414: 00$ & 1.6 & $\underline{3.14}$ & no data & $\sim 10 \mathrm{~L}$ & 247,000 & 0.34 & 48,000 & 370 \\
\hline main stem & Óbidos & 1.933 & 55.497 & $7 / 28 / 14 \quad 14: 00$ & 2.2 & 53.06 & 29 & $\sim 10 \mathrm{~L}$ & 247,000 & 0.34 & 48,000 & 370 \\
\hline main stem & Óbidos & 1.931 & 55.499 & $7 / 28 / 14$ 14:00 & 2.2 & 29.83 & no data & $\sim 10 \mathrm{~L}$ & 247,000 & 0.34 & 48,000 & 370 \\
\hline main stem & Óbidos & 1.933 & 55.498 & $7 / 28 / 1414: 00$ & 2.2 & 3.33 & no data & $\sim 10 \mathrm{~L}$ & 247,000 & 0.34 & 48,000 & 370 \\
\hline main stem & Óbidos & 1.942 & 55.496 & $7 / 28 / 14$ 13:00 & - & $\mathbf{0}$ & 29.2 & $>100 \mathrm{~L}$ & 247,000 & 0.34 & 48,000 & 370 \\
\hline main stem & Óbidos & no data & no data & $7 / 29 / 14$ & - & bed & no data & N/A & 247,000 & N/A & 48,000 & 370 \\
\hline main stem & Óbidos & no data & no data & $7 / 29 / 14$ & - & bed & no data & N/A & 247,000 & N/A & 48,000 & 370 \\
\hline main stem & Óbidos & no data & no data & $7 / 29 / 14$ & 1 & flood & no data & N/A & 247,000 & N/A & 48,000 & 370 \\
\hline
\end{tabular}

*=approximate

underlined $=$ samples analyzed by ramped oxidation.

bolded $=$ samples that were lipid extracted.

"bed"=bedload.; "flood"=floodplain deposit. 
Table 2. Substrates used to measure enzyme activities associated with suspended sediments collected within the Óbidos cross-section in July 2014. AMC is -amino-4methylcoumarin and MUB is 4-methylumbelliferone. Table credit: Andrew Steen.

\begin{tabular}{|c|c|c|c|}
\hline Substrate & Abbreviation & Enzyme & Element \\
\hline leucine-AMC & Leu-AMC & leucyl aminopeptidase & $\mathrm{N}$ \\
\hline Phenylalanine-AMC & Phe-AMC & phenyalanyl aminopeptidase & $\mathrm{N}$ \\
\hline $\begin{array}{l}\text { Ala-Ala-Phe-AMC } \\
\text { MUB-beta-N-acetvl }\end{array}$ & AAF-AMC & chymotrypsin & $\mathrm{N}$ \\
\hline glucosamine & MUB-NAG & $\mathrm{N}$-acetylglucosaminidase & $\mathrm{N}$ \\
\hline MUB-cellobiose & MUB-cello & cellulase & $\mathrm{C}$ \\
\hline MUB-beta glucose & MUB-beta-glu & beta-glucosidase & $\mathrm{C}$ \\
\hline MUB-beta xylose & MUB-xyl & xylanase & $\mathrm{C}$ \\
\hline MUB-PO4 & MUB-PO4 & phosphomonoesterase & $\mathrm{P}$ \\
\hline
\end{tabular}


Table 3. Total suspended sediment concentration, organic matter composition and grain size of all depth-specific samples collected at Óbidos in 2014, large-volume samples, and bed /floodplain samples. Errors for C:N and $\delta^{13} \mathrm{C}_{\mathrm{POC}}$ are reported. Relative errors of depthspecific $\mathrm{F}_{\mathrm{m}}$ values are $<3 \%$, and are not reported. Refer to Table 1 for sampling times of individual samples.

\begin{tabular}{|c|c|c|c|c|c|c|c|c|c|c|c|c|c|}
\hline & ڤี & 䓂 & 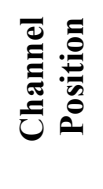 & $\begin{array}{l}\bar{n} \\
\hat{n} \\
\underline{B}\end{array}$ & $\begin{array}{l}\stackrel{0}{\circ} \\
\frac{1}{\circ}\end{array}$ & $\frac{z}{a}$ & تُ & $\underbrace{0}_{0}$ & 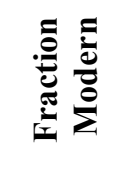 & 当 & 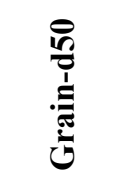 & 意 & 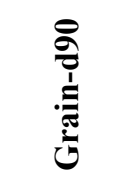 \\
\hline -- & -- & $m$ & $\mathrm{~km}$ & $m g / L$ & $m g / m g$ & $m g / m g$ & 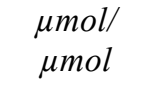 & $\%$ & unitless & $\mu m$ & $\mu m$ & $\mu m$ & $\mu m$ \\
\hline Óbidos & $6 / 8 / 05$ & 0 & - & no data & $0.85 \pm 0.01$ & $0.14 \pm 0.005$ & $7.3 \pm 0.5$ & $-28.5 \pm 0.05$ & 0.71 & no data & no data & no data & no data \\
\hline Solimões & $6 / 6 / 05$ & 0 & - & no data & $1.1 \pm 0.06$ & $0.17 \pm 0.003$ & $7.9 \pm 1.8$ & $-27.0 \pm 0.05$ & 0.72 & no data & no data & no data & no data \\
\hline Madeira & $6 / 4 / 05$ & 0 & - & no data & $0.50 \pm 0.01$ & $0.08 \pm 0.0004$ & $7.1 \pm 1.9$ & $-27.7 \pm 0.3$ & 0.67 & no data & no data & no data & no data \\
\hline main stem & $4 / 1 / 14$ & 0 & - & 55 & $1.4 \pm 0.01$ & $0.19 \pm 0.004$ & $8.5 \pm 0.2$ & $-28.1 \pm 0.06$ & 0.72 & no data & no data & no data & no data \\
\hline main stem & $4 / 2 / 14$ & 35.49 & 0.32 & 319 & $0.98 \pm 0.02$ & $0.12 \pm 0.001$ & $9.6 \pm 0.2$ & $-28.3 \pm 0.07$ & no data & 44 & 29 & 4 & 109 \\
\hline main stem & $4 / 2 / 14$ & 15.3 & 0.32 & 150 & $1.0 \pm 0.02$ & $0.12 \pm 0.001$ & $9.6 \pm 0.2$ & $-28.3 \pm 0.2$ & no data & 48 & 31 & 5 & 121 \\
\hline main stem & $4 / 2 / 14$ & 2.1 & 0.32 & 79 & $1.3 \pm 0.02$ & $0.20 \pm 0.001$ & $7.8 \pm 0.1$ & $-28.4 \pm 0.09$ & no data & 50 & 29 & 4 & 131 \\
\hline main stem & $4 / 2 / 14$ & 49.1 & 1.1 & 208 & $0.96 \pm 0.01$ & $0.13 \pm 0.001$ & $8.8 \pm 0.1$ & $-28.2 \pm 0.05$ & 0.77 & 63 & 44 & 6 & 153 \\
\hline main stem & $4 / 2 / 14$ & 30.15 & 1.1 & 233 & $0.93 \pm 0.01$ & $0.11 \pm 0.001$ & $10 \pm 0.1$ & $-28.2 \pm 0.03$ & 0.78 & 48 & 30 & 5 & 119 \\
\hline main stem & $4 / 2 / 14$ & 13.33 & 1.1 & 111 & $1.4 \pm 0.01$ & $0.19 \pm 0.002$ & $8.4 \pm 0.1$ & $-28.0 \pm 0.08$ & 0.78 & 43 & 27 & 4 & 106 \\
\hline main stem & $4 / 2 / 14$ & 2.7 & 1.1 & 72 & $1.5 \pm 0.01$ & $0.24 \pm 0.004$ & $7.4 \pm 0.1$ & $-28.1 \pm 0.03$ & 0.77 & 70 & 49 & 4 & 171 \\
\hline main stem & $4 / 2 / 14$ & 27.8 & 2.00 & 149 & $1.1 \pm 0.01$ & $0.15 \pm 0.001$ & $8.5 \pm 0.1$ & $-28.2 \pm 0.1$ & no data & 61 & 39 & 5 & 154 \\
\hline main stem & $4 / 2 / 14$ & 10.4 & 2.00 & 126 & $1.2 \pm 0.05$ & $0.16 \pm 0.003$ & $8.7 \pm 0.4$ & $-28.1 \pm 0.02$ & no data & 60 & 43 & 6 & 142 \\
\hline main stem & $4 / 2 / 14$ & 2.8 & 2.00 & 107 & $1.2 \pm 0.03$ & $0.17 \pm 0.002$ & $8.3 \pm 0.3$ & $-28.1 \pm 0.1$ & no data & 44 & 28 & 4 & 110 \\
\hline Tapajós & $7 / 27 / 14$ & bed & - & N/A & $0.14 \pm 0.002$ & $0.017 \pm 0.0003$ & $9.8 \pm 0.3$ & $-29.4 \pm 0.2$ & 1.02 & no data & no data & no data & no data \\
\hline Tapajós & $7 / 27 / 14$ & 0 & - & 1 & $16 \pm 0.13$ & $2.7 \pm 0.005$ & $6.8 \pm 0.1$ & $-31.0 \pm 0.1$ & 0.89 & no data & no data & no data & no data \\
\hline main stem & $7 / 28 / 14$ & 0 & - & 16 & $1.8 \pm 0.02$ & $0.23 \pm 0.003$ & $9.0 \pm 0.1$ & $-29.1 \pm 0.06$ & 0.77 & no data & no data & no data & no data \\
\hline main stem & $7 / 28 / 14$ & 42.8 & 0.34 & 741 & $0.79 \pm 0.04$ & $0.07 \pm 0.002$ & $14 \pm 0.9$ & $-28.5 \pm 0.1$ & no data & 80 & 69 & 11 & 165 \\
\hline
\end{tabular}




\begin{tabular}{|c|c|c|c|c|c|c|c|c|c|c|c|c|c|}
\hline main stem & $7 / 28 / 14$ & 20.6 & 0.34 & 135 & $1.0 \pm 0.003$ & $0.11 \pm 0.002$ & $11 \pm 0.2$ & $-28.8 \pm 0.03$ & no data & 71 & 52 & 9 & 163 \\
\hline main stem & $7 / 28 / 14$ & 3.5 & 0.34 & 103 & $0.85 \pm 0.02$ & $0.10 \pm 0.001$ & $10 \pm 0.3$ & $-28.8 \pm 0.03$ & no data & 66 & 51 & 8 & 146 \\
\hline main stem & $7 / 28 / 14$ & 54 & 1.6 & 305 & $0.51 \pm 0.02$ & $0.05 \pm 0.001$ & $11 \pm 0.5$ & $-28.4 \pm 0.2$ & 0.80 & 106 & 96 & 15 & 212 \\
\hline main stem & $7 / 28 / 14$ & 39.83 & 1.6 & 182 & $0.54 \pm 0.01$ & $0.06 \pm 0.002$ & $9.8 \pm 0.3$ & $-28.6 \pm 0.1$ & 0.78 & 80 & 66 & 9 & 176 \\
\hline main stem & $7 / 28 / 14$ & 30.4 & 1.6 & 169 & $0.77 \pm 0.02$ & $0.09 \pm 0.001$ & $11 \pm 0.3$ & $-28.9 \pm 0.05$ & 0.78 & 77 & 65 & 9 & 168 \\
\hline main stem & $7 / 28 / 14$ & 14.95 & 1.6 & 53 & $1.1 \pm 0.02$ & $0.12 \pm 0.004$ & $10 \pm 0.4$ & $-29.1 \pm 0.05$ & 0.77 & 60 & 45 & 7 & 139 \\
\hline main stem & $7 / 28 / 14$ & 3.14 & 1.6 & 44 & $1.3 \pm 0.02$ & $0.16 \pm 0.002$ & $9.4 \pm 0.2$ & $-28.9 \pm 0.06$ & 0.74 & 55 & 38 & 6 & 133 \\
\hline main stem & $7 / 28 / 14$ & 53.06 & 2.2 & 286 & $0.61 \pm 0.01$ & $0.07 \pm 0.001$ & $11 \pm 0.3$ & $-28.6 \pm 0.1$ & no data & 93 & 80 & 13 & 194 \\
\hline main stem & $7 / 28 / 14$ & 29.83 & 2.2 & 108 & $1.0 \pm 0.01$ & $0.11 \pm 0.001$ & $11 \pm 0.2$ & $-28.8 \pm 0.07$ & no data & 71 & 50 & 8 & 171 \\
\hline main stem & $7 / 28 / 14$ & 3.33 & 2.2 & 56 & $1.3 \pm 0.02$ & $0.14 \pm 0.0003$ & $11 \pm 0.2$ & $-28.9 \pm 0.07$ & no data & 62 & 42 & 7 & 153 \\
\hline main stem & $7 / 29 / 14$ & flood & 0 & N/A & $0.50 \pm 0.03$ & $0.05 \pm 0.001$ & $12 \pm 0.9$ & $-28.1 \pm 0.08$ & no data & no data & no data & no data & no data \\
\hline main stem & $7 / 29 / 14$ & bed & 0 & N/A & $0.06 \pm 0.002$ & $0.01 \pm 0.0004$ & $7.5 \pm 0.5$ & $-26.6 \pm 0.09$ & 0.60 & no data & no data & no data & no data \\
\hline main stem & $7 / 29 / 14$ & bed & 0 & N/A & $0.02 \pm 0.001$ & BDL & no data & $-26.9 \pm 0.02$ & 0.87 & no data & no data & no data & no data \\
\hline
\end{tabular}

$\mathrm{BDL}=$ below detection limit.

"bed"=bedload.; "flood"=floodplain deposit. 
Table 4. Stable $\delta^{13} \mathrm{C}$ and fraction modern $\left(\mathrm{F}_{\mathrm{m}}\right)$ of $\mathrm{CO}_{2}$ released within specific temperature intervals during two ramped oxidation analyses of the deepest $(54 \mathrm{~m})$ suspended sediment sample collected at Óbidos in July 2014. In the first run, the sample was untreated; in the second run, the sample was fumigated in concentrated hydrochloric acid, rinsed in Milli-Q water and freeze-dried prior to analysis. The mass-weighted sums of the $\delta^{13} \mathrm{C}$ and $\mathrm{F}_{\mathrm{m}}$ values across fractions were compared to the bulk $\delta^{13} \mathrm{C}_{\mathrm{POC}}$ and $\mathrm{F}_{\mathrm{m}, \mathrm{POC}}$ values, which were measured after acid fumigation only (no rinsing). Carbon yield $=$ total $\mu \mathrm{mol} \mathrm{CO}_{2}$ gas quantified in RPO fractions $/ \mu \mathrm{mol}$ expected from the bulk $\% \mathrm{OC}$ and sediment mass inserted into RPO system.

\begin{tabular}{|c|c|c|c|c|c|}
\hline Treatment & Temperature Interval & $\%$ total C & Fraction Modern & $\delta^{13} \mathrm{C}$ & \\
\hline-- & ${ }^{\circ} \mathrm{C}$ & $\%$ & unitless & $\%$ & \\
\hline Fumigation & $116-277^{\circ} \mathrm{C}$ & $24 \%$ & $0.89 \pm 0.002$ & $-30.7 \pm 0.1$ & \\
\hline+ & $277-332^{\circ} \mathrm{C}$ & $28 \%$ & $0.86 \pm 0.002$ & $-29.5 \pm 0.1$ & \\
\hline \multirow[t]{4}{*}{ Rinsing } & $332-394^{\circ} \mathrm{C}$ & $24 \%$ & $0.79 \pm 0.002$ & $-28.3 \pm 0.1$ & \\
\hline & $394-807^{\circ} \mathrm{C}$ & $24 \%$ & $0.53 \pm 0.002$ & $-28.0 \pm 0.1$ & \\
\hline & $\begin{array}{l}\text { Weighted } \\
\operatorname{sum}_{\mathbf{m}}\end{array}$ & $\begin{array}{l}\text { Weighted } \\
\text { sum } \delta^{13} C\end{array}$ & $\begin{array}{c}\text { Bulk } \\
\text { F }_{\mathrm{m}, \mathrm{POC}}\end{array}$ & $\begin{array}{c}\text { Bulk } \\
\delta^{13} \mathrm{C}_{\text {POC }}\end{array}$ & $\begin{array}{c}\text { C Yield } \\
(\%)\end{array}$ \\
\hline & 0.77 & -29.1 & 0.80 & -28.4 & 86 \\
\hline Treatment & Temperature Interval & $\%$ total C & Fraction Modern & $\delta^{13} \mathrm{C}$ & \\
\hline \multirow[t]{6}{*}{ Untreated } & $142-276^{\circ} \mathrm{C}$ & $22 \%$ & $0.94 \pm 0.002$ & $-31.9 \pm 0.1$ & \\
\hline & $276-325^{\circ} \mathrm{C}$ & $30 \%$ & $0.92 \pm 0.002$ & $-30.0 \pm 0.1$ & \\
\hline & $325-449^{\circ} \mathrm{C}$ & $36 \%$ & $0.80 \pm 0.002$ & $-28.1 \pm 0.1$ & \\
\hline & $449-704^{\circ} \mathrm{C}$ & $12 \%$ & $0.44 \pm 0.002$ & $-25.9 \pm 0.1$ & \\
\hline & $\begin{array}{l}\text { Weighted } \\
\operatorname{sum}_{\mathrm{m}}\end{array}$ & $\begin{array}{l}\text { Weighted } \\
\text { sum } \delta^{13} C\end{array}$ & $\begin{array}{c}\text { Bulk } \\
\text { F }_{\mathrm{m}, \mathrm{POC}}\end{array}$ & $\begin{array}{c}\text { Bulk } \\
\delta^{13} \mathrm{C}_{\text {POC }}\end{array}$ & $\begin{array}{c}\text { C Yield } \\
(\%)\end{array}$ \\
\hline & 0.82 & -29.3 & 0.80 & -28.4 & $106(100)$ \\
\hline
\end{tabular}


Table 5. Stable and radiocarbon isotope composition of deconvolved components from thermograms of all samples underlined in Table 1, except Madeira River POC. No deconvolved stable isotope data are available for samples where $\mathrm{CO}_{2}$ gas fractions were lost prior to analysis. $\mathrm{T}_{\max }$ is the temperature of each component peak maximum. In general, the deconvolution algorithm yielded at least three major components (F1, F2, F3) across all thermograms. In four samples, the algorithm divided F3 between two components, F3' and F4 (bolded), yielding a four-component fit. Refer to Table 1 for sampling times of individual samples.

\begin{tabular}{|c|c|c|c|c|c|c|c|}
\hline Location & Month & Depth & Peak & Tmax & $\begin{array}{c}\text { Fraction of } \\
\text { Total C } \\
\end{array}$ & $\delta^{13} \mathrm{C}$ & $\mathbf{F}_{\mathbf{m}}$ \\
\hline-- & $m m-y y y y$ & $m$ & -- & ${ }^{\circ} \mathrm{C}$ & $\%$ & $\%$ & unitless \\
\hline main stem & 062005 & 0 & $\mathrm{~F} 1$ & 308 & $57 \%$ & $-31.8 \pm 0.1$ & $0.80 \pm 0.002$ \\
\hline main stem & 062005 & 0 & F2 & 385 & $21 \%$ & $-27.2 \pm 0.2$ & $0.79 \pm 0.01$ \\
\hline main stem & 062005 & 0 & F3 & 483 & $22 \%$ & $-28.9 \pm 0.1$ & $0.36 \pm 0.003$ \\
\hline main stem & 062005 & 0 & F3' & N/A & $18 \%$ & N/A & $\mathbf{0 . 3 7} \pm \mathbf{0 . 0 0 4}$ \\
\hline main stem & 062005 & 0 & F4 & N/A & $4 \%$ & N/A & 0 \\
\hline Solimões & 062005 & 0 & $\mathrm{~F} 1$ & 311 & $65 \%$ & $-28.9 \pm 0.1$ & $0.80 \pm 0.002$ \\
\hline Solimões & 062005 & 0 & $\mathrm{~F} 2$ & 397 & $21 \%$ & $-26.8 \pm 0.1$ & $0.69 \pm 0.004$ \\
\hline Solimões & 062005 & 0 & F3 & 497 & $14 \%$ & $-27.3 \pm 0.1$ & $0.51 \pm 0.004$ \\
\hline Solimões & 062005 & 0 & F3' & N/A & $12 \%$ & N/A & $0.60 \pm 0.005$ \\
\hline Solimões & 062005 & 0 & $\mathrm{~F} 4$ & N/A & $2 \%$ & $\mathrm{~N} / \mathrm{A}$ & o \\
\hline main stem & 042014 & 49.1 & $\mathrm{~F} 1$ & 288 & $65 \%$ & no data & $0.95 \pm 0.01$ \\
\hline main stem & 042014 & 49.1 & $\mathrm{~F} 2$ & 404 & $30 \%$ & no data & $0.86 \pm 0.002$ \\
\hline main stem & 042014 & 49.1 & F3 & 523 & $5 \%$ & no data & $0.39 \pm 0.003$ \\
\hline main stem & 042014 & 30.15 & $\mathrm{~F} 1$ & 297 & $65 \%$ & no data & $0.93 \pm 0.002$ \\
\hline main stem & 042014 & 30.15 & $\mathrm{~F} 2$ & 404 & $29 \%$ & no data & $0.68 \pm 0.003$ \\
\hline main stem & 042014 & 30.15 & F3 & 524 & $6 \%$ & no data & $0.14 \pm 0.006$ \\
\hline main stem & 042014 & 2.7 & $\mathrm{~F} 1$ & 296 & $70 \%$ & no data & $0.93 \pm 0.001$ \\
\hline main stem & 042014 & 2.7 & $\mathrm{~F} 2$ & 416 & $25 \%$ & no data & $0.86 \pm 0.002$ \\
\hline main stem & 042014 & 2.7 & F3 & 507 & $6 \%$ & no data & $0.46 \pm 0.003$ \\
\hline main stem & 042014 & 2.7 & F3' & N/A & $5.4 \%$ & N/A & $0.50 \pm 0.003$ \\
\hline main stem & 042014 & 2.7 & F4 & N/A & $0.5 \%$ & N/A & o \\
\hline Tapajós & 072014 & 0 & $\mathrm{~F} 1$ & 315 & $62 \%$ & $-34.1 \pm 0.1$ & $0.94 \pm 0.003$ \\
\hline Tapajós & 072014 & 0 & $\mathrm{~F} 2$ & 421 & $35 \%$ & $-31.1 \pm 0.1$ & $0.93 \pm 0.004$ \\
\hline Tapajós & 072014 & 0 & F3 & 548 & $2 \%$ & $-36.4 \pm 1.7$ & $0.34 \pm 0.03$ \\
\hline main stem & 072014 & 54 & $\mathrm{~F} 1$ & 293 & $66 \%$ & $-31.1 \pm 0.1$ & $0.94 \pm 0.002$ \\
\hline main stem & 072014 & 54 & $\mathrm{~F} 2$ & 391 & $25 \%$ & $-26.6 \pm 0.2$ & $0.72 \pm 0.004$ \\
\hline main stem & 072014 & 54 & F3 & 500 & $10 \%$ & $-25.9 \pm 0.1$ & $0.33 \pm 0.004$ \\
\hline
\end{tabular}




\begin{tabular}{lccccccc} 
main stem & 072014 & 54 & F3' & N/A & $\mathbf{8 \%}$ & N/A & $\mathbf{0 . 3 8} \pm \mathbf{0 . 0 0 5}$ \\
main stem & 072014 & 54 & F4 & N/A & $\mathbf{1 \%}$ & N/A & $\mathbf{0}$ \\
main stem & 072014 & 30.14 & F1 & 288 & $70 \%$ & $-30.8 \pm 0.1$ & $0.94 \pm 0.002$ \\
main stem & 072014 & 30.14 & F2 & 416 & $27 \%$ & $-26.8 \pm 0.3$ & $0.58 \pm 0.01$ \\
main stem & 072014 & 30.14 & F3 & 527 & $3 \%$ & $-34.6 \pm 3.5$ & $0.17 \pm 0.04$ \\
main stem & 072014 & 3.14 & F1 & 295 & $71 \%$ & no data & $0.83 \pm 0.001$ \\
main stem & 072014 & 3.14 & F2 & 399 & $15 \%$ & no data & $0.62 \pm 0.004$ \\
main stem & 072014 & 3.14 & F3 & 493 & $14 \%$ & no data & $0.38 \pm 0.004$ \\
\hline
\end{tabular}



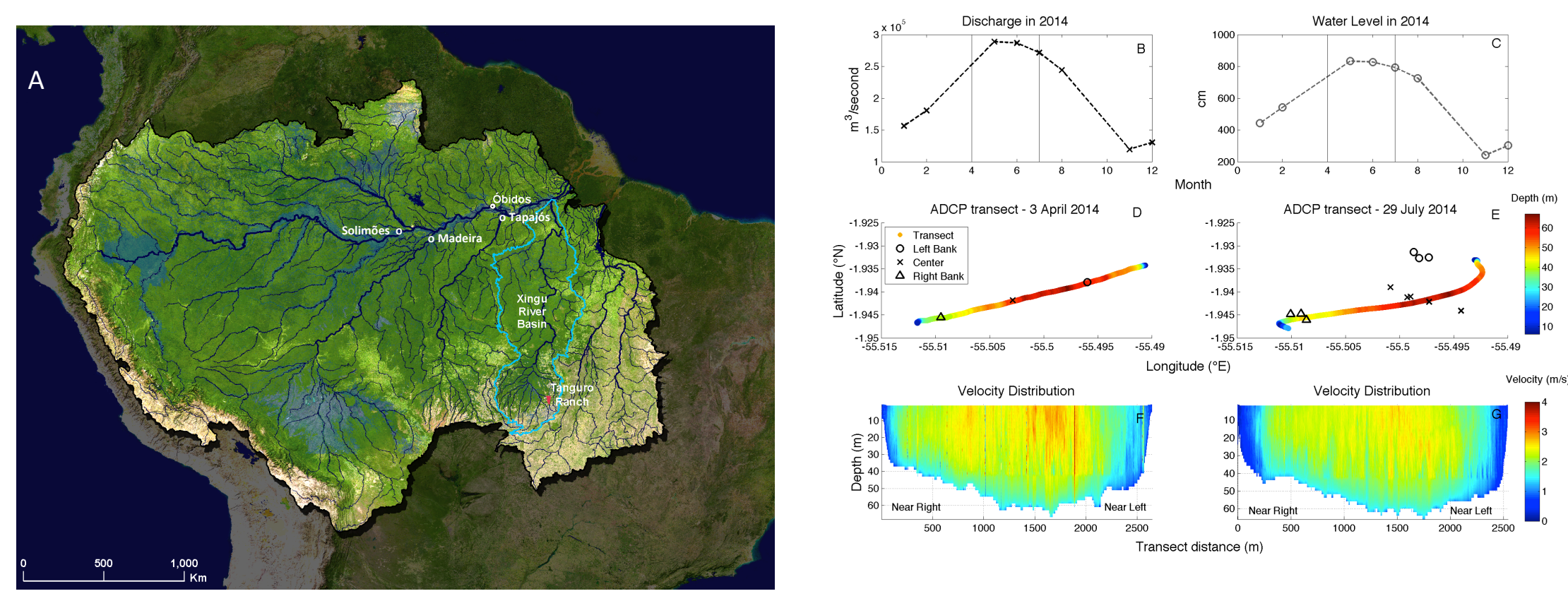

Figure 1. (a) The Amazon River Basin and all field sites from June 2005, April 2014 and July 2014. Image credit: Paul Lefebvre and Greg Fiske (Woods Hole Research Center). (b-c) Monthly-averaged main stem discharge and water level time-series in 2014, compiled by the Brazilian Agencia Nacional de Aguas. The symbols represent monthly averages and the dashed lines represent linear interpolations between the monthly averages. The vertical solid lines represent the two sampling months, April and July. (d-e)

Acoustic Doppler Current Profiler (ADCP) transects in latitude/longitude across the Amazon River at Óbidos in April and July 2014. Transects started at the right bank across from Óbidos, and ended at the left bank near Óbidos. The colorbar represents river depth (m). (f-g) Measured and extrapolated (Equation 1) water velocities within the cross-section at Óbidos in April 2014 and July 2014. The colorbar represents water velocity, $0-4 \mathrm{~m} / \mathrm{s}$. 
Rising Water (April 2014)
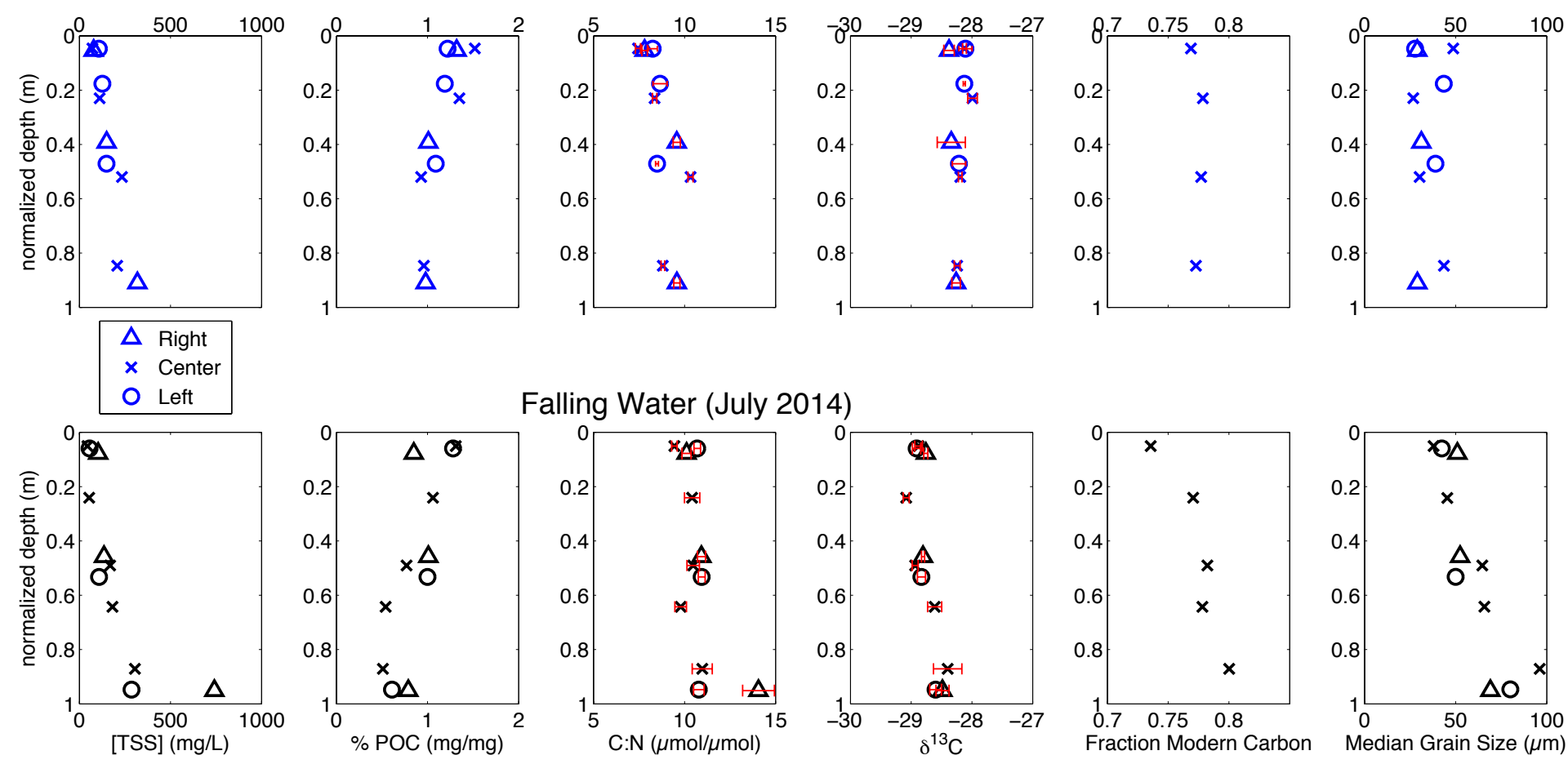

Falling Water (July 2014)
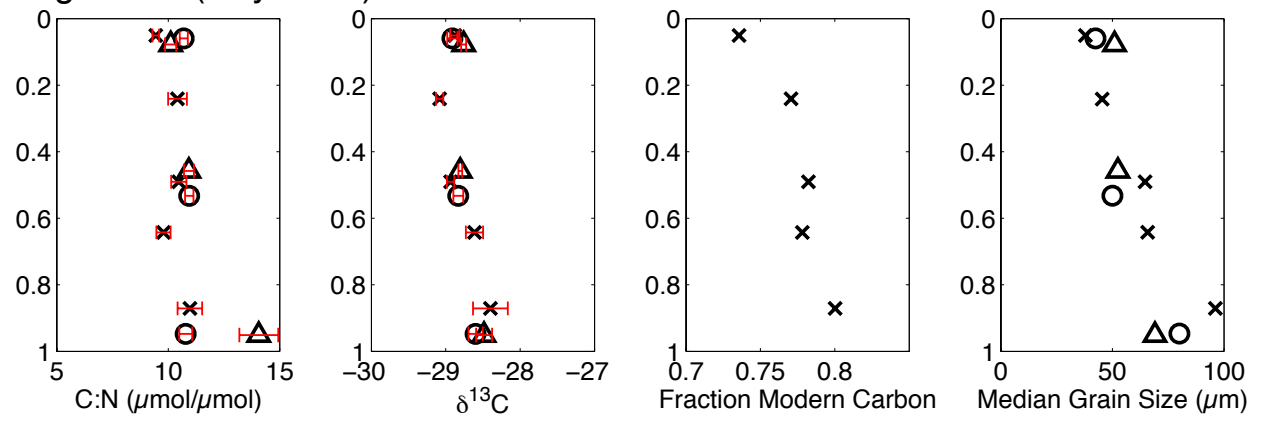

Figure 2. Profiles of TSS concentration, organic matter composition, and median grain size (d50) through depth profiles at Óbidos in April and July 2014. The profiles for each position in the transect are plotted separately as triangles (near right bank), circles (near left bank) and crosses (near center). Refer to Table 1 and Fig. 1 for channel position and GPS coordinates of the profiles. All y-axes are normalized to the river depth at the channel position of each profile. The errors in $\% \mathrm{POC}, \% \mathrm{PN}$ and fraction modern are relatively small and therefore not plotted. $\delta^{13} \mathrm{C}$ values are expressed in units of \%o. 

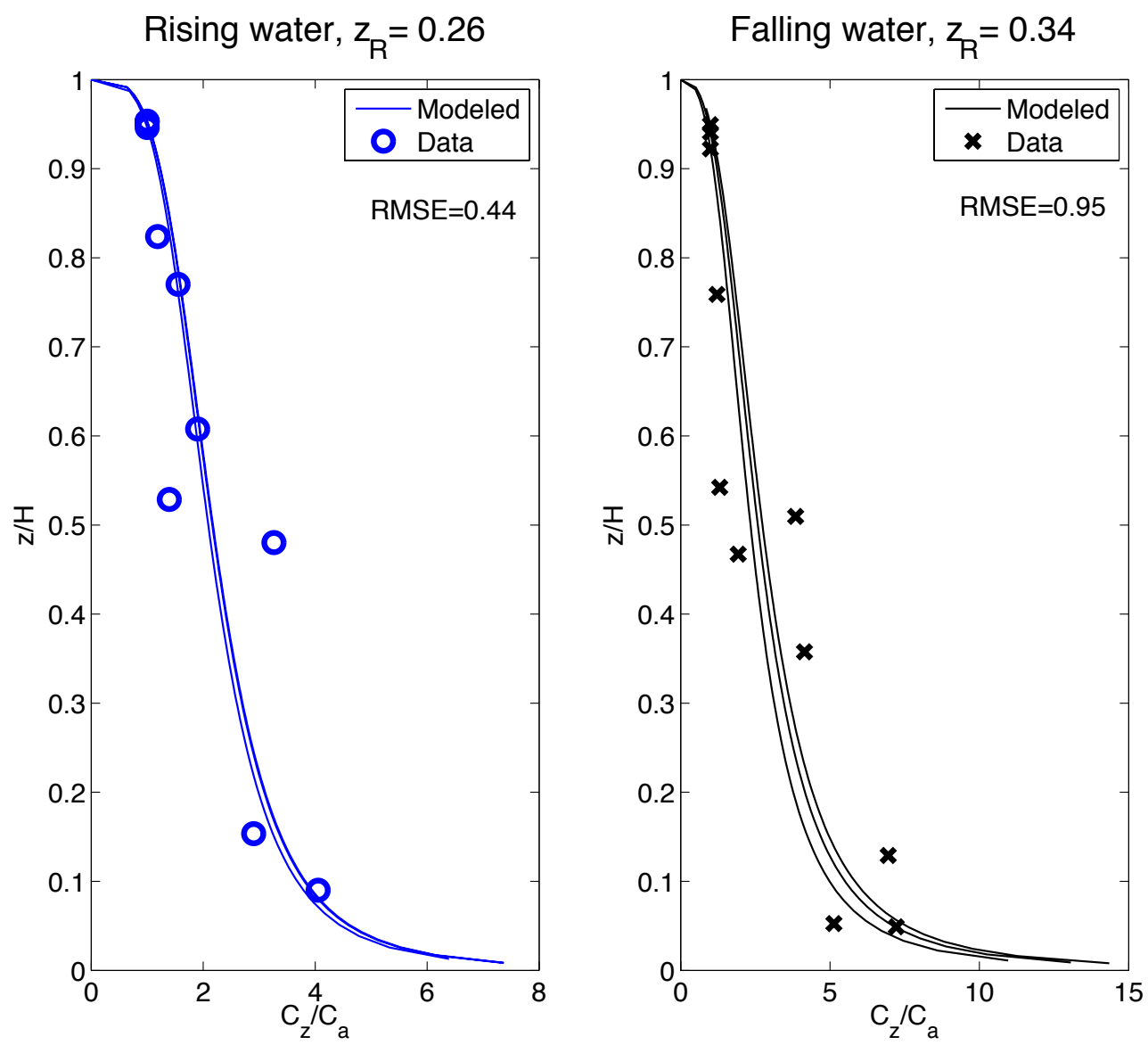

Figure 3. Fits of all depth-specific TSS concentration $\left(\mathrm{C}_{\mathrm{z}}\right)$ profiles measured at Óbidos in 2014 to the Rouse Equation (Equation 3; Rouse, 1950; Bouchez et al., 2011b). Observed and modeled $\mathrm{C}_{\mathrm{z}} / \mathrm{C}_{\mathrm{a}}$ values are plotted as a function of $\mathrm{z} / \mathrm{H} . \mathrm{z}$ is the height above the river bed $\mathrm{H}$ of each profile, and $\mathrm{C}_{\mathrm{a}}$ is the surface-most measured $\mathrm{C}_{\mathrm{z}}$ value of each profile. 


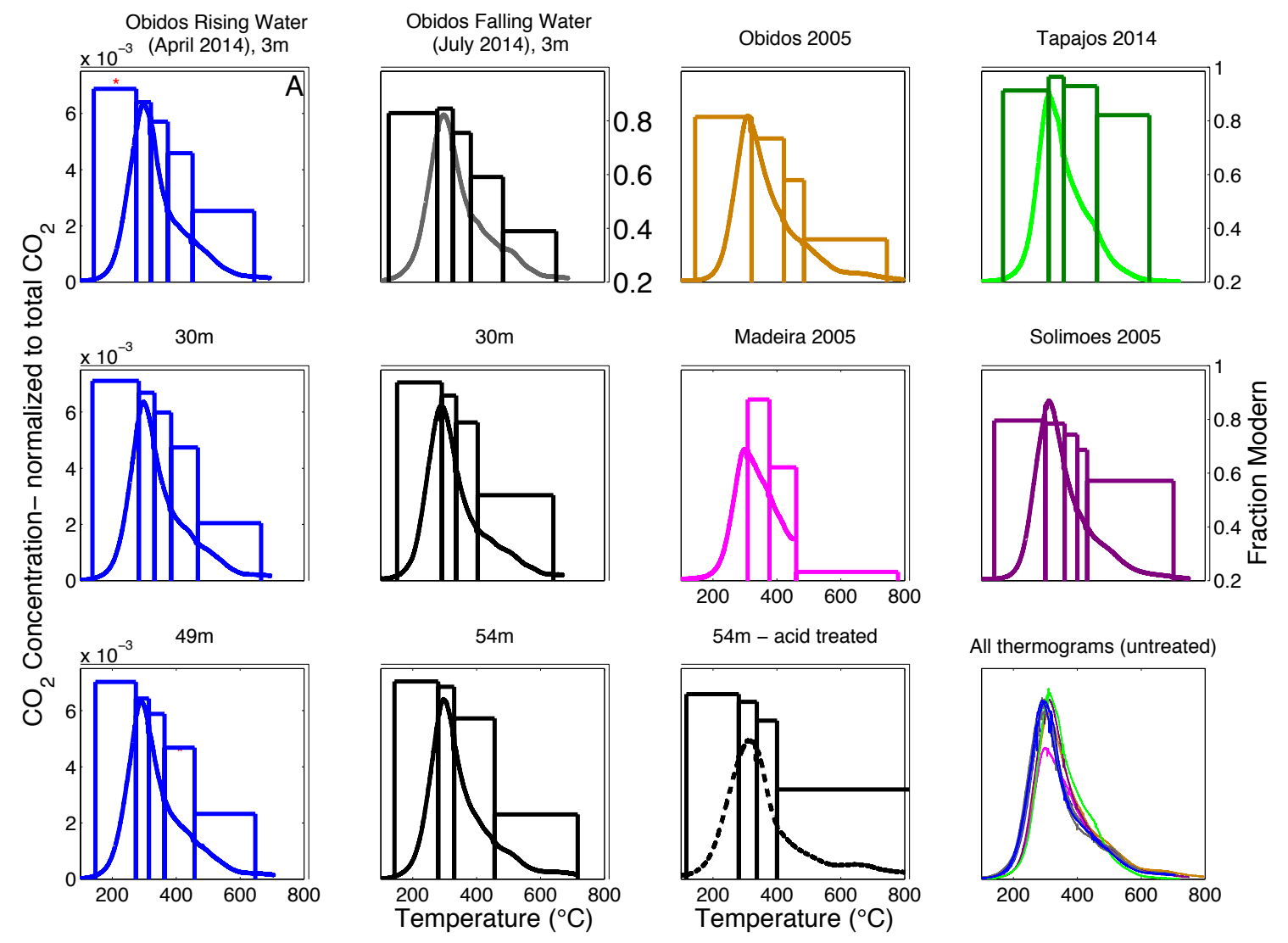




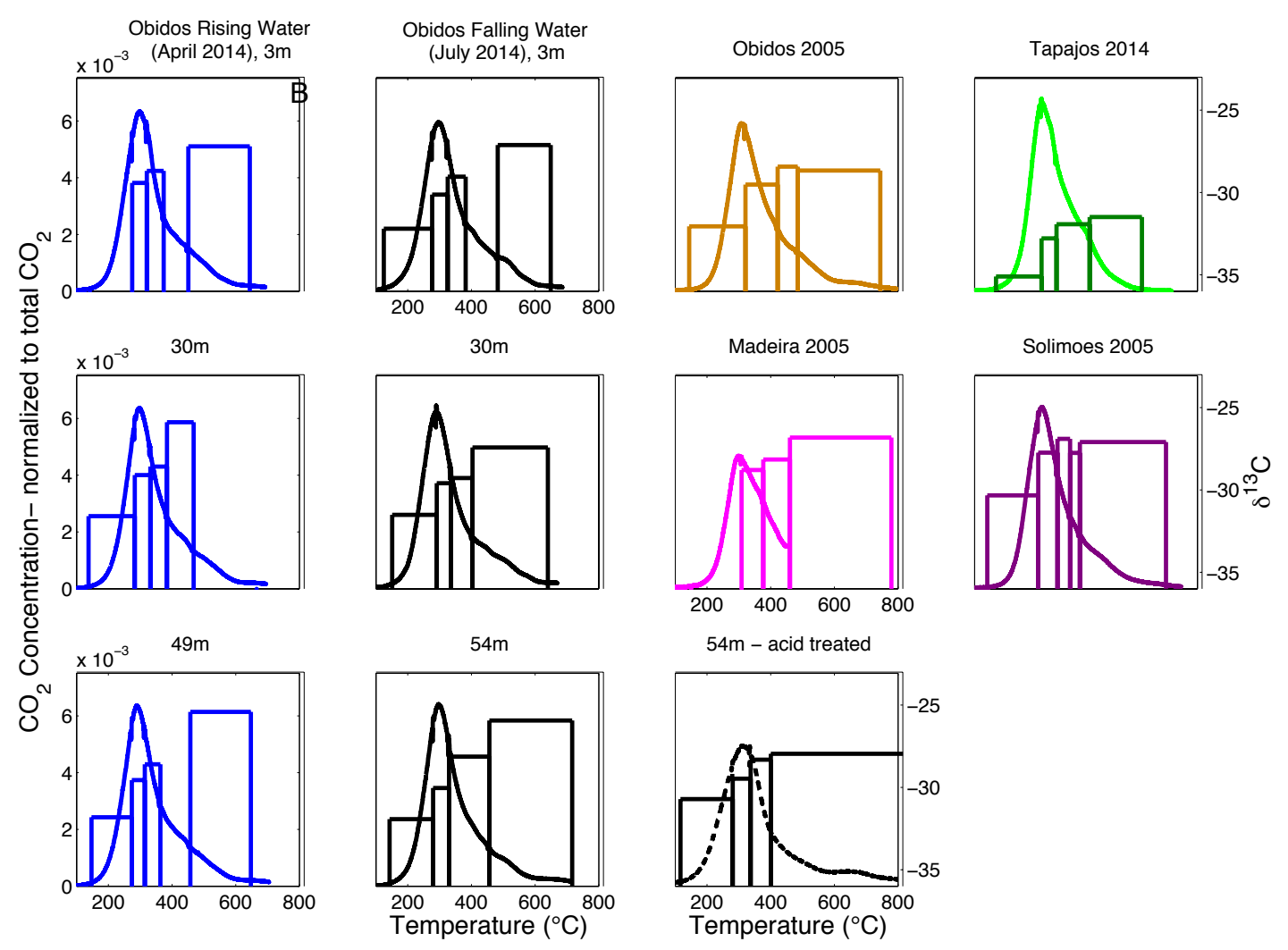

Figure 4. Ten thermograms (solid lines) generated by ramped oxidation of untreated suspended sediments from the Amazon main stem, and the Tapajós, Solimões and Madeira Rivers (Table 1). One sample from a deeper section of the main stem was additionally analyzed following acid-treatment (dashed line). The left-hand y-axes for the thermograms are all normalized to the total $\mathrm{CO}_{2}$ released during ramped oxidation analysis. The height of the bars indicates the (A) $\mathrm{F}_{\mathrm{m}}$ and (B) $\delta^{13} \mathrm{C}$ values (\%o) of $\mathrm{CO}_{2}$ trapped within distinct temperature intervals during ramped oxidation. The bottom-right panel in (A) shows all thermograms, excluding the Madeira River thermogram, plotted on the same axes. 

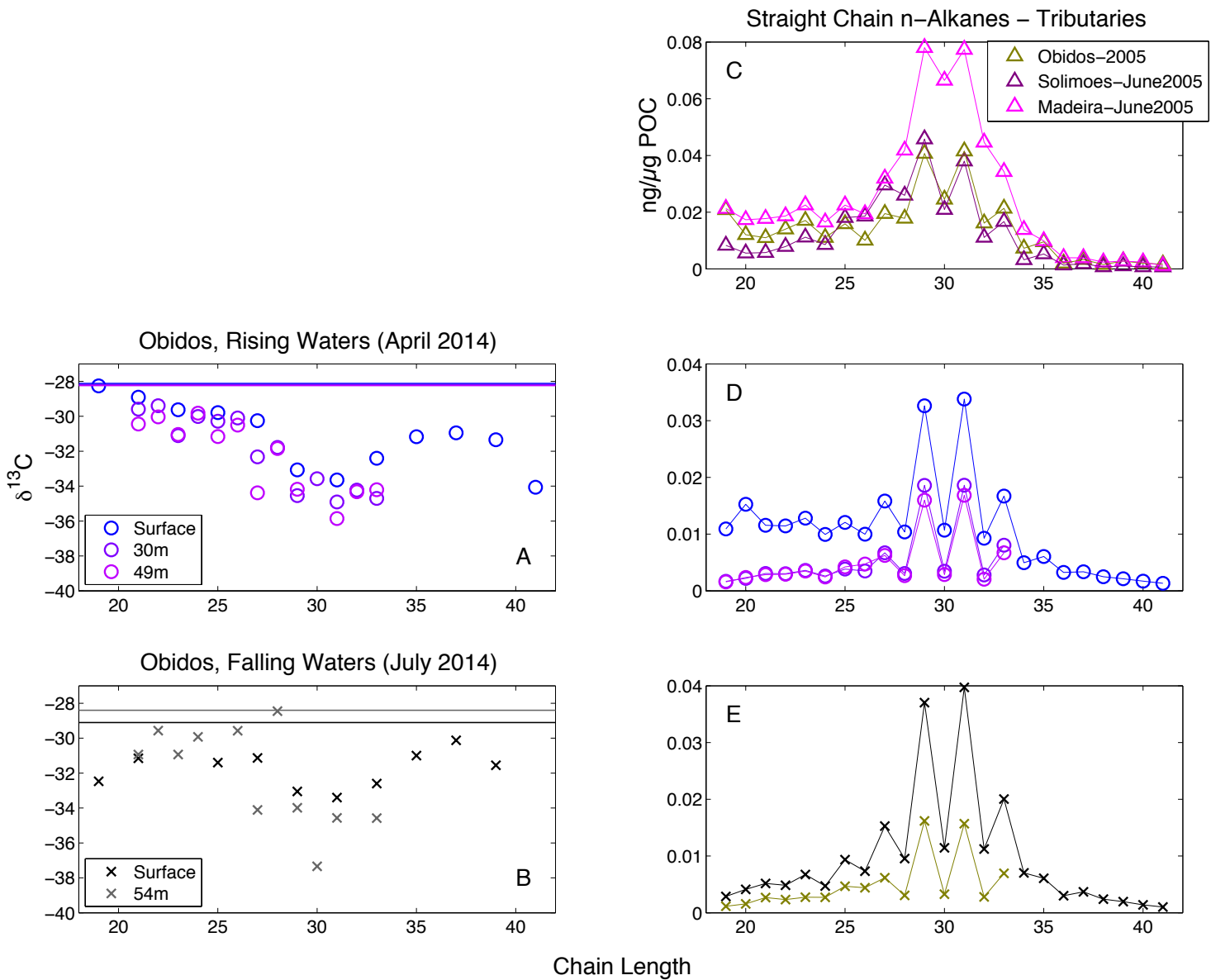

Figure 5. (a-b) $\delta^{13} \mathrm{C}$ values (\%) and (c-e) abundances of straight chain $n$-alkanes measured at Óbidos (surface and depth-specific), and the Madeira and Solimões Rivers (surface). The horizontal lines in a-b represent the $\delta^{13} \mathrm{C}$ value of the bulk POC, reported in Table 3. 

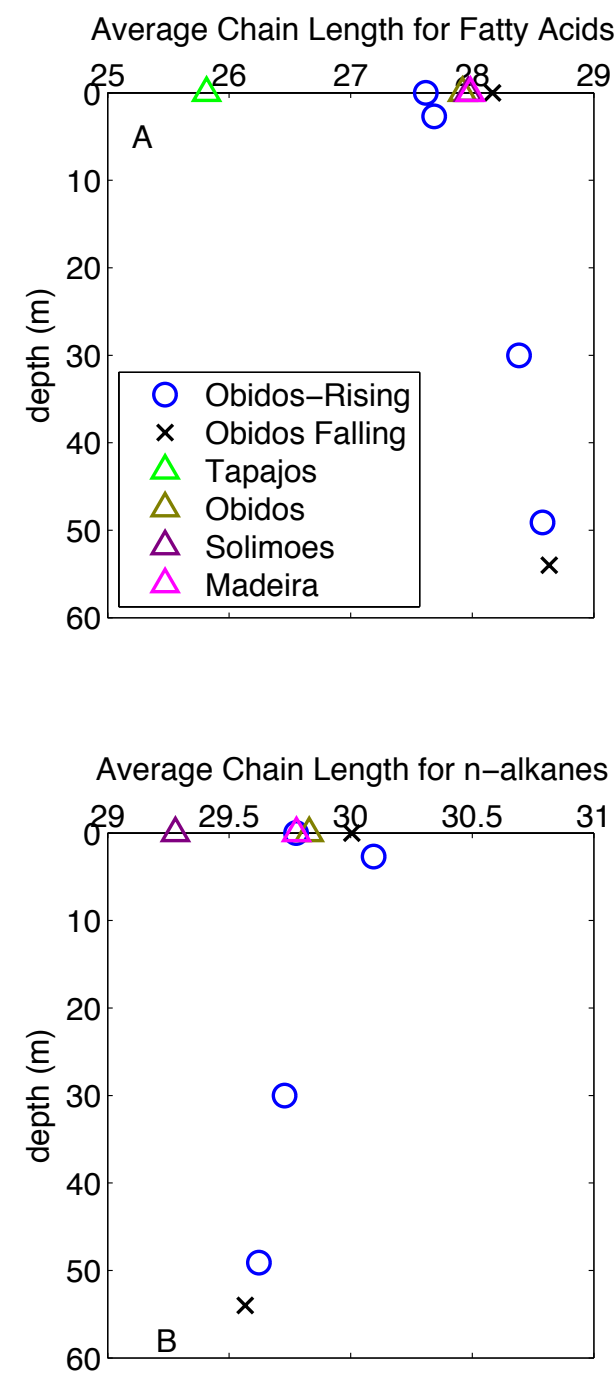

Figure 6. Profiles of average chain length (ACL) calculated in higher chain length fatty acids $\left(\mathrm{C}_{24}-\mathrm{C}_{34}\right)$ and $n$-alkanes $\left(\mathrm{C}_{25}-\mathrm{C}_{33}\right)$ in all 2005 and 2014 surface samples and four depth-specific samples collected at Óbidos in 2014. Refer to Equation 5 for ACL calculations. 
Straight Chain Fatty Acids- Tributaries
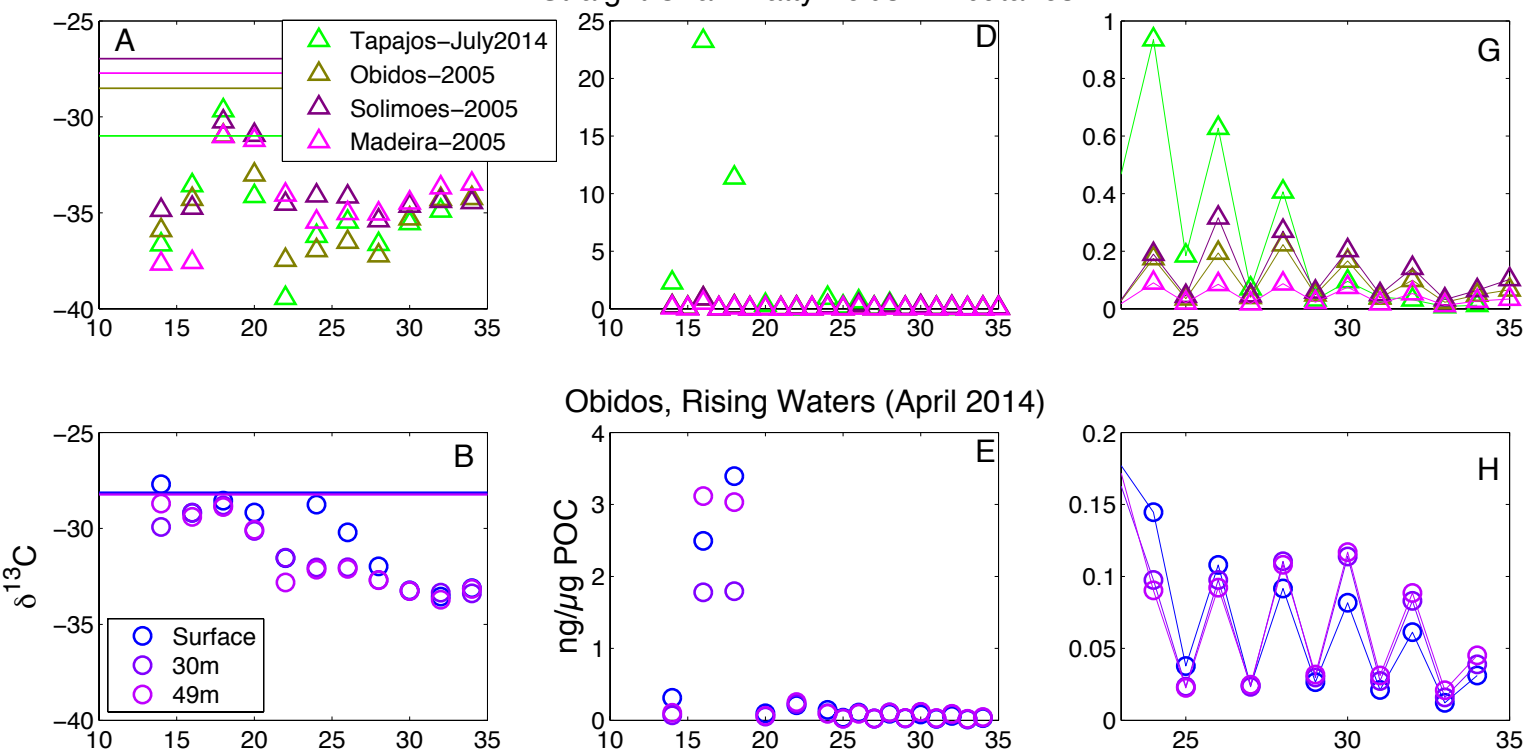

Obidos, Rising Waters (April 2014)
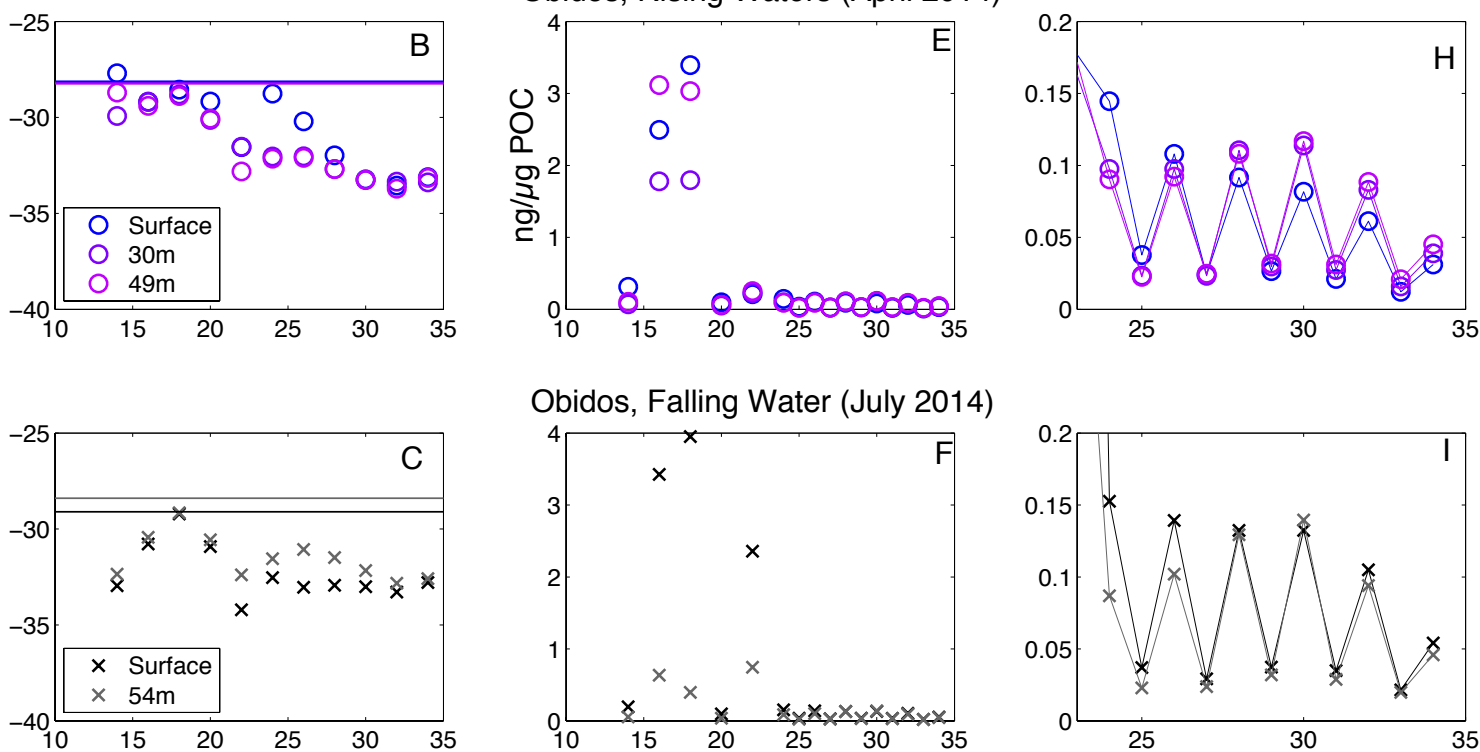

Obidos, Falling Water (July 2014)
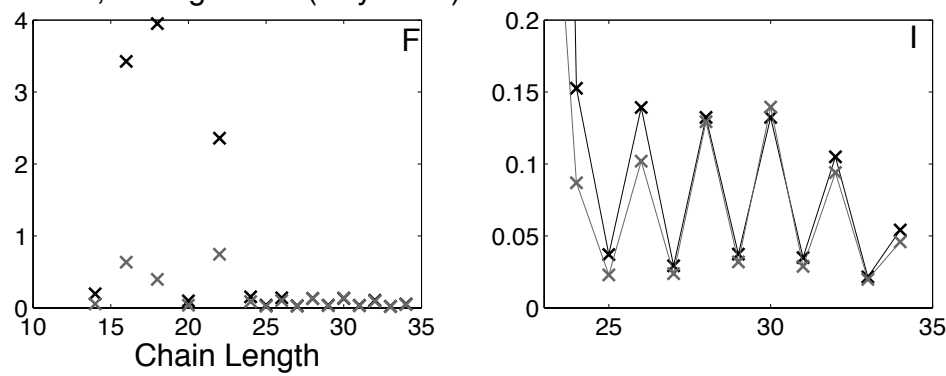

Figure 7. (a-c) $\delta^{13} \mathrm{C}$ values (\%o) and (d-i) abundances of straight chain fatty acids measured at Óbidos (surface and depth-specific), and the Madeira, Solimões and Tapajós Rivers. The horizontal lines in a-c represent the $\delta^{13} \mathrm{C}$ values of the bulk POC, reported in Table 3. 


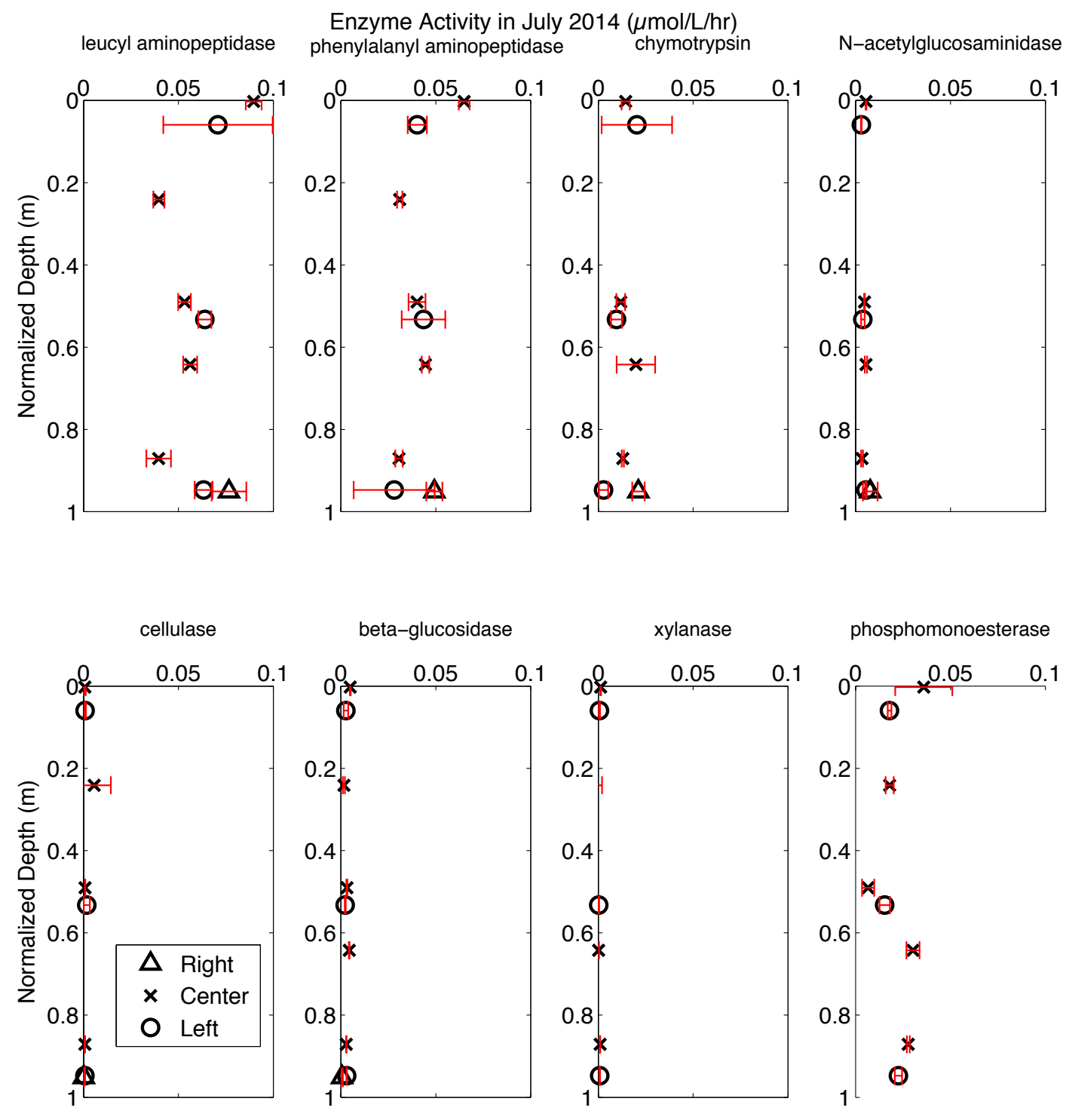

Figure 8. Activities of eight enzymes measured on particles within the Óbidos crosssection in July 2014. Data analysis credit: Andrew Steen. 

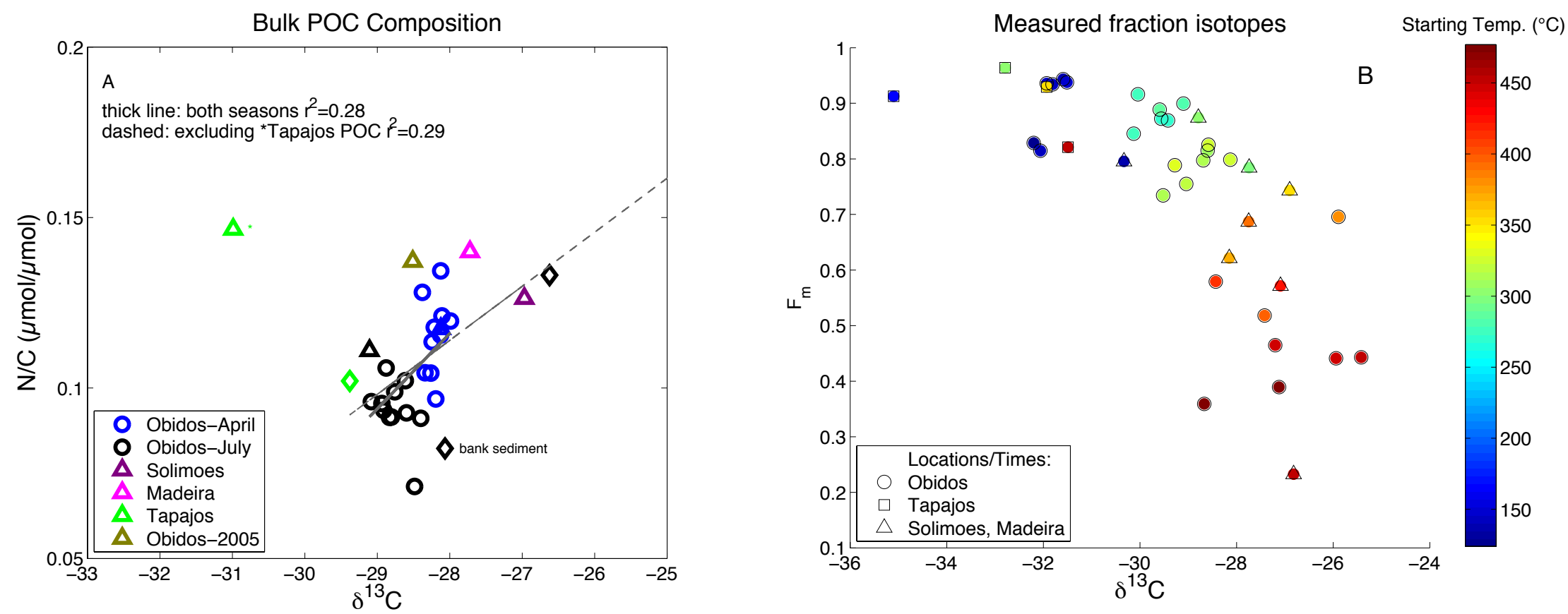

Figure 9. (a) Bulk N/C ratios as a function of $\delta^{13} \mathrm{C}_{\mathrm{POC}}(\%$ ) in all samples collected in June 2005, April 2014 and July 2014 . The colors refer to location and/or time (Table 1; Fig. 1), while the symbols refer to sample type (circles for depth-specific, triangles for surface, and diamonds for bed/floodplain samples). (b) $\mathrm{F}_{\mathrm{m}}$ and $\delta^{13} \mathrm{C}(\% \mathrm{o})$ values of $\mathrm{CO}_{2}$ collected and analyzed within specific temperature intervals during ramped oxidation of all samples shown in Fig. 4. The color bar represents starting temperature $\left({ }^{\circ} \mathrm{C}\right)$ of each $\mathrm{CO}_{2}$ gas interval, with warmer colors indicating higher starting temperatures. 


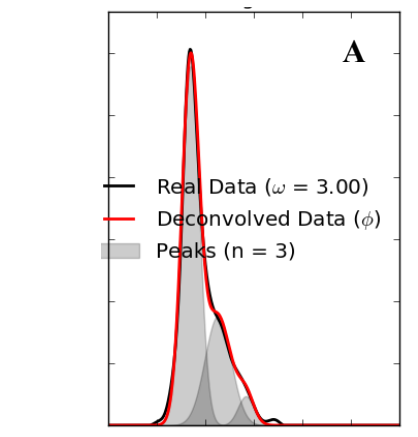

Main Stem $49.1 \mathrm{~m}$
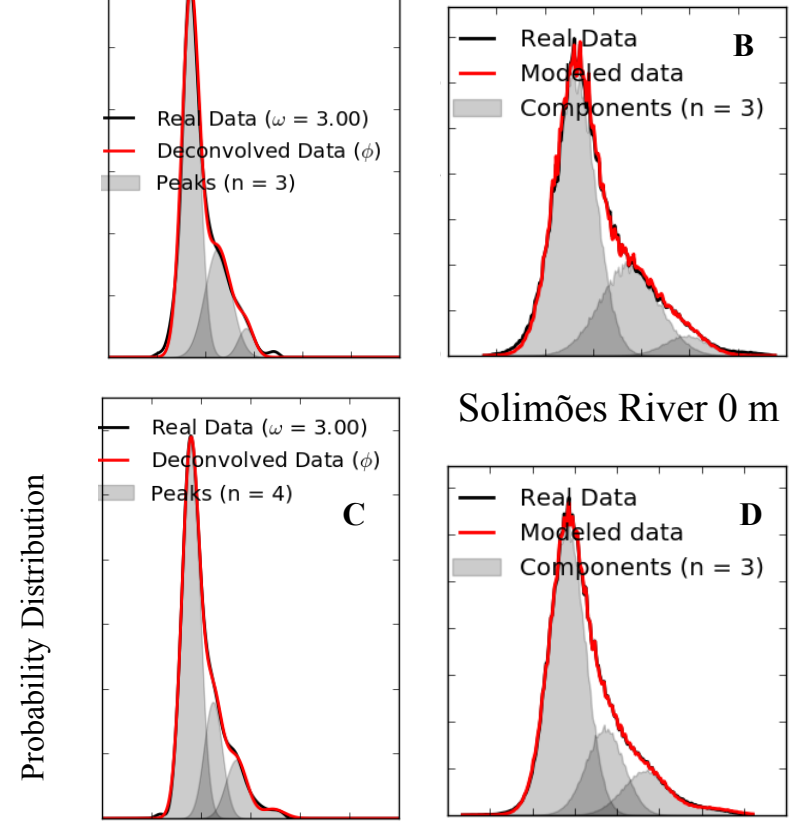

Solimões River 0 m
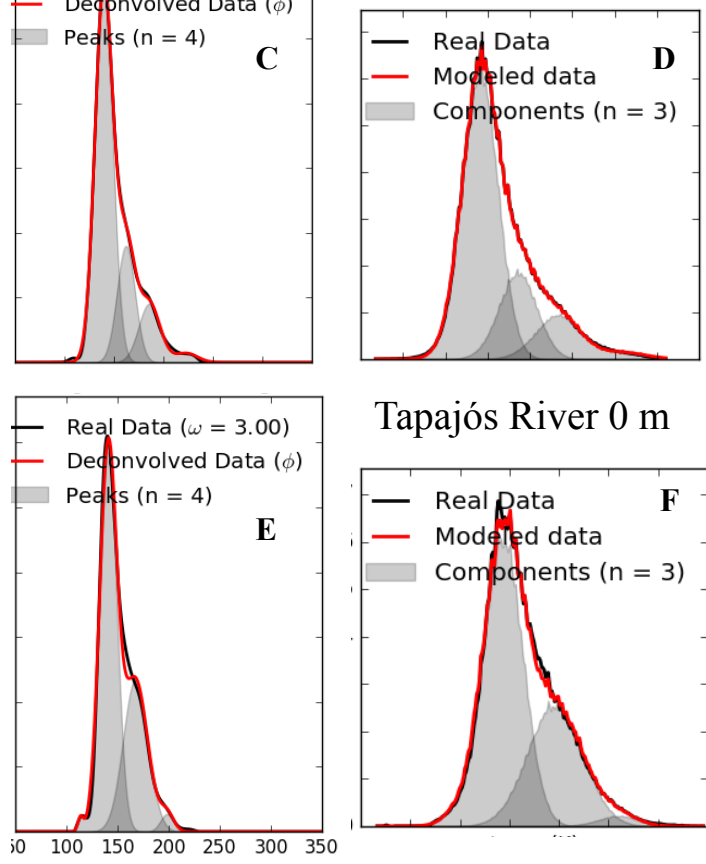

Tapajós River 0 m

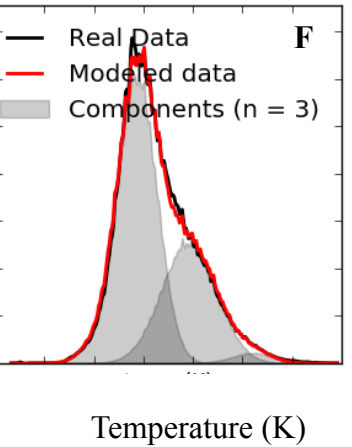

Figure 10. Deconvolution of three suspended sediment thermograms. (a, c, e) Probability distribution function (PDF) of activation energy of $\mathrm{CO}_{2}$ evolved (lines) and components (shaded peaks). In all examples, the sum of components (red line) fits well with the PDF of the raw thermogram (black line). (b, d, f) Fraction of $\mathrm{CO}_{2}$ evolved/temperature as a function of temperature for components resolved in panels a, c and e. The reconstructed thermograms (red lines) also compare well to the original thermograms (black lines). Only three components were resolved in a and e, while four were resolved in c. In c, the third and fourth components were combined prior to reconstructing the thermogram in $\mathrm{d}$. This range of deconvolution scenarios applied to the rest of the thermograms presented in Fig. 4. 


\section{Chapter 6: Conclusions}

Because of its sheer size, the deep ocean carbon reservoir regulates the carbon cycle and climate over centuries to millennia. Our view of this reservoir as a long-term buffer against the fossil fuel $\mathrm{CO}_{2}$ emissions relies on the assumption that it will remain unchanged in the Anthropocene (Steffen et al., 2011). However, climate change is likely to shift export and transfer efficiency of POC fixed by marine and terrestrial primary producers, which would directly impact the supply of carbon sequestered in this deep reservoir. It is difficult to detect changes in marine POC export fluxes, as large-scale, continuous monitoring of primary productivity over the ocean surface (i.e., by satellite) has been absent over most of the industrial era (Henson et al., 2010). However, Laufkötter et al. (2016) projected that export is likely to decrease in future climate change scenarios, and found that the magnitude and mechanism of change varied geographically. On land, climate change and landscape alteration by human development are not only expected to affect the total export of POC in rivers (e.g., Dias et al., 2015; Appendix C, Fig. S2), but also the source and composition of organic matter that is mobilized from land into the river system (Butman et al., 2015). In a large system like the Amazon River Basin, these changes could shift the balance between POC decomposition in the river and POC burial on the continental shelf (Langerwisch et al., 2016).

Thus, understanding the physical and biogeochemical mechanisms that control POC export and transfer to the deep ocean has bearing on our predictions of biological pump strength and river POC transport in future climate change scenarios. In this thesis, I have commented on the relative importance of different mechanisms that control POC transfer efficiency. The direction of the earliest chapter (chapter 2) led me to focus the remaining chapters (chapters 3-5) on the hypothesis that the quality of POC produced by different marine and terrestrial primary producers determines its fate during transport to the deep ocean. As characterizing POC by its quality and reactivity in the environment is challenging, much of the effort in these chapters was the search for a proxy that described both POC composition and reactivity. Consequently, this thesis further explores various applications of ramped pyrolysis/oxidation (RPO), an expanding technique for 
characterizing POC composition and reactivity by thermal stability (Rosenheim et al., 2008; Rosenheim and Galy, 2012; Rosenheim et al., 2013).

Perspectives of marine and terrestrial organic matter recycling in water remain largely separate in scientific literature. In their recent overview paper, Burd et al. (2016) highlighted the common challenges that both research communities face in modeling "vertical transport" in the ocean and "lateral transport" in rivers. They highlight several priorities for development, such as improving empirical measurements and models of microbe-mediated organic matter transformations (e.g., enzyme kinetics), and characterizing the biomolecular composition of POC over different gradients in degradation. The combined RPO analyses in chapters 4 and 5 describe POC composition across a spectrum of marine and terrestrial samples, ranging from the freshest POC produced in the ocean's euphotic zone and in axenic phytoplankton cultures to more highly degraded, century to millennium year old POC from soil organic carbon reservoirs in the Amazon River Basin (Fig. 1). In the middle of this spectrum is mesopelagic zone POC, which is more degraded than euphotic zone POC, but not as degraded as soilderived POC in the Amazon River.

The direct link between the euphotic and mesopelagic zone samples in Chapter 4 provided an opportunity to highlight different processes that may transform POC during degradation in the ocean's water column. The three thermogram profiles imply that a similar series of processes drive selective accumulation of a middle activation energy pool of POC with depth and selective loss of a lower activation energy POC pool. Two of three thermogram depth profiles also exhibit selective loss of a higher activation energy POC pool with depth. These transformations occur regardless of the composition of POC produced at the surface by phytoplankton. But, with the small number of samples in the data set, it is difficult to further assess the influence of different phytoplankton assemblages on the quality and recycling of POC transferred to the deep ocean.

If increasing degradation state manifests in a lower spread of activation energies of decomposition in organic matter, we would hypothesize that the processes that consistently transform POC in the three Southern Ocean depth profiles would lead to an even narrower activation energy distribution in soil-derived POC from the Amazon (Fig. 1). The Chapter 5 thermograms fit these expectations (Fig. 2d-f). Because thermogram 
gas fractions in Amazon River POC exhibit a large range in radiocarbon age as well as stable isotope composition, providing one more dimension for thermogram comparison than in the chapter 4 thermograms (Fig. 2a-c), the data allowed for apportionment of riverine POC among different terrestrial organic matter sources that vary in thermal stability. One implication of this partitioning in the context of chapter 4 and Fig. 1 is that the youngest soil-derived source, which makes up $\sim 2 / 3$ of total POC flux in the main stem, is more likely to degrade between Óbidos and the continental shelf than the other higher thermal stability POC components in the river. The spectrum illustrated in Fig. 1 also suggests that thermogram "narrowness" may potentially serve as a better proxy for degradation state of organic matter than thermal stability itself (Rosenheim et al. 2008; Rosenheim and Galy 2012).

The data sets across marine and terrestrial environments highlight important future steps in the application of the RPO method to studying the fate of organic matter. First, future RPO experiments should be more controlled to minimize environmental variables that confound data interpretations. This approach would help constrain the identity of biomolecules that oxidize at different temperatures, and the real-world processes that accompany transformations in thermal stability. For example, RPO analyses of POC collected from marine algae cultures inoculated with bacteria and left to degrade through time would help isolate the effects of degradation on POC thermal stability. This approach could be coupled to measurements of bacterial vs. algae cell populations to tease apart the effects of algae biomass degradation from conversion of algae biomass to heterotrophic biomass. This biomass could even be placed in a rolling tank (Engel et al., 2009) to simulate particle sinking and possibly molecular cross-linking processes (Hedges et al., 2000; Freeman, 2001). Meanwhile, in the marine environment, collecting larger quantities of the sinking POC size class from sediment traps or McLane pumps would allow for analysis of the particles that contribute directly to the biological pump.

Further, it is surprising that Amazon River POC oxidizes across overall lower temperatures than marine POC, even though it is much older and presumably more degraded than the samples in chapter 4 (Fig. 2d-f). This distinction indicates that the thermal stability of marine and terrestrial POC may not be comparable in absolute terms, 
and that the link between thermal stability and environmental reactivity needs finetuning. Explanations for these differences in marine and terrestrial POC thermal stability are beyond the scope of this thesis, but include the influence of different source materials, (phytoplankton vs. fresh vegetation) different heterotroph communities (marine vs. soil bacterial biomass), and different mineral matrices. Higher spatial-resolution sampling of the Amazon River along a transect from upstream of Óbidos to the plume, or coastal Atlantic sediments, would provide a better link between the source of soil-derived organic matter in riverine POC, its reactivity in the river system and its thermal stability determined by RPO analysis.

Finally, the applications of RPO analysis to three different sample sets in this thesis compel us to consider directions for improvement in future applications of the method. Perhaps the most important challenge to overcome is the presence of particulate inorganic carbon (PIC) in samples from different environments. Chapters 4 and 5 have shown that acid fumigation and rinsing prior to RPO analysis not only hydrolyze PIC in a sample, but also remove specific pools of POC and/or shift the thermal stability distribution of remaining POC in the sample. At the same time, it is difficult to isolate PIC from thermograms of samples that have complex organic matrices without fumigation. Continuous measurements of $\delta^{13} \mathrm{C}_{\text {of }} \mathrm{CO}_{2}$ evolved during ramped oxidation may help to better isolate and correct for PIC in these sample mixtures by its ${ }^{13} \mathrm{C}$ enriched signature.

\section{References}

Burd, A. B., Frey, S., Cabre, A., Ito, T., Levine, N. M., Lønborg, C., Long, M., Mauritz, M., Thomas, R. Q., and Stephens, B. M.: Terrestrial and marine perspectives on modeling organic matter degradation pathways, Global change biology, 22, 121 136, 2016.

Butman, D. E., Wilson, H. F., Barnes, R. T., Xenopoulos, M. A., and Raymond, P. A.: Increased mobilization of aged carbon to rivers by human disturbance, Nature Geoscience, 8, 112-116, 2015.

Dias, L. C. P., Macedo, M. N., Costa, M. H., Coe, M. T., and Neill, C.: Effects of land cover change on evapotranspiration and streamflow of small catchments in the Upper Xingu River Basin, Central Brazil, Journal of Hydrology: Regional Studies, 4, Part B, 108-122, 2015.

Engel, A., Abramson, L., Szlosek, J., Liu, Z., Stewart, G., Hirschberg, D., and Lee, C.: 
Investigating the effect of ballasting by $\mathrm{CaCO} 3$ in Emiliania huxleyi, II:

Decomposition of particulate organic matter, Deep Sea Research Part II: Topical

Studies in Oceanography, 56, 1408-1419, 2009.

Freeman, K. H.: Isotopic biogeochemistry of marine organic carbon, Reviews in Mineralogy and geochemistry, 43, 579-605, 2001.

Hedges, J. I., Eglinton, G., Hatcher, P. G., Kirchman, D. L., Arnosti, C., Derenne, S., Evershed, R. P., Kögel-Knabner, I., De Leeuw, J., and Littke, R.: The molecularly-uncharacterized component of nonliving organic matter in natural environments, Organic Geochemistry, 31, 945-958, 2000.

Henson, S. A., Sarmiento, J. L., Dunne, J. P., Bopp, L., Lima, I. D., Doney, S. C., John, J. G., and Beaulieu, C.: Detection of anthropogenic climate change in satellite records of ocean chlorophyll and productivity, 2010. 2010.

Langerwisch, F., Walz, A., Rammig, A., Tietjen, B., Thonicke, K., and Cramer, W.: Deforestation in Amazonia impacts riverine carbon dynamics, Earth Systems Dynamics, 7, 953-968, 2016.

Laufkötter, C., Vogt, M., Gruber, N., Aumont, O., Bopp, L., Doney, S., Dunne, J., Hauck, J., John, J., Lima, I., Seferian, R., and Völker, C.: Projected decreases in future marine export production: the role of the carbon flux through the upper ocean ecosystem, Biogeosciences, 13, 4023-4047, 2016.

Rosenheim, B. E., Day, M. B., Domack, E., Schrum, H., Benthien, A., and Hayes, J. M.: Antarctic sediment chronology by programmed - temperature pyrolysis: Methodology and data treatment, Geochemistry, Geophysics, Geosystems, 9, 2008.

Rosenheim, B. E. and Galy, V.: Direct measurement of riverine particulate organic carbon age structure, Geophysical Research Letters, 39, 2012.

Rosenheim, B. E., Roe, K. M., Roberts, B. J., Kolker, A. S., Allison, M. A., and Johannesson, K. H.: River discharge influences on particulate organic carbon age structure in the Mississippi/Atchafalaya River System, Global Biogeochemical Cycles, 27, 154-166, 2013.

Steffen, W., Grinevald, J., Crutzen, P., and McNeill, J.: The Anthropocene: conceptual and historical perspectives, Philosophical Transactions of the Royal Society A: Mathematical, Physical and Engineering Sciences, 369, 842-867, 2011. 


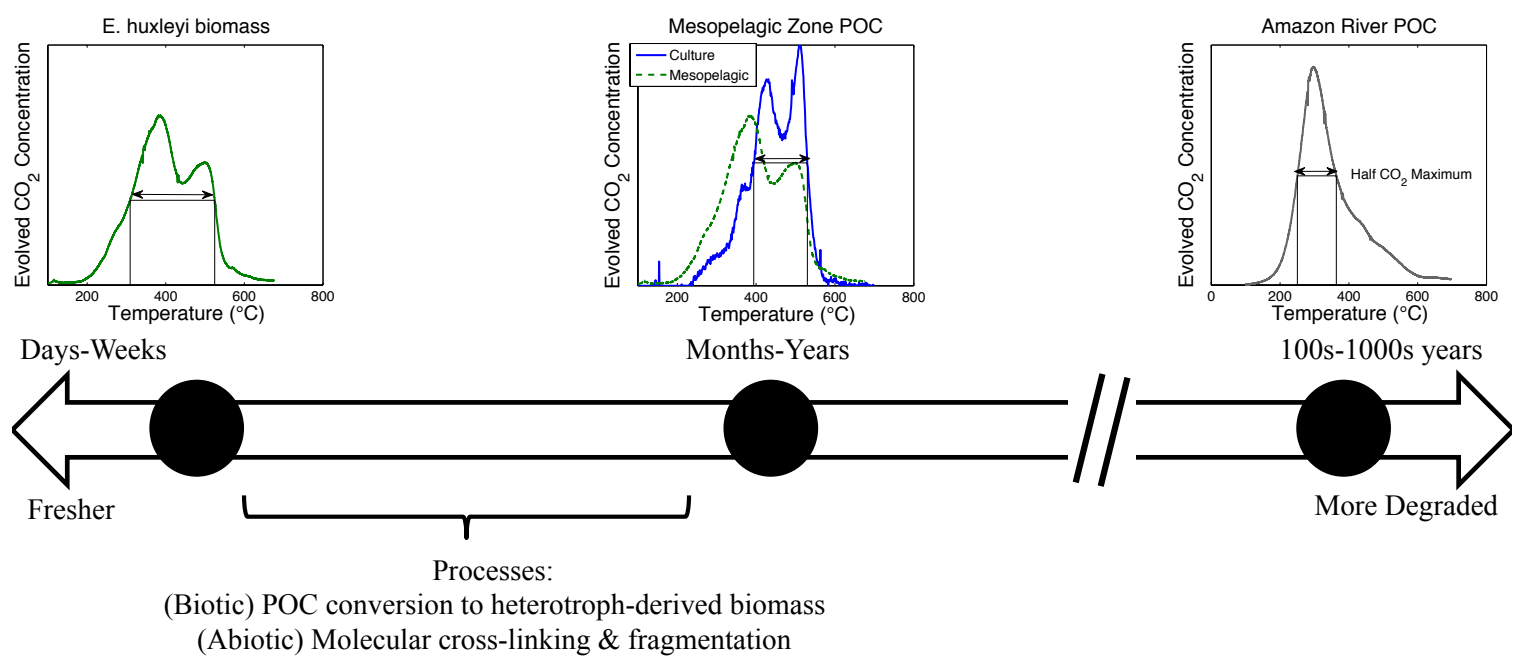

Figure 1. Conceptual schematic of differences in the activation energy or thermal stability distribution of POC at three stages of degradation. As POC degradation state increases, its activation energy distribution narrows in thermograms, as expressed below by arrow length at the $\mathrm{CO}_{2}$ concentration half-maximum of each thermogram (Appendix B, Fig. S4). Chapter 4 explored processes that may cause this decrease in activation energy range between fresh and mesopelagic zone POC, which potentially would further lead to differences between the mesopelagic zone and Amazon River POC. 
GB2-43 depth: $20 \mathrm{~m}$

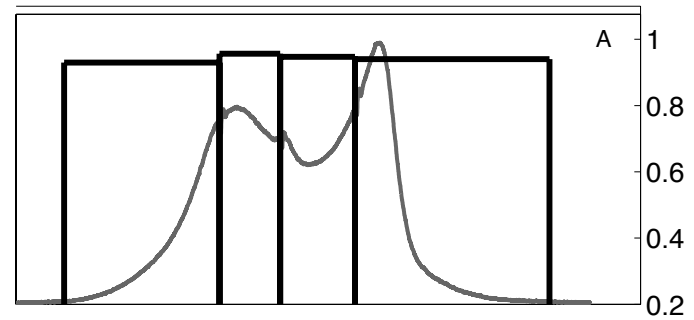

GB1-117 depth: 25m

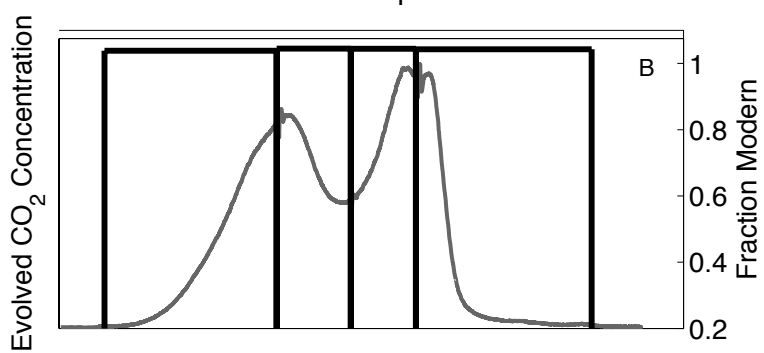

GB2-43 depth: $20 \mathrm{~m}$

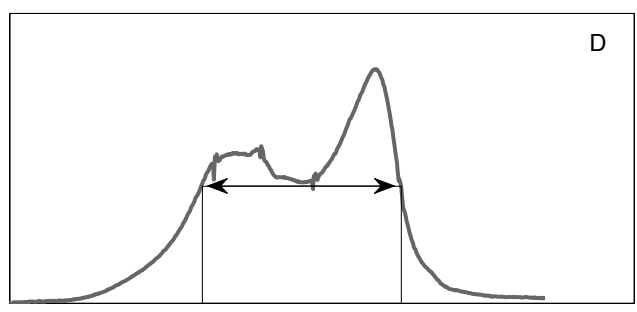

GB2-43 depth: 800m

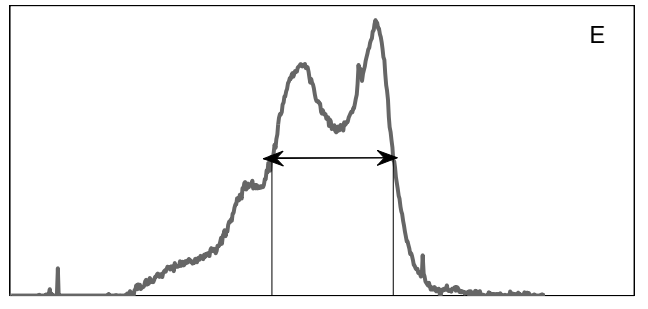

Amazon main stem April 2014 depth: 30m

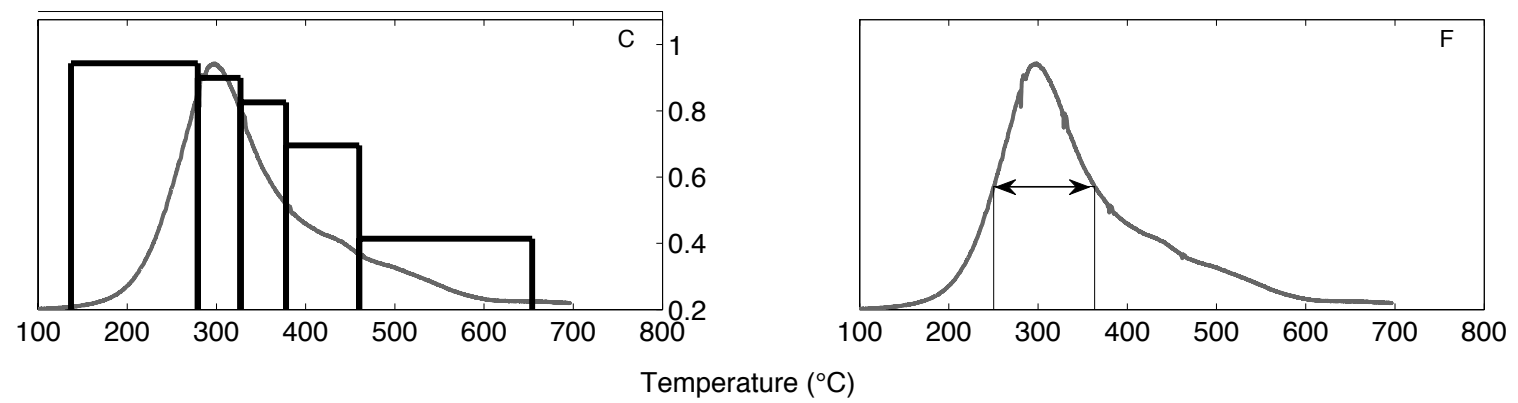

Figure 2. (a-c) Thermograms (solid lines) and fraction modern values of $\mathrm{CO}_{2}$ gas fractions (bar heights) collected during ramped oxidation of two Southern Ocean particle samples (a-b) and an Amazon River main stem sample (c). The variation in both $\delta^{13} \mathrm{C}$ and $\mathrm{F}_{\mathrm{m}}$ in the Amazon samples provide an additional dimension for comparing thermograms and POC source contributions to thermogram shape. (d-f) The thermal stability distributions of a euphotic zone sample thermogram (d), deeper mesopelagic zone sample thermogram (e), and an Amazon main stem sample thermogram (f). The arrows span the temperature range of the thermogram at half maximum $\mathrm{CO}_{2}$ concentrations (Appendix B, Fig. S4). 


\section{Appendix A}

Table S1 ${ }^{234}$ Th activity and flux profiles estimated at 27 stations along cruises GB1 and GB2. Fluxes were estimated by measuring total seawater ${ }^{234} \mathrm{Th}$ activity deficits relative to total seawater ${ }^{238} \mathrm{U}$ activity, as described in Section $2.4 .{ }^{234} \mathrm{Th}$ flux errors are propagated from ${ }^{234} \mathrm{Th}$ activity errors.

\begin{tabular}{|c|c|c|c|c|c|c|c|}
\hline Cruise & Station & Depth & $\begin{array}{l}{ }^{234} \mathrm{Th} \\
\text { Activity }\end{array}$ & $\begin{array}{l}{ }^{234} \text { Th Activity } \\
\text { Error }\end{array}$ & $\begin{array}{l}{ }^{238} \mathrm{U} \\
\text { Activity }\end{array}$ & ${ }^{234}$ Th Flux & $\begin{array}{l}{ }^{234} \text { Th Flux } \\
\text { Error }\end{array}$ \\
\hline- & - & $m$ & $d p m L^{-1}$ & $d p m L^{-1}$ & $d p m L^{-1}$ & $d p m m^{-2} d^{-1}$ & $d p m m^{-2} d^{-1}$ \\
\hline GB1 & 6 & 13.6 & 1.04 & 0.02 & 2.36 & 681 & 27 \\
\hline GB1 & 6 & 22.3 & 1.28 & 0.05 & 2.36 & 924 & 31 \\
\hline GB1 & 6 & 29.2 & 1.12 & 0.03 & 2.36 & 1,243 & 34 \\
\hline GB1 & 6 & 40.2 & 1.23 & 0.03 & 2.36 & 1,503 & 37 \\
\hline GB1 & 6 & 45.2 & 1.29 & 0.06 & 2.36 & 1,702 & 39 \\
\hline GB1 & 6 & 53.1 & 1.53 & 0.04 & 2.36 & 2,096 & 48 \\
\hline GB1 & 6 & 78 & 1.86 & 0.12 & 2.36 & 2,437 & 100 \\
\hline GB1 & 6 & 100.6 & 1.90 & 0.05 & 2.36 & 2,684 & 106 \\
\hline GB1 & 6 & 115 & 2.08 & 0.10 & 2.36 & 2,804 & 116 \\
\hline GB1 & 6 & 130 & 2.15 & 0.05 & 2.36 & 2,911 & 121 \\
\hline GB1 & 6 & 150.3 & 2.09 & 0.07 & 2.36 & 3,182 & 145 \\
\hline GB1 & 6 & 200 & 2.04 & 0.18 & 2.37 & 3,419 & 195 \\
\hline GB1 & 16 & 11.1 & 0.99 & 0.02 & 2.35 & 548 & 20 \\
\hline GB1 & 16 & 17.07 & 1.10 & 0.02 & 2.35 & 762 & 22 \\
\hline GB1 & 16 & 23.04 & 0.94 & 0.02 & 2.35 & 1,107 & 25 \\
\hline GB1 & 16 & 34.2 & 1.61 & 0.04 & 2.35 & 1,311 & 30 \\
\hline GB1 & 16 & 42.2 & 1.61 & 0.05 & 2.36 & 1,611 & 42 \\
\hline GB1 & 16 & 62.3 & 1.97 & 0.05 & 2.36 & 1,933 & 71 \\
\hline GB1 & 16 & 100.17 & 2.06 & 0.05 & 2.36 & 2,277 & 105 \\
\hline GB1 & 16 & 140.8 & 2.18 & 0.06 & 2.37 & 2,487 & 139 \\
\hline GB1 & 16 & 180.1 & 2.24 & 0.08 & 2.37 & 2,636 & 178 \\
\hline GB1 & 16 & 220.5 & 2.21 & 0.21 & 2.37 & 2,819 & 308 \\
\hline GB1 & 16 & 260.7 & 2.37 & 0.13 & 2.37 & 2,810 & 394 \\
\hline GB1 & 16 & 340.3 & 2.16 & 0.08 & 2.37 & 3,040 & 409 \\
\hline GB1 & 25 & 10.3 & 1.70 & 0.05 & 2.45 & 283 & 26 \\
\hline GB1 & 25 & 16.1 & 1.95 & 0.06 & 2.45 & 380 & 30 \\
\hline GB1 & 25 & 23.8 & 1.91 & 0.03 & 2.45 & 525 & 34 \\
\hline GB1 & 25 & 34.5 & 2.14 & 0.05 & 2.47 & 611 & 38 \\
\hline GB1 & 25 & 41.7 & 2.07 & 0.07 & 2.47 & 773 & 51 \\
\hline GB1 & 25 & 80 & 2.42 & 0.03 & 2.48 & 941 & 74 \\
\hline
\end{tabular}




\begin{tabular}{|c|c|c|c|c|c|c|c|}
\hline GB1 & 25 & 115 & 2.46 & 0.04 & 2.45 & 937 & 91 \\
\hline GB1 & 25 & 140.5 & 2.38 & 0.05 & 2.43 & 975 & 103 \\
\hline GB1 & 25 & 165.2 & 2.32 & 0.07 & 2.44 & 1,074 & 125 \\
\hline GB1 & 25 & 200.2 & 2.44 & 0.04 & 2.42 & 1,029 & 177 \\
\hline GB1 & 25 & 300 & 2.36 & 0.03 & 2.38 & 1,051 & 195 \\
\hline GB1 & 32 & 12.15 & 1.96 & 0.08 & 2.48 & 229 & 41 \\
\hline GB1 & 32 & 18 & 1.96 & 0.06 & 2.48 & 327 & 44 \\
\hline GB1 & 32 & 25.25 & 2.00 & 0.07 & 2.49 & 475 & 51 \\
\hline GB1 & 32 & 39.2 & 2.02 & 0.10 & 2.49 & 614 & 61 \\
\hline GB1 & 32 & 46 & 2.05 & 0.19 & 2.49 & 808 & 104 \\
\hline GB1 & 32 & 69.67 & 1.83 & 0.04 & 2.47 & 1,304 & 116 \\
\hline GB1 & 32 & 100.2 & 2.33 & 0.03 & 2.48 & 1,435 & 127 \\
\hline GB1 & 32 & 130.5 & 2.38 & 0.03 & 2.47 & 1,520 & 141 \\
\hline GB1 & 32 & 171 & 2.41 & 0.09 & 2.46 & 1,581 & 186 \\
\hline GB1 & 32 & 210 & 2.43 & 0.03 & 2.46 & 1,612 & 198 \\
\hline GB1 & 32 & 251 & 2.29 & 0.11 & 2.45 & 1,818 & 250 \\
\hline GB1 & 32 & 300.8 & 2.52 & 0.03 & 2.44 & 1,761 & 253 \\
\hline GB1 & 38 & 20.4 & 2.36 & 0.08 & 2.52 & 127 & 72 \\
\hline GB1 & 38 & 32.2 & 2.17 & 0.03 & 2.52 & 247 & 74 \\
\hline GB1 & 38 & 44.2 & 2.20 & 0.04 & 2.52 & 418 & 83 \\
\hline GB1 & 38 & 69 & 2.28 & 0.10 & 2.53 & 550 & 102 \\
\hline GB1 & 38 & 81 & 2.27 & 0.08 & 2.54 & 638 & 107 \\
\hline GB1 & 38 & 92 & 2.34 & 0.03 & 2.53 & 743 & 113 \\
\hline GB1 & 38 & 121 & 2.43 & 0.05 & 2.51 & 809 & 126 \\
\hline GB1 & 38 & 150 & 2.41 & 0.09 & 2.50 & 886 & 151 \\
\hline GB1 & 38 & 175 & 2.57 & 0.05 & 2.50 & 811 & 168 \\
\hline GB1 & 38 & 220 & 2.43 & 0.06 & 2.50 & 911 & 206 \\
\hline GB1 & 38 & 280.2 & 2.47 & 0.05 & 2.48 & 938 & 247 \\
\hline GB1 & 38 & 350.7 & 2.74 & 0.08 & 2.48 & 678 & 265 \\
\hline GB1 & 46 & 10 & 1.40 & 0.02 & 2.43 & 395 & 20 \\
\hline GB1 & 46 & 16.8 & 1.47 & 0.03 & 2.43 & 573 & 23 \\
\hline GB1 & 46 & 23 & 1.54 & 0.03 & 2.43 & 813 & 28 \\
\hline GB1 & 46 & 35.7 & 1.41 & 0.02 & 2.42 & 1,090 & 32 \\
\hline GB1 & 46 & 42.03 & 1.37 & 0.02 & 2.42 & 1,338 & 34 \\
\hline GB1 & 46 & 52.1 & 1.36 & 0.03 & 2.42 & 1,652 & 38 \\
\hline GB1 & 46 & 62.7 & 1.74 & 0.07 & 2.42 & 2,123 & 69 \\
\hline GB1 & 46 & 100.4 & 2.44 & 0.03 & 2.41 & 2,089 & 102 \\
\hline GB1 & 46 & 150.4 & 2.51 & 0.05 & 2.40 & 1,937 & 146 \\
\hline GB1 & 46 & 200.4 & 2.46 & 0.05 & 2.40 & 1,850 & 174 \\
\hline GB1 & 46 & 250.2 & 2.37 & 0.11 & 2.39 & 1,874 & 283 \\
\hline GB1 & 46 & 325.3 & 2.53 & 0.12 & 2.38 & 1,712 & 314 \\
\hline GB1 & 59 & 10.4 & 1.46 & 0.03 & 2.34 & 335 & 21 \\
\hline GB1 & 59 & 16.1 & 1.43 & 0.06 & 2.34 & 493 & 25 \\
\hline
\end{tabular}




\begin{tabular}{|c|c|c|c|c|c|c|c|}
\hline GB1 & 59 & 22.5 & 1.64 & 0.21 & 2.34 & 673 & 61 \\
\hline GB1 & 59 & 34 & 1.61 & 0.12 & 2.34 & 857 & 69 \\
\hline GB1 & 59 & 40 & 1.50 & 0.03 & 2.34 & 1,013 & 70 \\
\hline GB1 & 59 & 47 & 1.49 & 0.05 & 2.34 & 1,256 & 73 \\
\hline GB1 & 59 & 60 & 1.49 & 0.09 & 2.34 & 1,844 & 102 \\
\hline GB1 & 59 & 95 & 2.12 & 0.05 & 2.35 & 2,108 & 128 \\
\hline GB1 & 59 & 140 & 2.05 & 0.06 & 2.36 & 2,509 & 159 \\
\hline GB1 & 59 & 185 & 2.24 & 0.09 & 2.37 & 2,673 & 202 \\
\hline GB1 & 59 & 225 & 2.16 & 0.05 & 2.37 & 3,113 & 244 \\
\hline GB1 & 59 & 325 & 2.34 & 0.04 & 2.40 & 3,189 & 262 \\
\hline GB1 & 70 & 17 & 1.86 & 0.06 & 2.36 & 314 & 47 \\
\hline GB1 & 70 & 27 & 1.85 & 0.06 & 2.36 & 460 & 52 \\
\hline GB1 & 70 & 37 & 1.76 & 0.05 & 2.36 & 721 & 61 \\
\hline GB1 & 70 & 57.5 & 1.81 & 0.06 & 2.36 & 967 & 69 \\
\hline GB1 & 70 & 68 & 1.90 & 0.05 & 2.37 & 1,119 & 72 \\
\hline GB1 & 70 & 80 & 2.05 & 0.05 & 2.37 & 1,266 & 80 \\
\hline GB1 & 70 & 100 & 2.36 & 0.06 & 2.38 & 1,280 & 94 \\
\hline GB1 & 70 & 125 & 2.29 & 0.18 & 2.38 & 1,361 & 190 \\
\hline GB1 & 70 & 160 & 2.35 & 0.06 & 2.39 & 1,412 & 208 \\
\hline GB1 & 70 & 200 & 2.40 & 0.09 & 2.40 & 1,414 & 248 \\
\hline GB1 & 70 & 250 & 2.45 & 0.09 & 2.40 & 1,342 & 286 \\
\hline GB1 & 70 & 300 & 2.27 & 0.06 & 2.41 & 1,439 & 292 \\
\hline GB1 & 77 & 17 & 1.71 & 0.06 & 2.35 & 399 & 45 \\
\hline GB1 & 77 & 26 & 1.68 & 0.05 & 2.35 & 573 & 49 \\
\hline GB1 & 77 & 35 & 1.84 & 0.05 & 2.35 & 794 & 57 \\
\hline GB1 & 77 & 56 & 1.79 & 0.06 & 2.35 & 1,047 & 66 \\
\hline GB1 & 77 & 66 & 1.86 & 0.06 & 2.35 & 1,197 & 70 \\
\hline GB1 & 77 & 77 & 1.97 & 0.06 & 2.36 & 1,391 & 79 \\
\hline GB1 & 77 & 101 & 2.25 & 0.08 & 2.37 & 1,485 & 105 \\
\hline GB1 & 77 & 130 & 2.30 & 0.06 & 2.39 & 1,561 & 122 \\
\hline GB1 & 77 & 160 & 2.31 & 0.06 & 2.39 & 1,630 & 139 \\
\hline GB1 & 77 & 190 & 2.16 & 0.05 & 2.40 & 1,903 & 162 \\
\hline GB1 & 77 & 240 & 2.40 & 0.07 & 2.40 & 1,917 & 213 \\
\hline GB1 & 77 & 300 & 2.40 & 0.13 & 2.41 & 1,922 & 243 \\
\hline GB1 & 85 & 12.6 & 1.30 & 0.05 & 2.35 & 476 & 32 \\
\hline GB1 & 85 & 19 & 1.55 & 0.07 & 2.35 & 629 & 35 \\
\hline GB1 & 85 & 26 & 1.41 & 0.06 & 2.35 & 925 & 43 \\
\hline GB1 & 85 & 41 & 1.52 & 0.07 & 2.35 & 1,197 & 52 \\
\hline GB1 & 85 & 49 & 1.76 & 0.07 & 2.35 & 1,340 & 56 \\
\hline GB1 & 85 & 58 & 1.91 & 0.07 & 2.35 & 1,493 & 63 \\
\hline GB1 & 85 & 73 & 1.86 & 0.08 & 2.35 & 1,858 & 94 \\
\hline GB1 & 85 & 110 & 2.17 & 0.09 & 2.36 & 2,034 & 133 \\
\hline GB1 & 85 & 140 & 2.34 & 0.09 & 2.36 & 2,059 & 168 \\
\hline
\end{tabular}




\begin{tabular}{|c|c|c|c|c|c|c|c|}
\hline GB1 & 85 & 180 & 2.36 & 0.09 & 2.37 & 2,076 & 207 \\
\hline GB1 & 85 & 220 & 2.46 & 0.09 & 2.38 & 1,931 & 273 \\
\hline GB1 & 85 & 300 & 2.60 & 0.10 & 2.39 & 1,683 & 300 \\
\hline GB1 & 92 & 10 & 1.68 & 0.07 & 2.34 & 239 & 32 \\
\hline GB1 & 92 & 15 & 1.61 & 0.07 & 2.34 & 365 & 35 \\
\hline GB1 & 92 & 22 & 1.54 & 0.07 & 2.34 & 571 & 41 \\
\hline GB1 & 92 & 33 & 1.78 & 0.04 & 2.34 & 709 & 43 \\
\hline GB1 & 92 & 39 & 1.65 & 0.05 & 2.34 & 837 & 45 \\
\hline GB1 & 92 & 46 & 1.59 & 0.04 & 2.34 & 1,053 & 48 \\
\hline GB1 & 92 & 59 & 1.59 & 0.06 & 2.34 & 1,639 & 77 \\
\hline GB1 & 92 & 100 & 2.65 & 0.07 & 2.35 & 1,332 & 117 \\
\hline GB1 & 92 & 130 & 2.28 & 0.06 & 2.36 & 1,396 & 134 \\
\hline GB1 & 92 & 160 & 2.41 & 0.09 & 2.36 & 1,339 & 170 \\
\hline GB1 & 92 & 200 & 2.42 & 0.06 & 2.37 & 1,248 & 232 \\
\hline GB1 & 92 & 302 & 2.29 & 0.06 & 2.38 & 1,391 & 259 \\
\hline GB1 & 101 & 13.6 & 1.57 & 0.04 & 2.36 & 405 & 33 \\
\hline GB1 & 101 & 22 & 1.46 & 0.04 & 2.36 & 611 & 35 \\
\hline GB1 & 101 & 29.5 & 1.58 & 0.05 & 2.36 & 867 & 42 \\
\hline GB1 & 101 & 45 & 1.61 & 0.05 & 2.36 & 1,133 & 49 \\
\hline GB1 & 101 & 54 & 1.74 & 0.06 & 2.37 & 1,296 & 52 \\
\hline GB1 & 101 & 63 & 1.89 & 0.06 & 2.37 & 1,484 & 61 \\
\hline GB1 & 101 & 81 & 1.96 & 0.07 & 2.37 & 1,763 & 82 \\
\hline GB1 & 101 & 110 & 2.24 & 0.07 & 2.38 & 1,878 & 107 \\
\hline GB1 & 101 & 140 & 2.43 & 0.05 & 2.37 & 1,826 & 122 \\
\hline GB1 & 101 & 171 & 2.43 & 0.05 & 2.37 & 1,774 & 135 \\
\hline GB1 & 101 & 200 & 2.44 & 0.05 & 2.37 & 1,641 & 184 \\
\hline GB1 & 101 & 300 & 2.20 & 0.04 & 2.37 & 1,883 & 205 \\
\hline GB1 & 109 & 11.1 & 1.58 & 0.03 & 2.39 & 318 & 23 \\
\hline GB1 & 109 & 16.2 & 1.69 & 0.04 & 2.39 & 445 & 25 \\
\hline GB1 & 109 & 23.7 & 1.62 & 0.04 & 2.39 & 672 & 31 \\
\hline GB1 & 109 & 36.5 & 1.77 & 0.04 & 2.40 & 854 & 35 \\
\hline GB1 & 109 & 44 & 1.76 & 0.04 & 2.48 & 1,158 & 44 \\
\hline GB1 & 109 & 66 & 2.03 & 0.04 & 2.40 & 1,326 & 53 \\
\hline GB1 & 109 & 76 & 1.99 & 0.04 & 2.40 & 1,524 & 61 \\
\hline GB1 & 109 & 100 & 2.17 & 0.04 & 2.39 & 1,648 & 71 \\
\hline GB1 & 109 & 115 & 2.19 & 0.04 & 2.40 & 1,737 & 76 \\
\hline GB1 & 109 & 130 & 2.43 & 0.05 & 2.40 & 1,722 & 83 \\
\hline GB1 & 109 & 150 & 2.40 & 0.05 & 2.40 & 1,719 & 94 \\
\hline GB1 & 109 & 175 & 2.40 & 0.05 & 2.40 & 1,719 & 97 \\
\hline GB1 & 117 & 10.5 & 1.80 & 0.04 & 2.43 & 243 & 24 \\
\hline GB1 & 117 & 16.3 & 1.69 & 0.03 & 2.43 & 377 & 26 \\
\hline GB1 & 117 & 23 & 1.99 & 0.04 & 2.43 & 484 & 30 \\
\hline GB1 & 117 & 33 & 1.77 & 0.04 & 2.41 & 659 & 34 \\
\hline
\end{tabular}




\begin{tabular}{|c|c|c|c|c|c|c|c|}
\hline GB1 & 117 & 42 & 1.95 & 0.04 & 2.41 & 758 & 37 \\
\hline GB1 & 117 & 48 & 1.86 & 0.04 & 2.42 & 918 & 41 \\
\hline GB1 & 117 & 62 & 1.87 & 0.04 & 2.43 & 1,177 & 50 \\
\hline GB1 & 117 & 80 & 2.08 & 0.04 & 2.44 & 1,346 & 58 \\
\hline GB1 & 117 & 95 & 2.31 & 0.05 & 2.44 & 1,404 & 65 \\
\hline GB1 & 117 & 110 & 2.46 & 0.05 & 2.44 & 1,394 & 71 \\
\hline GB1 & 117 & 125 & 2.61 & 0.05 & 2.43 & 1,290 & 82 \\
\hline GB1 & 117 & 150 & 2.52 & 0.05 & 2.43 & 1,258 & 86 \\
\hline GB2 & 5 & 20 & 1.37 & 6.03 & 2.47 & 948 & 5,206 \\
\hline GB2 & 5 & 40 & 1.70 & 0.08 & 2.47 & 1,403 & 5,206 \\
\hline GB2 & 5 & 61 & 1.84 & 0.07 & 2.47 & 1,768 & 5,206 \\
\hline GB2 & 5 & 71 & 1.89 & 0.15 & 2.48 & 2,015 & 5,206 \\
\hline GB2 & 5 & 80 & 2.18 & 0.07 & 2.47 & 1,889 & 5,207 \\
\hline GB2 & 5 & 90 & 2.56 & 0.07 & 2.47 & 1,862 & 5,207 \\
\hline GB2 & 5 & 100 & 2.52 & 0.08 & 2.48 & 1,850 & 5,207 \\
\hline GB2 & 5 & 111 & 2.54 & 0.08 & 2.47 & 1,832 & 5,207 \\
\hline GB2 & 5 & 120 & 2.44 & 0.09 & 2.47 & 1,849 & 5,207 \\
\hline GB2 & 5 & 150 & 2.50 & 0.07 & 2.48 & 1,821 & 5,208 \\
\hline GB2 & 5 & 201 & 2.82 & 0.14 & 2.47 & 1,058 & 5,218 \\
\hline GB2 & 5 & 300 & 2.71 & 0.09 & 2.46 & 695 & 5,220 \\
\hline GB2 & 27 & 20 & 1.70 & 0.04 & 2.34 & 554 & 53 \\
\hline GB2 & 27 & 40 & 1.56 & 0.04 & 2.34 & 1,114 & 69 \\
\hline GB2 & 27 & 70 & 1.68 & 0.06 & 2.34 & 1,637 & 92 \\
\hline GB2 & 27 & 85 & 1.53 & 0.24 & 2.34 & 2,047 & 155 \\
\hline GB2 & 27 & 95 & 1.97 & 0.05 & 2.34 & 1,828 & 159 \\
\hline GB2 & 27 & 105 & 2.20 & 0.06 & 2.35 & 1,869 & 160 \\
\hline GB2 & 27 & 115 & 2.21 & 0.08 & 2.35 & 1,910 & 162 \\
\hline GB2 & 27 & 125 & 2.28 & 0.06 & 2.35 & 1,931 & 164 \\
\hline GB2 & 27 & 135 & 2.27 & 0.05 & 2.35 & 1,972 & 168 \\
\hline GB2 & 27 & 160 & 2.18 & 0.06 & 2.35 & 2,130 & 181 \\
\hline GB2 & 27 & 200 & 2.41 & 0.06 & 2.36 & 2,063 & 205 \\
\hline GB2 & 27 & 250 & 2.69 & 0.08 & 2.36 & 1,826 & 216 \\
\hline GB2 & 36 & 20 & 1.83 & 0.04 & 2.34 & 434 & 55 \\
\hline GB2 & 36 & 40 & 1.86 & 0.06 & 2.34 & 639 & 65 \\
\hline GB2 & 36 & 50 & 1.82 & 0.08 & 2.34 & 824 & 73 \\
\hline GB2 & 36 & 65 & 1.91 & 0.05 & 2.34 & 981 & 77 \\
\hline GB2 & 36 & 75 & 2.19 & 0.08 & 2.35 & 1,035 & 84 \\
\hline GB2 & 36 & 90 & 2.48 & 0.06 & 2.35 & 988 & 89 \\
\hline GB2 & 36 & 100 & 2.29 & 0.08 & 2.35 & 1,034 & 117 \\
\hline GB2 & 36 & 125 & 2.04 & 0.07 & 2.35 & 1,372 & 148 \\
\hline GB2 & 36 & 150 & 2.23 & 0.06 & 2.35 & 1,161 & 169 \\
\hline GB2 & 36 & 175 & 2.42 & 0.06 & 2.35 & 1,110 & 178 \\
\hline GB2 & 36 & 200 & 2.39 & 0.05 & 2.36 & 1,077 & 194 \\
\hline
\end{tabular}




\begin{tabular}{|c|c|c|c|c|c|c|c|}
\hline GB2 & 36 & 250 & 2.58 & 0.07 & 2.36 & 923 & 202 \\
\hline GB2 & 43 & 20 & 1.89 & 0.04 & 2.33 & 383 & 55 \\
\hline GB2 & 43 & 40 & 1.90 & 0.08 & 2.33 & 632 & 76 \\
\hline GB2 & 43 & 60 & 1.93 & 0.08 & 2.33 & 896 & 99 \\
\hline GB2 & 43 & 85 & 2.06 & 0.07 & 2.34 & 1,034 & 108 \\
\hline GB2 & 43 & 95 & 2.03 & 0.05 & 2.34 & 1,147 & 111 \\
\hline GB2 & 43 & 110 & 2.17 & 0.24 & 2.34 & 1,221 & 153 \\
\hline GB2 & 43 & 125 & 2.25 & 0.05 & 2.34 & 1,258 & 156 \\
\hline GB2 & 43 & 140 & 2.25 & 0.10 & 2.34 & 1,308 & 169 \\
\hline GB2 & 43 & 165 & 2.45 & 0.06 & 2.34 & 1,233 & 177 \\
\hline GB2 & 43 & 190 & 2.35 & 0.06 & 2.35 & 1,230 & 186 \\
\hline GB2 & 43 & 220 & 2.33 & 0.07 & 2.35 & 1,247 & 200 \\
\hline GB2 & 43 & 250 & 2.68 & 0.09 & 2.36 & 1,108 & 205 \\
\hline GB2 & 53 & 20 & 1.87 & 0.08 & 2.34 & 407 & 80 \\
\hline GB2 & 53 & 40 & 1.88 & 0.14 & 2.34 & 668 & 117 \\
\hline GB2 & 53 & 60 & 1.99 & 0.05 & 2.34 & 915 & 126 \\
\hline GB2 & 53 & 90 & 1.98 & 0.05 & 2.34 & 1,120 & 132 \\
\hline GB2 & 53 & 100 & 2.27 & 0.08 & 2.34 & 1,139 & 134 \\
\hline GB2 & 53 & 110 & 2.45 & 0.06 & 2.34 & 1,109 & 136 \\
\hline GB2 & 53 & 120 & 2.40 & 0.06 & 2.34 & 1,056 & 151 \\
\hline GB2 & 53 & 170 & 2.38 & 0.11 & 2.35 & 1,013 & 220 \\
\hline GB2 & 53 & 210 & 2.52 & 0.06 & 2.35 & 827 & 237 \\
\hline GB2 & 53 & 250 & 2.30 & 0.06 & 2.36 & 860 & 241 \\
\hline GB2 & 63 & 20 & 1.88 & 0.09 & 2.34 & 394 & 88 \\
\hline GB2 & 63 & 40 & 1.94 & 0.08 & 2.34 & 625 & 102 \\
\hline GB2 & 63 & 60 & 1.95 & 0.08 & 2.34 & 848 & 115 \\
\hline GB2 & 63 & 80 & 1.92 & 0.05 & 2.34 & 1,089 & 121 \\
\hline GB2 & 63 & 100 & 2.12 & 0.13 & 2.34 & 1,187 & 135 \\
\hline GB2 & 63 & 110 & 2.20 & 0.08 & 2.34 & 1,229 & 138 \\
\hline GB2 & 63 & 120 & 2.25 & 0.10 & 2.34 & 1,285 & 151 \\
\hline GB2 & 63 & 130 & 2.31 & 0.10 & 2.34 & 1,316 & 174 \\
\hline GB2 & 63 & 150 & 2.37 & 0.09 & 2.35 & 1,267 & 191 \\
\hline GB2 & 63 & 175 & 2.38 & 0.09 & 2.35 & 1,248 & 204 \\
\hline GB2 & 63 & 200 & 2.32 & 0.14 & 2.36 & 1,292 & 262 \\
\hline GB2 & 63 & 250 & 2.50 & 0.09 & 2.37 & 1,198 & 272 \\
\hline GB2 & 73 & 20 & 1.80 & 0.06 & 2.35 & 433 & 63 \\
\hline GB2 & 73 & 35 & 1.79 & 0.06 & 2.35 & 675 & 71 \\
\hline GB2 & 73 & 50 & 1.94 & 0.09 & 2.35 & 823 & 79 \\
\hline GB2 & 73 & 60 & 1.96 & 0.07 & 2.35 & 966 & 85 \\
\hline GB2 & 73 & 75 & 2.30 & 0.11 & 2.37 & 997 & 99 \\
\hline GB2 & 73 & 90 & 2.43 & 0.09 & 2.38 & 977 & 108 \\
\hline GB2 & 73 & 105 & 2.63 & 0.07 & 2.39 & 822 & 120 \\
\hline GB2 & 73 & 120 & 2.58 & 0.12 & 2.39 & 677 & 156 \\
\hline
\end{tabular}




\begin{tabular}{|c|c|c|c|c|c|c|c|}
\hline GB2 & 73 & 135 & 2.43 & 0.06 & 2.40 & 794 & 168 \\
\hline GB2 & 73 & 160 & 2.34 & 0.06 & 2.40 & 853 & 184 \\
\hline GB2 & 73 & 200 & 2.48 & 0.06 & 2.40 & 807 & 189 \\
\hline GB2 & 87 & 20 & 1.93 & 0.07 & 2.35 & 354 & 71 \\
\hline GB2 & 87 & 40 & 1.92 & 0.05 & 2.35 & 599 & 81 \\
\hline GB2 & 87 & 60 & 1.75 & 0.06 & 2.35 & 939 & 91 \\
\hline GB2 & 87 & 80 & 1.89 & 0.07 & 2.35 & 1,134 & 98 \\
\hline GB2 & 87 & 90 & 1.88 & 0.05 & 2.35 & 1,268 & 100 \\
\hline GB2 & 87 & 100 & 2.28 & 0.08 & 2.35 & 1,290 & 103 \\
\hline GB2 & 87 & 110 & 2.33 & 0.13 & 2.35 & 1,299 & 115 \\
\hline GB2 & 87 & 125 & 2.35 & 0.08 & 2.36 & 1,302 & 121 \\
\hline GB2 & 87 & 140 & 2.36 & 0.08 & 2.36 & 1,297 & 136 \\
\hline GB2 & 87 & 170 & 2.32 & 0.08 & 2.36 & 1,336 & 159 \\
\hline GB2 & 87 & 200 & 2.48 & 0.09 & 2.37 & 1,213 & 196 \\
\hline GB2 & 87 & 250 & 2.55 & 0.08 & 2.38 & 1,088 & 208 \\
\hline GB2 & 93 & 20 & 1.95 & 0.07 & 2.36 & 352 & 71 \\
\hline GB2 & 93 & 40 & 2.04 & 0.09 & 2.36 & 554 & 96 \\
\hline GB2 & 93 & 65 & 2.14 & 0.08 & 2.36 & 710 & 116 \\
\hline GB2 & 93 & 90 & 1.95 & 0.08 & 2.36 & 944 & 127 \\
\hline GB2 & 93 & 105 & 2.01 & 0.08 & 2.36 & 1,071 & 132 \\
\hline GB2 & 93 & 115 & 2.17 & 0.10 & 2.37 & 1,142 & 137 \\
\hline GB2 & 93 & 130 & 2.57 & 0.09 & 2.39 & 1,061 & 144 \\
\hline GB2 & 93 & 145 & 2.44 & 0.08 & 2.39 & 1,033 & 152 \\
\hline GB2 & 93 & 165 & 2.42 & 0.08 & 2.39 & 1,003 & 170 \\
\hline GB2 & 93 & 180 & 2.40 & 0.09 & 2.39 & 992 & 213 \\
\hline GB2 & 93 & 200 & 2.82 & 0.09 & 2.39 & 469 & 249 \\
\hline GB2 & 93 & 250 & 2.61 & 0.09 & 2.38 & 309 & 259 \\
\hline GB2 & 100 & 20 & 1.89 & 0.05 & 2.42 & 464 & 58 \\
\hline GB2 & 100 & 40 & 1.90 & 0.07 & 2.42 & 764 & 75 \\
\hline GB2 & 100 & 60 & 2.06 & 0.07 & 2.42 & 922 & 83 \\
\hline GB2 & 100 & 70 & 1.80 & 0.05 & 2.42 & 1,101 & 85 \\
\hline GB2 & 100 & 80 & 2.27 & 0.08 & 2.43 & 1,145 & 89 \\
\hline GB2 & 100 & 90 & 2.33 & 0.08 & 2.43 & 1,174 & 94 \\
\hline GB2 & 100 & 100 & 2.66 & 0.28 & 2.43 & 1,110 & 124 \\
\hline GB2 & 100 & 110 & 2.43 & 0.08 & 2.43 & 1,112 & 130 \\
\hline GB2 & 100 & 130 & 2.30 & 0.09 & 2.43 & 1,205 & 151 \\
\hline GB2 & 100 & 160 & 2.48 & 0.09 & 2.43 & 1,157 & 182 \\
\hline GB2 & 100 & 200 & 2.47 & 0.08 & 2.43 & 1,132 & 190 \\
\hline GB2 & 106 & 20 & 1.87 & 0.05 & 2.47 & 603 & 68 \\
\hline GB2 & 106 & 50 & 1.77 & 0.05 & 2.47 & 1,005 & 79 \\
\hline GB2 & 106 & 60 & 1.83 & 0.06 & 2.47 & 1,189 & 82 \\
\hline GB2 & 106 & 70 & 2.09 & 0.08 & 2.48 & 1,301 & 86 \\
\hline GB2 & 106 & 80 & 2.17 & 0.08 & 2.48 & 1,413 & 92 \\
\hline
\end{tabular}




\begin{tabular}{lrrrrrrr} 
GB2 & 106 & 95 & 2.45 & 0.09 & 2.48 & 1,426 & 107 \\
GB2 & 106 & 115 & 2.62 & 0.09 & 2.48 & 1,335 & 126 \\
GB2 & 106 & 140 & 2.50 & 0.06 & 2.48 & 1,320 & 138 \\
GB2 & 106 & 165 & 2.36 & 0.06 & 2.48 & 1,423 & 154 \\
GB2 & 106 & 200 & 2.49 & 0.07 & 2.47 & 1,405 & 186 \\
GB2 & 106 & 250 & 2.64 & 0.17 & 2.46 & 1,274 & 226 \\
GB2 & 112 & 10 & 2.11 & 0.08 & 2.42 & 136 & 40 \\
GB2 & 112 & 20 & 2.39 & 0.09 & 2.42 & 149 & 54 \\
GB2 & 112 & 35 & 2.29 & 0.08 & 2.42 & 199 & 65 \\
GB2 & 112 & 45 & 1.91 & 0.07 & 2.43 & 347 & 69 \\
GB2 & 112 & 55 & 1.80 & 0.07 & 2.42 & 526 & 73 \\
GB2 & 112 & 65 & 2.25 & 0.09 & 2.42 & 589 & 82 \\
GB2 & 112 & 80 & 2.20 & 0.08 & 2.43 & 717 & 97 \\
GB2 & 112 & 105 & 2.47 & 0.09 & 2.43 & 682 & 126 \\
GB2 & 112 & 135 & 2.66 & 0.09 & 2.42 & 466 & 160 \\
GB2 & 112 & 170 & 2.63 & 0.09 & 2.42 & 270 & 186 \\
GB2 & 112 & 200 & 2.69 & 0.10 & 2.42 & -39 & 223 \\
GB2 & 112 & 250 & 2.66 & 0.10 & 2.42 & -211 & 237 \\
GB2 & 119 & 10 & 1.73 & 0.19 & 2.42 & 347 & 96 \\
GB2 & 119 & 25 & 1.73 & 0.05 & 2.42 & 644 & 101 \\
GB2 & 119 & 40 & 1.77 & 0.06 & 2.42 & 923 & 106 \\
GB2 & 119 & 55 & 2.00 & 0.07 & 2.42 & 1,072 & 110 \\
GB2 & 119 & 65 & 2.16 & 0.07 & 2.43 & 1,147 & 113 \\
GB2 & 119 & 74 & 2.21 & 0.07 & 2.43 & 1,226 & 117 \\
GB2 & 119 & 90 & 2.43 & 0.08 & 2.43 & 1,223 & 124 \\
GB2 & 119 & 105 & 2.32 & 0.08 & 2.42 & 1,280 & 135 \\
GB2 & 119 & 130 & 2.60 & 0.08 & 2.43 & 1,127 & 158 \\
GB2 & 119 & 165 & 2.69 & 0.09 & 2.42 & 853 & 189 \\
GB2 & 119 & 200 & 2.50 & 0.08 & 2.42 & 756 & 218 \\
GB2 & 119 & 250 & 2.75 & 0.09 & 2.42 & 516 & 231 \\
\hline & & & & & & \\
& 119 & & \\
\end{tabular}


Table S2. ${ }^{234} \mathrm{Th}$ and POC fluxes at $\mathrm{z}_{\mathrm{Th} / \mathrm{U}}$, estimated at 27 stations along cruises GB1 and GB2. $\mathrm{z}_{\mathrm{Th} / \mathrm{U}}$ is the depth where ${ }^{234} \mathrm{Th}$ and ${ }^{238} \mathrm{U}$ activities re-establish secular equilibrium. Calculations of POC flux from ${ }^{234} \mathrm{Th}$ fluxes are described in Section 2.4. POC flux errors are propagated from ${ }^{234} \mathrm{Th}$ flux, and POC: $:^{234} \mathrm{Th}$ errors.

\begin{tabular}{|c|c|c|c|c|c|c|c|}
\hline Cruise & Station & $\mathrm{z}_{\mathrm{Th} / \mathrm{U}}$ & ${ }^{234}$ Th Flux & ${ }^{234} \mathrm{Th}$ Flux Error & $>51 \mu \mathrm{m} \mathrm{POC}:{ }^{234} \mathrm{Th}$ & POC Flux & POC Flux Error \\
\hline- & - & $m$ & $d p m m^{-2} d^{-1}$ & $d p m m^{-2} d^{-1}$ & umol dpm ${ }^{-1}$ & $m m o l ~ m^{-2} d^{-1}$ & $\mathrm{mmol} \mathrm{m} \mathrm{m}^{-2} 1$ \\
\hline GB1 & 6 & 130 & 2,911 & 121 & 2.0 & 5.7 & 0.25 \\
\hline GB1 & 16 & 140.8 & 2,487 & 139 & 2.6 & 6.6 & 0.37 \\
\hline GB1 & 25 & 115 & 937 & 91 & 1.7 & 1.6 & 0.18 \\
\hline GB1 & 32 & 131 & 1,581 & 186 & 1.3 & 2.0 & 0.20 \\
\hline GB1 & 38 & 121 & 809 & 126 & 2.7 & 2.2 & 0.35 \\
\hline GB1 & 46 & 100 & 2,089 & 102 & 2.8 & 5.9 & 0.32 \\
\hline GB1 & 59 & 95 & 2,108 & 128 & 2.9 & 6.1 & 0.42 \\
\hline GB1 & 70 & 100 & 1,280 & 94 & 4.3 & 5.5 & 0.44 \\
\hline GB1 & 77 & 100 & 1,485 & 105 & 6.0 & 9.0 & 1.3 \\
\hline GB1 & 85 & 140 & 2,059 & 168 & 5.9 & 12 & 1.0 \\
\hline GB1 & 92 & 100 & 1,332 & 117 & 3.8 & 5.1 & 0.47 \\
\hline GB1 & 101 & 140 & 1,826 & 122 & 1.8 & 3.3 & 0.23 \\
\hline GB1 & 109 & 130 & 1,722 & 83 & 1.0 & 1.6 & 0.09 \\
\hline GB1 & 117 & 110 & 1,394 & 71 & 1.0 & 1.4 & 0.09 \\
\hline GB2 & 5 & 90 & 1,862 & 5,207 & 1.3 & 2.5 & 6.9 \\
\hline GB2 & 27 & 105 & 1,869 & 160 & 1.9 & 3.5 & 0.32 \\
\hline GB2 & 36 & 90 & 988 & 89 & 2.0 & 2.0 & 0.18 \\
\hline GB2 & 43 & 125 & 1,258 & 156 & 3.7 & 4.6 & 0.58 \\
\hline GB2 & 53 & 100 & 1,139 & 134 & 3.9 & 4.4 & 0.53 \\
\hline GB2 & 63 & 130 & 1,316 & 174 & 4.6 & 6.1 & 0.81 \\
\hline GB2 & 73 & 75 & 997 & 99 & 4.9 & 4.9 & 0.49 \\
\hline GB2 & 87 & 100 & 1,290 & 103 & 2.9 & 3.8 & 0.33 \\
\hline GB2 & 93 & 130 & 1,061 & 144 & 1.2 & 1.2 & 0.18 \\
\hline GB2 & 100 & 90 & 1,174 & 94 & 2.8 & 3.3 & 0.27 \\
\hline GB2 & 106 & 95 & 1,426 & 107 & 0.9 & 1.2 & 0.10 \\
\hline GB2 & 112 & 105 & 682 & 126 & 0.8 & 0.6 & 0.11 \\
\hline GB2 & 119 & 90 & 1,223 & 124 & 2.5 & 3.0 & 0.31 \\
\hline
\end{tabular}


A
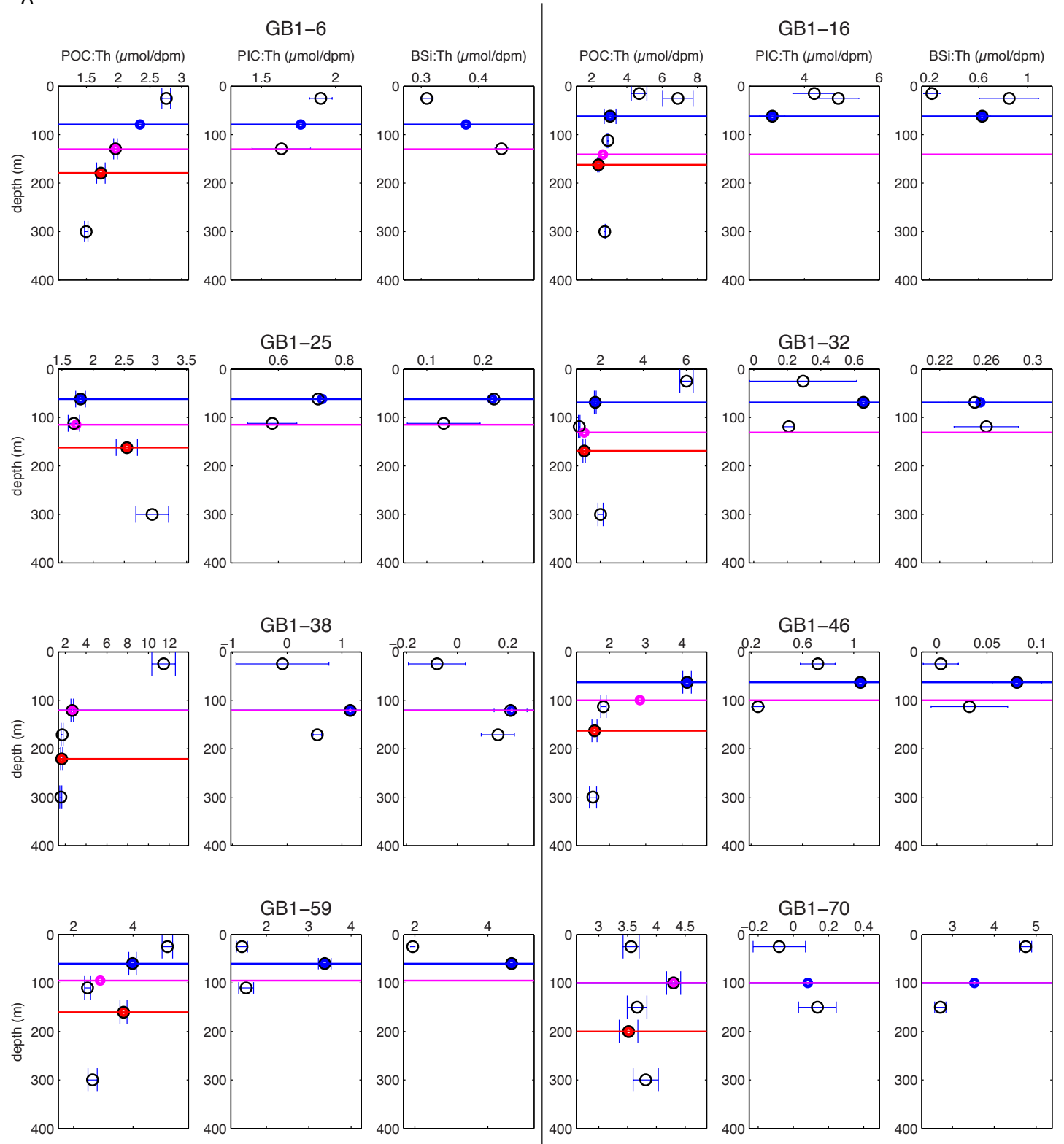

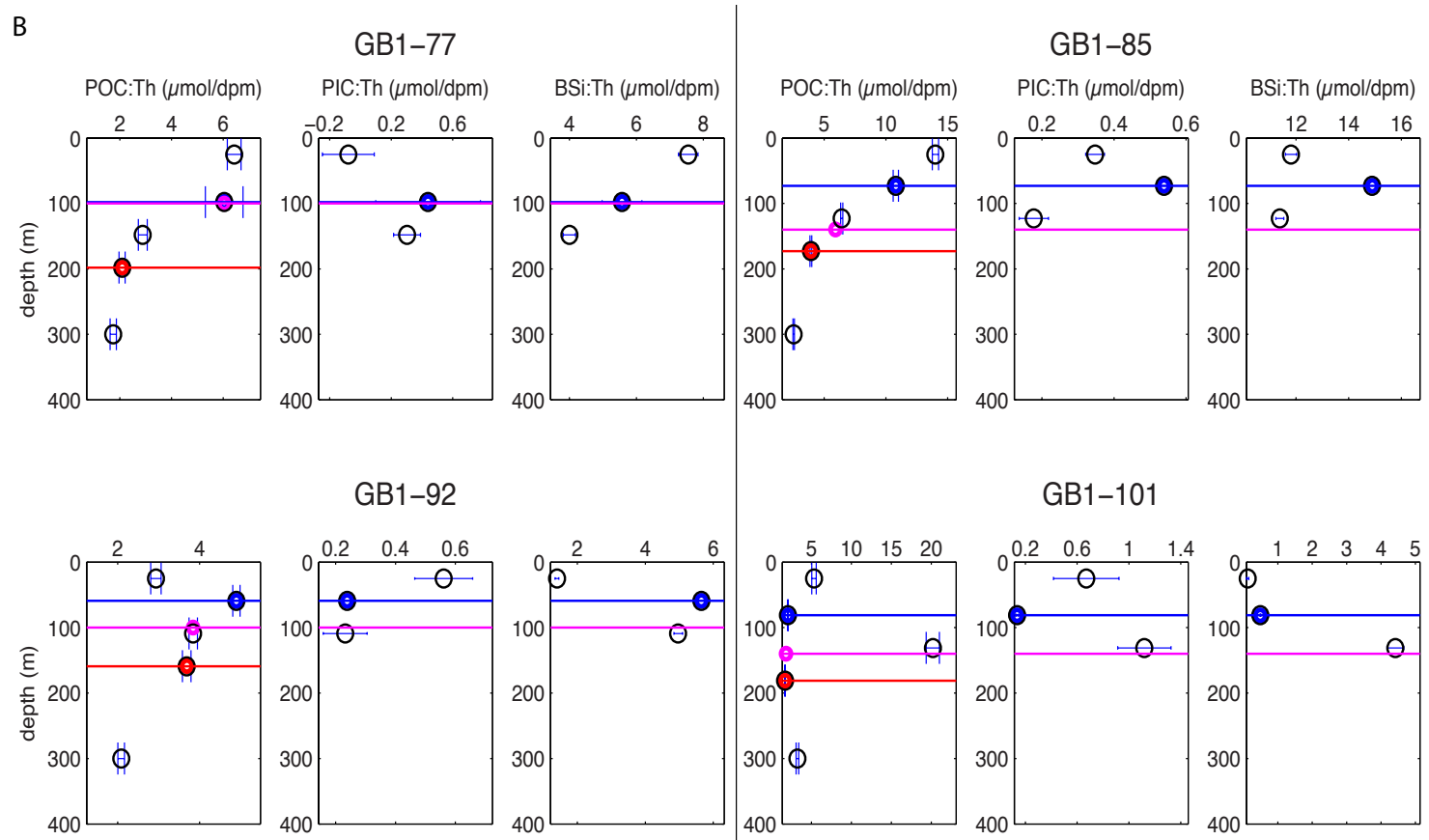

GB1-109
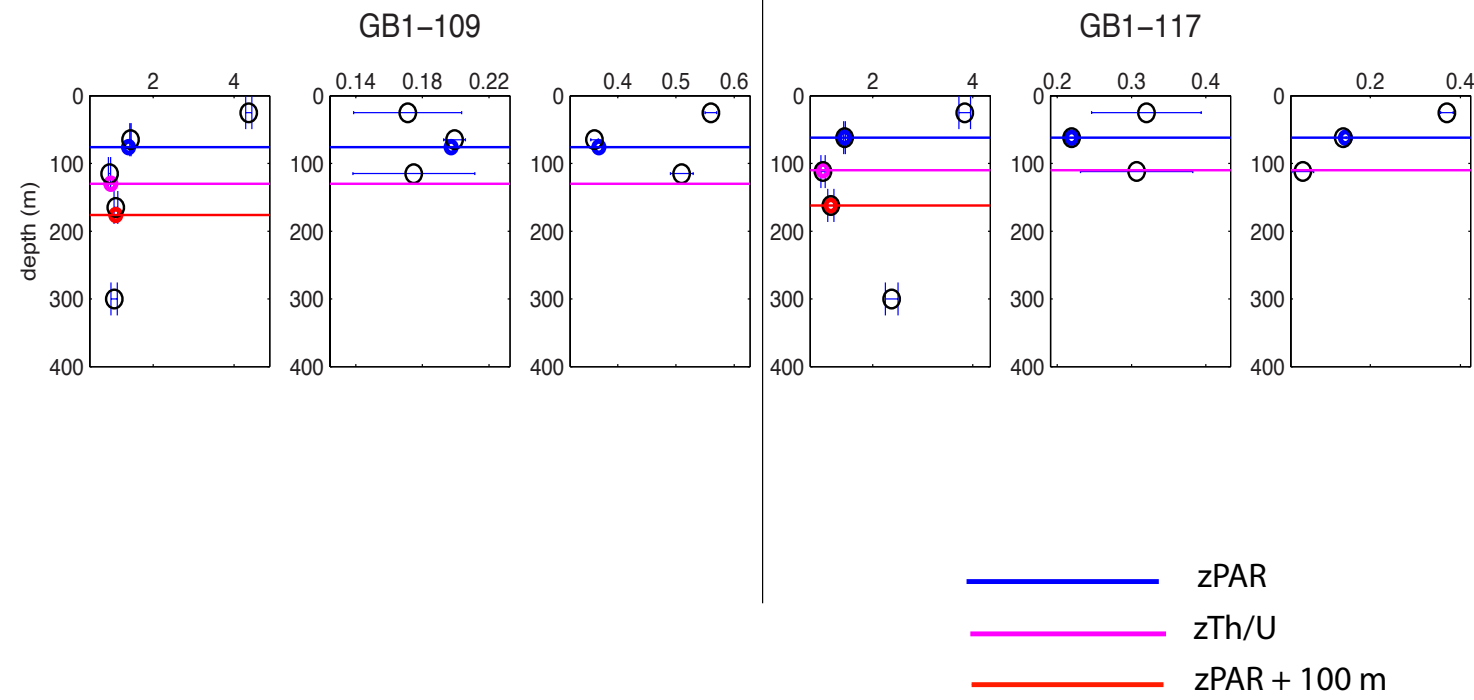
C
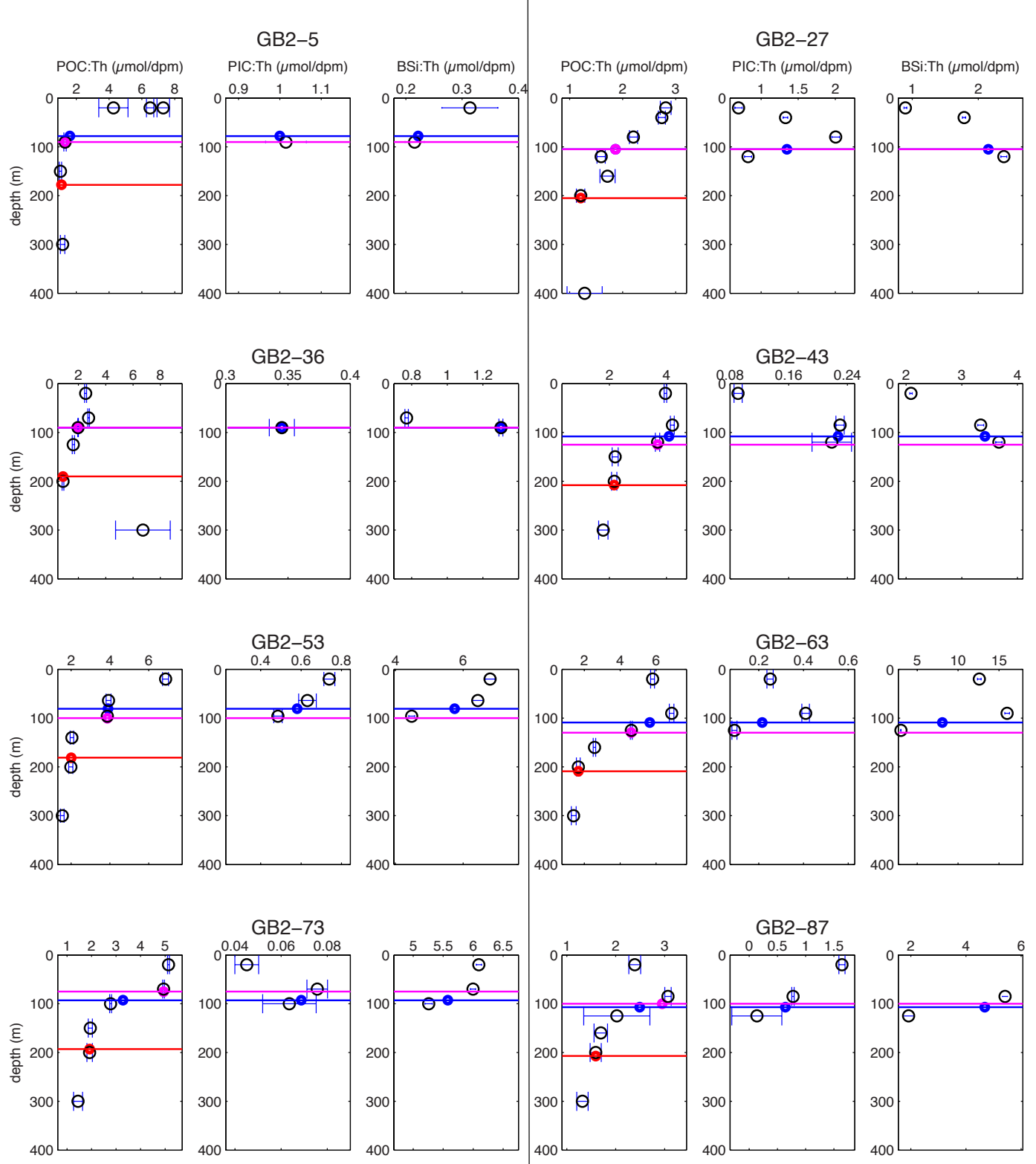
D
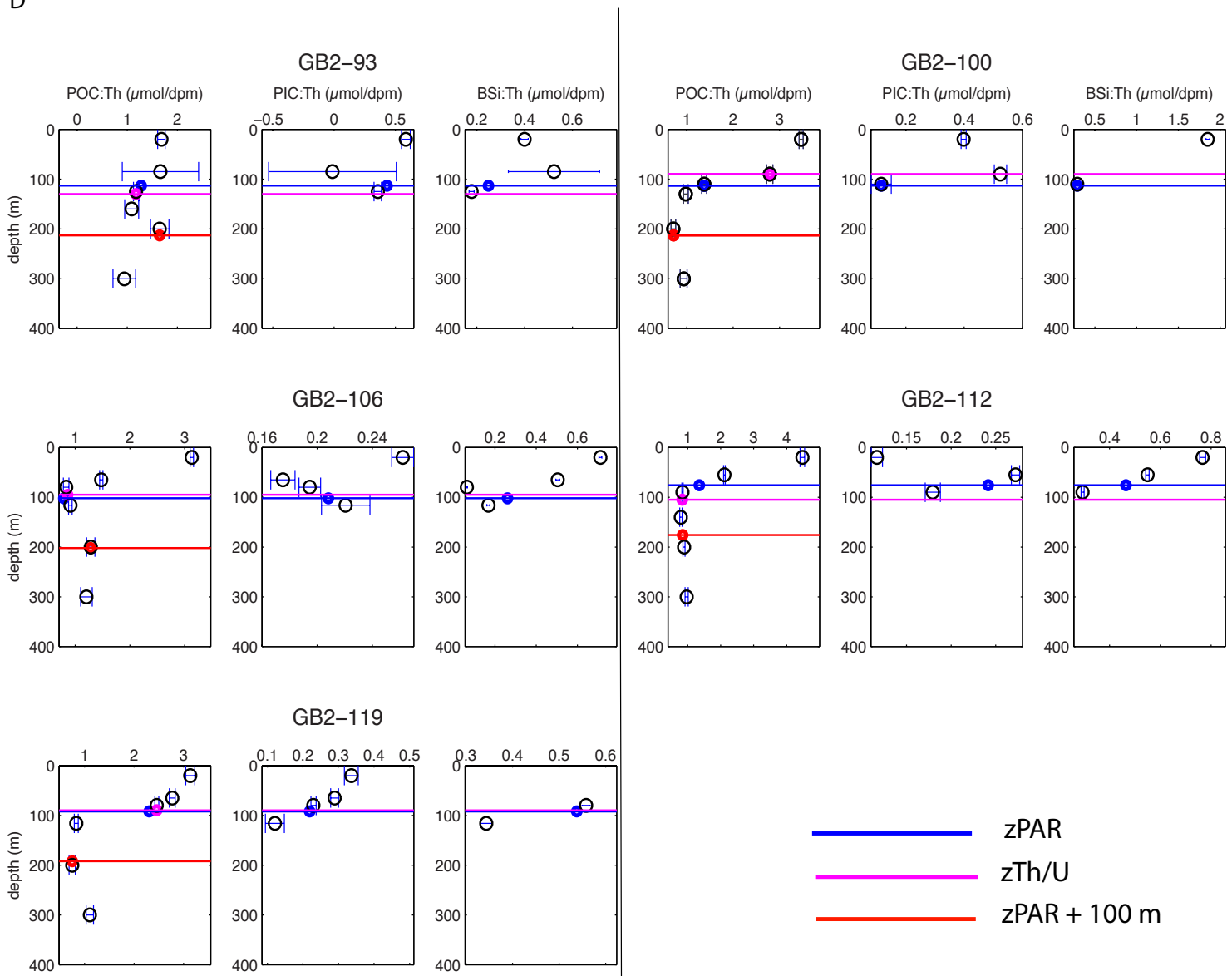

GB2-119
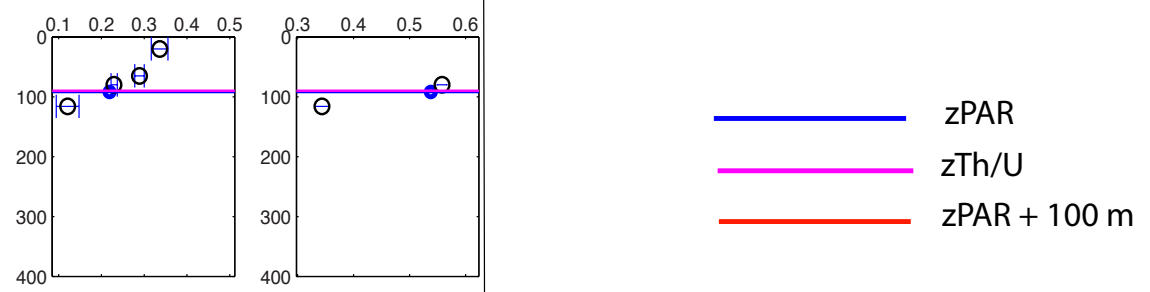

Figure S1. Profiles of $>51 \mu \mathrm{m}$ POC: $: 234 \mathrm{Th}$, PIC: $:{ }^{234} \mathrm{Th}$ and BSi: ${ }^{234} \mathrm{Th}$ above $400 \mathrm{~m}$. Black open circles represent measurements. Colored circles represent values at three possible depths (colored lines; see legend) in the POC: ${ }^{234} \mathrm{Th}$ panels, and at $\mathrm{Z}_{\mathrm{PAR}}$ (blue line) for the PIC: ${ }^{234} \mathrm{Th}$ and BSi: ${ }^{234} \mathrm{Th}$ panels. These values were interpolated when there were no measurements at these depths (refer to Tables 2 and 3 for specific stations). At station GB2-106, the BSi: ${ }^{234} \mathrm{Th}$ interpolation calculation excluded the anomalously low value at $80 \mathrm{~m}$. Error bars shown are the propagated errors of $>51 \mu \mathrm{m}$ [POC], [PIC], [BSi] and particulate ${ }^{234} \mathrm{Th}$ activity measurements. Note that "negative" values are below the instrument detection limit (see Section 2.3), and are equal to 0 within error. 

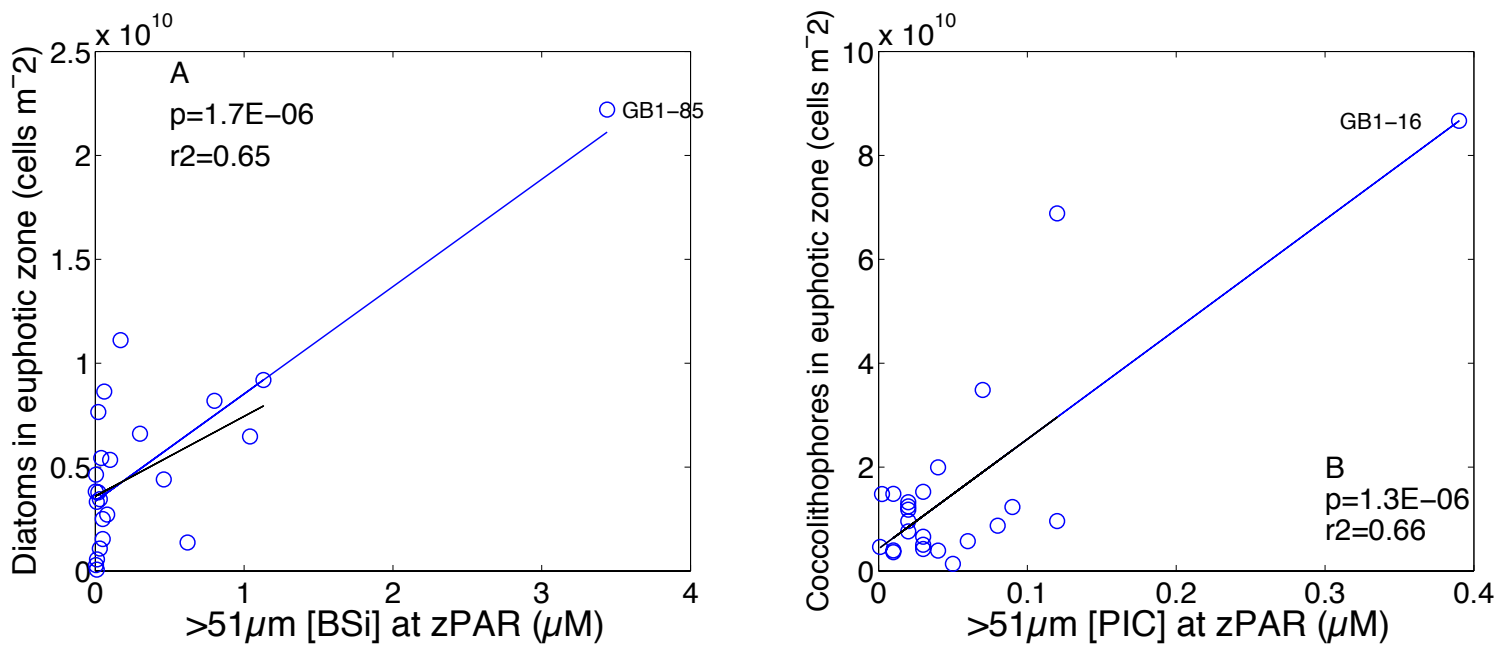

Figure S2. (A) Diatom cell counts integrated from surface to $\mathrm{Z}_{\mathrm{PAR}}\left(\right.$ cells $\mathrm{m}^{-2}$ ) as a function of $>51 \mu \mathrm{m}$ [BSi] at $\mathrm{Z}_{\mathrm{PAR}}$. (B) Integrated coccolithophore cell counts as a function of $>51$ $\mu \mathrm{m}[\mathrm{PIC}]$ at $\mathrm{Z}_{\mathrm{PAR}}$. Outliers for $>51 \mu \mathrm{m}$ [BSi] and [PIC] at stations GB1-85 and GB1-16, respectively, are defined according to Chauvenet's Theorem (Glover et al., 2011). Total euphotic zone cell counts of diatoms and coccolithphores are significantly correlated to $>51 \mu \mathrm{m}[\mathrm{BSi}]$ and $[\mathrm{PIC}]$ at $\mathrm{Z}_{\mathrm{PAR}}$, respectively. The significant linear relationships are plotted here as blue lines, with corresponding $\mathrm{p}$ and $\mathrm{r}^{2}$ values indicated. The regressions remain significant $(\mathrm{p}<0.05)$ even when excluding the outliers GB1-85 (Fig. S2a) and GB1-16 (Fig. S2b) from analysis (black lines). We note that cell counts are only available for the $<36 \mu \mathrm{m}$ size-fraction because of the methodology used for enumeration (see Supplemental Methods), while the biomineral measurements are of the $>51 \mu \mathrm{m}$ particle size-fraction (Section 2.2). Nonetheless, these relationships suggest that the $>51 \mu \mathrm{m}$ [BSi] and $[\mathrm{PIC}]$ at $\mathrm{Z}_{\mathrm{PAR}}$ do scale with the abundance of diatoms and coccolithophores in the euphotic zone of the water column. 


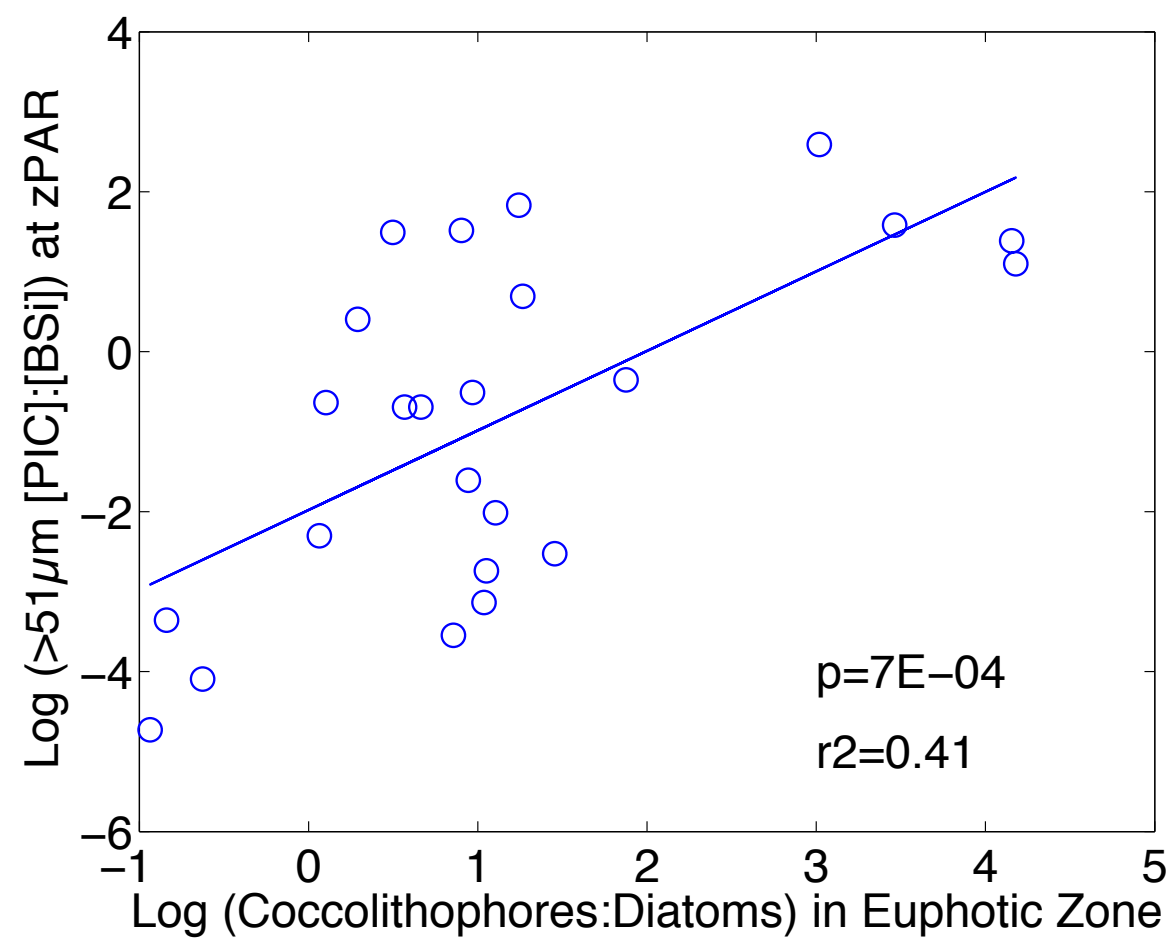

Figure $\mathrm{S} 3$. The natural $\log$ of the ratio of $>51 \mu \mathrm{m}[\mathrm{PIC}]:[\mathrm{BSi}]$ at $\mathrm{Z}_{\mathrm{PAR}}$ as a function of the natural log of the ratio of integrated coccolithophore: diatom cell counts in the euphotic zone. The significant linear relationship is plotted as a blue line, with a corresponding $\mathrm{p}$ and $r^{2}$ value indicated. This further supports the application of $>51 \mu \mathrm{m}$ size-fraction biomineral concentrations at $\mathrm{Z}_{\mathrm{PAR}}$ as a proxy for describing euphotic zone ecosystem composition in Section 4.7 and Fig. 10. Despite the different size-fractions that are represented by the biomineral measurements and the cell counts (see Supplemental Methods), the significant correlation nonetheless supports the use of $>51 \mu \mathrm{m}$ biomineral concentration ratios to describe the proportional abundance of certain phytoplankton types. 


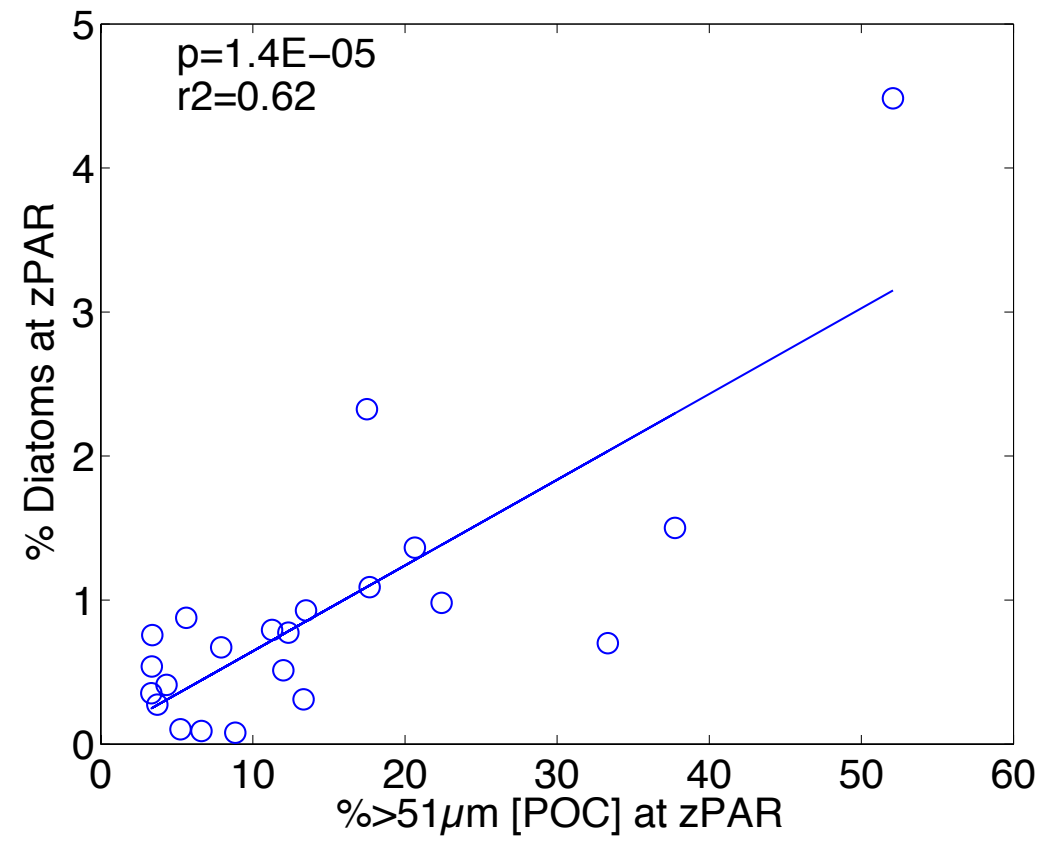

Figure S4. Percentage of total cells that are diatoms at $\mathrm{Z}_{\mathrm{PAR}}$ as a function of the $\%>51$ $\mu \mathrm{m}[\mathrm{POC}]$ at $\mathrm{Z}_{\mathrm{PAR}}$. The significant linear relationship is plotted as a blue line, with a corresponding $\mathrm{p}$ and $\mathrm{r}^{2}$ value indicated. This relationship shows that FlowCAM $®$ measurements of diatom abundance support our interpretation that the size fractionation of POC $\left(\%>51 \mu \mathrm{m}[\mathrm{POC}]\right.$ at $\left.\mathrm{z}_{\mathrm{PAR}}\right)$ determined from in-situ pump particle measurements (Section 2.2) reflects the relative abundance of diatoms. We note that there is no significant relationship between relative coccolithophore abundance and the size fractionation of POC. 


\section{Supplementary Methods for Figs. S2-S4}

The FlowCAM® imaging cytometer enumerated nano- and microplankton cells from $10 \mathrm{~mL}$ Niskin cast samples at all McLane pump stations except GB2-36, GB2-27 and GB2-119 (refer to Table 1 for station locations) (Poulton and Martin, 2010). Moreover, at stations GB1-38 and GB1-70, cell counts were missing at $\mathrm{Z}_{\mathrm{PAR}}$, and only measured at depths above and below ZPAR. The size range of counts was 5.6-35.5 $\mu \mathrm{m}$. While particles $>36 \mu \mathrm{m}$ (up to $200 \mu \mathrm{m}$ ) could be seen in the FlowCAM ${ }^{\circledR}$, they were rare in $10 \mathrm{~mL}$ samples, such that their normalized abundance could not be accurately calculated. Total diatom cell counts in the euphotic zone were approximated by summing FlowCam ${ }^{\circledR}$-derived diatom concentrations (cells $/ \mathrm{mL}$ ) at all depths above $\mathrm{Z}_{\mathrm{PAR}}$ :

$$
\text { total cell counts }=\sum_{1}^{\text {end }} \text { mean }\left[\frac{\text { cells }}{\mathrm{mL}}_{n}, \frac{\text { cells }}{\mathrm{mL}_{n-1}}\right] \times\left[z_{n}-z_{n-1}\right]
$$

where $\mathrm{n}$ is the measurement index number from the surface depth at $\mathrm{n}=1$ downward towards $Z_{\mathrm{PAR}}$ at $\mathrm{n}=$ "end". The unit for this summation is equivalent to cells $\mathrm{m}^{-2}$. Coccoliths and plated cells in the same Niskin samples were counted by birefringence microscopy (Balch et al., 2011). Total coccolithophore counts in the euphotic zone (cells $\mathrm{m}^{-2}$ ) were similarly estimated by summing the microscopy-based concentrations at all depths above ZPAR.

\section{Supplementary References}

Balch, W. M., Drapeau, D. T., Bowler, B. C., Lyczskowski, E., Booth, E. S., and Alley, D.: The contribution of coccolithophores to the optical and inorganic carbon budgets during the Southern Ocean Gas Exchange Experiment: New evidence in support of the Great Calcite Belt hypothesis, J. Geophys. Res., 116, C00F06, 2011.

Glover, D. M., Jenkins, W. J., and Doney, S. C.: Modeling methods for marine science., Cambridge University Press, 2011.

Poulton, N. J., and Martin, J. L. Imaging flow cytometry for quantitative phytoplankton analysis - FlowCAM. In: Karlson B, Cusack C, Bresnan E (eds) Microscopic and molecular methods for quantitative phytoplankton analysis, Vol Chapter 8. Intergovernmental Oceanographic Commission of UNESCO, Paris, France, 49-54, 2010. 


\section{Appendix B}

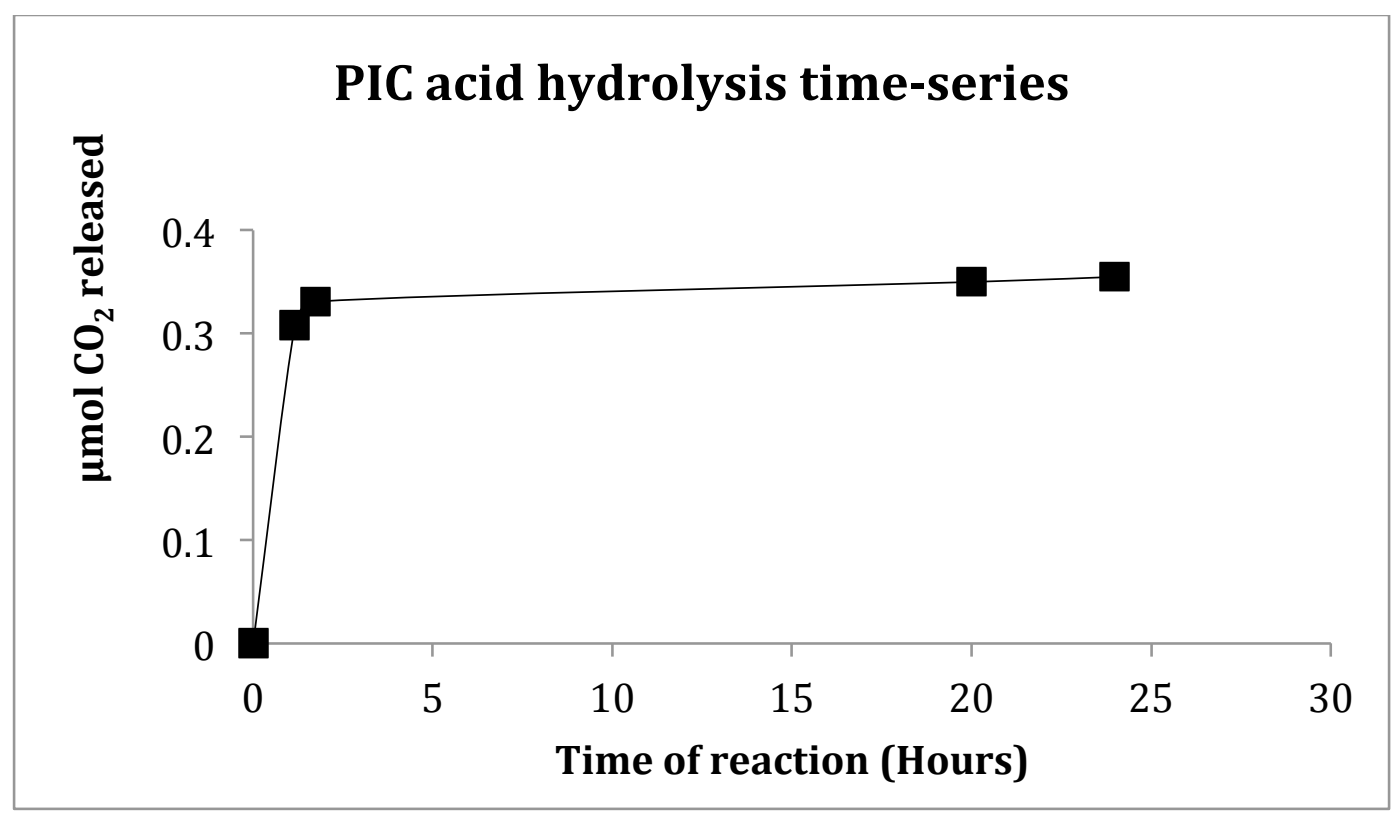

Figure S1. Quantity of PIC-derived $\mathrm{CO}_{2}$ released by acid hydrolysis of one Great Calcite Belt sample $(<51 \mu \mathrm{m})$ over $\sim 25$ hours. 


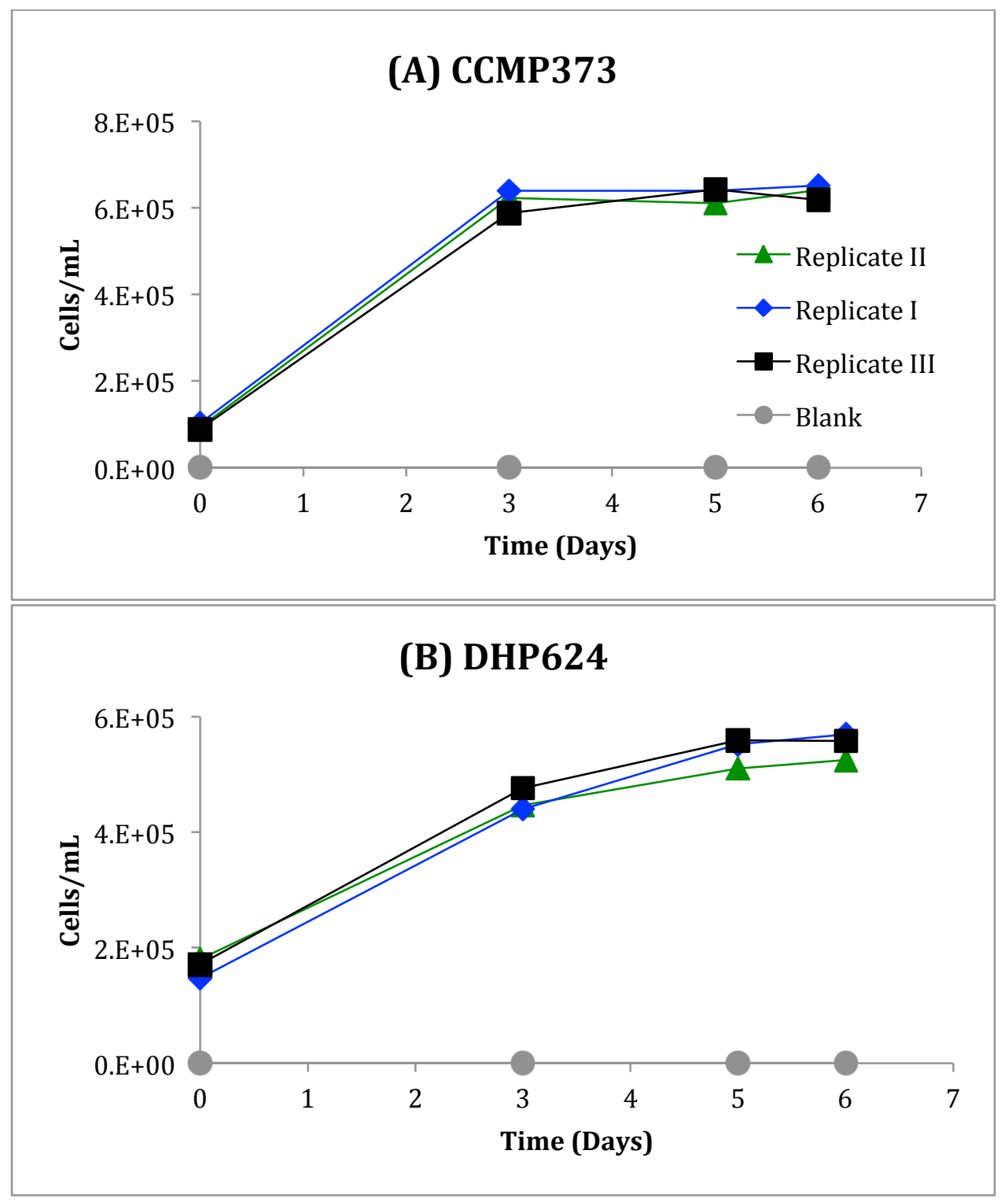

Figure S2. Cell concentrations over four time points during a six day incubation of $E$. huxleyi, strains CCMP373 (panel A) and DHP624 (panel B), in f/50 media (Guillard, 1975; Harvey et al., 2015). All cell counts are significantly higher than the blank, noninoculated $\mathrm{f} / 50$ media. 


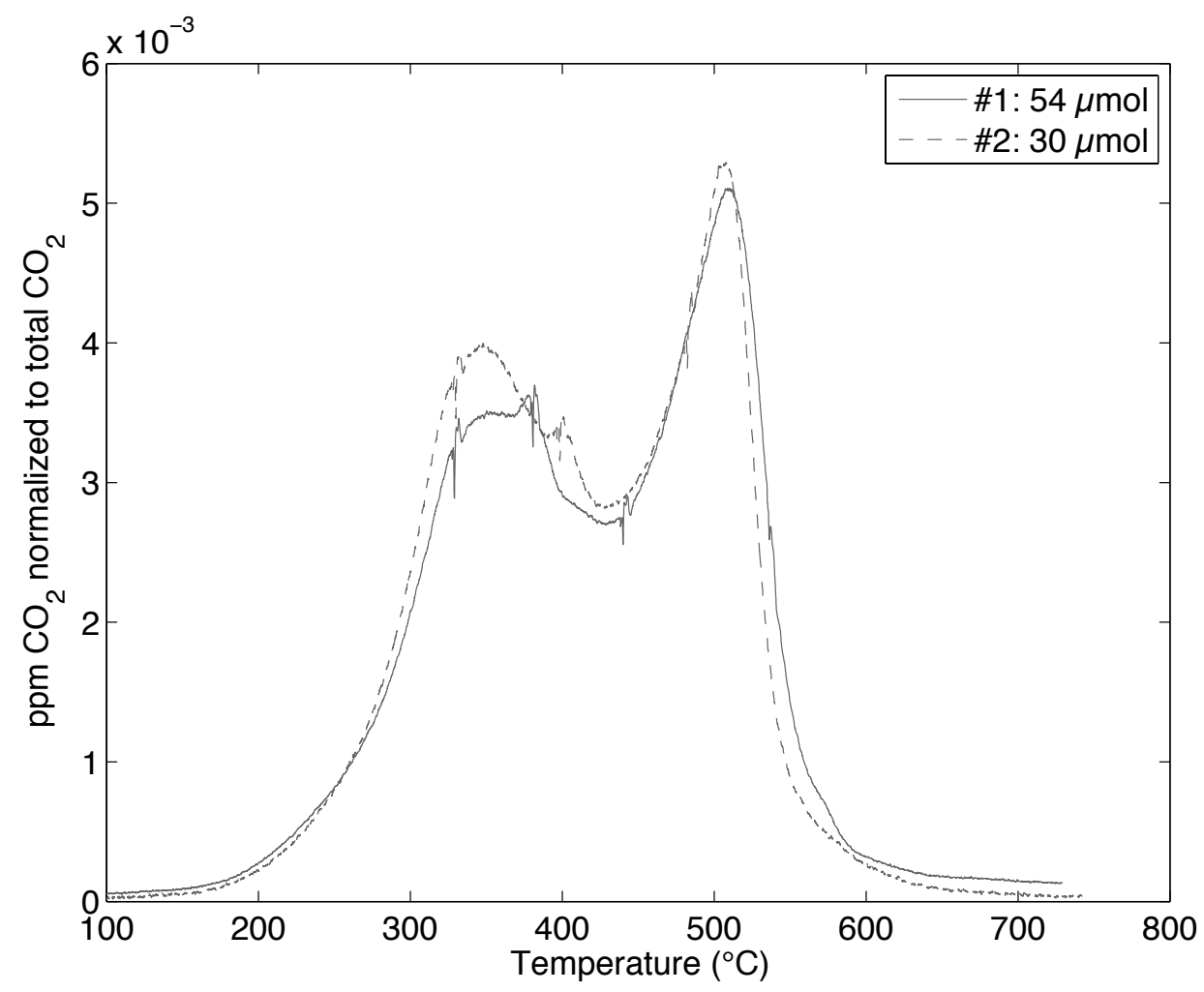

Figure S3. Two thermograms generated by ramped oxidation of the same Great Calcite Belt sample. RPO instrument conditions were kept as constant as possible between analyses. The $y$-axis is the $\mathrm{CO}_{2}$ concentration normalized to total $\mathrm{CO}_{2}$ evolved during the entire temperature ramp. The total $\mathrm{CO}_{2}$ evolved was $54 \mu \mathrm{mol}$ in the first analysis and 30 $\mu \mathrm{mol}$ in the second analysis. 
Fig. 11a-c

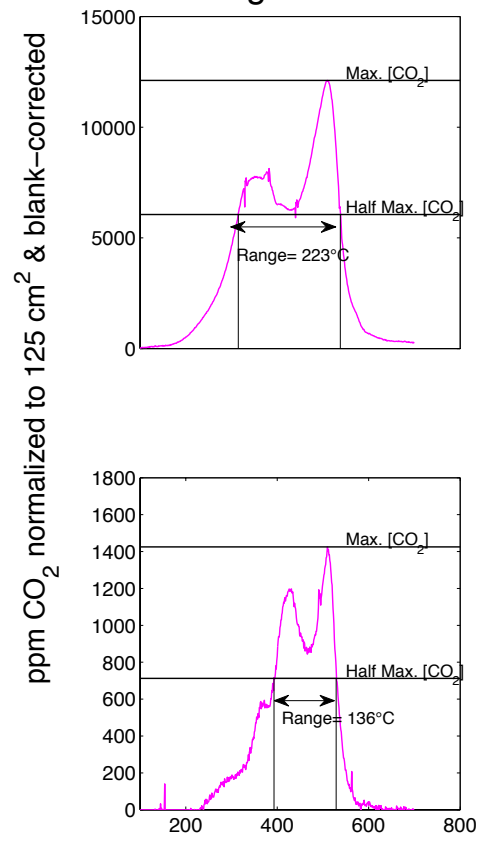

Fig. 11d-f
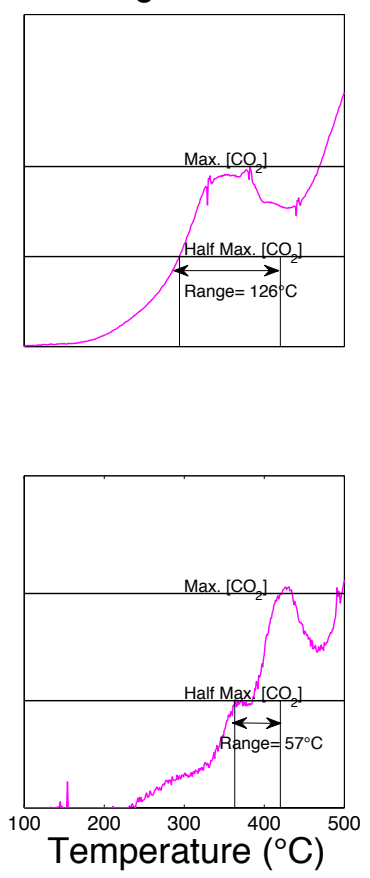

Fig. 11g-i
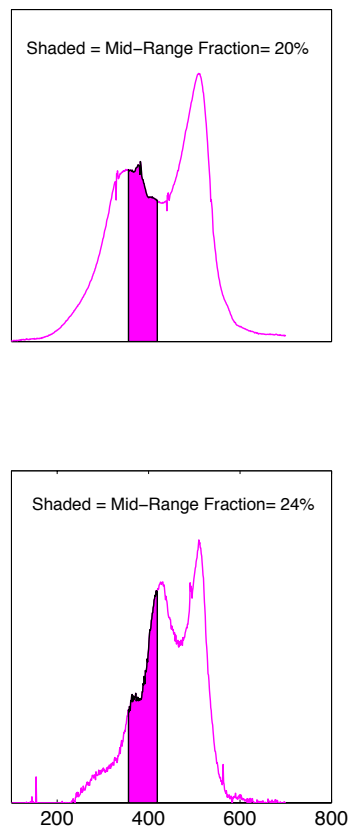

Figure S4. Examples of three metrics illustrated in Fig. 11, calculated just for the surfacemost POC-rich sample from GB2-43 (top three panels) and the deepest sample from GB2-43 (bottom three panels). The thermograms are blank-corrected and the y-axis is $\mathrm{CO}_{2}$ concentration normalized to the QMA filter active area, $125 \mathrm{~cm}^{2}$. The first column exemplifies the calculation of the temperature range of the entire thermogram half maximum $\mathrm{CO}_{2}$ concentration (Fig. 11a-c). The second column demonstrates calculation of the temperature range of the thermogram half maximum $\mathrm{CO}_{2}$ concentration below $420^{\circ} \mathrm{C}$ (Fig. 11d-f). The third row illustrates calculation of the proportion of total $\mathrm{CO}_{2}$ evolved within a middle temperature range, $355^{\circ} \mathrm{C}$ to $420^{\circ} \mathrm{C}$ (Fig. $11 \mathrm{~g}-\mathrm{i}$ ). 


\section{Supplementary References}

Guillard, R. R.: Culture of phytoplankton for feeding marine invertebrates. In: Culture of marine invertebrate animals, Springer, 1975.

Harvey, E. L., Bidle, K. D., and Johnson, M. D.: Consequences of strain variability and calcification in Emiliania huxleyi on microzooplankton grazing, Journal of Plankton Research, 37, 1137-1148, 2015. 


\section{Appendix C}

Table S1. Abundances and $\delta^{13} \mathrm{C}$ values of straight-chain $n$-alkanes $\left(\mathrm{C}_{19}-\mathrm{C}_{41}\right)$ in largevolume (>100 L) and depth-specific (10 L) samples collected in June 2005, April 2014 and July 2014. Refer to Table 1 in chapter 5 for sampling times of individual samples.

\begin{tabular}{|c|c|c|c|c|c|c|c|}
\hline Location & Date & Depth & $\begin{array}{l}\text { Chain } \\
\text { Length }\end{array}$ & Abundance & $\begin{array}{l}\text { Abundance } \\
\text { Error }\end{array}$ & $\delta^{13} \mathrm{C}$ & $\begin{array}{c}\delta^{13} \mathrm{C} \\
\text { Error }\end{array}$ \\
\hline -- & -- & -- & \# & $n g / \mu g P O C$ & $n g / \mu g P O C$ & $\%$ & $\%$ \\
\hline Main stem & $7 / 28 / 14$ & 0 & 19 & 2.87E-03 & $2.88 \mathrm{E}-04$ & -32.5 & 0.1 \\
\hline Main stem & $7 / 28 / 14$ & 0 & 20 & 4.12E-03 & 4.14E-04 & no data & no data \\
\hline Main stem & $7 / 28 / 14$ & 0 & 21 & $5.16 \mathrm{E}-03$ & $5.18 \mathrm{E}-04$ & -31.2 & 0.8 \\
\hline Main stem & $7 / 28 / 14$ & 0 & 22 & 4.86E-03 & $4.87 \mathrm{E}-04$ & no data & no data \\
\hline Main stem & $7 / 28 / 14$ & 0 & 23 & $6.74 \mathrm{E}-03$ & $6.76 \mathrm{E}-04$ & no data & 0.6 \\
\hline Main stem & $7 / 28 / 14$ & 0 & 24 & $4.71 \mathrm{E}-03$ & $4.72 \mathrm{E}-04$ & no data & no data \\
\hline Main stem & $7 / 28 / 14$ & 0 & 25 & $9.36 \mathrm{E}-03$ & $9.40 \mathrm{E}-04$ & -31.4 & 0.4 \\
\hline Main stem & $7 / 28 / 14$ & 0 & 26 & 7.33E-03 & $7.36 \mathrm{E}-04$ & no data & no data \\
\hline Main stem & $7 / 28 / 14$ & 0 & 27 & $1.53 \mathrm{E}-02$ & $1.53 \mathrm{E}-03$ & -31.1 & 0.1 \\
\hline Main stem & $7 / 28 / 14$ & 0 & 28 & $9.55 \mathrm{E}-03$ & $9.59 \mathrm{E}-04$ & no data & no data \\
\hline Main stem & $7 / 28 / 14$ & 0 & 29 & $3.70 \mathrm{E}-02$ & $3.72 \mathrm{E}-03$ & -33.1 & 0.0 \\
\hline Main stem & $7 / 28 / 14$ & 0 & 30 & $1.15 \mathrm{E}-02$ & $1.15 \mathrm{E}-03$ & no data & no data \\
\hline Main stem & $7 / 28 / 14$ & 0 & 31 & $3.97 \mathrm{E}-02$ & $3.99 \mathrm{E}-03$ & -33.4 & 0.1 \\
\hline Main stem & $7 / 28 / 14$ & 0 & 32 & 1.12E-02 & $1.13 \mathrm{E}-03$ & no data & no data \\
\hline Main stem & $7 / 28 / 14$ & 0 & 33 & $2.00 \mathrm{E}-02$ & $2.01 \mathrm{E}-03$ & -32.6 & 0.2 \\
\hline Main stem & $7 / 28 / 14$ & 0 & 34 & 7.02E-03 & $7.05 \mathrm{E}-04$ & no data & no data \\
\hline Main stem & $7 / 28 / 14$ & 0 & 35 & $6.09 \mathrm{E}-03$ & $6.11 \mathrm{E}-04$ & -31.0 & 0.3 \\
\hline Main stem & $7 / 28 / 14$ & 0 & 36 & $3.00 \mathrm{E}-03$ & $3.01 \mathrm{E}-04$ & no data & no data \\
\hline Main stem & $7 / 28 / 14$ & 0 & 37 & $3.69 \mathrm{E}-03$ & $3.71 \mathrm{E}-04$ & -30.1 & 2.0 \\
\hline Main stem & $7 / 28 / 14$ & 0 & 38 & $2.39 \mathrm{E}-03$ & $2.40 \mathrm{E}-04$ & no data & no data \\
\hline Main stem & $7 / 28 / 14$ & 0 & 39 & $1.97 \mathrm{E}-03$ & $1.98 \mathrm{E}-04$ & -31.6 & 1.8 \\
\hline Main stem & $7 / 28 / 14$ & 0 & 40 & $1.39 \mathrm{E}-03$ & $1.39 \mathrm{E}-04$ & no data & no data \\
\hline Main stem & $7 / 28 / 14$ & 0 & 41 & $1.01 \mathrm{E}-03$ & $1.01 \mathrm{E}-04$ & no data & no data \\
\hline Main stem & $4 / 1 / 14$ & 0 & 19 & $1.09 \mathrm{E}-02$ & $1.09 \mathrm{E}-03$ & -28.3 & 0.2 \\
\hline Main stem & $4 / 1 / 14$ & 0 & 20 & $1.53 \mathrm{E}-02$ & $1.53 \mathrm{E}-03$ & no data & no data \\
\hline Main stem & $4 / 1 / 14$ & 0 & 21 & $1.16 \mathrm{E}-02$ & $1.16 \mathrm{E}-03$ & -28.9 & 0.1 \\
\hline Main stem & $4 / 1 / 14$ & 0 & 22 & $1.14 \mathrm{E}-02$ & $1.15 \mathrm{E}-03$ & no data & no data \\
\hline Main stem & $4 / 1 / 14$ & 0 & 23 & $1.28 \mathrm{E}-02$ & $1.28 \mathrm{E}-03$ & -29.6 & 0.2 \\
\hline Main stem & $4 / 1 / 14$ & 0 & 24 & $9.95 \mathrm{E}-03$ & 9.97E-04 & no data & no data \\
\hline Main stem & $4 / 1 / 14$ & 0 & 25 & $1.21 \mathrm{E}-02$ & $1.21 \mathrm{E}-03$ & -29.8 & 0.1 \\
\hline Main stem & $4 / 1 / 14$ & 0 & 26 & $9.98 \mathrm{E}-03$ & $1.00 \mathrm{E}-03$ & no data & no data \\
\hline Main stem & $4 / 1 / 14$ & 0 & 27 & $1.58 \mathrm{E}-02$ & $1.59 \mathrm{E}-03$ & -30.3 & 0.4 \\
\hline
\end{tabular}




\begin{tabular}{|c|c|c|c|c|c|c|c|}
\hline Main stem & $4 / 1 / 14$ & 0 & 28 & $1.04 \mathrm{E}-02$ & $1.04 \mathrm{E}-03$ & no data & no data \\
\hline Main stem & $4 / 1 / 14$ & 0 & 29 & $3.26 \mathrm{E}-02$ & $3.27 \mathrm{E}-03$ & -33.1 & 0.3 \\
\hline Main stem & $4 / 1 / 14$ & 0 & 30 & $1.07 \mathrm{E}-02$ & $1.07 \mathrm{E}-03$ & no data & no data \\
\hline Main stem & $4 / 1 / 14$ & 0 & 31 & $3.38 \mathrm{E}-02$ & $3.39 \mathrm{E}-03$ & -33.7 & 0.2 \\
\hline Main stem & $4 / 1 / 14$ & 0 & 32 & $9.28 \mathrm{E}-03$ & $9.29 \mathrm{E}-04$ & no data & no data \\
\hline Main stem & $4 / 1 / 14$ & 0 & 33 & $1.67 \mathrm{E}-02$ & $1.67 \mathrm{E}-03$ & -32.4 & 0.3 \\
\hline Main stem & $4 / 1 / 14$ & 0 & 34 & 4.97E-03 & 4.98E-04 & no data & no data \\
\hline Main stem & $4 / 1 / 14$ & 0 & 35 & $6.05 \mathrm{E}-03$ & $6.06 \mathrm{E}-04$ & -31.2 & 0.4 \\
\hline Main stem & $4 / 1 / 14$ & 0 & 36 & $3.25 \mathrm{E}-03$ & $3.26 \mathrm{E}-04$ & no data & no data \\
\hline Main stem & $4 / 1 / 14$ & 0 & 37 & $3.37 \mathrm{E}-03$ & $3.38 \mathrm{E}-04$ & -31.0 & 0.3 \\
\hline Main stem & $4 / 1 / 14$ & 0 & 38 & $2.50 \mathrm{E}-03$ & $2.50 \mathrm{E}-04$ & no data & no data \\
\hline Main stem & $4 / 1 / 14$ & 0 & 39 & $2.14 \mathrm{E}-03$ & $2.14 \mathrm{E}-04$ & -31.3 & 0.7 \\
\hline Main stem & $4 / 1 / 14$ & 0 & 40 & $1.71 \mathrm{E}-03$ & $1.72 \mathrm{E}-04$ & no data & no data \\
\hline Main stem & $4 / 1 / 14$ & 0 & 41 & $1.33 \mathrm{E}-03$ & $1.34 \mathrm{E}-04$ & -34.1 & 0.7 \\
\hline Main stem & $6 / 8 / 05$ & 0 & 19 & $2.09 \mathrm{E}-02$ & $2.09 \mathrm{E}-03$ & no data & no data \\
\hline Main stem & $6 / 8 / 05$ & 0 & 20 & $1.21 \mathrm{E}-02$ & $1.21 \mathrm{E}-03$ & no data & no data \\
\hline Main stem & $6 / 8 / 05$ & 0 & 21 & $1.10 \mathrm{E}-02$ & $1.10 \mathrm{E}-03$ & no data & no data \\
\hline Main stem & $6 / 8 / 05$ & 0 & 22 & $1.40 \mathrm{E}-02$ & $1.40 \mathrm{E}-03$ & no data & no data \\
\hline Main stem & $6 / 8 / 05$ & 0 & 23 & $1.71 \mathrm{E}-02$ & $1.71 \mathrm{E}-03$ & no data & no data \\
\hline Main stem & $6 / 8 / 05$ & 0 & 24 & $1.10 \mathrm{E}-02$ & $1.11 \mathrm{E}-03$ & no data & no data \\
\hline Main stem & $6 / 8 / 05$ & 0 & 25 & $1.59 \mathrm{E}-02$ & $1.59 \mathrm{E}-03$ & no data & no data \\
\hline Main stem & $6 / 8 / 05$ & 0 & 26 & $1.01 \mathrm{E}-02$ & $1.01 \mathrm{E}-03$ & no data & no data \\
\hline Main stem & $6 / 8 / 05$ & 0 & 27 & $1.95 \mathrm{E}-02$ & $1.95 \mathrm{E}-03$ & no data & no data \\
\hline Main stem & $6 / 8 / 05$ & 0 & 28 & $1.78 \mathrm{E}-02$ & $1.79 \mathrm{E}-03$ & no data & no data \\
\hline Main stem & $6 / 8 / 05$ & 0 & 29 & $4.07 \mathrm{E}-02$ & $4.08 \mathrm{E}-03$ & no data & no data \\
\hline Main stem & $6 / 8 / 05$ & 0 & 30 & $2.45 \mathrm{E}-02$ & $2.46 \mathrm{E}-03$ & no data & no data \\
\hline Main stem & $6 / 8 / 05$ & 0 & 31 & $4.15 \mathrm{E}-02$ & $4.16 \mathrm{E}-03$ & no data & no data \\
\hline Main stem & $6 / 8 / 05$ & 0 & 32 & $1.61 \mathrm{E}-02$ & $1.62 \mathrm{E}-03$ & no data & no data \\
\hline Main stem & $6 / 8 / 05$ & 0 & 33 & $2.14 \mathrm{E}-02$ & $2.14 \mathrm{E}-03$ & no data & no data \\
\hline Main stem & $6 / 8 / 05$ & 0 & 34 & $7.28 \mathrm{E}-03$ & $7.30 \mathrm{E}-04$ & no data & no data \\
\hline Main stem & $6 / 8 / 05$ & 0 & 35 & $9.55 \mathrm{E}-03$ & $9.57 \mathrm{E}-04$ & no data & no data \\
\hline Main stem & $6 / 8 / 05$ & 0 & 36 & $2.00 \mathrm{E}-03$ & $2.00 \mathrm{E}-04$ & no data & no data \\
\hline Main stem & $6 / 8 / 05$ & 0 & 37 & $3.28 \mathrm{E}-03$ & $3.29 \mathrm{E}-04$ & no data & no data \\
\hline Main stem & $6 / 8 / 05$ & 0 & 38 & $1.55 \mathrm{E}-03$ & $1.56 \mathrm{E}-04$ & no data & no data \\
\hline Main stem & $6 / 8 / 05$ & 0 & 39 & $2.74 \mathrm{E}-03$ & $2.74 \mathrm{E}-04$ & no data & no data \\
\hline Main stem & $6 / 8 / 05$ & 0 & 40 & $2.00 \mathrm{E}-03$ & $2.00 \mathrm{E}-04$ & no data & no data \\
\hline Main stem & $6 / 8 / 05$ & 0 & 41 & $1.65 \mathrm{E}-03$ & $1.65 \mathrm{E}-04$ & no data & no data \\
\hline Solimões & $6 / 4 / 05$ & 0 & 19 & 8.29E-03 & $9.40 \mathrm{E}-04$ & no data & no data \\
\hline Solimões & $6 / 4 / 05$ & 0 & 20 & $5.56 \mathrm{E}-03$ & $6.31 \mathrm{E}-04$ & no data & no data \\
\hline Solimões & $6 / 4 / 05$ & 0 & 21 & $5.76 \mathrm{E}-03$ & $6.53 \mathrm{E}-04$ & no data & no data \\
\hline Solimões & $6 / 4 / 05$ & 0 & 22 & $7.86 \mathrm{E}-03$ & 8.91E-04 & no data & no data \\
\hline Solimões & $6 / 4 / 05$ & 0 & 23 & $1.12 \mathrm{E}-02$ & $1.27 \mathrm{E}-03$ & no data & no data \\
\hline Solimões & $6 / 4 / 05$ & 0 & 24 & $8.57 \mathrm{E}-03$ & $9.72 \mathrm{E}-04$ & no data & no data \\
\hline
\end{tabular}




\begin{tabular}{|c|c|c|c|c|c|c|c|}
\hline Solimões & $6 / 4 / 05$ & 0 & 25 & $1.81 \mathrm{E}-02$ & $2.05 \mathrm{E}-03$ & no data & no data \\
\hline Solimões & $6 / 4 / 05$ & 0 & 26 & $1.86 \mathrm{E}-02$ & $2.11 \mathrm{E}-03$ & no data & no data \\
\hline Solimões & $6 / 4 / 05$ & 0 & 27 & 2.95E-02 & $3.35 \mathrm{E}-03$ & no data & no data \\
\hline Solimões & $6 / 4 / 05$ & 0 & 28 & $2.59 \mathrm{E}-02$ & $2.94 \mathrm{E}-03$ & no data & no data \\
\hline Solimões & $6 / 4 / 05$ & 0 & 29 & $4.58 \mathrm{E}-02$ & $5.19 \mathrm{E}-03$ & no data & no data \\
\hline Solimões & $6 / 4 / 05$ & 0 & 30 & 2.09E-02 & $2.37 \mathrm{E}-03$ & no data & no data \\
\hline Solimões & $6 / 4 / 05$ & 0 & 31 & $3.80 \mathrm{E}-02$ & $4.31 \mathrm{E}-03$ & no data & no data \\
\hline Solimões & $6 / 4 / 05$ & 0 & 32 & $1.11 \mathrm{E}-02$ & $1.26 \mathrm{E}-03$ & no data & no data \\
\hline Solimões & $6 / 4 / 05$ & 0 & 33 & $1.67 \mathrm{E}-02$ & $1.89 \mathrm{E}-03$ & no data & no data \\
\hline Solimões & $6 / 4 / 05$ & 0 & 34 & $3.20 \mathrm{E}-03$ & 3.63E-04 & no data & no data \\
\hline Solimões & $6 / 4 / 05$ & 0 & 35 & $5.25 \mathrm{E}-03$ & $5.95 \mathrm{E}-04$ & no data & no data \\
\hline Solimões & $6 / 4 / 05$ & 0 & 36 & $1.35 \mathrm{E}-03$ & $1.53 \mathrm{E}-04$ & no data & no data \\
\hline Solimões & $6 / 4 / 05$ & 0 & 37 & $1.81 \mathrm{E}-03$ & $2.05 \mathrm{E}-04$ & no data & no data \\
\hline Solimões & $6 / 4 / 05$ & 0 & 38 & $7.15 \mathrm{E}-04$ & $8.11 \mathrm{E}-05$ & no data & no data \\
\hline Solimões & $6 / 4 / 05$ & 0 & 39 & $1.05 \mathrm{E}-03$ & $1.19 \mathrm{E}-04$ & no data & no data \\
\hline Solimões & $6 / 4 / 05$ & 0 & 40 & $6.93 \mathrm{E}-04$ & $7.85 \mathrm{E}-05$ & no data & no data \\
\hline Solimões & $6 / 4 / 05$ & 0 & 41 & $6.80 \mathrm{E}-04$ & 7.71E-05 & no data & no data \\
\hline Madeira & $6 / 6 / 05$ & 0 & 19 & $2.13 \mathrm{E}-02$ & $2.16 \mathrm{E}-03$ & no data & no data \\
\hline Madeira & $6 / 6 / 05$ & 0 & 20 & $1.73 \mathrm{E}-02$ & $1.76 \mathrm{E}-03$ & no data & no data \\
\hline Madeira & $6 / 6 / 05$ & 0 & 21 & $1.78 \mathrm{E}-02$ & $1.80 \mathrm{E}-03$ & no data & no data \\
\hline Madeira & $6 / 6 / 05$ & 0 & 22 & $1.87 \mathrm{E}-02$ & $1.90 \mathrm{E}-03$ & no data & no data \\
\hline Madeira & $6 / 6 / 05$ & 0 & 23 & $2.25 \mathrm{E}-02$ & $2.29 \mathrm{E}-03$ & no data & no data \\
\hline Madeira & $6 / 6 / 05$ & 0 & 24 & $1.65 \mathrm{E}-02$ & $1.67 \mathrm{E}-03$ & no data & no data \\
\hline Madeira & $6 / 6 / 05$ & 0 & 25 & $2.25 \mathrm{E}-02$ & $2.29 \mathrm{E}-03$ & no data & no data \\
\hline Madeira & $6 / 6 / 05$ & 0 & 26 & $1.94 \mathrm{E}-02$ & $1.97 \mathrm{E}-03$ & no data & no data \\
\hline Madeira & $6 / 6 / 05$ & 0 & 27 & $3.19 \mathrm{E}-02$ & $3.24 \mathrm{E}-03$ & no data & no data \\
\hline Madeira & $6 / 6 / 05$ & 0 & 28 & 4.18E-02 & $4.25 \mathrm{E}-03$ & no data & no data \\
\hline Madeira & $6 / 6 / 05$ & 0 & 29 & $7.80 \mathrm{E}-02$ & 7.92E-03 & no data & no data \\
\hline Madeira & $6 / 6 / 05$ & 0 & 30 & $6.65 \mathrm{E}-02$ & $6.75 \mathrm{E}-03$ & no data & no data \\
\hline Madeira & $6 / 6 / 05$ & 0 & 31 & 7.74E-02 & $7.86 \mathrm{E}-03$ & no data & no data \\
\hline Madeira & $6 / 6 / 05$ & 0 & 32 & 4.47E-02 & 4.54E-03 & no data & no data \\
\hline Madeira & $6 / 6 / 05$ & 0 & 33 & $3.43 \mathrm{E}-02$ & $3.48 \mathrm{E}-03$ & no data & no data \\
\hline Madeira & $6 / 6 / 05$ & 0 & 34 & $1.38 \mathrm{E}-02$ & $1.41 \mathrm{E}-03$ & no data & no data \\
\hline Madeira & $6 / 6 / 05$ & 0 & 35 & $9.87 \mathrm{E}-03$ & $1.00 \mathrm{E}-03$ & no data & no data \\
\hline Madeira & $6 / 6 / 05$ & 0 & 36 & $3.91 \mathrm{E}-03$ & $3.97 \mathrm{E}-04$ & no data & no data \\
\hline Madeira & $6 / 6 / 05$ & 0 & 37 & $3.89 \mathrm{E}-03$ & $3.96 \mathrm{E}-04$ & no data & no data \\
\hline Madeira & $6 / 6 / 05$ & 0 & 38 & $2.38 \mathrm{E}-03$ & $2.42 \mathrm{E}-04$ & no data & no data \\
\hline Madeira & $6 / 6 / 05$ & 0 & 39 & $2.75 \mathrm{E}-03$ & $2.79 \mathrm{E}-04$ & no data & no data \\
\hline Madeira & $6 / 6 / 05$ & 0 & 40 & $2.36 \mathrm{E}-03$ & $2.40 \mathrm{E}-04$ & no data & no data \\
\hline Madeira & $6 / 6 / 05$ & 0 & 41 & $1.16 \mathrm{E}-03$ & $1.18 \mathrm{E}-04$ & no data & no data \\
\hline Main stem & $7 / 28 / 14$ & 54 & 19 & $1.15 \mathrm{E}-03$ & $1.27 \mathrm{E}-04$ & no data & $\mathrm{NaN}$ \\
\hline Main stem & $7 / 28 / 14$ & 54 & 20 & $1.57 \mathrm{E}-03$ & $1.73 \mathrm{E}-04$ & no data & $\mathrm{NaN}$ \\
\hline Main stem & $7 / 28 / 14$ & 54 & 21 & $2.68 \mathrm{E}-03$ & $2.95 \mathrm{E}-04$ & -30.9 & 0.2 \\
\hline
\end{tabular}




\begin{tabular}{|c|c|c|c|c|c|c|c|}
\hline Main stem & $7 / 28 / 14$ & 54 & 22 & $2.33 \mathrm{E}-03$ & $2.56 \mathrm{E}-04$ & -29.6 & 0.4 \\
\hline Main stem & $7 / 28 / 14$ & 54 & 23 & $2.75 \mathrm{E}-03$ & $3.02 \mathrm{E}-04$ & -30.9 & 0.5 \\
\hline Main stem & $7 / 28 / 14$ & 54 & 24 & $2.72 \mathrm{E}-03$ & 2.99E-04 & -29.9 & 0.5 \\
\hline Main stem & $7 / 28 / 14$ & 54 & 25 & 4.67E-03 & $5.14 \mathrm{E}-04$ & no data & $\mathrm{NaN}$ \\
\hline Main stem & $7 / 28 / 14$ & 54 & 26 & 4.42E-03 & $4.86 \mathrm{E}-04$ & -29.6 & 0.6 \\
\hline Main stem & $7 / 28 / 14$ & 54 & 27 & $6.18 \mathrm{E}-03$ & $6.80 \mathrm{E}-04$ & -34.1 & 0.2 \\
\hline Main stem & $7 / 28 / 14$ & 54 & 28 & 3.07E-03 & $3.38 \mathrm{E}-04$ & -28.5 & 3.7 \\
\hline Main stem & $7 / 28 / 14$ & 54 & 29 & 1.62E-02 & $1.78 \mathrm{E}-03$ & -34.0 & 0.5 \\
\hline Main stem & $7 / 28 / 14$ & 54 & 30 & $3.26 \mathrm{E}-03$ & $3.59 \mathrm{E}-04$ & -37.3 & 0.5 \\
\hline Main stem & $7 / 28 / 14$ & 54 & 31 & $1.57 \mathrm{E}-02$ & $1.73 \mathrm{E}-03$ & -34.6 & 0.3 \\
\hline Main stem & $7 / 28 / 14$ & 54 & 32 & $2.79 \mathrm{E}-03$ & 3.07E-04 & no data & $\mathrm{NaN}$ \\
\hline Main stem & $7 / 28 / 14$ & 54 & 33 & $6.95 \mathrm{E}-03$ & 7.64E-04 & -34.6 & 1.2 \\
\hline Main stem & $4 / 2 / 14$ & 30.15 & 19 & $1.67 \mathrm{E}-03$ & $1.69 \mathrm{E}-04$ & no data & $\mathrm{NaN}$ \\
\hline Main stem & $4 / 2 / 14$ & 30.15 & 20 & $2.22 \mathrm{E}-03$ & $2.24 \mathrm{E}-04$ & no data & $\mathrm{NaN}$ \\
\hline Main stem & $4 / 2 / 14$ & 30.15 & 21 & $3.07 \mathrm{E}-03$ & $3.09 \mathrm{E}-04$ & -29.6 & 0.4 \\
\hline Main stem & $4 / 2 / 14$ & 30.15 & 22 & $3.02 \mathrm{E}-03$ & $3.05 \mathrm{E}-04$ & -29.4 & 0.1 \\
\hline Main stem & $4 / 2 / 14$ & 30.15 & 23 & 3.62E-03 & $3.65 \mathrm{E}-04$ & -31.1 & 0.1 \\
\hline Main stem & $4 / 2 / 14$ & 30.15 & 24 & $2.61 \mathrm{E}-03$ & $2.63 \mathrm{E}-04$ & -30.0 & 0.5 \\
\hline Main stem & $4 / 2 / 14$ & 30.15 & 25 & $3.84 \mathrm{E}-03$ & $3.87 \mathrm{E}-04$ & -30.3 & 0.3 \\
\hline Main stem & $4 / 2 / 14$ & 30.15 & 26 & $3.50 \mathrm{E}-03$ & $3.53 \mathrm{E}-04$ & -30.1 & 0.4 \\
\hline Main stem & $4 / 2 / 14$ & 30.15 & 27 & $6.71 \mathrm{E}-03$ & $6.77 \mathrm{E}-04$ & -32.3 & 0.2 \\
\hline Main stem & $4 / 2 / 14$ & 30.15 & 28 & $3.07 \mathrm{E}-03$ & $3.09 \mathrm{E}-04$ & -31.8 & 0.4 \\
\hline Main stem & $4 / 2 / 14$ & 30.15 & 29 & $1.86 \mathrm{E}-02$ & $1.88 \mathrm{E}-03$ & -34.5 & 0.1 \\
\hline Main stem & $4 / 2 / 14$ & 30.15 & 30 & $3.47 \mathrm{E}-03$ & $3.49 \mathrm{E}-04$ & -33.6 & 0.4 \\
\hline Main stem & $4 / 2 / 14$ & 30.15 & 31 & $1.86 \mathrm{E}-02$ & $1.88 \mathrm{E}-03$ & -34.9 & 0.0 \\
\hline Main stem & $4 / 2 / 14$ & 30.15 & 32 & $2.81 \mathrm{E}-03$ & $2.83 \mathrm{E}-04$ & -34.2 & 0.2 \\
\hline Main stem & $4 / 2 / 14$ & 30.15 & 33 & 8.04E-03 & $8.11 \mathrm{E}-04$ & -34.7 & 0.3 \\
\hline Main stem & $4 / 2 / 14$ & 2.7 & 19 & $0.00 \mathrm{E}+00$ & $0.00 \mathrm{E}+00$ & no data & $\mathrm{NaN}$ \\
\hline Main stem & $4 / 2 / 14$ & 2.7 & 20 & $0.00 \mathrm{E}+00$ & $0.00 \mathrm{E}+00$ & no data & $\mathrm{NaN}$ \\
\hline Main stem & $4 / 2 / 14$ & 2.7 & 21 & $3.59 \mathrm{E}-03$ & 3.61E-04 & no data & $\mathrm{NaN}$ \\
\hline Main stem & $4 / 2 / 14$ & 2.7 & 22 & $2.85 \mathrm{E}-03$ & $2.86 \mathrm{E}-04$ & no data & $\mathrm{NaN}$ \\
\hline Main stem & $4 / 2 / 14$ & 2.7 & 23 & $0.00 \mathrm{E}+00$ & $0.00 \mathrm{E}+00$ & no data & $\mathrm{NaN}$ \\
\hline Main stem & $4 / 2 / 14$ & 2.7 & 24 & $0.00 \mathrm{E}+00$ & $0.00 \mathrm{E}+00$ & no data & $\mathrm{NaN}$ \\
\hline Main stem & $4 / 2 / 14$ & 2.7 & 25 & $0.00 \mathrm{E}+00$ & $0.00 \mathrm{E}+00$ & no data & $\mathrm{NaN}$ \\
\hline Main stem & $4 / 2 / 14$ & 2.7 & 26 & $9.37 \mathrm{E}-03$ & $9.41 \mathrm{E}-04$ & no data & $\mathrm{NaN}$ \\
\hline Main stem & $4 / 2 / 14$ & 2.7 & 27 & $0.00 \mathrm{E}+00$ & $0.00 \mathrm{E}+00$ & no data & $\mathrm{NaN}$ \\
\hline Main stem & $4 / 2 / 14$ & 2.7 & 28 & $0.00 \mathrm{E}+00$ & $0.00 \mathrm{E}+00$ & no data & $\mathrm{NaN}$ \\
\hline Main stem & $4 / 2 / 14$ & 2.7 & 29 & $5.26 \mathrm{E}-03$ & $5.28 \mathrm{E}-04$ & no data & $\mathrm{NaN}$ \\
\hline Main stem & $4 / 2 / 14$ & 2.7 & 30 & $0.00 \mathrm{E}+00$ & $0.00 \mathrm{E}+00$ & no data & $\mathrm{NaN}$ \\
\hline Main stem & $4 / 2 / 14$ & 2.7 & 31 & $6.35 \mathrm{E}-03$ & $6.37 \mathrm{E}-04$ & no data & $\mathrm{NaN}$ \\
\hline Main stem & $4 / 2 / 14$ & 2.7 & 32 & $0.00 \mathrm{E}+00$ & $0.00 \mathrm{E}+00$ & no data & $\mathrm{NaN}$ \\
\hline Main stem & $4 / 2 / 14$ & 2.7 & 33 & $0.00 \mathrm{E}+00$ & $0.00 \mathrm{E}+00$ & no data & $\mathrm{NaN}$ \\
\hline Main stem & $4 / 2 / 14$ & 49.1 & 19 & $1.58 \mathrm{E}-03$ & $1.58 \mathrm{E}-04$ & no data & $\mathrm{NaN}$ \\
\hline
\end{tabular}




\begin{tabular}{lccccccc} 
Main stem & $4 / 2 / 14$ & 49.1 & 20 & $2.36 \mathrm{E}-03$ & $2.37 \mathrm{E}-04$ & no data & NaN \\
Main stem & $4 / 2 / 14$ & 49.1 & 21 & $2.85 \mathrm{E}-03$ & $2.86 \mathrm{E}-04$ & -30.4 & 0.7 \\
Main stem & $4 / 2 / 14$ & 49.1 & 22 & $2.92 \mathrm{E}-03$ & $2.93 \mathrm{E}-04$ & -30.0 & 0.0 \\
Main stem & $4 / 2 / 14$ & 49.1 & 23 & $3.48 \mathrm{E}-03$ & $3.49 \mathrm{E}-04$ & -31.0 & 0.2 \\
Main stem & $4 / 2 / 14$ & 49.1 & 24 & $2.45 \mathrm{E}-03$ & $2.46 \mathrm{E}-04$ & -29.8 & 0.1 \\
Main stem & $4 / 2 / 14$ & 49.1 & 25 & $4.22 \mathrm{E}-03$ & $4.23 \mathrm{E}-04$ & -31.2 & 0.1 \\
Main stem & $4 / 2 / 14$ & 49.1 & 26 & $4.74 \mathrm{E}-03$ & $4.75 \mathrm{E}-04$ & -30.5 & 0.3 \\
Main stem & $4 / 2 / 14$ & 49.1 & 27 & $6.24 \mathrm{E}-03$ & $6.25 \mathrm{E}-04$ & -34.4 & 0.5 \\
Main stem & $4 / 2 / 14$ & 49.1 & 28 & $2.68 \mathrm{E}-03$ & $2.68 \mathrm{E}-04$ & -31.8 & 0.4 \\
Main stem & $4 / 2 / 14$ & 49.1 & 29 & $1.60 \mathrm{E}-02$ & $1.60 \mathrm{E}-03$ & -34.2 & 0.1 \\
Main stem & $4 / 2 / 14$ & 49.1 & 30 & $2.88 \mathrm{E}-03$ & $2.88 \mathrm{E}-04$ & no data & NaN \\
Main stem & $4 / 2 / 14$ & 49.1 & 31 & $1.69 \mathrm{E}-02$ & $1.69 \mathrm{E}-03$ & -35.9 & 0.1 \\
Main stem & $4 / 2 / 14$ & 49.1 & 32 & $2.05 \mathrm{E}-03$ & $2.06 \mathrm{E}-04$ & -34.3 & 0.7 \\
Main stem & $4 / 2 / 14$ & 49.1 & 33 & $6.70 \mathrm{E}-03$ & $6.71 \mathrm{E}-04$ & -34.2 & 0.1 \\
\hline
\end{tabular}


Table S2. Abundances and $\delta^{13} \mathrm{C}$ values of fatty acids $\left(\mathrm{C}_{14}-\mathrm{C}_{34}\right)$ from large-volume $(>100$ L) and depth-specific (10 L) samples collected in June 2005, April 2014 and July 2014. Refer to Table 1 in chapter 5 for sampling times of individual samples.

\begin{tabular}{|c|c|c|c|c|c|c|c|}
\hline Location & Date & Depth & $\begin{array}{l}\text { Chain } \\
\text { Length }\end{array}$ & Abundance & $\begin{array}{c}\text { Abundance } \\
\text { Error }\end{array}$ & $\delta^{13} \mathrm{C}$ & $\begin{array}{c}\delta^{13} \mathrm{C} \\
\text { Error }\end{array}$ \\
\hline -- & -- & -- & \# & $n g / \mu g P O C$ & $n g / \mu g P O C$ & $\%$ & $\%$ \\
\hline Main stem & $4 / 1 / 14$ & 0 & 14 & 0.31171 & 0.031 & -27.7 & 0.1 \\
\hline Main stem & $4 / 1 / 14$ & 0 & 16 & 2.4949 & 0.250 & -29.2 & 0.2 \\
\hline Main stem & $4 / 1 / 14$ & 0 & 18 & 3.3937 & 0.340 & -28.6 & 0.3 \\
\hline Main stem & $4 / 1 / 14$ & 0 & 20 & 0.097067 & 0.010 & -29.2 & 0.2 \\
\hline Main stem & $4 / 1 / 14$ & 0 & 22 & 0.20945 & 0.021 & -31.6 & 0.5 \\
\hline Main stem & $4 / 1 / 14$ & 0 & 24 & 0.14455 & 0.014 & -28.8 & 0.4 \\
\hline Main stem & $4 / 1 / 14$ & 0 & 25 & 0.037764 & 0.004 & no data & no data \\
\hline Main stem & $4 / 1 / 14$ & 0 & 26 & 0.10798 & 0.011 & -30.2 & 0.5 \\
\hline Main stem & $4 / 1 / 14$ & 0 & 27 & 0.024168 & 0.002 & no data & no data \\
\hline Main stem & $4 / 1 / 14$ & 0 & 28 & 0.091665 & 0.009 & -32.0 & 0.5 \\
\hline Main stem & $4 / 1 / 14$ & 0 & 29 & 0.026517 & 0.003 & no data & no data \\
\hline Main stem & $4 / 1 / 14$ & 0 & 30 & 0.081735 & 0.008 & -33.2 & 0.2 \\
\hline Main stem & $4 / 1 / 14$ & 0 & 31 & 0.021069 & 0.002 & no data & no data \\
\hline Main stem & $4 / 1 / 14$ & 0 & 32 & 0.061277 & 0.006 & -33.5 & 2.3 \\
\hline Main stem & $4 / 1 / 14$ & 0 & 33 & 0.012159 & 0.001 & no data & no data \\
\hline Main stem & $4 / 1 / 14$ & 0 & 34 & 0.031169 & 0.003 & -33.1 & 0.1 \\
\hline Main stem & $7 / 28 / 14$ & 0 & 14 & 0.1952 & 0.020 & -33.0 & 0.0 \\
\hline Main stem & $7 / 28 / 14$ & 0 & 16 & 3.4245 & 0.344 & -30.8 & 0.4 \\
\hline Main stem & $7 / 28 / 14$ & 0 & 18 & 3.9505 & 0.397 & -29.2 & 0.2 \\
\hline Main stem & $7 / 28 / 14$ & 0 & 20 & 0.096981 & 0.010 & -30.9 & 0.0 \\
\hline Main stem & $7 / 28 / 14$ & 0 & 22 & 2.3583 & 0.237 & -34.2 & 0.5 \\
\hline Main stem & $7 / 28 / 14$ & 0 & 24 & 0.15264 & 0.015 & -32.5 & 0.6 \\
\hline Main stem & $7 / 28 / 14$ & 0 & 25 & 0.037073 & 0.004 & no data & no data \\
\hline Main stem & $7 / 28 / 14$ & 0 & 26 & 0.13925 & 0.014 & -33.0 & 0.4 \\
\hline Main stem & $7 / 28 / 14$ & 0 & 27 & 0.029239 & 0.003 & no data & no data \\
\hline Main stem & $7 / 28 / 14$ & 0 & 28 & 0.13231 & 0.013 & -32.9 & 0.6 \\
\hline Main stem & $7 / 28 / 14$ & 0 & 29 & 0.037333 & 0.004 & no data & no data \\
\hline Main stem & $7 / 28 / 14$ & 0 & 30 & 0.13233 & 0.013 & -33.0 & 0.2 \\
\hline Main stem & $7 / 28 / 14$ & 0 & 31 & 0.034962 & 0.004 & no data & no data \\
\hline Main stem & $7 / 28 / 14$ & 0 & 32 & 0.10498 & 0.011 & -33.3 & 0.3 \\
\hline Main stem & $7 / 28 / 14$ & 0 & 33 & 0.021529 & 0.002 & no data & no data \\
\hline Main stem & $7 / 28 / 14$ & 0 & 34 & 0.054067 & 0.005 & -32.8 & 0.2 \\
\hline Tapajós & $7 / 27 / 14$ & 0 & 14 & 2.2663 & 0.227 & -36.7 & 0.1 \\
\hline Tapajós & $7 / 27 / 14$ & 0 & 16 & 23.249 & 2.333 & -33.6 & 0.3 \\
\hline Tapajós & $7 / 27 / 14$ & 0 & 18 & 11.378 & 1.142 & -29.7 & 0.3 \\
\hline
\end{tabular}




\begin{tabular}{|c|c|c|c|c|c|c|c|}
\hline Tapajós & $7 / 27 / 14$ & 0 & 20 & 0.33744 & 0.034 & -34.1 & 0.6 \\
\hline Tapajós & $7 / 27 / 14$ & 0 & 22 & 0 & 0.000 & -39.4 & 0.2 \\
\hline Tapajós & $7 / 27 / 14$ & 0 & 24 & 0.93488 & 0.094 & -36.2 & 0.6 \\
\hline Tapajós & $7 / 27 / 14$ & 0 & 25 & 0.18406 & 0.018 & no data & no data \\
\hline Tapajós & $7 / 27 / 14$ & 0 & 26 & 0.62779 & 0.063 & -35.5 & 0.7 \\
\hline Tapajós & $7 / 27 / 14$ & 0 & 27 & 0.069807 & 0.007 & no data & no data \\
\hline Tapajós & $7 / 27 / 14$ & 0 & 28 & 0.4066 & 0.041 & -36.6 & 1.2 \\
\hline Tapajós & $7 / 27 / 14$ & 0 & 29 & 0.031529 & 0.003 & no data & no data \\
\hline Tapajós & $7 / 27 / 14$ & 0 & 30 & 0.095123 & 0.010 & -35.5 & 0.2 \\
\hline Tapajós & $7 / 27 / 14$ & 0 & 31 & 0.040663 & 0.004 & no data & no data \\
\hline Tapajós & $7 / 27 / 14$ & 0 & 32 & 0.031174 & 0.003 & -34.9 & 0.1 \\
\hline Tapajós & $7 / 27 / 14$ & 0 & 33 & 0.0079396 & 0.001 & no data & no data \\
\hline Tapajós & $7 / 27 / 14$ & 0 & 34 & 0.012265 & 0.001 & no data & no data \\
\hline Main stem & $6 / 8 / 05$ & 0 & 14 & 0.19 & 0.019 & -35.9 & 1.6 \\
\hline Main stem & $6 / 8 / 05$ & 0 & 15 & 0.063 & 0.006 & no data & no data \\
\hline Main stem & $6 / 8 / 05$ & 0 & 16 & 0.871 & 0.087 & -34.3 & 7.4 \\
\hline Main stem & $6 / 8 / 05$ & 0 & 17 & 0.018 & 0.002 & no data & no data \\
\hline Main stem & $6 / 8 / 05$ & 0 & 18 & 0.18 & 0.018 & -31.0 & 1.5 \\
\hline Main stem & $6 / 8 / 05$ & 0 & 19 & 0.05 & 0.005 & no data & no data \\
\hline Main stem & $6 / 8 / 05$ & 0 & 20 & 0.049 & 0.005 & -33.0 & 0.4 \\
\hline Main stem & $6 / 8 / 05$ & 0 & 21 & 0.047 & 0.005 & no data & no data \\
\hline Main stem & $6 / 8 / 05$ & 0 & 22 & 0.097 & 0.010 & -37.5 & 0.8 \\
\hline Main stem & $6 / 8 / 05$ & 0 & 23 & 0.028 & 0.003 & no data & no data \\
\hline Main stem & $6 / 8 / 05$ & 0 & 24 & 0.175 & 0.018 & -37.0 & 1.5 \\
\hline Main stem & $6 / 8 / 05$ & 0 & 25 & 0.035 & 0.004 & no data & no data \\
\hline Main stem & $6 / 8 / 05$ & 0 & 26 & 0.194 & 0.019 & -36.5 & 1.6 \\
\hline Main stem & $6 / 8 / 05$ & 0 & 27 & 0.04 & 0.004 & no data & no data \\
\hline Main stem & $6 / 8 / 05$ & 0 & 28 & 0.223 & 0.022 & -37.2 & 1.9 \\
\hline Main stem & $6 / 8 / 05$ & 0 & 29 & 0.049 & 0.005 & no data & no data \\
\hline Main stem & $6 / 8 / 05$ & 0 & 30 & 0.166 & 0.017 & -35.3 & 1.4 \\
\hline Main stem & $6 / 8 / 05$ & 0 & 31 & 0.038 & 0.004 & no data & no data \\
\hline Main stem & $6 / 8 / 05$ & 0 & 32 & 0.099 & 0.010 & -34.3 & 0.8 \\
\hline Main stem & $6 / 8 / 05$ & 0 & 33 & 0.023 & 0.002 & no data & no data \\
\hline Main stem & $6 / 8 / 05$ & 0 & 34 & 0.048 & 0.005 & -34.2 & 0.4 \\
\hline Main stem & $6 / 8 / 05$ & 0 & 35 & 0.066 & 0.007 & no data & no data \\
\hline Solimões & 062005 & 0 & 14 & 0.187 & 0.021 & -34.9 & 2.1 \\
\hline Solimões & 062005 & 0 & 15 & 0.046 & 0.005 & no data & no data \\
\hline Solimões & 062005 & 0 & 16 & 0.885 & 0.100 & -34.7 & 9.9 \\
\hline Solimões & 062005 & 0 & 17 & 0.017 & 0.002 & no data & no data \\
\hline Solimões & 062005 & 0 & 18 & 0.169 & 0.019 & -30.3 & 1.9 \\
\hline Solimões & 062005 & 0 & 19 & 0.012 & 0.001 & no data & no data \\
\hline Solimões & 062005 & 0 & 20 & 0.049 & 0.006 & -30.9 & 0.5 \\
\hline Solimões & 062005 & 0 & 21 & 0.018 & 0.002 & no data & no data \\
\hline
\end{tabular}




\begin{tabular}{|c|c|c|c|c|c|c|c|}
\hline Solimões & $6 / 4 / 05$ & 0 & 22 & 0.087 & 0.010 & -34.5 & 1.0 \\
\hline Solimões & $6 / 4 / 05$ & 0 & 23 & 0.031 & 0.004 & no data & no data \\
\hline Solimões & $6 / 4 / 05$ & 0 & 24 & 0.19 & 0.022 & -34.1 & 2.1 \\
\hline Solimões & $6 / 4 / 05$ & 0 & 25 & 0.044 & 0.005 & no data & no data \\
\hline Solimões & $6 / 4 / 05$ & 0 & 26 & 0.316 & 0.036 & -34.2 & 3.5 \\
\hline Solimões & $6 / 4 / 05$ & 0 & 27 & 0.046 & 0.005 & no data & no data \\
\hline Solimões & $6 / 4 / 05$ & 0 & 28 & 0.27 & 0.031 & -35.4 & 3.0 \\
\hline Solimões & $6 / 4 / 05$ & 0 & 29 & 0.059 & 0.007 & no data & no data \\
\hline Solimões & $6 / 4 / 05$ & 0 & 30 & 0.203 & 0.023 & -34.6 & 2.3 \\
\hline Solimões & $6 / 4 / 05$ & 0 & 31 & 0.05 & 0.006 & no data & no data \\
\hline Solimões & $6 / 4 / 05$ & 0 & 32 & 0.141 & 0.016 & -34.4 & 1.6 \\
\hline Solimões & $6 / 4 / 05$ & 0 & 33 & 0.032 & 0.004 & no data & no data \\
\hline Solimões & $6 / 4 / 05$ & 0 & 34 & 0.064 & 0.007 & -34.5 & 0.7 \\
\hline Solimões & $6 / 4 / 05$ & 0 & 35 & 0.102 & 0.012 & no data & no data \\
\hline Madeira & $6 / 6 / 05$ & 0 & 14 & 0.089 & 0.009 & -37.7 & 0.4 \\
\hline Madeira & $6 / 6 / 05$ & 0 & 15 & 0.024 & 0.002 & no data & no data \\
\hline Madeira & $6 / 6 / 05$ & 0 & 16 & 0.508 & 0.052 & -37.6 & 2.5 \\
\hline Madeira & $6 / 6 / 05$ & 0 & 17 & 0.013 & 0.001 & no data & no data \\
\hline Madeira & $6 / 6 / 05$ & 0 & 18 & 0.099 & 0.010 & -31.0 & 0.5 \\
\hline Madeira & $6 / 6 / 05$ & 0 & 19 & 0.006 & 0.001 & no data & no data \\
\hline Madeira & $6 / 6 / 05$ & 0 & 20 & 0.032 & 0.003 & -31.2 & 0.2 \\
\hline Madeira & $6 / 6 / 05$ & 0 & 21 & 0.01 & 0.001 & no data & no data \\
\hline Madeira & $6 / 6 / 05$ & 0 & 22 & 0.05 & 0.005 & -34.1 & 0.2 \\
\hline Madeira & $6 / 6 / 05$ & 0 & 23 & 0.018 & 0.002 & no data & no data \\
\hline Madeira & $6 / 6 / 05$ & 0 & 24 & 0.09 & 0.009 & -35.5 & 0.4 \\
\hline Madeira & $6 / 6 / 05$ & 0 & 25 & 0.021 & 0.002 & no data & no data \\
\hline Madeira & $6 / 6 / 05$ & 0 & 26 & 0.085 & 0.009 & -35.0 & 0.4 \\
\hline Madeira & $6 / 6 / 05$ & 0 & 27 & 0.018 & 0.002 & no data & no data \\
\hline Madeira & $6 / 6 / 05$ & 0 & 28 & 0.087 & 0.009 & -35.0 & 0.4 \\
\hline Madeira & $6 / 6 / 05$ & 0 & 29 & 0.023 & 0.002 & no data & no data \\
\hline Madeira & $6 / 6 / 05$ & 0 & 30 & 0.075 & 0.008 & -34.5 & 0.4 \\
\hline Madeira & $6 / 6 / 05$ & 0 & 31 & 0.018 & 0.002 & no data & no data \\
\hline Madeira & $6 / 6 / 05$ & 0 & 32 & 0.053 & 0.005 & -33.7 & 0.3 \\
\hline Madeira & $6 / 6 / 05$ & 0 & 33 & 0.012 & 0.001 & no data & no data \\
\hline Madeira & $6 / 6 / 05$ & 0 & 34 & 0.027 & 0.003 & -33.5 & 0.1 \\
\hline Madeira & $6 / 6 / 05$ & 0 & 35 & 0.034 & 0.003 & no data & no data \\
\hline Main stem & $7 / 28 / 14$ & 54 & 14 & 0.054832 & 0.006 & -32.4 & 0.4 \\
\hline Main stem & $7 / 28 / 14$ & 54 & 16 & 0.63583 & 0.070 & -30.4 & 0.2 \\
\hline Main stem & $7 / 28 / 14$ & 54 & 18 & 0.39584 & 0.044 & -29.2 & 0.1 \\
\hline Main stem & $7 / 28 / 14$ & 54 & 20 & 0.036354 & 0.004 & -30.6 & 1.1 \\
\hline Main stem & $7 / 28 / 14$ & 54 & 22 & 0.74563 & 0.082 & -32.4 & 0.4 \\
\hline Main stem & $7 / 28 / 14$ & 54 & 24 & 0.086899 & 0.010 & -31.5 & 0.3 \\
\hline Main stem & $7 / 28 / 14$ & 54 & 25 & 0.022954 & 0.003 & no data & no data \\
\hline
\end{tabular}




\begin{tabular}{|c|c|c|c|c|c|c|c|}
\hline Main stem & $7 / 28 / 14$ & 54 & 26 & 0.10196 & 0.011 & -31.1 & 0.8 \\
\hline Main stem & $7 / 28 / 14$ & 54 & 27 & 0.023842 & 0.003 & no data & no data \\
\hline Main stem & $7 / 28 / 14$ & 54 & 28 & 0.12934 & 0.014 & -31.5 & 0.1 \\
\hline Main stem & $7 / 28 / 14$ & 54 & 29 & 0.031932 & 0.004 & no data & no data \\
\hline Main stem & $7 / 28 / 14$ & 54 & 30 & 0.13955 & 0.015 & -32.2 & 0.2 \\
\hline Main stem & $7 / 28 / 14$ & 54 & 31 & 0.028885 & 0.003 & no data & no data \\
\hline Main stem & $7 / 28 / 14$ & 54 & 32 & 0.094013 & 0.010 & -32.8 & 0.3 \\
\hline Main stem & $7 / 28 / 14$ & 54 & 33 & 0.019822 & 0.002 & no data & no data \\
\hline Main stem & $7 / 28 / 14$ & 54 & 34 & 0.045886 & 0.005 & -32.6 & 0.8 \\
\hline Main stem & $4 / 2 / 14$ & 30.15 & 14 & 0.070165 & 0.007 & -29.9 & 1.3 \\
\hline Main stem & $4 / 2 / 14$ & 30.15 & 16 & 1.7788 & 0.179 & -29.2 & 0.4 \\
\hline Main stem & $4 / 2 / 14$ & 30.15 & 18 & 1.7946 & 0.181 & -28.8 & 0.3 \\
\hline Main stem & $4 / 2 / 14$ & 30.15 & 20 & 0.053737 & 0.005 & -30.1 & 0.3 \\
\hline Main stem & $4 / 2 / 14$ & 30.15 & 22 & 0.2279 & 0.023 & -31.5 & 0.6 \\
\hline Main stem & $4 / 2 / 14$ & 30.15 & 24 & 0.097517 & 0.010 & -32.0 & 0.3 \\
\hline Main stem & $4 / 2 / 14$ & 30.15 & 25 & 0.023434 & 0.002 & no data & no data \\
\hline Main stem & $4 / 2 / 14$ & 30.15 & 26 & 0.097554 & 0.010 & -32.0 & 0.3 \\
\hline Main stem & $4 / 2 / 14$ & 30.15 & 27 & 0.023332 & 0.002 & no data & no data \\
\hline Main stem & $4 / 2 / 14$ & 30.15 & 28 & 0.11045 & 0.011 & -32.7 & 0.2 \\
\hline Main stem & $4 / 2 / 14$ & 30.15 & 29 & 0.029705 & 0.003 & no data & no data \\
\hline Main stem & $4 / 2 / 14$ & 30.15 & 30 & 0.11388 & 0.011 & -33.3 & 0.2 \\
\hline Main stem & $4 / 2 / 14$ & 30.15 & 31 & 0.027346 & 0.003 & no data & no data \\
\hline Main stem & $4 / 2 / 14$ & 30.15 & 32 & 0.083013 & 0.008 & -33.3 & 0.3 \\
\hline Main stem & $4 / 2 / 14$ & 30.15 & 33 & 0.015861 & 0.002 & no data & no data \\
\hline Main stem & $4 / 2 / 14$ & 30.15 & 34 & 0.038895 & 0.004 & -33.4 & 0.9 \\
\hline Main stem & $4 / 2 / 14$ & 2.7 & 14 & 0.21517 & 0.022 & no data & no data \\
\hline Main stem & $4 / 2 / 14$ & 2.7 & 16 & 3.6379 & 0.365 & no data & $\mathrm{NaN}$ \\
\hline Main stem & $4 / 2 / 14$ & 2.7 & 18 & 3.4641 & 0.348 & no data & $\mathrm{NaN}$ \\
\hline Main stem & $4 / 2 / 14$ & 2.7 & 20 & 0.0699 & 0.007 & no data & no data \\
\hline Main stem & $4 / 2 / 14$ & 2.7 & 22 & 0.55703 & 0.056 & no data & $\mathrm{NaN}$ \\
\hline Main stem & $4 / 2 / 14$ & 2.7 & 24 & 0.078868 & 0.008 & no data & $\mathrm{NaN}$ \\
\hline Main stem & $4 / 2 / 14$ & 2.7 & 25 & 0.018353 & 0.002 & no data & no data \\
\hline Main stem & $4 / 2 / 14$ & 2.7 & 26 & 0.056486 & 0.006 & no data & $\mathrm{NaN}$ \\
\hline Main stem & $4 / 2 / 14$ & 2.7 & 27 & 0.022969 & 0.002 & no data & no data \\
\hline Main stem & $4 / 2 / 14$ & 2.7 & 28 & 0.050916 & 0.005 & no data & $\mathrm{NaN}$ \\
\hline Main stem & $4 / 2 / 14$ & 2.7 & 29 & 0.012918 & 0.001 & no data & no data \\
\hline Main stem & $4 / 2 / 14$ & 2.7 & 30 & 0.05081 & 0.005 & no data & $\mathrm{NaN}$ \\
\hline Main stem & $4 / 2 / 14$ & 2.7 & 31 & 0.011095 & 0.001 & no data & no data \\
\hline Main stem & $4 / 2 / 14$ & 2.7 & 32 & 0.034628 & 0.003 & no data & $\mathrm{NaN}$ \\
\hline Main stem & $4 / 2 / 14$ & 2.7 & 33 & 0.0078758 & 0.001 & no data & no data \\
\hline Main stem & $4 / 2 / 14$ & 2.7 & 34 & 0.016382 & 0.002 & no data & $\mathrm{NaN}$ \\
\hline Main stem & $4 / 2 / 14$ & 49.1 & 14 & 0.10537 & 0.011 & -28.7 & 1.3 \\
\hline Main stem & $4 / 2 / 14$ & 49.1 & 16 & 3.1154 & 0.312 & -29.4 & 0.3 \\
\hline
\end{tabular}




\begin{tabular}{lcccrccc} 
Main stem & $4 / 2 / 14$ & 49.1 & 18 & 3.0324 & 0.304 & -28.9 & 0.2 \\
Main stem & $4 / 2 / 14$ & 49.1 & 20 & 0.064186 & 0.006 & -30.1 & 0.3 \\
Main stem & $4 / 2 / 14$ & 49.1 & 22 & 0.25316 & 0.025 & -32.8 & 0.9 \\
Main stem & $4 / 2 / 14$ & 49.1 & 24 & 0.090366 & 0.009 & -32.1 & 0.3 \\
Main stem & $4 / 2 / 14$ & 49.1 & 25 & 0.022487 & 0.002 & no data & no data \\
Main stem & $4 / 2 / 14$ & 49.1 & 26 & 0.092227 & 0.009 & -32.1 & 0.1 \\
Main stem & $4 / 2 / 14$ & 49.1 & 27 & 0.024705 & 0.002 & no data & no data \\
Main stem & $4 / 2 / 14$ & 49.1 & 28 & 0.10805 & 0.011 & -32.7 & 0.2 \\
Main stem & $4 / 2 / 14$ & 49.1 & 29 & 0.031813 & 0.003 & no data & no data \\
Main stem & $4 / 2 / 14$ & 49.1 & 30 & 0.11688 & 0.012 & -33.2 & 0.2 \\
Main stem & $4 / 2 / 14$ & 49.1 & 31 & 0.031116 & 0.003 & no data & no data \\
Main stem & $4 / 2 / 14$ & 49.1 & 32 & 0.08853 & 0.009 & -33.7 & 0.2 \\
Main stem & $4 / 2 / 14$ & 49.1 & 33 & 0.020959 & 0.002 & no data & no data \\
Main stem & $4 / 2 / 14$ & 49.1 & 34 & 0.045168 & 0.005 & -33.2 & 0.3 \\
\hline
\end{tabular}


Table S3. Activities of eight enzymes measured on particles within the Óbidos crosssection in July 2014. Refer to chapter 5, Table 2 for enzyme substrate information. Data analysis credit: Andrew Steen.

\begin{tabular}{|c|c|c|c|c|}
\hline Channel Position & Depth & Substrate & Avg. Activity & S.D. Activity \\
\hline$k m$ & $m$ & -- & $\mu \mathrm{mol} / \mathrm{L} / \mathrm{hr}$ & $\mu \mathrm{mol} / \mathrm{L} / \mathrm{hr}$ \\
\hline 0.34 & 42.8 & Leu & 0.077 & 0.0091 \\
\hline 0.34 & 42.8 & Phe & 0.049 & 0.0042 \\
\hline 0.34 & 42.8 & AAF & 0.021 & 0.0033 \\
\hline 0.34 & 42.8 & NAG & 0.008 & 0.0039 \\
\hline 0.34 & 42.8 & Cello & 0.000 & 0.0002 \\
\hline 0.34 & 42.8 & b-glu & 0.001 & 0.0005 \\
\hline 0.34 & 42.8 & xyl & 0.000 & 0.0000 \\
\hline 1.6 & 54 & Leu & 0.040 & 0.0065 \\
\hline 1.6 & 54 & Phe & 0.031 & 0.0019 \\
\hline 1.6 & 54 & AAF & 0.013 & 0.0006 \\
\hline 1.6 & 54 & NAG & 0.003 & 0.0005 \\
\hline 1.6 & 54 & Cello & 0.001 & 0.0000 \\
\hline 1.6 & 54 & b-glu & 0.003 & 0.0001 \\
\hline 1.6 & 54 & xyl & 0.001 & 0.0001 \\
\hline 1.6 & 54 & PO4 & 0.028 & 0.0008 \\
\hline 1.6 & 39.83 & Leu & 0.056 & 0.0037 \\
\hline 1.6 & 39.83 & Phe & 0.045 & 0.0020 \\
\hline 1.6 & 39.83 & $\mathrm{AAF}$ & 0.020 & 0.0101 \\
\hline 1.6 & 39.83 & NAG & 0.005 & 0.0006 \\
\hline 1.6 & 39.83 & Cello & -0.001 & 0.0003 \\
\hline 1.6 & 39.83 & b-glu & 0.004 & 0.0002 \\
\hline 1.6 & 39.83 & xyl & 0.000 & 0.0002 \\
\hline 1.6 & 39.83 & PO4 & 0.030 & 0.0035 \\
\hline 1.6 & 30.4 & Leu & 0.053 & 0.0034 \\
\hline 1.6 & 30.4 & Phe & 0.040 & 0.0045 \\
\hline 1.6 & 30.4 & $\mathrm{AAF}$ & 0.012 & 0.0023 \\
\hline 1.6 & 30.4 & NAG & 0.005 & 0.0002 \\
\hline 1.6 & 30.4 & Cello & 0.001 & 0.0001 \\
\hline 1.6 & 30.4 & b-glu & 0.003 & 0.0003 \\
\hline 1.6 & 30.4 & PO4 & 0.007 & 0.0032 \\
\hline 1.6 & 14.95 & Leu & 0.040 & 0.0029 \\
\hline 1.6 & 14.95 & Phe & 0.031 & 0.0014 \\
\hline 1.6 & 14.95 & Cello & 0.006 & 0.0088 \\
\hline 1.6 & 14.95 & b-glu & 0.002 & 0.0006 \\
\hline 1.6 & 14.95 & xyl & -0.001 & 0.0033 \\
\hline 1.6 & 14.95 & PO4 & 0.018 & 0.0021 \\
\hline
\end{tabular}




\begin{tabular}{lcccc}
1.6 & 0.15 & Leu & 0.090 & 0.0042 \\
1.6 & 0.15 & Phe & 0.065 & 0.0028 \\
1.6 & 0.15 & AAF & 0.014 & 0.0022 \\
1.6 & 0.15 & NAG & 0.006 & 0.0002 \\
1.6 & 0.15 & Cello & 0.001 & 0.0004 \\
1.6 & 0.15 & b-glu & 0.005 & 0.0003 \\
1.6 & 0.15 & xyl & 0.001 & 0.0002 \\
1.6 & 0.15 & PO4 & 0.036 & 0.0150 \\
2.2 & 53.06 & Leu & 0.063 & 0.0047 \\
2.2 & 53.06 & Phe & 0.028 & 0.0214 \\
2.2 & 53.06 & AAF & 0.003 & 0.0025 \\
2.2 & 53.06 & NAG & 0.005 & 0.0004 \\
2.2 & 53.06 & Cello & 0.001 & 0.0001 \\
2.2 & 53.06 & b-glu & 0.003 & 0.0001 \\
2.2 & 53.06 & xyl & 0.001 & 0.0001 \\
2.2 & 53.06 & PO4 & 0.023 & 0.0019 \\
2.2 & 29.83 & Leu & 0.064 & 0.0035 \\
2.2 & 29.83 & Phe & 0.044 & 0.0115 \\
2.2 & 29.83 & AAF & 0.010 & 0.0029 \\
2.2 & 29.83 & NAG & 0.004 & 0.0009 \\
2.2 & 29.83 & Cello & 0.002 & 0.0016 \\
2.2 & 29.83 & b-glu & 0.002 & 0.0002 \\
2.2 & 29.83 & xyl & 0.000 & 0.0001 \\
2.2 & 29.83 & PO4 & 0.015 & 0.0028 \\
2.2 & 3.33 & Leu & 0.071 & 0.0288 \\
2.2 & 3.33 & Phe & 0.040 & 0.0050 \\
2.2 & 3.33 & AAF & 0.020 & 0.0186 \\
2.2 & 3.33 & NAG & 0.003 & 0.0001 \\
2.2 & 3.33 & Cello & 0.001 & 0.0004 \\
2.2 & 3.33 & b-glu & 0.003 & 0.0012 \\
2.2 & 3.33 & xyl & 0.001 & 0.0003 \\
2.2 & 3.33 & PO4 & 0.018 & 0.0010 \\
\hline & & & &
\end{tabular}



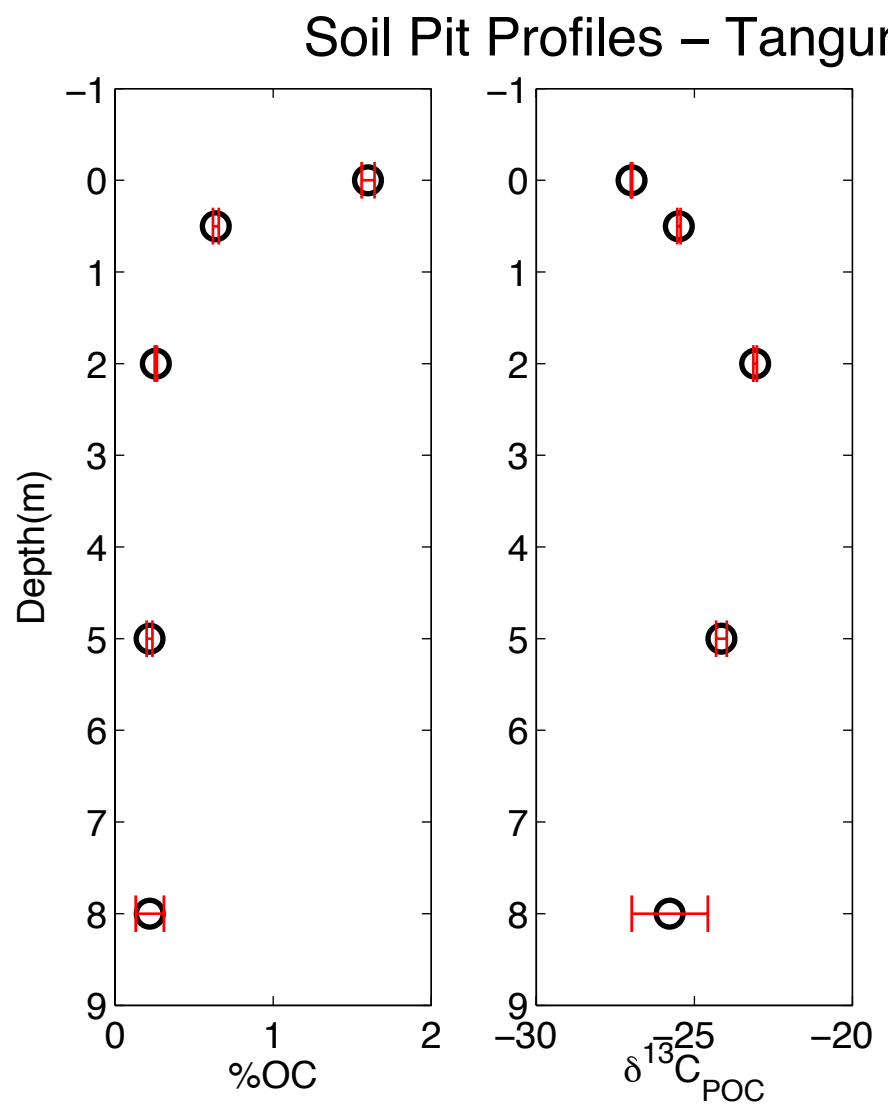

\section{Ranch}

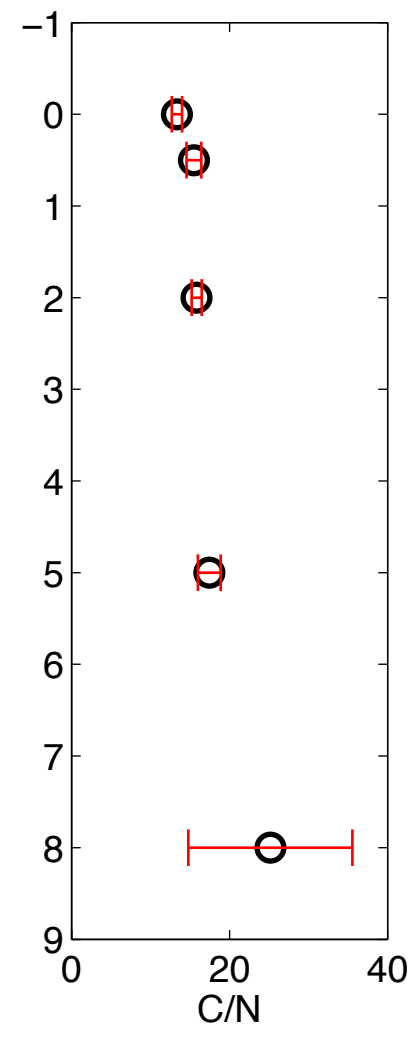

Figure S1. Profiles of weight \% particulate organic carbon (POC), bulk $\delta^{13} \mathrm{C}_{\mathrm{POC}}(\%)$ and $\mathrm{C} / \mathrm{N}$ of soils sampled at various depths from the surface to $8 \mathrm{~m}$ in a soil pit from the Tanguro ranch in the Southern Amazon. Refer to Fig. 1 in chapter 5 for approximate ranch location. 

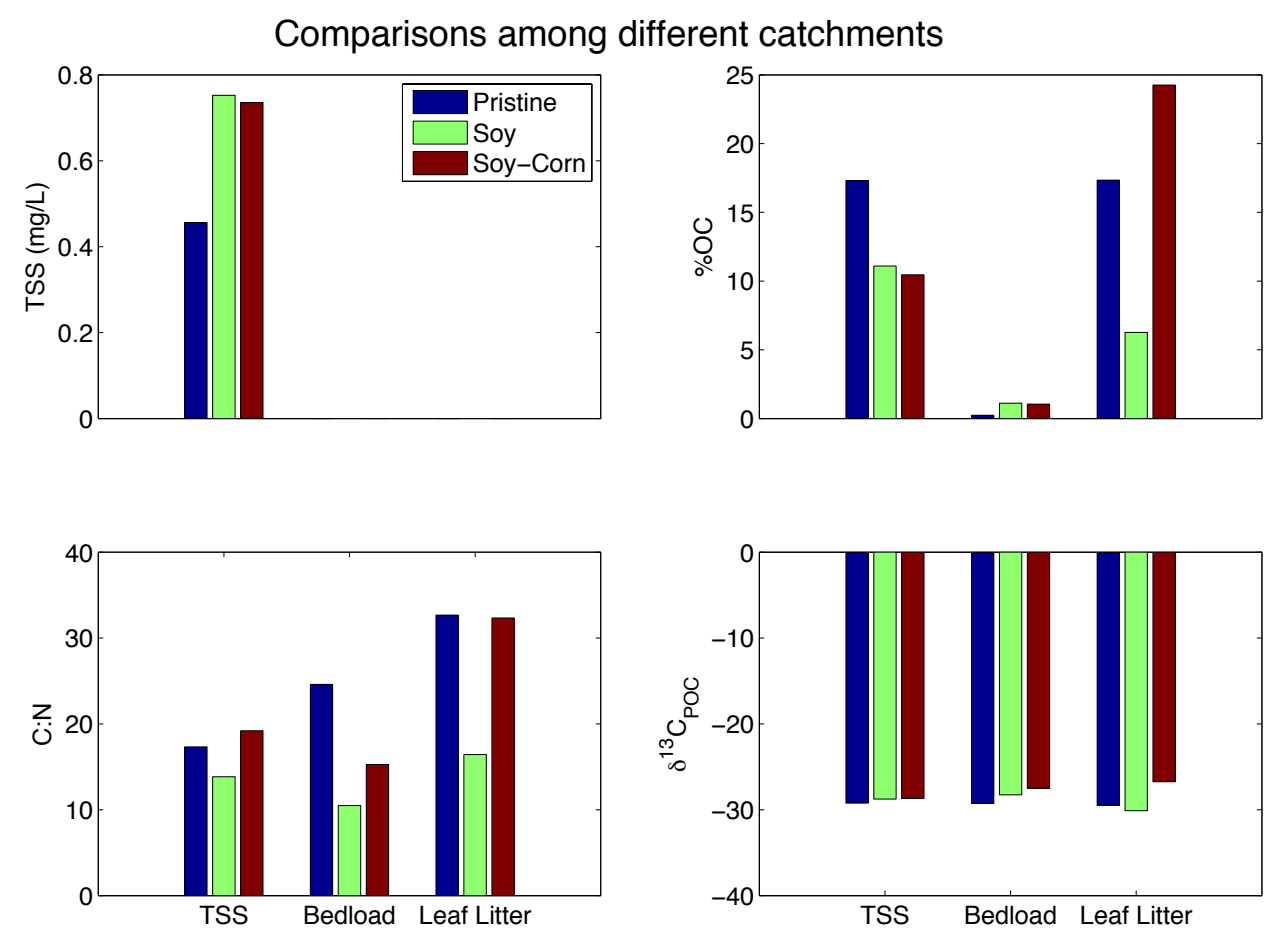

Figure S2. (a) Total suspended sediment concentrations in three streams draining through three land cover types across the Tanguro Ranch: pristine, soy fields, and rotating soy and corn fields. (b) \% organic carbon, (c) organic $\mathrm{C}: \mathrm{N}$ and (d) $\delta^{13} \mathrm{C}_{\mathrm{POC}}(\%)$ measured in total suspended sediments, bedload and leaf litter collected from these three streams. Refer to Fig. 1 in chapter 5 for ranch location. 


\section{Supplementary Methods for Figs. S1-S2}

During a field sampling trip to the Tanguro Ranch from November 12-20 2013, suspended sediment, bedload and suspended leaf litter samples were collected in three streams running through different catchments. Each catchment flushed through a

different land cover type: pristine rain forest, a soy field, and an alternating soy/crop field. All samples were gathered, prepared and analyzed according to methods described in chapter 5. Leaf litter samples was separated from suspended sediments using a $2 \mathrm{~mm}$ diameter sieve after the suspended material was freeze-dried.

In addition, a soil pit on the ranch was sampled on November 19 and 20, 2013 at five depths from surface to $8 \mathrm{~m}$. The soils were oven-dried overnight prior to organic composition analysis using methods described in chapter 5.

\section{Supplementary acknowledgements for Figs. S1-S2}

Many thanks to members of Instituto de Pesquisa Ambiental da Amazonia (IPAM) and the Woods Hole Research Center (Wendy Kingerlee, Marcia Macedo, Paul Lefebvre, and Michael Coe) for the assistance in the field work; Rob Spencer, Kate Bulygina, Valier Galy and Britta Voss in planning the sampling plan; and Carl Johnson for the analytical assistance. 